H INSWORTH EVE $L$ YN

MISHER KATHRYN E

MIS HEL

$\mathrm{R}$

C

E

$\mathrm{R}$

D
$D$
$N$
$D$
$D$
$R$

R

OR $\xi^{2}$

G

E

A R

$\boldsymbol{S}$ $\mathbf{E}$

V $|R G| \mathbf{N} \mid A$

N E W M A N

D E

PE P BAU

$\int^{2} \mathrm{~S}$

ङ

0

W $A \mathbf{T}$ S $0 \mathrm{~N}$

ALISON

REE D

R IZZO

$\mathrm{O}$

$\delta$

C G E

N I G H T IN G $A$ L E

MELE I S

$\mathbf{E}$

O

M

$\begin{array}{ll}L & \mathrm{R} \\ L & \mathrm{~S}\end{array}$

R

$\mathrm{S} R$

H « STED

JAUME•I

$\mathrm{K}$

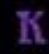

A B D E

FACTORES DETERMINANTES DEL USO DE MODELOS TEÓRICOS EN LA PRÁCTICA ENFERMERA

Departamento de Enfermería

Programa de Doctorado en Ciencias de la Salud

Universitat Jaume I de Castellón

ADELAIDA ZABALEGUI YÁRNOZ

Castellón de la Plana, 2014

PR S

E S

N

D

D

$\mathrm{R}$

T $\mathrm{R} A \mathrm{~B}$ L B E

Tesis Doctoral

SUSANA SANTOS RUIZ

Directora:
$S$

0
L

$0 L Y D I A$
PELLETIE

T IE?

E D

ELE । S

LEJ N I R G R

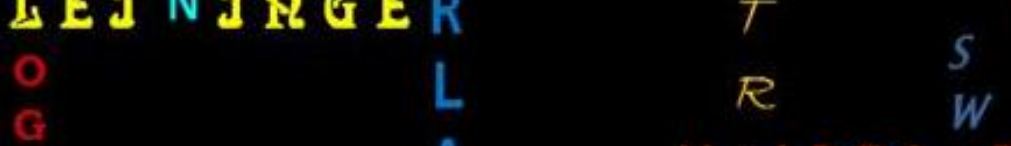





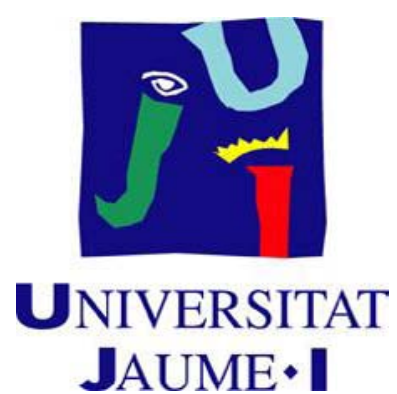

Tesis doctoral

\title{
FACTORES DETERMINANTES DEL USO DE MODELOS TEÓRICOS EN LA PRÁCTICA ENFERMERA
}

\author{
SUSANA SANTOS RUIZ \\ Departamento de Enfermería \\ Programa de Doctorado en Ciencias de la Salud \\ Universitat Jaume I de Castellón
}

Directora:

Adelaida Zabalegui Yárnoz

Castellón de la Plana, Mayo 2014 

"Los que se enamoran de la práctica sin la teoría son como los pilotos sin timón ni brújula, que nunca podrá saber adonde van".

Leonardo da Vinci (1452-1519) pintor, anatomista, arquitecto, artista, botánico, científico, escritor, escultor, filósofo, ingeniero, inventor, músico, poeta y urbanista italiano.

"De modo alguno, ningún modelo significa la panacea para la práctica, pero proporcionan un marco desde el que contemplar la práctica, la educación y la gestión de enfermería".

Stephen J. Cavanagh, RN, PhD, MPA. 1993. Decano Asociado de Asuntos Clínicos y Académicos. Colegio de Enfermería de Wayne State University. EE.UU.

"La teoría no es un lujo en la disciplina enfermera... sino una parte integral del léxico enfermero en la educación, la administración y la práctica".

Afaf I. Meleis, PhD, DrPS, FAAN. 2007. Decana de la escuela de Enfermería de la Universidad de Pennsylvania. EE.UU. 

A mi compañero de viaje... 



\section{Agradecimientos}

Cuando era niña, tuve una infancia complicada, pero gracias a una mujer fuerte, mi madre, supe que era posible enfrentarse a todo tipo de adversidades. Hoy es una de las personas a la que más tengo que agradecer mi desarrollo académico, ya que fue la persona que lidió intensamente para que creciera como persona en un entorno que no era nada favorecedor, aunque la salud no fuera siempre su mejor amiga. Durante mi largo camino hasta ahora, tuve la suerte de encontrarme a la mejor persona que se hallaba en el mundo, Moisés. Un gran hombre con la ternura de un niño. Compañero de fatigas, pero sobre todo de viaje. Un viaje simbiótico en la vida que decidimos caminar juntos, ampliando el camino con dos dulces compañías, Víctor y Marta. A todos ellos me veo en la obligación de corresponder en el final de esta etapa, la cima académica, a costa de su tiempo y en muchas ocasiones de su paciencia (no está demás recordar alguno de los dichos de mi hija que así lo corroboran: "cuando la acabas...", "que te queda...", "mi madre es aquella pringada que se pasa el día haciendo tesis"...). Decirles que ellos son infinitamente más importantes para mí que cualquier tesis o proyecto, que valoro por encima de todo el ánimo, calor y confort emocional brindado altruistamente por ellos cuando más me hizo falta. Son conocedores de que pasamos momentos personales difíciles, pero no por ello dejamos de ilusionarnos por las pequeñas cosas. Desde lo más profundo de mí ser, infinitas gracias.

Cuando inicié mis estudios de enfermería, poco podía imaginar que culminarían con un doctorado en Ciencias de la Salud, entre otras cosas porque académicamente no se nos permitía sino era a través de una senda paralela que no me apetecía recorrer. Pero durante la formación tuve la gran suerte de encontrarme con personas que hicieron que iniciara un nuevo pensamiento reflexivo desconocido por mí anteriormente. Sin saber mucho del tema, decidí aventurarme a un título propio universitario sin conocer a ciencia cierta si tendría validez homologada. Esta formación acrecentó en mí, un nuevo pensamiento crítico y me valió para compartir inquietudes durante el desayuno en la tercera del Hospital Taulí con Maria López. Ambas nos habíamos cuestionado en diversas ocasiones la escasez del uso de los modelos teóricos enfermeros en nuestras unidades hospitalarias. Esa inquietud fue el pábilo que prendió el tímido inicio de la tesis que aquí se presenta. Me permitió profundizar en la filosofía enfermera de la mano de otras compañeras asistenciales (Dolors Abril, Susana Varez y Maria Rocabert) y crecer en reflexión junto a colegas docentes: Lupe Sánchez, Lola Bardallo, Lidia Fernández y Joaquín Tomás. Pero sobre todo poder desarrollar profundamente el tema con Adela Zabalegui, mi directora de tesis. Persona que 
admiro por ser uno de los motores que han contribuido de forma notable a llevar a la enfermería española a su actual situación académica. Su expertez investigadora, ha permitido reconducir caminos angostos, brindándome siempre su ayuda para poder culminar este estudio con éxito.

Agradecer también a aquellos profesionales asistenciales, docentes, gestores y alumnos que respondieron a las cuestiones planteadas. A la Corporació Sanitaria Parc Taulí y a Montse Montaña (directora en aquel momento), que ayudaron premiando parte del proyecto y facilitaron el inicio de este estudio en el centro.

No quiero olvidar tampoco a aquellas personas con las que tropecé en estos últimos años, y que en parte también forman parte de la comitiva de esta última andadura, gracias a Lorena Molina, Carme Rosell, Carol Chabrera, y Esther Cabrera...y al resto de compañeros de la Escuela Superior de Ciencias de la Salud Tecnocampus, por ser siempre comprensibles conmigo, gracias por vuestra amistad, empatía, compañerismo y vuestros ánimos en horas bajas.

A todos gracias de corazón. 


\section{Abreviaturas}

AAOHN J

Adv Skin Wound Care ANS Adv Nurs Sci

ATS

AVC

BOE

Br J Nurs

Can Oncol Nurs J

Cancer Nurs

CANNT J

CAP

CCEE

$\mathrm{CD}$

$\mathrm{Cl}$

Clin J Oncol Nurs

Clin Nurse Spec

Contemp nurse

COT

Creat Nurs

Crit Care Nurs Q

CSPT

Dimens Crit Care Nurs

DM

DUE

Enferm Clin

Enferm Intensiva

EPOC

SEM

EE.UU.

EUICR

EUE

EUIG

Gastroenterol Nurs

gl

Health Care Manag (Frederick)

Holist Nurs Pract

Home Healthc Nurse

HTA

Hu Li Za Zhi

IAM

Int Emerg Nurs

IQ

Iran J Nurs Midwifery Res

Issues Ment Health Nurs
Official journal of the American Association of Occupational Health Nurses

Advances in Skin \& Wound Care

ANS. Advances in Nursing Science

Ayudante Técnico Sanitario

Accidente Vascular Cerebral

Boletín Oficial del Estado

British Journal of Nursing: BJN

Canadian Oncology Nursing Journal = Revue canadienne de nursing oncologique

Cancer Nursing

Canadian Association of Nephrology Nurses and Technicians

Centro de Atención Primaria

Consultas Externas (hospital)

Compact Disc

Cardiopatía Isquémica

Clinical Journal of Oncology Nursing

Clinical Nurse Specialist CNS

Contemporary Nurse

Cirugía Ortopédica y Traumatológica

Creative Nursing

Critical Care Nursing Quarterly

Corporació Sanitària Parc Taulí

Dimensions of Critical Care Nursing: DCCN

Diabetes Mellitus

Diplomado Universitario de Enfermería

Enfermería clínica

Enfermería intensiva / Sociedad Española de Enfermería Intensiva y Unidades Coronarias

Enfermedad Pulmonar Obstructiva Crónica

Servicio de Emergencias Médicas

Estados Unidos

Escola Universitària d'Infermeria Creu Roja

Escuela Universitaria de Enfermería

Escola Universitària d'Infermeria Gimbernat

Gastroenterology Nursing: the official journal of the Society of

Gastroenterology Nurses and Associates

Grados de libertad en las pruebas de contraste de hipótesis

The Health Care Manager

Holistic Nursing Practice

Home Healthcare Nurse

Hipertensión arterial

Hu li za zhi the journal of nursing

Infarto Agudo de Miocardio

International Emergency Nursing

Intervención quirúrgica

Iranian Journal of Nursing and Midwifery Research

Issues in Mental Health Nursing 
J Adv Nurs

J Am Psychiatr Nurses Assoc

J Burn Care Res

J Christ Nurs

J Clin Nurs

J Contin Educ Nurs

$\mathrm{J}$ Cult Divers

J Gerontol Nurs

J Health Hum Serv Adm

$J$ Korean Acad Nurs

J Natl Black Nurses Assoc

J Neurosci Nurs

J Nurs Educ

J Nurs Educ

J Nurs Manag

J Nurs Res

J Obstet Gynecol Neonatal

\author{
J Pediatr Nurs \\ J Prof Nurs \\ J Psychiatr Ment Health Nurs \\ J Sch Nurs
}

J Transcult Nurs

JCR

ICN

MCN Am J Matern Child Nurs

$\mathrm{MeSH}$

Nephrol Nurs J

Nurs Adm Q

Nurs Forum

Nurs Health Sci

Nurs Outlook

Nurs Philos

Nurs Res

Nurs Sci Q

Nurse Educ Pract

Nurse Educ Today

Oncol Nurs Forum

Online J Issues Nurs

ORL Head Neck Nurs

ORL
Journal of Advanced Nursing

Journal of the American Psychiatric Nurses Association

Journal of Burn Care \& Research: official publication of the American Burn Association

Journal of Christian Nursing: a quarterly publication of Nurses

Christian Fellowship

Journal of Clinical Nursing

Journal of Continuing Education In Nursing

Journal of Cultural Diversity

Journal of Gerontological Nursing

Journal of Health And Human Services Administration

Journal of Korean Academy of Nursing

Journal of National Black Nurses' Association: JNBNA

The Journal of Neuroscience Nursing: journal of the American As-

sociation of Neuroscience Nurses

The Journal of Nursing Education

The Journal of Nursing Education

Journal of Nursing Management

The journal of Nursing Research: JNR

Journal of Obstetric, Gynecologic, and Neonatal Nursing: JOGNN /

NAACOG (Nurses' Association of the American College of Obstetri-

cians and Gynecologists)

Journal of Pediatric Nursing

Journal of Professional Nursing: official journal of the American

Association of Colleges of Nursing

Journal of Psychiatric and Mental Health Nursing

The Journal of School Nursing: the official publication of the Na-

tional Association of School Nurses

Journal of Transcultural Nursing: official journal of the Transcultural Nursing Society / Transcultural Nursing Society

Journal Citation Reports

International Council of Nursing

Maternal Child Nursing, the American Journal of Maternal Child

Nursing

Medical Subject Headings

Nephrology Nursing Journal: journal of the American Nephrology

Nurses' Association

Nursing Administration Quarterly

Nursing Forum

Nursing \& Health Sciences

Nursing Outlook

Nursing Philosophy: an international journal for healthcare professionals

Nursing Research

Nursing Science Quarterly

Nurse Education in Practice

Nurse Education Today

Oncology Nursing Forum

Online Journal of Issues In Nursing [electronic resource]

ORL-Head and Neck Nursing: Official Journal of the Society of Oto-

rhinolaryngology and Head-Neck Nurses

Otorrinolaringología 
Ostomy Wound Manage

PADES

Pain Manage Nurs

Pediatr Nurs

Prof Inferm

Prog Transplant

PTC

PTR

RD

Rech Soins Infirm

Res Gerontol Nurs

Res Theory Nurs Pract

Rev Bras Enferm

Rev Enferm

Rev Esc Enferm Usp

Rev Gaucha Enferm

Rev Lat Am Enfermagem

Scand J Caring Sci

Self Care Depend Care Nurs

Soins

TBC

Transplant Proc

$\mathrm{UCl}$

UCIAS

UCP

UIC

UPP

URPA

Worldviews Evid Based Nurs
Ostomy Wound management

Programa de Atención Domiciliaria y Equipos de Soporte

Pain Management Nursing: official journal of the American Society of Pain Management Nurses

Pediatric Nursing

Professioni Infermieristiche

Progress in Transplantation: official publication, North American

Transplant Coordinators Organization

Prótesis total de cadera

Prótesis total de rodilla

Real Decreto

Recherche en Soins Infirmiers

Research in Gerontological Nursing

Research and Theory for Nursing Practice

Revista Brasileira de Enfermagem

Revista de Enfermería / Rol

Revista da Escola de Enfermagem da USP (Universidad de São

Paulo)

Revista Gaúcha de Enfermagem / EENFUFRGS (Escola de Enfermagem da Universidade Federal do Rio Grande e do Sul)

Revista Latino-americana de Enfermagem

Scandinavian Journal of Caring Sciences

Self-care, Dependent-Care \& Nursing: the official journal of the International Orem Society

Soins; la revue de référence infirmière

Tuberculosis

Transplantation Proceedings

Unidad de cuidados intensivos

Urgencias hospitalarias

Unidad de cuidados paliativos

Universitat Internacional de Catalunya

Úlcera por presión

Unidad de reanimación post anestésica

Worldviews on Evidence-Based Nursing / Sigma Theta Tau International, Honor Society of Nursing 


\section{Resumen}

La aplicación de la teoría en la práctica siempre ha sido un tema controvertido. Aplicar teoría enfermera implica compartir valores y creencias de las propuestas teóricas. Existen posicionamientos de profesionales experimentados que denuncian un desfase de la teoría enfermera y la tachan de ser ejercicios académicos. Aunque esta visión no es tan clara en nuestro territorio, ya que muchos centros sanitarios implementan teoría enfermera. El modelo de Virginia Henderson, modelo hegemónico de la práctica, ha sido normalmente bien valorado entre profesionales. Pese a que existen estudios que evalúan los modelos en situaciones concretas o a nivel filosófico, no se han hallado investigaciones que concreten cuáles son los factores que inciden directamente en el éxito o fracaso de la aplicación de una teoría concreta en la práctica a nivel nacional. Por ello el objetivo general de este estudio fue identificar cuáles eran los factores que determinan el uso de un modelo teórico enfermero que guíe la práctica profesional en nuestro contexto.

Metodología: Estudio descriptivo concretado en varios objetivos específicos tratados como fases diferentes del estudio y desarrollados en función de las exigencias investigadoras de cada momento (diseño emergente). Estos objetivos, por las características propias del tema de investigación, requirieron valerse de diversos métodos de recogida de datos sobre profesionales con diferentes perfiles formativos y ámbitos. Por lo que la investigación se basó en los "mixed methods", usando aproximaciones cuantitativas o cualitativas según fue preciso. Este trabajo constó por lo tanto de un total de 6 objetivos desarrollados en diferentes momentos temporales o fases.

La fase 1 abordó, mediante un diseño observacional transversal, la revisión de los planes de estudio de 109 universidades españolas identificadas como formadoras de la titulación de Diplomado en Enfermería por el Ministerio de Educación durante el curso 2008-2009. Se revisó el contenido a través de sus páginas webs, y se recogió toda la información posible de las asignaturas relacionadas con filosofía y metodología enfermera desarrollada en cualquier curso académico. Para el análisis de datos se elaboró una tabla que recogía la información necesaria de cada documento. Se utilizó media y desviación estándar para variables cuantitativas, y las categoricas se presentaron en forma de frecuencias y porcentajes.

La fase 2, se llevó a cabo mediante diseño cuantitativo que indagaba sobre la perspectiva de un amplio número de sujetos inmersos en el mundo laboral a nivel profesional $(n=204)$ o en periodo formativo ( $n=105)$. El propósito era determinar de qué forma los modelos teóricos impregnaban una práctica profesional no condicionada institucionalmente por un modelo 
conceptual concreto. Fueron estudiados profesionales de la Corporació Sanitaria Parc Taulí (CSPT) y alumnos en prácticas en el centro de Diplomatura de Enfermería de la Universitat Internacional de Catalunya ( $n=30)$, Escuela Universitaria de Enfermería Gimbernat $(n=30)$ y Escuela Universitaria de Enfermería Creu Roja ( $n=45)$. La recogida de datos se llevó a cabo mediante cuestionario de elaboración propia autocumplimentable y recogido anónimamente mediante urna cerrada. Se realizó un estudio descriptivo de las variables en forma de media y desviación estándar o frecuencias y porcentajes según la variable estudiada. Para el análisis comparativo se usó la chi-cuadrado de Pearson o correlacion lineal de Yates según necesidades muestrales, usando un intervalo de confianza del $95 \%$.

Para el desarrollo de la fase 3 se utilizó la etnografía como marco para el estudio del desarrollo de modelos de cuidados a pacientes cuidados en diversos servicios asistenciales. Para ello, se estudiaron un total de 190 trabajos de estudiantes de Máster Universitario en Ciencias de la Enfermería sobre aplicación teórica. Fueron elaborados por 539 enfermeras de un total de 6 universidades españolas durante los cursos académicos 1999-2010. Se analizó el contenido de estos trabajos de Máster siguiendo el esquema de Miles y Huberman y la estructura para el análisis de la eficacia de los modelos teóricos planteada por Chinn y Kramer.

Del mismo modo, con igual diseño se llevó a cabo la fase 4, en la que se analizaron trabajos relacionados con el desarrollo profesional y teórico de la Enfermería en España. Se analizaron un total de 154 trabajos sobre barreras y 133 sobre facilitadores del desarrollo teórico y profesional de la Enfermería en España. Examinados según análisis de contenido de Miles y Huberman. Los trabajos de la fase 3 y 4 provenían de una base de datos propia de la docente que impartió la asignatura de Modelos Teóricos dentro del Máster Universitario en Ciencias de la Enfermería.

Debido a que en estos trabajos no se mostraba la prioridad de los diferentes elementos, se estableció la fase 5 . Se realizó un estudio Delphi que indagó sobre la opinión de gestores de centros sanitarios y profesores universitarios de asignaturas relacionadas con la base conceptual enfermera $(n=31)$, sobre elementos facilitadores y barrera del uso y desarrollo de modelos enfermeros en la práctica española.

Debido a las premisas metodológicas expuestas, la totalidad de sujetos escogidos en todos los casos fue a través de muestreo de conveniencia.

Pese a que durante todo el proceso se realizó una revisión continua de la bibliografía, para finalizar el estudio se vio la necesidad de desarrollar una sexta fase que contemplara una revisión integradora de la literatura. El objetivo era describir la situación internacional detallada y actuali- 
zada de la aplicación de modelos teóricos concretos reconocidos tradicionalmente en la práctica. Para ello, se realizó una búsqueda exhaustiva sobre el tema en la base bibliográfica MEDLINE a través de Pubmed en la literatura publicada en los últimos 5 años en relación al tema. Se estudiaron las variables en forma de frecuencias y porcentajes, además de un análisis del contenido de cada uno de los artículos hallados.

En cuanto a consideraciones éticas se aseguró la confidencialidad de los datos de todos los profesionales y estudiantes involucrados en el estudio, así como se mantuvo el anonimato de las autorías de los trabajos de Máster. Para el desarrollo de la investigación se obtuvieron los permisos del Comité de Ética e Investigación Clínica tanto de la Corporació Sanitaria Parc Taulí (de los datos recogidos en su centro) como del Comité de Investigación de la Fundación Tecnocampus Mataró Maresme que acredita el compromiso ético de la totalidad del estudio.

Resultados: En relación a la formación, de los 109 centros universitarios incluidos, el $83,5 \%$ tenían el plan de estudios disponible en web y el 7,3\% se mostraban acorde a una base teórica concreta. El 56\% de los centros adjuntaban el plan docente de la asignatura relacionada con base conceptual enfermera. Los créditos dedicados a modelos y teorías de enfermería fueron 13,4 $\pm 2,4$ (de 6 a 19 créditos), de los que 6,7 $\pm 1,4$ eran prácticos. En cuanto a los contenidos, el 95,2\% incluía conocimientos sobre modelos teóricos, el 95,2\% sobre metodología enfermera y el 33,9\% sobre historia de la Enfermería. El 31,7\% de los centros seguían el modelo de V. Henderson. Un 15,3\% de los centros incluyeron otra asignatura obligatoria más en relación a teoría enfermera $(10,7 \pm 5,5$ créditos) y un $19,2 \%$ incluyeron una asignatura optativa sobre este tema ( $5 \pm 1,4$ créditos).

En relación a los modelos aplicados de forma implícita por estudiantes y profesionales de la CSPT, el modelo bajo el cual explicitan haber sido formados fue V. Henderson mayoritariamente en ambos grupos ( $74 \%$ en profesionales frente a $60 \%$ entre estudiantes). El $23,3 \%$ de los profesionales refirieron seguir modelo teórico en su práctica frente al $62,1 \%$ de estudiantes $(p<0,01)$. Afirmaron que siempre éste les era útil (14,6\% de los profesionales sobre el $14,6 \%$ de estudiantes con $\mathrm{p}<0,05)$. Ambos grupos manifestaron positividad al instaurar un modelo teórico en el centro $(63,2 \%$ frente a $65,7 \%, p>0,05)$. Porcentajes similares indicaron que debería ser diferente según el tipo de paciente $(11,5 \%$ versus $17,6 \%, p>0,05)$. Ambos grupos eligieron a V. Henderson como modelo en su práctica ( $35,3 \%$ frente al $51,4 \%$ de los estudiantes, $p<0,01)$.

En relación a los trabajos de Máster sobre modelos teóricos y el estudio de ventajas y desventajas percibidas por los profesionales sobre la aplicación de un modelo teórico, de 190 
procesos enfermeros, el $25,8 \%$ fueron bajo el modelo de $\mathrm{V}$. Henderson, un $22,6 \%$ con el modelo de D. Orem, un $22,1 \%$ bajo el de C. Roy, un $11,6 \%$ bajo H. Peplau, el 6,3\% con I. King, el 6,3\% con M. Leininger y un 5,3\% de los procesos usaron a B. Neuman. La mayoría de los trabajos se llevaron a cabo en hospitalización. No hubo ningún modelo recomendado para urgencias, cuidados intensivos o área quirúrgica. Se valoró como elementos positivos de los modelos: la claridad, el desarrollo de la valoración, la clarificación del rol enfermero y de la persona cuidada, además de la adaptación al proceso de cuidados sobre todo si permitía su uso conjunto con taxonomía enfermera. Como aspectos negativos entre otros, destacaron el elevado tiempo de implementación, la falta de instrumentos específicos para la valoración física y la sensación de reiteración mostrada en los elementos o conceptos de algunos modelos.

Referente a la perspectiva de los estudiantes de Máster acerca de los elementos que influenciaron el desarrollo teórico y profesional, se recogieron un mayor número de respuestas sobre barreras o factores limitantes (154 respuestas) que sobre factores facilitadores ( 77 respuestas). Los estudiantes indicaron que eran elementos facilitadores importantes, las políticas de gestión de los centros sanitarios, el apoyo de los gestores, el soporte legislativo, el aumento de recursos humanos, la disminución de la carga laboral y el cambio de modelo asistencial desde una visión medicalizada a la de salud para facilitar el avance. Así como, también creyeron que era necesario que se valorara la carrera profesional de la enfermera y se disminuyera la rotación de profesionales entre unidades asistenciales. Indicaron que otro elemento importante era la formación enfermera en bases conceptuales propias guiada por enfermeras, acompañada de mayor conocimiento de idiomas. Otro de los factores facilitadores era el apoyo de la sociedad al colectivo enfermero, la visibilización del trabajo real que hace la enfermera y su relevancia a nivel de la salud poblacional, así como el desarrollo de la investigación propia. También fueron valorados como factores facilitadores aspectos colectivos como la motivación, responsabilidad, compromiso, pensamiento crítico, liderazgo e interdisciplinariedad.

En cuanto a los factores facilitadores y limitantes o barrera descritos por los gestores y docentes del estudio siguiendo metodología Delphi (23 sujetos), destaca la priorización de los facilitadores "el liderazgo de las enfermeras" y "la sensibilidad y necesidad de las Direcciones de Enfermería de aplicar modelos teóricos en los pacientes" (ambos priorizados por 23 de los sujetos). En el caso de los elementos limitantes fueron priorizados temas ligados al propio carácter de algunos profesionales enfermeros: "el pragmatismo y la falta de reflexión personal de no tener la necesidad de basar la práctica en conocimiento propio" y "la falta de reconocimiento del uso de modelos en el desarrollo como disciplina" priorizados por 21 de los participantes. 
En cuanto a la revisión bibliográfica (realizada entre las publicaciones de los años 2008 y 2013) se incluyeron un total de 276 publicaciones. Gran número de las mismas se centraron en los modelos de R. Parse (21\%) y C. Roy (15,6\%). La mayoría de los artículos son teóricos (26\%), de autores estadounidenses (60,8\%), que trabajaban en el ámbito universitario $(82,2 \%)$.

Conclusiones: Respecto al objetivo principal se halló que la elección de un modelo teórico concreto para el trabajo responde a factores subjetivos, objetivos y contextuales. Pudiéndose clasificar en dos grandes grupos: intrínsecos y extrínsecos. Los factores intrínsecos del propio modelo evaluados como elementos facilitadores de la elección del mismo para la práctica fueron: la identificación personal con la filosofía, la formación recibida, el ser el más usado en el entorno propio, la facilidad de aplicación, la adecuación de la teoría a la persona cuidada y al contexto, la sencillez del lenguaje y de la valoración de la persona. Además de su generalidad, claridad de la descripción de la función enfermera, rapidez de implementación y registro, y adecuación al proceso enfermero. En cuanto a factores extrínsecos al modelo en relación a limitantes se encontraron: los relacionados con los centros asistenciales (falta de recursos, falta de proyectos propios, escasez de apoyo y rigidez institucional de funcionamiento), la propia formación académica, la concepción social de la enfermera, aspectos estereotipados como inherentes tradicionalmente al colectivo (baja motivación, poco liderazgo...) y la falta de desarrollo del rol propio profesional (percepción de falta de utilidad y la preferencia por otros instrumentos de orden metodológico pero no teórico). Como elementos facilitadores se encontraron la formación avanzada académica de las enfermeras, las cualidades personales de los profesionales (motivación, empatía,...), los cambios sociales, la participación en la gestión de los centros y el desarrollo del conocimiento propio de la disciplina (incluyendo la investigación). Se priorizaron como elementos muy influyentes el liderazgo clínico de las enfermeras y la sensibilidad y necesidad de las direcciones de enfermeria en aplicar modelos teóricos en los pacientes. Como elementos limitantes encontramos prioritariamente el pragmatismo y la ausencia de auto-crítica personal centrada en no tener la necesidad de basar la práctica profesional en conocimiento propio unido a una falta de reconocimiento del uso de modelos en el desarrollo como disciplina.

Palabras clave: Modelos de enfermería. Cuidados de enfermería. Métodos. Filosofía en enfermería.

\section{Abstract}

Application of theory into practice has been a controversial topic. Application of nursing theories involves sharing values and beliefs from the theoretical proposals. Some experienced 
professionals in the field believe that nursing theories need to be updated since they are only academic exercises. However, this point of view is not very clear in our field since many health centers implement Nursing Theory. The Virginia Henderson's model, hegemonic model of practice, has been generally well valued among professionals. Thus, there are studies that evaluate the models in very specific situations or philosophically. However, investigations have not looked into which factors determine the success or failure of the application of a particular theory into practice at national level. Therefore, the primary aim of this study was to identify the factors that determine the use of a nursing theoretical model to guide professional practice.

Methodology: It is a descriptive study carried out in different phases that were developed based on the research needs identified over time (emergent design). Specific aims were chosen for each phase. These phases, depending on the characteristics of the research topic, required of various methods of data collection that were used on professionals with different educational profiles and from different fields. Therefore, the present study used "mixed methods", selecting quantitative or qualitative approaches as it was required. The current work consisted of a total of 6 aims developed in different phases.

Phase 1 used a cross-sectional design, and reviewed the study plans of 109 Spanish universities in which the Bachellor of Nursing was taught during the academic year 2008-2009. All the Bachelor degrees were recognized by Ministry of Education. We revised the study content through their websites, and we collected all possible information of the subjects related to philosophy and nursing methodology developed throughout the degree. In order to analyze the data a table was created that contained all relevant information from each document. Means and standard deviations were used for continuous variables whereas categorical variables were presented in the form of frequencies and percentages.

Phase 2 was carried out using a quantitative design. It inquired about the point of view of a large number of subjects either nursing profesionals $(n=204)$ or nursing trainees $(n=105)$. The purpose was to determine how the theoretical models influenced professional practice in institutions that were not based by a specific conceptual model. Professionals of the Corporació Sanitària Parc Taulí (CSPT) and nursing students in training practices at the Universitat Internacional de Catalunya $(n=30)$, Gimbernat Nursing University School $(n=30)$ and Creu Roja Nursing University School $(n=45)$ were studied. Data collection was conducted through a self reported questionnaire, which was collected anonymously through closed ballot box. A descriptive study was conducted as mean and standard deviation or frequencies and percentages 
depending on the variable studied. Data analysis was carried out using The Pearson chi-square or linear correlation of Yates depending on the sample size. A 95\% confidence interval was used.

Ethnography was used in phase 3 as the framework for the study of the development of models of patients care in various health centers. A total of 190 essays from Masters students in Nursing Science on theoretical application were studied for this purpose. They were produced by 539 nurses from a total of 6 Spanish universities during the academic years 1999-2010. The content of these essays was analyzed following Miles and Huberman's scheme and Chinn and Kramer's structure to analyze the effectiveness of the theoretical models.

Phase 4, which followed the same methodology as phase 3 , analyzed essays related to the theoretical and professional development of Nursing in Spain. A total of 154 essays on barriers and 133 essays on facilitators of the theoretical and professional development of nursing in Spain were analyzed. They were examined according to the analysis of content of Miles and Huberman. The data for phase 3 and 4 was obtained directly from the database of teacher that taught the theoretical models module at the Master in Nursing Science.

Since the priority of the different elements was not shown in these assays, phase 5 was established. A Delphi study was performed. It investigated the opinions of managers of health centers and university teachers in subjects related to the conceptual basis of nursing $(n=31)$, with regards to facilitators and barriers on the use and development of nursing models in Spanish practice.

Due to the methodological premises exposed, all the subjects were chosen through convenience sampling.

We carried out a continuous literature review throughout the length of the present study. However, by the end of the study we felt the need to carry out phase 6 , which includes an integrative review of the literature. The aim was to describe the detailed and updated situation within Europe with regards to the implementation of specific theoretical models traditionally recognized in practice. In order to do this, an exhaustive search on the topic over the last 5 years (from 2008 to 2013) was conducted using the bibliographic database MEDLINE via Pubmed. We studied the variables in the form of frequencies and percentages. Furthermore, we carried out an analysis of the content of each of the articles found.

With regards to ethical considerations confidentiality of all the data was ensured. Furthermore, the authorship of the Master essays was not disclosed. 
Ethical approval to carry out the present study was obtained from the Ethics Committee and Clinical Research of both the CSPT (data collected in their center) and from the foundation of Mataró Tecnocampus Maresme. The foundation of Mataró Tecnocampus Maresme provided the ethical responsibility for the whole study.

Results: With regards to the formation, of the 109 university centers included, $83,5 \%$ had the plan of studies available on the web and the $7,3 \%$ were in accordance with a specific theoretical basis. Fifty six percent of the centers attached the study plan of the subject related to the conceptual nursing basis. The number of credits related to Nursing and Theory Models were 13,4 $\pm 2,4$ ( 6 to 19 credits) and $6,7 \pm 1,4$ of those were practical training. With regards to content, 95,2\% included content on Theoretical Models, the 95,2 \% on Nursing Methodology and the $33,9 \%$ on the History of Nursing. $31,7 \%$ of the centers followed Henderson's model. $15,3 \%$ of centers included another compulsory subject within the study plan in relation to Nursing Theory $(10,7$ $\pm 5,5$ credits) and $19,2 \%$ included an optional subject about this topic ( $5 \pm 1,4$ credits).

In relation to the models applied implicitly by students and professionals in the CSPT, the explicit model under which they were trained was mostly V. Henderson in both groups $(74 \%$ in professional vs. $60 \%$ among students). $23,3 \%$ of professionals reported to follow this theoretical model in their practice compared to $62,1 \%$ of students $(p<0,01) .14,6 \%$ of the professionals on the $14,6 \%$ of students $(p<0,05)$ claimed that the model was always useful for them. Both groups were positive to introduce a theoretical model in the center $(63,2 \%$ vs. $65,7 \%, p>0,05)$. Similar percentages indicated that the model should be different depending on the type of patient $(11,5 \%$ versus $17,6 \%, p>0,05)$. Both groups selected V. Henderson as a model in their practice $(35,3 \%$ versus $51,4 \%$ of the students, $p<0,01)$.

In relation to the Master's essays on theoretical models and the study of advantages and disadvantages perceived by the professionals on the implementation of a theoretical model the results are as follows: out of 190 care plans, $25,8 \%$ were under the model of V. Henderson, a $22,6 \%$ were under the model of D. Orem, a 22,1 \% under the model of C. Roy, a 11,6\% under the model of H. Peplau, 6,3\% under the model of I. King, the 6,3\% were under the modle of M. Leininger and 5,3\% of the care plans used the model of B. Neuman. Most of the essays were carried out in hospitals. There was no model recommended for emergency unit, intensive care or surgery area. Positive elements of the models were: the clarity, the development of the assessment, clarification on the role of the nurse and cared person and the adaptation of the care plan especially if it allowed its use with nurse taxonomy. Negative aspects of the model were, the ele- 
vated implementation time, the lack of specific instruments to carry out physical assessment and the repetitiveness of elements and concepts displayed in some models.

Regarding to the viewpoint of Masters students about the elements that influenced the theoretical and professional development, a greater number of responses were obtained on barriers or limiting factors (154 responses) than on facilitating factors (77 responses). The students indicated that they were important facilitator elements, the management policies of the health centers, the support of managers, the legislative support, the increase in human resources, the decrease in the workload and the change of care model from a medicalised-approach to an approach in which health focused on facilitating progress. They also believed it was necessary to recognize the professional career of the nurse and decrease employees mobility between health care units. They also indicated that another important factor was to train nurses on their own conceptual bases guided by nurses, accompanied by a greater knowledge of languages. Another of the facilitating factors was the society support to the nursing collective, the visibility of the actual work that the nurse does and its relevance to public health, as well as the development of our own research. They also valued as facilitator factors collective aspects such as motivation, responsibility, commitment, critical thinking, leadership and interdisciplinarity.

With regards to the limiting or facilitator factors and barriers described by managers and teachers of the study following Delphi methodology (23 subjects), prioritization of the facilitators "the leadership of the nurses" and "raising awareness of nursing managers to apply theoretical models to the patients" were highlighted by 23 of the subjects. With regards to the limiting aspects, the following topics linked to the individual character of some nurses where highlighted by 21 of the participants: "pragmatism and the lack of personal reflection not to have the need to base the practice on self-knowledge" and "the lack of recognition of the use of models in the development as a discipline".

In relation to the bibliographic review (conducted from the publication year 2008 to 2013) a total of 276 publications were included. The majority of them focused on the models proposed by R. Parse $(21 \%)$ and C. Roy (15,6\%). Most items are theoretical $(26 \%)$ of American authors $(60,8 \%)$, working in higher education $(82,2 \%)$.

Conclusions: With regard to the main aim of the study we found that the choice of a particular theoretical model in nursing relates to subjective, objective and contextual factors. These factors can be categorized into two main groups: intrinsic and extrinsic. The intrinsic factors evaluated as facilitators for the selection of a theoretical model for the practice were: personal identification with the philosophy, the training received, popularity in their own working envi- 
ronment, ease for implementation, adequacy of the theory to the patient and the context, language simplicity and assessment of the person. Its generality, the clarity of the nursing role description, quick implementation and registration, and alignment with the nursing process were also indentified. In relation to extrinsic factors the following limiting factors were found: those related to the health care centers (lack of resources, lack of their own projects, lack of support and institutional rigidity), academic training itself, the social conception of the nurse, stereotypes that has been traditionally associated to the collective (low motivation, little leadership...) and the lack professional (lack of usefulness perception and the preference for methodological instruments instead of theoretical). The following facilitator elements were found: higher academic training of nurses, the personal qualities of the professionals (motivation, empathy, ...), the social changes, the participation in the management of the centers and the development of the discipline own knowledge (including research). Both, clinical leadership of the nurses and raising awareness of nursing managers to apply theoretical nursing models in patients were identified as highly influential elements. As limiting elements we primarily found the pragmatism and lack of self-criticism associated with not having the need to base practice on own knowledge together with a lack of recognition of the use of models in the development as discipline.

Key words: Nursing models. Nursing care. Methods. Nursing philosophy 


\section{Índice de contenidos}

Agradecimientos

Abreviaturas III

Resumen VII

Abstract XI

Índice de contenidos XVII

Índice de tablas $X X I$

Índice de figuras $x x V$

1 Introducción 1

1.1

Planteamiento del problema. .5

1.2

Marco conceptual enfermero.

.9

1.3 Formación enfermera en nuestro entorno como elemento condicionante del desarrollo teórico y profesional

1.4 La influencia del modelo de Virginia Henderson como modelo formativo y clínico predominante en España

1.5 Desarrollo teórico y el desarrollo profesional en la disciplina enfermera, dos unidades indisolubles.

2 Objetivos 39

Objetivo general.

3 Metodología

Metodología para el desarrollo del primer objetivo específico: Describir el estado formativo de pregrado que ha podido influir en la implantación de modelos teóricos en la práctica de enfermería en España.

3.2 Metodología utilizada para dar respuesta al segundo objetivo específico:

Conocer qué modelo enfermero se aplica de forma implícita (sin ser regularizado institucionalmente) en la práctica profesional y su relación con la formación recibida. 
las ventajas y desventajas percibidas por los profesionales sobre el uso de un modelo teórico enfermero para el cuidado.

3.4 Metodología utilizada para dar respuesta al cuarto objetivo específico:

Identificar los elementos que han influenciado el uso teórico y desarrollo profesional de la enfermería en España desde la perspectiva de las enfermeras en periodo de formación de Máster.

3.5 Metodología utilizada para dar respuesta al quinto objetivo: Determinar los elementos que han facilitado y los que han impedido el uso y desarrollo de modelos teóricos en la práctica española desde la perspectiva de enfermeras gestoras y docentes

3.6 Metodología utilizada para dar respuesta al sexto objetivo específico: Describir el nivel de implantación de modelos enfermeros en la práctica actual a nivel internacional........77

Límitaciones del estudio

4.1 Resultados en relación al primer objetivo: Describir el estado formativo que ha podido influir en la implantación de modelos teóricos en la práctica

4.2 Resultados en relación al segundo objetivo: Conocer qué modelo enfermero se aplica de forma implícita (sin ser regularizado institucionalmente) en la práctica profesional y su relación con la formación recibida.

4.3 Resultados en relación al tercer objetivo: Conocer las ventajas y desventajas percibidas por los profesionales sobre el uso de un modelo teórico enfermero para el cuidado.109 4.4 Resultados en relación al cuarto objetivo: Identificar los elementos que han influenciado el uso teórico y desarrollo profesional de la enfermería en España desde la perspectiva de las enfermeras en periodo de formación de Máster

4.5 Resultados en relación al quinto objetivo: Determinar los elementos que han facilitado y los que han impedido el uso y desarrollo de modelos teóricos en la práctica española desde la perspectiva de enfermeras gestoras y docentes.

4.6

Resultados en relación al sexto objetivo: Describir el nivel de implantación de modelos enfermeros en la práctica actual a nivel internacional. 
5.1 Discusión objetivo 1: Describir el estado formativo de pregrado que ha podido influir en la implantación de modelos teóricos en la práctica de enfermería.

5.2 Discusión objetivo 2: Conocer qué modelo enfermero se aplica de forma implícita (sin ser regularizado institucionalmente) en la práctica profesional y su relación con la formación recibida.

5.3 Discusión objetivo 3: Conocer las ventajas y desventajas percibidas por los profesionales enfermeros sobre el uso del modelo teórico enfermero para el cuidado.

5.4 Discusión objetivo 4: Identificar los elementos que han influenciado el uso teórico y desarrollo profesional de la enfermería en España desde la perspectiva de las enfermeras en periodo de formación de Máster

5.5 Discusión objetivo 5: Determinar los elementos que han facilitado y los que han impedido el uso y desarrollo de modelos teóricos en la práctica española desde la perspectiva de enfermeras gestoras y docentes.

5.6 Discusión objetivo 6: Describir el nivel de implantación de modelos enfermeros en la práctica actual a nivel internacional

6. Conclusiones

7. Referencias

8. Anexos

Anexo 1

Certificados CEIC de Corporació Parc Taulí y Comité de Investigación de Fundació Tecnocampus 297

Anexo II 305

Carta de presentación y cuestionarios usados en relación al segundo objetivo 305

GLOSARIO DE TÉRMINOS:

Anexo III

Cartas de presentación, mails y cuestionarios enviados a los participantes en la técnica Delphi para dar respuesta al quinto objetivo

Anexo IV (Contenido del CD-ROM) 346

Tablas de resultados asociadas al objetivo 1: Describir el estado formativo de pregrado que ha podido influir en la implantación de modelos teóricos en la práctica de enfermería en España 
Tablas de resultados asociadas al objetivo 2: Conocer qué modelo enfermero se aplica de forma implícita (sin ser regularizados institucionalmente) en la práctica profesional y su relación con la formación recibida.

Tablas de resultados asociadas al objetivo 3: Conocer las ventajas y desventajas percibidas de profesionales enfermeros sobre el uso del modelo teórico enfermero para el cuidado. 371

Tablas de resultados asociadas al objetivo 4: Identificar los elementos que han influenciado el uso teórico y desarrollo profesional de la enfermería en España desde la perspectiva de las enfermeras en periodo de formación de Máster.

Tablas de resultados asociadas al objetivo 6: Describir el nivel de implantación de modelos enfermeros en la práctica actual a nivel internacional. 


\section{Índice de tablas}

Tabla 1: Ejemplos de modelos conceptuales y conceptos principales.

Tabla 2: Autoras de Teorías enfermeras 14

Tabla 3: Clasificación de Modelos y Teorías según Beck 16

Tabla 4: Tabla adaptada de las principales concepciones de la disciplina según las seis escuelas que describen Kérouac et al. (1996).

Tabla 5: Modelos enfermeros frecuentes en la literatura, interpretación del metaparadigma y algunos conceptos clave (Marriner \& Raile, 2003 y 2011)

Tabla 6: Análisis de los métodos usados en el estudio para asegurar la calidad de la investigación de los objetivos desarrollados mediante aproximaciones cualitativas 49

Tabla 7: Análisis cronológico del desarrollo de los objetivos específicos 50

Tabla 8: Datos característicos de cada uno de los centros universitarios. 56

Tabla 9: Título ofertado y estudiantes matriculados en el programa de Máster o Estudios Superiores en Ciencias de la Enfermería de red interuniversitaria 63

Tabla 10: Modelos aplicados en los trabajos y selección ( $n=373)$ 68

Tabla 11: Descripción de las categorías utilizadas para el análisis de los textos de los trabajos sobre modelos de los alumnos de Máster 69

Tabla 12: Descripción de las categorías utilizadas para el análisis de los textos de los trabajos sobre modelos de los alumnos de Máster 76

Tabla 13: Términos MeSH usados en la búsqueda y su definición en Medline 81

Tabla 14: Términos utilizados en la búsqueda de artículos basados en Teoristas enfermeras en Medline 82

Tabla 15: Asignaturas obligatorias en relación a modelos teóricos durante el curso académico 2008-2009 94

Tabla 16: Asignaturas optativas en relación a modelos teóricos durante el curso académico 2008-2009 96

Tabla 17: Centros donde cursaban o cursaron sus estudios los profesionales y estudiantes ( $n=309)$

Tabla 18: Ámbito y turno laboral o de prácticas de profesionales y estudiantes 98 
Tabla 19: Comparación entre los diferentes modelos usados en la formación para ambos grupos

Tabla 20: Datos sociodemográficos de la muestra de estudiantes

Tabla 21: Comparación entre las diferentes elecciones del seguimiento manifestado de un modelo teórico enfermero en la actividad laboral o en prácticas (profesionales $n=204$ ) estudiantes $n=105$ ) 100

Tabla 22: Modelos que manifiestan seguir en su práctica 101

Tabla 23: Creencia de utilidad del modelo teórico estudiado actual para el profesional y utilidad futura para el estudiante 101

Tabla 24: Comparación entre las diferentes elecciones de la frecuencia con la que creen identificarse con el modelo de cuidado que prestan 102

Tabla 25: Creencia de que se debe implantar un modelo en el centro de estudio (CSPT) 102

Tabla 26: Opinión sobre la aplicación de un modelo diferente en función del tipo de paciente

Tabla 27: Utilidad de los actuales registros para trabajar bajo un modelo teórico enfermero

Tabla 28: Características de los pacientes en los que fue aplicado el modelo de V. Henderson para la elaboración del proceso enfermero.

Tabla 29: Características de los pacientes en los que fue aplicado el modelo de D. Orem para la elaboración del proceso enfermero.

Tabla 30: Características de los pacientes en los que fue aplicado el modelo de C. Roy para la elaboración del proceso enfermero

Tabla 31: Características de los pacientes en los que fue aplicado el modelo de H. Peplau para la elaboración del proceso enfermero

Tabla 32: Características de los pacientes en los que fue aplicado el modelo de B. Neuman para la elaboración del proceso enfermero

Tabla 33: Características de los pacientes en los que fue aplicado el modelo enfermero de

I. King para la elaboración del proceso enfermero

Tabla 34: Características de los pacientes en los que fue aplicado el modelo enfermero de M. Leininger para la elaboración del proceso enfermero 
Tabla 35: Resumen de los ámbitos elegidos para la aplicación de los modelos

Tabla 36: Resumen de la adecuación del uso del modelo en los casos planteados (cuando así lo explicitaron los alumnos de forma textual) 155

Tabla 37: Situaciones en las que se recomendó el uso del modelo

Tabla 38: Aspectos evaluados como positivos de los modelos aplicados en los planes de cuidados (sombreados)

Tabla 39: Aspectos evaluados como negativos de los modelos aplicados en los planes de cuidados (sombreados)

Tabla 40: Análisis de los textos de la pregunta sobre los elementos facilitadores de la aplicación de modelos en la práctica (Delphi)

Tabla 41: Análisis de los textos de la pregunta sobre los elementos que han impedido la aplicación de modelos en la práctica (Delphi)

Tabla 42: Puntuación de los ítems del Delphi a la pregunta sobre elementos favorecedores para la aplicación de modelos teóricos en la práctica

Tabla 43: Puntuación de los ítems del Delphi a la pregunta sobre elementos desfavorables para aplicar modelos teóricos en la práctica

Tabla 44: Prioridad obtenidas sobre los factores que facilitan la aplicación de modelos en la práctica en la tercera ronda del Delphi

Tabla 45: Prioridad obtenidas sobre los factores que impiden la aplicación de modelos en la práctica en la tercera ronda del Delphi

Tabla 46: Publicaciones halladas en Pubmed al utilizar los principales términos Mesh junto a operadores booleanos que describen los artículos indexados en los mismos mediante la teoría enfermera en la base de datos y los artículos indexados en investigación enfermera

Tabla 47: Publicaciones halladas en Pubmed según teorista y años de publicación

Tabla 48: Publicaciones según la revista y tipo de de publicación

Tabla 49: Nacionalidad del autor y lugar de publicación de los artículos hallados.

Tabla 50: Publicaciones halladas para el modelo de R. Parse

Tabla 51: Publicaciones halladas para el modelo de Sor Callista Roy

Tabla 52: Publicaciones halladas para el modelo de Dorothea E. Orem 
Tabla 53: Publicaciones halladas para la teoría de Jean Watson

Tabla 54: Publicaciones halladas para el modelo de Madeleine M. Leininger 207

Tabla 55: Publicaciones halladas para el modelo de Betty Neuman 209

Tabla 56: Publicaciones halladas para el modelo de Martha E. Rogers 210

Tabla 57: Publicaciones halladas para la teoría de Peplau 210

Tabla 58: Publicaciones halladas para el modelo de Henderson 212

Tabla 59: Publicaciones halladas para el modelo de Imogene King

Tabla 60: publicaciones halladas para la teoría de Orlando 


\section{Índice de figuras}

Figura 1: Estructura jerárquica del conocimiento enfermero contemporáneo 10

Figura 2: Proceso de selección de los trabajos de Máster 67

Figura 3: Distribución de los centros según Comunidad Autónoma (CCAA) 93

Figura 4: Comparativo entre la edad en profesionales frente a los estudiantes 97

Figura 5: Modelo usado en la formación de los sujetos estudiados 99

Figura 6: Seguimiento manifestado de un modelo teórico enfermero en la actividad laboral o en prácticas (profesionales $n=204$, estudiantes $n=105$ ) 101

Figura 7: Frecuencia con la que creen identificarse con el modelo de cuidado que prestan 102

Figura 8: Modelo propuesto por los profesionales y estudiantes para trabajar en la atención asistencial 104

Figura 9: Mapa conceptual de los factores que determinan la elección de un modelo para la labor profesional expresados por los profesionales encuestados 107

Figura 10: Mapa conceptual de los factores que determinan la elección de un modelo para la labor profesional expresados por los estudiantes encuestados 108

Figura 11: Proceso de análisis de los planes de cuidados 110

Figura 12: Histograma de la distribución por edades de los pacientes a los que se aplicó el modelo de $V$. Henderson en el plan de cuidados 113

Figura 13: Histograma de la distribución por edades de los pacientes a los que se aplicó el modelo de $D$. Orem en el plan de cuidados 119

Figura 14: Histograma de la distribución por edades de los pacientes a los que se aplicó el modelo de C. Roy en el plan de cuidados 127

Figura 15: Histograma de la distribución por edades de los pacientes a los que se aplicó el modelo de H. Peplau en el plan de cuidados 136

Figura 16: Histograma de la distribución por edades de los pacientes a los que se aplicó el modelo de B. Neuman en el plan de cuidados 142

Figura 17: Histograma de la distribución por edades de los pacientes a los que se aplicó el modelo de l. King en el plan de cuidados 146 
Figura 18: Histograma de la distribución por edades de los pacientes a los que se aplicó el modelo de M. Leininger en el plan de cuidados 150

Figura 19: Comparativo de las edades frente a los modelos aplicados en los planes estudiados 154

Figura 20: Resumen de los hallazgos del estudio Delphi en cuanto a los elementos influenciadores de aplicación de modelos teóricos en la práctica 192

Figura 21: Identificación y selección de los artículos relevantes 194

Figura 22: Distribución de los artículos de modelos según continente de publicación 199

Figura 23: Publicaciones según el lugar de filiación laboral de los autores de los artículos 199 
1 Introducción 
Durante muchos años se cuidó al paciente bajo el prisma de modelo tradicional asociado al cuidado de la enfermedad y dependiente de la disciplina médica. No obstante, la práctica enfermera nos revela que no sólo actúa en situaciones de enfermedad; sino que se centra en el cuidado a la persona que, en continua interacción con su entorno, vive experiencias de salud (Kérouac, Pepin, Ducharme, Duquette \& Mayor, 1996). La práctica médica crea intervenciones vitales que se expresan en procesos diagnósticos, intervenciones quirúrgicas, tratamientos, etc. Sin embargo, la práctica enfermera en estrecha colaboración con otras disciplinas, permite a las personas hacer utilizar los recursos personales internos, dando sentido a sus experiencias de salud y de vida (Kerouac et al., 1996). Estos cuidados se expresan mediante intervenciones basadas en el apoyo, reconocimiento, asesoramiento y autorrespeto, entre otras y no sólo mediante la asunción de tareas tipificadas. Estas responsabilidades procedentes del centro de interés de la disciplina enfermera, permitieron que a partir de los años 50 y sobre todo entre los años 60 y 70, se impulsara la necesidad de elaborar marcos conceptuales teóricos propios para separar la disciplina enfermera de la formación médica para fomentar el desarrollo de conocimiento propio. Gracias a la estandarización de los estudios en EE.UU. de Máster y Doctorado en Ciencias de la Enfermería en los años 70', se incluyó la investigación como parte del currículo formativo enfermero. Este desarrollo de conocimiento enfermero se basó en la elaboración de la propia filosofía enfermera, estructurada en teorías y modelos enfermeros para obtener el reconocimiento de la disciplina como profesión diferenciada de la medicina. Los resultados de las primeras investigaciones enfermeras se desarrollaron bajo los rigores metodológicos y tutelados por otras disciplinas, esta situación dio lugar a resultados en algunos casos desvinculados del significado propio de la enfermera. Como consecuencia fomentó la necesidad de justificar los estudios dentro del marco conceptual enfermero. Fue una dilatación natural derivada de la etapa investigadora, por lo que investigación y teoría crearon unidas ciencia enfermera. Por lo tanto, estos marcos debían de conformar el desarrollo profesional, íntimamente asociado a la aplicación y desarrollo de evidencia en la disciplina (Marriner \& Raile, 2003). La filosofía enfermera es el resultado de una reflexión rigurosa sobre la naturaleza y el proceso enfermero, una formulación de ideas, una conceptualización de la realidad con el propósito de entenderla (Pearson, Vaughan \& FitzGerald, 2005).

Esta realidad no es ajena a nuestro contexto, tradicionalmente en nuestro país, la mayoría de los centros sanitarios han basado su práctica en el modelo centrado en la patología, en algunos escritos referenciado como modelo biomédico. Pero a partir de finales de los años noventa, a esta forma de atención en España, se fue integrando un modelo teórico de referencia para el trabajo enfermero que generalmente fue el modelo de Virginia Henderson. Esta forma de organizar el cuidado, fue implantándose mayormente en instituciones hospitalarias (Campo, Oriach, Viladot, Espinalt \& 
Fernández, 1999; Pina, Fernández \& Crespo, 1990), y fue extendida también de forma casi simultánea en el ámbito de la atención comunitaria (Besora, 1994). No obstante, no todos los centros implantaron esta metodología de trabajo, y los que lo hicieron, no lo realizaron ni de la misma forma o con la misma intensidad. Esta inmersión teórica española queda plasmada tanto a nivel docente como en las publicaciones científicas, con la prevalencia del modelo de Virginia Henderson como guía por encima del resto de los modelos. Sin embargo, esta situación es diferente a la hallada en otros países de Europa en los que, aunque hay alguna referencia relativa al seguimiento del modelo de Roper, Logan y Tierney (Hilton, 2004), no existen actualmente modelos teóricos enfermeros referentes para la práctica enfermera; sino que prevalece la aplicación de modelos de atención diversos que se ocupan de aspectos más costo efectivos que filosóficos, que garanticen una atención de calidad a las personas cuidadas.

Lo que sí parece común entre diferentes autores, es que el desarrollo de la filosofía y teoría enfermera es necesario para el progreso de la disciplina (Marriner \& Raile, 2003), ya que la mejora profesional va directamente ligada al incremento del cuerpo propio de conocimientos. Meleis (1992) sugirió que el progreso de la disciplina enfermera pasaba por cuatro etapas: la teórica, el desarrollo de una sintaxis, el desarrollo de conceptos y por último, el debate filosófico. Respecto a este debate, en la actualidad, se aprecia ausencia de concreción epistemológica entre los profesionales. Tal y como referencian diversos autores como Hernández, Moral y Esteban (1999) o M. López et al. (2006), en realidad sólo podemos hablar de corrientes teoréticas como modelos teóricos probables o como decía McCutcheon (2004), la filosofía enfermera práctica es un conglomerado teórico de modelos enfermeros. Esta idea ya es propia de la evolución científica tal y como comentaba Kuhn (1975) "hay también circunstancias, aunque las considero raras, en las que pueden coexistir pacíficamente dos paradigmas en el mismo periodo" (p. 16). En la realidad práctica se observa que los profesionales se ven influenciados por varios modelos formales y estructuras que no admiten una sola perspectiva (McCutcheon, 2004); de hecho, si nos centramos en el foco central de actuación de enfermería, se objetiva que las respuestas humanas son complejas y diversas, propias de la individualidad de cada persona. Esto podría explicar que una sola perspectiva teórica difícilmente dé una respuesta a todas ellas (Fornés, 2005; Zabalegui, 2000). Esta argumentación podría ser la causante de que no sean muchos los centros asistenciales que aplican modelos teóricos enfermeros de forma explícita y generalizada en el cuidado. Esta consideración unida a falta de evidencia científica de la utilidad de los modelos en cuanto a resultados en salud lleva a preguntarse a algunos autores sobre la vigencia de los modelos teóricos (Simpson, 1998). ¿Nos hallamos paralizados ante el debate filosófico que menciona Meleis (2011) y no desarrollamos investigación sobre efectividad y eficacia de aplicación? Lo que si se puede afirmar, es que hay evidencias sobre la implementación teórica en la práctica. 
Este hecho, entraña adoptar una nueva visión disciplinar y profesional que parece ser que entra en conflicto con los valores de nuestro sistema sanitario (Luis, Fernández \& Navarro, 2007). La coyuntura diversa planteada nos conduce a arrojar algo más de luz al tema, intentando clarificar de aquí en adelante los hechos relacionados con la aplicabilidad de los modelos teóricos en la práctica que influencia el progreso profesional. Por ello, el objetivo central de esta tesis fue identificar cuáles eran los factores asociados al uso de un modelo teórico enfermero que guíe la práctica enfermera en nuestro contexto. No fue tanto buscar una casuística del tema, sino más bien, se intentó evidenciar que es lo que los profesionales enfermeros (actores principales) opinaban sobre el tema, partiendo de sus propias vivencias individuales en diferentes entornos y ámbitos laborales.

\subsection{Planteamiento del problema}

Este apartado intenta trazar las ideas principales que justificaron este estudio. Por la literatura consultada, se partió de la necesidad de que se debería fundamentar la práctica enfermera en la teoría, y se reflexionó alrededor de la idea de que esta práctica podía estar dificultada por una serie de agentes que la limitaban, como las estancias hospitalarias cortas o la necesidad de disminuir costes asistenciales (Teffeteller \& Kish, 2012). A causa de estas posiciones divergentes halladas entre el desarrollo conceptual teórico a nivel formativo y su implementación en la práctica enfermera en España tal y como se argumentó en el inicio de la introducción, la razón básica de la elaboración de la tesis fue dar respuesta a cuáles son los factores que influyen en el desarrollo del conocimiento propio de la disciplina enfermera y en su aplicación en la práctica profesional.

Cuando se habla de aplicación de teoría en la práctica, es necesario analizar el histórico de implementación, en él podemos objetivar que siempre ha sido un tema controvertido. Desde el 1860, existen referencias bibliográficas sobre teoría enfermera que marcan el inicio de la enfermería profesional (Marriner \& Raile, 2003; Potter \& Perry, 2002). Sin embargo, en la década de los 90’ se advierte un gran vacío entre teoría y práctica (Goulet, Lauzon \& Ricard, 2003; Maben, Alter \& Mcleod, 2006) resultado de la privación de desarrollo del rol autónomo en la práctica, que provocó la represión de la aplicación completa de las intervenciones de Enfermería dentro de marcos conceptuales enfermeros (Zabalegui, 2000). Hecho importante si partimos de que el cuidado fundamentado científicamente debería originarse de la integración teórico - profesional (Alberdi, Artigas, Cuxart y Aguera, 2003). Curiosamente, existen prácticas como la de la astronomía, la física, la química o la biología que no evocan controversias sobre fundamentos (Khun, 1975), sin embargo si ocurre en otras disciplinas jóvenes, entre ellas podríamos incluir la ciencia enfermera. Quizás uno de los motivos de esta polémica sea que las corrientes de pensamiento en cuanto a la disciplina se originan en 
entornos lejanos al nuestro, influenciadas por enfoques anglosajones que podrían diferir de las visiones de los fenómenos ${ }^{1}$ según la perspectiva de profesionales españoles. Este hecho se ha objetivado sobre todo en términos de metodología enfermera, donde nacionalmente se está trabajando en la aplicación del proceso de atención de enfermería o proceso enfermero unido a taxonomía NANDA que en muchos casos implica gran dificultad por no poder ser aplicada de forma universal; ya sea por problemas de lenguaje, competencias profesionales o interpretaciones socioculturales (Granollers, Montanuy, Estany, Roca \& Ortega, 2006; Román et al., 2005). Volviendo al tema de la teoría, Luis et al. (2007) indican que al implementar un modelo en la práctica se origina un sistema cerrado resumido en "pensar, hacer y rendir cuentas" (p.45). A través de un sistema complejo formado por diferentes subsistemas: conceptual, teórico - metodológico e instrumental. Optar por un modelo conceptual en concreto implica compartir sus valores y creencias, conocer sus conceptos, proposiciones y sus elementos fundamentales. Posteriormente requiere su operativización a través de la aplicación de un método enfermero que organice y sistematice los cuidados, precisa desarrollar documentación, usar tecnología para dirigir la práctica y poder evaluar los resultados de las intervenciones enfermeras. En este análisis de la complejidad en la implementación de teoría en la práctica se conjugan conceptos de metodología y modelo teórico, el primero engloba la aplicación del segundo. Esta implementación debería ser la más frecuente, sin embargo, en los centros donde se aplica el proceso enfermero (método enfermero de trabajo) se están dejando de lado los modelos teóricos, basando sus registros en lenguajes estandarizados y/o patrones funcionales de salud elaborados por Marjory Gordon como mera herramienta de recogida de datos (Consejo General de Enfermería, 2003). En estas situaciones, no hay una reflexión paradigmática sobre el cuidado, sino en todo caso una reflexión pragmática mediante la aplicación de herramientas útiles en el mismo. Aun así, se constata que en lugares que aplican modelos teóricos, tampoco son habitualmente reflexionados, ni profundamente comprendidos por los profesionales que los aplican, por lo que difícilmente las enfermeras que los usan compartirían sus valores. Estas circunstancias llevan a posicionamientos de profesionales experimentados que denuncian un desfase de la teoría enfermera, y la tachan de ser ejercicios meramente académicos más que prácticas profesionales (Medina, 2005). A nivel internacional, se ha pasado de una visión de idolatría teórica en los años setenta a una visión crítica y escéptica a partir de los noventa. Autores como Wimpenny (2002) afirman que la teoría podría haber perdido su legitimidad. Cash (1990) y Biley (1992) anteriormente argumentaron que los modelos eran demasiado generales para ser aplicados y que probablemente tampoco iba a su favor la redundancia de los mismos en la historia enfermera. No obstante, este desencanto no es tan claro en nuestro territorio, ya que son todavía muchos centros los que implementan teoría enfermera

\footnotetext{
${ }^{1}$ Entendiendo por fenómeno aquello que es el principal tema de una disciplina (Marriner \& Raile, 2003).
} 
basada en el modelo de V. Henderson en sus servicios, por lo tanto se consideran útiles en los lugares en los que se aplican.

Wimpenny (2002) propuso a través de sus investigaciones, que el uso del término modelo era insuficiente para describir las perspectivas y variedades de modelos existentes. Sus estudios evidenciaron tres visiones diferenciadas en la aplicacion del modelo: la teórica (que está definida por la visión y propuesta de la teorista), la mental (formada por la comprensión personal de cada una de las enfermeras sobre el modelo) y la sustitutiva (que es el modelo que se aplica finalmente). Según el autor, las tres visiones deben ser congruentes para que la implementación en la asistencia tenga éxito. Si el uso del modelo es sólo el sustitutivo se podría concluir que en la actualidad su uso está extinguido, ya que sería más una herramienta funcional que un modo para desarrollar la profesión enfermera, principalmente teniendo en cuenta que puede que la enfermera que lo aplique no esté de acuerdo con los valores que postula el modelo. Aunque si esto ocurriera, la lógica indicaría que quizás el profesional debería optar por la búsqueda de un centro de trabajo en el que aplicaran una filosofía congruente a los valores propios. Analizando lo expuesto no es de extrañar, la existencia de visiones ambivalentes y divergencias sobre el impacto y la relevancia de filosofía, teorías y modelos conceptuales enfermeros en la práctica. Sobre todo cuando una única perspectiva es presentada como la panacea del cuidado en un entorno concreto, hecho patente en España, donde el modelo de V. Henderson ha sido hegemónico en el país. Sin embargo, algunos profesionales usaron modelos concretos para situaciones concretas, Griffith (1998) halló que se habían adoptado modelos dispares en diferentes unidades del mismo centro desde la perspectiva de experiencias propias, hallazgo ya descubierto en el trabajo de McKenna (1989). McKenna también encontró que gestores de áreas psiquiátricas mostraron mayor preferencia por tres modelos que reflejaban las conductas y necesidades que contenían un modelo de educación biomédico, en este caso seguramente, para continuar trabajando de igual modo al que lo hacían tradicionalmente.

Pese a que Aggleton y Chalmers en 1987 creyeron que el uso de la teoría podría ayudar al crecimiento del conocimiento profesional y proveer mejores experiencias a los estudiantes, existen escasas evidencias de tal impacto (M. E. Urra, 2009). En posteriores trabajos Aggleton y Chalmers (2000) indican desconocimiento de los problemas que han acompañado a los modelos pero saben su potencial de unificación en el desarrollo enfermero, sobretodo como dice Pearson (1992) y Johns (1994), si existe compromiso de los profesionales en su implementación (única forma de que tenga éxito su desarrollo). Entre las ventajas recogidas en la bibliografía sobre el uso de modelos, se hallan el beneficio para el paciente debido al enfoque sistemático y organizado que proporcionan para la práctica enfermera (Marriner \& Raile, 2003) y la facilitación de la gestión institucional. Los modelos 
ayudan a prestar un servicio asequible, accesible, comprendido y aceptado por el usuario y profesionales: mejora la relación entre el importe por servicio y la coordinación entre diferentes niveles asistenciales (Campo et al., 1999). Por ello, el uso de un modelo contribuye a la definición del producto enfermero y por lo tanto a la evaluación de su coste (Campo et al., 1999; Teixidor, 2002a) por lo que debería facilitar un manejo más eficiente de los recursos disponibles (Campo et al., 1999; Morales, 2004). El diagnóstico médico no determina el tiempo enfermero, intervienen también otras variables relacionadas con la etapa de desarrollo y las respuestas individuales de la personas a su proceso de salud-enfermedad (Teixidor, 2002b). Otros autores alegan entre las bondades a destacar que los modelos ayudan a establecer indicadores de calidad en el cuidado (M. E. Moreno, 2005).

Sin embargo, cuando se profundiza en el tema se evidencia una escasez de estudios que demuestren estas bondades, así como, tampoco se hallan estudios actuales sobre los factores que favorecen la aplicación de modelos teóricos. Si se manifiestan investigaciones que inciden en la brecha teórico - práctica entre los valores que se imparten en las aulas y la no aplicabilidad de los mismos en los lugares de trabajo. Posibles factores descritos en tal brecha, que podrían ser factores facilitadores o barrera de su implementación son: la hegemonía del modelo biomédico (con escasos modelos basados en el rol enfermero), la estructura organizativa de las instituciones (Goulet et al., 2003; Maben et al., 2006) y la elevada carga asistencial en las unidades de trabajo (Maben et al., 2006; Teixidor, 2002a). Igualmente, existen otros factores profesionales que impiden también su desarrollo que en muchos casos son aspectos relacionados con características de los entornos asistenciales. Maben et al. (2006) Ilaman "obeying covert rules" a estos factores. Las "reglas encubiertas" son prácticas de cuidado de los centros de trabajo diferentes o distorsionadas a las que se aprenden durante la etapa formativa. Pese a que el estudiante finaliza su carrera integrando entre otros valores conocimientos, procedimientos y actitudes de forma adecuada, estos son socializados en función de las necesidades del sistema con el que conviven, y éste socializa a su vez al personal de nueva incorporación. Modificando prácticas correctas por otras de menor rigor metodológico, basadas en una visión pragmática del cuidado. De esta manera prevalece la atención de aspectos físicos sobre el resto, el profesional no se implica profundamente en el cuidado de la persona atendida y se abortan nuevas sugerencias de trabajo. A esto se asocia la perspectiva de falta de utilidad y credibilidad de los modelos por las enfermeras base interesadas en "lo que es" realmente la práctica y no en lo que según otros "debería ser" (visión de la teoría por parte de las enfermeras) por lo que tradicionalmente los modelos se han considerado impracticables (Miller, 1985; M. E. Moreno, 2005). 


\subsection{Marco conceptual enfermero}

Para entender qué factores son los que han influenciado la aplicación de filosofia enfermera en la práctica, es necesario determinar la forma en la que el conocimiento enfermero ha ido evolucionando. Esto incluye tanto el conocer que se entiende por la base conceptual enfermera, como su estructura jerárquica de desarrollo, su estructuctura taxonómica, así como un breve resumen de su progreso histórico.

\subsection{1 ¿Qué se entiende por teoría o modelo de enfermería?}

En general, los Modelos o Teorías de Enfermería son el fruto de la indagación acerca de qué es Enfermería, quién es la persona que desarrolla la disciplina y qué es aquello que aporta específicamente a la atención de salud de las personas (Benavent, Francisco \& Ferrer, 2001). Por ello, el principal resultado es demarcar la identidad de la enfermera en el seno de la comunidad, estableciendo sus objetivos o foco de atención según el modelo adoptado. Por tanto, los modelos identifican y clarifican la relación y diferenciación de la enfermera con respecto a otros profesionales de salud (Alberdi et al., 2003; Benavent et al., 2001) y según Meleis (2011) evitan que la práctica esté basada únicamente en intuiciones, rutinas y rituales.

Dentro de sus características tienen en común el uso del razonamiento operativo para definir su contenido, permiten determinar y tratar la respuesta a la salud de las personas por su aproximación holística. Además, promueven teorías y conceptos bien definidos sujetos a investigación (Burney, 1992). Esta conexión entre teoría y metodología enfermera ha provocado que muchos profesionales identifiquen el modelo teórico con el plan de cuidados, particularmente con los registros escritos (Wimpenny, 2002) y confundan terminología metodológica con conceptos propios de filosofía enfermera (Santos, López, Varez \& Abril, 2008a). Pese a que la base filosófica enfermera está formada por diferentes niveles de concreción, habitualmente se usan como sinónimos en la literatura términos como modelo teórico, marco conceptual, filosofía o teoría enfermera (Pearson et al., 2005; Polit \& Beck, 2004). En un intento de matizar estos conceptos y sabiendo de antemano que en la presente tesis en ocasiones han sido y serán usados como sinónimos de la base conceptual enfermera, lo más coherente es iniciar una exposición sobre qué se entiende por componentes estructurales del conocimiento enfermero (Fawcett, 2005; Marriner \& Raile 2003). 


\subsubsection{Componentes del conocimiento enfermero}

La estructura jerárquica del conocimiento enfermero contemporáneo es un dispositivo heurístico complejo, que coloca a los componentes del conocimiento en una jerarquía basada en el nivel de abstracción. Esta complejidad conceptual, pese a que forma parte de la formación básica, es difícilmente comprendida en la formación pregraduada, incrementándose su entendimiento en fases posteriores de la formación postgraduada. Según el nivel de abstracción (de mayor a menor nivel de abstracción) el conocimiento enfermero está formado por diferentes componentes, tal y como se exponen en la figura 1. Cada uno de los componentes de la estructura jerárquica del conocimiento que se detallarán más adelante, está formado principalmente por conceptos y proposiciones y en algunos casos también asunciones.

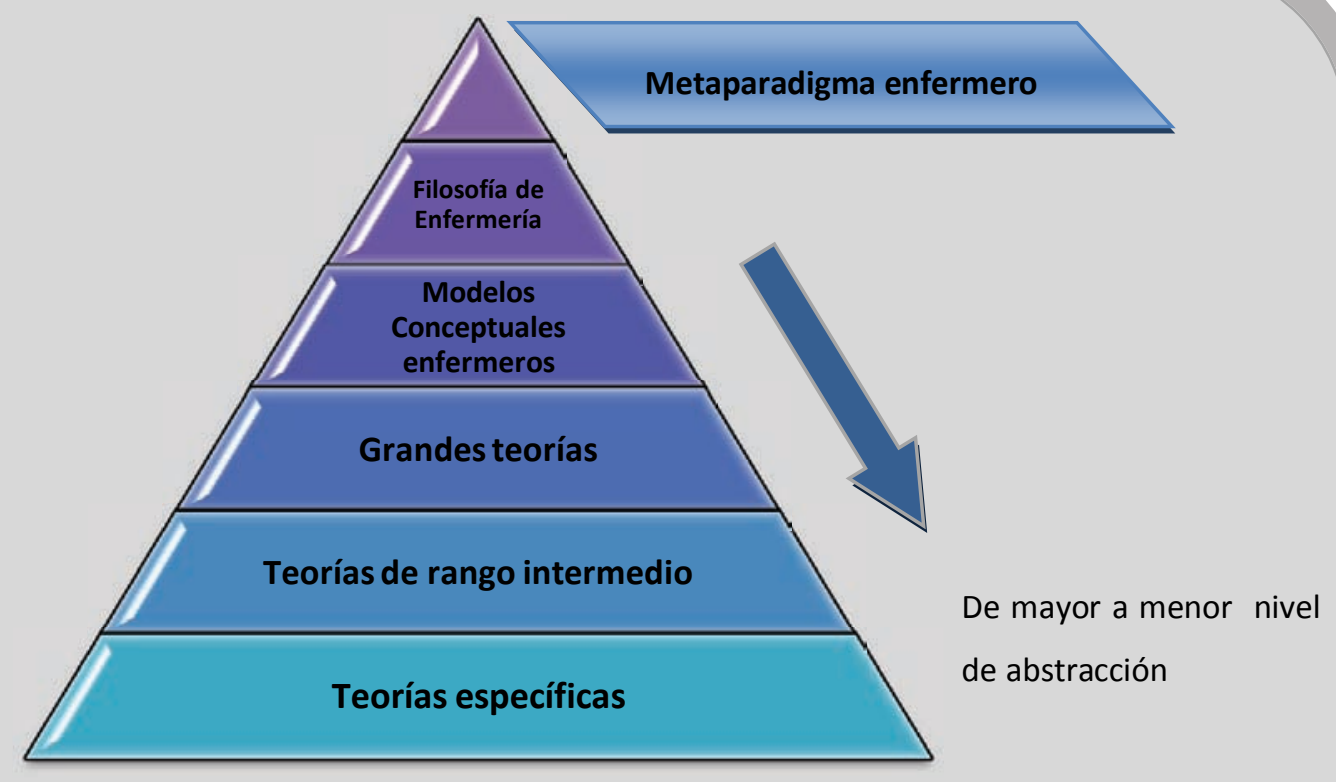

(Diagrama elaborado a partir de la obra de Fawcett, 2005)

\section{Figura 1: Estructura jerárquica del conocimiento enfermero contemporáneo}

Un concepto se define como "una frase o palabra que resume las características esenciales o propiedades de un fenómeno" (Fawcett, 2005, p.3). Son "formulaciones mentales de un objeto o un acontecimiento derivadas de la experiencia de percepción del individuo" (Potter \& Perry, 2002, p.90). Los conceptos clasifican y describen los fenómenos de interés y no pueden considerarse aislados de las teorías en las que se hallan inmersos ya que pueden tener significados diferentes en distintos sistemas teóricos (Marriner \& Raile, 2003). Cuando se realiza "una declaración sobre un concepto o una declaración de la relación entre dos o más conceptos" se forma una proposición 
(Fawcett, 2005, p.3). Su refutación solo se permite bajo investigación, es el "cómo" del cuidado. Por último, las asunciones configuran el "por qué" del cuidado e incluyen la perspectiva de la teorista sobre los valores, creencias sobre la naturaleza del ser humano, la salud y las metas profesionales; por lo que no son susceptibles de comprobación empírica ya que son datos totalmente subjetivos. No obstante deberían de ser oportunos con los valores de la sociedad objeto del cuidado y con los propios valores del profesional que los aplica (Luis et al., 2007).

Según comentan Luis et al. (2007), Adams en 1991 añadió otros elementos que dan sentido a las actuaciones enfermeras. Estos elementos son el objetivo de la profesión, el usuario del servicio, el rol profesional, la fuente de dificultad del usuario, la intervención enfermera y las consecuencias de la intervención. Todos estos elementos se hallan integrados en la definición que el International Council of Nursing (ICN) realiza de la enfermería y los completa integrando las funciones profesionales concretas,

"la enfermería abarca los cuidados, autónomos y en colaboración, que se prestan a las personas de todas las edades, familias, grupos y comunidades, enfermos o sanos, en todos los contextos, e incluye la promoción de la salud, la prevención de la enfermedad, y los cuidados de los enfermos, discapacitados, y personas moribundas. Funciones esenciales de la enfermería son la defensa, el fomento de un entorno seguro, la investigación, la participación en la política de salud y en la gestión de los pacientes y los sistemas de salud, y la formación".

Cabe decir que los elementos propuestos por Adams (1991) clarifican el papel concreto de la enfermera mediante una simplificación de lenguaje que podría ser mucho más comprensible para la comunidad enfermera que los propios conceptos de la estructura jerárquica. Sin embargo, se hace necesario desgranar cada uno de los componentes tal y como se recoge en la estructura jerárquica del conocimiento, desde la vehiculación de lo abstracto hacia el fenómeno concreto de la disciplina.

El metaparadigma enfermero está formado por los conceptos que identifican los fenómenos centrales de la disciplina y resume las misiones intelectuales y sociales de la misma (Fawcett, 2005). Distingue enfermería de otras disciplinas (Fawcett, 2005) y describe su finalidad (Kérouac et al., 1996; Marriner \& Raile, 2003). Los conceptos originales fueron: hombre, sociedad, salud y enfermería (Yura \& Torres, 1975). Aunque se aceptaron finalmente los elementos definidos por Fawcett en 1984, persona, entorno, salud y enfermería (Marriner \& Raile, 2003). Gracias a la manera particular con la que las enfermeras abordan la relación entre estos cuatro elementos, clarifican el campo de la enfermería. Se basan en la elaboración de una estructura mental en la cual las enfermeras basan su práctica y están influenciados por creencias, desarrollo personal y profesional 
(McCutcheon, 2004). Esto ha hecho, que las definiciones de los elementos del metaparadigma sean diferentes según la teoría o modelo enfermero, y que puedan estar explícitos o implícitos en cada uno de ellos (Kérouac et al., 1996). Es fundamental que los elementos identificados sean relevantes en el ámbito laboral, tanto para enfermería como para las personas atendidas según su estado de salud (Thorne, Canam, Dahinten, Hall, Henderson \& Reimer, 1998). Pese a que parece que existe un común acuerdo en aceptar estos cuatro conceptos como el metaparadigma enfermero, algunas autoras como Leininger (1995) manifiestaron que debería sustituirse el concepto de enfermería por el de cuidado. Por ello, en ocasiones, el debate sobre el metaparadigma enfermero ha creado mayor división que clarificación de la comunicación (Thorne et al., 1998).

Según el diccionario de la Real Academia Española (2001), el término Filosofía (Del latín philosophĭa, y del griego $\varphi(\lambda \circ \sigma o \varphi \alpha$ ) se refiere al: "1. f. Conjunto de saberes que busca establecer, de manera racional, los principios más generales que organizan y orientan el conocimiento de la realidad, así como el sentido del obrar humano". Por lo que "la función de cada filosofía es comunicar a los miembros de la disciplina y al público en general las creencias y valores de una disciplina particular" (Fawcett, 2005, p.10). Según Salsberry (1994) engloba demandas ontológicas, demandas epistémicas, demandas acerca de los fenómenos de interés para la disciplina de la Enfermería, demandas éticas sobre las acciones, prácticas y características de las enfermeras, resumidas en la filosofía del humanismo: respeto, dignidad, derechos, autonomía, beneficencia, etc. (Fawcett, 2005). Además, "especifica las definiciones de los conceptos del metaparadigma enfermero en todos los modelos conceptuales de Enfermería" (Marriner \& Raile, 2003, p.6). Es la orientación, la manera habitual de abordar la vida, la filosofía de una ciencia guía los valores que son la base del desarrollo de una disciplina (Meleis, 2011). Por lo que podríamos concluir que la filosofía enfermera es una forma global de ver nuestra profesión y cómo ésta se desarrolla de forma general en la sociedad.

Bajando un escalón en la complejidad, se encuentran los modelos conceptuales que son según indica Fawcett (2005):

"un conjunto de conceptos relativamente abstractos y generales que se ocupan de los fenómenos centrales de interés para una disciplina, las proposiciones que ampliamente describen estos conceptos, y las proposiciones que describen de forma relativamente abstracta y general las relaciones entre dos o más de los conceptos" (p.15).

Además según indica Marriner \& Raile (2003), "ofrecen diferentes puntos de vista de la enfermería según las características de cada modelo" (p.6), "pero no sugieren verdades" (p.7). La función de los modelos conceptuales es la de ser marcos de referencia, métodos de pensamiento sobre situaciones y procesos que dicen como observar e interpretar el fenómeno de interés de la 
disciplina. Por ello clarifican la razón de ser de las enfermeras y el objetivo del servicio que prestan a la sociedad (Fawcett, 2005). Son modelos abstractos que representan fenómenos reales, imágenes y patrones de pensamiento (Luis et al., 2007). El término modelo conceptual es sinónimo de marco conceptual, sistema conceptual, paradigma y matriz disciplinaria (Fawcett, 2005). Cada enfermera tiene una visión particular de lo que es la práctica enfermera, los modelos nos han de permitir ver los puntos comunes de estas visiones y por lo tanto la evolución de la disciplina (Reilly, 1975). Asimismo, las enfermeras usan múltiples marcos de referencia para sus actividades de forma implícita, que están en su concepto mental (Johnson, 1987) y usan muchos modelos para guiar sus acciones. Éstos están basados en creencias y valores propios, de familia, amigos,... Uno de los problemas de que cada uno de nosotros use un modelo individual es que, dificulta que los demás entiendan lo que pensamos y por qué hacemos lo que hacemos. Si nadie cuida de forma aislada, es importante, que el resto de nuestros compañeros puedan entendernos (Kalideen, 1993). Por ello, los modelos deberían especificar la misión, responsabilidad y límites de la profesión, y facilitar la comunicación entre las enfermeras; proveyendo un acercamiento sistemático para la investigación, educación, gestión y práctica, además de ser marcos objetivos de registros de los efectos de la enfermería (Johnson, 1987). Son modelos para la realidad, no modelos de la realidad; por lo que su nivel de abstracción no es el apropiado para dirigir la observación empírica (Luis et al., 2007).

En la tabla 1 se muestran como ejemplo algunos modelos conceptuales acompañados de los conceptos usados por sus autoras. Destacar como ya se comentó anteriormente, que en ocasiones el mismo concepto tiene diferentes connotaciones entre las diferentes propuestas teóricas.

\section{Tabla 1: Ejemplos de modelos conceptuales y conceptos principales.}

\begin{tabular}{|l|l|}
\hline $\begin{array}{l}\text { Autora y Modelo } \\
\text { conceptual }\end{array}$ & Conceptos principales del modelo \\
\hline $\begin{array}{l}\text { M.E. Levine } \\
\text { El modelo de } \\
\text { conservación }\end{array}$ & $\begin{array}{l}\text { Globalidad, adaptación, entorno, respuesta del organismo, troficognosis, conserva- } \\
\text { ción, principios de conservación (conservación de la energía, de la integridad } \\
\text { estructural, integridad personal, integridad social). }\end{array}$ \\
\hline $\begin{array}{l}\text { M.E. Rogers } \\
\text { Seres humanos } \\
\text { unitarios }\end{array}$ & $\begin{array}{l}\text { Campo de energía, universo de sistemas abiertos, proceso mútuo, pandimensionali- } \\
\text { dad. }\end{array}$ \\
\hline $\begin{array}{l}\text { C. Roy } \\
\text { El modelo de } \\
\text { adaptación }\end{array}$ & $\begin{array}{l}\text { Sistema, nivel de adaptación, problemas de adaptación, estímulo focal, estímulo con- } \\
\text { textual, estímulo residual, modo de adaptación, proceso de afrontamiento, } \\
\text { mecanismo innatos de afrontamiento, mecanismo de afrontamiento adquiridos, sub- } \\
\text { sistema regulador, subsistema relacionador, reacciones de adaptación, reacciones } \\
\text { ineficaces, proceso vital integrado, modo fisiológico y físico de adaptación, modo de } \\
\text { adaptación del autoconcepto de grupo, modo de adaptación del desempeño del rol, } \\
\text { modo de adaptación de la interdependencia, percepción. }\end{array}$ \\
\hline
\end{tabular}

Por último, en el nivel más bajo de abstracción hallamos la teoría que es según Fawcet (2005) "uno o más conceptos específicos y relativamente concretos que se derivan del modelo conceptual, 
las proposiciones que ampliamente describen estos conceptos, y las proposiciones que describen de forma relativamente concreta y específica las relaciones entre dos o más conceptos" (p.18). Es "un grupo de conceptos relacionados que proponen acciones que guíen la práctica que derivan de los modelos de Enfermería" (Marriner \& Raile, 2003, p.6), "un conjunto de enunciados y proposiciones, formados por conceptos y relaciones entre estos conceptos, organizados de manera coherente y sistemática que tiende a describir, explicar o predecir un fenómeno" (Kérouac et al., 1996, p.147). Su función según Fawcett (2005) es la de especificar los fenómenos contenidos por el modelo conceptual y proveer una estructura concreta para interpretar comportamientos, situaciones y hechos. Por este nivel de concreción, la teoría enfermera debería ser la aplicación conceptual que realmente viésemos explícitamente en la práctica enfermera. Sin embargo, filosofías como la de V. Henderson o modelos conceptuales como el de C. Roy, son aplicados de forma directa en la práctica. Lógicamente son más generales y amplios que las propias teorías, por lo que en muchas ocasiones surgen dificultades al ser concretados en el abordaje de los fenómenos que presentan pacientes particulares. A nivel nacional existen trabajos teóricos publicados al respecto (M. C. Fernández, 1998; Fornons, 2010), sin embargo, no se han hallado trabajos que indaguen la utilidad práctica de las aplicaciones teóricas en el territorio.

Las teorías se clasifican, según algunos autores, en grandes teorías y teorías de nivel medio en función de su nivel de abstracción y alcance (Fawcett, 2005; Marriner \& Raile, 2003). Algunas autoras relevantes en este campo se resumen en la tabla 2. Existen teorías que son únicamente origen del conocimiento enfermero y teorías que se derivan de otras disciplinas.

Tabla 2: Autoras de Teorías enfermeras

\begin{tabular}{|l|l|l|l|}
\hline $\begin{array}{l}\text { TIPO DE } \\
\text { TEORÍA }\end{array}$ & AUTORA & AÑO & TEORÍA \\
\hline $\begin{array}{l}\text { Grandes } \\
\text { Teorías }\end{array}$ & Leininger & $(1991)$ & $\begin{array}{l}\text { Teoría de los cuidados culturales enfermeros de la diversidad y de } \\
\text { la universalidad. }\end{array}$ \\
\cline { 2 - 4 } & Newman & $(1986)$ & Teoría de la salud como la expansión de la conciencia. \\
\cline { 2 - 4 } & Parse & $(1981,1998)$ & Teoría del desarrollo humano \\
\hline $\begin{array}{l}\text { Rango in- } \\
\text { termedio }\end{array}$ & Orlando & $(1961)$ & Teoría del proceso deliberativo enfermero. (T. predictiva) \\
\cline { 2 - 4 } & Peplau & $(1952,1992)$ & $\begin{array}{l}\text { Teoría de las relaciones interpersonales. } \\
\text { (T. descriptiva clasificadora) }\end{array}$ \\
\cline { 2 - 5 } & Watson & $(1985,1997)$ & $\begin{array}{l}\text { Teoría del cuidado Humano. } \\
\text { (T. explicativa) }\end{array}$ \\
\hline
\end{tabular}

(Adaptado de Fawcett, 2005; Marriner \& Raile, 2003)

No obstante, esta clasificación es algo confusa cuando se examinan compendios enfermeros que catalogan las teorías y modelos según el grado de abstracción, ya que, diferentes teóricas son 
ubicadas en diferentes grados de abstracción según el manual consultado. Pese a ello, se describirán a grandes rasgos las características de cada categoría.

La llamada gran teoría es la más abstracta, amplia y compleja. Es casi tan amplia como el modelo conceptual del cual procede (Marriner \& Raile, 2003). Está compuesta por proposiciones y conceptos menos abstractos que el modelo conceptual, pero no tan concretos como los de las teorías de nivel medio (Fawcett, 2005; Marriner \& Raile, 2003). Son un esquema estructural para grandes ideas, y proponen algo que es verdadero o demostrable, efecto que no se consigue en el modelo conceptual (Marriner \& Raile, 2003; Potter \& Perry, 2002). La teoría de nivel o rango medio es más delimitada. Está definida por conceptos y proposiciones específicos. Es usada para describir los fenómenos, los define concretamente, predice como ocurre o porque ocurre (Fawcett, 2005). Incorpora información sobre el estado de salud, el grupo de población o de edad del paciente, la ubicación o el área de práctica y la intervención de la enfermera (Marriner \& Raile, 2003; Potter \& Perry, 2002). Estas deberían ser sobre todo aquellas que deberían usarse en la observación empírica.

Sin embargo, el nivel de abstracción no ha sido únicamente el método usado para clasificar el conocimiento enfermero. Otra forma de estructurarlo se ha basado en tendencias, el origen disciplinar de la teoría o en las escuelas que fundamentan en su base filosófica o científica. Beck en 1976 planteó agrupar los modelos en cuatro categorías o tendencias (Bello et al., 2006). Para hacer esta agrupación analizó los modelos tratando de identificar qué relación existía, dentro de cada modelo, entre el concepto salud y el resto de los que conforman el metaparadigma y posteriormente, ver en cuántos de los modelos existentes se produce este tipo de relación; su clasificación queda resumida en la tabla 3 (adaptada de Benavent et al.,2011).

Según el uso de otras disciplinas para su desarrollo, se describen las teorías interdisciplinarias. Son ejemplos: las Teorías de sistemas, las de Necesidades humanas, los Modelos de salud y bienestar, de estrés y adaptación, Teorías del desarrollo y Teorías psicosociales (Potter \& Perry, 2002).

Kérouac et al. (1996) agruparon a las teóricas en escuelas según sus bases filosóficas y científicas. En concreto describieron seis escuelas: la escuela de las necesidades, de la interacción, de los efectos deseados, de la promoción de la salud, del ser humano unitario, y del "caring". Según los autores, cada teórica tiene una forma de ver el mundo y de practicar en él la ciencia. En la tabla 4 se resumen las principales características de cada escuela. 
Tabla 3: Clasificación de Modelos y Teorías según Beck

\begin{tabular}{|c|c|c|}
\hline TENDENCIA & $\begin{array}{l}\text { DESCRIPCIÓN DE LA TENDENCIA (relación de la salud con el resto de meta- } \\
\text { paradigmas) }\end{array}$ & AUTORA \\
\hline $\begin{array}{l}\text { Tendencia } \\
\text { ecologista }\end{array}$ & $\begin{array}{l}\text { Establecen una relación entre la naturaleza y el medio ambiente con la salud, } \\
\text { influyendo esta relación en el proceso de cuidar. }\end{array}$ & F. Nightingale \\
\hline \multirow{4}{*}{$\begin{array}{l}\text { Tendencia } \\
\text { existencialista }\end{array}$} & \multirow{4}{*}{$\begin{array}{l}\text { Establecen una clara relación entre la salud y las características preferente- } \\
\text { mente psicológicas de los individuos. }\end{array}$} & M. Levine \\
\hline & & H. Peplau \\
\hline & & N. Roper \\
\hline & & C. Roy \\
\hline $\begin{array}{l}\text { Tendencia } \\
\text { cósmica }\end{array}$ & $\begin{array}{l}\text { Existen modelos que muestran una clara relación entre la salud y el medio } \\
\text { ambiente que rodea al sujeto, entendido este medio ambiente como un sis- } \\
\text { tema abierto que comunica con el sujeto al cual puede influir, a la vez que } \\
\text { éste influye en él. }\end{array}$ & M. Rogers \\
\hline \multirow{2}{*}{$\begin{array}{l}\text { Tendencia } \\
\text { sociológica }\end{array}$} & \multirow{2}{*}{ Hacen referencia a la relación entre la salud y la dinámica social. } & D. Orem \\
\hline & & A. Meleis \\
\hline
\end{tabular}

Tabla 4: Tabla adaptada de las principales concepciones de la disciplina según las seis escuelas que describen Kérouac et al. (1996).

\begin{tabular}{|c|c|c|c|c|c|}
\hline & Influencias & $\begin{array}{l}\text { Responden a la } \\
\text { pregunta... }\end{array}$ & $\begin{array}{l}\text { El cuidado está } \\
\text { centrado en... }\end{array}$ & $\begin{array}{l}\text { La función de la en- } \\
\text { fermera }\end{array}$ & Teóricas relevantes \\
\hline 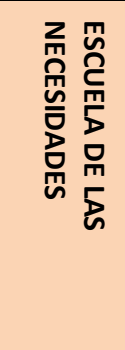 & $\begin{array}{l}\text { Necesidades de } \\
\text { Maslow y las } \\
\text { etapas de desa- } \\
\text { rrollo de Erickson. }\end{array}$ & $\begin{array}{l}\text { ¿Qué hacen las } \\
\text { enfermeras? }\end{array}$ & $\begin{array}{l}\text { La independencia de } \\
\text { la persona en la } \\
\text { satisfacción de sus } \\
\text { necesidades funda- } \\
\text { mentales o en su } \\
\text { capacidad de llevar a } \\
\text { cabo su autocuida- } \\
\text { do. }\end{array}$ & $\begin{array}{l}\text { Reemplazar a la per- } \\
\text { sona que durante un } \\
\text { tiempo no puede reali- } \\
\text { zar por sí sola las } \\
\text { actividades en relación } \\
\text { a su salud. } \\
\text { Ayudarla a lograr la } \\
\text { independencia en el } \\
\text { menor tiempo posible. }\end{array}$ & $\begin{array}{l}\text { V. Henderson } \\
\text { (1955) } \\
\text { F. Abdellah (1960) } \\
\text { D. Orem (1959) }\end{array}$ \\
\hline 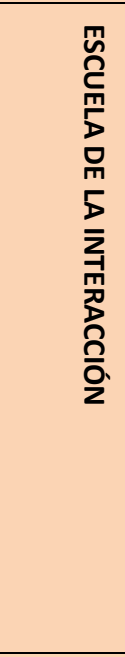 & $\begin{array}{l}\text { Teoría psicoana- } \\
\text { lista: } \\
\text { Teorías de la } \\
\text { interacción, fe- } \\
\begin{array}{lr}\text { nomenología y } \\
\text { existencialismo. }\end{array}\end{array}$ & $\begin{array}{l}\text { ¿Cómo hacen } \\
\text { las enfermeras } \\
\text { lo que están } \\
\text { haciendo? }\end{array}$ & $\begin{array}{l}\text { Una acción humani- } \\
\text { taria. } \\
\text { Los procesos de } \\
\text { interacción entre la } \\
\text { enfermera y la per- } \\
\text { sona. } \\
\text { Debe mantenerse la } \\
\text { integridad de la } \\
\text { persona que recono- } \\
\text { ce sus necesidades y } \\
\text { que tiende a su } \\
\text { actualización. } \\
\text { La enfermedad es } \\
\text { una experiencia que } \\
\text { puede permitir el } \\
\text { crecimiento de la } \\
\text { persona. }\end{array}$ & $\begin{array}{l}\text { Evaluar las necesida- } \\
\text { des de ayuda de la } \\
\text { persona, formular un } \\
\text { diagnóstico de enfer- } \\
\text { mería y planificar una } \\
\text { intervención. }\end{array}$ & $\begin{array}{l}\text { H. Peplau (1952) } \\
\text { J. Paterson (1961) } \\
\text { L. Zderad (1961) } \\
\text { I. Orlando Pelletier } \\
\text { (1962) } \\
\text { J. Travelbee (1964) } \\
\text { E. Wiedenbach } \\
\text { (1965) } \\
\text { I. King (1968) }\end{array}$ \\
\hline 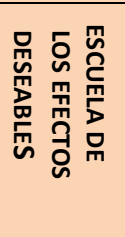 & $\begin{array}{l}\text { Teorías de adap- } \\
\text { tación y } \\
\text { desarrollo y en la } \\
\text { teoría general de } \\
\text { los sistemas. }\end{array}$ & $\begin{array}{l}\text { ¿Por qué las } \\
\text { enfermeras } \\
\text { hacen lo que } \\
\text { ellas hacen? Sin } \\
\text { ignorar el "qué" } \\
\text { y el "cómo". }\end{array}$ & $\begin{array}{l}\text { Restablecer un equi- } \\
\text { librio o preservar la } \\
\text { energía. }\end{array}$ & $\begin{array}{l}\text { Promover la adapta- } \\
\text { ción de la persona } \\
\text { para contribuir a la } \\
\text { salud. }\end{array}$ & $\begin{array}{l}\text { D. Johnson (1958) } \\
\text { L. Hall (1961) } \\
\text { M. Levine }(1967) \\
\text { C. Roy (1971) } \\
\text { B. Neuman (1975) }\end{array}$ \\
\hline
\end{tabular}




\begin{tabular}{|c|c|c|c|c|c|}
\hline & Influencias & $\begin{array}{l}\text { Responden a la } \\
\text { pregunta... }\end{array}$ & $\begin{array}{l}\text { El cuidado está } \\
\text { centrado en... }\end{array}$ & $\begin{array}{l}\text { La función de la en- } \\
\text { fermera }\end{array}$ & Teóricas relevantes \\
\hline 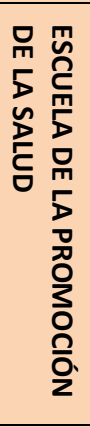 & $\begin{array}{l}\text { Teoría del apren- } \\
\text { dizaje social de } \\
\text { Bandura. }\end{array}$ & $\begin{array}{l}\text { ¿Qué hacen las } \\
\text { enfermeras? } \\
\text { "Qué" y "cómo" } \\
\text { lograrlo } \\
\text { ¿A quién van } \\
\text { dirigidos los } \\
\text { cuidados en- } \\
\text { fermeros? }\end{array}$ & $\begin{array}{l}\text { El punto de vista se } \\
\text { amplía a la familia } \\
\text { aprende de sus pro- } \\
\text { pias experiencias de } \\
\text { salud. }\end{array}$ & $\begin{array}{l}\text { Promoción de la salud } \\
\text { mediante el manteni- } \\
\text { miento, el fomento y } \\
\text { el desarrollo de salud } \\
\text { en la familia y de sus } \\
\text { miembros pro proce- } \\
\text { sos de activación del } \\
\text { aprendizaje. } \\
\text { Rol de agente facilita- } \\
\text { dor, estimulador y } \\
\text { motivador. }\end{array}$ & $\begin{array}{l}\text { M. Allen (1963) } \\
\text { N. Pender (1975) }\end{array}$ \\
\hline 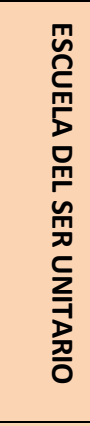 & $\begin{array}{l}\text { Teorías de la física } \\
\text { y de la teoría de } \\
\text { sistemas de Bon } \\
\text { Bertalanffy. } \\
\text { Existencialismo y } \\
\text { fenomenología. }\end{array}$ & $\begin{array}{l}\text { ¿A quién van } \\
\text { dirigidos los } \\
\text { cuidados en- } \\
\text { fermeros? }\end{array}$ & $\begin{array}{l}\text { La promoción de la } \\
\text { salud favoreciendo } \\
\text { una interacción } \\
\text { armoniosa entre el } \\
\text { hombre y el entorno } \\
\text { centrándose en los } \\
\text { campos de energía. }\end{array}$ & $\begin{array}{l}\text { Reconocer manifesta- } \\
\text { ciones propias de la } \\
\text { persona y que están } \\
\text { unidos a situaciones } \\
\text { de salud. La enfermera } \\
\text { ha de promover la } \\
\text { armonía y el bienestar } \\
\text { de la persona. } \\
\text { Persona y enfermera } \\
\text { actúan juntas en con- } \\
\text { senso. }\end{array}$ & $\begin{array}{l}\text { M. Rogers (1970) } \\
\text { M. Newman (1979) } \\
\text { R. R. Parse (1981) }\end{array}$ \\
\hline 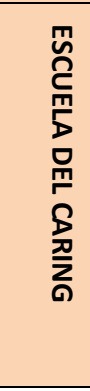 & $\begin{array}{l}\text { Existencialismo, } \\
\text { Metafísica, } \\
\text { Humanidades, el } \\
\text { arte y las ciencias. } \\
\text { Antropología. }\end{array}$ & $\begin{array}{l}\text { ¿Cómo las en- } \\
\text { fermeras hacen } \\
\text { lo que hacen? }\end{array}$ & $\begin{array}{l}\text { "El caring" como la } \\
\text { esencia de la disci- } \\
\text { plina. } \\
\text { Y la cultura }\end{array}$ & $\begin{array}{l}\text { Las enfermeras pue- } \\
\text { den mejorar la calidad } \\
\text { de los cuidados a las } \\
\text { personas si se abren a } \\
\text { dimensiones como la } \\
\text { espiritualidad y la } \\
\text { cultura y si integran los } \\
\text { conocimientos vincu- } \\
\text { lados a estas } \\
\text { dimensiones. }\end{array}$ & $\begin{array}{l}\text { M. Leininger (1978) } \\
\text { J. Watson (1979) }\end{array}$ \\
\hline
\end{tabular}

* El "caring" sustituye a la prevención, promoción y restauración de la salud. Es humanista y científico. Está formado por las acciones que permiten a la enfermera descubrir signos de mejora y deterioro en la persona. Facilitar, ayudar, respetando los valores, creencias la forma de vida y la cultura de las personas (Kérouac et al. 1996).

Dentro de la controversia epistemológica, hemos podido observar elementos que continúan acomplejando el conocimiento enfermero; entre ellos, la propia forma de categorizar la teoría enfermera. Existen tantas formas de clasificarla que provoca en muchas ocasiones mayor confusión que esclarecimiento del tema, ya que la misma teorista es clasificada de forma desigual en diferentes estructuras, provocando en ocasiones cierto desorden en el propio conocimiento. Esto una vez más ejemplifica la juventud de la disciplina.

Muchos son los modelos y teorías descritos en la literatura, sin embargo son redundantes algunos en la misma. Los modelos más referenciados tradicionalmente en la bibliografía son los modelos de H. Peplau, I. King, M. Rogers, B. Neuman, D. Orem, N. Pender, C. Roy, J. Watson, P. Benner, N. Roper, W.Logan, J.Tierney, R. Parse y M. Leininger (ver tabla 5 que recoge los aspectos característicos de los mismos en relación con su visión del metaparadigma y algunos conceptos que 
conforman la teoría). El modelo de Virginia Henderson no se ha incluido en la tabla, ya que, por su relevancia en el ámbito nacional, se desarrollará de forma más extensa posteriormente. 
Tabla 5: Modelos enfermeros frecuentes en la literatura, interpretación del metaparadigma y algunos conceptos clave (Marriner \& Raile, 2003 y 2011)

\begin{tabular}{|c|c|c|c|c|c|}
\hline $\begin{array}{l}\text { AUTORA/ AÑO/ } \\
\text { TEORÍA-MODELO }\end{array}$ & PERSONA & SALUD & ENTORNO & ENFERMERÍA & ALGUNOS CONCEPTOS CLAVE \\
\hline $\begin{array}{l}\text { H. Peplau } \\
\text { (1952) } \\
\text { Teoría de la En- } \\
\text { fermería } \\
\text { psicodinámica }\end{array}$ & $\begin{array}{l}\text { Hombre. Organis- } \\
\text { mo que vive en } \\
\text { equilibrio inestable. }\end{array}$ & $\begin{array}{l}\text { Implica un movimiento de la } \\
\text { personalidad y otros procesos } \\
\text { humanos en dirección a un } \\
\text { estilo de vida creativo, cons- } \\
\text { tructivo, productivo, personal } \\
\text { y comunitario. }\end{array}$ & $\begin{array}{l}\text { Fuerzas existentes fuera } \\
\text { del organismo y en el } \\
\text { contexto de la cultura del } \\
\text { que se adquiere la moral, } \\
\text { las costumbres y las cre- } \\
\text { encias. }\end{array}$ & $\begin{array}{l}\text { Proceso importante, terapéutico, interperso- } \\
\text { nal. Trabaja con otros procesos humanos que } \\
\text { hacen posible la salud para las personas en } \\
\text { las comunidades. Instrumento educativo, } \\
\text { una fuerza madura, que pretende promover } \\
\text { el desarrollo de la personalidad en dirección } \\
\text { a un estilo de vida creativo, constructivo, } \\
\text { productivo, personal y comunitario. }\end{array}$ & $\begin{array}{l}\text { Enfermería psicodinámica, relación } \\
\text { enfermera - paciente (orientación, } \\
\text { identificación, explotación, resolución), } \\
\text { roles enfermeros (suministradora de } \\
\text { recursos, educadora, líder, sustituta y } \\
\text { consejera) }\end{array}$ \\
\hline $\begin{array}{l}\text { I. King } \\
\text { (1968) } \\
\text { Modelo del mar- } \\
\text { co de sistemas } \\
\text { interacción y } \\
\text { teoría intermedia } \\
\text { de la consecución } \\
\text { de objetivos. }\end{array}$ & $\begin{array}{l}\text { Sistema abierto en } \\
\text { transacción con el } \\
\text { entorno. Son únicas } \\
\text { y holísticas. }\end{array}$ & $\begin{array}{l}\text { Estado dinámico dentro el } \\
\text { ciclo de la vida, la enferme- } \\
\text { dad es una interferencia. } \\
\text { Implica adaptación continua } \\
\text { al estrés en el entorno inter- } \\
\text { no y externo mediante el uso } \\
\text { óptimo de los recursos del } \\
\text { individuo para conseguir el } \\
\text { máximo rendimiento en la } \\
\text { vida diaria. } \\
\text { Es una función de la enferme- } \\
\text { ra, médico, paciente, familia } \\
\text { y otras interacciones. }\end{array}$ & $\begin{array}{l}\text { Las adaptaciones a la } \\
\text { vida y a la salud están } \\
\text { influidas por las interac- } \\
\text { ciones del individuo con } \\
\text { el entorno. } \\
\text { El entorno cambia cons- } \\
\text { tantemente. }\end{array}$ & $\begin{array}{l}\text { Conducta observable que se encuentra en los } \\
\text { sistemas de salud en la sociedad. Su objetivo } \\
\text { es ayudar a los individuos a mantener su } \\
\text { salud de manera que puedan ejercer sus } \\
\text { roles. } \\
\text { Es un proceso de acción, reacción, interac- } \\
\text { ción y transacción interpersonal. }\end{array}$ & $\begin{array}{l}\text { Sistemas conceptuales dinámicos (so- } \\
\text { ciales, interpersonales, y personales), } \\
\text { yo, metas o consecución de objetivos, } \\
\text { estrés percepción, juicio, acción, reac- } \\
\text { ción, interacción y transacción. }\end{array}$ \\
\hline $\begin{array}{l}\text { M. Rogers (1970) } \\
\text { Modelo de los } \\
\text { seres humanos } \\
\text { unitarios }\end{array}$ & $\begin{array}{l}\text { Sistema abierto. } \\
\text { Campo de energía } \\
\text { irreductible, indivi- } \\
\text { sible y } \\
\text { pandimensional } \\
\text { que se puede iden- } \\
\text { tificar gracias al } \\
\text { modelo y a las } \\
\text { características } \\
\text { evidentes, que son } \\
\text { específicas de todo } \\
\text { el conjunto. }\end{array}$ & $\begin{array}{l}\text { Poco definido. Usa salud } \\
\text { pasiva para simbolizar estado } \\
\text { bueno de salud y ausencia de } \\
\text { enfermedad y dolencias gra- } \\
\text { ves. } \\
\text { Es un valor definido por la } \\
\text { cultura o el individuo. }\end{array}$ & $\begin{array}{l}\text { Es un campo de energía } \\
\text { irreductible y pandimen- } \\
\text { sional que se identifica } \\
\text { por el modelo y las carac- } \\
\text { terísticas evidentes, } \\
\text { diferentes de los de las } \\
\text { partes. } \\
\text { Los campos del entorno } \\
\text { son infinitos. }\end{array}$ & $\begin{array}{l}\text { Profesión que requiere aprendizaje y que se } \\
\text { puede interpretar como una ciencia y como } \\
\text { un arte. } \\
\text { Interés por las personas y el mundo en el que } \\
\text { viven. } \\
\text { Integración de las personas y su entorno } \\
\text { como un universo pandimensional compues- } \\
\text { to por sistemas abiertos. } \\
\text { El fin es fomentar la salud y el bienestar para } \\
\text { todos los individuos. }\end{array}$ & $\begin{array}{l}\text { Campo de energía, universo de siste- } \\
\text { mas abiertos, patrón, } \\
\text { pandimensionalidad, resonancia, heli- } \\
\text { cidad, reciprocidad, sincronía, } \\
\text { homeodinámica. }\end{array}$ \\
\hline
\end{tabular}




\begin{tabular}{|c|c|c|c|c|c|}
\hline $\begin{array}{l}\text { AUTORA/ AÑO/ } \\
\text { TEORÍA-MODELO }\end{array}$ & PERSONA & SALUD & ENTORNO & ENFERMERÍA & ALGUNOS CONCEPTOS CLAVE \\
\hline $\begin{array}{l}\text { B. Neuman } \\
(1970) \\
\text { Modelo de sis- } \\
\text { temas }\end{array}$ & $\begin{array}{l}\text { Sistema cliente } \\
\text { abierto en interac- } \\
\text { ción recíproca con } \\
\text { el entorno. Com- } \\
\text { puesto dinámico de } \\
\text { interrelaciones } \\
\text { entre los factores } \\
\text { fisiológico, psicoló- } \\
\text { gico, sociocultural, } \\
\text { de desarrollo y } \\
\text { espiritual. }\end{array}$ & $\begin{array}{l}\text { Movimiento contínuo de } \\
\text { naturaleza dinámica que } \\
\text { cambia constantemente. Un } \\
\text { bienestar óptimo indica que } \\
\text { las necesidades totales del } \\
\text { sistema están satisfechas. }\end{array}$ & $\begin{array}{l}\text { Factores internos y exter- } \\
\text { nos que rodean e influyen } \\
\text { en el sistema cliente. Son } \\
\text { fuerzas del entorno los } \\
\text { elementos estresantes. }\end{array}$ & $\begin{array}{l}\text { Profesión única que se ocupa de todas las } \\
\text { variables que afectan al individuo frente al } \\
\text { estrés. }\end{array}$ & $\begin{array}{l}\text { Visión holística o integral, sistema } \\
\text { abierto (función o proceso, entrada y } \\
\text { salida, retroalimentación, negentropía, } \\
\text { estabilidad, sistema cliente, líneas de } \\
\text { resistencia y de defensa, elementos } \\
\text { estresantes, grado de reacción, pre- } \\
\text { vención (primaria, secundaria y } \\
\text { terciaria), reconstitución. }\end{array}$ \\
\hline $\begin{array}{l}\text { D. Orem } \\
\text { (1971) } \\
\text { Modelo enferme- } \\
\text { ro: Teoría del } \\
\text { déficit de auto- } \\
\text { cuidado }\end{array}$ & $\begin{array}{l}\text { Agente: persona } \\
\text { que se comprome- } \\
\text { te a realizar un } \\
\text { curso de acción o } \\
\text { que tiene el poder } \\
\text { de comprometerse } \\
\text { en un curso de } \\
\text { acción. } \\
\text { Incluye el agente } \\
\text { de cuidado depen- } \\
\text { diente (persona } \\
\text { que asume el auto- } \\
\text { cuidado de } \\
\text { personas importan- } \\
\text { tes para él). }\end{array}$ & $\begin{array}{l}\text { Autocuidado: } \\
\text { Práctica de las actividades } \\
\text { que las personas llevan a } \\
\text { cabo en determinados perio- } \\
\text { dos de tiempo, por su propia } \\
\text { parte y con el interés de } \\
\text { mantener el organismo vivo y } \\
\text { sano y continuar con el desa- } \\
\text { rollo personal y el bienestar. } \\
\text { Déficit de autocuidado sinó- } \\
\text { nimo de desviación de la } \\
\text { salud. }\end{array}$ & No lo define & $\begin{array}{l}\text { Actividad enfermera: capacidad desarrollada } \\
\text { por personas formadas en una relación legí- } \\
\text { tima para poder actuar, saber y ayudar a las } \\
\text { personas de esas relaciones a cubrir sus } \\
\text { necesidades terapéuticas de autocuidado y a } \\
\text { regular el desarrollo o el ejercicio de la acti- } \\
\text { vidad de su autocuidado. } \\
\text { Diseño enfermero: ofrecer guías para lograr } \\
\text { metas enfermeras. } \\
\text { Sistemas enfermeros: series y secuencias de } \\
\text { acciones prácticas deliberadas de las enfer- } \\
\text { meras. }\end{array}$ & $\begin{array}{l}\text { Autocuidado, cuidado dependiente, } \\
\text { requisitos de autocuidado (universales, } \\
\text { de desviación de la salud y de desarro- } \\
\text { llo), necesidades de autocuidado } \\
\text { terapéutico, actividad de autocuidado, } \\
\text { actividad de cuidado dependiente, } \\
\text { déficit de autocuidado, actividad en- } \\
\text { fermera, diseño enfermero, sistemas } \\
\text { enfermeros, métodos de ayuda, facto- } \\
\text { res condicionantes básicos. }\end{array}$ \\
\hline $\begin{array}{l}\text { N. Pender } \\
\text { (1975) } \\
\text { Teoría enferme- } \\
\text { ra: Modelo de } \\
\text { Promoción de la } \\
\text { salud. }\end{array}$ & No lo define & $\begin{array}{l}\text { No lo define, pero se intuye } \\
\text { que las personas buscan } \\
\text { crear condiciones de vida } \\
\text { mediante las cuales puedan } \\
\text { expresar su propio potencial } \\
\text { de salud humana. Tienen } \\
\text { autoconciencia reflexiva, } \\
\text { valoran sus propias compe- } \\
\text { tencias. }\end{array}$ & $\begin{array}{l}\text { No lo define, aunque se } \\
\text { intuye que las personas } \\
\text { interactúan con el entor- } \\
\text { no teniendo en cuenta } \\
\text { toda su complejidad } \\
\text { biopsicosocial, trans- } \\
\text { formándolo } \\
\text { progresivamente y siendo } \\
\text { transformados a lo largo } \\
\text { del tiempo. }\end{array}$ & $\begin{array}{l}\text { No lo define, aunque se intuye que según su } \\
\text { visión los profesionales sanitarios forman } \\
\text { parte del entorno interpersonal, que ejerce } \\
\text { influencia en las personas a lo largo de la } \\
\text { vida. } \\
\text { Buscan el cambio de conductas para la pro- } \\
\text { moción de la salud. }\end{array}$ & $\begin{array}{l}\text { Conducta previa relacionada, factores } \\
\text { personales (biológicos, psicológicos y } \\
\text { socioculturales), beneficios y barreras } \\
\text { percibidos de la acción, autoeficacia } \\
\text { percibida, afecto relacionado con la } \\
\text { actividad, influencias interpersonales y } \\
\text { situacionales, compromiso con un plan } \\
\text { de acción, demandas y preferencias } \\
\text { contrapuestas inmediatas, conducta } \\
\text { promotora de salud. }\end{array}$ \\
\hline
\end{tabular}




\begin{tabular}{|c|c|c|c|c|c|}
\hline $\begin{array}{l}\text { AUTORA/ AÑO/ } \\
\text { TEORÍA-MODELLO }\end{array}$ & PERSONA & SALUD & ENTORNO & ENFERMERÍA & ALGUNOS CONCEPTOS CLAVE \\
\hline $\begin{array}{l}\text { C. Roy } \\
(1976) \\
\text { Modelo de adap- } \\
\text { tación }\end{array}$ & $\begin{array}{l}\text { Ser biopsicosocial } \\
\text { en constante inter- } \\
\text { acción con el medio } \\
\text { ambiente cambian- } \\
\text { te. Sistemas } \\
\text { holísticos y adapta- } \\
\text { bles. }\end{array}$ & $\begin{array}{l}\text { Estado y proceso de ser y } \\
\text { volverse una persona total- } \\
\text { mente integrada. } \\
\text { Enfermedad: fallo de la inte- } \\
\text { gración. }\end{array}$ & $\begin{array}{l}\text { Todas las condiciones y } \\
\text { circunstancias que rode- } \\
\text { an y afectan el desarrollo } \\
\text { y comportamiento de la } \\
\text { persona. Incluye los estí- } \\
\text { mulos. }\end{array}$ & $\begin{array}{l}\text { Profesión que se dedica a la atención sanita- } \\
\text { ria y se centra en los procesos vitales y en los } \\
\text { modelos que se han de seguir, da importan- } \\
\text { cia a la promoción de la salud. Facilita la } \\
\text { adaptación valorando el comportamiento en } \\
\text { la adaptación e interviniendo alterando los } \\
\text { estímulos que le afectan. El objetivo de en- } \\
\text { fermería es ayudar al hombre a adaptarse a } \\
\text { los cambios en sus necesidades, fisiológicas, } \\
\text { autoconcepto, función social y su interde- } \\
\text { pendencia en la salud y la enfermedad. }\end{array}$ & $\begin{array}{l}\text { Nivel de adaptación, estímulos (focal, } \\
\text { contextual y residual), sistema, proce- } \\
\text { sos de afrontamiento (innatos y } \\
\text { adquiridos), subsistema regulador y } \\
\text { relacionador, respuestas de adapta- } \\
\text { ción, reacciones ineficaces, proceso } \\
\text { vital integrado, modo de adaptación } \\
\text { (fisiológico, autoconcepto de grupo, } \\
\text { función de rol e interdependencia), } \\
\text { percepción. }\end{array}$ \\
\hline $\begin{array}{l}\text { J. Watson } \\
\text { (1979) } \\
\text { Filosofía y teoría } \\
\text { del cuidado } \\
\text { transpersonal }\end{array}$ & $\begin{array}{l}\text { Ser humano, per- } \\
\text { sona, vida, } \\
\text { personalidad y yo. } \\
\text { Unidad de mente, } \\
\text { cuerpo, espíritu y } \\
\text { naturaleza. }\end{array}$ & $\begin{array}{l}\text { Unidad y armonía en la men- } \\
\text { te, el cuerpo y el alma. Grado } \\
\text { de congruencia entre el yo } \\
\text { percibido y el yo experimen- } \\
\text { tado. }\end{array}$ & Espacios de curación. & $\begin{array}{l}\text { Nombre y verbo. Conocimiento, pensamien- } \\
\text { to, valores, filosofía, compromiso y acción, } \\
\text { con cierto grado de pasión. Se centra en } \\
\text { entender la salud, la enfermedad y la expe- } \\
\text { riencia humana, fomentar y restablecer la } \\
\text { salud y prevenir la enfermedad. }\end{array}$ & $\begin{array}{l}\text { Factores de cuidados originales (siste- } \\
\text { ma humanístico - altruista de valores, } \\
\text { inculcación de la fe - esperanza, cultivo } \\
\text { de la sensibilidad, relación de ayuda - } \\
\text { confianza, expresión de los sentimien- } \\
\text { tos, enseñanza - aprendizaje } \\
\text { interpersonal, entorno de apoyo, grati- } \\
\text { ficación de las necesidades humanas, } \\
\text { fuerzas existenciales - fenomenológi- } \\
\text { cas. }\end{array}$ \\
\hline $\begin{array}{l}\text { P. Benner } \\
\text { (1980) } \\
\text { Filosofía del cui- } \\
\text { dado, sabiduría } \\
\text { clínica y ética de } \\
\text { la práctica en- } \\
\text { fermera. De } \\
\text { principiante a } \\
\text { experta }\end{array}$ & $\begin{array}{l}\text { Ser autointerpreta- } \\
\text { tivo. La persona va } \\
\text { definiéndose con } \\
\text { las experiencias } \\
\text { vitales. } \\
\text { Tiene una com- } \\
\text { prensión fácil y no } \\
\text { reflexiva de la iden- } \\
\text { tidad en el mundo. }\end{array}$ & $\begin{array}{l}\text { Lo que puede valorarse. } \\
\text { Diferentes modos de encon- } \\
\text { trarse en el mundo. }\end{array}$ & $\begin{array}{l}\text { Utiliza situación en vez de } \\
\text { entorno, para darle un } \\
\text { significado más social } \\
\text { (pasado, presente y futu- } \\
\text { ro que influyen en la } \\
\text { situación actual). } \\
\text { Interacción, interpreta- } \\
\text { ción y entendimiento de } \\
\text { la situación unidos a la } \\
\text { persona. }\end{array}$ & $\begin{array}{l}\text { Relación de cuidado. } \\
\text { Una condición que facilita la conexión y el } \\
\text { interés. } \\
\text { El cuidado incluye la posibilidad de ayudar y } \\
\text { ser ayudado. } \\
\text { Práctica del cuidado, cuya ciencia sigue una } \\
\text { moral y una ética del cuidado y la responsa- } \\
\text { bilidad. }\end{array}$ & $\begin{array}{l}\text { Principiante, principiante avanzada, } \\
\text { competente, eficiente } \\
\text { experto, aspectos de una situación, } \\
\text { atributos de una situación, competen- } \\
\text { cia, dominio } \\
\text { ejemplo, experiencia máxima, caso } \\
\text { paradigmático, importancia } \\
\text { comportamiento ético, hermenéutica }\end{array}$ \\
\hline
\end{tabular}




\begin{tabular}{|c|c|c|c|c|c|}
\hline AUTORA AÑO & PERSONA & SALUD & ENTORNO & ENFERMERÍA & ALGUNOS CONCEPTOS CLAVE \\
\hline $\begin{array}{l}\text { N. Roper, W. } \\
\text { Logan, J. Tierney } \\
\text { (1980) } \\
\text { Modelo de en- } \\
\text { fermería basado } \\
\text { en un modelo de } \\
\text { vida. }\end{array}$ & $\begin{array}{l}\text { Se caracteriza por } \\
12 \text { actividades } \\
\text { vitales. } \\
\text { La persona se defi- } \\
\text { ne en función de la } \\
\text { dependencia/ } \\
\text { Independencia de } \\
\text { las actividades. }\end{array}$ & $\begin{array}{l}\text { Usa definición dada por la } \\
\text { OMS. } \\
\text { También habla de indepen- } \\
\text { dencia con ayuda } \rightarrow \text { una } \\
\text { persona puede sentirse sana } \\
\text { aun cuando tenga una disca- } \\
\text { pacidad física o mental. }\end{array}$ & $\begin{array}{l}\text { Todo aquello que es } \\
\text { físicamente externo a la } \\
\text { persona. } \\
\text { Incluye a otras personas. } \\
\text { Es tan importante man- } \\
\text { tener un entorno seguro } \\
\text { que incluye apartados en } \\
\text { cada una de las activida- } \\
\text { des vitales. }\end{array}$ & $\begin{array}{l}\text { Es una ayuda a la persona para: } \\
\text { Prevenir problemas potenciales relacionados } \\
\text { con las actividades vitales que puedan con- } \\
\text { vertirse en problemas reales. Aliviar o } \\
\text { resolver problemas. Prevenir la recurrencia } \\
\text { de problemas ya tratados. Afrontar con espí- } \\
\text { ritu positivo cualquier problema incluida la } \\
\text { muerte y el estado agonizante de los pacien- } \\
\text { tes y el duelo de los allegados. }\end{array}$ & $\begin{array}{l}\text { Actividades vitales, duración de la vida, } \\
\text { continuo dependencia/independencia, } \\
\text { factores que influyen en las actividades } \\
\text { vitales, individualidad vital }\end{array}$ \\
\hline $\begin{array}{l}\text { R. Parse } \\
\text { (1981) } \\
\text { Teoría del desa- } \\
\text { rrollo humano }\end{array}$ & $\begin{array}{l}\text { Hombre-universo y } \\
\text { salud son insepara- } \\
\text { bles e irreducibles. } \\
\text { La persona cambia } \\
\text { y es cambiada por } \\
\text { el universo. Influ- } \\
\text { yen y están } \\
\text { influidas por los } \\
\text { demás, se relacio- } \\
\text { nan en estados } \\
\text { multidimensiona- } \\
\text { les. }\end{array}$ & $\begin{array}{l}\text { Es la evolución humana, } \\
\text { proceso fluido, creación y } \\
\text { responsabilidad personal. } \\
\text { Estructura el significado, la } \\
\text { cocreación de las pautas } \\
\text { rítmicas de las relaciones y la } \\
\text { cotrascendencia con lo posi- } \\
\text { ble. } \\
\text { Es un compromiso personal. }\end{array}$ & $\begin{array}{l}\text { Las personas cambian y } \\
\text { son cambiadas por el } \\
\text { universo. Influyen y son } \\
\text { influidas por otras perso- } \\
\text { nas. }\end{array}$ & $\begin{array}{l}\text { Ciencia cuya práctica es un arte interpretati- } \\
\text { vo. Servicio exclusivo para la humanidad. } \\
\text { La enfermera está en presencia real con el } \\
\text { individuo o familia mientras que ellos descu- } \\
\text { bren el significado personal de la situación y } \\
\text { realizan elecciones. }\end{array}$ & $\begin{array}{l}\text { Primer principio: estructurar el signifi- } \\
\text { cado (imaginación y valoración del } \\
\text { lenguaje), segundo principio: configu- } \\
\text { rar las pautas rítmicas (de la revelación } \\
\text { - ocultación, permisividad -limitación } \\
\text { de la conexión - separación), tercer } \\
\text { principio: cotrascendencia con lo posi- } \\
\text { ble (poder y la creación de la } \\
\text { transformación). }\end{array}$ \\
\hline $\begin{array}{l}\text { M. Leininger } \\
\text { (1984) } \\
\text { Teoría de la di- } \\
\text { versidad y } \\
\text { universalidad de } \\
\text { los cuidados } \\
\text { culturales }\end{array}$ & No definida & $\begin{array}{l}\text { Estado de bienestar. Se defi- } \\
\text { ne, valora y practica } \\
\text { culturalmente. } \\
\text { Capacidad de las personas } \\
\text { para realizar sus actividades } \\
\text { diarias bajo un modo de vida } \\
\text { culturalmente específico, } \\
\text { beneficioso y estructurado. }\end{array}$ & $\begin{array}{l}\text { Conjunto de hechos, } \\
\text { situaciones y experiencias } \\
\text { determinadas que otor- } \\
\text { gan significado a las } \\
\text { expresiones, interpreta- } \\
\text { ciones e interrelaciones } \\
\text { sociales humanas en } \\
\text { escenarios físicos, ecoló- } \\
\text { gicos, sociopolíticos o } \\
\text { culturales. }\end{array}$ & $\begin{array}{l}\text { Enfermería transcultural. } \\
\text { Profesión y disciplina humanista y científica } \\
\text { que se centra en los cuidados para ayudar, } \\
\text { apoyar, facilitar o capacitar a las personas o } \\
\text { grupos a que conserven o recuperen su } \\
\text { bienestar o salud, de un modo culturalmente } \\
\text { significativo y beneficioso o para ayudar a las } \\
\text { personas a que afronten impedimentos físi- } \\
\text { cos, mentales o la muerte. }\end{array}$ & $\begin{array}{l}\text { Cuidados culturales y profesionales, } \\
\text { universalidad y diversidad de los cui- } \\
\text { dados culturales, cultura, concepción o } \\
\text { visión el mundo. Dimensiones cultura- } \\
\text { les y de la estructura social (religión, } \\
\text { parentesco, política, economía, educa- } \\
\text { ción, tecnología y cultura). } \\
\text { Etnohistoria (hechos y experiencias } \\
\text { pasadas de los individuos que determi- } \\
\text { nan los comportamientos en un } \\
\text { contexto y tiempo determinados) } \\
\text { Conservación, negociación, reorienta- } \\
\text { ción o reestructuración de los cuidados } \\
\text { tradicionales. }\end{array}$ \\
\hline
\end{tabular}




\subsubsection{Corrientes de pensamiento enfermero}

Además de usar la clasificación de la complejidad del pensamiento enfermero, se puede analizar el progreso del conocimiento según la evolución histórica de la propia disciplina, englobando como las diferentes teoristas interpretaban los fenómenos de la disciplina a medida que también evolucionaba el propio cuidado de la salud en estos últimos dos siglos mediante el estudio del paradigma científico. La definición de los paradigmas se basa en los trabajos primeramente de Kuhn (1975) y posteriormente de Newman, Sime y Corcoran-Perry (1991) y Newman (1992). Kérouac et al. (1996) afirman que coexisten diversos paradigmas en igual momento histórico, aseveración que Khun (1975) también comparte sobre los paradigmas aunque, matizando que en raras ocasiones coexisten pacíficamente. Cada uno de los paradigmas acompaña a un nuevo nivel de desarrollo teórico y por lo tanto a una evolución profesional de la enfermería. A continuación se exponen las principales características de cada uno de los momentos históricos según la definición que hacen de ellos Kérouac et al. (1996), basándose principalmente en la descripción del metaparadigma.

De finales del siglo XIX hasta principios de los 50' aparecen dos orientaciones dentro del paradigma de la categorización, una ligada a la salud pública y otra centrada en la enfermedad y unida a la profesión médica. Los fenómenos son vistos como divisibles, medibles, ordenados y secuenciales. Las relaciones que se establecen son lineales y causales y con gran influencia del positivismo. En la orientación hacia la salud pública la persona tiene un componente físico, intelectual, emocional y espiritual. El entorno se estimaba como los aspectos físicos (luz, aire, calor, limpieza...) que permiten a la persona que sufre movilizar sus energías hacia la curación y hacia la prevención de la enfermedad. La salud era lo inverso a la enfermedad y además la voluntad de utilizar bien cada capacidad personal. El cuidado es un compuesto de arte y ciencia que requiere formación reglada. En la orientación hacia la enfermedad la persona es un todo formado por la suma de sus partes, cada parte es divisible, identificable e independiente. Por lo que se pueden separar las 4 dimensiones que forman parte del individuo. El entorno es un elemento aislado de la persona. Es físico, social, cultural, hostil al ser humano y por ello debe ser manipulado. La salud es un equilibrio anhelado y positivo; la enfermedad es lo negativo. La enfermera reemplaza las incapacidades, es la que tiene el conocimiento, y sus cuidados están ligados a la profesión médica. Su principal orientación es la enfermedad por lo que su intervención consiste en erradicar problemas, cubrir déficits y ayudar a los incapacitados. Es "hacer para" las personas (Kérouac et al., 1996).

De los años cincuenta y hasta los años setenta, se inicia el paradigma de la integración. Su visión se centra en la persona, y los fenómenos son contextuales y variables. Está influenciada por el positivismo. La experiencia clínica y la reflexión son el arranque de las primeras concepciones explíci- 
tas de la disciplina o modelos conceptuales. La persona es el eje central de la disciplina. Es un todo formado por la suma de sus partes que están interrelacionadas, es un ser bio - psico - socio - cultural - espiritual. La relación con la enfermera es circular e interaccional. Se espera de la persona una colaboración en su tratamiento. Significa "actuar con" la persona. El entorno es considerado de forma amplia, incluyéndose diversos contextos (histórico, social, político,....) en el que la persona vive en una relación cíclica (un entorno positivo, generará entornos positivos futuros). La salud y la enfermedad son dos formas distintas que cohabitan en interacción dinámica, por lo que la enfermera es consejera y ayuda a escoger los comportamientos de salud en función de las necesidades no satisfechas de las personas. Se contempla como una disciplina diferente de la médica, que adopta un método de trabajo sistemático (recogida de datos, análisis, intervención y evaluación). Esta realidad es la que podríamos decir que está presente en nuestro entorno de cuidado actualmente ya que, son ejemplos de esta corriente de pensamiento los modelos de necesidades. Modelos que se aplican de forma amplia y explícita en nuestro entorno asistencial (Kérouac et a., 1996).

Por último, a partir de los años setenta, se aprecia una corriente más amplia que se dirige hacia el mundo. La corriente de la transformación. El fenómeno se describe como único, complejo y global. Se describen elementos de interacción continua, recíproca y simultánea. Influencia de la fenomenología. La enfermera es partícipe junto a la persona de los cuidados. La persona es un ser único cuyas dimensiones forman una unidad y es indisociable de su entorno, es mayor que la suma de sus partes. La visión del entorno se amplía hacia un infinito (el universo) dentro de la visión de la transformación. Siendo distinto de la persona, el entorno coexiste con ella, por lo que están en continuo cambio, mútuo y simultáneo. La salud es una experiencia que engloba la unidad ser humanoentorno y se integra en la vida del individuo. Por ello la enfermera acompaña en las experiencias de salud de la persona. Es "estar con" la persona. La enfermera y la persona son partícipes de todo el proceso del cuidado, hay un respeto recíproco sin relación de poder (Kérouac et al., 1996).

Pese a ser esta última la corriente que es coetánea al momento actual, no es la forma compartida de ver los fenómenos disciplinares en todos los paises. Esto podría estar relacionado con la evolución y desarrollo de la disciplina a nivel territorial. Países como EE.UU. hace años que acceden a programas doctorales a diferencia de países como el nuestro, en el que el desarrollo teórico y por lo tanto profesional, se ha visto limitado por techos académicos. Sin embargo, no sólo este techo es la causa de la visión disciplinar, sino que existen otros factores o condicionantes que pueden ser la causa del poco desarrollo de la disciplina en nuestro país como podría ser la insistencia institucional en la aplicación de un modelo teórico concreto, así como la formación recibida por los profesionales. Esta reflexión requiere de una mayor concrecion expositora. Por ello se mostrará en adelante como 
se desarrolló la evolución en la formación disciplinar propia de nuestro país, así como se evidenciará la supremacía de un modelo enfermero hegemónico en España tanto en la formación como en la aplicación práctica asistencial, en concreto el modelo de V. Henderson.

\subsection{Formación enfermera en nuestro entorno como elemento condicionante del desarrollo teórico y profesional}

Tal y como ya se indicó anteriormente, otro de los elementos que hemos de tener en cuenta en la aplicación de modelos teoricos en la práctica, es el propio desarrollo profesional en nuestro medio. En España la disciplina enfermera ha pasado por diferentes etapas que distan del contexto internacional y por lo tanto, diferencian nuestra evolución del avance de la disciplina en otros países (Zabalegui \& Maciá, 2010). Estas etapas son decisivas en el desarrollo del conocimiento de nuestro propio cuerpo teórico y por lo tanto de la aplicación de la filosofía enfermera en la práctica disciplinaria nacional. Desde el punto de vista docente han tenido repercusión los fundamentos de la ciencia enfermera y el análisis de los modelos y teorías, así como, el uso del Proceso de Atención de Enfermería. Sin embargo, la utilización clínica de los instrumentos que se desarrollan durante el aprendizaje pregrado ha sido irregular, incompleto o ausente en muchos de los centros sanitarios (Brito, 2007). Veamos concretamente cómo la estructura de la etapa formativa condiciona estas cuestiones.

Si revisamos las competencias generales en el Boletín Oficial del Estado (BOE) hallamos que, sorprendentemente y pese a la aplicación irregular de teoría en la práctica, una de las competencias específicas, es conocer y aplicar los fundamentos y principios teóricos y metodológicos de la enfermería (ORDEN CIN/2134/2008). Concretamente dentro del Módulo de Ciencias de la Enfermería (60 ECTS) se hallan las siguientes competencias relacionadas:

Comprender desde una perspectiva ontológica y epistemológica, la evolución de los conceptos centrales que configuran la disciplina de enfermería, así como los modelos teóricos más relevantes, aplicando la metodología científica en el proceso de cuidar y desarrollando los planes de cuidados correspondientes.

Aplicar el proceso enfermero para proporcionar y garantizar el bienestar la calidad y seguridad a las personas atendidas (p.31682). 
El análisis de estas competencias debería cuestionar seriamente la aplicación de filosofía y metodología enfermera en aquellos ámbitos en los que la enfermera desarrolla su labor. No obstante, estas competencias son nuevas e inherentes a la nueva titulación de Grado, por este motivo se debe de considerar la influencia de la formación previa enfermera en la práctica española.

\subsubsection{La formación enfermera hasta 1977}

El Real Decreto de 27 de junio de 1952, unificó los planes de estudios heterogéneos existentes hasta aquel momento, Practicantes, Enfermeras y Matronas se unificaron en el título de Ayudante Técnico Sanitario (ATS). Con un régimen franquista, tenían dependencia absoluta de la medicina y su función era de sumisión al varón (Quintairos, 2008). La enseñanza incluía asignaturas como moral profesional, formación política y enseñanzas del hogar, delegando el conocimiento teórico al práctico. Las cualidades intelectuales se reducían a memoria, juicio recto y prudencia; las cualidades morales incluían paciencia con el enfermo y con la enfermedad, obediencia al médico, sinceridad, bondad, sentido de la dignidad, discreción, reserva, cordialidad, generosidad, servicio, pasividad e indecisión (Almansa, 2008). Se formaban enfermeras de carácter hospitalario, eminentemente técnico y con enfoque organicista (García \& Martínez, 2007). Esta formación encajaba con la formación que recibieron las enfermeras de otros países hasta los años cincuenta, por ello la visión de la persona de forma fraccionada ligada a la enfermedad perduró mayor tiempo en nuestro país que en otros. Muchos de los valores permanecen latentes en la práctica en nuestros días ya que, parte de enfermeras formadas en esos valores está en activo, además de que todavía algunos médicos y la propia sociedad comparten esa visión de la enfermería. Por otro lado, no todos los ATS solicitaron la convalidación de sus títulos por el de diplomado, ya que su convalidación sólo fue exigida en el caso de desear hacer docencia o proseguir la carrera académica, por lo que, el título previo permitía continuar en su lugar de trabajo sin causar cese y desarrollando la misma labor ${ }^{2}$. No obstante algunos centros sanitarios consideraron implantar niveles en la carrera profesional y estas enfermeras no pudieron acceder a ellos.

\footnotetext{
${ }^{2}$ Según una nota de prensa del Consejo General de Enfermería, en el año 2006 todavía habían más de 10.000 ATS en activo sin convalidar titulación. Hubieron diferentes convocatorias mediante el "curso de nivelación de ATS". Los últimos años a partir del 2003, fueron llevadas a cabo por la Universidad Nacional a Distancia y otras universidades, la útima convocatoria fue en el año 2008. Recuperado de http://www.cge.enfermundi.com/servlet/Satellite?blobcol=urldata\&blobheader=application\%2Fpdf\&blobk ey=id\&blobtable=MungoBlobs\&blobwhere $=1143614954115 \&$ cachecontrol=immediate\&csblobid=K28RddPUt czQKwY2MguZBAEk1ZWUobVcfsT7hNHMPv4tZQ8W31X3!-8246691!1245068497480\&ssbinary=true
} 


\subsubsection{El Diplomado de Enfermería}

Si bien en otros países la entrada de la enfermería en la universidad se realizó precozmente, en el año 1899 en EE.UU. y 1950 en Inglaterra (F. Hernández, 1996); en España no se reconoce su adscripción hasta 1977. En ese año aparece el R.D. 2128 sobre Integración en la Universidad de las Escuelas de ATS como Escuelas Universitarias de Enfermería. El título que otorgan dichas escuelas es el de Diplomado Universitario en Enfermería (DUE) y la primera promoción fue la de 1977 - 1980 (F. Hernández, 1996). En 1981, por Orden de 14 de septiembre, se habilitan los títulos para impartir docencia. Durante septiembre de 1984, se hace pública una resolución de la Secretaría de Estado para las Universidades e Investigación, aprobando la propuesta de la Comisión de las Pruebas de Idoneidad para el acceso al cuerpo de Profesores Titulares de Escuelas Universitarias en el área de Enfermería (Boletín Oficial del Estado: lunes 22 de octubre de 1984, Núm. 253). Por primera vez, esta disposición permitía a los profesionales de Enfermería ocupar plazas de Profesores Titulares de sus Escuelas Universitarias.

La formación enfermera a partir de entonces, se realiza desde un enfoque científico y desde una perspectiva holístico-humanista (García \& Martínez, 2007). Los planes de estudios para la titulación de Diplomado en Enfermería difieren entre las diferentes universidades españolas divergiendo los contenidos en la asignatura relacionada con la base conceptual enfermera. Sin embargo, gracias al desarrollo profesional, entra en la práctica enfermera el rol autónomo enfermero y la posibilidad de integrar tanto filosofía como metodología enfermera en la formación y por lo tanto ofrecer la oportunidad de que sean desarrolladas en la práctica. Aparecen áreas de conocimiento propias como la de "Ciencias de la Enfermería", emergiendo asignaturas como "Enfermería Fundamental" que integran entre otros conocimientos el estudio de las bases teóricas y el proceso enfermero ${ }^{3}$.

\subsubsection{Grado, Máster y Doctorado}

A partir de la declaración conjunta de los Ministros Europeos de Educación en Bolonia el 19 de junio de 1999 (Conferencia de Ministros Europeos responsables de la Educación Superior, 1999), se crea el área Europea de Educación Superior para la adopción de un sistema de titulaciones fácilmente comprensible y comparable en el continente. Veintiún países europeos deben consensuar un plan de estudios homologable entre los miembros de la Comunidad Europea (Bernués et al., 2004). Esto obliga al cambio de la titulación española de Diplomado a Grado (adaptar el sistema universitario español al Espacio Europeo de Enseñanza Superior) y por lo tanto a revisar perfiles académicos y

\footnotetext{
${ }^{3}$ Orden de 31 de octubre de 1977 por la que se dictan directrices para la elaboración de Planes de estudios de las Escuelas Universitarias de Enfermería.
} 
competencias profesionales, centrando la educación en el estudiante (Zabalegui et al., 2006). Se van publicando Reales Decretos (RD) que desarrollan los diferentes aspectos de esta adaptación, todo ello antes del 2010 (Bernués et al., 2004). Ya en el documento defendido por el Consejo Nacional de Enfermería 83/2000 aparece el Primer Proyecto de Ampliación y Reforma de la Carrera de Enfermería, con el que se pretendía abrir camino a los DUE hacia la Licenciatura y el Doctorado. Sin embargo y pese al esfuerzo del grupo de trabajo que llevaba el tema, no obtuvo el éxito esperado (Zabalegui \& Macià, 2010).

En los años noventa, aparecen nuevamente propuestas de proyectos de Licenciatura como el de la Universidad de Santiago de Compostela (ofertada como un segundo ciclo), con el objetivo de permitir el acceso al doctorado, sin embargo tampoco tuvo el resultado deseado y no prosperó. A partir del año 1996, se inicia el proyecto de una licenciatura como única titulación pero tampoco contó con el acuerdo académico codiciado. Tras estos frustrados intentos, fue la Conferencia Nacional de Directores de Escuelas Universitarias de Enfermería Estatales la que en 1997 propuso un nuevo proyecto de titulación de segundo ciclo que contaba entre 120 y 180 créditos y preparaba al profesional de enfermería para el desarrollo principalmente de la docencia, investigación y gestión. Así aparecieron a partir de ese año en diversas universidades el Título Propio de Segundo Ciclo de Licenciado de Enfermería, al amparo de la Ley de Reforma Universitaria. Entre los objetivos de la formación se hallaba el de discutir las bases teóricas, históricas y filosóficas de la Ciencia de Enfermería (Zabalegui \& Macià, 2010).

En el año 2005, se establece la ordenación de las enseñanzas universitarias oficiales y se determina que las enseñanzas universitarias conducentes a la obtención de títulos de carácter oficial y validez en todo el territorio nacional, se estructurarán en tres ciclos: Grado, Máster y Doctorado (RD 1393/2007; Zabalegui \& Cabrera, 2009). Este Real Decreto deroga el RD 55/2005 y RD 56/2005 que anteriormente regulaban el "Grado" y "Postgrado". El RD 1125/2003, establece el sistema de créditos y el sistema de calificaciones de las titulaciones de carácter oficial y con validez en España. Para entender las características de lo que se enuncia a continuación, es necesario conocer que se entiende por un crédito europeo o ECTS (European Credit Transfer System) que está definido en libro blanco del proyecto de la titulación de enfermería (Bernués et al., 2004):

El crédito europeo es la unidad de medida del haber académico que representa la cantidad de trabajo del estudiante para los objetivos del programa de estudios y que se obtiene por la superación de cada una de las materias que integran los planes de estudios. En esta unidad de medida se integran las enseñanzas teóricas y prácticas, así como otras actividades académicas dirigidas, con inclusión de las horas para alcanzar los objetivos formativos. (p.16). 
Este RD comentado (RD 1393/2007), implanta que el número total de créditos por curso académico sea de 60, de los que al menos 36 tendrán relación con las materias relacionadas con la rama de conocimiento ( 240 créditos formativos en total para la formación básica). En la asignación de créditos se computará el número de horas requeridas para la adquisición de conocimientos, capacidades y destrezas. Incluyendo clases teóricas y prácticas, las horas de estudio, las horas de seminarios, trabajos prácticos o proyectos, las horas para la preparación y realización de exámenes y pruebas de evaluación. El número de horas de un ECTS será de mínimo 25 y máximo de 30 . La titulación en el caso de la disciplina enfermera se adscribió a la rama del conocimiento de Ciencias de la Salud (Bernués et al., 2004).

Los contenidos y la importancia de las bases conceptuales enfermeras en la titulación de grado se resumen en las competencias ya descritas anteriormente del BOE (ORDEN CIN/2134/2008). Y en los contenidos formativos comunes mostrados en el documento de la Organización Colegial de Enfermería (2011) sobre el título de Grado en la materia de Fundamentos Teóricos y Metodológicos de la Enfermería (que constará de un mínimo de 10 créditos ECTS) encontramos que el enfermero/a titulado deberá:

Ser capaz de identificar, integrar y relacionar el concepto de salud y los cuidados desde una perspectiva histórica, para comprender la evolución del cuidado. Tener la capacidad de comprender reflexivamente los conceptos que configuran la disciplina enfermera, así como los modelos teóricos más relevantes, aplicando la metodología científica en el proceso de cuidar y desarrollando los planes de cuidados correspondientes (p.4).

En este RD 1393/2007 se especifica la formación que se precisa para la obtención de titulo de Máster y Doctor. La finalidad de las enseñanzas de Máster es:

La adquisición por el estudiante de una formación avanzada, de carácter especializado o multidisciplinar, orientada a la especialización académica o profesional, o bien a promover la iniciación en tareas investigadoras" (p.4040).

Uno de los Máster ofertados a partir de estas normativas es el Máster Universitario en Ciencias de la Enfermería verificado por parte del Consejo de Universidades, de acuerdo con el artículo 26 del RD 1393/2007, con carácter interuniversitario y que se desarrollaba dentro de una red integrada por siete Universidades Españolas (web Ministerio de Educación): Universidad de Alicante, Universitat Internacional de Catalunya, Universitat de Lleida, Universidad de Zaragoza, Universitat Rovira i Virgili (Tarragona), Universidad de Huelva y Universidad de Almería. Destacar que ya algunos de estos centros lo venían desarrollando desde el año 1999 como título propio de su facultad con la 
previsión de que en un futuro se contemplase como Máster Oficial Universitario (Zabalegui \& Macià, 2010).

En los contenidos formativos de este Máster interuniversitario se puede apreciar la elevada importancia de la base conceptual enfermera, ya que se oferta una asignatura relacionada con 10 créditos ECTS: "Teorías y Modelos enfermeros". La materia se fundamenta en la toma de decisiones orientadas a la búsqueda de la salud y calidad de vida de las personas, familia, grupo y comunidad, mediante la compresión y apropiación de los procesos en la construcción del conocimiento a través de las principales corrientes de pensamiento, escuelas, conceptos, filosofías, y métodos, así como las lógicas que sustentan la acción del cuidado de enfermería, con el objetivo de aplicar las teorías de enfermería en la práctica asistencial, la gestión, la docencia y la investigación (web Universitat Rovira i Virgili, Universitat Internacional de Catalunya y Universitat de Lleida).

En cuanto a la enseñanza de Doctorado se explicita que:

Tienen como finalidad la formación avanzada del estudiante en las técnicas de investigación, podrán incorporar cursos, seminarios u otras actividades orientadas a la formación investigadora e incluirá la elaboración y presentación de la correspondiente tesis doctoral, consistente en un trabajo original de investigación (p.4040).

Con lo expuesto queda bien clarificado que pese a que parece que en la práctica enfermera se evidencie un déficit de implantación de filosofía enfermera, los titulados la han de integrar de forma completa en su formación y por lo tanto lo coherente sería que hubiera mecanismos gubernamentales y organizativos que permitieran que estas bases se pudieran desarrollar de forma visible en la práctica tal y como indica la importancia de la materia en los planes de estudios. Sin embargo lamentablemente parece que estos contenidos en ocasiones se quedan meramente en contenido de trabajos académicos desarrollados en las aulas y no acaban de llegar a los lugares de trabajo.

\subsection{La influencia del modelo de Virginia Henderson como modelo formativo y clínico predominante en España}

Existen una gran diversidad de modelos teóricos en la disciplina enfermera, pero en el entorno español (contexto del presente estudio) parece ser que Virginia Henderson es la teórica referente en la mayoría de universidades y centros laborales. Una de las posibles causas de tal elec- 
ción podría estar condicionada por la traducción que hizo el ICN de su definición de la enfermería y la colaboración de la teorista en los años sesenta para la elaboración del libro "Principios básicos de los cuidados de enfermería" que expone las actividades que integran los servicios elementales de enfermería. Este hecho la internacionalizó, ya que, el resto de modelos teóricos no contaron con igual difusión (Organización Panamericana de Salud, 1961). Gestores y directores de las escuelas universitarias de enfermería fueron incorporando el modelo como guía en la práctica profesional. Posteriormente se introdujo en programas informatizados de registros de enfermería españoles difundiéndose desde la asistencia primaria a la terciaria. El software informático para la aplicación del mismo es el programa Gacela Care ${ }^{\circledR}$ (Merino, López, Marinas, Merino, Sánchez \& Vaca, 2008; Buergo, 2013).

Algunos defensores del modelo teorizan sobre sus valores, exponiendo que son congruentes a los valores de nuestra sociedad, alaban la sencillez de su lenguaje, su construcción abierta que permite la aplicación en varios ámbitos, la inclusión del rol de colaboración con otros profesionales, el empoderamiento del usuario como gestor de cambio y la posibilidad de ser usado con el proceso enfermero (Luis et al., 2007). Aunque existe quién critica de forma explícita a los seguidores del modelo tachándolos de poco innovadores por impedir la conversión al paradigma de la transformación y reprochando la asunción de un sólo modelo conceptual como limitante. Además reprenden contra los valores sociales cambiantes por la elevada tasa de inmigración y la diversidad social tanto por la procedencia de diferentes países como por la variedad cultural expresada entre las diferentes comunidades autónomas españolas (Irigibel-Uriz, 2007).

Pero para poder evaluar mejor el trabajo de la teorista, veamos de forma más concreta sus supuestos, elementos, asunciones y otros elementos filosóficos al igual que se mostró anteriormente con otras teoristas, aunque en este caso de una forma más detallada.

El trabajo de Henderson se enmarca en las filosofías. Su primera definición de Enfermería la publicó en 1955, incorporando principios fisiológicos y psicológicos (Harmer \& Henderson, 1955). Es uno de los modelos más conocidos, la definición de la función de la enfermera que dio fue acogida por el Consejo Internacional de Enfermería y su obra ha sido traducida a 25 idiomas (Luis et al., 2007). La teórica identificó 14 necesidades básicas en el paciente que integran los elementos del cuidado enfermero, es decir, todas las funciones enfermeras. No obstante, no especificó la definición de "necesidad" (Marriner \& Raile, 2003). Para la teorista, "la función única de una enfermera es ayudar al individuo, sano o enfermo, en la realización de aquellas actividades que contribuyan a su salud o a su recuperación (o a una muerte tranquila) y que éste podría realizar sin ayuda si tuviese la fuerza, la voluntad y el conocimiento necesarios"..."de tal forma que el individuo pueda ser inde- 
pendiente lo antes posible". La enfermera forma parte del equipo de salud, es independiente del médico, pero colabora con él en muchas ocasiones (Henderson, 1966). "Es un servicio de ayuda a la persona en la satisfacción de sus necesidades" (Luis et al., 2007 p.49). Asimismo puede y debe diagnosticar si la situación de la persona así lo requiere (Henderson \& Nite, 1978). Afirmó además, que la definición de Enfermería no debía perdurar en el tiempo, que la disciplina cambia según la época en la que se practica y depende además, de lo que hagan otros profesionales de la salud (Marriner \& Raile, 2003).

Describió asimismo, 3 niveles de relaciones entre la persona y la enfermera: la enfermera como sustituta, como ayudante, y como compañera del paciente (Henderson, 1964). No explicitó el término salud, pero utilizaba el término independencia como sinónimo (aunque independencia no era sinónimo de autonomía). Usó en ocasiones la definición de salud de la OMS. Consideraba que la misma dependía de la capacidad de la persona para satisfacer por sí misma las 14 necesidades. Afirmó que "es más importante la calidad de salud que la vida en sí misma, es ese margen de energía salud/física que permite trabajar del modo más eficaz y alcanzar el nivel potencial más alto de satisfacción en la vida" (Henderson \& Nite, 1978). Es una definición de salud acorde con el trabajo de la enfermera en un entorno médico de curación tradicional, aunque quizás ha sido discutida en el patrón del enfermo que requiera del cuidado indefinido por una tercera persona, ya que podría ser que el propio paciente no alcanzase ese elevado potencial de satisfacción vital del que habla por su dependencia. Esto provocaría que la meta de la enfermería no acabara de quedar clara en el modelo si concretamos en cierta tipología de pacientes con dependencias irreversibles.

Tampoco la autora dio su definición concreta de entorno, utilizó la del Webster's New Collegiate dictionary "Conjunto de todas las condiciones e influencias externas que afectan a la vida y al desarrollo de un organismo" (Henderson \& Nite, 1978). En esta definición incluyó a la familia como parte del entorno (Luis et al., 2007). Otro de los datos que nos indica que su modelo se orientó a la curación era su concepción de persona. Para ella la persona era un "paciente", un individuo que precisa ayuda para recuperar su salud y su independencia, o para tener una muerte tranquila, en el que mente y cuerpo son inseparables. Es un ser integral con elementos biológicos, psicológicos, socioculturales y espirituales que interactúan entre sí (Luis et al., 2007). Consideraba además al paciente y familia como una única unidad (Henderson, 1964).

De las diversas publicaciones a nivel nacional, la obra de Luis et al. "De la teoría a la práctica: el pensamiento de Virginia Henderson en el siglo XXI" es el manual más utilizado por los profesionales en el momento de decidir la implementación del modelo en el área clínica (Coll et al., 2007; Vernet, 2007) quizás por su fácil manejo y su presentación eminentemente práctica. Es por ello que 
a partir de aquí es el manual del que se extraen la mayoría de los valores con los que postula la teórica y que se detallan a continuación. Utilizar la mirada de las autoras del compendio y su análisis se argumentan por la elevada probabilidad de que sean los valores compartidos por aquellos profesionales que estudiaron y comprendieron el modelo para su puesta en marcha en la práctica española.

Como ya se ha comentado, la propuesta de V. Henderson se enmarca en las filosofías. La filosofía se compone de asunciones filosóficas y científicas. Por un lado, las asunciones filosóficas o valores del modelo distinguen la función propia de la enfermera aunque comparta actividades con otros profesionales. Estas asunciones son acordes todavía a las prácticas actuales y adecuadas a la definición de enfermería del International Council of Nursing. Según la teorista, cuando la enfermera asume el papel del médico, abandona su función propia, y es la sociedad la que espera un servicio de la enfermera que ningún otro profesional puede darle (su función propia). En cuanto a asunciones científicas, asume que la persona es un todo complejo con 14 necesidades básicas, que quiere la independencia y se esfuerza por lograrla y cuando la necesidad no está satisfecha la persona no es un todo. Otros datos a tener en cuenta en el modelo son sus componentes, en cuanto a su objetivo es el de ayudar a la persona a satisfacer sus necesidades básicas, enteniendo como persona al usuario que posee un déficit real o potencial en la satisfacción de sus necesidades básicas. Por ello el papel de la enfermera es el de suplir la autonomía de la persona o ayudarle a lograr la independencia. La enfermera evalúa la fuente de dificultad (área de dependencia) que son la falta de conocimiento (saber qué hacer y cómo hacerlo), la fuerza (poder hacer, incluye la fuerza física o psíquica, ha de ser una capacidad que pueda desarrollarse) o la voluntad (querer hacer) de la persona para satisfacer sus necesidades básicas. Una vez las evalua, las potencia para que la persona use al máximo su potencial de recursos. Por ello, estas tres fuentes de dependencia son un gran punto de partida de información para el diagnóstico enfermero y permiten simplificar los diagnósticos a un lenguaje más asequible a nivel nacional (Luis et al., 2007).

La enfermera actúa mediante la inclusión del centro de intervención que son las áreas de dependencia de la persona y utiliza los diferentes modos de intervención (aumentar, completar, reforzar o sustituir la fuerza y el conocimiento o aumentar, completar y reforzar la voluntad). Analizando la propuesta, se observa que son conceptos clave del modelo las necesidades básicas, los cuidados básicos, la dependencia/independencia y sus manifestaciones, la autonomía y el agente de autonomía asistida (Henderson, 1964; Luis et al., 2007).

Las necesidades básicas son un requisito, una condición necesaria para mantener la integridad del ser humano y están condicionadas por aspectos como la edad, carácter, estado anímico, etc. del usuario (Henderson, 1958). Son universales y especificas para cada persona. Sus estudios se ba- 
saban en la jerarquía de las necesidades humanas de Maslow en la que la satisfacción de las necesidades más básicas o subordinadas da lugar a la generación sucesiva de necesidades más altas. Sin embargo, esta es otra premisa que ha sido cuestionada en el modelo, ya que según la patología que presentan los individuos, existen necesidades más importantes que las puramente físicas y que aunque no se hallan en escalones inferiores de prioridad si pueden serlas para las personas cuidadas, como por ejemplo en un paciente con un trastorno mental (Luis et al., 2007), aunque la propia autora reconoce que pueden variar según la patología (Henderson, 1958). Las 14 necesidades básicas del paciente son (Henderson, 1991):

1. Respirar normalmente.

2. Comer y beber adecuadamente.

3. Eliminar por todas las vías corporales.

4. Moverse y mantener posturas adecuadas.

5. Dormir y descansar.

6. Escoger ropa adecuada; vestirse y desvestirse.

7. Mantener la temperatura corporal dentro de límites normales, adecuando la ropa y modificando el ambiente.

8. Mantener la higiene corporal y la integridad de la piel.

9. Evitar los peligros ambientales y evitar lesionar a otras personas.

10. Comunicarse con los demás expresando emociones, necesidades, temores u opiniones.

11. Vivir de acuerdo con los propios valores y creencias.

12. Ocuparse en algo de tal forma que su labor tenga un sentido de realización personal.

13. Participar en actividades recreativas.

14. Aprender, descubrir o satisfacer la curiosidad que conduce a un desarrollo normal y a usar los recursos disponibles.

Los cuidados básicos son el conjunto de intervenciones terapéuticas, reflexionadas y deliberadas que realizan las enfermeras, basadas en el juicio profesional y están dirigidos a satisfacer las necesidades básicas de las personas. Por otro lado, la dependencia y la independencia son conceptos muy ligados, se entiende como independencia el nivel óptimo de desarrollo del potencial de la persona para satisfacer las necesidades básicas determinado por las características personales y se manifiesta con indicadores de la conducta (reacción voluntaria) de la persona adecuadas y suficientes para satisfacer las necesidades básicas. Sin embargo, la dependencia es el desarrollo insuficiente del potencial de la persona, debido a una falta de fuerza, conocimientos o voluntad que impide satis- 
facer sus necesidades básicas. Esta dependencia es manifestada por indicadores de la conducta (reacción voluntaria) de la persona que resultan incorrectos, inadecuados o insuficientes para satisfacer las necesidades básicas (Henderson, 1964; Luis et al., 2007).

Otro término relevante es el de la autonomía. La autora la define como la capacidad física y psíquica de la persona que le permite satisfacer las necesidades básicas mediante acciones realizadas por ella misma. No debe confundirse con el término de independencia, ya que puede haber falta de autonomía por la edad y la etapa de desarrollo de la persona o porque ha perdido temporal o definitivamente la capacidad. Cuando el usuario carece de autonomía aparece el agente de autonomía asistida que es la persona que hace por él acciones encaminadas a satisfacer necesidades susceptibles de suplencia (Luis et al., 2007).

\subsection{Desarrollo teórico y el desarrollo profesional en la disciplina enfermera, dos unidades indisolubles.}

Una vez descrita la base conceptual que parece dominar el entorno formativo español, es interesante conocer la relación entre este desarrollo teórico y sus lazos con el desarrollo profesional. El desarrollo profesional y el teórico son un tándem indisoluble en el progreso enfermero como disciplina, ambos despliegues han sido paralelos, coétaneos y mutuamente influenciadores tal y como se discute a continuación.

Tal y como argumenta Durán (2007) basándose en estudios de Burns y Grove (2004) "para validar los hechos del mundo empírico de enfermería se requiere el desarrollo teórico que, junto con el desarrollo de la ciencia de enfermería, generarán el conocimiento disciplinar necesario para garantizar la autonomía de la práctica clínica".

El desarrollo profesional se entiende como las etapas que ha de salvar enfermería para conseguir el crecimiento como disciplina y demostrar su aportación al campo de la salud. Son muchos los factores descritos que influyen en este desarrollo: el cumplimiento de principios éticos (Antón \& Busquets, 1997), las cargas de trabajo y el desarrollo tecnológico (Mingote \& Pérez, 2003), el desarrollo de un lenguaje común (Arias, Aller, Ignacio \& Lorente, 2001), la dualidad historia - feminidad (Arriaga, Baca, Castaño \& Montoya, 2006), la formación continuada o carrera profesional (Ayuso et al., 2006), la práctica reflexiva (Richards \& Edwards, 2010) y la teoría enfermera entre otros (J. López, 2000). Concretamente ya en 1959, Bixler y Bixler indicaron que una profesión en su práctica utiliza un cuerpo definido y bien organizado de conocimiento especializado que está en el nivel intelectual del aprendizaje superior. Además, lucha por ayudar a sus profesionales para el trabajo desde 
la autonomía basándose en estándares propios, tomando responsabilidad entre ellos y favoreciendo el crecimiento profesional (Busquets, 1997; Marriner \& Raile, 2003).

J. López (2000) hace referencia a Van der Bruggen para describir lo que debería ser característico de una profesión. Enfermería debería prestar a la sociedad unos determinados servicios, estar preparada para ello y de acuerdo con un código ético. Además, debería asumir la organización y gestión de sus propios programas de formación y de sus actividades en su dimensión local, institucional, nacional e internacional, realizar la construcción de su propio campo de saber y por último llevar a cabo programas de investigación científica. Estas funciones son también referidas en la Ley de Ordenación de las Profesiones Sanitarias considerando a enfermería como profesión. Históricamente ya la Ley de 1855 como la Instrucción General de 1904 se ocupó de intentar regular el ejercicio del "arte de curar".

El uso del conocimiento particular para la enfermería basado en la teoría, es una condición propia de su práctica; sobre todo a medida que las enfermeras crecen profesionalmente (Marriner \& Raile, 2003). Se puede decir, que es principalmente significativo, ya que, el uso de teoría enfermera ha posibilitado a lo largo de la historia un marco conceptual para la investigación, otra herramienta clave e indispensable para el progreso profesional (C. López, Riu \& Forner, 2005). Esta importancia de los modelos teóricos se ve reflejada, en estudios recientes como el Registered Nurse Forecasting (RN4CAST) coordinado por Sermeus del que Moreno y cols. forman parte como colaboradores españoles. El estudio tenía el objetivo de analizar el clima laboral de las enfermeras europeas utilizando el cuestionario Nursing Work Index validado internacionalmente y desarrollado desde los hospitales magnéticos. Entre otros ítems, el propio cuestionario valora como un ítem positivo en el bienestar de las enfermeras, tener la percepción de desarrollar el cuidado en un modelo de enfermería en lugar de basarse en un modelo médico (Kramer \& Hafner, 1989). Concretamente el ítem evaluado era el de "fundamentos enfermeros para unos cuidados de calidad", incluso se asociaron los factores de la escala positivamente con la satisfacción y mejores experiencias en el cuidado percibidas por los propios pacientes. Entre los años 2009 y 2010, valoraron el clima laboral de las enfermeras en entornos hospitalarios sobre más de 5000 enfermeras, en una puntuación de 1 a 4, valoraron positivamente (con un 2,7) la relación de los cuidados de enfermería con un modelo enfermero y no médico, y que existiera una filosofía clara de enfermería que dominase el entorno de cuidados del paciente con un 2,3 (Instituto de Salud Carlos III, 2011). Hecho que revela la importancia del tema entre los profesionales.

Por lo tanto tal y como se ha ido viendo en toda la introducción y el marco conceptual de este estudio, conceptos como autonomía, responsabilidad, seguridad, satisfacción y control de la 
práctica son características profesionales (Luis et al., 2007). Estos elementos se ven vehiculados por el uso de modelos teóricos y permiten el favorecimiento y logro de un mayor estatus profesional. Diferenciar la aportación enfermera de los otros profesionales y desarrollar el liderazgo optimizando el valor de los cuidados aportados, viene marcado por el uso de marcos conceptuales propios que definan claramente la contribución diferencial de la enfermera como agente de salud de la población. Recordemos que, históricamente el inicio de rol autónomo profesional enfermero fue asociado al desarrollo de la teoría enfermera en los años cincuenta, posteriormente se integró en los planes de estudio junto a otro gran pilar, la investigación. De esta manera se posibilitó la evolución profesional y explica el porqué la base conceptual enfermera es esencial para la disciplina y no se puede analizar de forma independiente de su desarrollo como profesión, ya que ambos caminos han ido progresando de forma paralela. El desarrollo profesional no hubiese sido posibilitado sin el desarrollo de la filosofía enfermera, ya que se hubiese paralizado el avance en los conocimientos de otras disciplinas afines y por lo tanto bajo su sumisión. Por ello los factores o elementos que contribuyen o inhiben el crecimiento profesional van a ser similares a los que influyen en el desarrollo teórico de la profesión, esto concretamente es lo que justifica que en nuestro estudio se utilicen ambos aspectos para el estudio y comprensión del fenómeno concreto de la aplicación de modelos teóricos en la práctica enfermera. 
2 Objetivos 
Una vez expuestos los diferentes elementos del estado del problema, se plantean en la presente tesis un objetivo principal y otros secundarios que lo complementan o concretan y que se detallan a continuación.

\subsection{Objetivo general}

Identificar cuáles son los factores asociados al uso de un modelo teórico enfermero que guíe la práctica profesional en nuestro contexto.

\subsection{Objetivos específicos}

1. Describir el estado formativo de pregrado que ha podido influir en la implantación de modelos teóricos en la práctica de enfermería en España.

2. Conocer los modelos enfermeros que se aplican de forma implícita (sin ser regularizados institucionalmente) en la práctica profesional y su relación con la formación recibida.

3. Conocer las ventajas y desventajas percibidas por los profesionales enfermeros sobre el uso de un modelo teórico enfermero para el cuidado.

4. Identificar los elementos que han influenciado el uso teórico y desarrollo profesional de la enfermería en España desde la perspectiva de las enfermeras en periodo de formación de Máster.

5. Determinar los elementos que han facilitado y los que han impedido el uso y desarrollo de modelos teóricos en la práctica española desde la perspectiva de enfermeras gestoras y docentes

6. Describir el nivel de implantación de modelos enfermeros en la práctica actual a nivel internacional. 
3 Metodología 


\section{Metodología}

Hallar una total comprensión sobre la búsqueda de los factores asociados al uso de un modelo teórico en la práctica fue tarea compleja, ya que fueron muchos los elementos a tener en cuenta. Para llegar a tal finalidad, se precisó concretar la investigación en varios objetivos específicos tratados como fases diferentes del estudio y desarrollados en función de las exigencias investigadoras de cada momento. De forma que, fue una investigación flexible y emergente.

Estos objetivos, por las características propias del tema de investigación requirieron valerse de diversos métodos de recogida de datos sobre profesionales con diferentes perfiles formativos y de diversos ámbitos. Tal aproximación condicionó la fragmentación de la tesis en función de la respuesta a cada uno de los objetivos planteados; cada uno de ellos se respondió independientemente y de forma separada en el tiempo, ya que la consecución de los mismos, permitió desarrollarlos con proyectos simultáneos paralelos debido a que no se describieron requisitos previos entre el avance de los objetivos.

Por estos motivos de consecución expuestos y la variabilidad de aspectos a considerar, fue de gran utilidad la aplicación de lo que en inglés es ampliamente conocido como el tercer método o diseño de estudio los "mixed methods". La investigación mediante métodos mixtos ofrece lo mejor de métodos cualitativos unidos a métodos cuantitativos, es decir, las ideas en profundidad y la contextualización de la investigación cualitativa potencia los resultados obtenidos de la investigación cuantitativa más eficiente pero menos rica en matices. Estos enfoques son mucho más exhaustivos que abordar el problema desde un sólo punto de vista. Mediante estrategias y herramientas para tratar diferentes tipos de datos, permiten el cruce de las fronteras disciplinarias con un abordaje integral del problema de estudio (Creswell \& Clark, 2007). Por lo tanto, se usaron aproximaciones cuantitativas o cualitativas según fue preciso.

Se mostraron como necesarias para este estudio la complementariedad de ambas metodologías; en el sentido de que cada una de ellas atiende aspectos diferentes de una misma realidad (Ullin, Robinson \& Tolley, 2006). Algunos autores como Vera y Villalón (2005) abogan sobre las bondades de integrar diversos marcos metodológicos en una investigación, en concreto integrando la metodología cualitativa con la cuantitativa. Aunque "cuando se decide triangular, nos encontramos con el desafío de cómo poder responder a nuestra pregunta de investigación desde dos aproximaciones, que desde un punto de vista epistemológico se sustentan en premisas muy distintas" (Vera \& Villalón, 2005). En el presente estudio el rigor científico viene dado por una triangulación múltiple, por un lado mediante triangulación metodológica, y por otro, se está 
triangulando a nivel de datos, puesto que estos proceden de distintas fuentes de información. Esto nos asegurará una mayor comprensión de la complejidad del fenómeno (Vera, 2005, Burns \& Grove, 2004). Según Vera (2005) Betancourt en 1975 argumentó una mayor fiabilidad y validez los datos obtenidos a través de la convergencia de los resultados.

En la literatura consultada no se halló instrumento validado para medir los factores asociados a la aplicación de modelos teóricos en la práctica, el único estudio que quizás se asemeja, es la investigación llevada a cabo por Wimpenny en el 2002. En este estudio el autor abordó el tema mediante metodología cualitativa. En concreto utilizó la fenomenología mediante entrevistas a los profesionales enfermeros y halló que existían tres enfoques del término modelo teórico: el enfoque teórico, el mental y el sustitutivo. Este estudio fue el eje crucial para el desarrollo de la investigación que aquí se muestra. Siguiendo su línea argumental con el objeto de representar de forma fiel los diferentes aspectos en relación a los modelos, la presente tesis fue fragmentada en objetivos que van a buscar el significado de la base conceptual para los profesionales siguiendo los tres enfoques que plantea el autor (teórico, mental y sustitutivo). Se estudió el significado del enfoque como modelo teórico en la indagación en la formación enfermera y su aplicación en estudiantes, el enfoque del modelo mental en cuanto a profesionales que no los aplican en su práctica diaria pero que recuerdan los modelos reconstruyéndolos individualmente de forma mental añadiendo su experiencia y conocimiento personal que podría influenciar el cuidado el paciente. Y por último, pudimos objetivar el enfoque del modelo sustitutorio, mediante el estudio de la aplicación de modelos en diferentes casos particulares y la opinión de gestores y docentes sobre su aplicación, ya que son versiones funcionales del modelo teórico y son usados como guía en la práctica clínica, representando el esquema alrededor del cual las enfermeras pueden recoger datos y comunicarse y por el cual, la organización puede estandarizar la práctica.

Por ello, en la medida que la investigación fue avanzando, la comprensión de la realidad objeto de estudio permitió desvelar indicios y nuevos caminos a recorrer más que, presentar absoluta certeza de cada uno de los conocimientos hallados. Pese a que los objetivos de la tesis fueron ordenados para una presentación lógica de resultados, el desarrollo de los mismos se realizó condicionado por las necesidades investigadoras, partiendo de un diseño emergente posibilitado, como ya se ha comentado, por la combinación de métodos cuantitativos y cualitativos ("mixed methods"). Para hacerse una idea general de la aplicación de los diversos métodos, veamos a continuación de forma somera y resumida, el abordaje que se utilizó en cada uno de los objetivos, que veremos de forma más detallada en su apartado correspondiente. 
El primer objetivo, requirió de un abordaje descriptivo mediante la revisión de los planes de estudio de los centros acreditados por el Ministerio de Educación para la formación de Diplomados en Enfermería. El objetivo era describir el estado formativo de pregrado que había podido influir en la implantación de modelos teóricos en la práctica de enfermería en España. Por ello, se pasó a analizar que sucedía en las universidades respecto a la cuestión. Debido a la imposibilidad de acceder a cada una de las aulas (hecho que sería quimérico) se decidió indagar en las páginas web de las universidades, ya que la revisión bibliográfica del tema acreditó una ausencia de conocimiento sobre la oferta concreta educativa de los centros formativos de pregrado respecto a la base filosófica enfermera en España. Se precisaba de una técnica que midiese los datos de una forma objetiva, que nos diese un retrato lo más real al estado formativo del momento y que concretara al máximo los detalles, fue elegida por tanto la técnica cuantitativa gracias a su carácter reduccionista y comparativo (Gerrish \& Lacey, 2006). Este abordaje nos permitió objetivar y comparar la oferta entre los 109 centros universitarios españoles sobre formación pregrado en modelos y teorías enfermeras.

Para el segundo objetivo sobre conocer los modelos enfermeros que se aplican de forma implícita (sin ser regularizados institucionalmente) en la práctica profesional y su relación con la formación recibida, se optó por un diseño cuantitativo que indagara sobre el conocimiento de la perspectiva de un amplio número de personas inmersas en el mundo laboral a nivel profesional y/o formativo. Su utilización se fundamentó en la rigurosidad y objetividad para medir la percepción y estudiar la relación entre posibles factores asociados a la misma (Burns \& Grove, 2004), acorde al propósito de determinar de qué forma los modelos teóricos impregnaban una práctica profesional que no estaba condicionada institucionalmente por un modelo conceptual concreto. Este abordaje descriptivo cuantitativo es considerado como el método ideal de partida cuando existe poca información sobre el tema de estudio (Burns \& Grove, 2004), de hecho, se hallaron pocas investigaciones que abordaran la perspectiva de los profesionales en el tema (McKenna, 1990; Wimpenny, 2002).

El tercer y cuarto objetivo: conocer las ventajas y desventajas percibidas por los profesionales enfermeros sobre el uso de un modelo teórico enfermero concreto para el cuidado; e identificar los elementos que han influenciado el uso teórico y desarrollo profesional de la enfermería en España desde la perspectiva de las enfermeras en periodo de formación de Máster; planteaban la posibilidad de profundizar en el pensamiento profesional sobre el tema, mediante el análisis de los sujetos enfermeros como una subcultura dentro de los profesionales sanitarios (concretamente en la cultura del cuidar); sustentando el desarrollo de este objetivo sobre el marco de la 
etnografía. Este marco, pudo hacer entender los valores del grupo profesional estudiado en relación con sus experiencias en la aplicación de modelos teóricos, comparando el uso de los mismos con valores profesionales innatos, mediados también por la socialización del entorno sanitario y por los valores de las personas a las que cuidan. Esto se consiguió mediante el análisis de cómo se desarrolló la aplicación particular de un modelo en el cuidado de pacientes con patologías con las que los profesionales estaban familiarizados. Por el tipo de datos estudiados la metodología utilizada para el análisis nos permitía esa búsqueda de comprensión profunda y la visión de las variables de una forma más honda y deliberada. En este caso, el análisis cualitativo permitió conocer a fondo cuáles fueron los factores seleccionados como problemáticos y favorecedores para el desarrollo profesional y la implantación de modelos concretos en la práctica. Los resultados obtenidos reflejaron los diferentes puntos de vista que tenía enfermería sobre el tema, o lo que es lo mismo, permitió tener una imagen completa del objeto de estudio desde todas sus áreas.

Este mismo prisma etnográfico fue el paraguas que sustentó el analizar el alcance del fenómeno a nivel institucional, evaluando el sentir de docentes y gestores como parte relevante en las decisiones corporativas en la elección, desarrollo e implementación de modelos teóricos. Los hallazgos sobre factores facilitadores y limitantes o barrera llevaron a plantearse que prioridad seguían para profesionales determinantes de la difusión y aplicación de modelos teóricos; por ello se llevó a cabo siguiendo la técnica de consenso Delphi para responder de forma unificada y priorizada a la identificación de qué elementos han facilitado y han impedido el uso y desarrollo de modelos teóricos en la práctica española desde la perspectiva de enfermeras gestoras y docentes.

En relación al rigor en los objetivos abordados con metodología cualitativa, cabe destacar que se aseguró la credibilidad, la transferencia y la confirmabilidad de los resultados, mediante el análisis profundo y repetido de los textos abordados (recogidos ampliamente en los anexos). El elevado número de documentos analizados aseguró la recogida de gran número de situaciones durante diferentes años (cursos académicos), permitiendo la saturación de datos. Además, se hace referencia a las posibilidades de aplicar resultados de este estudio a otros contextos, pese a que la generalización no es posible por el carácter único e irrepetible de los contextos, sujetos y fenómenos del cuidado estudiados, sí cabe la posibilidad de algún tipo de transferencia dependiendo del grado de similitud entre los mismos. El que los documentos inicialmente carecieran de finalidad investigadora permitió la libertad de los informantes a comunicar sus trabajos sin interferencias por parte del investigador, por lo que aseguró la neutralidad de la información. Por último, la consistencia se obtuvo mediante la contrastación del mismo tema mediante métodos cualitativos y cuantitativos, así como la definición exhaustiva de cómo se llevó a cabo el análisis de 
los datos y la triangulación de resultados en diferentes sujetos (estudiantes, enfermeros asistenciales, gestores, profesores universitarios,...), contextos (atención primaria, especializada, universitaria,...) y métodos de recogida de datos (encuestas, análisis de documentos, delphi,...). Ver tabla 6 elaborada a partir de los criterios de rigor metodológico cualitativos propuestos por Guba en 1981 (Gimeno \& Pérez, 2008).

Tabla 6: Análisis de los métodos usados en el estudio para asegurar la calidad de la investigación de los objetivos desarrollados mediante aproximaciones cualitativas

\begin{tabular}{|c|c|c|}
\hline \multicolumn{2}{|c|}{$\begin{array}{l}\text { Criterios de rigor metodólogico en el aná- } \\
\text { lisis cualitativo }\end{array}$} & Métodos usados en nuestro estudio \\
\hline $\begin{array}{l}\text { Confirmabili- } \\
\text { dad }\end{array}$ & $\begin{array}{l}\text { (Fiabilidad externa, neu- } \\
\text { tralidad, objetividad) } \\
\text { Garantía de que los re- } \\
\text { sultados de una } \\
\text { investigación no están } \\
\text { sesgados por motivacio- } \\
\text { nes, intereses, y } \\
\text { perspectivas del } \\
\text { investigador }\end{array}$ & $\begin{array}{l}\text { Descripción de las características de los informantes y su } \\
\text { proceso de selección. } \\
\text { Uso de mecanismos de registro de opiniones y creencias } \\
\text { reflexionadas a través de los trabajos. } \\
\text { Explicación exhaustiva de cómo y cuando se recogieron los } \\
\text { datos en los informantes. } \\
\text { Explicación detallada de los métodos seguidos en el análisis } \\
\text { de los datos. } \\
\text { Uso del análisis de documentos de producción personal no } \\
\text { modificables. } \\
\text { Posicionamiento neutral del investigador que no mantiene } \\
\text { contacto con los informantes. }\end{array}$ \\
\hline Credibilidad & $\begin{array}{l}\text { (Validez interna, veraci- } \\
\text { dad) } \\
\text { Reflejo de una imagen } \\
\text { clara y representativa de } \\
\text { una realidad o situación } \\
\text { dada }\end{array}$ & $\begin{array}{l}\text { Análisis de gran número de textos de diferentes años } \\
\text { académicos. } \\
\text { Libertad de los informantes a comunicar sus trabajos sin } \\
\text { interferencias por parte del investigador. } \\
\text { Uso de transcripciones textuales para respaldar categorías } \\
\text { halladas. } \\
\text { Uso de la triangulación en la recolección de datos (diferen- } \\
\text { tes sujetos, contextos y forma de recogida). }\end{array}$ \\
\hline $\begin{array}{l}\text { Transferibili- } \\
\text { dad }\end{array}$ & $\begin{array}{l}\text { (Validez externa, aplica- } \\
\text { bilidad, generalización) } \\
\text { Grado en que puede } \\
\text { aplicarse los descubri- } \\
\text { mientos de una } \\
\text { investigación a otros } \\
\text { sujetos o contextos simi- } \\
\text { lares }\end{array}$ & $\begin{array}{l}\text { Muestreo teórico con descripción de los sujetos encuesta- } \\
\text { dos y forma de recogida de datos con el objetivo de } \\
\text { maximizar la recogida de información. } \\
\text { Recogida de datos de un gran número de participantes, es } \\
\text { decir datos descriptivos del fenómeno.Sujetos de diferentes } \\
\text { contextos (de trabajo y residencia), con diferentes forma- } \\
\text { ciones y niveles asistenciales, por lo que probablemente } \\
\text { pueden transferirse los resultados al sentir de la profesión } \\
\text { enfermera española. } \\
\text { Pistas de revisión: se adjuntan los textos analizados en el } \\
\text { anexo. }\end{array}$ \\
\hline Consistencia & $\begin{array}{l}\text { (Replicabilidad, fiabilidad } \\
\text { interna, dependencia). } \\
\text { Repetición de los resul- } \\
\text { tados cuando se realizan } \\
\text { investigaciones } \\
\text { con los mismos sujetos e } \\
\text { igual contexto }\end{array}$ & $\begin{array}{l}\text { Descripción de los informantes. } \\
\text { Identificación de las técnicas de análisis de los datos. } \\
\text { Triangulación de métodos cualitativos con cuantitativos. } \\
\text { Uso del análisis de documentos de producción personal } \\
\text { reflexionados no modificables. } \\
\text { Saturación de los datos: permitido por el análisis de gran } \\
\text { número de textos de sujetos de diferentes contextos rele- } \\
\text { vantes para el problema de estudio. }\end{array}$ \\
\hline
\end{tabular}


Finalmente y con toda la información obtenida, se decidió realizar una revisión más amplia del tema a nivel internacional para poder ser contrastada con los resultados hallados mediante el sexto objetivo (describir el nivel de implantación de modelos enfermeros en la práctica actual a nivel internacional). La búsqueda exhaustiva llevada a cabo en la base bibliográfica sanitaria gratuita más relevante internacionalmente, dio a conocer la aplicación de modelos en la práctica en la actualidad y puso de manifiesto cuáles fueron los modelos prevalentes en el ámbito internacional.

Debido a estas premisas expuestas, la población fue escogida en todos los casos mediante muestreo de conveniencia. Seleccionados intencionada o accidentalmente por pertenecer a diferentes grupos sociales representativos y por su capacidad para informar al investigador sobre el tema de indagación. Por todo el planteamiento expuesto, son los propios objetivos planteados los que guiaron el desarrollo de esta tesis doctoral. Para clarificar al lector el desarrollo cronológico de cada uno de los objetivos, su temporalizacion ha sido descrita en la tabla 7.

Tabla 7: Análisis cronológico del desarrollo de los objetivos específicos

\begin{tabular}{|l|l|l|l|l|l|l|l|l|}
\hline $\begin{array}{l}\text { Describir el estado formativo de pregrado que } \\
\text { ha podido influir en la implantación de mode- } \\
\text { los teóricos en la práctica de enfermería. }\end{array}$ & & & & & & & & \\
\hline
\end{tabular}

A continuación se realizará una exposición detallada y concreta en cuanto a la aproximación metodológica usada para dar respuesta a cada objetivo particular. 


\subsection{Metodología para el desarrollo del primer objetivo especifico:}

\section{Describir el estado formativo de pregrado que ha podido influir en la implantación de modelos teóricos en la práctica \\ de enfermería en España.}

Debería ser un hecho que la formación en filosofía recibida por los estudiantes de pregrado de Enfermería fuese un factor relevante y determinante para su práctica futura, por lo que el abordaje de los modelos y teorías de enfermería en el aula debería guiar la implementación de marcos conceptuales enfermeros en la práctica. Esa base troncal se desarrolla normalmente en el primer año de formación universitaria y su desarrollo impregna de forma transversal a otras asignaturas de diferentes años académicos. Siguiendo el hilo argumental explicitado en la introducción, se elaboró esta etapa con el propósito de conocer cuál era la oferta educativa en formación básica pregrado ofrecida por las diferentes universidades en cuanto a teorías y modelos enfermeros en los programas educativos y objetivar cuáles podrían ser los elementos asociados a prácticas futuras filosóficas y si había discrepancias entre las diferentes ofertas respecto al tiempo y contenido curricular, partiendo de la premisa de que todos los planes docentes debían de seguir las indicaciones dictadas por la Agencia Nacional de Evaluación de la Calidad y Acreditación, recogidas en el "Libro Blanco del Título de Grado en Enfermería" (Bernués et al., 2004).

\subsubsection{Diseño}

Esta fase, se abordó a través de un diseño observacional transversal descriptivo llevado a cabo mediante la revisión detallada de los planes de estudio de los 109 centros que en aquellos momentos impartían su formación en la titulación de Diplomado de Enfermería en España (curso 2008-2009).

\subsubsection{Poblacion de estudio}

Se valoraron la totalidad de las universidades españolas que ofertaban formación pregrado en Enfermería, es decir, la Diplomatura de Enfermería en aquel momento. Se incluyeron un total de 109 centros universitarios, de diferentes Universidades de España en las que se cursaba el título de Diplomado en Enfermería durante el curso 2008/2009. Estos centros fueron identificados 
a partir del listado de oferta de titulaciones para Diplomados de Enfermería existente en la web del Ministerio de Educación con fecha de acceso 10 enero de $2009^{4}$.

\subsubsection{Variables de estudio}

En la revisión de las páginas oficiales web y los planes de estudio de las diferentes universidades se estudiaron las siguientes variables:

- Nombre del centro universitario.

- Nombre del centro universitario al que pertenecía el plan de estudios.

- Comunidad Autónoma en el cuál estaba situado el centro universitario.

- Disponibilidad de web del centro universitario.

- Dirección de la web consultada.

- Disponibilidad de plan de estudios en la web.

- Año explicitado del plan de estudios expuesto en web.

- Nombre/s de la/s asignatura/s relacionada/s con la base conceptual enfermera.

- Carácter de la asignatura: siendo obligatoria, optativa o de libre elección.

- Número de créditos $L R U^{5}$ de la asignatura relacionada con la base conceptual.

- Adscripción del centro a teórica enfermera: se aceptó como teoría /modelo guía de la formación en el centro, cuando éste recogía de forma explícita la teorista influyente como tal en la filosofía del centro o cuando lo expresaba de forma indirecta en el contenido de la asignatura, ya que se especificaba en el temario como única teoría desarrollada en su totalidad.

- Curso en el que se impartía la asignatura relacionada con la base conceptual enfermera (primero, segundo o tercer curso).

- Contenido de la asignatura relacionada con la base conceptual enfermera (copia textual del contenido que presentaban en el plan de estudios de la red).

${ }^{4} \mathrm{En}:$

https://www.educacion.gob.es/notasdecorte/jsp/busquedaDo.do?opcionMenu=BusquedaSimple\&codTi poUniversidad=T\&nomTipoUniversidad=Todas\&codUniversidad=T\&nomUniversidad=Todas\&nomTitula =DiplomadoenEnfermería\&codRama $=431005 \&$ nomRama $=$ CienciasdelaSalud\&codAut $=00 \&$ codProv $=00 \&$ tip oEnsenanza=CICLO

${ }^{5}$ Se recogen los créditos LRU (Ley de Reforma Universitaria) y no ECTS, ya que los planes de estudios pertenecen al curso 2008-09, en el que todavía no se había desarrollado el plan Bolonya. 


\subsubsection{Recogida de los datos}

Se identificaron los centros que ofertaban formación de Diplomado de Enfermería en la página web del Ministerio de Educación (un total de 109). Una vez identificados, se pasó a consultar las webs oficiales de las universidades con la intención de poder valorar los planes de estudio propuestos. La revisión se realizó entre los meses de enero - junio de 2009.

En Internet se examinó la presencia de filosofía del centro, el programa general o plan de estudios y los contenidos sobre filosofía enfermera en los planes cuando el programa de la asignatura estaba disponible en web.

Una vez visualizado el plan de estudios del centro universitario, se seleccionaron aquellas asignaturas que tenían relación con el objeto de estudio. Estas asignaturas fueron identificadas a través de diferentes palabras clave relacionadas con filosofía enfermera o metodología (por la relación entre el proceso de enfermería y la aplicación de modelos teóricos) en sus enunciados incluían: "teoría”, "modelo", "fundamental”, "fundamentos", "teóricos”, “básico", "básica”, "introducción", "fundamentación", “epistemología", "metodología”, “método", "diagnóstico", "proceso enfermero", "historia de enfermería", "rol autónomo", “cuidado", “pensamiento"...

Una vez identificada la asignatura se accedía al contenido para recoger las variables de estudio. La información de cada una de las variables antes señaladas se fueron registrando en una tabla elaborada con el objetivo de análisis posterior.

\subsubsection{Análisis de los datos}

El análisis de los datos se realizó a través de la descripción de las variables cuantitativas en forma de media y desviación estándar. Las variables categóricas se representaron en forma de frecuencias y porcentajes mediante el uso del paquete estadístico SPSS 16.0 para Windows.

En cuanto al análisis de datos en los planes de estudio, se cuantificaron los planes en los que en sus contenidos se hacía alusión al aprendizaje de los siguientes conocimientos: base conceptual enfermera (mediante aparición explícita de temas en relación a filosofía o inclusión de las diferentes teóricas enfermeras), historia de la enfermería y metodología enfermera. 


\title{
3.2 Metodología utilizada para dar respuesta al segundo objetivo específico: Conocer qué modelo enfermero se aplica de forma implícita (sin ser regularizado institucionalmente)
} en la práctica profesional y su relación con la formación

\author{
recibida
}

Acorde a la preocupación ya manifestada sobre la brecha teórico - práctica entre la formación, el quehacer diario y los factores que podrían incidir en aplicar teoría enfermera; se planteó conocer si profesionales y estudiantes escogerían un modelo enfermero para su práctica, y el motivo por el que aceptarían o rechazarían dicha elección. Para dar respuesta a este objetivo se realizó un estudio sobre la perspectiva teórica de estudiantes y profesionales de la Corporació Sanitaria del Parc Taulí (CSPT). Los motivos de la elección de dicho centro para el estudio, fueron por un lado, la facilidad de acceso a los profesionales ya que la investigadora trabajaba en la institución en aquel momento, y por otro, era una población no condicionada, ya que en el momento de la recogida de datos no había un modelo teórico explícito institucional que guiara el cuidado. Esto hizo que los profesionales respondieran en base a perspectivas propias y no basadas en ideas proyectadas por la institución en la que trabajaban; es decir, el hecho de los profesionales tuvieran un modelo teórico institucionalizado, hubiese podido condicionar o mediar su posicionamiento hacia el mismo. Basándose en esta percepción más neutral y propia del modelo pudimos aproximarnos a analizar cualidades de lo que Wimpenny (2002) llama enfoque mental del modelo.

El estudio sobre la aplicación de modelos teoricos en la práctica pertenece a un estudio mayor realizado sobre estudiantes y profesionales que abarcaba diferentes aspectos. Filosóficos por un lado que englobaban preguntas sobre modelos teóricos y elementos del metaparadigma enfermero, y por otro preguntas sobre metodología enfermera. Por el tema que nos ocupa en este estudio, sólo se presentarán los resultados en relación a los factores de aplicación de modelos teóricos en la práctica enfermera.

\subsubsection{Diseño}

El diseño utilizado se basaba en un estudio descriptivo, observacional, transversal a través de la implementación de cuestionario autoelaborado por el equipo investigador. 


\subsubsection{Población de estudio}

Como ya se ha comentado en esta fase se estudiaron 2 tipologías de sujetos: profesionales y estudiantes.

Profesionales: La investigación se desarrolló en la Corporació Sanitaria Parc Taulí (CSPT). Según la información obtenida de su web (2010) era una entidad jurídica pública de carácter institucional integrada por la Generalitat de Catalunya, el Ayuntamiento de Sabadell, la Universitat Autònoma de Barcelona, la Fundació Hospital i Casa de la Beneficència de Sabadell, la Caixa d'Estalvis de Sabadell, Sabadell Mutual y Mutualitat de Previsió Social. Esta corporación estaba formada por seis centros: Hospital de Sabadell, Salud Mental, UDIAT (Unidad de Diagnóstico por la Imagen), Albada (Centro Sociosanitario), Sabadell Gent Gran (Centro de servicios para personas mayores) y un centro de salud de Atención Primaria. Disponía de 769 camas (487 camas de atención de agudos y 282 camas de atención sociosanitaria) y cubría once poblaciones con más de 400.000 habitantes de referencia. El personal de enfermería (conjunto de enfermeras y auxiliares de enfermería) estaba formado por unas 1300 personas ${ }^{6}$.

Pese a que la institución tenía recogida de forma concreta el número total de profesionales enfermeros en plantilla, no pudo concretar el número exacto de profesionales, ya que las plantillas enfermeras varían continuamente, bien por posibles bajas de los profesionales o cambios en las dotaciones según las necesidades puntuales de las diferentes unidades. Por este tema pese a que inicialmente se planteó la necesidad de aleatorizar la muestra, no fue posible calcular la muestra ya que no podríamos asegurar la oportunidad de acceder a todos los individuos y se optó por el muestreo de conveniencia. Para asegurar la mayor representación posible de profesionales, se decidió invitar a participar en el estudio a todas las enfermeras presentes en el momento de la entrega de cuestionarios en sus lugares de trabajo, muestreo accidental durante varios días y en diferentes turnos durante una semana (llegando a una $\mathrm{N}=545$ ). Estos profesionales desempeñaban su labor explícita bajo un modelo estándar de atención, un modelo tradicional basado en la patología del paciente (en el momento de la recogida de datos el centro no disponía de metodología o modelo enfermero oficialmente declarado). Se ofreció la posibilidad de participar a todos los profesionales independientemente del ámbito asistencial del centro, turno y tipo de contratación que dieron su consentimiento oral para participar en el estudio.

Los criterios de inclusión de los profesionales fueron:

\footnotetext{
${ }^{6}$ Información obtenida de web de la Corporació Sanitària Parc Taulí: http://www.tauli.cat
} 
- Experiencia de más de 3 meses trabajando en el centro para garantizar un mínimo conocimiento de la asistencia sanitaria.

- Disponer de la titulación de Diplomado en Enfermería o Ayudante Técnico Sanitario.

- Voluntariedad de participación y estar en activo en el momento en el que se recogieron los datos.

Por consiguiente, se excluyeron a aquellos profesionales que no cumplieron los criterios de inclusión.

Estudiantes: Fueron invitadas a participar en el estudio, las 4 universidades que tenían conveniados créditos prácticos en la CSPT. De estas, sólo tres desearon participar en el estudio: la Universitat Internacional de Catalunya (UIC, en Sant Cugat), la Escola Universitària d'Infermeria Creu Roja (EUICR, en Terrassa) y la Escuela Universitaria de Enfermería Gimbernat (EUIG, en Sant Cugat). La primera es un centro privado y las dos escuelas son centros adscritos a la Universidad Autónoma de Barcelona. En la tabla 8 se resumen las principales características de cada uno de los centros.

Tabla 8: Datos característicos de cada uno de los centros universitarios.

\begin{tabular}{|c|c|c|c|}
\hline & EUICR & EUIG & UIC \\
\hline Horario & Mañana y tarde & Mañana & Mañana \\
\hline $\begin{array}{l}\text { Estudiantes } \\
\text { por año } \\
\text { académico }\end{array}$ & 225 estudiantes & 88 estudiantes & 80 estudiantes \\
\hline $\begin{array}{l}\text { Filosofía mani- } \\
\text { festada por el } \\
\text { centro en cuan- } \\
\text { to al perfil } \\
\text { profesional }\end{array}$ & $\begin{array}{l}\text { Perfil profesional enfer- } \\
\text { mero que tenga como } \\
\text { eje el compromiso per- } \\
\text { sonal y profesional y } \\
\text { como elementos claves } \\
\text { la capacidad de reflexio- } \\
\text { nar y de construir la } \\
\text { propia práctica profesio- } \\
\text { nal en un marco de } \\
\text { necesidades y demandas } \\
\text { cambiantes dónde per- } \\
\text { sona y comunidad han } \\
\text { de adquirir protagonis- } \\
\text { mo. }\end{array}$ & $\begin{array}{l}\text { La actuación profesional transmi- } \\
\text { tida se orienta hacia la aplicación } \\
\text { del Proceso Enfermero y se fo- } \\
\text { menta la utilización de técnicas e } \\
\text { innovaciones pedagógicas basa- } \\
\text { das en la interacción y la } \\
\text { participación que promueven la } \\
\text { formación integral y una rápida } \\
\text { incorporación dentro el mundo } \\
\text { laboral. }\end{array}$ & $\begin{array}{l}\text { El currículum enfatiza } \\
\text { la investigación y el } \\
\text { liderazgo profesional: } \\
\text { Docencia, Investiga- } \\
\text { ción, y aprendizaje, y } \\
\text { se asienta en la inter- } \\
\text { relación entre los } \\
\text { conceptos Persona, } \\
\text { Salud, Enfermería, y } \\
\text { Medioambiente, que } \\
\text { son a su vez la base } \\
\text { de diferentes mode- } \\
\text { los de enfermería. }\end{array}$ \\
\hline $\begin{array}{l}\text { Modelo enfer- } \\
\text { mero de } \\
\text { referencia para } \\
\text { guiar la docen- } \\
\text { cia }\end{array}$ & Virginia Henderson & $\begin{array}{l}\text { No tienen modelo teórico refe- } \\
\text { rente, siguen los Patrones } \\
\text { Funcionales de Salud de Marjory } \\
\text { Gordon para el desarrollo de } \\
\text { metodología enfermera }\end{array}$ & Sor Callista Roy \\
\hline
\end{tabular}




\begin{tabular}{|l|l|l|l|}
\hline $\begin{array}{l}\text { Asignatura que } \\
\text { incluye la base } \\
\text { filosófica con- } \\
\text { ceptual } \\
\text { enfermera }\end{array}$ & $\begin{array}{l}\text { Fundamentos de Enfer- } \\
\text { mería (asignatura } \\
\text { troncal, anual) }\end{array}$ & $\begin{array}{l}\text { Fundamentos de Enfermería } \\
\text { (asignatura troncal) }\end{array}$ & $\begin{array}{l}\text { EUIG } \\
\text { Fundamentos de } \\
\text { Enfermería }\end{array}$ \\
\hline Créditos & $\begin{array}{l}15 \text { créditos (8 teóricos y } \\
7 \text { prácticos) }\end{array}$ & 15 créditos (teórico-prácticos) & $\begin{array}{l}15 \text { créditos (teórico- } \\
\text { prácticos) }\end{array}$ \\
\hline Contenido de la \\
asignatura & $\begin{array}{l}\text { El metaparadigma y } \\
\text { escuelas de pensamiento } \\
\text { enfermero, el modelo de } \\
\text { Virginia Henderson, el } \\
\text { método de trabajo en- } \\
\text { fermero, los } \\
\text { procedimientos enfer- } \\
\text { meros y las estancias } \\
\text { prácticas }\end{array}$ & $\begin{array}{l}\text { Modelo Holístico de salud, inspi- } \\
\text { rado en los 11 Patrones } \\
\text { Funcionales de Salud de Marjory } \\
\text { Gordon y su aplicación en el pro- } \\
\text { ceso enfermero. } \\
\text { Aportaciones teóricas y filosóficas } \\
\text { de la disciplina. }\end{array}$ & $\begin{array}{l}\text { Aunque } \text { marco referencial, en } \\
\text { el primer trimestre } \\
\text { de la asignatura se } \\
\text { exponen también las } \\
\text { bases de otras teóri- } \\
\text { cas. } \\
\text { Desarrollo del proce- } \\
\text { so de atención de } \\
\text { enfermería. }\end{array}$ \\
\hline
\end{tabular}

Se estudió a la población total de estudiantes, un total de 105 estudiantes, 45 de EUICR, 30 de EUIG y 30 de la UIC. Todos ellos eran estudiantes que cursaban segundo o tercer año de la diplomatura. Se escogieron justamente estos cursos, ya que los alumnos reciben formación en filosofía y metodología enfermera en el primer año de carrera. A partir del segundo año, se les instruye sobre fisiopatología, por lo que inician la conexión entre la teoría y la respuesta de los individuos a diferentes situaciones de salud. Por lo tanto, a partir del segundo año, deberían de tener un pensamiento en relación a filosofía enfermera crítico y mejor fundamentado.

El único criterio de inclusión de los estudiantes en la tesis fue desear participar de forma voluntaria en el estudio.

\subsubsection{Variables}

Las variables analizadas en profesionales y estudiantes fueron:

\section{Variable principal:}

Perspectiva sobre la aplicación de Modelos y Teorías enfermeras: es la percepción de los profesionales y estudiantes sobre los modelos y teorías que podrían ser aplicados en la práctica enfermera.

Evaluada por las siguientes dimensiones: 
- Seguimiento de un modelo en la práctica: el entrevistado contestó explícitamente si creía seguir un modelo de forma implícita en su práctica y si creía que cuidaba bajo el modelo con el que se identificaba (ya que no había ningún modelo impuesto a nivel institucional, sólo se realizaba en el centro una valoración enfermera muy simple basada en los Patrones Funcionales de Marjory Gordon). Preguntas 12 y 31 del cuestionario de profesionales y 12 y 31 del de estudiantes.

- Utilidad de los modelos teóricos en la práctica: los sujetos entrevistados respondieron a si opinaban que los modelos que estudiaron les serían útiles en su práctica diaria. Pregunta 13 del cuestionario de profesionales y 13 en el de estudiantes.

- Aplicabilidad de los modelos en la práctica: los profesionales y estudiantes evaluaron la posible aplicación de modelos teóricos en la práctica mediante exponer si existía la posibilidad de que institucionalmente se implantase un modelo en la práctica del hospital, si éste debía ser diferente en función de las características de los propios pacientes y si las hojas de registro actuales favorecían trabajar bajo modelo teórico. Además escogieron un modelo teórico para el cuidado y expusieron libremente los motivos de su elección. Preguntas 14, 15, 32 y 37 del cuestionario de profesionales y 14, 15, 32 y 37 del cuestionario de estudiantes.

\section{Variables secundarias:}

- $\quad$ Edad (de profesionales y estudiantes).

- Sexo (de profesionales y estudiantes).

- Escuela universitaria donde se cursaba o se cursaron los estudios de Enfermería.

- Nivel formativo de los profesionales: Ayudante Técnico Sanitario (ATS), Diplomado en Enfermería (DUE) o ambas titulaciones.

- Especialidad o ámbito: en el que trabajaban los profesionales o realizaban sus prácticas los estudiantes.

- Turno: turno de trabajo en los profesionales o turno de prácticas de los estudiantes.

- Curso de los estudiantes. 
- Años de experiencia: como enfermera/o en profesionales y como auxiliares de enfermería en los estudiantes.

- Años de experiencia en la CSPT: como enfermera/o en profesionales.

- Formación complementaria sobre teoría enfermera: formación complementaria de los profesionales (cursos/ Postgrado / Máster) o asignaturas optativas /libre elección de los estudiantes relacionadas con modelos y teorías de enfermería.

- Modelo enfermero formativo: modelo enfermero que había guiado la formación universitaria (en profesionales y estudiantes).

\subsubsection{Recogida de los datos}

Para el estudio de profesionales hospitalarios y estudiantes se realizaron dos cuestionarios anónimos de elaboración propia, rectificados tras su revisión por el departamento de epidemiología de la CSPT, con preguntas adaptadas según fuera un grupo u otro, que se cumplimentó dentro del horario laboral o de prácticas. Los cuestionarios fueron entregados en mano entre abril y mayo de 2006 a profesionales y entre septiembre de 2006 y junio de 2007 a estudiantes. Ambos cuestionarios necesitaban aproximadamente 20 minutos para su cumplimentación. Los profesionales los rellenaron en su ámbito laboral, se les dio un margen de 15 días para su entrega en urna anónima, para incrementar su participación se realizó una reunión informativa previa con las gestoras de las unidades que transmitirían el objetivo del estudio y se hizo publicidad del mismo mediante la Intranet del centro. En el caso de los estudiantes los cuestionarios fueron repartidos en el hospital durante las reuniones de seminario que tuvieron con sus tutores académicos de prácticas. En el caso de UIC por problemas de accesibilidad fue necesario además acudir a la misma universidad para que los estudiantes, a los que no se tuvo acceso dentro del centro, rellenaran y entregaran allí mismo los cuestionarios.

El cuestionario de los profesionales constaba de 37 preguntas, de las que aquí se presentan los resultados de 17. En el caso del cuestionario de los estudiantes, se formularon 39 preguntas, ya que además se incluyeron 3 preguntas específicas sobre el Proceso de Enfermería, de las que aquí se analizan 15 para dar respuesta al objetivo de estudio. Ambos cuestionarios incluían respuestas cerradas de única opción, de opción múltiple y respuestas abiertas relacionadas con modelos y metodología enfermera (en el anexo II se pueden ver las preguntas del cuestiona- 
rio completo que recogen las variables sociodemográficas y las variables en relación a la aplicación de modelos teóricos que se analizan en este estudio resaltadas en azul).

Para probar el nivel de comprensión de ambos cuestionarios se realizó una prueba piloto pidiendo la colaboración de 10 profesionales enfermeros de diferentes ámbitos asistenciales y de 10 estudiantes. Modificando algunos puntos que no habían quedado claros inicialmente.

Los cuestionarios constaban de tres partes (Anexo II):

1. Carta de presentación: informaba del estudio a realizar.

2. Glosario de términos: su intención fue servir como elemento facilitador para la comprensión de algunos términos utilizados en la encuesta.

3. Preguntas del cuestionario: Recogía las diferentes variables a estudiar así como los datos demográficos necesarios para el análisis. Algunas preguntas dejaban la elección de contestarse libremente para evitar sesgos por falta de opciones no recogidas en las respuestas cerradas.

\subsubsection{Análisis de los datos}

Para el análisis de los datos se realizó un estudio descriptivo de todas las variables incluidas, expresando los resultados de las variables cuantitativas en forma de media, desviación típica (máxima y mínima), y en forma de frecuencias y porcentajes para las variables cualitativas. Para el análisis comparativo entre las diferentes variables se usó la chi-cuadrado de Pearson o la corrección lineal de Yates cuando la distribución muestral así lo requirió. A través del uso del paquete estadístico SPSS 16.0 para Windows.

Las preguntas de los cuestionarios que recogían texto abierto fueron analizadas siguiendo el diagrama de Miles y Huberman (1994). Se releyeron repetidamente los textos, detectándose los temas surgidos, y se codificaron para conseguir una presentación, reducción e interpretación de la información y así llegar a un marco explicativo del fenómeno de estudio (Ullin et al., 2006). 


\subsection{Metodología utilizada para dar respuesta al tercer objetivo}

\section{específico: Conocer las ventajas y desventajas percibidas por los profesionales sobre el uso de un modelo teórico enfermero para el cuidado.}

El tercer objetivo específico se planteó con la intención de describir de forma detallada la percepción de los profesionales sobre el uso de modelos teóricos en situaciones concretas, sólo así fue posible el poder evidenciar sus ventajas y desventajas; o lo que es lo mismo, podríamos deducir que factores facilitan o limitan la aplicación de modelos teóricos en la práctica (objetivo central de nuestro estudio). Este era un reto complejo, ya que la aplicación de modelos teóricos en el contexto de trabajo enfermero es reducido y en muchas ocasiones el profesional utiliza registros elaborados a partir de modelos teóricos, pero no conocen los principios fundamentales de éste (conceptos, supuestos, proposiciones...), o no han profundizado en el estudio y comprensión del modelo. Es por ello que se desestimó encuestar directamente a profesionales que usaban un modelo teórico en su práctica (era difícil asegurar y controlar su nivel de comprensión). Para ello lo más adecuado fue buscar información de una fuente fiable de profesionales en los que se hubiera asegurado el haber ahondado en el estudio de la base conceptual enfermera en relación al contexto inmediato de cuidado en el que trabajaban y conocían de forma profunda. El análisis de la información obtenida de los trabajos de los estudiantes de Máster de Ciencias de la Enfermería dio respuesta a tal objetivo. A estos estudiantes se les solicitó que, desde su propia experiencia, abordasen diferentes respuestas o soluciones a diversas situaciones de problemas de salud en pacientes concretos (en relación a una patología). Esta respuesta o solución debía estar enmarcada en un modelo concreto de enfermería que había sido estudiado previamente en el programa de Máster de Ciencias de la Enfermería. Por lo tanto respondieron de forma eficaz a nuestro propósito, ya que los trabajos académicos se basaron principalmente en el estudio del modelo usado y en la percepción o interpretación de la experiencia profesional de los estudiantes de Máster. Este trabajo era parte de las acticidades académicas de estos alumnos dentro de la asignatura de Teorías y Modelos de Enfermería de 10 ECTS.

\subsubsection{Diseño}

Para el abordaje de este objetivo, se utilizó el paradigma cualitativo centrado en aspectos descriptivos, pretendiendo explorar cuáles son los factores de la aplicación de modelos teóricos basándonos en el análisis de documentos, método ya utilizado en otras ciencias como la educa- 
ción (F. López, 2002). Este análisis, se fundamentó en la etnografía, por la visión del fenómeno del cuidado como un hecho cultural, ya que, se estudia sólo a enfermeras que desarrollan su labor en España, en centros con políticas similares de salud y sujetos cuidados a priori con similares rasgos culturales. Entendiendo como cultura, el contexto particular y el propio entorno sanitario. Los profesionales enfermeros siguen patrones de conducta aprendidos que son transmitidos socialmente, las llamadas "reglas encubiertas" (Maben et al., 2006). Por este motivo, comparten valores, ideas, preconcepciones... y han estado socializados a través de la enseñanza y la capacitación (Gerrish \& Lacey, 2006). Por ello la perspectiva que tienen como grupo es un área justificada de estudio mediante la etnografía. Entre los profesionales comparten un conocimiento tácito pero que no lo expresan entre ellos. Este conocimiento podría ser el de su perspectiva personal sobre filosofía enfermera. En los trabajos plasman la propia percepción del uso de un modelo en su quehacer diario como enfermeros. Son los propios profesionales los que conocen los problemas específicos con los que se enfrentan en sus unidades de trabajo, y conocen de forma profunda si un modelo teórico podría tener cabida y de qué forma dentro de los mismos.

Pese a que el método de la observación participante junto con las entrevistas son los métodos más utilizados en la etnografía (Gerrish \& Lacey, 2006), en nuestro caso, la única forma de recoger datos fue el estudio de los trabajos de Máster, como si estos se trataran de documentos históricos que representan a su cultura enfermera en relación al tema de estudio. Los documentos describen la aplicación de modelos teóricos en situaciones concretas, los valores de las enfermeras; es el método de recogida de datos llamado "examinador" por Wolcott (1994) referenciado en Gerrish y Lacey (2006). Este método es aceptado como complementario en los estudios etnográficos. El motivo de elegir esta forma de investigar viene determinado por la complejidad de la cuestión. Si nos introdujésemos en un entorno real de trabajo, podríamos sólo evidenciar que ocurre con la aplicación del modelo de Henderson que es el que se aplica con mayor frecuencia en el entorno sanitario, aunque de forma parcial, ya que tal y como se ha disertado anteriormente, no podemos asegurar que aquellos que lo aplican lo comprenden en profundidad. De esta forma perderíamos información de factores de aplicación de otros modelos quizás no tan conocidos y que pueden aportar evidencia para su estudio y consideración por otros centros sanitarios que pudieran plantearse su adopción. Es decir, los resultados obtenidos muestran nuevos hallazgos que pueden prevenir posibles elementos que podrían hacer fracasar su empleo. Asimismo otro potente argumento es el deseo de determinar cuáles son los factores que determinan la aplicación genérica de modelos teóricos en la práctica y no únicamente de un modelo particular como el de Virginia Henderson. En España no se han implementado la mayor parte de estos mo- 
delos, por lo que la observación directa o la obtención de datos mediante entrevistas a enfermeros no es un método eficaz para dar respuesta al objetivo.

\subsubsection{Población}

La población de estudio fueron estudiantes que cursaban los títulos de Máster en Ciencias de Enfermería de red interuniversitaria (previamente Título Propio Superior en Enfermería) durante los cursos 1999-2000 y 2009-2010, una población aproximada de 2000 estudiantes (tabla 9).

Tabla 9: Título ofertado y estudiantes matriculados en el programa de Máster o Estudios Superiores en Ciencias de la Enfermería de red interuniversitaria

\begin{tabular}{|c|c|c|c|}
\hline Universidad & Año & Título & $\begin{array}{c}\text { Alumnos ma- } \\
\text { triculados }\end{array}$ \\
\hline \multirow[t]{2}{*}{$\begin{array}{l}\text { Universitat Interna- } \\
\text { cional de Catalunya }\end{array}$} & $\begin{array}{l}1999- \\
2007\end{array}$ & Título Propio Superior en Enfermería & 148 \\
\hline & $\begin{array}{l}2007- \\
2008\end{array}$ & Máster en Ciencias de la Enfermería & 45 \\
\hline \multirow[t]{2}{*}{$\begin{array}{l}\text { Universidad de Ali- } \\
\text { cante }\end{array}$} & $\begin{array}{l}1998- \\
2007\end{array}$ & Título Propio Superior en Enfermería & 738 \\
\hline & $\begin{array}{l}2005- \\
2008\end{array}$ & Máster en Ciencias de la Enfermería & 225 \\
\hline \multirow[t]{2}{*}{$\begin{array}{l}\text { Universidad de } \\
\text { Huelva }\end{array}$} & $\begin{array}{l}1999- \\
2007\end{array}$ & Título Propio Superior en Enfermería & 180 \\
\hline & $\begin{array}{l}\text { Sin } \\
\text { datos }\end{array}$ & Máster en Ciencias de la Enfermería & Sin datos \\
\hline \multirow[t]{2}{*}{$\begin{array}{l}\text { Universidad de Al- } \\
\text { mería }\end{array}$} & $\begin{array}{l}2000- \\
2003\end{array}$ & Título Propio Superior en Enfermería & Sin datos \\
\hline & $\begin{array}{l}2007- \\
2008\end{array}$ & Máster en Ciencias de la Enfermería & 23 \\
\hline \multirow[t]{2}{*}{$\begin{array}{l}\text { Universitat Rovira y } \\
\text { Virgili }\end{array}$} & $\begin{array}{l}1999- \\
2007\end{array}$ & Título Propio Superior en Enfermería & 233 \\
\hline & $\begin{array}{l}2007- \\
2008\end{array}$ & Máster en Ciencias de la Enfermería & 40 \\
\hline \multirow[t]{2}{*}{$\begin{array}{l}\text { Universitat de Llei- } \\
\text { da }\end{array}$} & $\begin{array}{l}1999- \\
2007\end{array}$ & Título Propio Ciencias Sanitarias Enfermería & 147 \\
\hline & $\begin{array}{l}2007- \\
2008\end{array}$ & Máster en Ciencias de la Enfermería & 40 \\
\hline
\end{tabular}

Fuente: Zabalegui \& Macià, 2010

Se estudiaron mediante el análisis de contenido de documentos académicos pertenecientes a la base de datos propia de la docente (Dra. A. Zabalegui) que impartió la asignatura sobre filosofía enfermera: "Teorías y Modelos" con 10 créditos ECTS. Estos documentos formaron parte 
de la evaluación académica de los estudiantes. La muestra estudiada fue seleccionada mediante muestreo de conveniencia, seleccionando a aquellos estudiantes cuyos trabajos eran accesibles por estar en la base de datos citada. Los estudiantes eran de universidades situadas en las provincias de Barcelona, Lérida, Tarragona, Huelva, Almería y Alicante, que en el momento del análisis cursaban los estudios postgraduados citados. No se estudiaron trabajos de estudiantes de la universidad Autónoma de Madrid, ni de la universidad de Zaragoza que también cursaban la titulación dentro de la red interuniversitaria ya que no se tuvo acceso a los trabajos de los mismos. Estas universidades cursaban la asignatura con otra profesora y diferente metodología de desarrollo para esta materia.

Tal y como se ha comentado, era necesario poder contar con la percepción de sujetos que conocieran en profundidad los modelos teóricos que iban a ser objetivo de su análisis y que además tuvieran una buena base profesional que permitiera la crítica de los mismos desde sus propias experiencias y realidades profesionales. Los participantes tuvieron la oportunidad de deliberar sobre la aplicación de modelos en situaciones prácticas reales, por lo que cumplían con los criterios de comprensión y deliberación sobre el modelo teórico y serían los informantes idóneos de los que podríamos obtener información relevante. La ventaja principal es que estos profesionales habían reflexionado y profundizado en los modelos, de esta forma evitamos la desviación típica en la práctica del uso de los modelos como simples herramientas de recogida de datos (Wimpenny, 2002).

El perfil de los estudiantes era diverso en edad, situación familiar, perfil formativo, contexto sanitario, ámbito (asistencial, gestión y docente) y lugar de procedencia. No sólo de las propias comunidades autónomas donde se ubicaban las universidades, sino de otras diferentes que siguieron sus estudios de forma presencial o mediante Intranet virtual. Justamente esta heterogeneidad podía ofrecer un testimonio característico enfermero sobre el desarrollo teórico y profesional de la disciplina (Zabalegui \& Macià, 2010).

Se estudió inicialmente la totalidad del los trabajos disponibles en la base de datos ( $n=373)$, de esta forma nos asegurábamos recoger el máximo de información posible de los mismos. Cabe en este momento destacar la validez de las fuentes de datos analizadas, la bibliografía indica que los textos son una sólida fuente primaria que otorgan mayor validez y fiabilidad de la información obtenida. El investigador para asegurar la exactitud de la información debe conocer dónde, cuándo, por qué y por quién fue escrito un documento (Burns \& Grove, 2004), sin más limitaciones que su pertinencia y su posibilidad de acceso (F. López, 2002). Estas premisas son la que cumple la presente investigación. Además, la literatura investigadora considera como válidos 
los documentos que se generaron para propósitos personales y que pudieran existir anteriormente al proyecto, es decir, que no fueran generados como resultado del estudio, pero que sí que pueden ser usados como parte de la investigación, como es el caso del trabajo académico aquí presentado por los estudiantes (Knobel \& Lankshear, 2001).

El contenido de este trabajo académico sobre aplicación de modelos teóricos, consistió en el desarrollo de un proceso de atención de enfermería en una situación enfermera - cliente desarrollado mediante una, dos o tres propuestas teóricas de elección personal (tanto la situación propuesta como el modelo usado). Tras haber profundizado en el tema, los estudiantes de Máster compararon las bondades y desventajas de los modelos usados y por lo tanto, de este modo evidenciaron la posible utilidad de los mismos en la práctica. Los trabajos recogidos fueron tanto de elaboración individual como grupal, por lo que el número de enfermeras participantes en estos trabajos fue un total de 539.

\section{Criterios de inclusión}

Trabajos impresos de estudiantes de Máster cuyo contenido desarrollaba un análisis reflexionado sobre el uso del modelo teórico presentado en base al caso concreto analizado.

Trabajos en los que el modelo fue usado en un número considerable de planes de cuidados (más de 10 planes).

\section{Criterios de exclusión}

Fueron descartados aquellos trabajos de estudiantes sobre modelos teóricos que carecieron de análisis reflexionado en relación al modelo teórico aplicado y la situación particular analizada o que fueron usados en menos de 10 planes de cuidados.

\subsubsection{Variables de estudio}

Las variables analizadas en los trabajos fueron:

- Autora del modelo teórico analizado.

- Edad del paciente al que se aplicaba el plan de cuidados.

- Patología que padecía el paciente.

- Dispositivo sanitario en el que se desarrollaba el plan de cuidados y/o el servicio en la que estaba ingresado el paciente en el caso de estar hospitalizado. 
- Eficacia del modelo utilizado: se entiende como la capacidad del modelo para dar respuesta al problema de salud del caso concreto planteado, que fue analizado mediante estudio cualitativo del contenido del trabajo sobre "el análisis de la eficacia del modelo" contenido en el trabajo académico sobre modelos teóricos presentado.

- Aplicabilidad del modelo teórico: es la propuesta de uso del modelo en diferentes entornos sanitarios, determinadas patologías o determinados pacientes expuestos por parte del estudiante una vez trabajados en profundidad.

No se describieron posiciones profesionales, ámbitos de trabajo o territoriales de los estudiantes que elaboraron los trabajos, primero por mantener completamente el anonimato de los autores y segundo porque todos los comentarios fueron considerados de igual validez, no era objetivo del estudio buscar diferencias entre ellos, sino describir la realidad del tema de estudio.

\subsubsection{Recogida de los datos}

La recogida de datos se realizó mediante la obtención de los trabajos escritos impresos de los estudiantes sobre la aplicación de modelos teóricos en una situación clínica enfermero - cliente.

La persona que se encargó de hacer la propuesta del trabajo y recoger posteriormente los escritos fue la profesora en ese momento de la asignatura de Modelos y Teorías del Máster en los años estudiados. La solicitud del trabajo universitario se llevó a cabo en horario lectivo con un objetivo puramente académico. Una vez dadas las indicaciones, se dejó un espacio temporal para poder elaborar los trabajos de forma reflexionada durante el tiempo en el que se desarrolló la asignatura de Modelos y Teorías. Previamente a la realización del trabajo académico, los alumnos recibieron formación teórico-práctica sobre filosofía científica y modelos enfermeros (aproximadamente 100 horas lectivas en aula), tiempo que permitió el correcto desarrollo del trabajo reflexivo solicitado.

Tal y como se ha explicado anteriormente, se recogieron la totalidad de los trabajos elaborados ( $n=373$ ). Pese a que los estudios cualitativos recogen habitualmente un número de sujetos limitado, nuestra intención fue analizar el máximo de trabajos posibles y de esta forma asegurar que se llegara a la redundancia y saturación de información en los mismos, posibilitando la recogida máxima de datos potenciales para poder dar una respuesta completa al objetivo planteado. 
De los 373 trabajos potenciales, se presentan finalmente los resultados de 190 planes de cuidados ya que el resto fueron descartados bien por usar los Patrones Funcionales de Marjory Gordon (descartados por no ser éste un modelo teórico), por carecer de evaluación crítica del modelo en relación al caso presentado, ser copia de otros trabajos, o con evidencia de críticas y reflexiones copiadas literalmente de bibliografía referente. También se descartaron los trabajos en los que el modelo había sido usado en menos de 10 planes, ya que, impediría un análisis detallado del modelo ya que había la previsión de que no hallaríamos saturación de los datos en ese bajo número (ver figura 2).

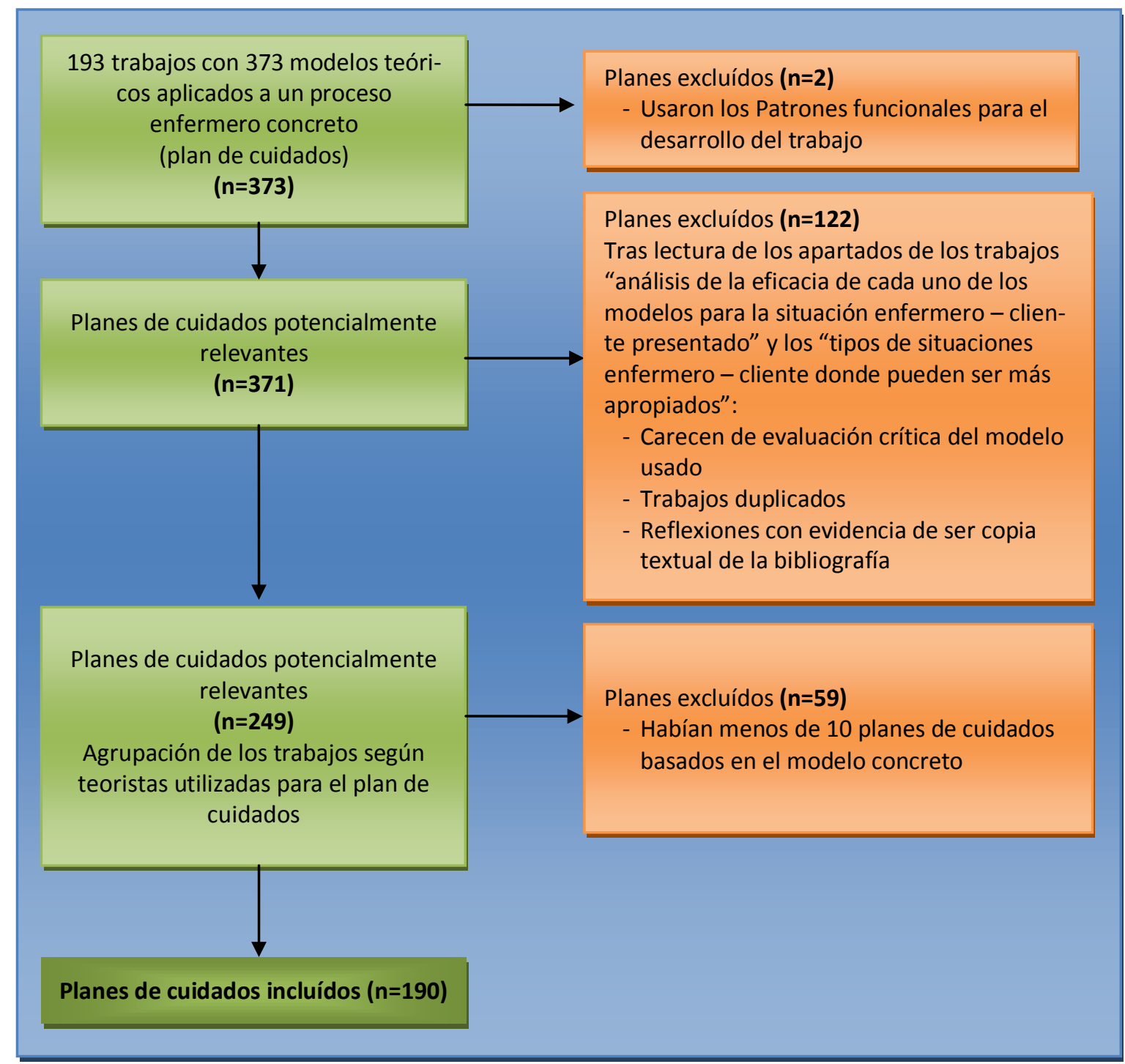

Figura 2: Proceso de selección de los trabajos de Máster 
La tabla 10 presenta el número de trabajos disponibles los inicialmente válidos y los finalmente incluidos en el análisis según la teorista empleada en el plan de cuidados.

Tabla 10: Modelos aplicados en los trabajos y selección ( $n=373$ )

\begin{tabular}{|c|c|c|}
\hline $\begin{array}{l}\text { Teorista usada en el } \\
\text { proceso enfermero }\end{array}$ & $\begin{array}{l}\text { Número de procesos enfer- } \\
\text { meros totales disponibles y } \\
\quad \text { porcentaje relativo }\end{array}$ & $\begin{array}{l}\text { Procesos que cumplían con criterios } \\
\text { de inclusión de análisis inicial: re- } \\
\text { flexión para el análisis en la tesis y } \\
\text { porcentaje relativo }\end{array}$ \\
\hline V. Henderson & $75(20,1 \%)$ & $49(19,7 \%)$ \\
\hline D. Orem & $66(17,7 \%)$ & $43(17,3 \%)$ \\
\hline C. Roy & $60(16 \%)$ & $42(16,9 \%)$ \\
\hline H. Peplau & $29(7,8 \%)$ & $22(8,8 \%)$ \\
\hline B. Neuman & $18(4,8 \%)$ & $10(4 \%)$ \\
\hline I. King & $17(4,5 \%)$ & $12(4,8 \%)$ \\
\hline M. Leininger & $17(4,5 \%)$ & $12(4,8 \%)$ \\
\hline M. Rogers & $13(3,5 \%)$ & $9(3,6 \%)$ \\
\hline L. Hall & $13(3,5 \%)$ & $6(2,4 \%)$ \\
\hline J. Watson & $12(3,2 \%)$ & $8(3,2 \%)$ \\
\hline R. Parse & $11(2,9 \%)$ & $9(3,6 \%)$ \\
\hline N. Pender & $9(2,4 \%)$ & $5(2 \%)$ \\
\hline P. Benner & $7(1,9 \%)$ & $5(2 \%)$ \\
\hline J. Travelbee & $6(1,6 \%)$ & $3(1,2 \%)$ \\
\hline M. Newman & $4(1 \%)$ & $3(1,2 \%)$ \\
\hline $\begin{array}{l}\text { N. Roper, W.Logan y A. } \\
\text { Tierney }\end{array}$ & $4(1 \%)$ & $2(0,8 \%)$ \\
\hline I. Orlando Pelletier & $4(1 \%)$ & $4(1,6 \%)$ \\
\hline D. Johnson & $3(0,8 \%)$ & $1(0,4 \%)$ \\
\hline M. Levine & $2(0,5 \%)$ & $2(0,8 \%)$ \\
\hline F. Abdellah & $2(0,5 \%)$ & $2(0,8 \%)$ \\
\hline M. Mishel & $1(0,26 \%)$ & 0 \\
\hline M. Gordon & $2(0,5 \%)$ & $\begin{array}{c}0 \\
\text { (No se contempla como modelo teóri- } \\
\text { co) }\end{array}$ \\
\hline $\begin{array}{l}\text { Total procesos enfer- } \\
\text { meros }\end{array}$ & $373(100 \%)$ & $\begin{array}{c}249(66,7 \%), \text { de los que se aceptan a } \\
\text { estudio } 190(50,9 \%)\end{array}$ \\
\hline
\end{tabular}

Casillas sombreadas: procesos descartados en el anàlisis por el bajo número, no aseguraba saturación de los datos

\subsubsection{Análisis de los datos}

En cuanto al análisis de los datos fue elaborado siguiendo el esquema planteado por Miles y Huberman (1994), método aconsejado para el análisis de datos escritos ya existentes que se recolectan como parte del estudio (Knobel \& Lankshear, 2001). Se recogieron todos los textos escritos por los estudiantes y mediante lectura repetida del texto se llegó a la reducción de los datos e indujo a la codificación de los mismos. La reducción en códigos y el desarrollo de categorías y subcategorías siguiendo una agrupación por temas, permitieron el establecimiento de mo- 
delos o marcos explicativos del fenómeno de estudio. En el caso concreto del análisis de la eficacia del modelo, se siguió la estructura de análisis planteada en fuentes documentales sobre modelos y teorías enfermeras (Marriner \& Raile, 2003) también usado en textos de Chinn y Kramer (1998), clasificando los comentarios en cinco categorías (ver tabla 11).

Tabla 11: Descripción de las categorías utilizadas para el análisis de los textos de los trabajos sobre modelos de los alumnos de Máster

\begin{tabular}{|l|l|}
\hline CATEGORÍAS & DESCRIPCION DE LA CATEGORÍA \\
\hline $\begin{array}{l}\text { CATEGORÍA 1: } \\
\text { CLARIDAD }\end{array}$ & $\begin{array}{l}\text { Se refiere a la claridad de la teoría en cuanto a conceptos, definicio- } \\
\text { nes y supuestos. }\end{array}$ \\
\hline $\begin{array}{l}\text { CATEGORÍA 2: } \\
\text { SIMPLICIDAD }\end{array}$ & Capacidad para guiar la práctica, teoría comprensible. \\
\hline $\begin{array}{l}\text { CATEGORÍA 3: } \\
\text { GENERALIDAD }\end{array}$ & $\begin{array}{l}\text { Capacidad de la teoría para poder ser extensible a la mayor parte de } \\
\text { situaciones. }\end{array}$ \\
\hline $\begin{array}{l}\text { CATEGORÍA 4: } \\
\text { PRECISIÓN EMPÍRICA }\end{array}$ & $\begin{array}{l}\text { Se entiende como el punto en el que los conceptos de la teoría están } \\
\text { emplazados en la realidad observable. Importancia empírica. En nues- } \\
\text { tro caso en este apartado se analizará la adecuación de la teoría o } \\
\text { modelo al caso propuesto, a su utilidad. }\end{array}$ \\
\hline $\begin{array}{l}\text { CATEGORÍA 5: } \\
\text { CONSECUENCIAS DEDUCIBLES }\end{array}$ & $\begin{array}{l}\text { Entenderemos como consecuencias deducibles, aquellas consecuen- } \\
\text { cias directas sobre la práctica, ya sea a nivel de dirección de la } \\
\text { práctica enfermera, definición del rol profesional, consecuencias en la } \\
\text { persona cuidada o incluso a nivel más general consecuencias sobre el } \\
\text { sistema de salud nacional. }\end{array}$ \\
\hline
\end{tabular}

En el análisis de datos, se siguen una serie de métodos para evitar el sesgo posible derivado de la propia investigación cualitativa y así proporcionar un mayor rigor metodológico. Para asegurar la credibilidad, confirmabilidad y transferibilidad (Sánchez \& Salamanca, 2013) se usa la triangulación de los datos ya que se obtiene información de diferentes fuentes, métodos y diseños para establecer los factores que condicionan la aplicación de modelos teóricos en la práctica. La síntesis de información aportada en los resultados, pese a que es dificil de confirmar por los autores de los documentos por su no accesibilidad, fue obtenida procedente de una reflexión personal de los profesionales, que antes de entregar los documentos procedieron a varias relecturas del mismo ya que era un trabajo evaluador y por lo tanto la información extraída de los trabajos puede considerarse como veraz y adecuada al propósito de estudio. Se aceptan de antemano, que si los trabajos incluyen contenido reflexionado, se entiende y se asumen todas las perspectivas como igualmente valiosas. En cuanto a la transferibilidad se cerciora mediante la recogida de un gran número de trabajos de una gran muestra de sujetos (así se recogen casos confirmantes y excluyentes). Además se cuenta con los datos descriptivos necesarios de los sujetos de estudio y la forma concreta en la que fue recogida la información para permitir su replicabilidad (teniendo en cuenta que el propio paso del tiempo puede modificar los contextos en los que la información fue obtenida). No olvidemos además la gran representatividad de los 
participantes en el fenómeno que se intentó interpretar y estudiar, ya que como ya hemos ido indicando, son profesionales que poseían suficiente experiencia clínica, habían sido formados en filosofía enfermera y habían reflexionado ampliamente en el tema de estudio.

\subsection{Metodología utilizada para dar respuesta al cuarto objetivo específico: Identificar los elementos que han influenciado el uso teórico y desarrollo profesional de la enfermería en} España desde la perspectiva de las enfermeras en periodo de formación de Máster

Para este objetivo se abordaron los elementos que influían en el desarrollo de modelos teóricos en la práctica. Se recogió la información en relación al desarrollo teórico y profesional, ya que se creyó que de esta forma el análisis sería más claro y congruente por la elevada asociación entre el uso de marcos conceptuales propios y el desarrollo profesional. Ambos despliegues han sido paralelos, coétaneos y mutuamente influenciadores, tal y como se explicitó y argumentó en el marco teórico de la presente tesis. Los elementos precursores o limitantes de la aplicación práctica de los modelos teóricos van a ser factores coinfluenciadores tanto en el nacimiento como profesión, como en el desarrollo de la teoría enfermera. Justamente el acreciento de marcos conceptuales propios fue el trampolín que impulsó el desarrollo de la enfermería como ciencia y profesión.

\subsubsection{Diseño}

Al igual que para el tercer objetivo, se realizó un abordaje descriptivo mediante técnicas de análisis de contenido. Igualmente se amparó este objetivo bajo el prisma de la etnografía, partiendo de que la visión del fenómeno del cuidado es un hecho cultural y se estudia concretamente en enfermeras que desarrollan su trabajo en un ámbito concreto, España. Entendiendo como cultura, el propio entorno sanitario. Los objetivos tercero y cuarto comparten la argumentación en cuanto a los motivos de elección del diseño.

\subsubsection{Población}

La población de estudio es la misma que se recoge en el cuarto objetivo, ya que forman parte de la misma base de datos.

\section{Criterios de inclusión}


De entrada se recogieron el máximo posible de respuestas, sin excluir ninguno de los textos que recogían el trabajo de los estudiantes.

\section{Criterios de exclusión}

Aquellos documentos que no respondían al objetivo de este estudio.

\subsubsection{Variables estudiadas}

- Elementos facilitadores: se entiende por elemento facilitador aquellos factores que han favorecido el desarrollo teórico y profesional de la disciplina enfermera. Se midieron a través de las respuestas dadas por los estudiantes de Título Propio o Máster en Ciencias de la Enfermería.

- Elementos limitantes o barrera: son aquellos factores que han entorpecido el desarrollo teórico y profesional de la disciplina enfermera. Se midieron a través de las respuestas dadas por los estudiantes de Título Propio o Máster en Ciencias de la Enfermería.

\subsubsection{Recogida de los datos}

Se analizaron los textos de los estudiantes que contestaron voluntariamente por escrito a dos preguntas formuladas:

a. ¿Cuáles crees que han sido los elementos que han favorecido el desarrollo teórico y profesional de la enfermería en España?

b. ¿Cuáles crees que han sido las barreras que han impedido la evolución teórica y profesional de la enfermería en España?

La recogida de información se realizó en horario lectivo en hojas diferentes y separadas, una para las barreras y otra para los elementos favorecedores.

\subsubsection{Análisis de los datos}

En cuanto al análisis de los datos se realizó el mismo tipo de análisis que en el cuarto objetivo, siguiendo las recomendaciones de análisis de contenido descritos por Miles y Huberman (1994), continuando la agrupación por temas de forma que se unieron palabras, frases y otras unidades de texto con significados similares que se agruparon en diferentes categorías y subcategorías iniciada de forma inductiva tras la lectura repetida de los textos. Los criterios de rigor 
metodológico son comunes a los explicitados para el cuarto objetivo, ya que presentan igual diseño de estudio.

\subsection{Metodología utilizada para dar respuesta al quinto objetivo:} Determinar los elementos que han facilitado y los que han impedido el uso y desarrollo de modelos teóricos en la práctica española desde la perspectiva de enfermeras

gestoras y docentes

Pese a que en el quinto objetivo se recogieron gran cantidad de ítems en relación al desarrollo teórico y profesional de la enfermería, se halló la ausencia de información en cuanto a la importancia de los mismos. Por ello en este momento, como diseño cualitativo emergente se hizo necesario conocer cuáles de aquellos elementos se consideraban como prioritarios para tal desarrollo. Sabiendo de antemano que dos de los factores importantes en la aplicación de modelos teoricos era la formación y la gerencia de los centros sanitarios, se decidió evaluar el tema en gerentes y docentes enfermeros. Para ello se utilizó la técnica de consenso: el Delphi.

\subsubsection{Diseño}

Esta fase de aproximación descriptiva se llevó a cabo mediante recogida y análisis de datos con técnica cualitativa. Se pretendía llegar al acuerdo sobre qué elementos estaban directamente implicados en la aplicación de modelos teóricos en la práctica entre los profesionales docentes y gestores. La Técnica de Delphi es un método efectivo para conseguir consenso en un grupo, sin que los integrantes se reúnan de forma física, como en este estudio, ya que su reunión era compleja por pertenecer a diferentes lugares geográficos. El fin del uso de la técnica fue lograr un consenso fiable entre las opiniones de un grupo de expertos, a través de la respuesta anónima a una serie de cuestionarios. Uno de los criterios de selección de la misma, es que tal y como comentan Yañez y Cuadras (2008), tiene la ventaja de producir retroalimentación que estimula la generación de nuevas ideas de forma controlada en los participantes, aunque el intercambio de información entre los expertos no es libre, es dirigida por el coordinador del Delphi. De este modo gradualmente se va obviando la información no relevante. Por lo tanto, su 
uso permitió identificar y/o priorizar preferencias o soluciones a problemas prácticos por parte de un grupo de expertos (Oteo, 2006; Yañez \& Cuadras, 2008). Pero, qué se entiende por "experto", la calificación de "experto" es un factor fundamental (Okoli \& Pawlowski, 2004). Según Keeney, Hasson y McKenna (2001) la identificación de los expertos es uno de los principales aspectos discutibles del uso de la técnica Delphi. Kennedy (2004) cree confuso definir por experto sólo a aquel que es un especialista en su campo. Sin embargo, una definición que ha recibido cierta aprobación y que se aproxima a la definición de experto en nuestro estudio, es definir al experto como: aquellos que puedan realizar contribuciones válidas, dado que poseen conocimientos basados en la práctica y experiencia actualizadas (Kennedy, 2004; Price, 2005). Estos son los gestores por su condición de agenciar el cuidado y los docentes como especialistas por el estudio profundo de la materia en relación a filosofía enfermera.

\subsubsection{Sujetos de estudio}

Se invitó inicialmente a participar a un total de 25 gestores y 25 docentes que al igual que los estudiantes de Máster en Ciencias de la Enfermería de red interuniversitaria desarrollaban su trabajo en cualquier ámbito territorial, justamente para poder evidenciar una visión global del fenómeno. El muestreo utilizado fue el de bola de nieve o cadena (Burns \& Grove, 2004). Se sabe por otros estudios con igual técnica sobre población enfermera que suele haber una tasa de respuesta inferior al 50\% (Comet-Cortes et al., 2010), por lo que de esta manera nos asegurábamos una respuesta de al menos 10 profesionales de cada categoría, siguiendo las recomendaciones de que el número de participantes oscile entre 10-18, según recomiendan Okoli y Pawlosky (2004). Estudios realizados bajo esta metodología, señalan que parece necesario un mínimo de siete expertos teniendo en cuenta que el error disminuye notablemente por cada experto añadido hasta llegar a los siete expertos y no es aconsejable recurrir a más de 30 (Amezcua \& Jimenez, 1996).

En cuanto al muestreo en cadena es un muestreo práctico, eficiente y económico que permite establecer una relación de confianza con los nuevos participantes gracias a la presentación que hace el sujeto ya incluido en el proyecto. Además facilita el acceso a personas difíciles de identificar (Fuentelsaz, 2004; Icart, Fuentelsaz \& Pulpón, 2001; Martín-Crespo \& Salamanca, 2007). Los primeros informantes se escogieron por ser conocidos por los investigadores, por sus publicaciones en revistas o localizados a través de las páginas web de sus centros de trabajo (directores/as de Enfermería de diferentes hospitales nacionales y profesores/as de universidades españolas). Estos informantes nos proporcionaron además los contactos de posteriores sujetos 
con las características definidas en los criterios de inclusión que pudieron proporcionar información útil para el estudio.

Los criterios de selección para los gestores fueron:

- Estar desarrollando su labor de gestión en un hospital en el que se siguiese explícitamente un modelo enfermero en la práctica. El hecho de seguir un modelo en la práctica fue conocido o bien porque en la página web del centro se hacía referencia al marco conceptual enfermero de la Institución u otras fuentes (como el preguntar a profesionales de diferentes centros, u obtener esta información por publicaciones de profesionales en relación al tema).

Los criterios usados para los docentes fueron:

- Haber sido docente activo de asignaturas en relación a Bases conceptuales enfermeras para la titulación de Grado, Diplomado de Enfermería y/o Máster Universitario que incluya asignaturas en relación al conocimiento enfermero. Pese a que durante estos últimos años (momento en el que se desarrolla este objetivo) ha habido una transformación docente mediada por la adaptación al nuevo Espacio de Educación Superior, que ha modificado la misma titulación a la de Grado en Enfermería y el plan Bolonya ha provocado una modificación de la metodología educativa en el aula; los contenidos formativos y la mayoría de los docentes siguen siendo los mismos que formaron a los enfermeros diplomados. Por lo que este cambio no modifica que sean ellos los informantes clave que aporten su percepción en cuanto a los factores que influyen en el uso y desarrollo de los modelos en la práctica.

Inicialmente, se pensó invitar al estudio sólo a gestores de áreas clínicas/hospitales en los que se aplicaran actualmente modelos teóricos enfermeros en la práctica. Sin embargo, se consideró interesante el poder contar con la opinión de docentes universitarios sobre el tema, ya que podían enriquecer al grupo con sus aportaciones, incluyendo factores que pudieran no haber sido considerados por los gestores ampliando posibilidades de elección entre gestores.

Por ello, ambos perfiles se entendieron como decisivos en la implementación de teoría enfermera. Los docentes por la relevancia de su visión como impregnadores en su práctica formativa (este fue uno de los factores que condicionaron la elección de un modelo teórico por los estudiantes en el segundo objetivo) y por la objetivación en publicaciones en modelos teóricos en la bibliografía revisada, que se relacionan directamente en número con la teórica que guía la forma- 
ción (Escuredo, 2003; Richart et al., 1999). La importancia de la perspectiva de los gestores viene dada porque son los órganos responsables en la toma de decisión de la adopción de un modelo en el área clínica y en el diseño de estrategias para su implementación según las características de los centros (Luis et al., 2007; McKenna, 1989; Santos, 2008a).

\subsubsection{Variables de estudio}

Las variables que fueron consideradas en el estudio de gestores y docentes fueron:

- Cargo profesional: docente o gestor.

- Formación académica: Diplomado, Máster Oficial, Doctor /a, Licenciado/a.

- Ámbito de trabajo: gestor (Asistencial), docente (universitario) u ambos.

- Provincia de trabajo.

- Años de antigüedad en el cargo de docente o gestor.

- Elementos facilitadores: Elementos que han facilitado el uso de modelos teóricos en la práctica española.

- Elementos limitantes o barrera: Elementos que han impedido el uso de modelos teóricos en la práctica española.

\subsubsection{Recogida y análisis de los datos}

Con el propósito de alcanzar el objetivo de este apartado, se contactó con los posibles candidatos (gestores y docentes) vía mail invitándoles a participar en el estudio mediante una carta de presentación que recogía los objetivos del estudio y solicitaba su consentimiento de participación (ver en anexo III consentimiento informado).

A los sujetos que desearon participar se les envió un cuestionario online elaborado mediante la plataforma online surveymonkey ${ }^{\circledR}$ que recogía los datos sociodemográficos para la descripción de la muestra y dos preguntas a contestar. Además se añadió un espacio para que los sujetos pudieran comentar experiencias, opiniones o sugerencias. No era objeto del Delphi, pero se creyó interesante dejar abierta la posibilidad de expresión libre de los sujetos de estudio.

El método utilizado, tal y como comentan Okoli y Pawlowski (2004), es un método ágil, especialmente entre expertos de lugares geográficamente distantes. Para los envíos se siguieron las pautas de Amezcua y Jiménez (1996), las fases de la recogida de datos mediante la técnica Delphi en gestores y docentes se exponen a continuación. 
1. Elaboración de la pregunta: Tras la revisión bibliográfica sobre el tema, se objetiva una ausencia de publicaciones en cuanto a la efectividad o experiencia en la aplicación de modelos teóricos en nuestro contexto, esto unido a la información obtenida de los estudiantes de Máster en Ciencias de la Enfermería estudiados en el tercer y cuarto objetivo de la presente tesis doctoral , permitió concretar dos preguntas como inicio del Delphi:

- ¿Cuáles cree que han sido los elementos que han facilitado o facilitan el uso y desarrollo de modelos teóricos en la práctica española?

- ¿Cuáles cree que han sido los elementos que han impedido o impiden el uso y desarrollo de modelos teóricos en la práctica española?

2. Selección de los participantes: se definió el grupo de expertos como gestores de áreas clínicas u hospitales en los que se aplicaban modelos teóricos y profesores universitarios docentes en Fundamentos epistemológicos de la Enfermería de cualquier territorio español. Eran un grupo heterogéneo que compartían interés sobre el mismo tema y que podía verse mútuamente enriquecido por las aportaciones recíprocas.

3. Reclutamiento vía mail de los expertos: Invitación a participar en el estudio que contenía presentación de la autora, objetivo del estudio, agradecimiento previo y consentimiento informado (se realizaron dos sondeos, el primero en abril-mayo 2012, y el segundo en septiembre - octubre 2012).

4. El establecimiento del procedimiento a seguir para realizar el Delphi se puede visualizar en la tabla 12

Tabla 12: Descripción de las categorías utilizadas para el análisis de los textos de los trabajos sobre modelos de los alumnos de Máster

\begin{tabular}{|l|c|c|c|}
\hline \multicolumn{1}{|c|}{ Cuestionario } & Fecha envío & Fecha límite de respuesta & $\mathrm{n}$ \\
\hline $\begin{array}{l}\text { Primer cuestionario con pre- } \\
\text { guntas }\end{array}$ & 19 de octubre 2012 & 5 de noviembre 2012 & 24 \\
\hline $\begin{array}{l}\text { Segundo cuestionario } \\
\text { Puntuación likert a las pro- } \\
\text { puestas enviadas }\end{array}$ & 10 de noviembre 2012 & 24 de noviembre 2012 & 23 \\
\hline $\begin{array}{l}\text { Tercer cuestionario } \\
\text { Priorización de cada respues- } \\
\text { ta }\end{array}$ & 30 de noviembre 2012 & 14 de diciembre 2012 & 23 \\
\hline
\end{tabular}

5. Envío en fecha establecida del cuestionario vía mail y nuevamente carta de presentación que contenía la presentación de la autora, objetivo del estudio, agradecimiento previo, y fecha límite para la llegada de respuestas (Anexo III). 
6. Análisis del primer cuestionario mediante el análisis de textos (uso del programa ATLAS-TI 6.2) y elaboración del segundo cuestionario que incluyó una síntesis de ideas extraídas de las categorías emergentes halladas en los textos enviados por los expertos.

7. Envío del segundo cuestionario vía mail solicitando puntuar los ítems o elementos extraídos de las aportaciones de los expertos en cuanto a su potencial para favorecer o impedir la aplicación de modelos en la práctica, con un rango de puntuación entre 1 y 10 (Siendo 10 el máximo potencial). Acompañado de carta de agradecimiento y con la fecha límite de respuesta.

8. Análisis de los resultados, anotándose en cada ítem el número de participantes que lo seleccionaron, la puntuación máxima, mínima, media y desviación estándar de cada uno de los ítems o elementos.

9. Envío de un tercer cuestionario vía mail con los resultados del segundo cuestionario, solicitando priorizar 20 de los ítems o elementos de los mismos del 1 al 20. Siendo el catalogado como 1 el más importante. Acompañado de carta de agradecimiento y con la fecha límite de respuesta.

10. Nuevo análisis del consenso final y envío a los participantes del informe final.

\subsection{Metodología utilizada para dar respuesta al sexto objetivo especifico: Describir el nivel de implantación de modelos enfermeros en la práctica actual a nivel internacional.}

Los marcos teóricos, tal y como se ha argumentado en la introducción de la tesis, proporcionan una base fundamental para el progreso de la enfermería y constituyen los mecanismos que permiten organizar el cuidado. Enmarcar lo que se investiga dentro de un marco teórico es ventajoso para el desarrollo de la disciplina. Por este motivo, se estimó interesante poder conocer si la aplicación internacional de modelos teóricos enfermeros era relevante y profundizar en que modelos se usan en la práctica de la disciplina. Este objetivo se analizó mediante una revisión integradora de la literatura. La evidencia de la importancia de la implantación de modelos en la práctica, viene dada por su uso y los factores que lo condicionan. Su uso se justifica directamente con la fundamentación de publicaciones sobre el tema, tanto en artículos de investigación como de aplicación de caso único mediante planes de cuidados enfermeros. Se revisaron las bases de datos de Cochrane Database of Systematic Rewiews (CDSR) y la Database of Abstract of Rewiews os Effectiveness (DARE). En esta exploración se encontró alguna revisión como la de Butler et al. 
2011 que hablaba de modelos de personal de enfermería u otras como el estudio de R. Fernández, Johnson, Tran y Miranda (2012) que evaluaba la formación enfermera como factor que influencia en el resultado sobre la salud de los pacientes, pero ninguna de ellas en relación concreta con aplicación de teoría enfermera. Por ello se planteó la búsqueda en bases de datos con gran relevancia en el ámbito de las Ciencias de la Salud. Se estimó que las más adecuadas para realizar la búsqueda bibliográfica serían CINAHL o MEDLINE. Siguiendo la recomendación de algunos estudios que comparan las dos bases de datos más potentes internacionalmente, se optó por la base MEDLINE por diferentes motivos: las búsquedas en enfermería producen un mayor número de referencias y con mayor sensibilidad al tema de estudio (Brazier \& Begley ,1996), recoge un mayor número de abstract de los artículos (Subirana, Solá, García, Gich \& Urrútia, 2005) y además, no requiere de subscripción, por lo que es la base internacionalmente más fácilmente asequible para las enfermeras, ya que es gratuita y sólo requiere acceso a Internet. Por consiguiente se usó MEDLINE a través de PubMed. Pubmed incluye más de 23 millones de citas de la literatura biomédica de MEDLINE, revistas de ciencias biológicas, y libros en línea. Con un total de 246 revistas de enfermería ${ }^{7}$. Se intentó dar respuesta a este objetivo mediante la búsqueda de artículos que incluyeran, analizaran o presentaran el modelo, dando relevancia al país de publicación, tipo de persona que recibe el cuidado y modelo utilizado.

\subsubsection{Diseño}

El diseño de esta etapa del estudio era un revisión integradora siguiendo los pasos explicitados por Whittemore y Knalf (2005), por lo tanto un diseño observacional retrospectivo que pretendía describir el nivel de implantación de los modelos enfermeros a nivel internacional, mediante la síntesis del contenido de artículos primarios sobre el tema.

Una revisión integradora es un método específico de examen que resume la literatura empírica o teórica para proporcionar una comprensión más integral de un fenómeno particular o un problema de salud. El método de revisión integradora es un enfoque que permite la inclusión de diversos trabajos en la revisión (experimentales, no experimentales, estudios teóricos, etc.) y tiene el potencial de desempeñar un papel más importante en la práctica basada en la evidencia para la enfermería, contribuyendo a la presentación de variada perspectivas sobre un fenómeno (Whittemore \& Knalf, 2005).

\footnotetext{
${ }^{7}$ Referencia de: National Library of Medicine, disponible en: http://www.nlm.nih.gov/archive/20061025/bsd/nursing_journal_titles.html
} 


\subsubsection{Poblacion de estudio}

Se consideraron para el estudio el total de referencias bibliográficas de los artículos publicados en la base de datos de Pubmed durante el periodo enero de 2008- enero 2013. Incluyéndose aquellos trabajos con presencia de abstract en la base de datos independientemente de su idioma. Lo ideal sería haber contado sólo con aquellos estudios empíricos donde se comparase trabajar bajo modelo enfermero o modelo tradicional, pero la revisión en el tema apuntaba carencia de este tipo de estudios, tanto a nivel nacional como internacional, por lo que mayoritariamente serían informes de casos o series de casos, con poca evidencia. Se optó por el índice internacional de salud más consultado (MEDLINE), además de por las bondades ya comentadas, por ser una base en la que se recogen publicaciones que en su mayoría son de revisión por pares que asegura la calidad de los artículos. Se concretaron estos años debido a que en estos últimos años los sistemas de salud han sido reformados o mediados por la crisis económica internacional que los envuelve (Dávila \& González, 2009), esto ha podido influir en la forma de proveer el cuidado y por lo tanto en la posibilidad de aplicar nuevos modelos enfermeros que den mejores resultados en salud, como podría ser en procesos de cronicidad. Incluso se considera justamente también la posibilidad de que se hayan abortado la aplicación de modelos teóricos por el coste de la aplicación de los mismos.

\subsubsection{Variables de estudio}

Las variables que se contemplaron en el estudio de los diferentes artículos fueron:

- Referencia del artículo: referencia bibliográfica utilizada en la base de datos.

- País de publicación: país en el que es publicada la revista estudiada.

- Nacionalidad del autor: país de origen que manifiestó el autor o autores del artículo.

- Centro de trabajo del autor: a nivel general lugar explicitado de filiación del autor, institución hospitalaria, institución comunitaria, universidad y otros que engloban el resto de posibilidades.

- Tipo de artículo: se contempló la clasificación del mismo según el Manual de Estilo de Publicaciones de la Asociación Americana de Psicología (American Psychological Association, 2010). Clasificando los artículos en 5 grupos:

a. Estudios empíricos: primera publicación de estudios originales. 
b. Artículos de reseñas de literatura o revisión: evaluaciones críticas acerca de estudios e investigaciones ya publicados.

c. Artículos teóricos: los autores toman investigaciones anteriores para dar a conocer una nueva teoría dentro de la misma línea de las investigaciones encontradas, o analizan las teorías existentes en determinados campos para señalar imprecisiones en trabajos previos.

d. Artículos metodológicos: dan nuevas metodologías o modifican las que ya se dieron luego de un minucioso análisis de las mismas.

e. Estudios de caso: son aquellos artículos que ilustran un problema, indican algún modo de resolverlo o esclarecen los elementos necesarios de un problema de investigación.

- Tema tratado: se analiza cualitativamente el tema tratado mediante la elaboración de una base de datos que incluye el tema de cada artículo.

- Modelo teórico aplicado: las autoras consideradas eran teóricas que elaboraron filosofías, modelos conceptuales y teorías (siguiendo la clasificación de Marriner \& Raile, 2003). De todas las teoristas que recoge la obra, se seleccionaron las más relevantes en las publicaciones fundamentándose en el estudio previo de Richart sobre el mismo tema. (Richart, Cabrero \& Flores, 1999). Las teoristas usadas para la búsqueda fueron Faye Glen Abdellah, Lydia Hall, Virginia Henderson, Dorothy Johnson, Imogene M. King, Madeleine M. Leininger, Myra Estrin Levine, Betty Neuman, Dorothea E. Orem, Rizzo Parse, Ida Orlando Pelletier, Hildegard E. Peplau, Martha E. Rogers, Sor Callista Roy, Joyce Travelbee, Jean Watson, Nancy Roper Winifred Logan y Alison J. Tierney y Ernestine Wiedenbach.

\subsubsection{Recogida de los datos}

Para el recuento de referencias correspondientes a autores de modelos de enfermería se utilizó una parrilla ad hoc. La búsqueda se realizó en el mes de enero, contemplando del 15 de enero de 2008 al 15 de enero de 2013. Se acudió a la base de datos de Medline, y se utilizaron términos de búsqueda en relación a base filosófica enfermera, investigación y aplicación de modelos teóricos en la práctica, buscando similitud y adecuación de términos con los descriptores del tesauro de la National Library of Medicine (Medical Subject Headings o MeSH). Partiendo de que cuando se realiza una búsqueda por los descriptores (palabras o frases controladas), se obtienen resultados más precisos y se reduce el número de trabajos irrelevantes a los intereses de los in- 
vestigadores ${ }^{8}$. Los términos MeSH de búsqueda concreta utilizados y sus definiciones están recogidos en la tabla 13.

Tabla 13: Términos MeSH usados en la búsqueda y su definición en Medline

\begin{tabular}{|c|c|}
\hline Término MeSH & Definición del término \\
\hline "Models, Nursing" & $\begin{array}{l}\text { Los modelos teóricos que simulan el comportamiento o las } \\
\text { actividades de enfermería, incluyendo cuidados de enfer- } \\
\text { mería, administración y economía, la teoría, la evaluación, la } \\
\text { investigación y la educación. }\end{array}$ \\
\hline "Philosophy, Nursing" & $\begin{array}{l}\text { Filosofía enfermera. Término situado bajo el término filoso- } \\
\text { fía. }\end{array}$ \\
\hline "Nursing Process" & $\begin{array}{l}\text { La suma total de las actividades de enfermería que incluye la } \\
\text { evaluación (identificación de las necesidades), intervención } \\
\text { (dando respuesta a las necesidades), y la evaluación (valida- } \\
\text { ción de la eficacia de la ayuda prestada). }\end{array}$ \\
\hline "Nursing Research" & $\begin{array}{l}\text { La investigación llevada a cabo por las enfermeras, por lo } \\
\text { general en el ámbito clínico, en las áreas de la práctica clíni- } \\
\text { ca, evaluación, educación en enfermería, administración de } \\
\text { enfermería, y la metodología. }\end{array}$ \\
\hline "Nursing Evaluation Research" & $\begin{array}{l}\text { Investigación llevada a cabo por enfermeras que utiliza en- } \\
\text { trevistas, recogida de datos, observación, encuestas, etc., } \\
\text { para evaluar la disciplina enfermera, la salud, la clínica y los } \\
\text { programas de formación y de estudio de enfermería, demos- } \\
\text { trando el valor de dicha evaluación }\end{array}$ \\
\hline "Clinical Nursing Research" & $\begin{array}{l}\text { La investigación llevada a cabo por las enfermeras en el } \\
\text { ámbito clínico y está diseñado para proporcionar informa- } \\
\text { ción que ayudará a mejorar la atención al paciente. } \\
\text { Contempla también a otros profesionales participantes en la } \\
\text { investigación }\end{array}$ \\
\hline $\begin{array}{l}\text { "Nursing Methodology Rese- } \\
\text { arch" }\end{array}$ & $\begin{array}{l}\text { Investigación llevada a cabo por las enfermeras respecto a } \\
\text { las técnicas y métodos para la ejecución de proyectos y para } \\
\text { documentar la información, se incluyen los métodos de en- } \\
\text { trevistar a los pacientes y la recogida de datos. El concepto } \\
\text { incluye la exploración de las cuestiones metodológicas, tales } \\
\text { como la subjetividad humana y la experiencia humana. }\end{array}$ \\
\hline "Nursing Diagnosis" & $\begin{array}{l}\text { Conclusiones derivadas de la valoración de enfermería y } \\
\text { establece un perfil del estado de salud del paciente que } \\
\text { puede precisar de la aplicación de intervenciones de enfer- } \\
\text { mería. }\end{array}$ \\
\hline
\end{tabular}

Destacar que se consideraron relevantes sobre todo los dos primeros términos ya que eran los que deberían incluir todos los artículos que incluyeran teoría enfermera. Estos términos se utilizaron combinados entre ellos y combinados con otras palabras clave (tal y como se puede

\footnotetext{
${ }^{8}$ Extraído de tutorial de uso de Pubmed: http://www.emoacap.es/Modulo\%20IV/tutorial4.htm
} 
observar en la tabla 14). Estas otras palabras fueron los nombres propios de las teoristas, que debido a que no estaban indexados en los descriptores, fueron empleados de forma completa o parcial (nombre y/o apellidos) o diferentes denominadores de su modelo o teoría en forma de lenguaje natural. De hecho, también se usaron estos últimos datos de forma simplificada sin aplicar los términos MeSH con la intención de minimizar posibles pérdidas de documentos en la exploración que no estuvieran indexados por el término MeSH usado. Además se aplicaron en la búsqueda los siguientes limitadores:

\begin{tabular}{|l|l|}
\hline Límite utilizado & Activado \\
\hline Publication Dates & Published in the last 5 years \\
\hline Text Availability & Abstract available \\
\hline
\end{tabular}

No se limitó el idioma de la publicación, ya que la intención era obtener el mayor número de artículos y una visión internacional de los mismos. Su contenido podía ser analizado aunque de forma más breve por el resumen en inglés contenido en la base de datos. Los descriptores MeSH y/o las palabras clave usados en la búsqueda para cada autora concreta o modelo se resumen en la tabla 14.

Tabla 14: Términos utilizados en la búsqueda de artículos basados en Teoristas enfermeras en Medline

\begin{tabular}{|c|c|}
\hline $\begin{array}{l}\text { Teorista /s y filosofía, } \\
\text { modelo o teoría anali- } \\
\text { zada }\end{array}$ & $\begin{array}{l}\text { Palabras clave y/o descriptores MeSH usados en la búsqueda en Medline me- } \\
\text { diante Pubmed }\end{array}$ \\
\hline $\begin{array}{l}\text { Rosemarie Rizzo Parse } \\
\text { La evolución humana }\end{array}$ & $\begin{array}{l}\text { “Models, Nursing[Mesh] AND 1", “Nursing Process[Mesh] AND 1", “Nursing Re- } \\
\text { search[Mesh] AND 1", “Nursing Evaluation Research[Mesh] AND 1", “Clinical } \\
\text { Nursing Research[Mesh] AND 1", “Nursing Methodology Research[Mesh] AND } \\
\text { 1", “Philosophy, Nursing[Mesh] AND 1", “Nursing Diagnosis[Mesh] AND 1", } \\
\text { "Parse's","parse human becoming", "parse theory” y "parse's theory” }\end{array}$ \\
\hline $\begin{array}{l}\text { Sor Callista Roy } \\
\text { El modelo de adapta- } \\
\text { ción }\end{array}$ & $\begin{array}{l}\text { “Models, Nursing[Mesh] AND 2", "Nursing Process[Mesh] AND 2", “Nursing Re- } \\
\text { search[Mesh] AND 2", “Nursing Evaluation Research[Mesh] AND 2", "Clinical } \\
\text { Nursing Research[Mesh] AND 2", “Nursing Methodology Research[Mesh] AND } \\
\text { 2", "Philosophy, Nursing[Mesh] AND 2", “Nursing Diagnosis[Mesh] AND 2", "2 } \\
\text { adaptation", "2 adaptation model", "Roy's" y "Roy's adaptation model” }\end{array}$ \\
\hline $\begin{array}{l}\text { Dorothea E. Orem } \\
\text { La teoria enfermera } \\
\text { del déficit de autocui- } \\
\text { dado }\end{array}$ & 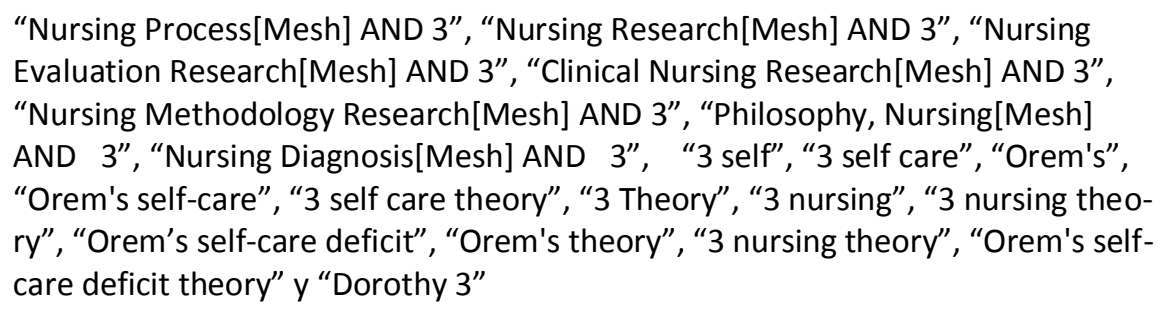 \\
\hline
\end{tabular}




\begin{tabular}{|c|c|}
\hline $\begin{array}{l}\text { Teorista /s y filosofía, } \\
\text { modelo o teoría anali- } \\
\text { zada }\end{array}$ & $\begin{array}{l}\text { Palabras clave y/o descriptores MeSH usados en la búsqueda en Medline me- } \\
\text { diante Pubmed }\end{array}$ \\
\hline $\begin{array}{l}\text { Jean Watson } \\
\text { Filosofía y ciencia del } \\
\text { cuidado }\end{array}$ & $\begin{array}{l}\text { "Models, Nursing[Mesh] AND 4", "Nursing Process[Mesh] AND 4", “Nursing Re- } \\
\text { search[Mesh] AND 4", “Nursing Evaluation Research[Mesh] AND 4", "Clinical } \\
\text { Nursing Research[Mesh] AND 4", “Nursing Methodology Research[Mesh] AND } \\
\text { 4", "Philosophy, Nursing[Mesh] AND 4", “Nursing Diagnosis[Mesh] AND 4", } \\
\text { "Jean Watson's", "Watson's", "4 caring theory", "Watson's theory", "Jean Wat- } \\
\text { son's theory", "Watson's caring theory" y "Jean Watson's theory of human } \\
\text { caring” }\end{array}$ \\
\hline $\begin{array}{l}\text { Madeleine } \\
\text { M. Leininger } \\
\text { Cultura de los cuida- } \\
\text { dos: teoría de la } \\
\text { diversidad y de la } \\
\text { universalidad }\end{array}$ & 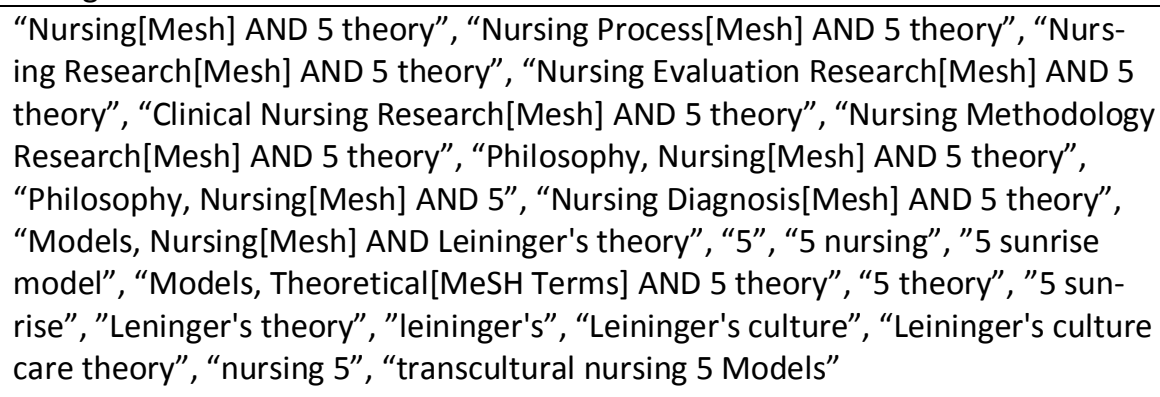 \\
\hline $\begin{array}{l}\text { Betty Neuman } \\
\text { Modelo de sistemas }\end{array}$ & $\begin{array}{l}\text { "Models, Nursing[Mesh] AND 6", "Nursing Process[Mesh] AND 6", "Nursing Re- } \\
\text { search[Mesh] AND 6", “Nursing Evaluation Research[Mesh] AND 6", "Clinical } \\
\text { Nursing Research[Mesh] AND 6", “Nursing Methodology Research[Mesh] AND } \\
\text { 6", "Philosophy, Nursing[Mesh] AND 6", “Nursing Diagnosis[Mesh] AND 6, "6", } \\
\text { "Neuman's model", "6 systems model", "Betty's 6", "6 Theory" y "the 6 systems } \\
\text { model" }\end{array}$ \\
\hline $\begin{array}{l}\text { Martha E. Rogers } \\
\text { Seres humanos }\end{array}$ & $\begin{array}{l}\text { "Models, Nursing[Mesh] AND 7", "Nursing Process[Mesh] AND 7", "Nursing Re- } \\
\text { search[Mesh] AND 7", “Nursing Evaluation Research[Mesh] AND 7", "Clinical } \\
\text { Nursing Research[Mesh] AND 7", "Nursing Methodology Research[Mesh] AND } \\
\text { 7", "Philosophy, Nursing[Mesh] AND 7", "Nursing Diagnosis[Mesh] AND 7", "7 } \\
\text { unitary" y "7 nursing theory" }\end{array}$ \\
\hline $\begin{array}{l}\text { Hildelgard Peplau } \\
\text { Enfermería psico- } \\
\text { dinámica }\end{array}$ & $\begin{array}{l}\text { "Models, Nursing[Mesh] AND 8", "Nursing Process[Mesh] AND 8", “Nursing Re- } \\
\text { search[Mesh] AND 8", “Nursing Evaluation Research[Mesh] AND 8", "Clinical } \\
\text { Nursing Research[Mesh] AND 8", “Nursing Methodology Research[Mesh] AND } \\
\text { 8", "Philosophy, Nursing[Mesh] AND 8", "Nursing Diagnosis[Mesh] AND 8", “8", } \\
\text { "8 theory", "Peplau's theory", "Peplau's interpersonal", "8 nursing", "theory 8" y } \\
\text { "nursing theory 8" }\end{array}$ \\
\hline $\begin{array}{l}\text { Virginia Henderson. } \\
\text { Definición de la en- } \\
\text { fermera clínica }\end{array}$ & $\begin{array}{l}\text { "Models, Nursing[Mesh] AND Virginia Henderson's model”, “Models, Nurs- } \\
\text { ing[Mesh] AND 9", "Nursing Process[Mesh] AND 9", “Nursing Process[Mesh] } \\
\text { AND Henderson's model", “Nursing Research[Mesh] AND 9", “Nursing Evalua- } \\
\text { tion Research[Mesh] AND 9", "Clinical Nursing Research[Mesh] AND 9", “Nursing } \\
\text { Methodology Research[Mesh] AND 9", "Nursing Diagnosis[Mesh] AND 9", "Vir- } \\
\text { ginia Henderson's" y “Virginia Henderson's theory”. }\end{array}$ \\
\hline $\begin{array}{l}\text { Imogene M. King } \\
\text { El marco de sistemas } \\
\text { interactivo y la teoría } \\
\text { de la consecución de } \\
\text { objetivos }\end{array}$ & $\begin{array}{l}\text { "Models, Nursing[Mesh] AND } 10 \text { model", "Models, Nursing[Mesh] AND } 10 \text { theo- } \\
\text { ry", "Nursing Process[Mesh] AND } 10 \text { model", "Nursing Process[Mesh] AND } 10 \\
\text { theory", "Nursing Research[Mesh] AND } 10 \text { model", "Nursing Evaluation Re- } \\
\text { search[Mesh] AND } 10 \text { model", "Clinical Nursing Research[Mesh] AND } 10 \text { model", } \\
\text { "Nursing Methodology Research[Mesh] AND } 10 \text { model", "Philosophy, Nurs- } \\
\text { ing[Mesh] AND } 10 \text { model", "Philosophy, Nursing[Mesh] AND 10", "Nursing } \\
\text { Diagnosis[Mesh] AND } 10 \text { model", "Models, Nursing[Mesh] AND King's model”, } \\
\text { "King's model", "King's nursing model", "King's theory", "King's theory of goal } \\
\text { attainment", "Imogene King's theory" }\end{array}$ \\
\hline
\end{tabular}




\begin{tabular}{|c|c|}
\hline $\begin{array}{l}\text { Teorista /s y filosofía, } \\
\text { modelo o teoría anali- } \\
\text { zada }\end{array}$ & $\begin{array}{l}\text { Palabras clave y/o descriptores MeSH usados en la búsqueda en Medline me- } \\
\text { diante Pubmed }\end{array}$ \\
\hline $\begin{array}{l}\text { Ida Jean Orlando } \\
\text { Pelletier } \\
\text { Enfermería psico- } \\
\text { dinámica }\end{array}$ & 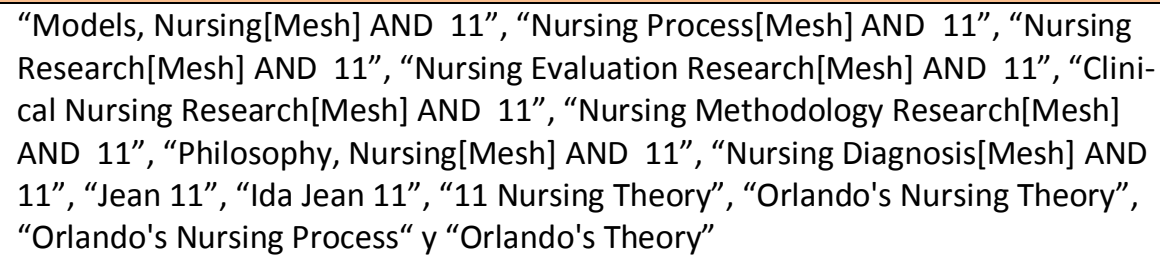 \\
\hline $\begin{array}{l}\text { Nancy Roper, Wini- } \\
\text { fred Logan y Alison } \\
\text { Tierney. } \\
\text { Modelo de enfermería } \\
\text { basado en un modelo } \\
\text { de vida. }\end{array}$ & $\begin{array}{l}\text { "Models, Nursing”[Mesh] AND 12", “Nursing Process”[Mesh] AND 12", “Nursing } \\
\text { Research" [Mesh] AND “Roper", "Nursing Evaluation Research"[Mesh] AND 12", } \\
\text { "Clinical Nursing Research[Mesh] AND 12", "Nursing Methodology Re- } \\
\text { search[Mesh] AND 12", "Philosophy, Nursing[Mesh] AND 12", “Nursing } \\
\text { Diagnosis[Mesh] AND 12", "12 Logan and Tierney" y "12 Logan". }\end{array}$ \\
\hline $\begin{array}{l}\text { Dorothy Johnson } \\
\text { El Modelo del Sistema }\end{array}$ & $\begin{array}{l}\text { "Models, Nursing[Mesh] AND } 13 \text { model", "Models, Nursing[Mesh] AND } 13 \text { theo- } \\
\text { ry", "Nursing Process[Mesh] AND } 13 \text { model", "Nursing Process[Mesh] AND } 13 \\
\text { theory", "Nursing Research[Mesh] AND } 13 \text { model", "Nursing Evaluation Re- } \\
\text { search[Mesh] AND } 13 \text { model", "Clinical Nursing Research[Mesh] AND } 13 \text { model", } \\
\text { "Nursing Methodology Research[Mesh] AND } 13 \text { model", "Philosophy, Nurs- } \\
\text { ing[Mesh] AND } 13 \text { model", "Philosophy, Nursing[Mesh] AND 13", "Nursing } \\
\text { Diagnosis[Mesh] AND } 13 \text { model", "Models, Nursing[Mesh] AND Johnson's mod- } \\
\text { el", "Johnson's model" y "Johnson's theory". }\end{array}$ \\
\hline $\begin{array}{l}\text { Lydia Hall } \\
\text { Modelo de introspec- } \\
\text { ción, cuidado y } \\
\text { curación }\end{array}$ & $\begin{array}{l}\text { "Models, Nursing[Mesh] AND } 14 \text { model", "Models, Nursing[Mesh] AND } 14 \text { theo- } \\
\text { ry", "Nursing Process[Mesh] AND } 14 \text { model", "Nursing Process[Mesh] AND } 14 \\
\text { theory", "Nursing Research[Mesh] AND } 14 \text { model", "Nursing Evaluation Re- } \\
\text { search[Mesh] AND } 14 \text { model", "Clinical Nursing Research[Mesh] AND } 14 \text { model", } \\
\text { "Nursing Methodology Research[Mesh] AND } 14 \text { model", "Philosophy, Nurs- } \\
\text { ing[Mesh] AND } 14 \text { model", "Nursing Diagnosis[Mesh] AND } 14 \text { model", "Models, } \\
\text { Nursing[Mesh] AND Hall's model" y "Hall's model". }\end{array}$ \\
\hline $\begin{array}{l}\text { Myra Estrine Levine } \\
\text { El modelo de conser- } \\
\text { vación }\end{array}$ & 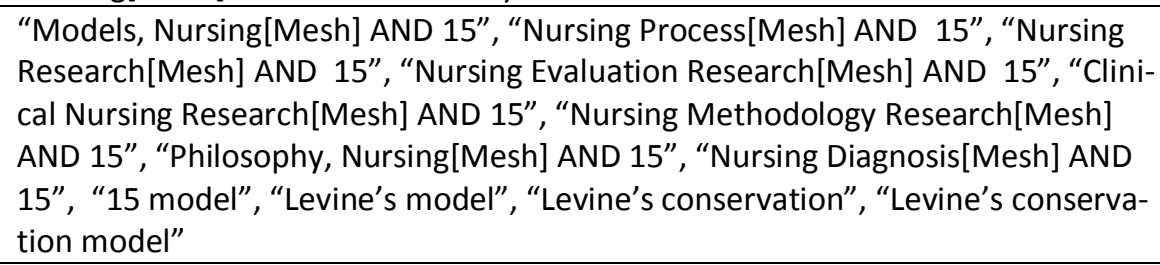 \\
\hline $\begin{array}{l}\text { Faye Glen Abdellah } \\
21 \text { problemas de En- } \\
\text { fermería }\end{array}$ & 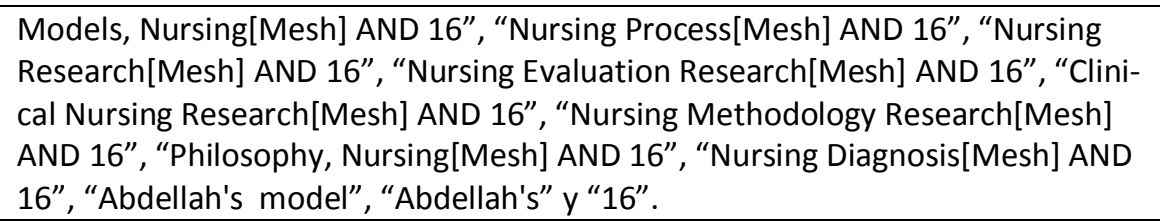 \\
\hline $\begin{array}{l}\text { Joyce Travelbee } \\
\text { Modelo de relación } \\
\text { persona a persona }\end{array}$ & $\begin{array}{l}\text { "Models, Nursing[Mesh] AND 17", "Nursing Process[Mesh] AND 17", "Nursing } \\
\text { Research[Mesh] AND 17", “Nursing Evaluation Research[Mesh] AND 17", “Clini- } \\
\text { cal Nursing Research[Mesh] AND 17", “Nursing Methodology Research[Mesh] } \\
\text { AND 17", “Philosophy, Nursing[Mesh] AND 17", “Nursing Diagnosis[Mesh] AND } \\
\text { 17", "Joyce 17", "17" y "17 theory" }\end{array}$ \\
\hline $\begin{array}{l}\text { Ernestine Wiedenbach } \\
\text { El arte de la ayuda en } \\
\text { la enfermería clínica }\end{array}$ & 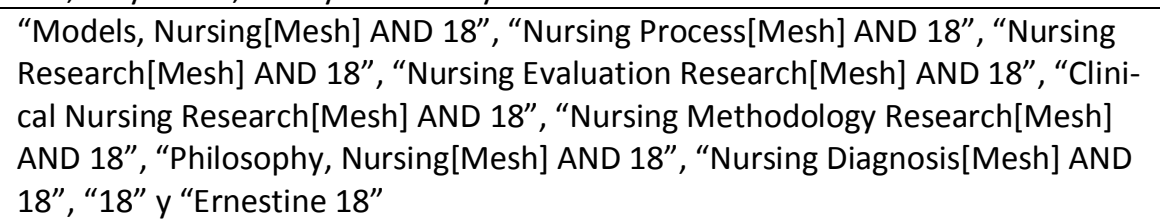 \\
\hline
\end{tabular}

${ }^{1}$ Parse, ${ }^{2}$ Roy, ${ }^{3}$ Orem, ${ }^{4}$ Watson, ${ }^{5}$ Leininger, ${ }^{6}$ Neuman, ${ }^{7}$ Rogers, ${ }^{8}$ Peplau, ${ }^{9}$ Henderson, ${ }^{10}$ King, ${ }^{11}$ Orlando,

${ }^{12}$ Roper, ${ }^{13}$ Johnson, ${ }^{14}$ Hall, ${ }^{15}$ Levine, ${ }^{16}$ Abdellah, ${ }^{17}$ Travelbee, ${ }^{18}$ Wiedenbach 


\subsubsection{Análisis de los datos}

Se accedió a los artículos o bien en forma de abstract o bien en forma de texto completo. El análisis de los datos se realizó a través de la descripción de las variables en forma de frecuencias y porcentajes mediante el uso del paquete estadístico SPSS 16.0 para Windows. Para analizar el contenido de los artículos se realizó una breve reseña del tema que trataba cada uno de ellos. 


\subsection{Límitaciones del estudio}

Se hallaron diferentes limitaciones en cada uno de los objetivos planteados. En cuanto al primer objetivo, destacar que el análisis de los datos contenidos en la web reflejaba sólo aquellos datos que cada universidad explicitaba sobre su modelo formativo, por lo que el contenido real impartido en el aula podría diferir de lo mostrado en web. Los resultados podrían haber dado simplemente una visión parcial del estado formativo. Además no todas las universidades tenían web o mostraban sus planes de estudio, por lo que la información en cuanto a créditos, objetivos, temario... fue limitada.

Con respecto al segundo objetivo, sobre el abordaje en el centro hospitalario, remarcar que una de las mayores limitaciones con las que contó el presente trabajo fue la elección de la muestra, por la gran dotación de enfermeras en el centro, su eventualidad y dotación variable, ya que es una población con cifras fluctuantes que dificulta en gran medida la cuantificación. Igualmente, la complejidad del tema unido a la elevada carga de trabajo en las unidades y el tiempo largo de cumplimentación del cuestionario podrían haber disminuido la tasa de respuesta. Además se cuenta con los resultados de un único centro hospitalario, por lo que limita su representatividad respecto a la totalidad de centros españoles.

En cuanto al tercer y cuarto objetivo, la investigación sobre los trabajos de Máster en Ciencias de la Enfermería, una muestra de 190 procesos enfermeros puede no reflejar una completa imagen de la realidad al ser trabajos académicos de aplicación de modelos en casos que no siempre podrían ser reales. Sin embargo el que sean profesionales de enfermería con experiencia clínica, podría asegurar que el examen y análisis de los modelos sobre situaciones de salud fuese más elaborado justamente por tal motivo. Remarcar que, los documentos presentan un carácter indirecto, ya que no permiten al que los utiliza un contacto directo con los hechos o sujetos, sino a través de los documentos (F. López, 2002). Por lo que eventualmente no permitirían al investigador cumplir rigurosamente con la credibilidad solicitada en la investigación cualitativa, ya que los sujetos autores de los documentos no son accesibles, y por lo tanto no se puede solicitar que confirmen las deducciones elaboradas. Decir además, que pese a que la bibliografía indica que las categorías en el análisis de contenidos deben ser exhaustivas, de exclusión mutua y con un único principio clasificatorio (Miles \& Huberman, 1994), pudo no darse esa exhaustividad e incluso alguno de los contenidos pudo formar parte de más de una categoría, ya que tales decisiones están afectadas por la subjetividad del punto de vista del propio investigador. Además los resultados pueden no ser extrapolables a otros contextos o momentos. 
Respecto al quinto objetivo que usó la técnica Delphi, en el envío de las preguntas vía mail pudo haber una serie de sucesos que provocaran la pérdida de información como errores en las direcciones de correo electrónico, bloqueo del correo por remitente desconocido u otros. Por otro lado, tener en cuenta la controversia sobre el uso de la técnica Delphi. C. Pérez (2000) comenta que se trata de una técnica usada en los estudios cualitativos, pero difiere de que sea considerada como tal alegando que las técnicas de metodología cualitativa producen información primaria y no secundaria como las técnicas de consenso. Además hace una crítica a los métodos usados en la técnica no cumplimentables según la perspectiva cualitativa, datos contradictorios a Yáñez y Cuadra (2008). Sin embargo, para el objeto de nuestro estudio era la técnica idónea de consenso a implementar.

En relación al sexto objetivo, respecto a la información obtenida de las publicaciones, cabe la posibilidad de perder gran parte de información importante publicada en revistas no indexadas en la base de datos consultada, la privación de aquellos artículos que pese a que hablaran del tema de estudio no dispusieran de resumen de su publicación, o literatura gris no incluida. 


\subsection{Consideraciones éticas}

Se aseguró la confidencialidad de los datos a la totalidad de los participantes siguiendo las siguientes acciones:

Tanto los estudiantes de Diplomado en Enfermería como los profesionales estudiados en el segundo objetivo dentro de la CSPT dieron su consentimiento oral para participar en el estudio. Los cuestionarios que cumplimentaron no recogían datos que los pudieran identificar y su recogida se realizó mediante una urna cerrada que impedía la posible retirada o visionado de los cuestionarios por personas ajenas al estudio. Además, el estudio contó con la aprobación de las universidades implicadas y del Comité de Ética e Investigación Científica del CSPT: la primera fase en profesionales llevaba por título "Aplicabilidad de modelos y teorías de Enfermería en la realidad asistencial. Primera fase". Con el código CEIC: 20066508. Y la segunda fase de desarrollo bajo el título "Filosofía del cuidar: perspectiva de los estudiantes de enfermería versus perspectiva de los profesionales asistenciales". Con código CEIC: 20066548. (Anexo I)

La confidencialidad de los autores de los trabajos de los estudiantes de Título propio o Máster en Ciencias de la Enfermería quedó asegurada por la no divulgación de ninguno de los datos de autoría, territorialidad o universidad procedente. Para evitar juicios de valor se fotocopiaron las páginas de interés de los documentos originales excluyendo cualquier dato de la autoría en los mismos, de forma que el material que se analiza es el propio texto del trabajo sin hacer mención a identidad personal, universidad o territorio al que pertenecen los autores.

En el caso de los gestores y docentes participantes en la técnica Delphi, la participación del grupo fue anónima y voluntaria. Se envió una carta de invitación a participar y sólo se hicieron llegar las preguntas de estudio si el profesional experto invitado accedió a recibirlos. Los correos fueron enviados utilizando la modalidad de "copia oculta", de manera que no se tenía acceso a las direcciones del resto del grupo, para mantener la confidencialidad entre los participantes.

El proyecto en su totalidad (incluyendo cada una de las fases y objetivos) fue presentado además al Comité de Investigación de la Universidad Tecnocampus Mataró - Maresme, obteniéndose su aprobación (Anexo I). 
4 Resultados 


\subsection{Resultados en relación al primer objetivo: Describir el estado}

formativo que ha podido influir en la implantación de modelos teóricos en la práctica

Para dar respuesta a la descripción del estado formativo que habría podido influir en la implantación de modelos teóricos en la práctica, durante el año 2009 (desde marzo a junio de 2009), se realizó una revisión de los planes de estudios de las diferentes escuelas de enfermería y universidades a través de la consulta de sus páginas web. La finalidad fue contextualizar la formación en fundamentos teóricos dentro de la formación general de la titulación de Diplomado, por lo que cuando se hable de créditos se hablará siempre de créditos tradicionales o de la Ley de Reforma Universitaria (LRU). El listado de universidades y las páginas web consultadas se obtuvo de la página del Ministerio de Educación (en el anexo IV del CD).

Se estudiaron un total de 109 centros que impartían la titulación de Diplomado en Enfermería en España. La distribución de los centros por Comunidades Autónomas se puede ver en la figura 3.

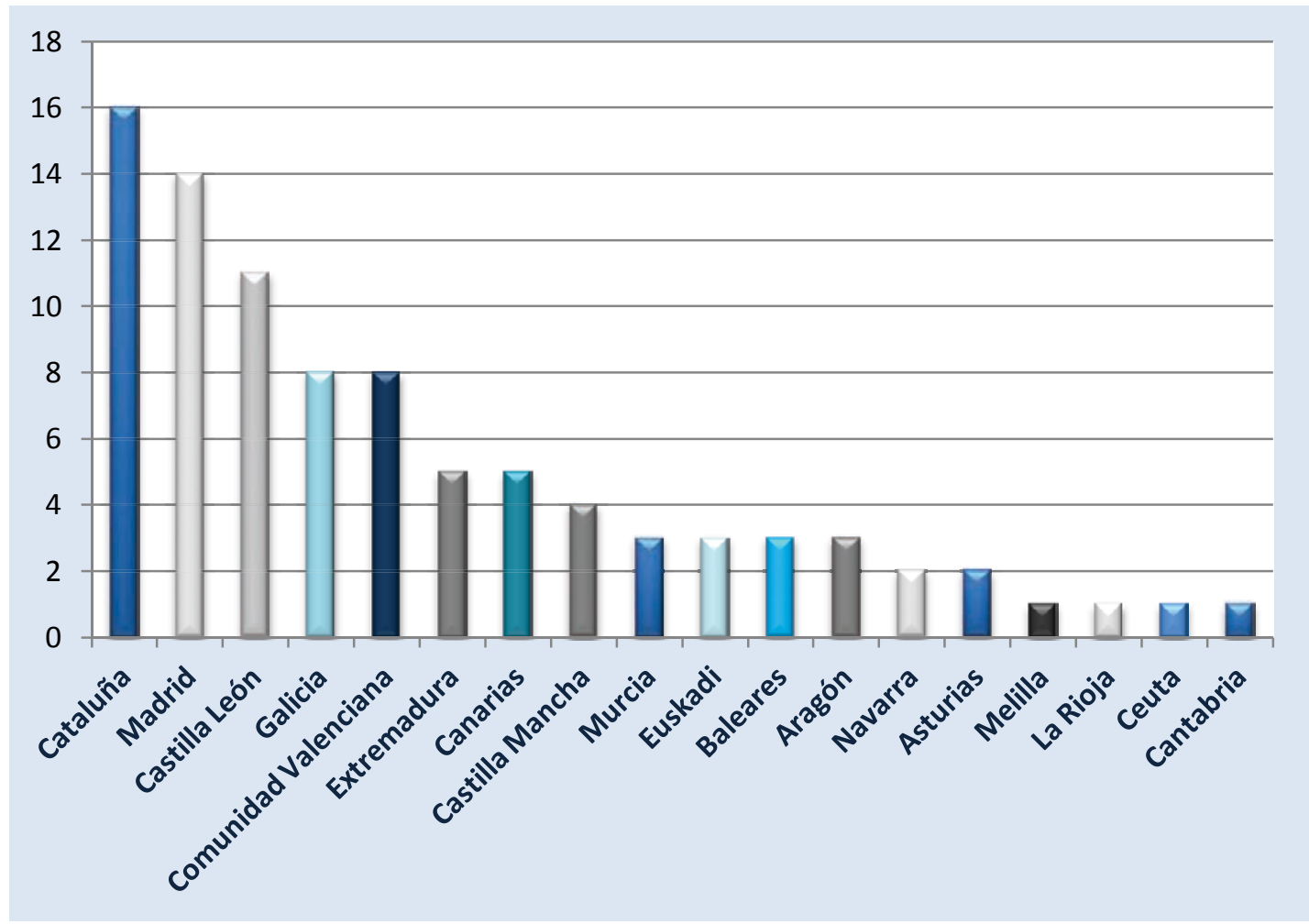

Figura 3: Distribución de los centros según Comunidad Autónoma (CCAA) 
Todos los centros disponían de web, pero en 9 de ellos (8,25\%), la información obtenida fue mínima (nombre del centro y breve reseña de los estudios). Los cursos académicos estudiados fueron mayoritariamente los planes de estudios ofertados por los centros para el curso 2008-2009 (67\%), en el 24,8\% de los casos no aparecía el curso académico al que pertenecía el plan. El 83,5\% de escuelas de enfermería o universidades tenían su plan de estudios accesible desde la web de su universidad siendo el plan del año 2000 (14,7\%) el más frecuente, aunque en el 32,1\% de los casos no constaba esta información. Esta misma información analizada en la página del Ministerio de Educación, indicaba que el plan más frecuente era el del año 2001 en las universidades españolas $(14,7 \%)$.

Sólo el 7,3\% de las universidades se manifestaban de acuerdo con una base teórica concreta, adscribiéndose explícitamente a una teorista enfermera. Para denominar los conocimientos en relación al objeto de estudio usaban mayoritariamente el término "Fundamentos de Enfermería" (78,9\%). Todos los centros desarrollaban una asignatura principal en el primer curso de la diplomatura. Otras denominaciones usadas para la misma asignatura fueron "Enfermería Fundamental" (5,5\%), "Historia y Fundamentos del Cuidado" (5,5\%) y "Fundamentos Teóricos - Historia de la Enfermería y Documentación" (1,8\%). El 27,5\% de los centros dedicaron 15 créditos LRU a la asignatura básica. Las asignaturas obligatorias ofertadas, así como su dotación en créditos se pueden ver en la tabla 15.

Tabla 15: Asignaturas obligatorias en relación a modelos teóricos durante el curso académico 2008-2009

\begin{tabular}{|l|l|l|}
\hline Nombre de la asignatura & Créditos LRU & $\begin{array}{l}\text { Curso } \\
\text { académico }\end{array}$ \\
\hline Cuidados de Enfermería & De 16 a 19 (según universidad) & Primero \\
\hline Enfermería Básica & 9 & Primero \\
\hline Enfermería Fundamental & De 14 a 16,5 (según universidad) & Primero \\
\hline Fundamentos de Enfermería & De 4,5 a 19 (según universidad) & Primero \\
\hline Fundamentos de Enfermería II & De 7 a 9 (según universidad) & Primero \\
\hline Fundamentos de los Cuidados de Enfermería & 4,5 & Primero \\
\hline $\begin{array}{l}\text { Fundamentos Teóricos - Historia de Enfermería y Do- } \\
\text { cumentación }\end{array}$ & 9 & Primero \\
\hline Fundamentos Teóricos e Historia de la Enfermería & 9 & Primero \\
\hline Historia y fundamentos de los cuidados & 6,5 & Primero \\
\hline Historia y fundamentos del cuidado & 10 & Primero \\
\hline Modelos de Cuidados Enfermeros & 4,5 & Primero \\
\hline Modelos de Cuidados Enfermeros II* & 4,5 & Tercero \\
\hline
\end{tabular}

*Sólo ofertada por una universidad 
De los centros que declararon los créditos de la asignatura (93), el número medio de créditos que se dedicaba fue de 13,4 2,4. (Mínimo de 4,5 y máximo de 19 créditos). Concretaron la dedicación de sus créditos 65 centros, de ellos $6,7 \pm 1,4$ eran créditos prácticos y $6,9 \pm 1,8$ créditos eran teóricos. De los 61 centros en los que se podía disponer del contenido de la asignatura, manifestaron que el contenido práctico de la asignatura eran prácticas de laboratorio en un $37,6 \%$ y un 33,9\% incluían prácticas clínicas; el resto no lo diferenció.

La mayoría de las universidades no hacían alusión al modelo que guiaba principalmente su formación dentro del plan de estudios de la asignatura (56,9\%). Cuando analizamos los datos obtenidos a través de los objetivos de la asignatura, por sus contenidos o porque así lo explicitó en algún momento el docente, hallamos que el 31,2\% seguían el modelo de Virginia Henderson. En porcentajes muy inferiores, el 4,6\% indicaron basarse en los patrones funcionales de Marjory Gordon, el 2,8\% en Dorothea E. Orem, un 1,8\% utilizaban indistintamente V. Henderson y D. Orem, el 0,9\% era guiado por Sor Callista Roy. Un 1\% usaba indistintamente V. Henderson y M. Leininger y el 0,9\% indicaron seguir a J. Watson como teórica referente.

Sólo fue posible analizar el contenido del plan docente de la asignatura en el $56 \%$ de los centros (sólo 61 centros tenían disponible el plan docente completo). De estos, el 95,2\% incluían Modelos y Teorías de Enfermería, el 95,2\% contenían conocimientos sobre Metodología Enfermera y el 33,9\% incluían conocimientos sobre Historia de la Enfermería.

En cuanto a la introducción en el temario de teoristas en su contenido de forma explícita (es decir, que incluyeran explícitamente su nombre en el programa de la asignatura), el $82 \%$ de Ios centros nombraban a Virginia Henderson, el 36,1\% designaban a Dorothea E. Orem, el 29,5\% a Sor Callista Roy, el 32,8\% Florence Nightingale, el 23\% Hildegard E. Peplau, el 19,7\% Marjory Gordon (aunque no es un modelo teórico), el 18\% Martha E. Rogers, el 6,9\% Madeleine M. Leininger, un 3,9\% Imogene M. King y el 8,2\% nombra a otras teóricas.

De los centros que mostraban su plan de estudios (91), el 15,3\% de ellos incluyeron otra asignatura obligatoria en relación a teoría enfermera (realizada mayoritariamente en primer curso de la diplomatura) con un media de $10,7 \pm 5,5$ créditos y un $19,2 \%$ ofertaron asignaturas optativas relacionadas, con una media de $5 \pm 1,4$ créditos. Las asignaturas optativas, su dotación en créditos y la información sobre su curso académico se pueden ver en la tabla 16. 
Tabla 16: Asignaturas optativas en relación a modelos teóricos durante el curso académico 2008-2009

\begin{tabular}{|l|l|l|}
\hline Nombre de la asignatura & Créditos LRU & Curso académico \\
\hline $\begin{array}{l}\text { Análisis de la Evolución de las Teorías y Modelos de En- } \\
\text { fermería }\end{array}$ & $\begin{array}{l}\text { De 4,5 a 6,5 } \\
\text { (según universidad) }\end{array}$ & Tercero \\
\hline Escuelas de Pensamiento Enfermero & 5 & No especifica \\
\hline Historia de la Enfermería & 3,6 & No especifica \\
\hline $\begin{array}{l}\text { Historia, Teorías, Modelos, Metodología Diagnóstica en } \\
\text { Enfermería }\end{array}$ & 6 & Primero \\
\hline Modelos Conceptuales y Teorías Enfermeras & 4,5 & Tercero \\
\hline Modelos de Enfermería y campos de actuación & 5 & No especifica \\
\hline Rol autónomo de la enfermera en el área asistencial & 3 & No especifica \\
\hline Tendencias del Pensamiento Enfermero & 4,5 & Segundo \\
\hline Teoría de Enfermería & 5 & Primero \\
\hline Teorías en Enfermería & 5 & Tercero \\
\hline Teorías y Modelos de Enfermería & 4,5 & Primer o segundo curso \\
\hline
\end{tabular}

\subsection{Resultados en relación al segundo objetivo: Conocer qué} modelo enfermero se aplica de forma implícita (sin ser

\section{regularizado institucionalmente) en la práctica profesional y}

su relación con la formación recibida.

A continuación se detallan los resultados obtenidos que responden al segundo objetivo en profesionales y estudiantes de prácticas de la CSPT en relación a la aplicación de un modelo teórico enfermero en la práctica.

El índice de respuesta de los profesionales fue del 38\% de 545 profesionales invitados $(n=204)$, frente al 98\% de 107 estudiantes invitados ( $n=105)$. En cuanto a los datos sociodemográficos de los sujetos se observa que los estudiantes eran más jóvenes con una media de edad de $24 \pm 6$ frente a $37 \pm 9$ años de los profesionales, tal y como se aprecia en la figura 4 .

Diecinueve profesionales eran hombres (9\%), en relación a 17 estudiantes (16\%). No hallándose diferencias significativas entre los porcentajes (valor Chi-quadrado de Pearson de $3,685,1 \mathrm{gl}^{9}$ con $\left.\mathrm{p}>0,05\right)$. Los centros en los que cursaron sus estudios se resumen en la tabla 17 .

\footnotetext{
${ }^{9}$ Grados de libertad
} 


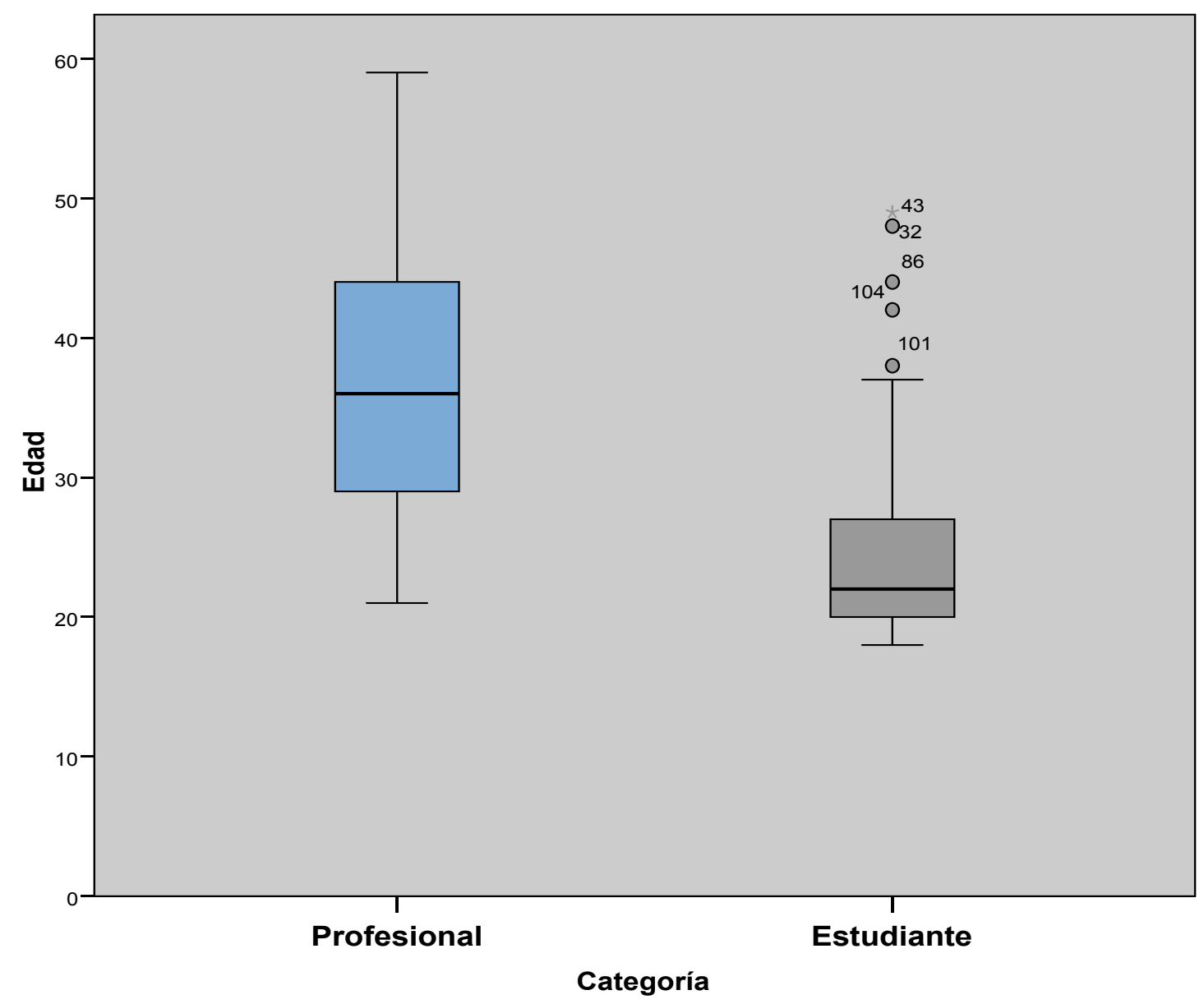

Figura 4: Comparativo entre la edad en profesionales frente a los estudiantes

Tabla 17: Centros donde cursaban o cursaron sus estudios los profesionales y estudiantes $(n=309)$

\begin{tabular}{|c|c|c|}
\hline CATEGORÍA & CENTROS FORMATIVOS & $\begin{array}{c}\text { Porcentaje } \\
\text { (sobre profesionales o } \\
\text { estudiantes) }\end{array}$ \\
\hline \multirow{15}{*}{$\begin{array}{l}\text { PROFESIONALES } \\
\mathrm{n}=\mathbf{2 0 4}\end{array}$} & EUIG & $16,7 \%(34)$ \\
\hline & EUICR & $16,2 \%(33)$ \\
\hline & Escuela de ATS Epione $^{\mathrm{a}}$ & $11,8 \%(24)$ \\
\hline & EUE Sant Pau & $11,3 \%(23)$ \\
\hline & EUE Vall Hebrón & $11,3 \%(23)$ \\
\hline & EUE Bellvitge & $8,3 \%(17)$ \\
\hline & EUE Hospital Clínic & $5,4 \%(11)$ \\
\hline & EUE del Mar & $4,9 \%(10)$ \\
\hline & Otras (otras CCAA o países) & $3,9 \%(8)$ \\
\hline & EUE Vic & $3,4 \%(7)$ \\
\hline & EUE Sant Joan de Déu & $2,5 \%(5)$ \\
\hline & EUE Blanquerna & $1,0 \%(2)$ \\
\hline & UIC & $1,0 \%(2)$ \\
\hline & EUE Manresa & $0,5 \%(1)$ \\
\hline & Perdidos (no dan información) & $2 \%(4)$ \\
\hline
\end{tabular}




\begin{tabular}{|l|l|c|}
\hline \multicolumn{1}{|c|}{ CATEGORÍA } & \multicolumn{1}{|c|}{ CENTROS FORMATIVOS } & $\begin{array}{c}\text { Porcentaje } \\
\text { (sobre profesionales o } \\
\text { estudiantes) }\end{array}$ \\
\hline \multirow{2}{*}{$\begin{array}{l}\text { ESTUDIANTES } \\
n=105\end{array}$} & EUIG & $28,6 \%(30)$ \\
\cline { 2 - 3 } & EUICR & $42,8 \%(45)$ \\
\cline { 2 - 3 } & UIC & $28,6 \%(30)$ \\
\hline
\end{tabular}

${ }^{a}$ Escuela de ATS Epione: escuela de enfermería situada en la Clínica infantil del niño Jesús en Sabadell que estuvo formando ATS desde 1966 a 1979, además de la Especialidad de Pediatría y Puericultura (Fuente de la información ORDEN de 2 de mayo de 1974 de: http://www.boe.es/boe/dias/1974/08/30/pdfs/A18006-18007.pdf).

En cuanto a titulaciones, el 14,2\% (29) de la muestra de profesionales eran ATS de los que el 9,3\% (19) obtuvieron posteriormente la titulación de DUE. El 48\% (50) de los estudiantes manifestaron haber trabajado como Auxiliares de Enfermería. En cuanto a experiencia laboral previa, los profesionales habían trabajado una media de 14,1 \pm 9,3 años (de los cuáles 12,9 \pm 9,1 años habían trabajado en la CSPT) y de los Auxiliares de Enfermería la mitad había trabajado más de 2 años. Las unidades y turnos a los que pertenecían profesionales y estudiantes se resumen en la tabla 18.

Con respecto a la elección del modelo que guió su formación (podían optar por más de un modelo), el modelo bajo el cual refieren haberse formado fundamentalmente (ver figura 5 y tabla 19) fue el de V. Henderson en ambos grupos, pero en diferentes proporciones: $74 \%$ (151) entre los profesionales y 60\% (63) entre los estudiantes (Valor Chi-cuadrado 6,399, 1 gl, p<0,05).

Tabla 18: Ámbito y turno laboral o de prácticas de profesionales y estudiantes

\begin{tabular}{|c|c|c|c|}
\hline & & Profesionales & Estudiantes \\
\hline \multirow{9}{*}{ Ámbito } & Hospitalización Medicina Interna & $16,2 \%(33)$ & $8,8 \%(9)$ \\
\hline & Hospitalización quirúrgica $^{1}$ & $20,1 \%(41)$ & $33,3 \%(34)$ \\
\hline & Servicio de Nefrología $^{2}$ & $13,2 \%(27)$ & $2,9 \%(3)$ \\
\hline & Centro Sociosanitario & $9,3 \%(19)$ & -- \\
\hline & Unidades de Críticos ${ }^{3}$ & $8,3 \%(17)$ & $13,7 \%(14)$ \\
\hline & Hospitalización Materno-infantil & $10,3 \%(21)$ & $21,6 \%(22)$ \\
\hline & Centro de Salud Mental & $4,4 \%(9)$ & -- \\
\hline & Gestión & $4,4 \%(9)$ & -- \\
\hline & Servicios externos ${ }^{4}$ & $13,7 \%(28)$ & $19,6 \%(20)$ \\
\hline \multirow{5}{*}{ Turno } & Horario completo mañana & $38,5 \%(77)$ & $61,5 \%(64)$ \\
\hline & Horario completo tarde & $28 \%(56)$ & $38,5 \%(40)$ \\
\hline & Horario completo noche & $17 \%(34)$ & -- \\
\hline & Horario completo partido & $11 \%(22)$ & -- \\
\hline & Horario a tiempo parcial & $5,5 \%(11)$ & -- \\
\hline
\end{tabular}




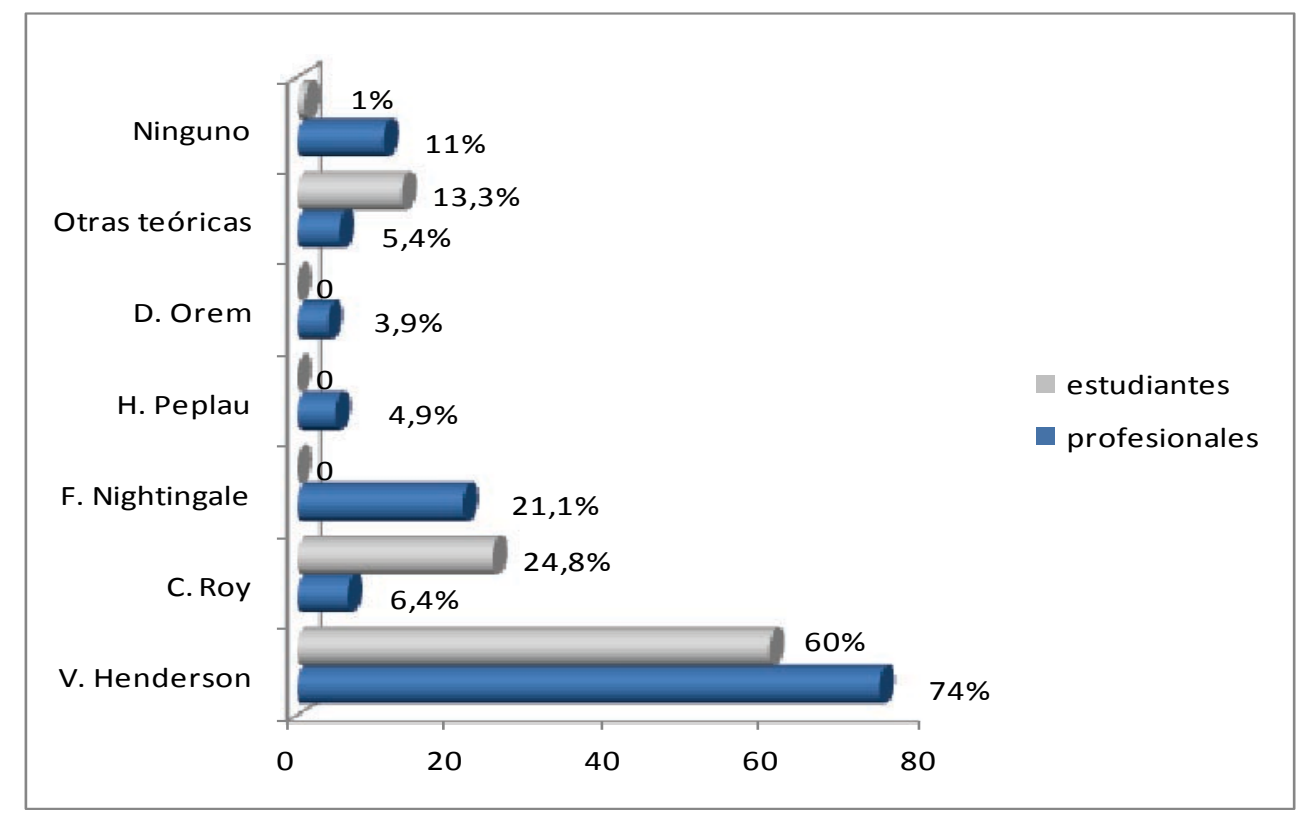

Figura 5: Modelo usado en la formación de los sujetos estudiados

Dentro de los otros modelos explicitados, sólo algunos de los profesionales comentan que siguieron los Patrones de Gordon (5 profesionales), NANDA ( 2 profesionales), PAE, Riopelle y todos los modelos que se les da como opción (1 profesional de cada grupo).

Tabla 19: Comparación entre los diferentes modelos usados en la formación para ambos grupos

\begin{tabular}{|l|l|l|l|}
\hline $\begin{array}{l}\text { Comparación entre las diferentes } \\
\text { elecciones (profesionales } \\
\text { /estudiantes) }\end{array}$ & $\begin{array}{l}\text { Valor } \\
\text { Chi-cuadrado }\end{array}$ & gl & $\begin{array}{l}\text { Significación asintó- } \\
\text { tica (bilateral) }\end{array}$ \\
\hline Ninguno & 10,898 & 1 & $<0,05$ \\
\hline Otras Teóricas & 5,879 & 1 & $<0,05$ \\
\hline F. Nightingale & 25,710 & 1 & $<0,01$ \\
\hline C. Roy & 21,256 & 1 & $<0,01$ \\
\hline V. Henderson & 6,399 & 1 & $<0,05$ \\
\hline H. Peplau* & -- & -- & -- \\
\hline D. Orem* & -- & -- & -- \\
\hline
\end{tabular}

*No se recoge, poco relevante por ser pequeños los porcentajes que escogen ambas opciones.

Los datos sociodemográficos detallados anteriormente, se pueden apreciar por escuelas y se muestran en la tabla 20. 
Tabla 20: Datos sociodemográficos de la muestra de estudiantes

\begin{tabular}{|c|c|c|c|c|}
\hline $\begin{array}{l}\text { Pregunta del cuestiona- } \\
\text { rio }\end{array}$ & $\begin{array}{l}\text { Opciones de } \\
\text { respuesta }\end{array}$ & EUICR & EUIG & UIC \\
\hline Edad del estudiante & Media & $24,2 \pm 6,3$ & $22,8 \pm 4,1$ & $25,5 \pm 7,2$ \\
\hline Sexo del estudiante & $\begin{array}{l}\text { Hombres } \\
\text { Mujeres }\end{array}$ & $\begin{array}{l}13,3 \%(6) \\
86,7 \%(39)\end{array}$ & $\begin{array}{l}13,3 \%(4) \\
86,7 \%(26)\end{array}$ & $\begin{array}{l}23,3 \%(7) \\
76,7 \%(23)\end{array}$ \\
\hline $\begin{array}{l}\text { Año de inicio de la ca- } \\
\text { rrera }\end{array}$ & & $2002-2006$ & $2003-2006$ & 2004-2006 \\
\hline \multirow[t]{2}{*}{$\begin{array}{l}\text { Trabajo como sanitario } \\
\text { previamente }\end{array}$} & Sí & $\begin{array}{l}44,4 \% \text { (20) } \\
\text { (60\% más de } 2 \\
\text { años) }\end{array}$ & $\begin{array}{l}60 \% \text { (18) } \\
\text { (57\% más de } 2 \\
\text { años) }\end{array}$ & $\begin{array}{l}40 \%(12) \\
\text { (18,2\% más de } 2 \\
\text { años) }\end{array}$ \\
\hline & No & $55,6 \%(25)$ & $40 \%(12)$ & $60 \%(28)$ \\
\hline \multirow{6}{*}{$\begin{array}{l}\text { Modelo/s verbalizado/s } \\
\text { por los estudiantes } \\
\text { como guía de su forma- } \\
\text { ción }\end{array}$} & V. Henderson & $100 \%(45)$ & $46,7 \%(14)$ & $13,8 \%(4)$ \\
\hline & C. Roy & -- & -- & $86,2 \%(25)$ \\
\hline & F. Nightingale & -- & $3,3 \%(1)$ & -- \\
\hline & Ninguno & -- & $3,3 \%(1)$ & -- \\
\hline & Otras teóricas & -- & $46,7 \%(14)$ & -- \\
\hline & No contesta & -- & -- & $3,3 \%(1)$ \\
\hline
\end{tabular}

En cuanto a la formación complementaria en modelos teóricos, el 23,5\% (48) de los profesionales afirman haber recibido tal formación en cursos de formación continuada o postgrados. Los estudiantes comentan que han realizado alguna asignatura optativa en relación al tema en un $24,8 \%(26)$.

Otro de los datos importantes de los encuestados fue si usaban un modelo en su práctica asistencial, sólo lo hicieron el $23,3 \%$ (47) de los profesionales mientras que los estudiantes refirieron que si los usaban en el 62,1\% (64) de los casos (chi-cuadrado de Pearson de 65,621, gl 1 y $p<0,01)$. Destacar que un $8,4 \%(17)$ de los profesionales y un $18,4 \%(19)$ estudiantes no supieron contestar a la pregunta formulada. (Tabla 21 y figura 6 ).

Tabla 21: Comparación entre las diferentes elecciones del seguimiento manifestado de un modelo teórico enfermero en la actividad laboral o en prácticas (profesionales $n=204$ / estudiantes $n=105$ )

\begin{tabular}{|l|l|l|l|}
\hline Elecciones & $\begin{array}{l}\text { Valor } \\
\text { Chi- } \\
\text { cuadrado }\end{array}$ & gl & $\begin{array}{l}\text { Significación } \\
\text { asintótica } \\
\text { (bilateral) }\end{array}$ \\
\hline Refieren seguir un modelo teórico en su práctica & 44,521 & 1 & $<0,01$ \\
\hline Refieren que no siguen un modelo teórico en su práctica & 65,331 & 1 & $<0,01$ \\
\hline No saben si siguen un modelo en su práctica & 6,593 & 1 & $<0,05$ \\
\hline
\end{tabular}




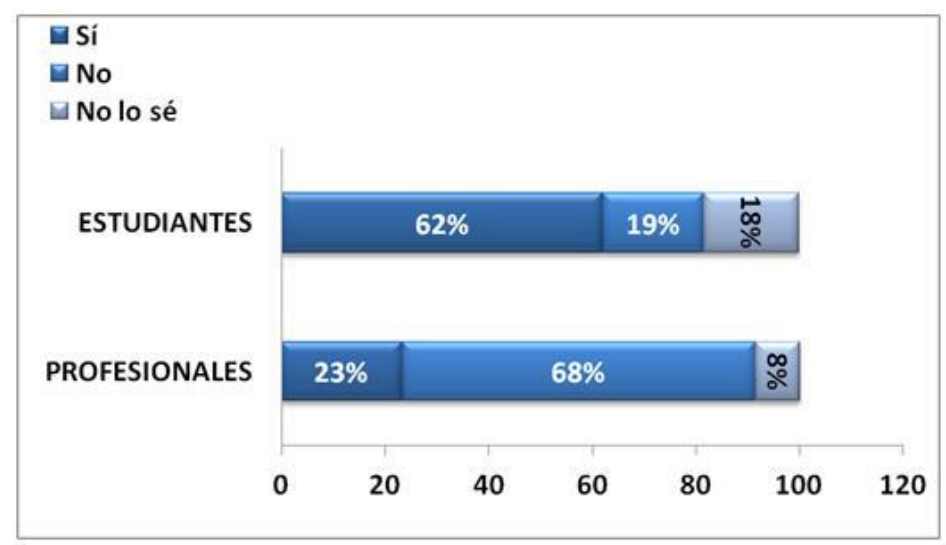

Figura 6: Seguimiento manifestado de un modelo teórico enfermero en la actividad laboral o en prácticas (profesionales $n=204$, estudiantes $n=105$ )

Pese a la respuesta afirmativa de los grupos, cuando se les preguntó por el modelo seguido, sólo lo indicaron el $22 \%$ de los profesionales y el $60 \%$ de los estudiantes. De estos, la mayoría escogieron la filosofía de Henderson. Los modelos seguidos por los entrevistados se exponen en la tabla 22.

Tabla 22: Modelos que manifiestan seguir en su práctica

\begin{tabular}{|l|c|c|c|}
\hline & Profesional & Estudiante & Total \\
\hline V. Henderson & $86,7 \%(39)$ & $82,5 \%(52)$ & $84,3 \%(91)$ \\
\hline C. Roy & -- & $15,9 \%(10)$ & $9,3 \%(10)$ \\
\hline Ninguno & $2,2 \%(1)$ & $1,6 \%(1)$ & $1,9 \%(2)$ \\
\hline Otros & $11,1 \%(5)$ & -- & $4,6 \%(5)$ \\
\hline Total (n) & 45 & 63 & 108 \\
\hline
\end{tabular}

En cuanto a si creían que les era útil (en profesionales) o les será útil (en estudiantes) el modelo teórico enfermero que estudiaron para la práctica asistencial, más del 50\% de ambos grupos afirman que sí, aunque no siempre comentan que les será útil (tabla 23).

Tabla 23: Creencia de utilidad del modelo teórico estudiado actual para el profesional y utilidad futura para el estudiante

\begin{tabular}{|l|c|c|c|c|c|c|}
\hline & Total & Profesional & Estudiante & $\begin{array}{l}\text { Valor } \\
\text { Chi- } \\
\text { cuadrado }\end{array}$ & $\begin{array}{l}\text { gl } \\
\text { Significación } \\
\text { asintótica } \\
\text { (bilateral) }\end{array}$ \\
\hline Sí, siempre & $17,9 \%(54)$ & $14,6 \%(29)$ & $24,3 \%(25)$ & 4,264 & 1 & $<0,05$ \\
\hline A veces & $54,5 \%(164)$ & $52,5 \%(104)$ & $58,3 \%(60)$ & 0,896 & 1 & $>0,05$ \\
\hline No & $18,6 \%(56)$ & $25,3 \%(50)$ & $5,8 \%(6)$ & 16,886 & 1 & $<0,01$ \\
\hline No lo sé & $9,0 \%(27)$ & $7,6 \%(15)$ & $11,7 \%(12)$ & 1,378 & 1 & $>0,01$ \\
\hline Total $(\mathbf{n})$ & 301 & 198 & 103 & & & \\
\hline
\end{tabular}


Referente a si se identifican con el modelo con el que cuidaban a las personas, las respuestas fueron similares, los estudiantes dijeron sí en un $88 \%$ (92) y los profesionales en un $83 \%$ (169). Ver más detalles en tabla 24 y la figura 7.

Tabla 24: Comparación entre las diferentes elecciones de la frecuencia con la que creen identificarse con el modelo de cuidado que prestan

\begin{tabular}{|l|c|c|c|c|c|}
\hline & Profesionales & Estudiantes & $\begin{array}{l}\text { Valor } \\
\text { Chi-cuadrado }\end{array}$ & gl & $\begin{array}{l}\text { Significación } \\
\text { asintótica } \\
\text { (bilateral) }\end{array}$ \\
\hline Nunca & $11,1 \%(21)$ & $3,9 \%(4)$ & 4,399 & 1 & $<0,05$ \\
\hline Casi nunca & $6,3 \%(12)$ & $7,8 \%(8)$ & 0,221 & 1 & $>0,05$ \\
\hline A veces & $54,7 \%(104)$ & $46,6 \%(48)$ & 1,771 & 1 & $>0,05$ \\
\hline Casi siempre & $16,3 \%(31)$ & $30,1 \%(31)$ & 7,604 & 1 & $<0,01$ \\
\hline Siempre & $11,6 \%(22)$ & $11,7 \%(12)$ & 0,000 & 1 & $>0,05$ \\
\hline Total (n) & 190 & 103 & & & \\
\hline
\end{tabular}

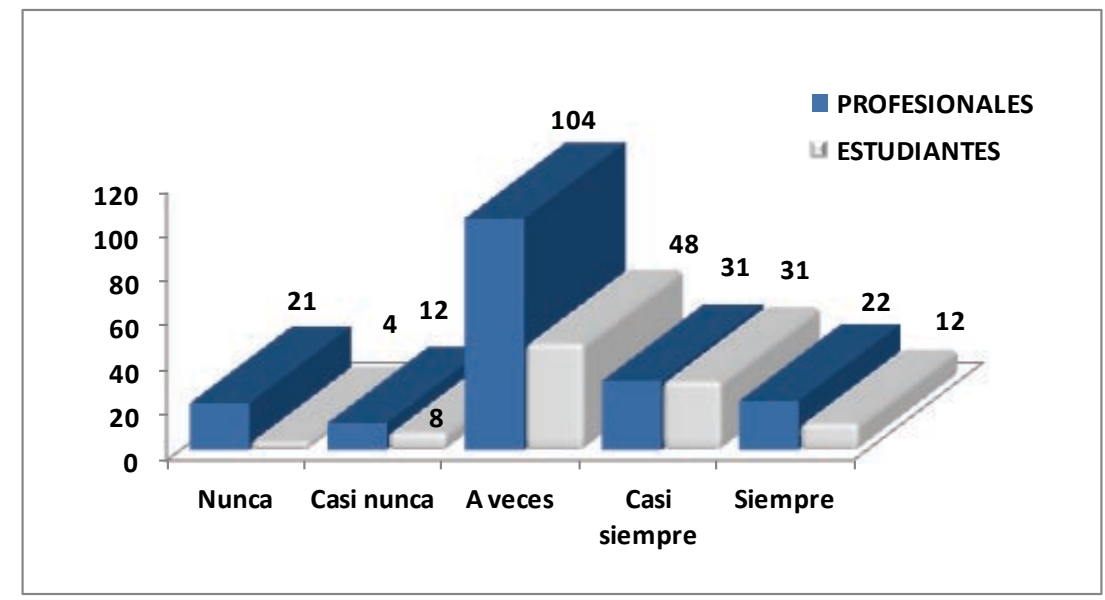

Figura 7: Frecuencia con la que creen identificarse con el modelo de cuidado que prestan

Respecto a si sería positivo implantar un modelo en el centro, así lo creyeron el 66\% (69) de los estudiantes y el 63\% (129) de los profesionales, no hallándose diferencias estadísticamente significativas en las elecciones (tabla 25).

Tabla 25: Creencia de que se debe implantar un modelo en el centro de estudio (CSPT)

\begin{tabular}{|l|c|c|c|c|c|c|}
\hline & Profesional & Estudiante & Total & $\begin{array}{l}\text { Valor } \\
\text { Chi- } \\
\text { cuadrado }\end{array}$ & gl & $\begin{array}{l}\text { Significación } \\
\text { asintótica } \\
\text { (bilateral) }\end{array}$ \\
\hline Sí & $63,2 \%(129)$ & $65,7 \%(69)$ & $64,1 \%(198)$ & 0,185 & 1 & $>0,05$ \\
\hline No & $7,4 \%(15)$ & $12,4 \%(13)$ & $9,1 \%(28)$ & 2,172 & 1 & $>0,05$ \\
\hline A veces & $29,4 \%(60)$ & $21,9 \%(23)$ & $26,9 \%(83)$ & 1,988 & 1 & $>0,05$ \\
\hline Total $(\mathbf{n})$ & 204 & 105 & $100 \%$ & & & \\
\hline
\end{tabular}


El modelo debería ser diferente al menos para algunas situaciones concretas (tipo de paciente) según el $85 \%$ de los profesionales (172) y el 51\% de los estudiantes (51). Ver tabla 26 . Sólo los estudiantes en un pequeño número indicaron que podía ser V. Henderson (6 estudiantes) o D. Orem (1 estudiante). Los profesionales no indicaron ninguno. Si unificamos los porcentajes de "si" y "a veces", obtenemos que el $86 \%$ de los profesionales lo creen necesario frente a un $49 \%$ de los estudiantes (valor chi-cuadrado de 47,824, gl 1, p<0,01).

Tabla 26: Opinión sobre la aplicación de un modelo diferente en función del tipo de paciente

\begin{tabular}{|l|c|c|c|c|c|c|}
\hline & Profesional & Estudiante & Total & $\begin{array}{l}\text { Valor } \\
\text { Chi- } \\
\text { cuadrado }\end{array}$ & gl & $\begin{array}{l}\text { Significación } \\
\text { asintótica } \\
\text { (bilateral) }\end{array}$ \\
\hline No & $0,5 \%(1)$ & $35,6 \%(37)$ & $12,5 \%(39)$ & 80,111 & 1 & $<0,01$ \\
\hline A veces & $74,5 \%(149)$ & $31,7 \%(33)$ & $59,9 \%(182)$ & 47,452 & 1 & $<0,01$ \\
\hline Sí & $11,5 \%(23)$ & $17,6 \%(18)$ & $13,5 \%(41)$ & 2,746 & 1 & $>0,05$ \\
\hline No lo sé & $13,5 \%(27)$ & $15,4 \%(16)$ & $14,1 \%(43)$ & 0,200 & 1 & $>0,05$ \\
\hline Total (n) & 200 & 104 & & & & \\
\hline
\end{tabular}

En cuanto a la posibilidad de que los registros usados en la CSPT en el momento del estudio permitan trabajar bajo un modelo teórico, la mayoría de los profesionales refieren que no lo permiten. Los resultados hallados en el tema se encuentran en la tabla 27.

Tabla 27: Utilidad de los actuales registros para trabajar bajo un modelo teórico enfermero

\begin{tabular}{|l|c|c|c|c|c|c|}
\hline & Profesional & Estudiante & Total & $\begin{array}{l}\text { Valor } \\
\text { Chi- } \\
\text { cuadrado }\end{array}$ & gl & $\begin{array}{l}\text { Significación } \\
\text { asintótica } \\
\text { (bilateral) }\end{array}$ \\
\hline Sí & $16,6 \%(32)$ & $46,9 \%(46)$ & $26,8 \%(78)$ & 30,532 & 1 & $<0,01$ \\
\hline No & $62,7 \%(121)$ & $26,5 \%(26)$ & $50,5 \%(147)$ & 34,005 & 1 & $<0,01$ \\
\hline A veces & $20,7 \%(40)$ & $26,5 \%(26)$ & $22,7 \%(66)$ & 1,249 & 1 & $>0,05$ \\
\hline Total (n) & 193 & 98 & & & & \\
\hline
\end{tabular}

Por último se les cuestionó por la posibilidad de escoger un modelo teórico para la práctica y el motivo de dicha elección. En este caso, al menos el 50\% de los encuestados optó por dar respuesta. Siendo los profesionales los que contestaron en menor proporción. Los datos cuantitativos de las respuestas se recogen en la figura 8.

Se hallaron diferencias estadísticamente significativas entre todos los porcentajes de elección $(p<0,01)$. El 35,3\% (72) de los profesionales eligieron V. Henderson respecto al 51,4\% (54) de los estudiantes. El 43,9\% (89) de los profesionales dejaron la pregunta en blanco ante el $27,6 \%$ (29) de los estudiantes. Es importante identificar que sólo un 16,7\% (34) de los profesionales no querían trabajar bajo un modelo enfermero frente al 1,9\% (2) de los estudiantes. Cuatro estudiantes $(3,8 \%)$ optaron por Sor Callista Roy y $2(1,9 \%)$ por H. Peplau. Estos modelos no fueron escogidos por los profesionales. El 4,4\% (9) de los profesionales indicó en texto libre respuestas 
como "Nightingale", "NANDA", "Gordon", "Orem", "paradigmas", "diagnósticos" y "necesidades". En los estudiantes este porcentaje fue del 13\% (14 estudiantes) incluyendo respuestas del tipo "Marjory Gordon", "PAE", "enfermería de roles" y "enfermería humanista”.

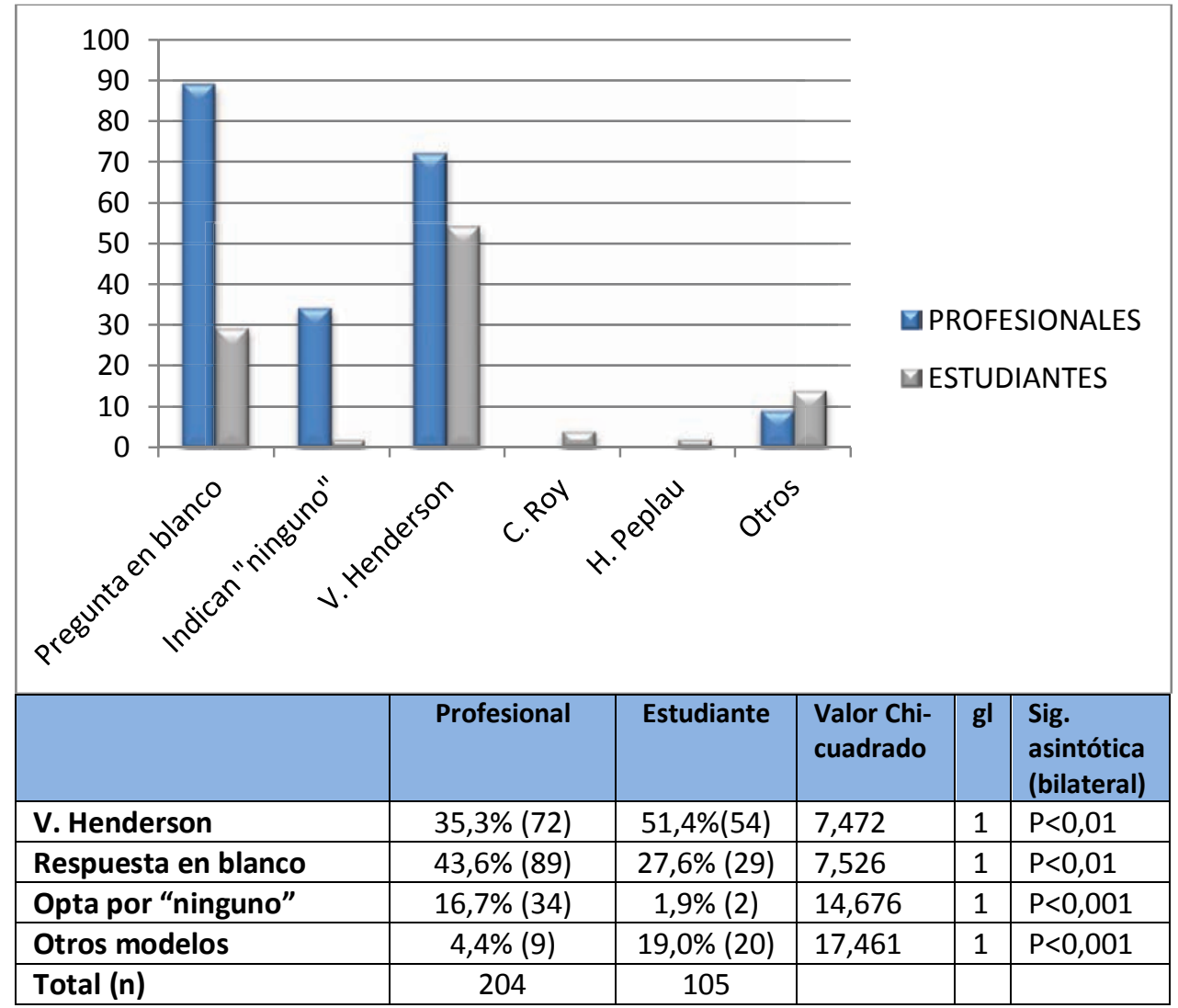

Figura 8: Modelo propuesto por los profesionales y estudiantes para trabajar en la atención asistencial

En cuanto a los datos cualitativos hallados en esta pregunta, indicar que éstos tras su lectura repetida fueron clasificados en base a 4 categorías de elección (V. Henderson, C. Roy, respuesta en blanco y otros). A su vez se elaboraron subcategorías en relación a las expresiones verbales usadas en la argumentación de las diferentes elecciones, hallándose 5 subcategorías. La subcategoría 1 se refiere a los comentarios relacionados con la elección del modelo por las características del mismo para el cuidado. Son aquellos comentarios que hablan del modelo en general, pero que indican que finalidad tiene el modelo, cómo se aplica, conceptos clave de las autoras de los modelos, etc. Ejemplos de esta categoría son "trabaja con las necesidades básicas" (CP78) o "introduce rol autónomo del paciente" (CP78). La subategoría 2 son los adjetivos relacionados con la elección del modelo por su utilidad e incluye expresiones que indican claramente cualidades de los modelos elegidos. Algunos de los textos incluidos en esta categoría son "claro" (CP187), "sen- 
cillo" (CP188), "bien definido" (CP78). La subcategoría 3 se refiere a los comentarios relacionados con la elección del modelo por preferencias personales y son aquellas expresiones que hacen alusión a las propias preferencias o capacidades de los sujetos encuestados. Comentarios recogidos en esta categoría son "estoy de acuerdo" (CP42), "con el que más familiarizada estoy" (CP142). La subcategoría 4 recoge aquellos comentarios relacionados con la elección del modelo por la formación recibida y engloba comentarios asociados a la etapa formativa ya sea universitaria o no. En este caso se recogen expresiones como por ejemplo "usaba en mi universidad" (CP112), "estudios en la universidad" (CP75). Por último, la subcategoría 5 es la que incluye otras expresiones que por su gran diversidad no pudieron ser catalogadas en un apartado único. Toda esta miscelánea fue incluida en esta categoría. La totalidad de expresiones recogidas se hallan en el anexo IV del CD adjunto.

Tras categorizar las expresiones verbales, se realizó un diagrama explicativo o mapa conceptual para exponer la elección de un modelo concreto de actuación y clarificar qué motivos son los que les hacen a profesionales y estudiantes decidirse por un modelo en concreto. Los datos en referencia al modelo elegido y los factores relacionados se resumen en las figuras 9 y 10.

Cuando se les cuestiona a los profesionales sobre el por qué escogen un modelo o metodología a pesar de obtener algunas respuestas en blanco, en cada una de las categorías analizadas, destacan los que la elección precisa viene dada principalmente por conocimiento del modelo en su formación, por la estandarización del modelo ya en otros centros sanitarios (experiencia más o menos demostrada del modelo), porque piensan que es el que mejor se adapta a las unidades de trabajo, por las propias características del modelo y/o por la identificación de los profesionales con la filosofía del mismo.

Los que no se deciden por un modelo lo atribuyen al desconocimiento, a creer que son poco prácticos, que necesitan mucho tiempo para ser desarrollados, que no existe el ideal, o porque creen que tienen la posibilidad de combinar varios. Además, creen que no son adecuados en la práctica y que carecen de utilidad.

Destacar que, el espacio destinado para responder esta pregunta fue utilizado por los profesionales, en alguna ocasión, para describir situaciones particulares como la falta de tiempo, cargas excesivas de trabajo y disconformidad con los superiores.

En el caso de los estudiantes al elegir un modelo teórico enfermero para su futura práctica, indican principalmente que lo hacen por ser el modelo usado en su formación universitaria y por la facilidad para su aplicación. En concreto, mayoritariamente optan por el modelo de V. Henderson porque indican que engloba completamente el cuidado a la persona mediante la valoración de sus catorce necesidades, por ser holístico. No obstante, indican de la misma manera, que les gustaría tener mayor formación sobre el tema. Quienes dejan la pregunta en blanco (se 
desconoce si es sinónimo de indicar "ninguno"), en su mayoría no indican el porqué de su abstención. En un pequeño número, indican que no optan por un modelo ya que señalarían uno en concreto según las características de la persona a cuidar o prefieren la combinación de varios para la práctica.

Existe un número importante de estudiantes que optan por metodologías de trabajo y no por modelos enfermeros, aunque no indican que la opción elegida no sea un modelo enfermero. Entre opciones que no son modelos se escoge el uso de los patrones funcionales de Marjory Gordon o la NANDA porque es el método o guía que orientó su formación, o el PAE, porque "es estructurado" y "engloba las catorce necesidades".

\section{Resumen de los datos más relevantes para este segundo objetivo:}

Son pocos los profesionales recibieron formación complementaria en relación al tema de modelos (23,5\%). Los estudiantes afirmaron seguir siempre un modelo en su práctica en mayor porcentaje que los profesionales (62,1\% versus $23,3 \%$ ). Ambos grupos vieron como positivo la implantación institucional de un modelo en los centros de trabajo. La mayoría de profesionales y estudiantes manifiestaron que siguen el modelo de V. Henderson en su práctica diaria o desearían hacerlo. Los factores que determinaron su elección fue ser el modelo guía de formación (conocían sus características principales) y porque se identificaban con su filosofía. Aun así ambos grupos manifiestaron un conocimiento limitado en el tema. 


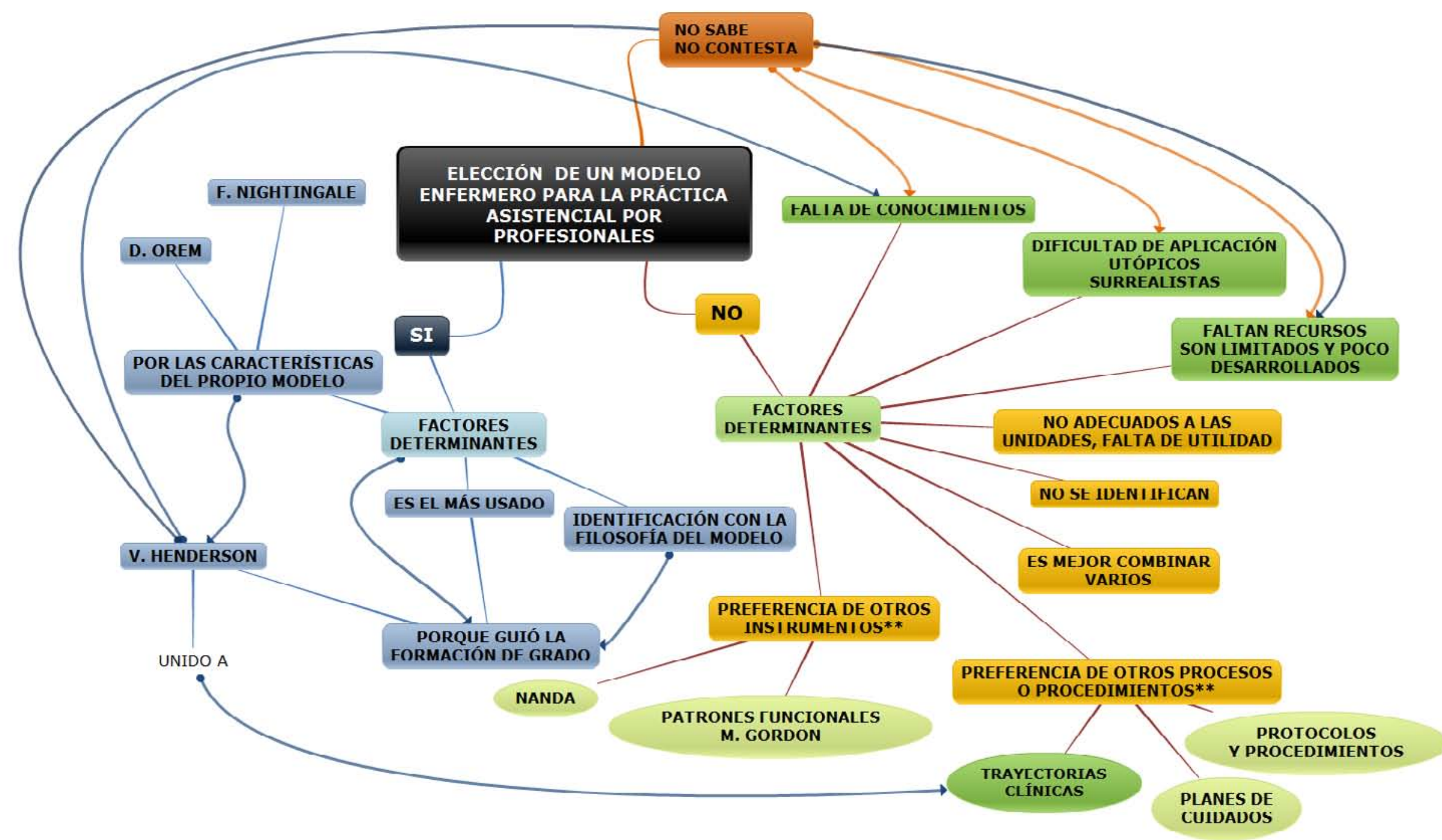

Figura 9: Mapa conceptual de los factores que determinan la elección de un modelo para la labor profesional expresados por los profesionales encuestados 
**Los datos recogidos no son modelos teóricos: posible confusión por los encuestados

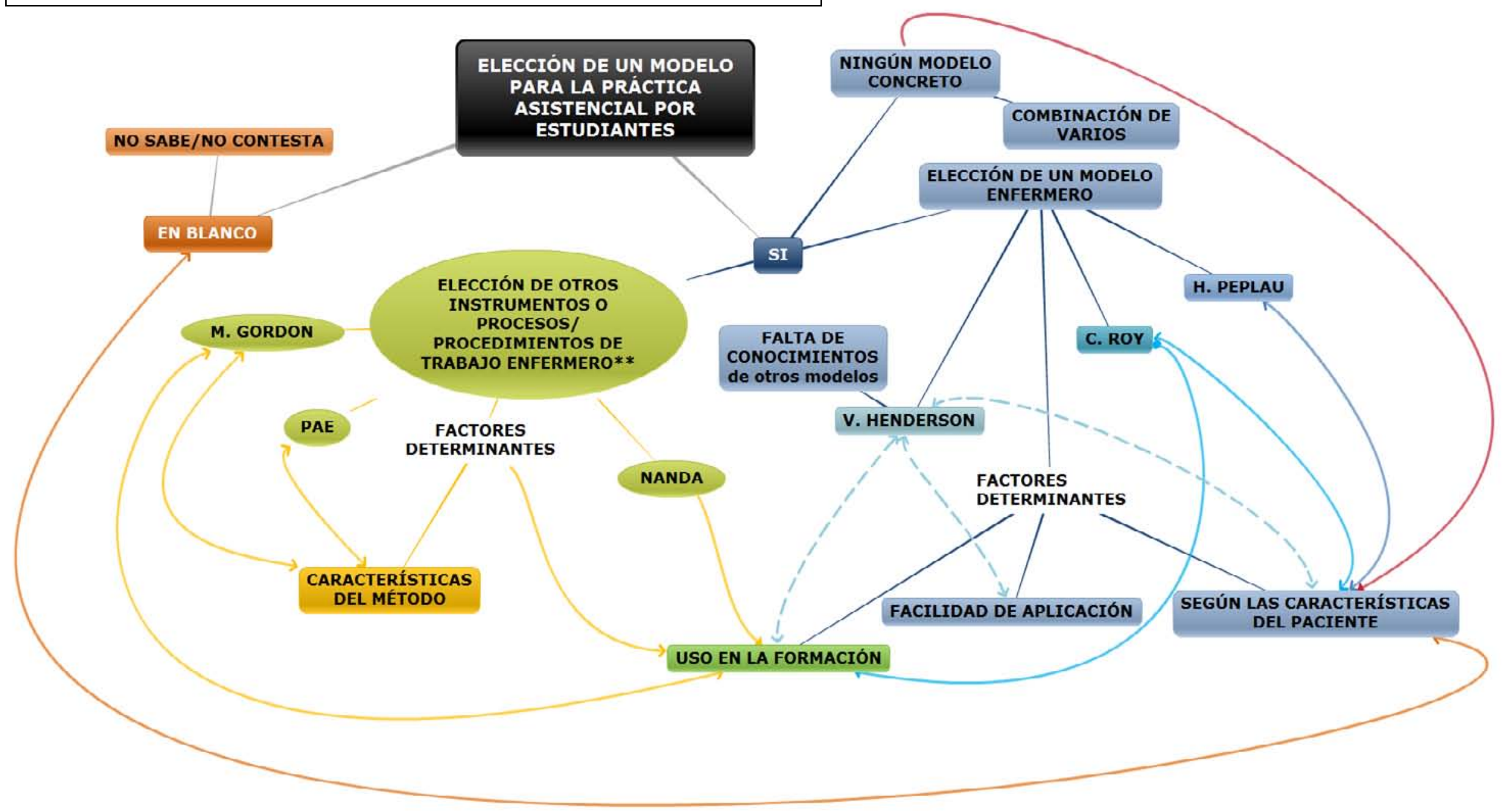

Figura 10: Mapa conceptual de los factores que determinan la elección de un modelo para la labor profesional expresados por los estudiantes encuesta- 


\subsection{Resultados en relación al tercer objetivo: Conocer las ventajas y desventajas percibidas por los profesionales sobre el uso de}

un modelo teórico enfermero para el cuidado.

Para conocer las ventajas y desventajas de la aplicación de un modelo concreto a la práctica (tal y como se expone en la metodología), se les solicitó a los estudiantes que desde su propia experiencia, fuesen capaces de abordar diferentes respuestas a diferentes situaciones de salud en relación a una patología, tras la comprensión profunda de un modelo enfermero. Estos trabajos entregados en formato texto, bien en soporte papel o en archivo informático, son los analizados para el trabajo que aquí se presenta. Los resultados obtenidos tienen gran relación con los factores condicionantes de la aplicación de un modelo teórico en la práctica y van a poner luz no sólo sobre el uso del modelo de V. Henderson, sino sobre otros menos conocidos (de ahí su gran interés). En los trabajos seleccionados, se escogieron aquellos párrafos que tenían relación directa con el uso de los modelos y su aplicación en la práctica y se realizó el análisis de los textos. La búsqueda de variables y el proceso de análisis de los textos se concretan en la figura 11.

Los textos y/o párrafos, se analizaron siguiendo la técnica cualitativa descrita en la metodología de estudio y fueron ordenándose según el significado de su contenido hasta llegar al análisis y reducción de datos final que se presenta siguiendo el esquema explicado.

En la exposición de las categorías y subcategorías que se describirán a continuación para cada modelo analizado en los planes de cuidados se exponen ejemplos de citas textuales como ilustrativas para cada tema o categoría. La totalidad de los escritos textuales que sirvieron para el análisis de los textos en los diferentes procesos, se halla en el anexo IV (recogido en el CD adjunto). Se puede observar que se recogió texto en castellano y en catalán, ya que era el lenguaje utilizado en los trabajos. De esta manera se evitaron cambios o interpretaciones erróneas en el contenido por su traducción. Los textos van acompañados de la letra " $\mathrm{T}$ " (de trabajos) y el número que se le dio en el análisis para ser clasificados.

Destacar que, de todos los planes elaborados, se analizó sólo la crítica al modelo cuando habían más de 10 procesos en los que los alumnos habían realizado una reflexión crítica hacia el mismo, ya que se consideró que un número de análisis inferior aportaría un conocimiento parcial, no asegurando la saturación de datos en relación al modelo concreto estudiado. Por este motivo, fueron descartados los trabajos que aplicaban los modelos de Martha E. Rogers, Lydia Hall, Jean Watson, Rosemarie Parse, Nola Pender, Patricia Benner, Joyce Travelbee, Margaret Newman, 
Roper, Logan y Tierney, Ida J. Orlando Pelletier, Dorothy Johnson, Myra Levine, Faye Abdellah y Merle Mishel. Se presentan finalmente los resultados del análisis de 190 procesos (de los inicialmente 373 disponibles, un 50,9\%) basados en los modelos de V. Henderson, D. Orem, C. Roy, H. Peplau, B. Neuman, I. King y M. Leiniger.

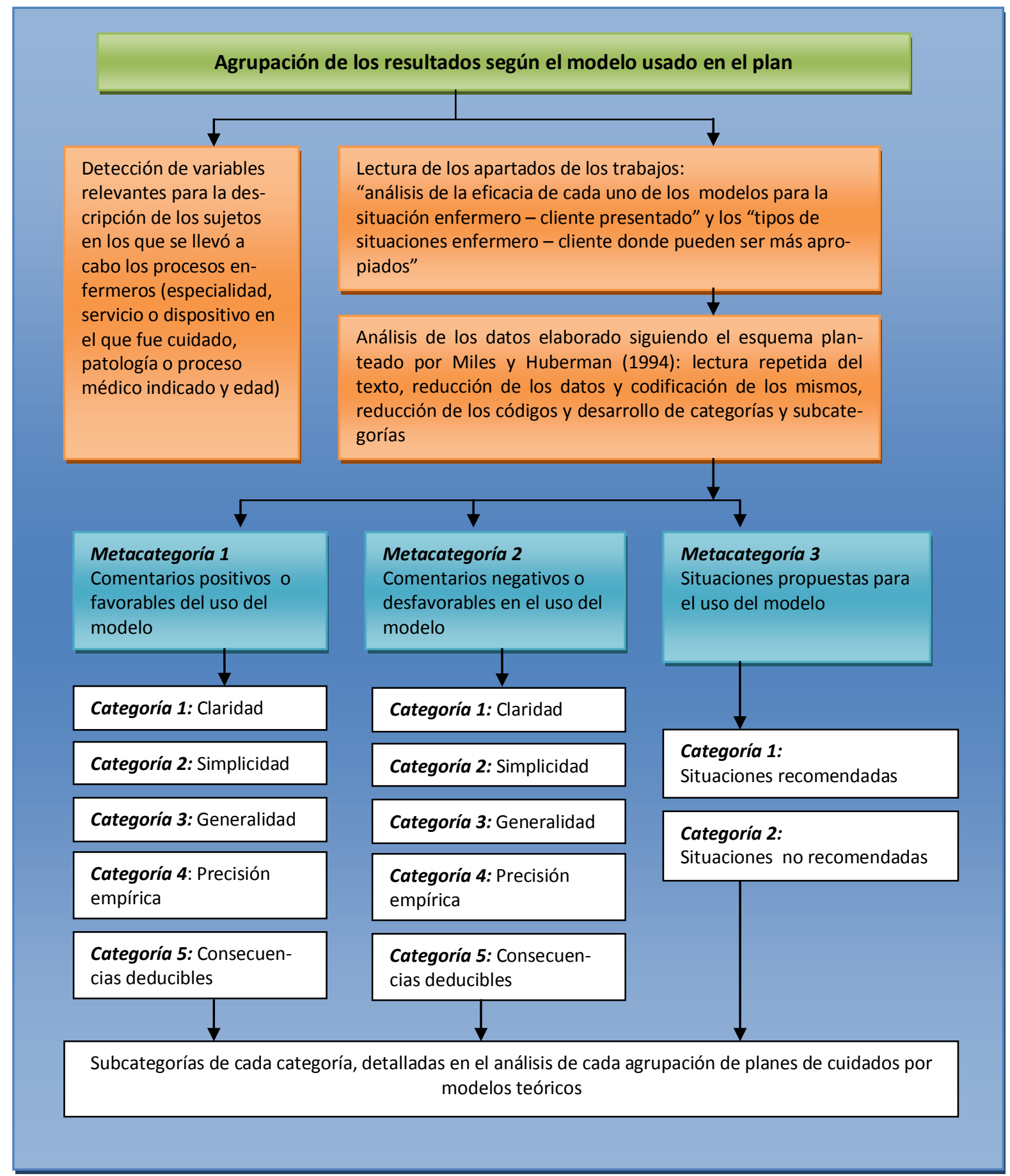

Figura 11: Proceso de análisis de los planes de cuidados 
El perfil de los estudiantes fue diverso en edad, situación familiar, perfil formativo, contexto sanitario, ámbito (asistencial, gestión y docente), años de experiencia laboral y lugar de procedencia (ver tabla 9, extraída de Zabalegui \& Macià, 2010).

A continuación se realizará la descripción de los resultados fragmentados para cada una de las teoristas, siguiendo para cada una de ellas el mismo criterio de análisis y evaluación:

1. Descripción de los sujetos en los que se fue aplicado el plan de cuidados siguiendo el modelo: histograma, edad media, especialidad y patología o proceso médico.

2. Exposición de las situaciones en las que fue recomendado el uso del modelo.

(Pese a que en el trabajo se les indicó que manifestasen en que otras situaciones podría ser aplicado el modelo, muchos de los estudiantes no lo indicaron o incluso indicaron en que situaciones creían que no deberían ser aplicados).

3. Aspectos positivos en relación al modelo aplicado, siguiendo el análisis de las teorías utilizado por Marriner \& Raile, 2003 (adaptado de Chinn \& Kramer, 1998).

4. Aspectos negativos en relación al modelo aplicado, siguiendo el análisis de las teorías propuesto por Marriner \& Raile, 2003 (adaptado de Chinn \& Kramer, 1998).

\subsubsection{ANÁLISIS DE LOS TRABAJOS EN RELACIÓN AL USO DE VIRGINA HENDERSON EN LA PRÁCTICA}

\subsubsection{Descripción de los sujetos en los que fue aplicado el plan de cuidados siguiendo el modelo de V. Henderson}

Se hallaron un total de 75 trabajos que usaron la aplicación del modelo de Virginia Henderson en sus procesos. De éstos, 49 fueron escogidos para el análisis. La media de edad de los sujetos en los que fueron aplicados era de 54,5 \pm 17,3 años (el menor tenía 16 años y el mayor 91 años). Ver figura 12. La especialidad médica a la que pertenece el paciente y su patología o proceso médico recogido en el proceso enfermero se resume en la tabla 28. 
Tabla 28: Características de los pacientes en los que fue aplicado el modelo de V. Henderson para la elaboración del proceso enfermero.

\begin{tabular}{|c|c|c|c|}
\hline Especialidad médica & Situación de salud planteada & Edad & $\begin{array}{l}\text { Código } \\
\text { del } \\
\text { trabajo }\end{array}$ \\
\hline \multirow{10}{*}{$\begin{array}{l}\text { Atención domiciliaria y Cen- } \\
\text { tro de Atención Primaria }\end{array}$} & Accidente Vascular Cerebral (AVC) & 91 & $\mathrm{T70}$ \\
\hline & Seguimiento Diabetes Mellitus (DM) & 60 & T13 \\
\hline & Seguimiento DM. Abandono de tratamiento & 58 & T14 \\
\hline & Seguimiento DM. Pérdida visual & 66 & T57 \\
\hline & Control post AVC & 59 & T1 \\
\hline & Cuidador paciente con demencia & 71 & T9 \\
\hline & Cuidador paciente con demencia & 50 & T71 \\
\hline & Seguimiento adolescencia & 16 & T103 \\
\hline & $\begin{array}{l}\text { Esclerosis Lateral Amiotrófica. Cura estoma catéter } \\
\text { gastrostomía percutánea }\end{array}$ & 55 & T107 \\
\hline & Anorexia nerviosa & 18 & T116 \\
\hline \multirow{6}{*}{ Cardiología } & Ángor & 35 & T15 \\
\hline & Ángor & 64 & T59 \\
\hline & Infarto Agudo de Miocardio (IAM) & 52 & T17 \\
\hline & Pericarditis & 66 & T99 \\
\hline & Colocación prótesis mitral & 45 & T4 \\
\hline & Colocación prótesis mitral & 54 & T18 \\
\hline \multirow{9}{*}{$\begin{array}{ll}\text { Cirugía: } & \\
- & \text { Digestiva } \\
- & \text { Vascular } \\
\text { - } & \text { Traumatológica } \\
\text { - } & \text { Urología } \\
& \text { ORL }\end{array}$} & Trasplante hepático & 54 & T120 \\
\hline & Neo colon-Colostomizado & 61 & T5 \\
\hline & Neo colon-Colostomizado & 37 & T12 \\
\hline & Resección gástrica & 61 & T10 \\
\hline & $\begin{array}{l}\text { Úlceras en ambas extremidades inferiores sobrein- } \\
\text { fectadas }\end{array}$ & 62 & T54 \\
\hline & Traumatismo Craneoencefálico por accidente & 26 & T2 \\
\hline & Accidente tráfico con fracturas varias & 24 & T55 \\
\hline & Neo de Próstata & 60 & T115 \\
\hline & Neo de laringe. Laringuectomía & 53 & T100 \\
\hline Medicina Interna & Coma y debut DM & 45 & T121 \\
\hline Neumología & Enfermedad Pulmonar Obstructiva Crónica (EPOC) & 89 & T109 \\
\hline \multirow{3}{*}{ Neurología } & AVC & 76 & T97 \\
\hline & AVC & 68 & T118 \\
\hline & AVC. Síndrome de cautiverio. Traqueostomía & 54 & T91 \\
\hline \multirow{3}{*}{ Oncología } & Neo pulmón & 70 & T3 \\
\hline & Neo pulmón & 46 & T16 \\
\hline & Neo de Mama. Mastectomía (IQ) & 62 & T67 \\
\hline \multirow{4}{*}{ Salud Mental } & Anorexia nerviosa & 23 & T11 \\
\hline & Trastorno Psicótico. Nigeriana & 35 & T94 \\
\hline & Trastorno bipolar & 53 & T110 \\
\hline & Desintoxicación cocaína & 30 & T111 \\
\hline $\begin{array}{l}\text { Unidad de Reanimación } \\
\text { Post- Anestésica (URPA) }\end{array}$ & Duodenopancrectomía & 51 & $\mathrm{~T} 112$ \\
\hline \multirow{2}{*}{ Residencia y larga estancia } & Demencia & 79 & T122 \\
\hline & Alzheimer & 77 & T68 \\
\hline \multirow{2}{*}{$\begin{array}{l}\text { Servicio de Emergencias } \\
\text { Médicas (SEM) }\end{array}$} & AVC & 80 & T104 \\
\hline & Cardiopatía isquémica & 68 & T90 \\
\hline \multirow{3}{*}{$\begin{array}{l}\text { Unidad de Cuidados Intensi- } \\
\operatorname{vos}(\mathrm{UCl})\end{array}$} & IAM & 50 & T6 \\
\hline & Ángor & 38 & T117 \\
\hline & $\begin{array}{l}\text { Edema Agudo de Pulmón. Insuficiencia renal (termi- } \\
\text { nal) }\end{array}$ & 49 & T123 \\
\hline
\end{tabular}




\begin{tabular}{|l|l|l|l|}
\hline \multirow{2}{*}{ Especialidad médica } & Situación de salud planteada & Edad & $\begin{array}{l}\text { Código } \\
\text { del } \\
\text { trabajo }\end{array}$ \\
\hline \multirow{2}{*}{ Urgencias (UCIAS) } & Fractura cúbito y radio. Acude por dolor posterior & 46 & $\mathrm{~T} 7$ \\
\cline { 2 - 5 } & Disnea & 65 & $\mathrm{~T} 8$ \\
\cline { 2 - 4 } & EPOC agudizada & 57 & T66 \\
\hline $\begin{array}{l}\text { Unidad de Cuidados Paliati- } \\
\text { vos (UCP) }\end{array}$ & Neo de Próstata. Terminal & 64 & T108 \\
\hline
\end{tabular}

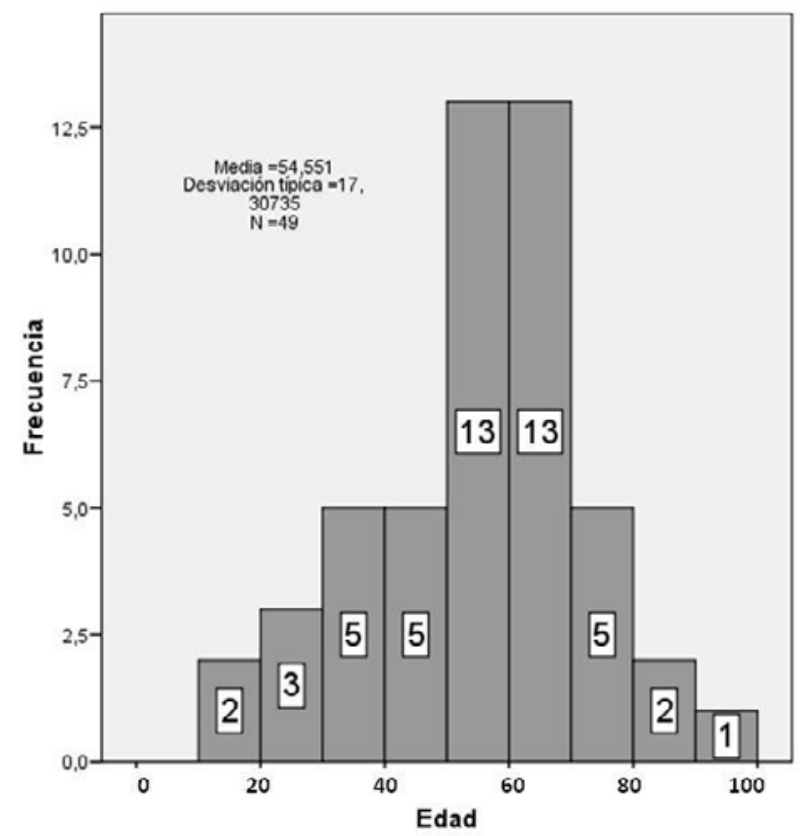

Figura 12: Histograma de la distribución por edades de los pacientes a los que se aplicó el modelo de $V$. Henderson en el plan de cuidados

\subsubsection{Situaciones para las que fue recomendado el modelo de V. Henderson}

El modelo de V. Henderson fue recomendado para diferentes situaciones o procesos, sin embargo su sugerencia en la mayoría de los casos fue poco fundamentada. Quizás en las recomendaciones que se registraron mayores argumentos fueron en su indicación en procesos agudos y crónicos con seguimiento en atención primaria o domiciliaria.

("Es más aplicable a nivel clínico por su rapidez de aplicación... atiende las necesidades

fisiológicas que son las predominantes en las fases agudas tratadas en las unidades hospitalarias", "Cualquier persona que sufra un cuadro agudo, generalmente se podría aplicar en instituciones cerradas", "pacientes crónicos que necesitan atención domiciliaria continuada... en este caso las actuaciones de enfermería necesitarían más apoyo por parte de que las personas que le rodeen y la colaboración de la familia")

También se recomendó su uso en salud mental y para la atención a las adicciones. 
("pacientes con problemas de salud mental", "alcohólicos")

Aunque algunos estudiantes no estuvieron de acuerdo con tal recomendación.

(“...aunque con los pacientes psiquiátricos es más difícil de aplicar excepto la promoción de la salud", "...no son de la suficiente eficacia en el campo de la psiquiatría ya que este modelo no abarca con suficiente profundidad y relevancia los aspectos psicológicos").

Del mismo modo, controversia generó su uso en unidades de atención al paciente crítico como urgencias o la unidad de cuidados intensivos.

("...se puede aplicar en los servicios de urgencias (Inter o extra hospitalarios)", "Situación de urgencias, actuación rápida" "UCl... en unidades donde los patrones fisiológicos cambian con mucha rapidez", "...se pueden excluir los servicios de urgencias y cuidados intensivos")

Algunos estudiantes aconsejaron el uso del modelo en lugares de larga estancia y cuidados en la última etapa de la vida. Y ya con una frecuencia mucho menor, fue recomendado en pediatría, para la docencia y la investigación. Varios estudiantes indicaron que era un modelo aplicable en cualquier ámbito por su generalidad.

("puede aplicarse en cualquier contexto... cierta continuidad en el tiempo... porque hay necesidades que se valoran con unos días de contacto y los objetivos que se planifican pueden ser a largo plazo").

\subsubsection{Aspectos positivos de la aplicación de modelo de V. Henderson}

Las reflexiones positivas hacia el modelo de V. Henderson se resumen en considerar que en cuanto a la claridad, fue considerado un modelo claro y sencillo.

("Ias necesidades son muy claras y están perfectamente definidas...más fácil de entender y aplicar " (T1), “...lenguaje mucho más asequible (T55)”).

En referencia a la simplicidad los estudiantes argumentan que facilitaba la valoración a través de las necesidades básicas.

("simplifica la etapa de valoración...permite que a lo largo de la asistencia distintos profesionales puedan completar la valoración" (T1), "(alteración del patrón del sueño) el esquema de valoración de necesidades básicas determina con rapidez y precisión a 
partir del análisis de las manifestaciones de dependencia...se fijan objetivos y se planifican cuidados a partir de la detección de la fuente de dificultad"(T12)).

Además el modelo clarificaba las acciones a realizar por la enfermera y evaluaba el proceso o intervención enfermera, incluso para las personas que habitualmente no hacen un seguimiento continuado del paciente.

("más rápido y organizado... no se suelen escapar las cosas importantes... la experiencia como enfermera volante... para este tipo de profesionales es muy difícil seguir un modelo... con Henderson podría ser muy asequible ..."(T3), "expone de forma clara el rol autónomo de la enfermera"(T9)). ("...los resultados son eficaces y legitiman la acción enfermera"(T121)).

Si analizamos la generalidad del modelo, vemos que según los estudiantes era un modelo completo y universal, aplicable a un gran número de diversidad de pacientes, incluyendo incluso la variable cultural.

("abarca todas las funciones posibles de la enfermería" (T117), "seguimiento exhaustivo de todo lo que el enfermo precisa"(T123), "se puede aplicar a cualquier paciente, ya que la enfermedad va unida a necesidad"(T1), "Ia situación teorética del modelo es muy abierta y permite adoptarlo a las variantes culturales y sociales específicas de cada entorno y situación de cuidados... resulta coherente con nuestros valores culturales"(T107)).

En cuanto a la precisión empírica era un modelo adaptable, adecuado y útil a diferentes situaciones planteadas. Las situaciones en las que fue indicado el uso del modelo como resolutivo de forma explícita por los alumnos fueron: en un paciente en control posterior a un AVC en atención primaria (T1), paciente en cirugía vascular con úlceras en ambas extremidades inferiores sobreinfectadas (T54), paciente con neo de colon colostomizado ingresado en cirugía (T5), paciente con disnea en urgencias (T8), cuidador de paciente con demencia seguido en atención primaria (T9), paciente con ángor en unidad de cardiología (T59), paciente con cardiopatía isquémica atendido por el SEM (T90), paciente con ángor en UCI (T117), paciente con IAM en cuidados intensivos (T6), paciente en cardiología que ingresa para colocación de prótesis mitral (T18),paciente con EPOC en neumología (T109) y paciente con neo de próstata ingresado en urología (115).

("nos permite elegir las necesidades que según cada caso sean más prioritarias" (T1), "se adapta a nuestra realidad sociosanitaria...filosofía eficaz y ha resuelto de forma 
satisfactoria la situación de salud" (T9), "ha solucionado el problema del paciente..."(T54) , "más apropiado para nuestro trabajo...ya que orienta nuestros cuidados a la búsqueda de necesidades básicas alteradas en el paciente, que es a priori nuestro objetivo por ser una situación de emergencias" (T90), "Ia aplicación del modelo... a nuestra situación enfermero cliente no ha sido difícil de realizar" (T109) ).

Acerca de las consecuencias deducibles, el desarrollo del modelo en la atención potenciaba el papel de la persona en el cuidado, mejoraba la comunicación inter y multidisciplinar y consideraba el entorno familiar. Su utilidad también fue argumentada por los estudiantes a su fácil accesibilidad y comprensión por ser el modelo más usado, conocido y trabajado en España.

("Concha no pudo participar... si el marido, a través de la entrevista con él se evidencian sus propias dependencias... permite la reconversión de Concha y su marido en receptores de cuidados" (T122), "reconocimiento del potencial de la persona para cambiar, para afrontar, y para interrelacionarse con los demás y su entorno... propicia la toma de conciencia de las ventajas de desarrollar un estilo de vida sano y de mejorar o mantener un entorno saludable al afirmar que la persona / familia actúa como agente de sus propios cuidados... reconocimiento del potencial de la persona para cambiar , para afrontar, y para interrelacionarse con los demás y su entorno...propicia la toma de conciencia de las ventajas de desarrollar un estilo de vida sano y de mejorar o mantener un entorno saludable al afirmar que la persona / familia actúa como agente de sus propios cuidados" (T107), "Ia elaboración y el registro del mismo facilita la comunicación con otros miembros del equipo de salud... familiar entre los profesionales... a lo largo de la Diplomatura he elaborado PAE basados en el modelo de Henderson....en mi vida laboral he seguido trabajando con su modelo" (T2)).

Además, según los estudiantes era un modelo adaptable al plan de cuidados enfermero, costo - eficaz, que permitía ser usado unido a metodología enfermera y/o taxonomía NANDA y por lo tanto unificaba criterios entre los profesionales.

("...plan de cuidados individualizado e interdisciplinario" (T2), "requiere menos inversión de tiempo...más ágil" (T1), "permite detectar con rapidez los problemas que se presentan", "ha demostrado validez y eficacia... mayor facilidad de aplicabilidad"(T18), "...no he encontrado ninguna dificultad en aplicar las alteraciones en el paciente a los diagnósticos de la NANDA... tampoco... a la hora de la aplicación del Proceso de Atención de Enfermeria (T116)", "a supuesto al menos, en la mayoría de centros sanitarios y profesionales se unificaran algunos criterios"(T104)). 


\subsubsection{Aspectos negativos en relación a la aplicación del modelo de V. Henderson}

No fueron muchos los alumnos que hicieron comentarios negativos respecto al modelo. Algunos estudiantes lo tacharon de confuso con respecto a la claridad y complejo en cuanto a la simplicidad, sobre todo en el caso de aparecer dependencia en el paciente.

("su diagrama de representación es gráfico y visual pero poco útil" (T111), "el hecho de repasar las 14 necesidades básicas reviste cierta complejidad cuando se produce una alteración de la necesidad y se consideran todos los parámetros relacionados con la misma" (T109)).

En cuanto a la generalidad argumentan que es limitado, con una visión parcial biomédica tradicional ligada a la enfermedad.

("enfoque biomédico y también físico...su objetivo es la enfermedad" (T71), "asume que la investigación en enfermería debería dirigirse más al campo de la medicina" (T120)).

Con respecto a la precisión empírica, algunos estudiantes no encontraron su aplicabilidad en los casos o situaciones propuestas, concretamente hallaron problemas al aplicar el modelo sobre pacientes en el servicio de urgencias por la intensidad rápida del cuidado sobre sólo los elementos físicos vitales y en salud mental por la falta de colaboración del paciente.

\section{("...hay necesidades en las que no vamos a intervenir desde la emergencia, como la de vestirse, el reposo y sueño, trabajar y realizarse, actividades lúdicas... serían abarcados desde otros niveles (T90)", "per un cas com el que estem tractant... és correcte però no dona una resposta final al problema... a nivell de psiquiatria és difícil d'actuar en base a la seva teoria ja que... és necessària la intervenció del pacient en el seu procés d'estabilització"(T110)).}

Asimismo en el análisis por consecuencias deducibles, muchos de los estudiantes comentaron que era un modelo incompleto, ya que, la valoración estaba centrada sobre todo en necesidades fisiológicas.

("Ias principales necesidades que hay tipificadas son principalmente las fisiológicas... en el caso de que el profesional de enfermería considere importante otra necesidad... deberá anotarla y desarrollarla en el apartado observaciones de enfermería" (T1), "si consideramos el conjunto de las 14 necesidades... se centran en aspectos físicos... demasiado énfasis en aspectos físicos... la valoración que hace del cliente.. .falte la percepción por parte del paciente" (T54)). 
Además cuando se aplicaba el modelo, los alumnos refirieron que el mismo no consideraba la comunidad, grupo social o entorno. Pese a que el modelo habla de la familia, parece no dejar claro según los estudiantes el cómo abordar a la misma.

("se centra en la clínica...no trata las relaciones con el grupo o comunidad" (T2), "apenas contempla el elemento entorno, como elemento que interactúa con la persona" (T4), ("aunque su definición contempla a la familia, no define como se puede actuar para que la familia contemple las necesidades del paciente"(T91)).

Lo tildaron de reduccionista sobre todo en cuanto a su definición de salud como sinónimo de independencia, este razonamiento les llevó a pensar que el paciente crónico parecía no tener espacio para el uso del modelo en su cuidado.

("Ia definición de salud es limitada...salud=independencia, enfermedad=dependencia, "deja un hueco en los pacientes crónicos... poder calificarlo como diabético sano, ya que según Henderson nuestro paciente va a depender siempre de la enfermería...cronifica a los crónicos" (T4)).

Por otro lado creen que les requería largo tiempo de implementación y lo describieron como reiterativo en la valoración de las necesidades.

("valoración de las 14 necesidades sea muy larga" (T71), "demasiado repetitivo...hay necesidades que se solapan" (T55)).

Los estudiantes encontraron que se centra demasiado en la función enfermera y no en la participación de la persona cuidada, llegando a hacer comentarios de que era un modelo paternalista.

("atención paternalista" (T70), "no propuso intervenciones distintas a la del papel de sustituto. Por tanto esta perspectiva parece entrar en contradicción con el concepto de independencia"(T120)).

\subsubsection{ANÁLISIS DE LOS TRABAJOS EN RELACIÓN AL USO DE DOROTHEA E. OREM EN} LOS PROCESOS ENFERMEROS

\subsubsection{Descripción de los sujetos en los que fue aplicado el plan de cuidados siguiendo} el modelo de D. Orem

De la totalidad de los trabajos recogidos, 66 utilizaron a Dorothea E. Orem para el desarroIlo del proceso enfermero. De estos se analizaron sólo 43 que eran los que presentaron 
comentarios reflexionados hacia la aplicabilidad del modelo, el resto fueron descartados para el estudio. El modelo fue aplicado en pacientes con una edad media de 54,7 $\pm 23,4$ (sujeto menor: 2 años, sujeto mayor 98). Ver figura 13. Las especialidades médicas y patologías de las personas en las que fue aplicado el modelo se resumen en la tabla 29.

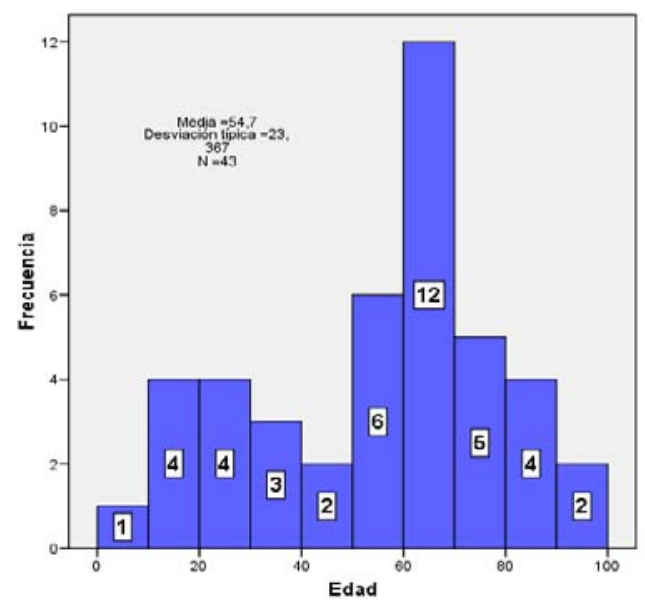

Figura 13: Histograma de la distribución por edades de los pacientes a los que se aplicó el modelo de D. Orem en el plan de cuidados

\subsubsection{Situaciones para las que fue recomendado el uso del modelo de D. Orem}

El modelo de Orem fue recomendado tanto para situaciones agudas en hospital como situaciones de recuperación posterior o prevención terciaria. Así como, en casos de patología crónica y seguimiento en primaria, en el proceso del embarazo y en el abordaje de adolescentes. Sobre todo se hizo alusión a todos aquellos procesos que requerían de un aprendizaje de autocuidado por la relevancia del mismo dentro del modelo.

("procesos quirúrgicos en los que necesita adquirir unas habilidades de autocuidado...", "consulta de enfermería de pacientes con patología crónica", "atención primaria...sistema de apoyo educativo y parcialmente compensatorio", "cuando un paciente presenta déficit de AC tales como: una relación de cuidado dependiente de un niño, cuidados a pacientes psiquiátricos, pacientes con diabetes... ictus...", "con limitaciones físicas...donde la evolución del paciente permita recuperar al máximo sus capacidades e incrementar la independencia y la autoestima", "incumplimiento terapéutico", "superado el momento agudo de la enfermedad... para poder llegar a ser lo más autosuficiente de cara a su reinserción social", "joven con debut DM"). 
De la misma manera se vio adecuado en el cuidado de personas con alto grado de dependencia y centros de larga estancia, ya que los largos periodos de ingreso facilitaban según ellos, la aplicación del modelo.

\section{("ya que el paciente permanece el tiempo suficiente para que los problemas}

encontrados o las necesidades puedan ser intervenidas en contra de lo que ocurre en las emergencias").

Tabla 29: Características de los pacientes en los que fue aplicado el modelo de D. Orem para la elaboración del proceso enfermero.

\begin{tabular}{|c|c|c|c|}
\hline Especialidad médica & Situación de salud planteada & Edad & $\begin{array}{l}\text { Código del } \\
\text { trabajo }\end{array}$ \\
\hline \multirow{9}{*}{$\begin{array}{l}\text { Atención Domiciliaria y Cen- } \\
\text { tro de Atención Primaria } \\
\text { (CAP) }\end{array}$} & Seguimiento DM. Hipertensión arterial (HTA) & 62 & $\mathrm{~T} 22$ \\
\hline & Seguimiento DM. Pérdida visual & 66 & T57 \\
\hline & Seguimiento DM & 60 & $\mathrm{~T} 72$ \\
\hline & Seguimiento DM & 19 & T85 \\
\hline & Seguimiento AVC & 91 & T70 \\
\hline & $\begin{array}{l}\text { Control de herida quirúrgica post histerec- } \\
\text { tomía }\end{array}$ & 36 & T24 \\
\hline & Control HTA. Mal cumplidor & 66 & T80 \\
\hline & $\begin{array}{l}\text { Seguimiento y control niño sano (adolescen- } \\
\text { cia) }\end{array}$ & 16 & T103 \\
\hline & $\begin{array}{l}\text { Seguimiento tras Prótesis Total de Cadera } \\
\text { (PTC) }\end{array}$ & 80 & T60 \\
\hline \multirow{2}{*}{ Hospitalización Cardiología } & Ángor & 64 & T59 \\
\hline & Pericarditis & 66 & T99 \\
\hline Consultas externas (CCEE) & $\begin{array}{l}\text { Seguimiento DM gestacional (Paciente de } \\
\text { etnia gitana) }\end{array}$ & 16 & T86 \\
\hline \multirow{10}{*}{$\begin{array}{ll}\text { Hospitalización Cirugía } \\
\bullet & \text { General } \\
- & \text { Digestiva } \\
\cdot & \text { Vascular } \\
- & \text { Urología } \\
- & \text { Traumatología (COT) }\end{array}$} & Neo colon. Colostomizado & 61 & T21 \\
\hline & Neo colon. Colostomizado & 80 & T83 \\
\hline & Neo colon. Colostomizado & 45 & T88 \\
\hline & Neo laringe. Laringuectomía & 62 & T75 \\
\hline & $\begin{array}{l}\text { Síndrome de Wilson. Desbridamiento Ulcera } \\
\text { por presión (UPP) en trocánter. Traqueosto- } \\
\text { mizado. }\end{array}$ & 27 & T81 \\
\hline & Neo mama. Mastectomía & 35 & T52 \\
\hline & Neo mama. Mastectomía & 36 & T61 \\
\hline & Trasplante hepático & 54 & T120 \\
\hline & $\begin{array}{l}\text { Úlcera isquémica, amputación extremidad } \\
\text { inferior (EI) }\end{array}$ & 75 & $\mathrm{~T} 27$ \\
\hline & PTC & 72 & T29 \\
\hline \multirow{2}{*}{$\begin{array}{l}\text { Servicio de Emergencias } \\
\text { médicas }\end{array}$} & Cardiopatía isquémica (Cl) & 68 & T90 \\
\hline & AVC & 80 & T104 \\
\hline $\begin{array}{l}\text { Servicio de enfermedades } \\
\text { infecciosas }\end{array}$ & $\begin{array}{l}\text { Tuberculosis (TBC). Síndrome de Down. Pre- } \\
\text { cariedad familiar }\end{array}$ & 22 & T26 \\
\hline \multirow{3}{*}{$\begin{array}{l}\text { Cuidados en unidades de } \\
\text { larga estancia }\end{array}$} & Alzheimer & 77 & T68 \\
\hline & Neo próstata. Terminal & 64 & T108 \\
\hline & PTC & 68 & T28 \\
\hline \multirow{2}{*}{$\begin{array}{l}\text { Hospitalización Maternidad } \\
\text { Medicina Interna }\end{array}$} & Sala de Partos. Gestación a término. Cesárea & 26 & T84 \\
\hline & Coma y debut diabético & 45 & T121 \\
\hline
\end{tabular}




\begin{tabular}{|l|l|l|l|}
\hline Especialidad médica & Situación de salud planteada & Edad & $\begin{array}{l}\text { Código del } \\
\text { trabajo }\end{array}$ \\
\hline \multirow{5}{*}{ Neurología } & AVC & 75 & T73 \\
\cline { 2 - 4 } & AVC & 76 & T97 \\
\cline { 2 - 4 } & AVC & 68 & T118 \\
\cline { 2 - 4 } & AVC & 55 & T167 \\
\cline { 2 - 4 } & AVC. Síndrome de Cautiverio. Traqueostomía & 54 & T91 \\
\cline { 2 - 4 } & Incontinencia & 86 & T96 \\
\hline Pediatría & Fractura de fémur & 2 & T77 \\
\hline \multirow{3}{*}{ Salud Mental } & Trastorno Psicótico & 22 & T79 \\
\cline { 2 - 4 } & Trastorno Mental no especificado & 53 & T110 \\
\hline \multirow{5}{*}{ UCIAS } & Neumonía & 50 & T25 \\
\cline { 2 - 4 } & Neumonía & 98 & T74 \\
\cline { 2 - 4 } & Parto & 17 & T31 \\
\cline { 2 - 4 } & EPOC agudizado & 57 & T66 \\
\hline
\end{tabular}

Asimismo, se indicó para el cuidado en la última etapa vital, aunque no era el modelo ideal en esa situación para todos los estudiantes.

("enfermos terminales en tratamiento y control del dolor", "no sería útil en el ámbito de cuidados paliativos").

Algunos de los estudiantes lo vieron aplicable en cualquier ámbito o en cualquier etapa vital, aunque algunos discrepan de su adecuación al ámbito de pediatría justificado porque los niños no pueden practicar el autocuidado.

("aplicable a cualquier situación de enfermería", "independiente de la edad de los individuos", "en nens, adolescents, adults o vells", "en el campo de la pediatría es muy difícil de aplicar porque ella se basa en actividades de autocuidado y este tipo de población no las puede desarrollar").

Aunque algunos estudiantes recomendaron el modelo en el cuidado de la salud mental, otros argumentaron que no era adecuado por carecer, de una valoración profunda de aspectos psicológicos. Igualmente desestimaron su uso en el ámbito de las urgencias, pero no argumentaron motivos.

("pacients amb trastorn mental", "Alcoholismo", "Drogadicción", "no son de la suficiente eficacia en el campo de la psiquiatría ya que ninguno de estos modelos abarcan con suficiente profundidad y relevancia los aspectos psicológicos"). 
En cuanto a la claridad, el modelo de Orem fue un modelo calificado de claro y sencillo, sobre todo en relación a sus conceptos y definiciones.

("claridad y sencillez de los conceptos...facilidad y flexibilidad en la aplicación"(T79)).

Al evaluar los estudiantes el modelo, en relación a la simplicidad, indicaron que era un modelo que facilitaba la valoración, clarificaba las acciones enfermeras (sobre todo las de rol autónomo gracias a los sistemas enfermeros) y evaluaba el proceso realizado.

("capacidad del modelo...de contemplar aspectos importantes...requisitos de autocuidado, de desarrollo y de desviación de la salud...brinda la posibilidad de acceder a esferas no tan físicas" (T59), "la valoración...ha sido muy completa...nos ha parecido fácil la valoración...más parecida...Henderson a la que estamos más acostumbradas" (T96), “...se presta poco a la subjetividad enfermera a la hora de calificar las acciones de enfermería como totalmente , parcialmente compensatorias o apoyo educativo..." (T26), “...el modelo de Orem nos aporta dos diagnósticos más ...capacidad del modelo de Orem de contemplar aspectos tan importantes para la autora como requisitos de autocuidado en caso de desviación de salud" (T59), “...hace hincapié en el por qué de la necesidad de cuidados, cual es la limitación que impide o dificulta el autocuidado" (T80), “...capacidad para poder diseñar un sistema u otro de enfermería en función de las necesidades del cliente...permite usar varios sistemas a la vez" (T81), “...nos permite, mediante las operaciones tecnológico - profesionales de cuidado de casos, asegurarnos de que el proceso de enfermería es efectivo y dinámico, con lo cual realizamos la evaluación de todo el proceso de enfermería" (T96)).

Por los textos de los trabajos, podemos extraer que lo consideraron un modelo completo y universal en referente a la generalidad, valoraron positivamente la amplitud de valoración de los requisitos que hace el modelo, que permitía hacerlo extensible a variadas situaciones.

("...cubre perfectamente todos los requisitos que nuestra paciente debe de realizar para cuidar de sí mismo y de su futuro hijo" (T84), "es uno de los modelos más completos que hay... se puede aplicar en muchos campos" (T96)).

Acerca de la precisión empírica, el modelo era adaptable, adecuado y útil en muchos de los casos propuestos. En concreto y de forma manifiesta, el modelo fue adecuado en el abordaje de un paciente del servicio de enfermedades infecciosas con una TBC y un síndrome de Down (T26), en un paciente con una PTC en un centro de larga estancia (T29), en la asistencia a un parto 
en urgencias (T31), en un paciente con un ángor en la unidad de cardiología (T59), en el seguimiento de un paciente con DM en atención primaria (T72), en un paciente con fractura de fémur en pediatría (T77), en un paciente con un trastorno psicótico en salud mental (T79) y en un paciente con síndrome de Wilson traqueostomizado con una UPP en trocánter desbridada (T81).

("para este caso clínico nos ha resultado mucho más sencillo aplicar" (T26), "se adapta a la situación del caso" (T29), "es el más acertado para el caso planteado...promoción de su autocuidado...el perfil que más se acerca a esto, son los enfermos crónicos" (T72), “gestión eficaz en el caso de Vicente...facilidad y flexibilidad en la aplicación” (T79)).

Como consecuencias deducibles de su uso, los estudiantes alegaron que incrementaba la colaboración de la persona en su cuidado, fomentaba el derecho a elegir de la persona y empoderaba o capacitaba a la persona para colaborar en su propio cuidado, haciéndola una parte activa del proceso. Además, visibilizaba la aportación enfermera en el cuidado, dando relevancia al aspecto psicosocial del mismo.

("a infermeria ens va bé que no depenguin tant de nosaltres...tenim a molts pacients assignats i moltes tasques a fer...el fet de fer-los-hi educación sanitària...ajudar-los a ferse les cures...els estem ajudant i traient-nos feina de sobre" (T25), "recursos proceden en su mayor parte, de las capacidades físicas y cognitivas del individuo... mayor respeto por la autonomía de los pacientes y una mayor capacidad de comprensión hacia él como elemento activo del proceso de cuidados", "La enfermera por excelencia es la principal agente educadora de salud" (T80), "se hace referencia a la etapa evolutiva...se puede aplicar bien a nuestro caso...trata de los temores $e$ inseguridades y emociones que se experimentan en una etapa tan compleja de la vida como es la maternidad" (T84)).

Además el modelo de D. Orem se creyó que daba relevancia a las diferentes etapas del desarrollo de la persona, incluyendo la promoción y la educación para de la salud. Además, incluía a la familia en el cuidado y tenía en cuenta el resto del entorno.

("Ia promoció d'un entorn favorable que potencii el desenvolupament personal i l'ajudi a afrontar la nova etapa amb perspectiva de futur...contempla les autocures del desenvolupament (T103)", "nos dirige a una promoción de la salud" (T61), "se contempla la educación" (T31), "es integral, incluye a la familia en el cuidado... y al resto de la comunidad"(T167)) 
Era según los alumnos de Máster, un modelo costo -efectivo y adecuado a la actual situación en la sanidad de nuestro entorno. Igualmente era compatible con el uso de la taxonomía NANDA.

("reduciendo gastos sanitarios estatales, pues las curas se las proporcionaría a sí mismo el propio paciente o agencia de autocuidado" (T61), "correspondencia con NANDA" (T79)).

\subsubsection{Aspectos negativos en la aplicación del modelo de D. Orem}

Como aspectos negativos el modelo fue visto en relación a la claridad como reiterativo y complejo, justamente los requisitos fueron vistos como poco excluyentes en la valoración de la persona y los conceptos fueron tachados de ser poco claros.

("...nos ha resultado muy repetitivo en la recogida de datos en la valoración...los requisitos de autocuidado se solapan en los distintos campos" (T29), "...serias dificultades para entender el significado de los términos y la estructura interna de la teoría" (T22), "requereix de maduresa personal de la infermera així com a condicions favorables al pacient que li falicitin l'autocura"' (T83)).

En cuanto a la simplicidad los alumnos hallaron problemas en la valoración, la encontraron incompleta mayormente en relación a la valoración psicológica de la persona. También quedaron poco claros aspectos como la valoración del dolor o de la autoestima.

\section{("...nos ha resultado complejo conceptualizar los diferentes recursos de autocuidado...deja fuera aspectos tan importantes como son los espirituales, humanísticos y existenciales y tiene poco en cuenta los factores psicológicos y la autoestima del paciente" (T22), "...no encontramos donde encuadrar aspectos como el dolor, cuidados de la herida, ansiedad y el proceso de duelo; no sabemos si es que no los contempla o por su falta de claridad en los conceptos" (T52), "No valora aspectos como la higiene que se podría englobar en los requisitos según el desarrollo, pero pensamos que estaría más claro englobarlos en los universales" (T73)).}

En referencia a la generalidad vieron el modelo como inadecuado a las necesidades de nuestro entorno y sistema de salud, por el compromiso que solicitaba del paciente en el propio proceso de salud. El argumento se basó en que tradicionalmente el paciente ha sido sujeto pasivo en su cuidado. 
("...bastante complejo en nuestro medio...en nuestro país no está del todo implantada la cultura del aprendizaje de hábitos saludables" (T57), "...sitúa al individuo la responsabilidad de adquirir la información y las capacidades que necesita para hacerse cargo de sus propias necesidades de salud y buscar ayuda y consejo en otros...buscar información o solicitar consejo requiere de muchas habilidades...no todos los miembros de la sociedad tendrán suficientemente desarrollados las capacidades necesarias" (T86), “...no lo vemos facilitando una sistemática de trabajo orientada hacia la emergencia, ya que nos quedaríamos siempre en un sistema de cuidados totalmente o parcialmente compensatorio a pesar de que el cliente tenga necesidad de ser atendido por la agencia de enfermería desde un sistema de apoyo educativo" (T90), “...la institución como tal no favorece que los pacientes reivindiquen sus autocuidados, pues cuando éstos llegan al hospital los tratamos como nulos...lo mismo ocurre con la familia que deja de actuar como lo ha venido haciendo" (T91).

Además lo valoraron como inadecuado a alguno de los casos presentados, en el caso concreto de un paciente con una amputación de la extremidad inferior por una úlcera isquémica (T27), en un paciente con neumonía en urgencias (T74), en el seguimiento de una persona de etnia gitana en gestación seguida en consultas externas (T86) y en un paciente con un AVC portador de traqueostomía y con un síndrome de cautiverio tratado en la unidad de neurología que no puede comunicarse (T91).

("Consideramos que es inespecífico e inadecuado para aplicarlo en nuestro caso ya que se centra en el autocuidado satisfactorio del paciente” (T27), “...en una situación aguda como el caso presentado...numerosos obstáculos a la hora de aplicar la teoría" (T74), “...habrá casos como el nuestro en los que la persona temporalmente es incapaz de realizar elecciones o tomar decisiones o en la que las decisiones que tome no sean las adecuadas, la ansiedad, el temor u otras preocupaciones pueden ser más prioritarias que las necesidades del individuo... nos llevaría a la justificación de la no elección de este método para nuestro caso... María nos manifiesta en sus verbalizaciones poca necesidad de información, de saber más o de adquirir conocimientos, premisas que son necesarias... para la aplicación de su modelo" (T86), "se centra en la relación contractual entre la enferma y la enfermera, pero en nuestro caso concreto no se puede establecer esa relación... no conocemos realmente si la paciente desea ser independiente $o$ cuidada" (T91)). 
Como consecuencias deducibles de la aplicación del modelo, argumentaron los alumnos que fue inadecuado para ser usado con personas sanas y encontraron un vacio en el modelo para el abordaje de la promoción de la salud.

("...he encontrado a faltar el cuidado de las personas sanas, ya que Orem solamente dirige el cuidado cuando existen carencias. No habla en ningún momento del concepto de salud como promoción de la salud y prevención de la enfermedad" (T96))

Igualmente arguyeron que el modelo era deficitario ya que no tenía en cuenta a la familia (aunque el paciente no pueda comunicarse) y necesitaba elevado tiempo de implementación para su desarrollo.

“...no se tiene en cuenta a la familia en la toma de decisiones sobre un cliente que esté inconsciente o en coma” (T24), “...es muy amplio lo que complica el proceso” (T31)).

Además se vió inadecuado para ser usado unido al proceso enfermero y/o taxonomía NANDA, principalmente en el momento de intentar encajar los diagnósticos enfermeros asociados al déficit de autocuidado que inicialmente parecerían ser los más asociados al modelo, debido a situaciones intermedias de dependencia presentadas por el paciente.

("...al no necesitar nuestro paciente una asistencia totalmente compensatoria por parte del agente de autocuidado dependiente, no hemos podido nombrar ningún diagnóstico propio de Orem que aparezca en la NANDA sobre los autocuidados" (T22), “...dificultad de delimitación de los pasos del proceso de enfermería..."(T29), “...dificultad encontrada a la hora de poder utilizar y aplicar el sistema de clasificación de diagnósticos de la NANDA por la idiosincrasia de éste, lo cual hizo demorar más el tiempo" (T59), “...no poder utilizar y aplicar el sistema de clasificación de diagnósticos de la NANDA" (T120)).

\subsubsection{ANÁLISIS DE LOS TRABAJOS EN RELACIÓN AL USO DE SOR CALLISTA ROY EN LOS PROCESOS ENFERMEROS}

4.3.3.1 Descripción de la muestra de los pacientes en los que se elaboró el plan de cuidados siguiendo el modelo de C. Roy

Se obtuvieron 60 trabajos que usaron el modelo de Sor Callista Roy para el desarrollo de su plan de cuidados. De éstos, se analizaron 42 que fueron los que mostraron reflexión sobre la aplicación del modelo. La edad media de los pacientes en los que fue aplicado fue de $48,7 \pm 18,6$ 
años. El menor tenía 28 días y el mayor 75 años. Ver figura 14. Las patologías y especialidades de los pacientes en el que fue aplicado las podemos ver en la tabla 30.

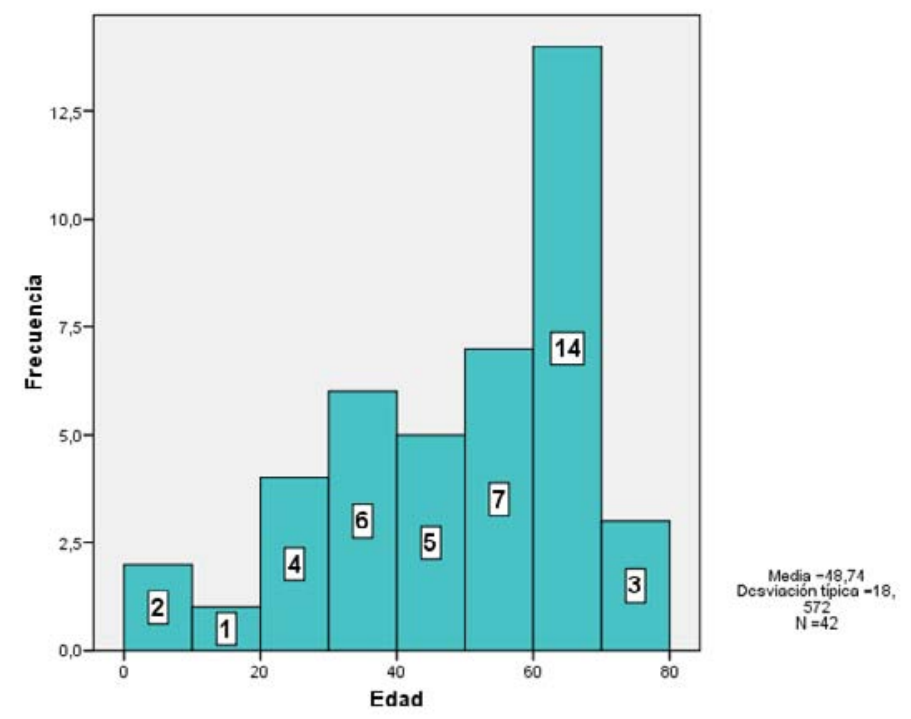

Figura 14: Histograma de la distribución por edades de los pacientes a los que se aplicó el modelo de C. Roy en el plan de cuidados

Tabla 30: Características de los pacientes en los que fue aplicado el modelo de C. Roy para la elaboración del proceso enfermero

\begin{tabular}{|l|l|l|l|}
\hline Especialidad médica & Situación de salud planteada & Edad & $\begin{array}{l}\text { Código de } \\
\text { los trabajos }\end{array}$ \\
\hline \multirow{5}{*}{$\begin{array}{l}\text { Centro de Atención Primaria } \\
\text { y atención domiciliaria }\end{array}$} & Control post AVC & 59 & $\mathrm{~T} 1$ \\
\cline { 2 - 5 } & Seguimiento DM & 60 & $\mathrm{~T} 13$ \\
\cline { 2 - 5 } & Seguimiento DM. Abandono tratamiento & 58 & $\mathrm{~T} 14$ \\
\cline { 2 - 5 } & Seguimiento DM. HTA & 62 & $\mathrm{~T} 22$ \\
\cline { 2 - 5 } & Seguimiento DM & 29 & $\mathrm{~T} 47$ \\
\cline { 2 - 5 } & Educación DM & 65 & $\mathrm{~T} 53$ \\
\cline { 2 - 5 } & Control herida post-histerectomía & 36 & $\mathrm{~T} 24$ \\
\cline { 2 - 5 } & IAM, consejo antitabaco & 58 & $\mathrm{~T} 33$ \\
\cline { 2 - 5 } & Control HTA & 48 & $\mathrm{~T} 39$ \\
\hline \multirow{4}{*}{ Hospitalización Cardiología } & Obesidad & 66 & $\mathrm{~T} 46$ \\
\hline & Ángor & 35 & $\mathrm{~T} 15$ \\
\cline { 2 - 5 } & Colocación prótesis mitral & 52 & $\mathrm{~T} 17$ \\
\cline { 2 - 5 } & Colocación prótesis mitral & 54 & $\mathrm{~T} 18$ \\
\hline
\end{tabular}




\begin{tabular}{|c|c|c|c|}
\hline Especialidad médica & Situación de salud planteada & Edad & $\begin{array}{l}\text { Código de } \\
\text { los trabajos }\end{array}$ \\
\hline \multirow{9}{*}{$\begin{array}{l}\text { Hospitalización Cirugía } \\
\text { - } \quad \text { Digestiva } \\
\text { - } \quad \text { Cirugía Vascular } \\
\text { - Traumatología }\end{array}$} & Neo colon. Colostomizado & 61 & T5 \\
\hline & Neo colon. Colostomizado & 37 & T12 \\
\hline & Neo colon. Colostomizado & 61 & T21 \\
\hline & $\begin{array}{l}\text { Neo colon. Obstrucción colostomía y Neo de } \\
\text { pulmón }\end{array}$ & 66 & T44 \\
\hline & Tumor gástrico. Resección gástrica & 61 & T10 \\
\hline & $\begin{array}{l}\text { Úlcera isquémica, amputación Extremidad infe- } \\
\text { rior }\end{array}$ & 75 & $\mathrm{~T} 27$ \\
\hline & Úlcera pie DM & 35 & T38 \\
\hline & $\begin{array}{l}\text { Traumatismo Cráneo Encefálico por accidente de } \\
\text { tráfico }\end{array}$ & 26 & $\mathrm{~T} 2$ \\
\hline & PTC & 72 & T29 \\
\hline Hospital de día de Oncología & Quimioterapia en neo de mama & 64 & T37 \\
\hline \multirow{2}{*}{$\begin{array}{l}\text { Servicio de enfermedades } \\
\text { infecciosas }\end{array}$} & TBC. Síndrome de Down. Precariedad familiar & 22 & T26 \\
\hline & Infección por tuberculosis. Origen magrebí & 35 & T32 \\
\hline Neurología & AVC, rechazo a tratamiento & 63 & T45 \\
\hline \multirow{5}{*}{ Hospitalización Oncología } & Neo de pulmón & 70 & T3 \\
\hline & Neo de pulmón & 46 & T16 \\
\hline & Neo de mama. Mastectomía & 35 & T52 \\
\hline & Linfoma & 62 & T48 \\
\hline & Neo de boca & 66 & T49 \\
\hline \multirow{2}{*}{$\begin{array}{l}\text { Hospitalización Pediatría- } \\
\text { neonatos }\end{array}$} & Bronquitis aguda & 2 & T42 \\
\hline & $\begin{array}{l}\text { Bajo peso al nacer (gemelas } 28 \text { días). Bronquioli- } \\
\text { tis }\end{array}$ & 0 & T51 \\
\hline Hospitalización Salud Mental & Anorexia nerviosa & 23 & T11 \\
\hline $\begin{array}{l}\text { Cuidados en unidades de } \\
\text { larga estancia, residencia }\end{array}$ & PTC & 68 & T28 \\
\hline $\begin{array}{l}\text { Unidad de Cuidados Intensi- } \\
\text { vos }\end{array}$ & IAM & 50 & T6 \\
\hline \multirow{5}{*}{ Servicio de Urgencias } & Fractura cúbito y radio. Dolor posterior & 46 & $\mathrm{T7}$ \\
\hline & Disnea & 65 & T8 \\
\hline & Neumonía. Hernia de Hiatus & 50 & $\mathrm{~T} 25$ \\
\hline & Parto & 17 & T31 \\
\hline & Intento de autolisis, síndrome depresivo & 42 & T41 \\
\hline
\end{tabular}

\subsubsection{Situaciones para las que fue recomendado el uso del modelo de C. Roy}

El modelo de adaptación de Sor Callista Roy según los estudiantes podía ser aplicado en múltiples situaciones, la mayoría en relación a procesos de adaptación a nuevas situaciones de salud. Al igual que los anteriores fue un modelo recomendado para situaciones de salud - enfermedad tanto agudas como crónicas y de seguimiento en atención primaria. Especialmente en procesos que requerían de adaptación de la persona a su situación de salud.

("Mayor ayuda en unidades de hospitalización", "el modelo es aplicable a nivel

hospitalario pero creemos que se adecúa más a nivel de enfermería comunitaria",

"unitat de cures intensives coronaria, quirófan", "enfermedades crónicas... deberán 
adaptarse a su nueva situación", "enfermedades crónicas... que los pacientes aprendan a vivir con ellas. Si no conseguimos su adaptación no conseguiremos su colaboración", "atención primaria en las que estamos más tiempo en contacto con el enfermo y podemos incidir en la modificación de conductas o estímulos").

Su uso también fue sugerido en situaciones más concretas como en los procesos de embarazo y parto, y en pediatría, por la acomodación a la nueva experiencia vital de la maternidad.

("en parteras porque tienen que adaptarse no sólo al cambio de rol sino a su cambio físico y al bebé", "en unitats pediàtriques perque permet valorar les necessitats psicològiques encobertes dels nens").

Un aspecto importante del modelo que se destacó fue su uso en pacientes que han sufrido alguna pérdida y requieren de adaptación a sus nuevas limitaciones o capacidades. Así como, en la formación de cuidadores informales.

("Podría aplicarse a situaciones... en las que cliente y familiares necesiten crear mecanismos de afrontamiento para adaptarse a nueva situación que acarrea la enfermedad... parapléjicos o cualquier tipo de invalidez", "amputaciones de miembros, parapléjicos o tetrapléjicos... enfermedades degenerativas... deberán adaptarse a su nueva situación", "programas de apoyo de cuidadores informales").

Asimismo se creyó adecuado para el abordaje de procesos de salud mental y atención a las adicciones por su abordaje del aspecto psicológico.

("programas de rehabilitación a drogodependientes", "en las que el paciente sufra desordenes de tipo psicológico y afectivo, déficit de conocimientos severos", "pacientes psicológicos ej. Anorexia. Es importante valorar su autoconcepto así como todos los modos de adaptación.").

Los centros de larga estancia y situaciones de final de la vida, fueron también ámbitos en los que se aconsejó el modelo objetando que las largas estancias de los pacientes permitían el poder aplicar el modelo de forma exitosa.

("podría adaptarse bien a un recurso sociosanitario... dónde los pacientes pueden participar en el plan de cuidados y en resolución de problemas", "en ancianos porque identificaría los sistemas de apoyo afectivo, problemas de autoconcepto y su función de rol", "Situaciones de duelo... desadaptación a vivir sin el ser querido", "cuidados paliativos donde exista mayor tiempo de contacto con el paciente"). 
Pese a que algunos estudiantes indicaron que podía ser aplicado en cualquier contexto, no lo indicaron como útil en situaciones de salud - enfermedad que cambiaran rápidamente como cuidados intensivos, urgencias o quirófano.

("...excepto UCl donde los cambios en el estado de salud... se producen con mucha rapidez", "En la unidad de urgencias solo podríamos atender una de las cuatro formas de adaptación: la de las necesidades fisiológicas", "en unidades como $\mathrm{UCl}$, urgencias o quirófano puede que no resulte útil", "no en pacientes en los que los cambios son rápidos").

4.3.3.3 Aspectos positivos en relación a la aplicación del modelo de C. Roy

Fueron varias características del modelo las que fueron evaluadas como positivas. Los estudiantes indicaron que acerca de su claridad era un modelo que en cuanto a sus conceptos y definiciones era claro y sencillo.

(“...pero al ser claros, precisos y delimitados no nos ha resultado difícil manejarlos" (T22), “...claro en cuanto a conceptos" (T46)).

En referencia a su simplicidad, los comentarios recogidos indicaron que su forma de valorar era completa, tanto a nivel del individuo, como con su inclusión del entorno como elemento relevante.

("...introduce conceptos nuevos como son los agentes estresantes que influyen en la adaptación al medio... incluye... las relaciones con el grupo o comunidad... define a la persona como un ser biopsicosocial desarrollando todos sus aspectos" (T2), "es mucho más conciso para valorar la relación hombre - entorno ... posee categorías específicas para valorar el autoconcepto y el desempeño del rol en todo lo que le rodea, como el entorno" (T12), "No busca solament les causes físiques directes, si no que va més enllà buscant també altres causes secundàries i fins i tot el propi sentiment de la pacient que sent en aquella situació" (T25)).

De la misma manera se destacó que el modelo clarificaba las acciones a realizar en el cuidado, incluyendo el proceso de diagnóstico enfermero y su evaluación.

(“...vemos la causa holística, no patológica o biológica...mejora la planificación...mayor calidad de la atención de enfermería porque está más tiempo con el paciente” (T3), “...a partir del análisis de los comportamientos... y la evaluación de los estímulos relacionados con estos comportamientos... se realice con facilidad un diagnóstico de enfermería de su 
estado de adaptación" (T12), “...parámetros más concretos...se pueden medir mejor los resultados" (T53)).

Los estudiantes consideraron que era un modelo completo y universal en cuanto a su generalidad, debido como ya se ha comentado, tanto a la valoración psicológica que hace de la persona, como a causa de la amplia evaluación del entorno de la misma.

("más abierto...no tan solo aborda al individuo enfermo... también aquellos factores que intervienen en el proceso de atención de la persona...más complejo... posibilidad de aplicación a una persona sana"(T11), "según el modo adaptativo de autoconcepto de Roy, la señora $M$ ve alterada su imagen corporal debido a las heridas quirúrgicas y en el desempeño de roles ve alterado su rol de madre y esposa...es más completo" (T17), "más amplia, no solo abarca el aspecto físico, sino que incluye factores como el personal, interpersonal... espiritual" (T21)).

En referencia a la precisión empírica, los comentarios reflejaron que era un modelo adaptable, adecuado y útil en muchos de los casos planteados. Fue de eficacia en el caso del cuidado de un paciente en un CAP con un AVC (T1) en la situación de un paciente con neo de pulmón ingresado en oncología (T16), en varios pacientes con neo de colon colostomizados ingresados en cirugía $(T 5, T 12, T 21)$, en un paciente al que se le amputa una extremidad inferior por una úlcera isquémica en cirugía vascular (T27), en una paciente con una neo de mama a la que se le practicó una mastectomía en la unidad de oncología (T52) y en una paciente con anorexia nerviosa ingresada en salud mental (T11). Asimismo fue exitoso al ser manejado en un niño ingresado en pediatría por una bronquitis aguda (T42).

“...son de gran utilidad en el caso planteado" (T1), "para este caso concreto es más completo ... puesto que es básica la adaptación de la paciente a la nueva situación y una conducta adaptada puede condicionar de manera importante el curso del tratamiento quimioterápico" (T16), "el mejor modelo que podemos aplicar... en este caso" (T21), "lo consideramos válido para nuestro caso por centrarse en el proceso de adaptación del individuo...adaptación a una nueva situación" (T27), "se adecua mejor porque trata aspectos como el dolor, cuidados de la herida y brazos afectados tras la intervención, la ansiedad y el proceso de duelo" (T52), "Ia persona alcanzaría su objetivo, que sería el de conseguir un estado óptimo de bienestar"(T11), "el model és eficaç... la gran capacitat d'adaptació per part del nen afavoreix la seva curació"(T42)).

En el análisis de los textos en base a la subcategoría consecuencias deducibles, se argumentó que el modelo incrementaba la colaboración de la persona en el cuidado, e incentivaba la 
motivación tanto de la persona como del profesional. Además facilitaba reconocer diagnósticos enfermeros a través de los problemas de adaptación.

("...aumenta la motivación del profesional y del paciente por mútua interacción y acercamiento... más confianza y seguridad" (T3), "mayor participación del paciente en el plan de cuidados" (T4), "nos muestra la necesidad de interactuar más a menudo con el paciente" (T7), "usando el modelo...hemos reconocido fácilmente un diagnóstico de alto riesgo" (T24), "Ia separació dels dos nivells, el físic i el psicològic... permet identificar els problemes d'adaptació...diagnòstics d'infermeria"' (T42)).

\subsubsection{Aspectos negativos en relación al uso del modelo de C. Roy}

Con respecto a comentarios negativos sobre la aplicación del modelo de C. Roy, indicar que fueron mayores en extensión que los comentarios positivos. Las categorías y subcategorías halladas resumen que el modelo era con respecto a la claridad, un modelo reiterativo en cuanto la valoración de estímulos, cuestionando los estudiantes si era necesaria la amplia valoración que hacía del comportamiento, aunque aún así algún estudiante hizo alusión a que la parte física quedaba poco valorada. Por otra parte, lo definieron como complejo de entender, principalmente en relación al lenguaje utilizado por la autora en la definición de los conceptos principales de la teoría.

“...en cada modo adaptativo y al identificar los estímulos que estaban actuando, los repetíamos de forma reiterada" (T32), "estímulos iguales o muy similares afectan a los modos de rol, autoconcepto e interdependencia con lo que nos cuestionamos si es necesario diseccionar en tantos aspectos un comportamiento, si el englobarlo nos haría perder matices importantes o si por el contrario ganaríamos tiempo de análisis" (T38), “...es más complejo y su lenguaje también... más complicado su manejo... dificultad de lenguaje y comprensión... conceptos más dificutosos" (T3), "Integrar tantos conceptos... y sus conceptos hace que se considere una teoría compleja y poco clara" (T12), "complejidad de los conceptos manejados" (T32), "Complicado integrar tantos conceptos y me da la sensación de que pierdes datos... los aspectos fisiológicos no quedan tan detallados" (T18)),

Y observaron que el modelo presentaba carencias en cuanto a la concreción de cómo implementarlo en el cuidado, lo vieron muy teórico y poco práctico. Faltaba esclarecer, según los estudiantes, el rol de la enfermera y el papel del propio paciente, causando problemas para poder priorizar los cuidados prestados. 
("se queda tan solo en definiciones, no diciendo como aplicarlo a los cuidados de enfermería" (T1), "No especifica com utilitzar el seu model... diu que la infermera será requerida quan la persona... es quedi amb poques energies... Això no està definit al model" (T6), "hemos encontrado confusión para catalogar a que instancia permanece ciertas conductas de ML" (T15), "encontramos a faltar alguna directriz sobre si un modo de adaptación es prioritario a otro en cuanto a conseguir eficacia de nuestras adaptaciones" (T38), "no ens queda clar si el paper del pacient és actiu o pasiu" (T42)).

En el análisis de la simplicidad los comentarios volvieron a reflejar complejidad en su aplicación por mostrar subjetividad y sobre todo, en relación a la valoración. Creyeron que era poco específica de la persona, y que el cuidado a través del modelo era poco concreto.

("el rol del cuidador no está bien definido" (T1), "más subjetivo... dificultad en la recogida de información y puesta en marcha del plan de cuidados"(T2), "Ia clasificación de los estímulos... dependen de la situación y de la propia percepción de la enfermera... disparidad en las valoraciones... valoración subjetiva"(T3), "un estímulo no siempre da como resultado siempre una misma conducta ... identificación de los estímulos no siempre tan fácil, ni actuar sobre ellos" (T4), "problemas para identificar los roles primarios, secundarios y terciarios de la paciente... difícil reconocer los estímulos de cada comportamiento anómalo y de qué tipo eran estos" (T24), "una de las principales dificultades radica en la identificación correcta de los estímulos, focales, contextuales y especialmente los residuales" (T28), "a l'hora de la realització del PAE, hi havia confusió a l'hora de classificar les conductes en els quatre modes adaptatius: les fronteres no són massa clares i tendeixen a solapar-se" (T42)).

En cuanto a la generalidad, se extrajo que era un modelo poco adaptable, mayormente en procesos en los que hay cambios rápidos de salud.

("Ia aplicación del modelo en episodios agudos nos parece menos eficaz, ya que no recoge aspectos del cuidado que son tratados exclusivamente por la enfermera, no se adapta al ritmo de cambio del proceso del paciente" (T29), "se encuentra en una UCI neonatal... el estado de salud cambia con rapidez, es difícil llegar a un estado de adaptación en cada situación nueva" (T51)).

Además comentan que el modelo tenía una visión parcial, sólo de la enfermedad y no sería aplicable a personas con buen estado de salud, por lo que le ven una visión puramente orientada a la enfermedad y poco aplicable a personas con deterioro de la comunicación. 
("al estar orientado... hacia una visión biomédica, encontramos cierta dificultad en trabajar aspectos psicosociales de la persona" (T29), "se centra en la persona enferma... obvia a la sana (adaptada)" (T4), "nuestra visión biologista, nos dificultó la aplicación de este modelo, ya que enfocábamos los problemas del paciente más hacia su enfermedad" (T32), "es muy importante la comunicación verbal...importancia de que el paciente se pueda comunicar... difícil su aplicación en personas con problemas de comunicación social... te basas más en la familia y no en el paciente... puede dar una percepción equivocada del problema" (T3)).

Asimismo, en algún caso, fue cuestionada su aplicabilidad (precisión empírica), en el caso de una paciente con anorexia nerviosa hospitalizada en salud mental por la propia alteración de la imagen de la persona que no le permite reconocer su problema.

("...presente caso... una dificultad en el modo adaptativo de autoconcepto, dado que la paciente no tiene ninguna conciencia de enfermedad y por lo tanto no asume su rol de enferma"(T11)).

También aunque de forma menos específica cuestionaron la utilidad del modelo para el caso de un magrebí con TBC ingresado en la unidad de infecciosas.

(“...nos plantemos su aplicabilidad real” (T32)).

En cuanto a consecuencias deducibles, pese a que reconocieran que no les quedaba claro el papel del paciente, algunos estudiantes argumentaron que la aplicación del modelo implicaba un rol dependiente de la persona cuidada, ya que es la enfermera la que toma las decisiones en el cuidado de forma particular.

(“...confiere a la enfermera un papel importante dentro de la intervención, haciendo al paciente más dependiente del cuidador" (T22), "hay poco margen para interrelacionar con el paciente, y la enfermera unilateralmente decide que comportamientos están adaptados... y sobre que estímulos se debe actuar" (T38)).

Igualmente los estudiantes objetaron que el modelo presentaba problemas para ser informatizado por el largo tiempo necesario de implementación, que lo hace inadecuado para nuestro contexto de trabajo. De la misma manera, comentaron que requiería de capacitación y formación adicional de la enfermera

("es más difícil su informatización... excesivas hojas de registro" (T3), "es mucho más minucioso y lleva más tiempo...necesita mucho tiempo para una buena recogida de datos... eso en un 
hospital es algo utópico... excesivas hojas de registro" (T3), "El proceso de elaboración nos ha llevado mucho tiempo y nos ha resultado largo" (T15), "Se necesita mucha intuición y empatía... no están capacitados todos los profesionales de enfermería" (T3)).

El modelo fue visto como reduccionista e incompleto, creyeron que simplificaba la salud a una conducta, justamente por el análisis exhaustivo de los comportamientos de los individuos que no siempre quedaban claros.

("reduce a la persona a una conducta... la salud es medida en términos exclusivamente conductuales ... no contempla la adaptación del enfermero-paciente ... excluye aspectos espirituales, humanísticos y existenciales... el modelo es reduccionista contemplando solamente 4 modos de adaptación" (T4), "tenemos dudas de encuadrar actividades que habitualmente realiza la enfermera y no quedan reflejadas en el plan de cuidados... Ias categorías las consideramos poco claras, encontrando problema a la hora de encasillar un comportamiento" (T29), "No desarrolla los aspectos de prevención y promoción de la salud" (T4)).

Otro de los problemas hallados en su uso, fue la poca adaptación para su empleo con la taxonomía NANDA.

("el lenguaje utilizado para el diagnóstico no corresponde al propuesto por NANDA" (T29)).

\subsubsection{ANÁLISIS DE LOS TRABAJOS EN RELACIÓN AL MODELO DE HILDEGARD E. PEPLAU} EN LA PRÁCTICA

4.3.4.1 Descripción de los sujetos en los que fue aplicado el plan de cuidados siguiendo el modelo de H. Peplau

De los 29 trabajos accesibles que aplicaron el modelo de H. Peplau, 22 fueron los analizados para nuestro estudio. La media de edad entre los sujetos fue de 57,8 $\pm 17,2$ años (el menor tenía 2 y el mayor 89 años), ver figura 15. La especialidad médica a la que pertenece el paciente y su patología se resumen en la tabla 31. 


\subsubsection{Situaciones para las que fue recomendado el modelo de H. Peplau}

En cuanto a las situaciones en las que podía ser usado el modelo, los estudiantes expusieron diversas, sin embargo su indicación no fue argumentada en la mayoría de los casos. Los diferentes comentarios de los alumnos de Máster concretaron que el modelo debería ser adecuado para ser aplicado en procesos agudos y crónicos

("en una unidad hospitalaria donde hay personas con problemas de salud agudos", “alteración física (dolor, infección, traumatismo) donde la enfermera a través de la relación con el paciente y gracias a las cuatro fases del modelo permitirán la resolución del mismo", "enfermería comunitaria y enfermería psiquiátrica ...progreso de la personalidad del enfermo").

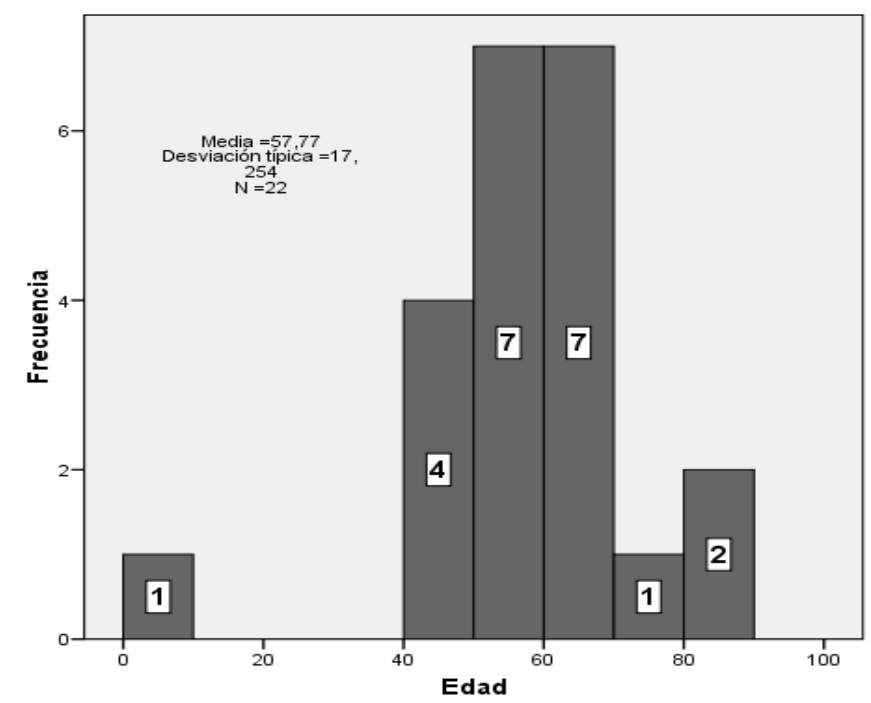

Figura 15: Histograma de la distribución por edades de los pacientes a los que se aplicó el modelo de H. Peplau en el plan de cuidados

Tabla 31: Características de los pacientes en los que fue aplicado el modelo de H. Peplau para la elaboración del proceso enfermero

\begin{tabular}{|c|c|c|c|}
\hline Especialidad médica & Situación de salud planteada & Edad & $\begin{array}{l}\text { Código del } \\
\text { trabajo }\end{array}$ \\
\hline \multirow{5}{*}{$\begin{array}{l}\text { Atención domiciliaria y } \\
\text { Centro de Atención } \\
\text { Primaria }\end{array}$} & Educación DM & 65 & T53 \\
\hline & Educación DM & 60 & T72 \\
\hline & Control y seguimiento obesidad & 66 & T46 \\
\hline & $\begin{array}{l}\text { Esclerosis Lateral Amiotrófica. Cura catéter gas- } \\
\text { trostomía percutánea }\end{array}$ & 55 & T107 \\
\hline & Depresión por muerte familiar & 51 & T128 \\
\hline
\end{tabular}




\begin{tabular}{|c|c|c|c|}
\hline Especialidad médica & Situación de salud planteada & Edad & $\begin{array}{l}\text { Código del } \\
\text { trabajo }\end{array}$ \\
\hline \multirow{5}{*}{$\begin{array}{cl}\text { Cirugía } & \\
\text { - } & \text { Digestivo } \\
\text { - } & \text { Vascular } \\
\text { - } & \text { Otorrino } \\
\text { - Urología }\end{array}$} & $\begin{array}{l}\text { Neo colon. Obstrucción colostomía y neo de } \\
\text { pulmón }\end{array}$ & 66 & T44 \\
\hline & Necrosis quinto metatarsiano - amputación & 55 & T147 \\
\hline & Neo de laringe. Laringuectomía & 52 & T100 \\
\hline & Incontinencia & 86 & T96 \\
\hline & Neo de próstata. Prostatectomía & 60 & T115 \\
\hline \multirow{2}{*}{ Medicina Interna } & Infección respiratoria & 65 & T69 \\
\hline & Coma y debut DM & 45 & T121 \\
\hline Neumología & EPOC & 89 & T109 \\
\hline \multirow{2}{*}{ Neurología } & AVC. Rechazo a tratamiento & 63 & T45 \\
\hline & AVC & 55 & T167 \\
\hline Oncología & Neo de pulmón. Metástasis hepáticas & 48 & T125 \\
\hline PADES & $\begin{array}{l}\text { Soporte a cuidadora de persona dependiente } \\
\text { (madre y hermana) }\end{array}$ & 59 & T145 \\
\hline Pediatría & Fractura de fémur & 2 & T77 \\
\hline Psiquiatría & Trastorno bipolar con intento de autolisis & 45 & T164 \\
\hline \multirow{2}{*}{$\begin{array}{l}\text { Residencia y larga es- } \\
\text { tancia }\end{array}$} & Demencia & 79 & T122 \\
\hline & $\begin{array}{l}\text { Fractura de cúbito y radio. Esquizofrenia. Pro- } \\
\text { blema social }\end{array}$ & 58 & T155 \\
\hline Sala hemodiálisis & $\begin{array}{l}\text { Insuficiencia renal en diálisis. Mal cumplidor de } \\
\text { tratamiento. Marroquí }\end{array}$ & 47 & T149 \\
\hline
\end{tabular}

Los procesos relacionados con salud mental, fueron otros de los ámbitos recomendados. Además de ser aconsejado para ser usado en unidades de larga estancia, como sociosanitarios o residencias, incluso en el trato con la familia.

("en áreas de salud mental donde el contacto suele ser más intenso y prolongado", "cuidados de larga duración donde se pueden conseguir espacios de intimidad que favorezcan la interacción", "familias en proceso de duelo").

Vieron limitaciones para el uso del modelo en situaciones en las que la persona tenía un deterioro en la comunicación bien por su etapa de desarrollo, por su patología, o por decisión propia del paciente a no interaccionar, destacan que la comunicación era imprescindible para la aplicación del modelo.

("Ia utilització d'aquest model queda limitat en el treball amb pacients senils, nounats, comatosos... en aquesta situació la relació infermera - pacient és unilateral, per tant, no pot considerar-se amb el qualificatiu de general", "no se puede aplicar en niños pequeños, pacientes en coma, marginados sociales, drogodependientes, etc.").

Asimismo no fue recomendado para situaciones de escaso contacto temporal con el paciente como urgencias, ya que es un modelo que requería elevado tiempo de implementación. 
("No todos los pacientes pueden ser educados para la consecución de la salud debido al limitado tiempo de contacto [como ocurre en urgencias] o bien cuando se trata de pacientes que no son receptivos al intento de promoción de la salud").

\subsubsection{Aspectos positivos en relación a la aplicación del modelo de H. Peplau}

Los comentarios de los estudiantes sobre el modelo en relación a la claridad fueron que era un modelo sencillo y claro.

("más explicativo...sencillez en el manejo...más completo" (T16)).

En cuanto a la subcategoría de la simplicidad, creyeron que era un modelo que realizaba una valoración psicológica completa de la persona cuidada, clarificaba las acciones a realizar en el cuidado y evaluaba el proceso del mismo. Sobre todo en situaciones en los que la dimensión psicológica era parte relevante de los mismos.

("...permite extraer tanta información... como experiencia tiene la enfermera... predominantemente de carácter emocional... investigando en los sentimientos y emociones para, a partir de ahí, identificar las necesidades del cliente" (T122), "eficaç per aquest tipus de pacient oncològic per poder desenvolupar la part psicològica, en les primeres fases de la relació amb moltes preguntes i pors" (T125), "los resultados son eficaces" (T121), “...es el que mejor ayuda a desempeñar el rol profesional y permite comprender diversos aspectos de la relación enfermera paciente, ofreciendo directrices para la intervención” (T107), “...fases por las que transcurre el proceso son fácilmente identificables, incluso para la familia, de forma que permite a la enfermera explicar orientativamente lo que sucederá a continuación ... información que se recoge es global” (T122), “...visión que te permita explorar e incorporar ...sentimientos y conductas de las intervenciones enfermeras" (T128).

En cuanto a la generalidad fue un modelo, según los estudiantes, completo; sobre todo en cuanto al papel de la enfermera, quedaban bien descritos los roles a adoptar por la misma. Era un modelo que según los estudiantes puede ser aplicado en diferentes situaciones

("considerar las observaciones objetivas y subjetivas en cada uno de los diferentes roles enfermeros permite valorar todas las alternativas desde un punto de vista holístico" (T145), y lo ven útil para completar o usar unido a otros modelos "complemento idóneo para potenciar positivamente otros modelos" (T121), "para utilizarlo en diferentes ámbitos" (T155)). 
Al analizar los comentarios en relación a la precisión empírica, ha sido denominado como adaptable y de utilidad en los casos planteados. Manifiestamente el modelo ha sido resolutivo en los siguientes casos: en un paciente con obesidad del que se hace seguimiento en primaria (T46), en un paciente oncológico ingresado por una neo de pulmón con metástasis hepáticas (T125), en un paciente seguido en atención primaria por depresión tras muerte familiar (T128), para hacer soporte a una cuidadora en atención domiciliaria (T145), en un paciente ingresado en cirugía vascular que ha sufrido una amputación del quinto metatarsiano (T147), en un paciente mal cumplidor del tratamiento seguido en el servicio de hemodiálisis (T149) y en un paciente con fractura de cúbito y radio con esquizofrenia y problema social ingresado en una residencia de larga estancia (T149).

('...nos ha parecido más conveniente...la persona que nosotros presentábamos sufría un problema de negación. No se trataba de un problema realmente físico, sino psicológico" (T46), "moldeable y dúctil...maleable... eficaz y eficiente" (T121), "flexible" (T155), "eficaç per aquest tipus de pacient oncològic per poder desenvolupar la part psicològica, en les primeres fases de la relació amb moltes preguntes i pors" (T125), "valorar la efectividad...del caso de la Sra. C.J, todo el equipo coincide en la aplicación del modelo de Hildegard E. Peplau" (T128), "He conseguido mis metas con Jorge mediante la promoción del desarrollo de sus habilidades para afrontar sus problemas... muy eficaz...permite que la enfermera asuma distintos roles, sea capaz de controlar sus emociones y de proporcionar un apoyo terapéutico apropiado al paciente... comparte muy bien la finalidad que pretendo dar en el caso... que él solucione sus problemas, habiendo sido aconsejado anteriormente, una vez salga del hospital" (T147)).

En cuanto a consecuencias deducibles, según los estudiantes el modelo incrementaba la colaboración en el cuidado de la propia persona, le daba un papel activo y procuraba relevancia al rol de la enfermera, incrementando las habilidades interpersonales y enriqueciendo a ambos miembros de la relación. Además comentaron que implicaba a la familia en el cuidado.

("el Sr. J, se ha informado mejor acerca de su estado y ha podido valorar y cooperar de una manera más eficiente. Necesitaba ser capaz de formular preguntas; éste le proporcionó información y una mayor introspección de su situación (más seguridad) ...el paciente participó activamente en la resolución del problema y potenció la relación...más participativo en su cuidado" (T115), "anima a desarrollar habilidades interpersonales" (T128), "Los dos hemos aprendido el proceso de resolución de problemas a partir de nuestra relación... empatiza mucho con sus pacientes" 
(T147), “...fases por las que transcurre el proceso son fácilmente identificables, incluso para la familia ...contiene las herramientas para conectar con la parte más psicológica y espiritual de la familia...la enfermera establece una relación con el marido y otra con Concha, ambas encaminadas a la satisfacción de las necesidades de ella" (T122)).

\subsubsection{Aspectos negativos en relación al uso del modelo de H. Peplau}

Los estudiantes de Máster también vieron aspectos negativos en la implementación del modelo. No realizaron comentarios negativos que se pudieran integrar en la categoría de claridad. En cuanto a la simplicidad los estudiantes argumentan que el modelo tenía una visión parcial en la valoración y subjetividad en la misma, carecía de evaluación concreta de la dimensión biológica de la persona. Catalogaban a la enfermera del modelo de Peplau como poco técnica, pero con una gran base en habilidades interpersonales. Lo vieron limitado en patologías que provocaban limitación cognitiva en la persona.

( "se centra en exceso en el aspecto psico-afectivo de la persona y poco en los procesos bio-físicos y sociales ... la enfermera que refleja tiene escasa capacitación técnica" (T167), "el concepto de salud que describe...es incompleto... no toma en cuenta las clásicas patologías orgánicas con padecimientos crónicos, incapacidades físicas y otras secuelas que limiten la capacidad cognitiva o instrumental de la persona" (T167)).

Además objetaron que ni permitía evaluar resultados, ni clarificaba cuando poner en marcha las intervenciones en el cuidado. Vieron complejo definir el progreso de la persona en las diferentes etapas propuestas por el modelo, incluso plantearon la inoperatividad del modelo si el paciente no evolucionaba entre dichas etapas.

("Ia evaluación... dificultosa” (T155), “...no contempla de manera clara el estancamiento de la persona en una de ellas o la no evolución hacia la siguiente, con lo que la dependencia estaría presente (en el caso de un TCE con secuelas) y no podría así promover la total autorrealización" (T167), "tampoc veig clara la identificació de la fase durant la relació, crec que es solapen, però en una relació continuada es reiteren les fases d'identificació amb l'aparició de nous problemes... no tots els rols són aplicables a tot tipus de pacients...quan és un cas d'un malalt amb patologia més física és difícil identificar el rol que la infermera està adoptant" (T125)).

En cuanto a la generalidad fue un modelo que podría ser aplicado en pacientes con problemas en la comunicación. 
("...más difícil llevar a cabo...hay situaciones concretas en que no se puede aplicar ...paciente inconsciente" (T100), "...sólo se puede aplicar a personas adultas y sin alteraciones que afecten a la capacidad de comunicación" (T122)).

Fue poco resolutivo, según los estudiantes, en algunos de los casos planteados: en paciente con neo de colon y de pulmón en la unidad de cirugía (T44), en un paciente de pediatría con fractura de fémur (T77) y en un paciente con demencia en una unidad de larga estancia (T122).

("...la fase resolución puede no tener lugar en nuestro caso pues el vínculo enfermera cliente terminará con la muerte del paciente" (T44)) "no es útil en nuestro casi... no sólo precisamos cuidados psicológicos por parte de la enfermera, sino que necesita cubrir las necesidades básicas del paciente y su familia" (T77), "este modelo no nos resulta eficaz" (T122)).

En cuanto a consecuencias deducibles, según los comentarios de los estudiantes era un modelo que exigía habilidades de comunicación de la enfermera que lo utiliza y receptividad a la misma por parte de la persona cuidada.

("Ia enfermera no puede paliar un problema si este no es percibido como tal por el propio paciente" (T72), "o que simplemente no quiere hablar, difícilmente podremos llevarlo a cabo" (T100), "si la experiencia previa de la enfermera es inexistente, o lo es en este campo, la adhesión de ambas partes no permite crear las relaciones humanas impres-cindibles para llevar a cabo las 4 fases del proceso" (T122), "dependerá mucho de la habilidad de la enfermera para entablar una relación adecuada con el paciente y su familia... limitado en pacientes con nula o poca capacidad de comunicación" (T128)).

Otra de los evidencias destacadas negativas del modelo es que no tenía en cuenta el entorno y/o familia (aunque algún estudiante argumentó lo contrario), y provocaba una carga emocional extra en el profesional que lo utilizaba.

("...cliente, es un elemento individual sin referentes en su entorno más inmediato, que es generalmente la familia... en este caso sin la familia no se puede establecer un plan de cuidados de calidad" (T122), "...apoyo personal por parte del centro para digerir las emociones...requiere una gran entrega por parte de la enfermera... implicación emocional" (155)). 
Los estudiantes cuestionaron su desarrollo en los centros, ya que creían que era inadecuado para ser utilizado con los registros actuales enfermeros y requería largo tiempo y elevados costes para su implementación.

(“... difícil hacer encajar los conceptos del modelo ...en una estructura de documentación ya existente, tendría que realizarse nuevos registros" (T155), "requiere tiempo... limitado tiempo de contacto que tienen las enfermeras [como ocurre en urgencias]" (T45), "se invierte un tiempo en establecerlas" (T53), "En cuanto al tiempo se necesitan ingresos prolongados...el tiempo de registro también sería un problema al ser demasiado extenso...en una unidad de muchos pacientes requeriría una estructuración de las tareas y un aumento del personal" (T155), "la enfermera no tendría tiempo de encargarse de sus funciones asistenciales" (T167)).

\subsubsection{ANÁLISIS DE LOS TRABAJOS EN RELACIÓN AL MODELO DE BETTY NEUMAN EN LA} PRÁCTICA

\subsubsection{Descripción de los sujetos en los que fue aplicado el modelo de B. Neuman en el} plan de cuidados

Se tuvo acceso a 18 trabajos, de los que fueron seleccionados 10 por su calidad en la reflexión. El histograma de edades de los sujetos de la muestra se presenta a continuación (figura 16). La mayor parte de los sujetos tenían entre 50 y 70 años. La patología y especialidad de los mismos se muestra en la tabla 32.

Figura 16: Histograma de la distribución por edades de los pacientes a los que se aplicó el modelo de B. Neuman en el plan de cuidados

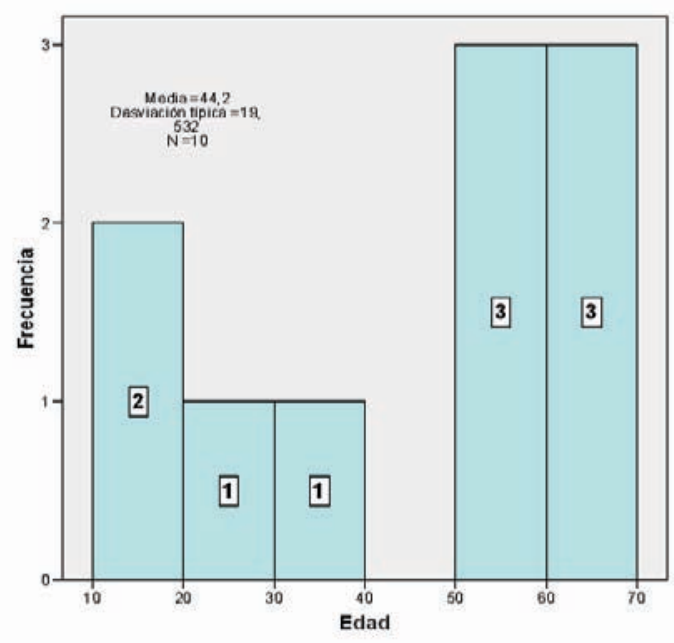


Tabla 32: Características de los pacientes en los que fue aplicado el modelo de B. Neuman para la elaboración del proceso enfermero

\begin{tabular}{|l|l|l|l|}
\hline \multirow{2}{*}{ Especialidad médica } & Situación de salud planteada & Edad & $\begin{array}{l}\text { Código de } \\
\text { los trabajos }\end{array}$ \\
\hline \multirow{2}{*}{ CAP } & IAM, consejo antitabaco & 58 & $\mathrm{~T} 33$ \\
\cline { 2 - 4 } & Sobrecarga del cuidador de persona dependiente & 50 & $\mathrm{~T} 71$ \\
\hline CCEE nefrología & Insuficiencia renal crónica & 50 & $\mathrm{~T} 132$ \\
\hline \multirow{4}{*}{$\begin{array}{l}\text { CIRVA } \\
\text { (COT) }\end{array}$} & $\begin{array}{l}\text { Úlceras en ambas extremidades inferiores sobrein- } \\
\text { fectadas }\end{array}$ & 62 & $\mathrm{~T} 54$ \\
\hline Maternidad & Accidente tráfico. Politraumático & 24 & $\mathrm{~T} 55$ \\
\cline { 2 - 5 } & PTC & 65 & $\mathrm{~T} 134$ \\
\cline { 2 - 4 } & PTC & 65 & $\mathrm{~T} 143$ \\
\cline { 2 - 4 } & $\begin{array}{l}\text { Amputación extremidad inferior derecha por acci- } \\
\text { dente tráfico }\end{array}$ & 34 & $\mathrm{~T} 140$ \\
\hline Neurología & Parto bebé prematuro & 16 & $\mathrm{~T} 131$ \\
\hline
\end{tabular}

4.3.5.2 Situaciones para las que fue recomendado el modelo de B. Neuman

Una vez se analizaron los textos de los estudiantes, los lugares o situaciones en las que fue recomendado el uso del modelo fueron procesos agudos y crónicos con seguimiento en atención primaria.

("Hospitalizados", "Maternidad", "más indicado en atención primaria...se puede llegar a conocer más de cerca el entorno del paciente...iremos conociendo todos aquellos factores estresantes potenciales y/o reales que afectan al paciente. Es aquí donde desde un principio podemos empezar a intervenir desde la primaria hasta la terciaria", "enfoque hacia la prevención primaria...es muy difícil concienciar a la persona...de todos aquellos hábitos y costumbres que sería conveniente que erradicara y una vez identificados poder hacer incidencia en ellos para que la enfermedad no volviera a aparecer... los factores estresantes pueden aparecer en las tres líneas de defensa: de resistencia, normal y línea flexible de defensa").

Además se recomendó su uso en salud mental y centros de larga estancia.

("psiquiatría infanto-juvenil en el que las interacciones con el entorno son complejas","resulta aplicable en todas aquellas situaciones donde la relación enfermera - paciente va a ser muy larga", "residencias asistidas, centros de rehabilitación, asilos", "instituciones para enfermos crónicos, ya que lo consideramos un método integral para cubrir las necesidades de los pacientes con múltiples problemas de 
salud", "pacientes geriátricos en los que las referencias familiares y sociales llegan a influir bastante en su recuperación y recidivas").

También se aconsejó para ser empleado en los cuidadores y en los procesos de duelo.

("reeducación de personas que prestan cuidados", "Pacient de primària dependent que consulta per astènia, anorèxia després de pèrdua d'un familiar proper: dol inefectiu. Podria ser valorat l'entorn creat, la rel-lació infermera-pacient i pacient-cuidador, les variables psicològiques").

Sólo un estudiante no recomendó el modelo para una situación concreta, la hospitalización, pero no argumentó tal contraindicación.

\subsubsection{Aspectos positivos en relación al uso del modelo de B. Neuman}

Las reflexiones positivas sobre la aplicación del modelo en cuanto a la claridad fueron inexistentes. En cambio en relación a la generalidad, se comentó que era un modelo completo y universal.

("Ia teoría es bastante completa" (T54), "Amplitud" (T132), "modelo universal adaptable a todo tipo de pacientes, y es especialmente útil en aquellos que precisan abordaje multidisciplinar" (T132)).

En relación a la precisión empírica argumentaron que era un modelo adaptable, adecuado y/o útil a muchos de los casos presentados. Los casos concretos en los que el modelo fue de utilidad de forma explícita fueron: un paciente seguido en un centro de atención primaria con un IAM y consejo antitabaco (T33), un paciente con insuficiencia renal en seguimiento por CCEE de nefrología (T132) y dos pacientes con una PTC ingresados en COT (T134).

("se adapta con facilidad y es completo...lo hacen idóneo para la aplicación para nuestro caso concreto" (T33), "para este paciente...es un modelo muy apropiado...Ia posibilidad de contemplar los tres tipos de prevención en la intervención va a ser un factor más para incrementar el éxito de nuestras intervenciones" (T132), "eficaz en esta situación enfermera cliente" (T134), "la Sra. Carmen está en condiciones de realizar su proceso homeostático que le permita restablecer y mantener su equilibrio y en consecuencia su salud" (T143)).

En cuestión de consecuencias deducibles comentaron que era un modelo que incrementaba la colaboración en el cuidado de la persona, daba relevancia al rol propio de la enfermera y 
tenía en cuenta a la familia. Además creyeron que les fue útil el abordaje a la prevención que realizaba.

("Ias enfermeras desarrollaríamos un mayor respeto por la autonomía de los pacientes y una mayor capacidad de comprensión hacia él como elemento activo del proceso de cuidados" (T127), "la infermera no decideix ni tampoc imposa el tractament del pacient sinó que és aquest qui decideix on vol arribar... el protagonista és el pacient" (T140), “...podemos hacer un análisis más profundo de la familia... completo a la hora de tratar un grupo, familia,..." (T71), "los niveles de prevención nos es útil para poder actuar precozmente, antes que la estructura básica entre en crisis" (T143)).

\subsubsection{Aspectos negativos del uso del modelo de B. Neuman}

En cuanto a los aspectos negativos del modelo de B. Neuman, en relación a la claridad, era un modelo complejo en lenguaje en cuanto a definiciones y aplicación.

(“...resulta extraño hablar al paciente de sistemas e interacciones... Complejidad del lenguaje... Resulta más complejo" (T55)).

Si analizamos los comentarios, al agruparlos por la simplicidad, los estudiantes interpretaron que presentaba elevada dificultad en la valoración física y era confuso para el seguimiento del plan continuado del paciente incidiendo en el formato de recogida de datos en la valoración.

("...es fácil pasar por alto algunas necesidades físicas debido al formato de recogida de datos" (T54), "según Neuman nuestras intervenciones deben dirigirse desde la prevención primaria, secundaria y terciaria... en este caso nos resulta imposible evitar el accidente... al sólo constar de tres fases resulta complicado saber dónde se debe poner la información que se va recogiendo, todo queda engrosado en apartados muy amplios donde la información se disipa" (T55)).

A destacar los comentarios que se englobaron en relación a la generalidad del modelo, se mostró inadecuado para personas con pérdidas de memoria o problemas en la comunicación y no lo creyeron aplicable en pacientes en situación aguda de su enfermedad.

("...en un caso de accidente... imposible saber nada del paciente anterior al accidente... no conocemos su forma de actuar habitualmente, ni la capacidad de enfrentarse a los problemas... la aplicación... se hace realmente trabajosa y difícil" (T55), "però és més difícil d'aplicar en pacients aguts...tant el temps, com l'espai, com el moviment es veuen reduits"(T140)). 
No se hicieron comentarios negativos que pudieran ser englobados en la categoría de precisión empírica. Como consecuencias deducibles requería elevado tiempo de implementación y cambios conceptuales en cuanto a la visión tradicional de la enfermedad.

("condiciona el compromiso de un abordaje enfermero con una dedicación de tiempo mayor en el caso de las visitas ambulatorias y una consideración de incrementar la complejidad de los sistemas de registros actuales" (T132), "implica modificar la forma de pensar de la infermera...i abandonar la idea que tenim de salut (com absència de malaltia" (T140)).

\subsubsection{ANÁLISIS DE LOS TRABAJOS EN RELACION AL MODELO DE IMOGENE M. KING EN}

LA PRÁCTICA

4.3.6.1 Descripción de los sujetos en los que fue aplicado el modelo de I. King en el plan de cuidados

De los 17 procesos enfermeros que usaron a I. King para su desarrollo, se utilizaron 12 para el presente análisis. En la figura 17 se puede objetivar la distribución por edades de los sujetos en los que fue aplicado el modelo y en la tabla 33 podemos ver su proceso patológico y especialidad o lugar donde fue aplicado.

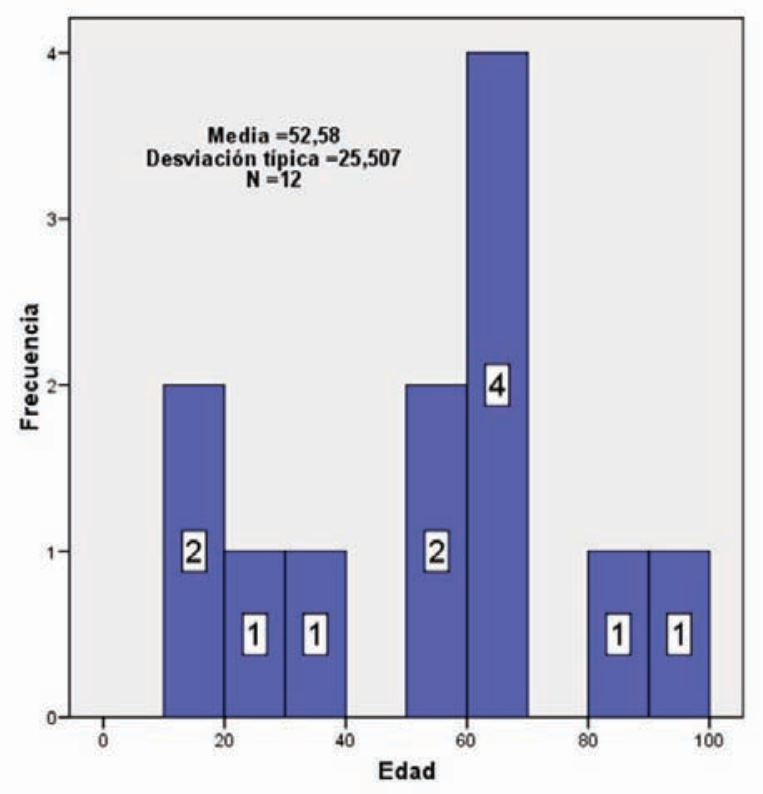

Figura 17: Histograma de la distribución por edades de los pacientes a los que se aplicó el modelo de I. King en el plan de cuidados 
Tabla 33: Características de los pacientes en los que fue aplicado el modelo enfermero de I. King para la elaboración del proceso enfermero

\begin{tabular}{|c|c|c|c|}
\hline Especialidad médica & Patología /Diagnóstico médico & Edad & $\begin{array}{l}\text { Código del traba- } \\
\text { jo }\end{array}$ \\
\hline \multirow{5}{*}{$\begin{array}{l}\text { Atención domiciliaria y } \\
\text { Centro de Atención } \\
\text { Primaria }\end{array}$} & Seguimiento tras PTC & 80 & T60 \\
\hline & Seguimiento DM & 29 & T47 \\
\hline & Educación DM. Debut. & 68 & T136 \\
\hline & Seguimiento adolescencia & 16 & T103 \\
\hline & Depresión por muerte familiar & 51 & T128 \\
\hline CCEE Hospital & Desnutrición (Marroquí) & 50 & T135 \\
\hline \multirow{2}{*}{ Traumatología } & PTC & 65 & T134 \\
\hline & PTC & 65 & T143 \\
\hline \multirow{2}{*}{$\begin{array}{l}\text { Hospitalización Mater- } \\
\text { nidad }\end{array}$} & Parto adolescente de bebé prematuro & 16 & T131 \\
\hline & Parto por cesárea & 31 & T168 \\
\hline Oncología & Linfoma & 62 & T48 \\
\hline Urgencias & Neumonía & 98 & T74 \\
\hline
\end{tabular}

4.3.6.2 Situaciones para las que fue recomendado el modelo de I. King

Fueron pocas las situaciones en las que fue recomendado el uso del modelo de I. King. Los estudiantes hicieron algunas recomendaciones para su uso en atención primaria, investigación y en la etapa de la adolescencia, pero sin argumentar los motivos. Además, comentaron que no sería recomendable en niños o personas con problemas en la comunicación.

("en cualquier situación que pueda haber interacción mediante la comunicación...es importante que haya una buena predisposición por parte de los dos...intercambio de opiniones y percepciones", "paciente que su estado vital nos permita comunicación").

\subsubsection{Aspectos positivos de la aplicación del modelo de I. King}

Las reflexiones positivas hacia el modelo de I. King se resumen en cuanto a la claridad, en que era un modelo claro y sencillo, que según la simplicidad clarificaba las acciones a realizar por el profesional de enfermería a través de la especificación clara del abordaje de objetivos o metas mediante las transacciones.

("Io más importante son los objetivos que se establecen en las transacciones establecidas entre enfermera y cliente" (T47), "va a la búsqueda de soluciones... centrado en conseguir objetivos deduciéndolos sobre el estado actual del paciente y sus posibilidades de éxito mediante un trabajo estandarizado y pensado" (T128)).

En relación a la generalidad tildaron al modelo como completo y en cuestión de precisión empírica era adaptable a diferentes situaciones. Indicaron de forma textual que les había sido de 
utilidad en el caso de un paciente con neumonía atendida en urgencias (T74), un parto prematuro de una adolescente y un parto por cesárea en maternidad (T131, T168).

("...dels models més complerts" (T60), "en el caso que nos ocupa... sería plausible ya que se trata de un caso donde el paciente es capaz de comunicarse" (T74), "nos ha permitido abarcar toda la complejidad que representa el caso elegido... nos ha permitido organizar un plan de cuidados en el que hemos podido dar forma a toda la información que íbamos recabando en el banco de datos" (T131), "se ajusta perfectamente al caso que planteamos... una intervención quirúrgica... no deja de ser una fuente de estrés" (T168)).

En cuanto a consecuencias deducibles, razonaron que aportaba conocimiento a la enfermera y potenciaba el papel de la persona en el cuidado tratándolo como un igual. Asimismo, comentaron que daba relevancia al aspecto psicosocial, al entorno y a la comunicación con la persona cuidada.

("...aporta coneixements i habilitats per aplicar el PAI" (T60), "ofrece la posibilidad de tratar al paciente como un igual y a partir de aquí trabajar por el bien mútuo" (T74), "tuvo en cuenta la interrelación entre el ser humano y la sociedad... participación del paciente en el logro de metas" (T128), "sea protagonista de su parto... cuando recibimos información podemos decidir... hacernos responsables de nuestro proceso de salud" (T168), "visión que te permita explorar e incorporar el significado psicológico de los hechos, sentimientos y conductas de las intervenciones enfermeras" (T128), "nos permite tratar al paciente en su totalidad y en relación abierta con su entorno" (T143), "uno de los aspectos más importantes... la comunicación en este tipo de procesos hace que la mujer tenga una vivencia más positiva del proceso" (T168)).

\subsubsection{Aspectos negativos en relación a la aplicación del modelo de I. King}

En cuanto a los comentarios negativos del modelo, destacaron que en relación a la simplicidad es un modelo que implicaba subjetividad principalmente en la valoración.

("Ia percepció és individual i subjectiva i pot portar a situacions contradictòries...la comunicació pot ser errònea depenent de l'explicació i la recepció" (T60)).

Al analizar los comentarios en relación a la generalidad fue un modelo que se mostró limitado si había trastornos en la comunicación. 
("Se centra principalmente a las fases de planificación y aplicación del PAE, que en pacientes que no pueden interaccionar mediante la comunicación verbal sea difícil de aplicar" (T48), "limitado en pacientes con nula o poca capacidad de comunicación" (T128)).

Además comentaron que no era un modelo aplicable en nuestro entorno o en algunos de los casos planteados (en cuanto a precisión empírica), no fue decisivo en el caso de un paciente con neumonía tratado en urgencias (T74), ni en la atención al parto de una adolescente con un bebé prematuro (T131).

("otra cuestión sería.... si el sistema sanitario está preparado para incluir la participación de los pacientes... el sistema está enfocado más hacia los profesionales... necesitaría un proceso de "reeducación" de los profesionales para que se admitiera no solo la voz sino el voto de nuestros pacientes" (T74), "en alguna ocasión nuestros objetivos han sido incongruentes con los de la paciente" (T131)).

En relación a las consecuencias deducibles del modelo, los estudiantes abstrajeron que la recogida de datos no era sistemática, y que daba poca relevancia a la valoración física del paciente, además requiería de largo tiempo para su implementación y no era aplicable si la persona cuidada no deseaba colaborar.

("...me he centrado más en necesidades psicológicas o emotivas" (T48), “...poco preocupado por una recogida de datos sistemática o una evaluación eficaz... no se destaca el componente físico del paciente" (T128), "requerimiento de tiempo y mucha dedicación por parte del profesional y de la persona afectada" (T136), "que no es vulgui col/laborar en les tasques a realizar. De vegades el client està negatiu a tot el que se li oferta" (T60)).

\subsubsection{ANÁLISIS DE LOS TRABAJOS EN RELACION AL MODELO DE MADELEINE M.} LEININGER EN LA PRÁCTICA

4.3.7.1 Descripción de los sujetos en los que fue aplicado el modelo de M. Leininger en el plan de cuidados

De los 17 procesos enfermeros, se utilizaron 12 para el presente análisis de la aplicación del modelo de M. Leininger. En la figura 18 se puede ver la distribución por edades de los suje- 
tos en los que fue aplicado el proceso siguiendo el modelo. La tabla 34 muestra el proceso patológico y especialidad o lugar donde fue aplicado.

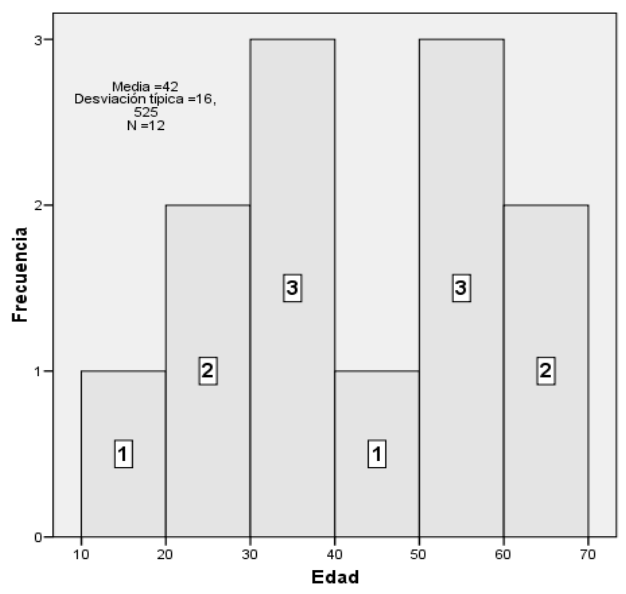

Figura 18: Histograma de la distribución por edades de los pacientes a los que se aplicó el modelo de M. Leininger en el plan de cuidados

Tabla 34: Características de los pacientes en los que fue aplicado el modelo enfermero de M. Leininger para la elaboración del proceso enfermero

\begin{tabular}{|l|l|l|l|}
\hline Especialidad médica & Patología /Diagnóstico médico & Edad & $\begin{array}{l}\text { Código del traba- } \\
\text { jo }\end{array}$ \\
\hline $\begin{array}{l}\text { Centro de Atención } \\
\text { Primaria }\end{array}$ & $\begin{array}{l}\text { Control heridas posterior a intervención } \\
\text { quirúrgica hallux valgus }\end{array}$ & 62 & T150 \\
\hline CCEE Hospital & Ángor & 68 & T141 \\
\hline Unidad de Cardiología & $\begin{array}{l}\text { Seguimiento DM gestacional (Paciente de } \\
\text { etnia gitana) }\end{array}$ & 16 & T86 \\
\hline Cirugía Traumatológica & $\begin{array}{l}\text { Síndrome de Wilson. Úlcera por presión en } \\
\text { trocánter. Traqueostomía }\end{array}$ & 27 & T181 \\
\hline Unidad de Ginecología & $\begin{array}{l}\text { Necrosis miomatosa y endometriosis. Re- } \\
\text { chazo a tratamiento }\end{array}$ & 50 & T151 \\
\hline $\begin{array}{l}\text { Unidad de enfermeda- } \\
\text { des infecciosas }\end{array}$ & Infección por TBC. Origen Magrebí & 35 & T32 \\
\hline Sala de Maternidad & Parto por cesárea. Marroquí & 20 & T166 \\
\hline Salud Mental & Trastorno Psicótico. Nigeriana & 35 & T94 \\
\hline Sala Hemodiálisis & $\begin{array}{l}\text { Insuficiencia renal. Mal cumplidor del tra- } \\
\text { tamiento. Origen Magrebí }\end{array}$ & 47 & T149 \\
\hline $\begin{array}{l}\text { Centro Centro de larga } \\
\text { estancia }\end{array}$ & $\begin{array}{l}\text { Fractura de cúbito y radio. Esquizofrenia. } \\
\text { Problema social }\end{array}$ & 58 & T155 \\
\hline Urgencias & $\begin{array}{l}\text { Herido pierna izquierda accidentalmente } \\
\text { por traslado en patera (persona de raza } \\
\text { negra, africano) }\end{array}$ & 36 & T146 \\
\hline
\end{tabular}




\subsubsection{Situaciones para las que fue recomendado el modelo de M. Leininger}

El modelo de M. Leininger fue recomendado para ser usado en atención primaria, en salud mental y en personas de diferentes entornos culturales. Un estudiante comentó que podría ser generalizable a cualquier situación. Los estudiantes no hicieron comentario alguno en cuanto a situaciones de no aplicabilidad del modelo.

("consultes planificades per portar a terme una dieta", "pacientes psiquiátricos, pacientes anoréxicas", "intervenciones de enfermería donde exista interacción cultural y el individuo pueda expresar sus creencias, valores...", "aunque...en el fondo cada persona tiene de base su biografía, una educación, valores, orden de prioridades, etc....que no siempre son compartidos por las demás personas").

4.3.7.3 Aspectos positivos de la aplicación del modelo de M. Leininger

Las reflexiones positivas hacia el modelo M. Leininger se resumieron en cuanto a la claridad, fue considerado un modelo claro y sencillo. Con respecto a la simplicidad según los alumnos clarificaba el rol enfermero.

(Comprensiva... bien organizados y definidos para su estudio en culturas concretas" (T86), "model fàcil d'entendre però alhora complex i profund" (T150), "permite valorar con profundidad el estado" (T141), "on es necessita un gran coneixement de la persona $i$ del seu entorn" (T150), "útil para identificar los diagnósticos de enfermería" (T141)).

En el análisis de los textos en cuanto a la precisión empírica, era un modelo calificado como adaptable y aplicable en algunos de los casos planteados. Específicamente los casos en los que se concretó su utilidad fueron: en el seguimiento en CCEE de una paciente de etnia gitana en gestación (T86), en una paciente magrebí ingresada en cardiología por desnutrición (T135), en un paciente con ángor seguido en CCEE (T141) y en un paciente seguido en primaria para control de herida quirúrgica tras intervención de hallux valgus (T150).

("...útil y aplicable... más adecuado para nuestro caso...es una chica que pertenece a una etnia diferente a la nuestra, donde el concepto de familia, de salud/enfermedad, de procreación o de convivencia varia considerablemente" (T86), “...tenerse en cuenta valores y las creencias de la cultura marroquí le hemos ayudado y apoyado para que mantenga su bienestar" (T135), “...es eficaz para la situación de V.S.P ya que permite planificar cuidados para mejorar las condiciones de vida de la paciente... muy útil para empatizar con la paciente" (T141), “...aplicable al nostre cas" (T150)). 
De los comentarios que hacen alusión a las consecuencias deducibles, los estudiantes alegaron que favorecía el papel activo de la persona en el cuidado, daba relevancia a la comunicación y aportaba cuidados culturalmente adaptados.

('...utilizamos métodos para que el paciente pueda entender y cooperar de forma directa lo cual hace que el modelo sea más eficaz" (T135), "una participación activa del paciente en el proceso" (T151), “...importancia comunicación entre enfermerapaciente" (T151), "...favorece la proporción de cuidado enfermero específico y congruente culturalmente" (T81), “...los problemas que atañen al campo cultural se resuelven mejor con Leininger... permite dar una atención coherente al paciente respetando los valores de su cultura... preservando, acomodando o remodelando sus creencias a sus problemas de salud" (T149)).

\subsubsection{Aspectos negativos en relación a la aplicación del modelo de M. Leiniger}

Entre los aspectos que no convencieron del modelo de Leininger, algunos alumnos comentaron que en cuanto a la claridad era confuso y carecía de concreción para ser aplicado.

("ambigüedad y poca concreción acerca de cómo aplicar prácticamente el modelo... manejamos los conceptos de preservación, acomodación y remodelación, no habiendo quedado muy claros" (T32)).

No hicieron comentarios en cuanto a la simplicidad, pero si a la generalidad, tachándolo de incompleto.

("li manca una vessant... crec que és simple. Només desenvolupa en el seu model les dimensions de l'estructura cultural i social" (T94), "modelo parcial, poco útil dentro de un mismo marco social" (T146)).

En la categoría de precisión empírica, tuvieron problemas para que el modelo se pudiera aplicar en nuestro contexto o al caso concreto planteado, pese a ser usado en situaciones que a priori podrían ser las más indicadas. Bien por la deficiente formación de las propias enfermeras en aspectos culturales, o por las propias características de las personas cuidadas. No fue adecuado en una paciente con necrosis miomatosa y endometriosis con negativa a ser tratada en unidad de ginecología (T151), tampoco en un paciente con fractura de cúbito y radio y esquizofrenia en centro centro de larga estancia (T155), o en el parto de una mujer marroquí (T166).

("...nuestro sistema sanitario carece de las capacidades para que el modelo de Leininger sea llevado a la práctica... los propios profesionales, ya que carecemos de la formación 
suficiente en cuanto a transculturalidad que propone" (T81), "...esperábamos que nos aportara herramientas muy valiosas para mejorar el cuidado en nuestra población inmigrante con la que trabajamos" (T32), "Aplicabilidad sobre el caso clínico: M.L. sí, pero no es el más adecuado modelo" (T151), "tal vez no sea el adecuado para este cliente... debido a la esquizofrenia que presenta es muy complicado aplicar las tres posibles clases de asistencia de preservar como dar y reestructurar los cuidados culturales" (T155), "en el caso estudiado el problema principal es el cultural, situación en que el modelo de Leininger parecía adecuado, pero se pueden desconsiderar aspectos trascendentales del mismo caso relativos a factores inferiores como la mala nutrición directamente relacionada con ayuno ritual, a pesar de que la paciente soporta, paradójicamente una obesidad" (T166)).

En relación a consecuencias deducibles, los estudiantes discutieron la recogida de datos, comentando que era escasa la valoración física del paciente, requiería largo tiempo para su implementación y formación adicional de la enfermera/o. Además, fue tachado como inoportuno para aplicar el proceso enfermero.

("se dirige directamente a los valores de expresión, creencias, y acciones fundamentadas en estilos de vida y la cultura sin profundizar, a nuestro juicio, en la parte biológica" (T166), "poco tangible, no referente a necesidades físicas ni biológicas" (T146), "no sirve como una regla de valoración anatómico - fisiológico" (T155), "a mes d'una bona planificiació del temps... per poder portar a terme una bona valoració de la persona i poder aplicar be el model és necessari fer un plantejament en el temps" (T150), "requiere, por tanto cierta formación en Antropología" (T86), "precisa de gran conocimiento de las características de cada cultura" (T151), "difícil de amoldar al PAE" (T146)).

\subsubsection{Resumen de los datos obtenidos en este objetivo}

Una vez expuestos los resultados para los diferentes modelos aplicados en los planes de cuidados, la información fue sintetizada teniendo en cuenta la edad de las personas cuidadas, la resolución aportada a los casos planteados y los ámbitos en los que fue propuesto el modelo.

Respecto a un breve análisis cuantitativo, en la figura 19 se pueden comparar las edades con los modelos aplicados en los planes. El modelo de D. Orem es el que se ha aplicado en un mayor rango de edades, podríamos decir que es también el modelo más aplicado en los pacientes de edad avanzada. El modelo aplicado a sujetos más jóvenes fue el de M. Leininger. 


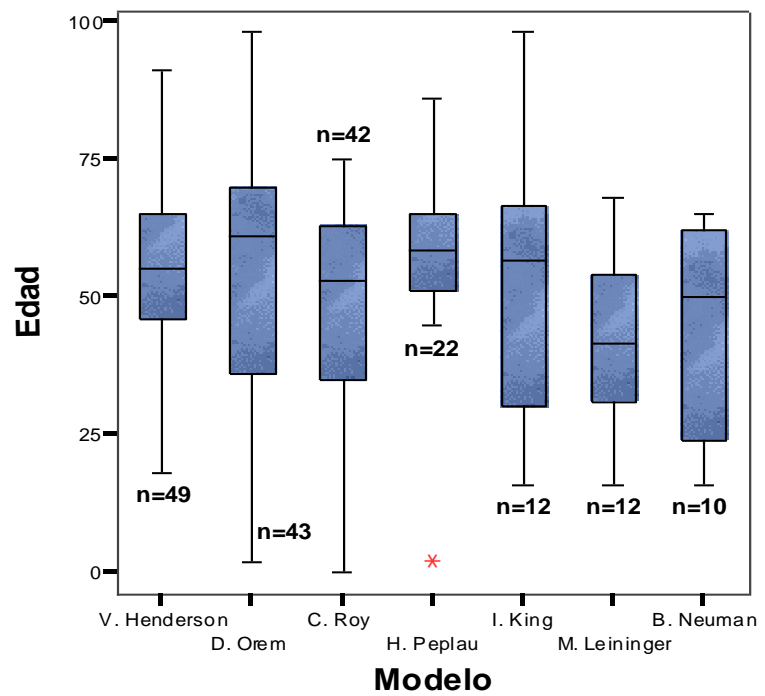

Figura 19: Comparativo de las edades frente a los modelos aplicados en los planes estudiados

En atención primaria, los modelos más usados fueron los de C. Roy, D. Orem y V. Henderson. No obstante, la mayoría de los trabajos se llevaron a cabo en hospitalización. En las especialidades médicas se aplicaron preferentemente también los modelos nombrados, destacando la aplicación del modelo de autocuidado de Orem en neurología y en unidades de larga estancia. En las unidades especiales como urgencias también se usaron los mismos modelos. Destacar que no es relevevante hacer un análisis exhaustivo para el resto de ámbitos por el poco número de planes de cuidados recogidos en ellos. Los datos concretos se recogen en la tabla 35.

Tabla 35: Resumen de los ámbitos elegidos para la aplicación de los modelos

\begin{tabular}{|c|c|c|c|c|c|c|c|c|c|}
\hline Ámbito & & $\begin{array}{l}\text { B. Neu- } \\
\text { man }\end{array}$ & $\begin{array}{l}\text { C. } \\
\text { Roy }\end{array}$ & $\begin{array}{l}\text { D. } \\
\text { Orem }\end{array}$ & $\begin{array}{l}\text { H. Pe- } \\
\text { plau }\end{array}$ & I. King & $\begin{array}{l}\text { M. Lei- } \\
\text { ninger }\end{array}$ & $\begin{array}{l}\text { V. Hen- } \\
\text { derson }\end{array}$ & Total \\
\hline \multirow{2}{*}{ Atención comunitaria } & Rto. & 2 & 10 & 9 & 5 & 5 & 1 & 10 & 42 \\
\hline & $\%$ & 4,8 & 23,8 & 21,4 & 11,9 & 11,9 & 2,4 & 23,8 & 100 \\
\hline \multirow{2}{*}{$\begin{array}{l}\text { Hospitalización cardio- } \\
\text { logía }\end{array}$} & Rto. & 0 & 4 & 2 & 0 & 0 & 1 & 6 & 13 \\
\hline & $\%$ & 0 & 30,8 & 15,4 & 0 & 0 & 7,7 & 46,2 & 100 \\
\hline \multirow{2}{*}{ Hospitalización cirugía } & Rto. & 5 & 9 & 10 & 5 & 2 & 1 & 9 & 41 \\
\hline & $\%$ & 12,2 & 22 & 24,4 & 12,2 & 4,9 & 2,4 & 22 & 100 \\
\hline \multirow{2}{*}{$\begin{array}{l}\text { Hospitalización medi- } \\
\text { cina interna }\end{array}$} & Rto. & 0 & 2 & 2 & 2 & 0 & 1 & 1 & 8 \\
\hline & $\%$ & 0 & 25 & 25 & 25 & 0 & 12,5 & 12,5 & 100 \\
\hline \multirow{2}{*}{$\begin{array}{l}\text { Hospitalización neu- } \\
\text { mología }\end{array}$} & Rto. & 0 & 0 & 0 & 1 & 0 & 0 & 1 & 2 \\
\hline & $\%$ & 0 & 0 & 0 & 50 & 0 & 0 & 50 & 100 \\
\hline \multirow{2}{*}{$\begin{array}{l}\text { Hospitalización neuro- } \\
\text { logía }\end{array}$} & Rto. & 1 & 1 & 6 & 2 & 0 & 0 & 3 & 13 \\
\hline & $\%$ & 7,7 & 7,7 & 46,2 & 15,4 & 0 & 0 & 23,1 & 100 \\
\hline \multirow{2}{*}{$\begin{array}{l}\text { Hospitalización onco- } \\
\text { logía }\end{array}$} & Rto. & 0 & 6 & 0 & 1 & 1 & 0 & 3 & 11 \\
\hline & $\%$ & 0 & 54,5 & 0 & 9,1 & 9,1 & 0 & 27,3 & 100 \\
\hline \multirow{2}{*}{$\begin{array}{l}\text { Salud mental (CCEE y/o } \\
\text { hospitalización) }\end{array}$} & Rto. & 0 & 1 & 2 & 1 & 0 & 1 & 4 & 9 \\
\hline & $\%$ & 0 & 11,1 & 22,2 & 11,1 & 0 & 11,1 & 44,4 & 100 \\
\hline
\end{tabular}




\begin{tabular}{|c|c|c|c|c|c|c|c|c|c|}
\hline Ámbito & & $\begin{array}{l}\text { B. Neu- } \\
\text { man }\end{array}$ & $\begin{array}{l}\text { C. } \\
\text { Roy }\end{array}$ & $\begin{array}{l}\text { D. } \\
\text { Orem }\end{array}$ & $\begin{array}{l}\text { H. Pe- } \\
\text { plau }\end{array}$ & I. King & $\begin{array}{l}\text { M. Lei- } \\
\text { ninger }\end{array}$ & $\begin{array}{l}\text { V. Hen- } \\
\text { derson }\end{array}$ & Total \\
\hline \multirow{2}{*}{$\begin{array}{l}\text { Unidad de reanimación } \\
\text { postquirúrgica }\end{array}$} & Rto. & 0 & 0 & 0 & 0 & 0 & 0 & 1 & 1 \\
\hline & $\%$ & 0 & 0 & 0 & 0 & 0 & 0 & 100 & 100 \\
\hline \multirow{2}{*}{$\begin{array}{l}\text { Residencia, centro de } \\
\text { larga estancia }\end{array}$} & Rto. & 0 & 1 & 3 & 2 & 0 & 1 & 2 & 9 \\
\hline & $\%$ & 0 & 11,1 & 33,3 & 22,2 & 0 & 11,1 & 22,2 & 100 \\
\hline \multirow{2}{*}{$\begin{array}{l}\text { Urgencias (SEM o hos- } \\
\text { pitalarias) }\end{array}$} & Rto. & 0 & 4 & 6 & 0 & 1 & 1 & 5 & 17 \\
\hline & $\%$ & 0 & 23,5 & 35,3 & 0 & 5,9 & 5,9 & 29,4 & 100 \\
\hline \multirow{2}{*}{$\begin{array}{l}\text { Unidad de cuidados } \\
\text { intensivos }\end{array}$} & Rto. & 0 & 1 & 0 & 0 & 0 & 0 & 3 & 4 \\
\hline & $\%$ & 0 & 25 & 0 & 0 & 0 & 0 & 75 & 100 \\
\hline \multirow{2}{*}{$\begin{array}{l}\text { Unidad de cuidados } \\
\text { paliativos }\end{array}$} & Rto. & 0 & 0 & 0 & 1 & 0 & 0 & 1 & 2 \\
\hline & $\%$ & 0 & 0 & 0 & 50 & 0 & 0 & 50 & 100 \\
\hline \multirow{2}{*}{ CCEE hospital } & Rto. & 1 & 0 & 1 & 1 & 1 & 3 & 0 & 7 \\
\hline & $\%$ & 14,3 & 0 & 14,3 & 14,3 & 14,3 & 42,9 & 0 & 100 \\
\hline \multirow{2}{*}{$\begin{array}{l}\text { Hospitalización mater- } \\
\text { nidad - sala de partos }\end{array}$} & Rto. & 1 & 1 & 1 & 0 & 2 & 1 & 0 & 6 \\
\hline & $\%$ & 16,7 & 16,7 & 16,7 & 0 & 33,3 & 16,7 & 0 & 100 \\
\hline \multirow{2}{*}{$\begin{array}{l}\text { Hospitalización Pe- } \\
\text { diatría }\end{array}$} & Rto. & 0 & 2 & 1 & 1 & 0 & 0 & 0 & 4 \\
\hline & $\%$ & 0 & 50 & 25 & 25 & 0 & 0 & 0 & 100 \\
\hline \multirow{2}{*}{$\begin{array}{l}\text { Hospitalización gineco- } \\
\text { logía }\end{array}$} & Rto. & 0 & 0 & 0 & 0 & 0 & 1 & 0 & 1 \\
\hline & $\%$ & 0 & 0 & 0 & 0 & 0 & 100 & 0 & 100 \\
\hline \multirow{2}{*}{ Totales } & Rto. & 10 & 42 & 43 & 22 & 12 & 12 & 49 & 190 \\
\hline & $\%$ & 5,3 & 22,1 & 22,6 & 11,6 & 6,3 & 6,3 & 25,8 & 100 \\
\hline
\end{tabular}

Las tablas 36 y 37 resumen las situaciones en para las que cada modelo podría ser adecuado, destacar que los modelos que fueron recomendados para diferentes problemas de salud fueron el modelo de V. Henderson, D. Orem y C. Roy; exceptuando el servicio de urgencias, unidad de cuidados intensivos y área quirúrgica, en los que ningún modelo fue recomendado.

Tabla 36: Resumen de la adecuación del uso del modelo en los casos planteados (cuando así lo explicitaron los alumnos de forma textual)

\begin{tabular}{|c|c|c|}
\hline Modelo & $\begin{array}{l}\text { Ámbito y patología de los pacientes para los que el } \\
\text { modelo fue resolutivo }\end{array}$ & $\begin{array}{l}\text { Ámbito y patología en los que no fue } \\
\text { del todo adecuado su uso }\end{array}$ \\
\hline V. Henderson & $\begin{array}{l}\text { - Atención primaria: seguimiento post AVC, cui- } \\
\text { dador paciente con demencia. } \\
\text { - Hospitalización: úlceras vasculares, neo de co- } \\
\text { lon, Cl, valvulopatía cardíaca, EPOC, neo de } \\
\text { próstata. } \\
\text { - Urgencias: disnea. } \\
\text { - UCI: Cl. }\end{array}$ & $\begin{array}{l}\text { - Urgencias: en cardiopatía isquémica } \\
\text { - Salud mental: trastorno bipolar }\end{array}$ \\
\hline
\end{tabular}




\begin{tabular}{|c|c|c|}
\hline Modelo & $\begin{array}{l}\text { Ámbito y patología de los pacientes para los que el } \\
\text { modelo fue resolutivo }\end{array}$ & $\begin{array}{l}\text { Ámbito y patología en los que no fue } \\
\text { del todo adecuado su uso }\end{array}$ \\
\hline D. Orem & $\begin{array}{l}\text { - } \quad \text { Atención primaria: seguimiento DM. } \\
\text { - Hospitalización: TBC (Síndrome de Down), Cl, } \\
\text { síndrome de Wilson. } \\
\text { - Salud mental: trastorno psicótico. } \\
\text { - Sala de partos: parto. } \\
\text { - } \quad \text { Pediatría: fractura de fémur } \\
\text { - } \quad \text { Centro de larga estancia: PTC }\end{array}$ & $\begin{array}{l}\text { - Hospitalización: isquemia en extremi- } \\
\text { dades con amputación y en síndrome } \\
\text { de cautiverio } \\
\text { - Urgencias: neumonía } \\
\text { - Consultas externas: seguimiento de la } \\
\text { gestación de paciente de etnia gitana. }\end{array}$ \\
\hline C. Roy & $\begin{array}{l}\text { - Atención primaria: seguimiento post AVC } \\
\text { - Hospitalización: neo de colon ( } 3 \text { casos), isque- } \\
\text { mia en extremidades con amputación, neo de } \\
\text { mama mastectomizada, } \\
\text { - Pediatría: bronquitis aguda }\end{array}$ & $\begin{array}{l}\text { - Salud mental: anorexia } \\
\text { - Hospitalización: TBC persona ma- } \\
\text { grebí } \\
\text { - Salud mental: anorexia }\end{array}$ \\
\hline B. Neuman & $\begin{array}{l}\text { - Atención primaria: seguimiento post IAM y } \\
\text { consejo antitabaco. } \\
\text { - Hospitalización: PTC ( } 2 \text { casos). } \\
\text { - CCEE: Nefropatia. }\end{array}$ & \\
\hline I. King & - Sala de partos: parto por cesárea. & $\begin{array}{l}\text { - Urgencias: neumonía. } \\
\text { - Sala de partos: parto prematuro en } \\
\text { adolescente. }\end{array}$ \\
\hline H. Peplau & $\begin{array}{l}\text { - Atención primaria: seguimiento obesidad, se- } \\
\text { guimiento depresión tras muerte de un } \\
\text { familiar, soporte a cuidadora. } \\
\text { - Hospitalización: neo de pulmón, isquemia en } \\
\text { extremidades con amputación. } \\
\text { - CCEE: Nefropatía (mal cumplidor de tratamien- } \\
\text { to, marroquí). } \\
\text { - Centro de larga estancia: fractura cubito y radio } \\
\text { con esquizofrenia. }\end{array}$ & $\begin{array}{l}\text { - Hospitalización: neo de colon y } \\
\text { pulmón. } \\
\text { - Pediatría: fractura de fémur. } \\
\text { - Centro de larga estancia: demencia. }\end{array}$ \\
\hline M. Leininger & $\begin{array}{l}\text { - Atención primaria: seguimiento post interven- } \\
\text { ción hallux valgus. } \\
\text { - CCEE: seguimiento embarazo (etnia gitana), } \\
\text { seguimiento Angor } \\
\text { - Hospitalización: desnutrición (magrebí) }\end{array}$ & $\begin{array}{l}\text { - Hospitalización: necrosis miomato- } \\
\text { sa y endometrosis } \\
\text { - Centro de larga estancia: fractura } \\
\text { de cúbito y radio con esquizofrenia } \\
\text { - Sala de partos: parto (marroquí) }\end{array}$ \\
\hline
\end{tabular}


Tabla 37: Situaciones en las que se recomendó el uso del modelo

\begin{tabular}{|c|c|c|c|c|c|c|c|}
\hline Ámbito /Teorista & $\begin{array}{l}\text { V. Hender- } \\
\text { son }\end{array}$ & $\begin{array}{c}\text { D. } \\
\text { Orem }\end{array}$ & $\begin{array}{l}\text { C. } \\
\text { Roy }\end{array}$ & $\begin{array}{l}\text { H. Pe- } \\
\text { plau }\end{array}$ & $\begin{array}{l}\text { B. Neu- } \\
\text { man }\end{array}$ & I. King & $\begin{array}{l}\text { M. Leinin- } \\
\text { ger }\end{array}$ \\
\hline $\begin{array}{l}\text { Atención comunitaria } \\
\text { /domiciliaria }\end{array}$ & $\uparrow$ & $\uparrow$ & $\uparrow$ & & & $\uparrow$ & $\uparrow$ \\
\hline $\begin{array}{l}\text { Hospitalización en procesos } \\
\text { agudos }\end{array}$ & $\uparrow$ & $\uparrow$ & $\uparrow$ & $\uparrow$ & $\leftrightarrow$ & & \\
\hline $\begin{array}{l}\text { Hospitalización maternidad - } \\
\text { sala de partos, seguimiento } \\
\text { del embarazo }\end{array}$ & & $\uparrow$ & $\uparrow$ & & & & \\
\hline $\begin{array}{l}\text { Urgencias (SEM o hospitala- } \\
\text { rias) }\end{array}$ & $\leftrightarrow$ & $\downarrow$ & $\downarrow$ & $\downarrow$ & & & \\
\hline $\begin{array}{l}\text { Unidad de cuidados intensi- } \\
\text { vos }\end{array}$ & $\leftrightarrow$ & & $\downarrow$ & & & & \\
\hline Área quirúrgica & & & $\downarrow$ & & & & \\
\hline $\begin{array}{l}\text { Rehabilitación y adaptación } \\
\text { a nueva situación de salud } \\
\text { (procesos crónicos) }\end{array}$ & $\uparrow$ & $\uparrow$ & $\uparrow$ & $\uparrow$ & $\uparrow$ & & \\
\hline Adolescencia & & $\uparrow$ & & & & $\uparrow$ & \\
\hline Pediatría & $\uparrow$ & $\leftrightarrow$ & $\uparrow$ & & & & \\
\hline $\begin{array}{l}\text { Salud mental (CCEE y/o hos- } \\
\text { pitalización, tratamiento de } \\
\text { adicciones) }\end{array}$ & $\leftrightarrow$ & $\leftrightarrow$ & $\uparrow$ & $\uparrow$ & $\uparrow$ & & $\uparrow$ \\
\hline $\begin{array}{l}\text { Residencia, centro de larga } \\
\text { estancia }\end{array}$ & $\uparrow$ & $\uparrow$ & $\uparrow$ & $\uparrow$ & $\uparrow$ & & \\
\hline $\begin{array}{l}\text { Unidad de cuidados paliati- } \\
\text { vos }\end{array}$ & $\uparrow$ & $\uparrow$ & $\uparrow$ & & & & \\
\hline $\begin{array}{l}\text { Abordaje de cuidadores in- } \\
\text { formales }\end{array}$ & & & $\uparrow$ & $\uparrow$ & $\uparrow$ & & \\
\hline Procesos de duelo & & & & & $\uparrow$ & & \\
\hline Docencia & $\uparrow$ & & & & & & \\
\hline Investigación & $\uparrow$ & & & & & $\uparrow$ & \\
\hline Culturas minoritarias & & & & & & & $\uparrow$ \\
\hline
\end{tabular}

个 Recomendado

$\downarrow$ No recomendado

$\leftrightarrow$ Controversia en la recomendación, ya que hay alumnos que no lo recomendarían

Los aspectos mejor valorados en la elección de un modelo son la clarificación del rol propio, la potenciación del rol de la persona cuidada en su cuidado y su claridad y sencillez de aplicación (tal y como se puede evaluar en los aspectos evaluados como positivos de los diferentes modelos estudiados en la tabla 38). 
Tabla 38: Aspectos evaluados como positivos de los modelos aplicados en los planes de cuidados (sombreados)

\begin{tabular}{|c|c|c|c|c|c|c|c|}
\hline Aspectos valorados & 1 & 2 & 3 & 4 & 5 & 6 & 7 \\
\hline \multicolumn{8}{|l|}{ Claro y sencillo } \\
\hline \multicolumn{8}{|l|}{ Facilita la valoración completa } \\
\hline \multicolumn{8}{|l|}{ Valora de la dimensión psicológica } \\
\hline \multicolumn{8}{|l|}{ Clarifica el rol enfermero } \\
\hline \multicolumn{8}{|l|}{ Evalúa el proceso. } \\
\hline \multicolumn{8}{|c|}{ Útil aunque no se tenga continuidad en el cuidado del paciente } \\
\hline \multicolumn{8}{|c|}{ Gran amplitud de aplicación a diversidad de pacientes } \\
\hline \multicolumn{8}{|c|}{ Se adapta a la variable sociocultural, el entorno del paciente } \\
\hline \multicolumn{8}{|c|}{ Potencia el rol de la persona en el propio cuidado (empodera) } \\
\hline \multicolumn{8}{|l|}{ Mejora la comunicación entre disciplinas } \\
\hline \multicolumn{8}{|l|}{ Considera el entorno familiar } \\
\hline \multicolumn{8}{|l|}{ Fácil para hallar información sobre el modelo } \\
\hline \multicolumn{8}{|c|}{ Se adapta al plan de cuidados y al uso de terminología NANDA. } \\
\hline \multicolumn{8}{|l|}{ Relevancia al aspecto psicosocial } \\
\hline \multicolumn{8}{|c|}{ Relevancia al desarrollo madurativo de la persona } \\
\hline \multicolumn{8}{|l|}{ Incluye promoción y educación para la salud } \\
\hline \multicolumn{8}{|l|}{ Costo - efectivo } \\
\hline Hace hincapié en el diagnóstico enfermero & & & & & & & \\
\hline
\end{tabular}

1. V. Henderson, 2. D. Orem, 3. C. Roy, 4. H. Peplau, 5. B. Neuman, 6. I. King, 7. M. Leininger

Sin embargo, entre los aspectos que peor son valorados de los modelos son su largo tiempo de implementación y que sea poco útil en la valoración física de la persona. Podemos ver que existe un mayor número de aspectos evaluados como negativos que como positivos (ver tabla 39).

Tabla 39: Aspectos evaluados como negativos de los modelos aplicados en los planes de cuidados (sombreados)

\begin{tabular}{|c|c|c|c|c|c|c|}
\hline Aspectos valorados como negativos & 1 & 2 & 3 & 4 & 5 & 7 \\
\hline Confuso y complejo si aparece depend & & & & & & \\
\hline Limitado a una visión biomédica tradic & & & & & & \\
\hline Incompleto por centrarse en aspectos & & & & & & \\
\hline Valoración física deficitaria & & & & & & \\
\hline Reiterativo en la valoración. & & & & & & \\
\hline Subjetividad en la valoración & & & & & & \\
\hline
\end{tabular}




\begin{tabular}{|c|c|c|c|c|c|c|}
\hline Aspectos valorados como negativos & 2 & 3 & 4 & 5 & 6 & 7 \\
\hline \multicolumn{7}{|c|}{ No deja claro cómo abordar a la familia, grupo social o entorno. } \\
\hline \multicolumn{7}{|l|}{ No valora la familia } \\
\hline \multicolumn{7}{|c|}{ Reduccionista sobre todo en su definición de salud sinónimo de independencia. } \\
\hline \multicolumn{7}{|l|}{ Requiere largo tiempo de implementación. } \\
\hline \multicolumn{7}{|c|}{ Paternalista, muy centrado en el quehacer enfermero y poco en el del paciente } \\
\hline \multicolumn{7}{|l|}{ Conceptos complejos } \\
\hline \multicolumn{7}{|l|}{ Dificultad para valorar dolor y autoestima } \\
\hline \multicolumn{7}{|l|}{ Inadecuado para situaciones de salud (no enfermedad) } \\
\hline \multicolumn{7}{|c|}{ Inadecuado al sistema de salud por elevado compromiso del paciente en su cuidado } \\
\hline \multicolumn{7}{|c|}{ No se adapta a terminología NANDA en situaciones de dependencia parcial } \\
\hline \multicolumn{7}{|l|}{ Falta concreción de cómo o cuando aplicarlo } \\
\hline \multicolumn{7}{|l|}{ Rol del paciente dependiente } \\
\hline \multicolumn{7}{|l|}{ No prioriza } \\
\hline \multicolumn{7}{|c|}{ No es útil en situaciones de salud rápidamente cambiantes } \\
\hline \multicolumn{6}{|l|}{ Precisa de gran capacitación de la enfermera } & \\
\hline \multicolumn{7}{|l|}{ Complejidad para valorar comportamientos } \\
\hline \multicolumn{7}{|c|}{ Poco aplicable en el cuidado de personas con limitaciones cognitivas o comunicativas } \\
\hline \multicolumn{7}{|l|}{ No permite evaluar resultados } \\
\hline \multicolumn{6}{|l|}{ Elevada carga emocional en la enfermera } & \\
\hline \multicolumn{7}{|l|}{ No adecuado a registros actuales } \\
\hline \multicolumn{6}{|l|}{ Elevado costes de aplicación } & \\
\hline \multicolumn{7}{|l|}{ No adecuado a situaciones agudas de enfermedad } \\
\hline No adecuado a su uso junto al proceso enfermero & & & & & & \\
\hline
\end{tabular}

1. V. Henderson, 2. D. Orem, 3. C. Roy, 4. H. Peplau, 5. B. Neuman, 6. I. King, 7. M. Leininger

4.4 Resultados en relación al cuarto objetivo: Identificar los elementos que han influenciado el uso teórico y desarrollo profesional de la enfermería en España desde la perspectiva de las enfermeras en periodo de formación de Máster

Se analizaron la totalidad de las respuestas dadas por los estudiantes en relación a los elementos que han influenciado el uso y desarrollo teórico y profesional de la enfermería. La ma- 
yoría de las mismas se implementaron en forma de listado enumerando los factores que creían relacionados con el desarrollo teórico y profesional de la enfermería y fueron pocos los que realizaron las respuestas en forma de texto narrado.

Debido a la extensión del objetivo, se realizó un análisis primeramente de los factores limitantes o barrera hallados y posteriormente se analizaron los elementos facilitadores. Se partió de un total de 301 trabajos, de los que se descartaron 14, por ausencia de análisis en relación a la propuesta realizada, por letra ilegible, o por evidenciarse ausencia de reflexión propia. Analizándose finalmente 154 trabajos en relación a elementos limitantes y 133 en relación a elementos facilitadores.

La totalidad de las citas textuales que argumentaban las categorías se hallan en el anexo IV del CD adjunto, en los resultados presentados se resaltan sólo algún verbatim de ejemplificación de las categorías. Las respuestas se clasificaron según los sujetos, se le asignó la letra "B" a los trabajos sobre barreras, y " $F$ " a los trabajos sobre facilitadores. Esta letra se acompañó el número de sujeto, de forma aleatoria, sin seguir orden prefijado en la asignación numérica. Por ello cada cita en los resultados va precedida de este código entre paréntesis.

El perfil de los estudiantes fue diverso en edad, situación familiar, perfil formativo, contexto sanitario, ámbito (asistencial, gestión y docente), años de experiencia laboral y lugar de procedencia. Son los mismos sujetos que se presentaron en el anterior objetivo (ver tabla 9, extraída de Zabalegui \& Macià, 2010).

\subsubsection{Resultados en relación a factores limitantes o barreras de aplicación de modelos teóricos en la práctica}

Se analizaron un total de 154 trabajos individuales. Tras la lectura repetida, se fueron clasificando los comentarios registrados en función de diferentes categorías. Una vez establecidas estas categorías, se procedió a relectura de las respuestas o comentarios clasificándolos en subcategorías dentro de cada una de las categorías.

Las categorías halladas en cuanto a los factores limitantes para el desarrollo teórico y profesional fueron:
4.4.1.1 Política no favorecedora de los centros sanitarios.
4.4.1.2 Escasa formación de las enfermeras.
4.4.1.3 Infravaloración social de la profesión enfermera.
4.4.1.4 Carácter indiferente del colectivo enfermero.
4.4.1.5 Falta de rol autónomo profesional. 


\subsubsection{POLÍTICA NO FAVORECEDORA DE LOS CENTROS SANITARIOS}

Se incluyeron en esta categoría todos los comentarios que hacían referencia a que las barreras fundamentalmente eran debidas a las estrategias llevadas a cabo en la gestión de los centros sanitarios, en cuanto a la organización del trabajo con respecto al desempeño de la labor enfermera. En 70 trabajos aparecieron comentarios incluidos en esta categoría (45,5\%). Se exponen a continuación acompañados de citas textuales ejemplificantes de los trabajos de los estudiantes.

a) Falta de recursos humanos y sobrecarga laboral.

("Falta de tiempo"(B2), "Ratios de enfermería - paciente bajos" (B4), "Sobrecarga de trabajo"( B22), "La presión asistencial"( B10), "Precariedad laboral"(B1)).

b) Gestión realizada de los centros sanitarios.

("...direcciones de enfermería cubrían para sacar trabajo y no como agentes de salud" (B13), "Contradicción de la política de la administración en materia de recursos humanos enfermeros y la planificación estratégica... no se detectan acciones en materia de cobertura y creación de puestos enfermeros... politización de los gestores... no se mantiene la continuidad de las políticas o líneas precedentes... muchos proyectos quedan inconclusos... pérdida de recursos" (B19), "Falta de participación en la toma de decisiones"(B42, B128)).

c) Apoyo recibido de las instituciones sanitarias.

("Falta de apoyo de instituciones sanitarias... falta de apoyo institucional y económico" (B36, B39), "Las instituciones sanitarias no han hecho grandes esfuerzos para que la profesión enfermera sea reconocida por su capacidad de ejecutar programas de salud" (B72)).

d) Estructura biomédica de las instituciones.

("Presión de técnicos y médicos" (B40, B43, B44), "Visión medicalizada de la salud y la enfermedad" (B127, B128), "La falta de orientación de los servicios de salud hacia un modelo de cuidados para la promoción y la prevención... crear la estructura para el desarrollo de la función" (B148)).

e) Baja retribución y contrato laboral precario que impiden continuidad en el cuidado.

("Retribuciones no siempre acordes al grado de formación y responsabilidad... Influencia negativa de la turnicidad" (B19)).

f) Exceso de medios de tratamiento y diagnóstico técnicos orientados al diagnóstico y tratamiento físico de la enfermedad. 
("Tecnificación" (B39, B127, B128), “Exceso de medidas terapéuticas diagnósticas" (B12)).

g) Socialización de los profesionales en prácticas rituales no basadas en evidencia científica.

("Los profesionales incorporados más recientemente con un gran potencial son absorbidos rápidamente por el sistema" (B14)).

\subsubsection{ESCASA FORMACIÓN DE LAS ENFERMERAS}

La categoría de formación de las enfermeras incluyó todos aquellos comentarios que se asociaron a la formación de los profesionales, tanto a nivel de pregrado como de postgrado, incluyendo alegaciones del tipo de falta de motivación, componente histórico, etc. pero en relación a la enseñanza enfermera. Un total de 85 trabajos hicieron alusión a este contenido (55,2\%). Reduciéndose a las siguientes categorías:

a) Referentes históricos negativos para el desarrollo profesional.

("Hasta 1977 la enfermería no fue estudio universitario... fue para ser una diplomatura... carrera media" (B21), “Órdenes religiosas” (B36, B39)).

b) Falta de desarrollo de las especialidades enfermeras.

("Asume campos de salud sin formación específica" (B138, B139, B141), "Los sucesivos gobiernos no acaban de desarrollar las leyes de especialización en enfermería" (B72)).

c) Ausencia de cuerpo de conocimiento propio.

("Se ha alimentado del resto de ciencias sin preocuparse de nutrir la suya propia" (B138, B139), "La práctica de la enfermería no ha avanzado a la misma velocidad que su desarrollo teórico... necesitamos coger el poder de los propios conocimientos generados en las teorías" (B42), "Falta de marco conceptual propio español” (B141)).

d) Insuficiente formación de postgrado.

("Los posgrado o Másteres... han servido más para lograr la entrada al mercado laboral que para la formación de la disciplina" (B144), "Falta de continuidad de los estudios... Dificultad para acceder a Máster por escasez de plazas... Poco tiempo para realizar estudios de postgrado" (B17)).

e) Formación guiada por profesionales médicos.

("Profesorado médico $\rightarrow$ visión biomédica" (B2, B127, B128), “Formación... realizada por licenciados en diferentes disciplinas como medicina, farmacia, químicas" (B96), “En algunas universidades el departamento de Enfermería depende de la facultad de 
Medicina... favorece que se vea supeditada a la profesión médica a nivel académico" (B145)).

f) Brecha entre teoría y práctica enfermera.

("Discordancia entre la formación ofertada en la universidad y la demanda del mercado laboral ...la formación impartida en la universidad va por delante de la demanda laboral... ha sido muy difícil organizar y desplegar el tipo de práctica cientifica y humana que los profesionales podemos desarrollar... Disociación teórico - práctica" (B19).

g) Escasa formación continuada de los profesionales de enfermería.

("Pobre formación continua" (B140), "Cursos de formación casi siempre referidos a actividades asistenciales" (B90)).

h) Insuficiente formación en el Grado/Diplomado Universitario de Enfermería.

("La formación generalista... no adecuada las expectativas o al posterior desarrollo profesional" (B75), "Deterioro de la formación pregrado, con disminución de los créditos de prácticas" (B99)).

i) Heterogeneidad profesional.

("En un mismo centro de trabajo existen diferentes niveles académicos entre los mismos profesionales... aún sigo conociendo ATS... que manifiestan no querer realizar los cursos de nivelación porque ya están bien como están” (B92) “No todas las profesiones... tienen el mismo grado de formación ni... es requisito para acceder a según qué puestos de trabajo" (B27)).

j) Falta de motivación para la propia formación como disciplina.

("Los profesionales no están interesados en enseñar... personas que reniegan por un motivo u otro de la función docente... los estudiantes viven esta situación con agobios y les supone una barrera para su aprendizaje... Hay compañeros que tienen suficiente con realizar técnicas básicas... repercute en una formación no actualizada" (B27))

k) Formación inadecuada de docentes universitarios.

("Actitudes de los profesionales docentes... paternalistas... o autoritarios... Falta de experiencia práctica de algunos profesores de nueva incorporación... El profesorado titular de las asignaturas de la Diplomatura de Enfermería no participa en labores asistenciales... Falta de formación para la docencia de gran parte del profesorado" (B46), "Existe un numero de profesores que no son titulados en Enfermería... como unos profesionales que no han sido formados en disciplina enfermera pueden transmitir valores y principios" (B145)). 
I) Barreras idiomáticas.

("Escaso conocimiento de inglés" (B95)).

m) Falta de reconocimiento de la formación enfermera.

("La organización sanitaria no premia lo suficiente la formación académica" (B91), "Las empresas no facilitan la formación de sus trabajadores... la formación llega a ser vivida como un castigo" (B27)).

\subsubsection{INFRAVALORACIÓN SOCIAL DE LA PROFESIÓN ENFERMERA}

Dentro de esta categoría, se agruparon aquellos comentarios en relación a lo que se espera socialmente de la profesión enfermera, la imagen social de la enfermera y las propias características de la población cuidada. En 90 trabajos (58,4\% de los trabajos) se hallaron comentarios con respecto a esta categoría que se clasifican en:

a) Profesión tradicionalmente femenina.

("Profesión femenina" (B22, B88, B96, B127, B128), "Los pocos cargos de responsabilidad los acaparan los profesionales de sexo masculino... discriminación sexual de la mujer... falta de ambición profesional... La palabra cuidar está relacionada con la función social de la mujer... la Enfermería es tratada... no como profesión" (B145)).

b) Concepción errónea del rol enfermero por la sociedad.

("La enfermería no se conoce... para la sociedad... es simplemente mano de obra, nuestro trabajo depende de los médicos, y nosotras solo ejecutamos órdenes" (B26), "La población sigue identificando a los enfermeros con las actuaciones delegadas del diagnóstico médico y colaborativo" (B31)).

c) Inadecuada política sanitaria del gobierno en relación a la Enfermería.

("Reconocimiento de la administración... queda mucho por andar en lo que se refiere a la participación y representación de la Enfermería en los órganos de decisión de alto nivel en la administración sanitaria... Hace falta un marco normativo... para asegurar que todo enfermero tenga los conocimientos, capacidades y cualidades para desempeñar un servicio profesional de calidad" (B19)).

d) Características de la población cuidada.

("Aproximación de las experiencias y vivencias del paciente y la dificultad que a veces encontramos para recoger esto de una manera formal y científica" (B10), "Alto nivel de innovaciones tecnológicas... se valora más a las profesionales por ser expertas en el 
manejo de estas tecnologías que en el rol autónomo que deberían ejercer" (B145),

"Nuevas demandas de salud" (B56)).

e) Apoyo social deficitario hacia la profesión enfermera.

("Falta mayor apoyo por parte de la sociedad" (B56), "No estamos valorados por la sociedad" (B57))

f) Influencia de los medios de comunicación.

("Imagen de los medios de comunicación" (B42), "Falta de información y promoción de nuestra profesión...y los medios de comunicación" (B73)).

\subsubsection{CARÁCTER INDIFERENTE DEL COLECTIVO ENFERMERO}

La categoría carácter del colectivo, incluyó aquellos comentarios en relación a las propias características de los profesionales de enfermería como colectivo. Aparecen comentarios en 76 trabajos (49,3\% de los trabajos). Se resumieron en las categorías que se exponen a continuación.

a) Falta de unión y apoyo entre el propio colectivo.

("Falta cooperación entre los profesionales de enfermería como colectivo" (B8), "Falta de sentimiento corporativo" (B69)).

b) Conformidad como colectivo.

("Conformidad" (B15, B38, B40, B41, B42, B43, B44, B45, B48, B51, B55, B137, B147,

B150), "Acomodarse a ciertos puestos de trabajo y no renunciar a determinadas tareas para no asumir otras" (B75)).

c) Baja motivación.

("Actitudes y creencias de los propios enfermeros... desmotivación, desinterés" (B93)).

d) Falta de responsabilidad y compromiso del colectivo.

("Falta de compromiso" (B5), "Falta de responsabilidad en cuidados básicos...falta de iniciativas" (B12)).

e) Baja autovaloración como colectivo.

("Nos cuesta creernos nuestra profesión ante la sociedad, no la defendemos...

autoestima de colectivo baja" (B25), "Imagen que los propios profesionales damos y tenemos de nosotros como profesión... infravalorándonos " (B75)).

f) Falta de liderazgo de Enfermería.

("Obedientes y subordinadas" (B150), "Tampoco hemos sabido vender lo que podríamos llegar a hacer" (B77), "Falta de líderes" (B5, B68)). 
g) Falta de reflexión de la propia práctica.

("Enfermería no se detiene a pensar, no planifica, solo actúa" (B12), "Trabajar desde la tradición oral y el "savoir faire"...no se ha potenciado que enfermería desarrollara una capacidad crítica" (B25)).

h) Resistencia al cambio.

("Nuestro colectivo... no están de acuerdo con el desarrollo de la enfermería como profesión y para ellas el trabajo siguen siendo simplemente las técnicas" (B15), "Hemos sido nosotros mismos quienes sólo hemos querido hacer trabajo de soporte del médico... Muchas enfermeras no defienden desarrollar las cuatro funciones... sólo creen que hace falta desarrollar la faceta asistencial" (B25)).

i) Falta de apoyo de los Colegios profesionales de Enfermería.

("Falta de apoyo de los colegios profesionales para luchar por el desarrollo de la profesión" (B69), "Lentitud y dificultad para reflejar los cambios en la formación... en el campo laboral... los Colegios de Enfermería deberían implicarse en la búsqueda de salidas laborales" (B78)).

\subsubsection{FALTA DE ROL AUTÓNOMO PROFESIONAL}

En cuanto al rol profesional se refiere a la agrupación en temas relacionados con la propia definición de las actividades llevadas a cabo como profesionales de Enfermería tanto en el campo de la propia disciplina, como en relación otras disciplinas sanitarias. Esta clasificación podría coincidir con la función de la enfermera como profesional en el equipo de salud. Se recogieron comentarios en 100 trabajos (64,9\%). Los comentarios se agruparon en:

a) Falta de desarrollo del rol propio.

("Asume tareas delegadas que no lo son propias y deja a un lado las suyas" (B138, B139, B140, B141), "Miedo a asumir responsabilidades...Inseguridad para tomar decisiones, quizás por falta de preparación teórica en algunos campos" (B69)).

b) Subordinación médica.

("Falta de autonomía y dependencia jerarquizada con respecto al colectivo médico" (B10), "Profesional auxiliar de la medicina...Autoridad médica" (B18), "Un médico apenas conoce que Enfermería tenemos nuestros propios diagnósticos, que realizamos actividades y valoraciones...solo prima el diagnóstico médico y su importancia está por encima de todo lo demás" (B58)).

c) Características del trabajo desempeñado habitualmente. 
("Trabajo muy centrado en la técnica, rutinario y repetitivo" (B150), "Olvidando que la técnica es un medio y no una finalidad" (B25)).

d) Falta de colaboración interdisciplinar.

("Falta de reconocimiento...por parte de otros profesionales de la salud" (B74, B127, B135), "Las relaciones entre médicos y enfermeras no permite una sinergia entre las intervenciones de ambos" (B14), "Rivalidad de intereses de otros profesionales que tradicionalmente han tenido más poder social, económico y político" (B82)).

e) Falta de aplicación de marcos conceptuales propios.

("No hemos sido capaces de pensar y trabajar con metodología enfermera" (B7), "No somos conscientes...aplicando el método científico o un modelo concreto enfermero"(B25), "En la unidad que yo trabajo...se olvidan...de la evaluación...del seguimiento, de las curas y el informe al alta" (B35), "No hemos desarrollado ningún modelo que se adapte a la realidad española, los modelos y teorías americanas no han terminado de encajar ya que nos resulta difícil ponerlos en práctica" (B151)).

f) Falta de cuantificación del producto enfermero.

("Falta de evaluación de los cuidados enfermeros" (B42, B137)).

g) Relación con profesionales subordinados del equipo.

("a veces se eluden responsabilidades y dejando a otros profesionales las decisiones que nos implican a nosotras legalmente" (B145), "Excesiva delegación de tareas a Auxiliares de Enfermería" (B2)).

h) Limitación en investigación enfermera.

Dentro de esta categoría, se incluyeron todos aquellos comentarios en relación a la función investigadora enfermera. Algunos ejemplos de comentarios se muestran a continuación.

("Las enfermeras tienen grandes dificultades para acudir a la biblioteca en busca de referencias que puedan ayudarlas en su trabajo" (B14), "Corta y poca experiencia investigadora... ausencia de contenidos en metodología de investigación" (B24), "Poca formación de los profesionales en metodología de la investigación" (B144), "Escasa formación y destreza de los enfermeros en lectura e informes de investigación" (B95) "Dificultad para la financiación de investigaciones que puedan llevar a la realización de nuevas teorías más especificas a cada ámbito de enfermería" (B16), "Poca ayuda de las instituciones, de los centros de trabajo, de las empresas farmacéuticas y de las instituciones académicas a la investigación enfermera. El dinero está destinado a otros profesionales" (B144)). 


\subsubsection{Resultados en relación a los elementos facilitadores}

Se cuestionó y analizó un total de 133 trabajos individuales. Fueron excluidos 14 trabajos por letra ininteligible, no contestar a lo que se le solicitaba o por carencia de reflexión. En los restantes, se procedió con el análisis siguiendo la misma metodología utilizada para el análisis de las barreras. A continuación se presentan las categorías halladas en cuanto a los elementos facilitadores del desarrollo teórico y profesional:
4.4.2.1 Formación avanzada de las enfermeras.
4.4.2.2 Carácter propio y emprendedor de los profesionales.
4.4.2.3 Cambios sociales.
4.4.2.4 Mejora en la gestión interna de los centros sanitarios
4.4.2.5 Desarrollo del cuerpo de conocimientos propio.
4.4.2.6 Investigación en la propia disiciplina.

Dentro de cada una de las categorías expuestas se pudieron fragmentar los textos en subcategorías tal y como se detalla más adelante. Cada una de las subcategorías se ejemplifica con alguno de los comentarios obtenidos de los textos (la totalidad de los mismos se hallan en el anexo IV del CD adjunto).

\subsubsection{FORMACIÓN AVANZADA DE LAS ENFERMERAS}

Se han incluido en esta categoría aquellos comentarios que hicieron alusión a la formación enfermera, tanto a la formación básica como a la reglada. Un total 77 trabajos acopian comentarios de esta categoría $(57,9 \%)$. Las enfermeras manifestaron que la formación es uno de los elementos que van a facilitar el desarrollo profesional de la disciplina, creyendo importante diferentes aspectos agrupados en subcategorías:

a) La formación pregrado.

("El cambio de los estudios de Enfermería (ATS a Diplomado de Enfermería)" (F16), "Se exige un nivel superior de conocimientos para acceder a la formación de Enfermería" (F81)).

b) La formación postgrado o continuada.

("Bolonia... estudios superiores universitarios" (F70), "Acceso segundo y tercer ciclo de Enfermería" (F125)).

c) La formación en valores. 
("Transmitir a los futuros profesionales el amor que deben de tener a su profesión" (F1),

"Que luchen por la autonomía de su propio trabajo" (F1)).

d) La formación en otras disciplinas diferentes a la Enfermería.

("Doctores en otras disciplinas" (F79), "Enfermeros motivados que han cursado otras carreras universitarias, sin dejar su profesión enriqueciéndola" (F29)).

\subsubsection{CARÁCTER PROPIO Y EMPRENDEDOR DE LOS PROFESIONALES}

Otros de los comentarios aportados se podrían englobar en las características o cualidades de los propios profesionales como elementos favorecedores. Se agruparon comentarios en 69 trabajos (51,9\% de los trabajos). Entre estos se distinguieron las categorías:

e) Motivación de las enfermeras y del propio colectivo.

("Colectivo de enfermeras que realmente están motivados"(F32), "Esfuerzos de muchos enfermeros/as que han creído su profesión" (F16), "Interés manifiesto por el colectivo de enfermería en adquirir más conocimientos" (F76)).

f) Empatía y asertividad.

("Asertividad, empatía y altruismo...preocupación por el componente social del paciente" (F129)).

g) Capacidad de observación.

("Profesión altamente observadora" (F129), "Enfermeras como grandes observadoras" (F130)).

h) Capacidad de reflexión.

("Pensamiento reflexivo... interpretativo" (F84), "Pensamiento crítico" (F8, F69, F71, F84, F104)).

i) Competitividad.

("Nuevas generaciones de enfermeras con una visión más clara de la disciplina" (F125),

"Espíritu emprendedor del colectivo enfermero" (F128)).

j) Autonomía.

("Educación para la salud...nos da puntos de cara a la sociedad... prescripción enfermera." (F50), "Reafirmar las competencias y habilidades... potenciar el trabajo autónomo" (F84), "Mayor autonomía en las tareas a desarrollar... acceso a plazas 
docentes" (F57), "La autonomía que desarrollan los enfermeros en las consultas de crónicos" (F60)).

k) Vocación.

(“vocación" (F39, F85)).

\subsubsection{CAMBIOS SOCIALES}

En la lectura detallada se extrajeron comentarios que podrían ser incluidos en esta categoría. Fueron comentarios en relación a los cambios en las estructuras sociales, y por lo tanto, la modificación de valores y normas de la sociedad que eran reconocidos como facilitadores del desarrollo enfermero. Los comentarios en relación al cambio social referenciados incluyen aspectos acontecidos en estos últimos años, que provocan el éxito del desarrollo profesional enfermero. Aparecen comentarios sobre esta temática en 87 trabajos (65,4\%). Engloban:

a) El mayor reconocimiento social.

("Cambio en la valoración de los pacientes... reconocimiento por parte de la sociedad" (F52) "Cada día la sociedad está más concienciada de que existe un profesional que trabaja por su salud" (F60)).

b) Los cambios de género.

("Aumento de los hombres en la profesión" (F2), "acontecimientos históricos que afectaron a la mujer como su inserción laboral, derecho a voto, etc." (F50), "cambio socio-cultural del hombre en como parte integrante en los hogares como motor... integración de la mujer en el mercado laboral" (F92)).

c) La política social del estado.

("Énfasis de la OMS... importancia de la Educación para la salud" (F6), "creación y utilización de Programas de Salud de Enfermería" (F7), "Obligatoriedad de la LOGSE y nueva LOE de Educación para la Salud de los colegios" (F17, F70), "Sindicatos, colegios de enfermería" (F28, F29, F30, F32, F33, F58, F62, F64), "Comparación con otros países... colaboración internacional para conseguir acreditación universitaria" (F33)).

d) El cambio en las necesidades de población.

("Importancia de la prevención en materia de salud, aplicándose programas de Enfermería en atención primaria que se desarrollan íntegramente por enfermeros" 
(F57), "Necesaria sobre todo para cuidar y atender a la población envejecida"

(F6), “Consultas de Enfermería... para una asistencia más específica” (F7)).

e) El uso de las tecnologías de la información y de la comunicación.

("Desarrollo de medios de comunicación: revistas, internet" (F73), "Humanizar muchas de las técnicas... nos adaptamos a las tecnologías" (F133), "Avenços tecnològics" (F38)).

\subsubsection{MEJORA EN LA GESTIÓN INTERNA DE LOS CENTROS SANITARIOS}

Se han incluido en esta categoría, aquellos comentarios que hicieron alusión a la dirección o administración de las empresas como elemento facilitador del desarrollo profesional y teórico. Aparecen comentarios de esta categoría en 33 de los trabajos recogidos (24,8\%). La categoría hallada se fragmentó en en 2 subcategorías:

a) Gestión de los centros de trabajo.

("Coordinación entre todos los profesionales de la salud... abordaje interdisciplinario" (F1), "Horarios de trabajo intensivos... nuevos cargos... para dirigir nuestras propias competencias" (F7), "Organizar y dirigir los servicios de Enfermería" (F14), "La gestión enfermera en manos de los propios enfermeros" (F61)).

b) Mejoras laborales.

("Mejora contratos laborales" (F2), "Estabilidad laboral” (F10, F34, F85), “...creando una mejor situación laboral... reconocimiento de la carrera profesional" (F68)).

\subsubsection{DESARROLLO DEL CUERPO DE CONOCIMIENTOS PROPIO DE LA DISCIPLINA}

La categoría del desarrollo del cuerpo de conocimientos propios engloba los comentarios que hacen alusión de forma directa a la base conceptual enfermera. Se hallaron en un total de 35 trabajos $(26,3 \%)$ dos subcategorías que hacen alusión al rol propio como disciplina:

a) Metodología Enfermera.

("La aparición de diagnósticos enfermeros, así como de intervenciones y actividades propias de la enfermería" (F1), "...enfrontament pràctica i teoria per poder arribar a formar noves metodologies" (F36, F39), “...utilización del proceso enfermero" (F96)).

b) Modelos Teóricos.

("...estudios realizados por otras autoras enfermeras como Florence Nightingale o Dorothea Orem... quienes han desarrollado modelos de actuación a seguir.... modelos 
de actuación. Un nuevo avance sería que los Centros de Salud, los Hospitales o individualmente las unidades, se decantaran por un modelo u otro" (F50), “...desarrollar en la práctica diferentes teorías" (F12)).

\subsubsection{INVESTIGACIÓN EN LA PROPIA DISCIPLINA}

En esta categoría se recogieron aquellos comentarios que hicieron alusión a la actividad científica de las enfermeras /os en los trabajos de investigación. Se hallaron en 107 trabajos $(80,4 \%)$.

("Investigaciones encaminadas a incrementar su cuerpo disciplinar" (F14), "...investigar la tesis doctoral" (F18), "Sociedades científicas" (F74, F78), “...metodología investigadora en la formación curricular de los alumnos...investigación y método científico" (F70), “Publicaciones científicas" (F79, F87), “...financiación de la investigación enfermera" (F79)).

\subsubsection{Resumen de los resultados en relación a la aplicación de los modelos teóricos en la práctica y los elementos facilitadores y barrera hallados para el desarrollo teórico y profesional}

Una vez vistos estos resultados, y teniendo en cuenta la asociación entre el desarrollo profesional y teórico, podemos concretar que como factores condicionantes para la aplicación de modelos teoricos, los estudiantes de Máster indicaron que era un elemento importante las políticas de gestión de los centros sanitarios, haciendo alusión a que se precisa del apoyo de los gestores y del gobierno, un aumento de recursos humanos, disminuir la sobrecarga laboral, y modificar la visión medicalizada de la salud para facilitar el avance. Así como, también creyeron que era necesario que se valorara la carrera profesional y se disminuyera la rotación de profesionales en las unidades de trabajo. Además de las políticas de gestión, indicaron que otro elemento importante era la formación enfermera. El crecimiento disciplinar con la formación en bases conceptuales propias favorecía, según los estudiantes de Máster, la implementación de teoría; haciendo hincapié en que esta formación debía estar guiada por las propias enfermeras que son las que conocen profundamente los valores de la profesión. Esa formación debía ir acompañada de mayor conocimiento de idiomas (especialmente el inglés). Otro de los elementos que creyeron determinantes fue el propio apoyo de la sociedad al colectivo, el visibilizar el trabajo real que hace la enfermera y evidenciar su relevancia a nivel de la salud poblacional. El propio carácter como colectivo, la motivación, responsabilidad, compromiso, reflexión y liderazgos podría promover cambios en la labor ejecutada e imagen profesional. Otro de los ejes es el desarrollo de trabajo 
interdisciplinar, con la inclusión de marcos conceptuales adaptados a la propia necesidad nacional, pero también con la introducción de metodología enfermera y fomento de la investigación en el campo. Mejorar la aportación del rol propio de la enfermera en los equipos y que este rol sea reconocido por el resto de disciplinas sanitarias, unido al fomento del propio papel investigador.

\subsection{Resultados en relación al quinto objetivo: Determinar los elementos que han facilitado y los que han impedido el uso y desarrollo de modelos teóricos en la práctica española desde la perspectiva de enfermeras gestoras y docentes.}

Inicialmente se invitó a participar a 25 gestores y 25 docentes para el estudio Delphi. Sin embargo, por la baja tasa de respuesta (aproximadamente respondieron el 20\% de los sujetos invitados), se decidió ir incrementando el número de invitados para conseguir un tamaño de muestra de entre 20 y 30 participantes (teniendo en cuenta las tasas de respuesta de estudios previos que habían seguido la metodología indicada). Tras invitar a 41 gestores y 43 docentes, 18 gestores y 13 docentes aceptaron formar parte del grupo de expertos. Pese a que fueron 31 las personas que aceptaron participar, al primer cuestionario enviado respondieron sólo 24 profesionales (tasa de respuesta $77,4 \%$ ), número suficiente para dar por válido el método tal y como se deralló en la metodología.

En cuanto a los datos sociodemográficos, eb relación a la categoría profesional un $45,8 \%$ (11) eran profesores universitarios de asignaturas relacionadas con el marco conceptual enfermero, el 37,5\% (9) eran gestores de áreas clínicas y un 16,7\% (4) desempeñaban su trabajo en ambos ámbitos. Respecto a la titulación universitaria, indicaron que además del Diplomado de Enfermería, poseían el título de Máster Universitario un 50\% (12), eran licenciados un 12,5\% (3) y tenían la titulación de Doctor el 25\% (6).

En cuanto a datos laborales, el 37,5\% (9) indicaron trabajar en el hospital, el 37,5\% (9) en la universidad y el $25 \%$ (6) indicaron que trabajan en ambos ámbitos. Una persona de las que marcó universidad indicó también que desarrollaba su labor en Atención Primaria. Respecto a los años de experiencia en su actividad actual, el 16,4\% (4) indicó llevar menos de 5 años, el 8,3\% (2) entre 5 y 10 años y el 75\% (18) llevaban más de 10 años en su puesto actual. La actividad la de- 
sarrollaban en las provincias de Barcelona (8), Cantabria (1), Santa Cruz de Tenerife (2), Madrid (4), Jaén (1), Lleida (1), Granada (4), Islas Baleares (2) y Valencia (1). Tanto docentes, como gestores eran representativos de diferentes provincias españolas en su ámbito. No se concretan los centros de trabajo, ya que se deseaba mantener al máximo el anonimato de los sujetos encuestados y así se les aseguró al solicitar su participación en el estudio.

\subsubsection{Resultados primera ronda del Delphi}

A la primera pregunta del primer formulario (¿Cuáles cree que han sido los elementos que han facilitado o facilitan el uso y desarrollo de modelos teóricos en la práctica española?), los expertos enviaron un total de 68 comentarios sobre elementos facilitadores, que fueron numerados mediante las letras CF (de comentario facilitadores). Mediante el análisis de los textos, se codificaron en 8 metacategorías o unidades de significado, de las cuáles a través de la lectura repetida, la síntesis de ideas y resumen los textos literales emergieron 25 categorías. Éstas, fueron los ítems a puntuar del segundo cuestionario.

A continuación en la tabla 40 se presentan cada una de las metacategorías obtenidas, con las categorías emergentes y la transcripción literal de los textos ejemplificantes de cada una de ellas.

Tabla 40: Análisis de los textos de la pregunta sobre los elementos facilitadores de la aplicación de modelos en la práctica (Delphi)

\begin{tabular}{|c|c|c|}
\hline $\begin{array}{l}\text { METACATEGORÍA } \\
\text { ("familiy") }\end{array}$ & $\begin{array}{l}\text { CATEGORÍA ("codes") } \\
\text { (Ítems para el segundo cues- } \\
\text { tionario) }\end{array}$ & $\begin{array}{l}\text { TRANSCRIPCIÓN LITERAL DE LOS TEXTOS ("quo- } \\
\text { tes") }\end{array}$ \\
\hline \multirow[b]{2}{*}{$\begin{array}{l}\text { 1. Modelos de } \\
\text { cuidados }\end{array}$} & $\begin{array}{l}\text { El cambio del modelo asisten- } \\
\text { cial orientado a paciente y } \\
\text { familia }\end{array}$ & $\begin{array}{l}\text { "Al cambiar la concepción del modelo asistencial } \\
\text { orientado al paciente y familia" (CF24) }\end{array}$ \\
\hline & $\begin{array}{l}\text { La identificación en relación a } \\
\text { un modelo de los centros sani- } \\
\text { tarios }\end{array}$ & $\begin{array}{l}\text { "La identificación de los centros hospitalarios en } \\
\text { un modelo conceptual de cuidados" (CF5) } \\
\text { "Plasmar y contextualizar los modelos teóricos de } \\
\text { cuidados en la rutina de trabajo de los enferme- } \\
\text { ros facilita su empleo" (CF55) }\end{array}$ \\
\hline
\end{tabular}




\begin{tabular}{|c|c|c|}
\hline $\begin{array}{l}\text { METACATEGORÍA } \\
\text { ("familiy") }\end{array}$ & $\begin{array}{l}\text { CATEGORÍA ("codes") } \\
\text { ('́tems para el segundo cues- } \\
\text { tionario) }\end{array}$ & $\begin{array}{l}\text { TRANSCRIPCIÓN LITERAL DE LOS TEXTOS ("quo- } \\
\text { tes") }\end{array}$ \\
\hline \multirow{7}{*}{$\begin{array}{l}\text { 2. Autonomía pro- } \\
\text { fesional }\end{array}$} & $\begin{array}{l}\text { La creencia y necesidad perso- } \\
\text { nal de los profesionales en la } \\
\text { aplicación de un modelo de } \\
\text { cuidados }\end{array}$ & $\begin{array}{l}\text { "El interés personal de cada enfermero que los } \\
\text { estudia y aplica" (CF13) } \\
\text { "Los profesionales que a nivel personal creen en } \\
\text { la importancia del modelo de cuidados" (CF46) }\end{array}$ \\
\hline & $\begin{array}{l}\text { La aspiración de mejorar la } \\
\text { práctica enfermera mediante } \\
\text { innovación propia }\end{array}$ & $\begin{array}{l}\text { "La aspiración de mejora de la práctica profesio- } \\
\text { nal con la incorporación de innovaciones propias } \\
\text { de enfermería" (CF27) }\end{array}$ \\
\hline & $\begin{array}{l}\text { La estrategia de poder para } \\
\text { clarificar la aportación perso- } \\
\text { nal y diferenciarla de otros } \\
\text { profesionales de salud }\end{array}$ & $\begin{array}{l}\text { "Siguen siendo considerados, en la actualidad por } \\
\text { algunos enfermeros/as como una estrategia de } \\
\text { poder necesario para clarificar su aportación } \\
\text { profesional, y a la vez diferenciarla de la de otros } \\
\text { profesionales de la salud, especialmente de los } \\
\text { médicos" (CF45) } \\
\text { "Ganar prestigio de cara a otras profesiones" } \\
\text { (CF65) } \\
\text { "El ser conscientes de la importancia que la en- } \\
\text { fermería tiene en el mundo sanitario" (CF67) }\end{array}$ \\
\hline & $\begin{array}{l}\text { La aspiración de mejorar la } \\
\text { práctica enfermera mediante } \\
\text { innovación propia }\end{array}$ & $\begin{array}{l}\text { "La aspiración de mejora de la práctica profesio- } \\
\text { nal con la incorporación de innovaciones propias } \\
\text { de enfermería" (CF27) }\end{array}$ \\
\hline & $\begin{array}{l}\text { El compromiso de desarrollo } \\
\text { como disciplina de docentes y } \\
\text { asistenciales }\end{array}$ & $\begin{array}{l}\text { "El compromiso profesional de docentes y asis- } \\
\text { tenciales en el desarrollo de la disciplina" (CF35) }\end{array}$ \\
\hline & $\begin{array}{l}\text { El trabajo desarrollado por las } \\
\text { enfermeras de Atención Prima- } \\
\text { ria }\end{array}$ & $\begin{array}{l}\text { "El trabajo realizado por las enfermeras de aten- } \\
\text { ción primaria" (CF44) }\end{array}$ \\
\hline & $\begin{array}{l}\text { El desarrollo del pensamiento } \\
\text { crítico en la profesión ya que } \\
\text { los modelos facilitan la re- } \\
\text { flexión }\end{array}$ & $\begin{array}{l}\text { "La reflexión sobre la importancia de estos para } \\
\text { guiar la práctica" (CF33) } \\
\text { "Las Escuelas de Enfermería incorporan en su } \\
\text { currículum el desarrollo de pensamiento crítico" } \\
\text { (CF28) } \\
\text { "La necesidad de demostrar que Enfermería sigue } \\
\text { madurando como profesión clínica- Ganar presti- } \\
\text { gio de cara a otras profesiones" (CF2) } \\
\text { "El hecho de que los modelos fomentan la re- } \\
\text { flexión, indagación y pensamiento sobre qué } \\
\text { hacemos enfermería" (CF66) } \\
\text { "La necesidad de reflexionar sobre el trabajo que } \\
\text { hacemos" (CF1) } \\
\text { "Creo que cuando la Enfermería comprende que } \\
\text { debe aplicar el método científico a sus activida- } \\
\text { des" (CF18) } \\
\text { "La reflexión sobre la importancia de éstos para } \\
\text { guiar la práctica y como vía para desarrollar la } \\
\text { autonomía profesional" (CF33) }\end{array}$ \\
\hline
\end{tabular}




\begin{tabular}{|c|c|c|}
\hline $\begin{array}{l}\text { METACATEGORÍA } \\
\text { ("familiy") }\end{array}$ & $\begin{array}{l}\text { CATEGORÍA ("codes") } \\
\text { (ítems para el segundo cues- } \\
\text { tionario) }\end{array}$ & $\begin{array}{l}\text { TRANSCRIPCIÓN LITERAL DE LOS TEXTOS ("quo- } \\
\text { tes") }\end{array}$ \\
\hline \multirow{5}{*}{$\begin{array}{l}\text { 3. Metodología } \\
\text { enfermera }\end{array}$} & $\begin{array}{l}\text { El desarrollo de planes de cui- } \\
\text { dados en la práctica }\end{array}$ & $\begin{array}{l}\text { "El desarrollo de planes de cuidados, dónde la } \\
\text { valoración que hace la enfermera está estableci- } \\
\text { da según marcos teóricos" (CF34) } \\
\text { "con la metodología enfermera" (CF39) }\end{array}$ \\
\hline & $\begin{array}{l}\text { La incorporación de NANDA, } \\
\text { NIC y NOC en los planes } \\
\text { académicos }\end{array}$ & $\begin{array}{l}\text { "La incorporación de la NANDA, NIC, NOC en los } \\
\text { planes académicos universitarios" (CF60) }\end{array}$ \\
\hline & $\begin{array}{l}\text { El uso de lenguajes comunes, } \\
\text { estandarizados }\end{array}$ & $\begin{array}{l}\text { "y el uso de lenguajes estandarizados" (CF4O) } \\
\text { "El uso de Modelos Conceptuales de Enfermería } \\
\text { en la práctica asistencial, ha garantizado que } \\
\text { todas las enfermeras compartan un lenguaje } \\
\text { común con concepciones similares respecto a los } \\
\text { paradigmas enfermeros, persona, salud, entorno } \\
\text { y cuidados que caracterizan el rol profesional" } \\
\text { (CF50) }\end{array}$ \\
\hline & $\begin{array}{l}\text { El uso de estructuras teóricas } \\
\text { para la valoración enfermera }\end{array}$ & $\begin{array}{l}\text { "La utilización de las estructuras de valoración de } \\
\text { algunos modelos teóricos para la elaboración de } \\
\text { los protocolos de recogida de datos y seguimien- } \\
\text { to de pacientes (papel o informatizados)" (CF64) }\end{array}$ \\
\hline & $\begin{array}{l}\text { El informe de enfermería al } \\
\text { alta para la continuidad del } \\
\text { cuidado }\end{array}$ & $\begin{array}{l}\text { "El informe de Enfermería al alta para continui- } \\
\text { dad de cuidados entre diferentes niveles } \\
\text { asistenciales (primaria-especializada-entorno } \\
\text { sociosanitario)" (CF62) }\end{array}$ \\
\hline \multirow[b]{2}{*}{ 4. Liderazgo } & $\begin{array}{l}\text { El liderazgo clínico entre las } \\
\text { enfermeras/os }\end{array}$ & $\begin{array}{l}\text { "La aparición del liderazgo clínico entre las en- } \\
\text { fermeras" (CF43) }\end{array}$ \\
\hline & $\begin{array}{l}\text { La sensibilidad y necesidad de } \\
\text { las Direcciones de Enfermería } \\
\text { de aplicar modelos teóricos en } \\
\text { los pacientes }\end{array}$ & $\begin{array}{l}\text { "así como la estructuración de la historia clínica } \\
\text { basada en un modelo ha permitido su utilización } \\
\text { (CF7) } \\
\text { Sensibilización de las Direcciones enfermeras en } \\
\text { la formación y adopción de dichos modelos en sus } \\
\text { instituciones" (CF9) } \\
\text { "Los elementos que pueden facilitar el empleo de } \\
\text { modelos teóricos en la práctica sería que aumen- } \\
\text { tasen las propuestas de puesta en práctica de los } \\
\text { mismos. Aunque fuesen de teorías de rango me- } \\
\text { dio" (CF10) } \\
\text { "En el ejercicio profesional es imprescindible que } \\
\text { el modelo adoptado impregne todas los proyec- } \\
\text { tos y decisiones que desde la dirección enfermera } \\
\text { se desarrollen" (CF12) } \\
\text { "Direcciones de Enfermería que siguen un modelo } \\
\text { teórico" (CF17) } \\
\text { "el cuadro de mandos de la institución incorpora } \\
\text { resultados de cuidados" (CF30) } \\
\text { "Las direcciones de enfermería que están } \\
\text { sensibilizadas en el tema" (CF47) }\end{array}$ \\
\hline
\end{tabular}




\begin{tabular}{|c|c|c|}
\hline $\begin{array}{l}\text { METACATEGORÍA } \\
\text { ("familiy") }\end{array}$ & $\begin{array}{l}\text { CATEGORÍA ("codes") } \\
\text { (Ítems para el segundo cues- } \\
\text { tionario) }\end{array}$ & $\begin{array}{l}\text { TRANSCRIPCIÓN LITERAL DE LOS TEXTOS ("quo- } \\
\text { tes") }\end{array}$ \\
\hline \multirow[b]{4}{*}{ 5. Formación } & $\begin{array}{l}\text { El desarrollo de titulaciones de } \\
\text { postgrado }\end{array}$ & "El desarrollo de los postgrados oficiales" (CF58) \\
\hline & $\begin{array}{l}\text { El ser el nexo entre asistencia, } \\
\text { gestión y docencia }\end{array}$ & $\begin{array}{l}\text { "Es el nexo de unión entre los tres grandes cam- } \\
\text { pos de la enfermería actual: asistencia, gestión y } \\
\text { docencia" (CF51) }\end{array}$ \\
\hline & $\begin{array}{l}\text { La divulgación por los profeso- } \\
\text { res de universidad que los } \\
\text { conocen en profundidad y faci- } \\
\text { litan la comprensión de los } \\
\text { alumnos }\end{array}$ & $\begin{array}{l}\text { "El desarrollo realizado desde el punto vista teó- } \\
\text { rico y de divulgación por los profesionales } \\
\text { dedicados a la docencia" (CF37) } \\
\text { "Los profesores de Universidad que de verdad } \\
\text { saben de Modelos y los explican con claridad, } \\
\text { facilitando la comprensión a los alumnos"(CF49) }\end{array}$ \\
\hline & $\begin{array}{l}\text { La incorporación de los mode- } \\
\text { los teóricos en la formación } \\
\text { universitaria y los nuevos pla- } \\
\text { nes de estudio }\end{array}$ & $\begin{array}{l}\text { "La incorporación de estos modelos teóricos en } \\
\text { los curriculares de enfermería" (CF4) } \\
\text { "Formación universitaria donde se trabajan di- } \\
\text { chos modelos teóricos" (CF8) } \\
\text { "Es muy importante la formación pregrado de los } \\
\text { modelos teóricos, que ayudan a definir la actua- } \\
\text { ción enfermera a la persona y a la comunidad" } \\
\text { (CF11) } \\
\text { "Planes de Estudios que incorporen los modelos } \\
\text { teóricos" (CF16) } \\
\text { "desde luego gracias su desarrollo desde las Es- } \\
\text { cuelas de enfermería y a muchas enfermeras que } \\
\text { comprendieron que ese era el camino para la } \\
\text { aplicación de los cuidado" (CF19) } \\
\text { "El ámbito universitario en que se desarrollan los } \\
\text { estudios de enfermería" (CF25) } \\
\text { "la formación de los profesionales incluye compe- } \\
\text { tencias de valoración de necesidades de } \\
\text { cuidados" (CF29) } \\
\text { "La formación de la Enfermería en la Universidad, } \\
\text { ya que permite que el alumnado estudie las dife- } \\
\text { rentes concepciones teóricas y modelos de } \\
\text { enfermería" (CF32) } \\
\text { "La formación con el desarrollo de la nueva me- } \\
\text { todología docente centrada en las competencias" } \\
\text { (CF52) } \\
\text { "Pero sin duda, el ámbito universitario puede } \\
\text { contribuir a que esto cambie. Si no hay una for- } \\
\text { mación específica será imposible su uso y } \\
\text { desarrollo en la práctica asistencial" (CF56) } \\
\text { "Los nuevos planes de estudio universitarios" } \\
\text { (CF68) } \\
\text { "La estructuración del programa educativo en } \\
\text { enfermería" (CF69) } \\
\text { "La incorporación de la formación de las enfer- } \\
\text { meras a la universidad" (CF57) }\end{array}$ \\
\hline
\end{tabular}




\begin{tabular}{|c|c|c|}
\hline $\begin{array}{l}\text { METACATEGORÍA } \\
\text { ("familiy") }\end{array}$ & $\begin{array}{l}\text { CATEGORÍA ("codes") } \\
\text { (Ítems para el segundo cues- } \\
\text { tionario) }\end{array}$ & $\begin{array}{l}\text { TRANSCRIPCIÓN LITERAL DE LOS TEXTOS ("quo- } \\
\text { tes") }\end{array}$ \\
\hline \multirow[t]{2}{*}{$\begin{array}{l}\text { 6, Producto en- } \\
\text { fermero }\end{array}$} & $\begin{array}{l}\text { El interés profesional por defi- } \\
\text { nir el producto enfermero }\end{array}$ & $\begin{array}{l}\text { "El interés de la profesión, por definir el producto } \\
\text { enfermero y dar a conocer datos estadísticos } \\
\text { sobre el coste-beneficio del producto enfermero" } \\
\text { (CF15) } \\
\text { "Liderazgo clínico: la cartera de servicios de la } \\
\text { división de enfermería se define con criterios de } \\
\text { resultados de cuidados" (CF29) }\end{array}$ \\
\hline & $\begin{array}{l}\text { La relación entre el coste y la } \\
\text { efectividad de los cuidados }\end{array}$ & $\begin{array}{l}\text { "La relación entre coste-efectividad de los cuida- } \\
\text { dos" (CF23) }\end{array}$ \\
\hline \multirow{3}{*}{ 7. Investigación } & $\begin{array}{l}\text { El papel de las asociaciones } \\
\text { científicas }\end{array}$ & $\begin{array}{l}\text { "El papel que han jugado y siguen jugando dife- } \\
\text { rentes asociaciones científicas" (CF41) }\end{array}$ \\
\hline & $\begin{array}{l}\text { La existencia de literatura } \\
\text { científica sobre el tema }\end{array}$ & $\begin{array}{l}\text { "La existencia de literatura científica de países } \\
\text { más avanzados en el tema (americanos princi- } \\
\text { palmente).La existencia de traducciones a la } \\
\text { literatura científica española de los modelos" } \\
\text { (CF26) } \\
\text { "Las influencias de la bibliografía de EE.UU. pre- } \\
\text { ferentemente" (CF36) }\end{array}$ \\
\hline & $\begin{array}{l}\text { La investigación y difusión en } \\
\text { congresos de trabajos con } \\
\text { base teórica y metodológica }\end{array}$ & $\begin{array}{l}\text { "El avance en la investigación enfermera" (CF2O) } \\
\text { "El incremento de la investigación en el seno de la } \\
\text { disciplina enfermera" (CF42) } \\
\text { "Los congresos y jornadas en las que se presentan } \\
\text { los trabajos desde los modelos y la metodología" }\end{array}$ \\
\hline 8. Informatización & $\begin{array}{l}\text { La informatización de la docu- } \\
\text { mentación clínica y el plan de } \\
\text { cuidados }\end{array}$ & $\begin{array}{l}\text { Los sistemas informatizados, es decir la docu- } \\
\text { mentación informática (como por ejemplo } \\
\text { Gacela)" (CF6) } \\
\text { "Las herramientas informáticas, siempre que lo } \\
\text { faciliten y que no sean farragosas" (CF14) } \\
\text { "La incorporación de los nuevos sistemas de in- } \\
\text { formación para el trabajo" (CF38) } \\
\text { "Ios sistemas de información" (CF53) } \\
\text { "la apuesta de las administraciones por la infor- } \\
\text { matización de la historia clínica y, por ende, del } \\
\text { proceso enfermero" (CF54) } \\
\text { "La historia clínica electrónica (que incorpora } \\
\text { PAE)" (CF61) }\end{array}$ \\
\hline
\end{tabular}

A la segunda pregunta enviada del primer formulario (¿Cuáles cree que han sido los elementos que han impedido o impiden el uso y desarrollo de modelos teóricos en la práctica española?), los expertos enviaron un total de 81 comentarios sobre elementos impedidores, que fueron numerados mediante la letra $\mathrm{Cl}$ (de comentario impedimento). Mediante el análisis de los textos, se codificaron en 8 metacategorías o unidades de significado, de las cuáles a través de la lectura repetida, la síntesis de ideas y resumen los textos literales emergieron 36 categorías. Éstas, al igual que en los elementos facilitadores, fueron los ítems a puntuar del segundo cuestio- 
nario. A continuación en la tabla 41 se presentan cada una de las metacategorías obtenidas, con su transcripción literal y las categorías emergentes.

Tabla 41: Análisis de los textos de la pregunta sobre los elementos que han impedido la aplicación de modelos en la práctica (Delphi)

\begin{tabular}{|c|c|c|}
\hline $\begin{array}{l}\text { METACATEGORÍA } \\
\text { ("family") }\end{array}$ & $\begin{array}{l}\text { CATEGORÍA ("codes" ) } \\
\text { (Ítem segundo cuestionario) }\end{array}$ & $\begin{array}{l}\text { TRANSCRIPCIÓN LITERAL DE LOS TEXTOS ("quo- } \\
\text { tes") }\end{array}$ \\
\hline \multirow{4}{*}{ 1. Modelo Teórico } & $\begin{array}{l}\text { El propio lenguaje, la compleji- } \\
\text { dad de los modelos y su } \\
\text { ambigüedad }\end{array}$ & $\begin{array}{l}\text { "El lenguaje que utilizan es difícil de comprender. } \\
\text { Los términos usados para definir los conceptos } \\
\text { Ileva a confusión entre las enfermeras y la pobla- } \\
\text { ción en general" (CI31) } \\
\text { "La complejidad de los conceptos" (CI46) } \\
\text { "Los modelos biomédicos han sido rechazados por } \\
\text { muchos colectivos. Aunque el carácter abstracto } \\
\text { del modelo dificulta su desarrollo" (CI64) } \\
\text { "Dificultad en la comprensión de los distintos mo- } \\
\text { delos" (CI68) } \\
\text { "Distintas interpretaciones de un mismo modelo" } \\
\text { (CI70) }\end{array}$ \\
\hline & $\begin{array}{l}\text { La falta de modelos contextua- } \\
\text { lizados en nuestro país } \\
\text { (propios) }\end{array}$ & $\begin{array}{l}\text { "La mayoría de las teorías han sido elaboradas } \\
\text { por enfermeras de otros países, con un sistema } \\
\text { educativo y sistema organizativo de salud diferen- } \\
\text { te del nuestro" (CI34) } \\
\text { "El adoctrinamiento o dogmatización en su uso. } \\
\text { Dado que son importados, creo que hay que adap- } \\
\text { tarlos a nuestro contexto incorporando los } \\
\text { aspectos universales que contienen y equiparar a } \\
\text { nuestro contexto los menos universales" (CI36) } \\
\text { "La no existencia de modelos propios de enferme- } \\
\text { ras españoles. Alguna rara excepción hay } \\
\text { enfermería sistémica creo" (CI4O) } \\
\text { "La inexistencia de un modelo autóctono, propio } \\
\text { español" (Cl80) }\end{array}$ \\
\hline & $\begin{array}{l}\text { La variabilidad de modelos teó- } \\
\text { ricos }\end{array}$ & $\begin{array}{l}\text { "La variabilidad de modelos teóricos" (CI8) } \\
\text { "Diversidad de modelos conceptuales hace que } \\
\text { sea imposible conocerlos todos y poder compro- } \\
\text { bar en la práctica si son adecuados o no" (CI30) } \\
\text { "La existencia de diferentes modelos teóricos ha } \\
\text { generado mucha discrepancia entre los profesio- } \\
\text { nales" (Cl63) }\end{array}$ \\
\hline & $\begin{array}{l}\text { Las propias características de } \\
\text { los modelos que en ocasiones } \\
\text { no permiten la adaptación ade- } \\
\text { cuada a la realidad del centro } \\
\text { en el que se aplica }\end{array}$ & $\begin{array}{l}\text { "Son muy estáticos y a veces no permiten adap- } \\
\text { tarlos adecuadamente a la realidad del centro } \\
\text { donde se aplica" (CI9) } \\
\text { "Así como el discurso muy generalizado por parte } \\
\text { de los profesionales de enfermería de la falta de } \\
\text { operatividad de los mismos" (CI11) } \\
\text { "supuesta utopía. Son una representación alejada } \\
\text { de la realidad" (CI35) } \\
\text { "No han sido desarrollados desde la práctica clíni- } \\
\text { ca" (CI57) }\end{array}$ \\
\hline
\end{tabular}




\begin{tabular}{|c|c|c|}
\hline \multirow[t]{2}{*}{ 2. Legislación } & $\begin{array}{l}\text { La ausencia de legislación que } \\
\text { obligue a trabajar con metodo- } \\
\text { logía enfermera en las } \\
\text { instituciones sanitarias }\end{array}$ & $\begin{array}{l}\text { "Ausencia de legislación que obligue a trabajar } \\
\text { con metodología enfermera en las instituciones } \\
\text { sanitarias" (CI51) }\end{array}$ \\
\hline & $\begin{array}{l}\text { El poco interés en reflejar el } \\
\text { producto enfermero }\end{array}$ & $\begin{array}{l}\text { "La poca importancia que se le ha dado a docu- } \\
\text { mentar lo que hacemos" (Cl2) }\end{array}$ \\
\hline \multirow{8}{*}{$\begin{array}{l}\text { 3. Profesional en- } \\
\text { fermero }\end{array}$} & $\begin{array}{l}\text { La confusión entre el objeto de } \\
\text { la disciplina enfermera y la fina- } \\
\text { lidad de la práctica }\end{array}$ & $\begin{array}{l}\text { "Confusión existente con relación al objeto de la } \\
\text { disciplina enfermera y a la finalidad de la práctica } \\
\text { enfermera" (Cl73) }\end{array}$ \\
\hline & $\begin{array}{l}\text { El pragmatismo y la falta de } \\
\text { reflexión personal de no tener } \\
\text { la necesidad de basar la prácti- } \\
\text { ca en conocimiento propio }\end{array}$ & $\begin{array}{l}\text { "Escaso análisis de los modelos previo a su utiliza- } \\
\text { ción" (CI72) } \\
\text { "Propensos a seguir directrices establecidas sin } \\
\text { pensar en las posibilidades que ofrecían la aplica- } \\
\text { ción de estos modelos en la práctica" (CI26) } \\
\text { "No sentir la necesidad de desarrollar conocimien- } \\
\text { to donde basar nuestra práctica" (CI3) } \\
\text { "No valorar la importancia de la enfermera como } \\
\text { profesional autónomo" (CI47) }\end{array}$ \\
\hline & $\begin{array}{l}\text { La falta de utilidad percibida } \\
\text { por los profesionales que han } \\
\text { trabajado con metodología }\end{array}$ & $\begin{array}{l}\text { "La poca utilidad, que en algunas ocasiones, los } \\
\text { profesionales han observado en el trabajo con } \\
\text { metodología enfermera" (Cl49) }\end{array}$ \\
\hline & $\begin{array}{l}\text { El que las enfermeras que se } \\
\text { incorporan a la asistencia no } \\
\text { integran su aportación en las } \\
\text { actuaciones que realizan }\end{array}$ & $\begin{array}{l}\text { "Cuando las enfermeras se incorporan a la asis- } \\
\text { tencia no integran su aportación a las actuaciones } \\
\text { que realizan" (CI11) }\end{array}$ \\
\hline & $\begin{array}{l}\text { La falta de formación de los } \\
\text { profesionales en modelos teóri- } \\
\text { cos }\end{array}$ & $\begin{array}{l}\text { "La falta de formación" (CI5) } \\
\text { "No interiorización de los conceptos del modelo } \\
\text { por parte de los profesionales" (CI13) } \\
\text { "El desconocimiento por falta de formación" } \\
\text { (CI23) } \\
\text { "Requiere además, una preparación trabajada y } \\
\text { consensuada por quienes tienen que emplearla" } \\
\text { (CI38) } \\
\text { "Los profesionales asistenciales (la inmensa ma- } \\
\text { yoría) no tienen conocimientos sobre los Modelos, } \\
\text { no los entienden" (CI59) } \\
\text { "Falta de formación o formación ambigua" (CI43) } \\
\text { "O formados en modelos teóricos (antigüedad vs } \\
\text { utilización frecuente de los mismos)" (CI80) }\end{array}$ \\
\hline & $\begin{array}{l}\text { El propio dogmatismo profesio- } \\
\text { nal por un único modelo teórico }\end{array}$ & $\begin{array}{l}\text { "Existe mucho dogmatismo: se es de una teoría o } \\
\text { de otra, con determinada enemistad. Creo que lo } \\
\text { importante no es suscribirse a un modelo, sino } \\
\text { identificar la naturaleza de los cuidados (Collière) } \\
\text { y los elementos del metaparadigma, paradigma } \\
\text { de cuidados" (Cl45) }\end{array}$ \\
\hline & $\begin{array}{l}\text { La barrera idiomática que impi- } \\
\text { de conocer de forma profunda } \\
\text { los textos originales de las teo- } \\
\text { ristas }\end{array}$ & $\begin{array}{l}\text { "La barrera del idioma dificulta la accesibilidad a } \\
\text { las fuentes en inglés o francés. En los años } 70 \text { y } 80 \\
\text { los textos que se tradujeron se siguen copiando } \\
\text { con transmisión plana de los conocimientos. La } \\
\text { decisión de traducir unos u otros es de editoriales, } \\
\text { asociaciones, etc." (CI44) }\end{array}$ \\
\hline & $\begin{array}{l}\text { Las actuales líneas de pensa- } \\
\text { miento vinculadas a práctica } \\
\text { basada en la evidencia }\end{array}$ & $\begin{array}{l}\text { "Actualmente hay una línea de pensamiento más } \\
\text { común entre el personal de enfermería vinculada } \\
\text { a la práctica basada en la evidencia" (CI65) }\end{array}$ \\
\hline
\end{tabular}




\begin{tabular}{|c|c|c|}
\hline $\begin{array}{l}\text { METACATEGORÍA } \\
\text { ("family") }\end{array}$ & $\begin{array}{l}\text { CATEGORÍA ("codes" ) } \\
\text { (Ítem segundo cuestionario) }\end{array}$ & $\begin{array}{l}\text { TRANSCRIPCIÓN LITERAL DE LOS TEXTOS (“quo- } \\
\text { tes") }\end{array}$ \\
\hline $\begin{array}{l}\text { 3. Profesional en- } \\
\text { fermero }\end{array}$ & $\begin{array}{l}\text { El desinterés profesional por los } \\
\text { modelos }\end{array}$ & $\begin{array}{l}\text { "Desinterés en esta área" (CI22) } \\
\text { "El inmovilismo de cierto sector profesional" } \\
\text { (CI28) } \\
\text { "La falta de motivación de los profesionales" } \\
\text { (CI50) } \\
\text { "Poca valoración por profesionales poco habitua- } \\
\text { dos" (CI79) }\end{array}$ \\
\hline \multirow{6}{*}{ 4. Implantación } & $\begin{array}{l}\text { La falta de reconocimiento del } \\
\text { uso de modelos en el desarrollo } \\
\text { como disciplina (sólo se entien- } \\
\text { de el desarrollo profesional en } \\
\text { la organización con el objetivo } \\
\text { de la mejora laboral) }\end{array}$ & $\begin{array}{l}\text { "El desarrollo profesional no se entiende en la } \\
\text { propia disciplina, sino en la organización en la que } \\
\text { se trabaja y muy frecuentemente con el objetivo } \\
\text { de la mejora laboral como único objetivo" (CI19) }\end{array}$ \\
\hline & $\begin{array}{l}\text { La falta de condicionamiento de } \\
\text { las direcciones enfermeras en el } \\
\text { modelo de atención, formación } \\
\text { continuada, carrera profesio- } \\
\text { nal,...pese a identificarse con } \\
\text { un modelo teórico }\end{array}$ & $\begin{array}{l}\text { "Las instituciones sanitarias y en concreto las } \\
\text { direcciones enfermeras suelen haber definido un } \\
\text { modelo teórico enfermero pero raramente éste } \\
\text { condiciona el posicionamiento de la dirección: } \\
\text { modelo de atención, formación continuada, desa- } \\
\text { rrollo profesional, carrera profesional,..." (CI21) }\end{array}$ \\
\hline & $\begin{array}{l}\text { La informatización no adecuada } \\
\text { (en ocasiones prima el registro } \\
\text { de la actividad sobre la misma } \\
\text { actividad) }\end{array}$ & $\begin{array}{l}\text { "Precisamente la apuesta por la informatización, } \\
\text { si no se hace desde una óptica adecuada, convier- } \\
\text { te al enfermero en un etiquetador, primando (en } \\
\text { ocasiones) el registro de lo que hace, frente a por } \\
\text { qué se hace o si es adecuado hacerlo" (CI67) }\end{array}$ \\
\hline & $\begin{array}{l}\text { La decisión unilateral de gesto- } \\
\text { res en la aplicación de modelos } \\
\text { sin la implicación de los propios } \\
\text { profesionales }\end{array}$ & $\begin{array}{l}\text { "Nunca funciona implantándola desde arriba en } \\
\text { una institución" (Cl23) }\end{array}$ \\
\hline & $\begin{array}{l}\text { La operativización que compor- } \\
\text { ta su implementación para } \\
\text { poder llevar los modelos a la } \\
\text { práctica (documentación, in- } \\
\text { formes...) }\end{array}$ & $\begin{array}{l}\text { "La documentación necesaria para ponerlos en } \\
\text { práctica es excesiva y laboriosa, muchas veces } \\
\text { impracticable en el día a día de la práctica" (CI32) } \\
\text { "La operatización que comporta su implementa- } \\
\text { ción, desde los instrumentos de valoración (1era } \\
\text { fase del PAE a los informes de alta por ejemplo" } \\
\text { (CI37) } \\
\text { "La dificultad para el manejo de la metodología y } \\
\text { de los lenguajes estandarizados en soporte papel" } \\
\text { (CI52) }\end{array}$ \\
\hline & $\begin{array}{l}\text { Las estrategias de incorporación } \\
\text { y adaptación de los modelos a } \\
\text { la práctica que en ocasiones se } \\
\text { centran en marcos de valora- } \\
\text { ción que se alejan de los } \\
\text { modelos teóricos }\end{array}$ & $\begin{array}{l}\text { "Las estrategias de incorporación y adaptación de } \\
\text { estos modelos teóricos a la práctica enfermera" } \\
\text { (CI7) } \\
\text { "El planteamiento utilitarista del proceso enfer- } \\
\text { mero centrado en marcos de valoración que se } \\
\text { alejan de los modelos teóricos" (CI17) }\end{array}$ \\
\hline \multirow{3}{*}{ 5. Liderazgo } & El poder de la clase médica & $\begin{array}{l}\text { "Y el poder de la clase médica" (CI56) } \\
\text { "El miedo/peligro que se observa en otros colecti- } \\
\text { vos profesionales que ven intrusión en parte de su } \\
\text { actividad" (CI76) }\end{array}$ \\
\hline & $\begin{array}{l}\text { La falta de autoestima de los } \\
\text { propios profesionales }\end{array}$ & "Autoestima profesional baja" (CI71) \\
\hline & $\begin{array}{l}\text { La falta de apoyo por parte de } \\
\text { las direcciones enfermeras }\end{array}$ & $\begin{array}{l}\text { "Las direcciones de enfermería ( la inmensa ma- } \\
\text { yoría), hablan sobre Modelos a nivel teórico, entre } \\
\text { colegas, pero no los conocen y no les parece im- } \\
\text { portante su utilización" (CI61) }\end{array}$ \\
\hline
\end{tabular}




\begin{tabular}{|c|c|c|}
\hline $\begin{array}{l}\text { METACATEGORÍA } \\
\text { ("family") }\end{array}$ & $\begin{array}{l}\text { CATEGORÍA ("codes" ) } \\
\text { (Ítem segundo cuestionario) }\end{array}$ & $\begin{array}{l}\text { TRANSCRIPCIÓN LITERAL DE LOS TEXTOS (“quo- } \\
\text { tes") }\end{array}$ \\
\hline 5. Liderazgo & $\begin{array}{l}\text { La ausencia de liderazgo clínico } \\
\text { e institucional enfermero }\end{array}$ & $\begin{array}{l}\text { "Ausencia de liderazgo en la institución y de lide- } \\
\text { razgo clínico" (CI42) } \\
\text { "El papel sumiso de la enfermera y la relación de } \\
\text { subordinación a la clase médica" (CI54) }\end{array}$ \\
\hline \multirow{5}{*}{$\begin{array}{l}\text { 6. Organización del } \\
\text { cuidado }\end{array}$} & $\begin{array}{l}\text { La confusión entre la herra- } \\
\text { mienta y el modelo, los } \\
\text { formularios utilizados no susti- } \\
\text { tuyen el pensamiento crítico } \\
\text { profesional }\end{array}$ & $\begin{array}{l}\text { "Se confunde la herramienta con el modelo: el } \\
\text { formulario de valoración, o el formulario de la } \\
\text { estación clínica no sustituye al pensamiento críti- } \\
\text { co de los profesionales" (CI25) }\end{array}$ \\
\hline & $\begin{array}{l}\text { La organización de las institu- } \\
\text { ciones basadas en el modelo } \\
\text { médico (en la enfermedad), que } \\
\text { no exige ni potencia el uso de } \\
\text { los modelos }\end{array}$ & $\begin{array}{l}\text { "La influencia del modelo médico" (CI6) } \\
\text { "También creo que aún pervive el modelo bio- } \\
\text { médico" (CI6) } \\
\text { "Intentar aplicar de manera muy rigurosa y puris- } \\
\text { ta los modelos teóricos en un contexto sanitario } \\
\text { donde los cuidados son secundarios (hegemonía } \\
\text { del curar en detrimento del cuidar)" (CI29) } \\
\text { "No precisan su utilización, para una asistencia a } \\
\text { los pacientes biomédica" (CI60) } \\
\text { "La demanda que el sistema hace sobre lo que la } \\
\text { enfermera debe desarrollar ni exige, ni potencia la } \\
\text { utilización de los modelos" (CI74) }\end{array}$ \\
\hline & $\begin{array}{l}\text { La falta de recursos humanos } \\
\text { para el desarrollo del trabajo } \\
\text { enfermero, presión asistencial }\end{array}$ & $\begin{array}{l}\text { "La queja de la falta de recursos humanos para el } \\
\text { desarrollo del trabajo enfermero" (CI51) } \\
\text { "Las tareas rutinarias favorecidas por la presión } \\
\text { asistencial, el aumento de las necesidades de } \\
\text { cuidados y la fragmentación de los mismos" (CI66) } \\
\text { "Poco tiempo (la asistencia a pie de cama lo ocu- } \\
\text { pa todo)" (CI78) }\end{array}$ \\
\hline & $\begin{array}{l}\text { La falta de efectividad explícita } \\
\text { demostrada de los modelos en } \\
\text { la práctica clínica }\end{array}$ & $\begin{array}{l}\text { "No son estrategias, recursos, instrumentos que } \\
\text { redunden de forma explícita sobre la mejora de la } \\
\text { práctica clínica-comunitaria de los profesionales. } \\
\text { Más bien son ejercicios conceptuales y teóricos" } \\
\text { (CI58) } \\
\text { "La dificultad para monitorizar seguimiento y } \\
\text { control de objetivos" (CI77) }\end{array}$ \\
\hline & $\begin{array}{l}\text { La estructura organizacional de } \\
\text { las propias instituciones }\end{array}$ & $\begin{array}{l}\text { "Estructura organizativa de los hospitales" (CI27) } \\
\text { "Su implementación en la práctica requiere cam- } \\
\text { bios organizativos" (CI37) } \\
\text { "La división del trabajo en las unidades de enfer- } \\
\text { mería por tareas, y realizando una atención } \\
\text { bastante fragmentada del usuario" (CI53) } \\
\text { "Las estructuras de gestión" (CI55) } \\
\text { "La rigidez de los métodos tradicionales de traba- } \\
\text { jo" (CI75) }\end{array}$ \\
\hline
\end{tabular}




\begin{tabular}{|c|c|c|}
\hline $\begin{array}{l}\text { METACATEGORÍA } \\
\text { ("family") }\end{array}$ & $\begin{array}{l}\text { CATEGORÍA ("codes" ) } \\
\text { (Ítem segundo cuestionario) }\end{array}$ & $\begin{array}{l}\text { TRANSCRIPCIÓN LITERAL DE LOS TEXTOS (“quo- } \\
\text { tes”) }\end{array}$ \\
\hline $\begin{array}{l}\text { 6. Organización del } \\
\text { cuidado }\end{array}$ & La falta de apoyo institucional & $\begin{array}{l}\text { "Políticas restrictivas" (CI15) } \\
\text { "La falta de apoyo institucional" (CI17) }\end{array}$ \\
\hline 7. Investigación & $\begin{array}{l}\text { La falta de investigación en } \\
\text { marcos de nuestra propia disci- } \\
\text { plina }\end{array}$ & $\begin{array}{l}\text { "A menudo la investigación se realiza en el ámbito } \\
\text { biomédico" (Cl20) }\end{array}$ \\
\hline \multirow{4}{*}{$\begin{array}{l}\text { 8. Brecha teórico- } \\
\text { práctica }\end{array}$} & $\begin{array}{l}\text { La divergencia entre el mundo } \\
\text { académico y el asistencial }\end{array}$ & $\begin{array}{l}\text { "La divergencia entre el mundo académico y el } \\
\text { asistencial" (CI1) } \\
\text { "La dicotomía de lo que se enseña en las escuelas } \\
\text { de enfermería y la práctica. La socialización a la } \\
\text { inversa está garantizada" (CI41) }\end{array}$ \\
\hline & $\begin{array}{l}\text { La falta de continuidad de los } \\
\text { propios modelo durante la for- } \\
\text { mación universitaria, son vistos } \\
\text { en unas pocas asignaturas du- } \\
\text { rante la carrera }\end{array}$ & $\begin{array}{l}\text { "Los profesores de Universidad, de toda la planti- } \\
\text { lla académica que constituyen los cuatro años de } \\
\text { Grado, solo se plantean los Modelos dos o tres } \\
\text { profesores que los conocen con más profundidad, } \\
\text { el resto de las asignaturas ni se nombran (por } \\
\text { desconocimiento de los profesores), viviéndolos } \\
\text { los alumnos como asignaturas "Marías" que tie- } \\
\text { nen que aprobar, no como parte de su identidad } \\
\text { profesional" (CI62) }\end{array}$ \\
\hline & $\begin{array}{l}\text { El hecho de que las teorías se } \\
\text { utilizaran para ubicar la enfer- } \\
\text { mería como profesión sólo } \\
\text { dentro del mundo académico }\end{array}$ & $\begin{array}{l}\text { "El hecho de que Las Teorías de enfermería se } \\
\text { utilizaron principalmente para establecer el lugar } \\
\text { de la profesión dentro de la universidad y asíse } \\
\text { estableció con más fuerza en el mundo académi- } \\
\text { co" (CI4) } \\
\text { "La formación de una élite académica alejada de } \\
\text { la práctica asistencial" (CI) }\end{array}$ \\
\hline & $\begin{array}{l}\text { La no visibilización de los mode- } \\
\text { los estudiados una vez la } \\
\text { enfermera/o llega a la práctica }\end{array}$ & $\begin{array}{l}\text { "No continuidad de la formación universitaria en } \\
\text { el ámbito laboral" (CI14) } \\
\text { "El no desarrollo es debido a la prácticamente } \\
\text { inexistencia de proyectos en la práctica" (CI16) }\end{array}$ \\
\hline
\end{tabular}

Además se recogieron comentarios recibidos libremente en el espacio que se dejó para sugerencias sobre el tema de la aplicación de modelos teóricos. Entre ellos se expresaba que los modelos no eran adecuados por ser demasiado teóricos, estaban poco adaptados a las necesidades y que carecían en muchos casos de plantilla de valoración. Pusieron de manifiesto que sería interesante marcar todo el curriculum enfermero bajo un mismo modelo, y que el desarrollo del trabajo de fin de grado de los alumnos puede ser un espacio idóneo para usar y probar los mode- 
los. También comentaron que era relevante la motivación enfermera y su formación homogeneizada en el tema, incluso citaron alguna fuente bibliográfica por si podía ser de utilidad en el trabajo.

\subsubsection{Resultados segunda ronda del Delphi}

En esta segunda ronda respondieron al segundo formulario enviado un total de 23 sujetos, cada uno de los ítems, fue priorizado por un mínimo de 20 expertos. Se completaron por tanto el 91,3\% de las puntuaciones de los ítems. En la tabla 42 se recogen la puntuación máxima y mínima, la media y la desviación de cada uno de los ítems valorados de la primera pregunta del Delphi: Puntúe de 1 a 10 cada uno de los elementos siguientes, en función de la consideración que tienen cada uno de ellos en FAVORECER la aplicación de los modelos teóricos en la práctica. Siendo 1 la menor influencia y 10 la mayor influencia. El ítem que fue mejor puntuado fue el de "La sensibilidad y necesidad de las Direcciones de Enfermería de aplicar modelos teóricos en los pacientes" con una media de $8,5 \pm 1,6$.

Tabla 42: Puntuación de los ítems del Delphi a la pregunta sobre elementos favorecedores para la aplicación de modelos teóricos en la práctica

\begin{tabular}{|c|c|c|c|c|c|}
\hline & $\mathbf{N}$ & Mínimo & Máximo & Media & $\begin{array}{l}\text { Desviación } \\
\text { típica }\end{array}$ \\
\hline $\begin{array}{l}\text { La sensibilidad y necesidad de las Direcciones de } \\
\text { Enfermería de aplicar modelos teóricos en los } \\
\text { pacientes }\end{array}$ & 23 & 3 & 10 & 8,5 & 1,6 \\
\hline $\begin{array}{l}\text { El uso de estructuras teóricas para la valoración } \\
\text { enfermera }\end{array}$ & 23 & 3 & 10 & 8,2 & 1,8 \\
\hline El liderazgo clínico entre las enfermeras/os & 23 & 3 & 10 & 8,1 & 2,1 \\
\hline $\begin{array}{l}\text { El desarrollo del pensamiento crítico en la profe- } \\
\text { sión ya que los modelos facilitan la reflexión }\end{array}$ & 23 & 3 & 10 & 8,1 & 2,0 \\
\hline $\begin{array}{l}\text { La creencia y necesidad personal de los profesio- } \\
\text { nales en la aplicación de un modelo de cuidados }\end{array}$ & 23 & 2 & 10 & 8,0 & 2,6 \\
\hline $\begin{array}{l}\text { El compromiso de desarrollo como disciplina de } \\
\text { docentes y asistenciales }\end{array}$ & 23 & 3 & 10 & 7,9 & 1,7 \\
\hline $\begin{array}{l}\text { La estrategia de poder para clarificar la aporta- } \\
\text { ción personal y diferenciarla de otros } \\
\text { profesionales de salud }\end{array}$ & 21 & 3 & 10 & 7,6 & 2,4 \\
\hline $\begin{array}{l}\text { La informatización de la documentación clínica y } \\
\text { el plan de cuidados }\end{array}$ & 23 & 3 & 10 & 7,6 & 1,6 \\
\hline El desarrollo de planes de cuidados en la práctica & 23 & 2 & 10 & 7,5 & 2,3 \\
\hline $\begin{array}{l}\text { El interés profesional por definir el producto en- } \\
\text { fermero }\end{array}$ & 23 & 2 & 10 & 7,5 & 2,3 \\
\hline $\begin{array}{l}\text { La investigación y difusión en congresos de traba- } \\
\text { jos con base teórica y metodológica }\end{array}$ & 23 & 3 & 10 & 7,5 & 2,4 \\
\hline $\begin{array}{l}\text { La identificación en relación a un modelo de los } \\
\text { centros sanitarios }\end{array}$ & 22 & 3 & 10 & 7,5 & 2,1 \\
\hline $\begin{array}{l}\text { El cambio del modelo asistencial orientado a pa- } \\
\text { ciente y familia }\end{array}$ & 23 & 3 & 10 & 7,4 & 2,1 \\
\hline $\begin{array}{l}\text { La incorporación de los modelos teóricos en la } \\
\text { formación universitaria y los nuevos planes de } \\
\text { estudio }\end{array}$ & 22 & 3 & 10 & 7,4 & 2,1 \\
\hline
\end{tabular}




\begin{tabular}{|l|c|c|c|c|c|}
\hline & $\mathrm{N}$ & Mínimo & Máximo & Media & $\begin{array}{c}\text { Desviación } \\
\text { típica }\end{array}$ \\
\hline La existencia de literatura científica sobre el tema & 23 & 3 & 10 & $\mathbf{7 , 4}$ & 2,1 \\
\hline $\begin{array}{l}\text { La aspiración de mejorar la práctica enfermera } \\
\text { mediante innovación propia }\end{array}$ & 23 & 3 & 10 & $\mathbf{7 , 4}$ & 1,9 \\
\hline El uso de lenguajes comunes, estandarizados & 23 & 1 & 10 & $\mathbf{7 , 2}$ & 2,5 \\
\hline El papel de las asociaciones científicas & 23 & 3 & 9 & $\mathbf{7 , 1}$ & 1,5 \\
\hline El desarrollo de titulaciones de postgrado & 23 & 2 & 10 & $\mathbf{7 , 1}$ & 2,1 \\
\hline $\begin{array}{l}\text { La incorporación de NANDA, NIC y NOC en los } \\
\text { planes académicos }\end{array}$ & 23 & 1 & 10 & $\mathbf{7 , 0}$ & 2,4 \\
\hline $\begin{array}{l}\text { La relación entre el coste y la efectividad de los } \\
\text { cuidados }\end{array}$ & 23 & 3 & 10 & $\mathbf{6 , 7}$ & 2,3 \\
\hline $\begin{array}{l}\text { El informe de Enfermería al alta para la continui- } \\
\text { dad del cuidado }\end{array}$ & 23 & 1 & 10 & $\mathbf{6 , 7}$ & 2,4 \\
\hline El ser el nexo entre asistencia, gestión y docencia & 22 & 3 & 10 & $\mathbf{6 , 6}$ & 2,1 \\
\hline $\begin{array}{l}\text { El trabajo desarrollado por las enfermeras de } \\
\text { Atención Primaria }\end{array}$ & 23 & 3 & 9 & $\mathbf{6 , 5}$ & 1,9 \\
\hline $\begin{array}{l}\text { La divulgación por los profesores de universidad } \\
\text { que los conocen en profundidad y facilitan la } \\
\text { comprensión de los alumnos }\end{array}$ & 23 & 2 & 10 & $\mathbf{6 , 4}$ & 2,2 \\
\hline
\end{tabular}

En cuanto a la priorización de los elementos que impiden la aplicación de modelos teóricos (Segunda pregunta del Delphi: Puntúe de 1 a 10 cada uno de los elementos mostrados a continuación, en función de la consideración que tienen cada uno de ellos en IMPEDIR la aplicación de los modelos teóricos en la práctica. Siendo 1 la menor influencia y 10 la mayor influencia). El ítem que fue mejor puntuado fue el de "La falta de investigación en marcos de nuestra propia disciplina" con una priorización de $8,6 \pm 1,9$. El resto de los ítems puntuados se pueden ver en la tabla 43.

Tabla 43: Puntuación de los ítems del Delphi a la pregunta sobre elementos desfavorables para aplicar modelos teóricos en la práctica

\begin{tabular}{|l|c|c|c|c|c|}
\hline & $\mathbf{N}$ & Mínimo & Máximo & Media & $\begin{array}{c}\text { Desviación típi- } \\
\text { ca }\end{array}$ \\
\hline $\begin{array}{l}\text { La falta de investigación en marcos de } \\
\text { nuestra propia disciplina }\end{array}$ & 21 & 3 & 10 & $\mathbf{8 , 6}$ & 1,9 \\
\hline El desinterés profesional por los modelos & 21 & 3 & 10 & $\mathbf{8 , 6}$ & 1,9 \\
\hline $\begin{array}{l}\text { La organización de las instituciones ba- } \\
\text { sadas en el modelo médico (en la } \\
\text { enfermedad), que no exige ni potencia el } \\
\text { uso de los modelos }\end{array}$ & 21 & 3 & 10 & $\mathbf{8 , 4}$ & 1,7 \\
\hline $\begin{array}{l}\text { La ausencia de liderazgo clínico e institu- } \\
\text { cional enfermero }\end{array}$ & 21 & 3 & 10 & $\mathbf{8 , 3}$ & 1,6 \\
\hline $\begin{array}{l}\text { La no visibilización de los modelos estu- } \\
\text { diados una vez la enfermera/o llega a la } \\
\text { práctica }\end{array}$ & 21 & 3 & 10 & $\mathbf{8 , 1}$ & 1,8 \\
\hline $\begin{array}{l}\text { La falta de continuidad de los propios } \\
\text { modelo durante la formación universita- } \\
\text { ria, son vistos en unas pocas asignaturas } \\
\text { durante la carrera }\end{array}$ & 21 & 3 & 10 & $\mathbf{8 , 1}$ & 1,7 \\
\hline
\end{tabular}




\begin{tabular}{|c|c|c|c|c|c|}
\hline & $\mathbf{N}$ & Mínimo & Máximo & Media & $\begin{array}{l}\text { Desviación } \\
\text { típica }\end{array}$ \\
\hline $\begin{array}{l}\text { La falta de condicionamiento de las di- } \\
\text { recciones enfermeras en el modelo de } \\
\text { atención, formación continuada, carrera } \\
\text { profesional,...pese a identificarse con un } \\
\text { modelo teórico }\end{array}$ & 21 & 2 & 10 & 8,1 & 2,1 \\
\hline $\begin{array}{l}\text { La falta de reconocimiento del uso de } \\
\text { modelos en el desarrollo como disciplina } \\
\text { (sólo se entiende el desarrollo profesio- } \\
\text { nal en la organización con el objetivo de } \\
\text { la mejora laboral) }\end{array}$ & 21 & 3 & 10 & 8,1 & 1,9 \\
\hline $\begin{array}{l}\text { El pragmatismo y la falta de reflexión } \\
\text { personal de no tener la necesidad de } \\
\text { basar la práctica en conocimiento propio }\end{array}$ & 21 & 3 & 10 & 8,0 & 1,8 \\
\hline $\begin{array}{l}\text { El hecho de que las teorías se utilizaran } \\
\text { para ubicar la enfermería como profe- } \\
\text { sión sólo dentro del mundo académico }\end{array}$ & 21 & 3 & 10 & 7,8 & 1,9 \\
\hline $\begin{array}{l}\text { La confusión entre la herramienta y el } \\
\text { modelo, los formularios utilizados no } \\
\text { sustituyen el pensamiento crítico profe- } \\
\text { sional }\end{array}$ & 21 & 2 & 10 & 7,8 & 2,1 \\
\hline $\begin{array}{l}\text { El poco interés en reflejar el producto } \\
\text { enfermero }\end{array}$ & 20 & 3 & 10 & 7,7 & 1,9 \\
\hline $\begin{array}{l}\text { La falta de formación de los profesiona- } \\
\text { les en modelos teóricos }\end{array}$ & 21 & 3 & 10 & 7,6 & 2,1 \\
\hline $\begin{array}{l}\text { La informatización no adecuada (en oca- } \\
\text { siones prima el registro de la actividad } \\
\text { sobre la misma actividad) }\end{array}$ & 21 & 3 & 10 & 7,6 & 2,1 \\
\hline $\begin{array}{l}\text { El que las enfermeras que se incorporan } \\
\text { a la asistencia no integran su aportación } \\
\text { en las actuaciones que realizan }\end{array}$ & 21 & 3 & 10 & 7,5 & 2,0 \\
\hline $\begin{array}{l}\text { La falta de apoyo por parte de las direc- } \\
\text { ciones enfermeras }\end{array}$ & 21 & 2 & 10 & 7,4 & 2,2 \\
\hline $\begin{array}{l}\text { La confusión entre el objeto de la disci- } \\
\text { plina enfermera y la finalidad de la } \\
\text { práctica }\end{array}$ & 21 & 3 & 10 & 7,2 & 1,8 \\
\hline $\begin{array}{l}\text { La falta de modelos contextualizados en } \\
\text { nuestro país (propios) }\end{array}$ & 21 & 3 & 10 & 7,2 & 2,2 \\
\hline $\begin{array}{l}\text { La falta de utilidad percibida por los pro- } \\
\text { fesionales que han trabajado con } \\
\text { metodología }\end{array}$ & 20 & 3 & 10 & 7,2 & 2,2 \\
\hline $\begin{array}{l}\text { El propio dogmatismo profesional por un } \\
\text { único modelo teórico }\end{array}$ & 21 & 3 & 10 & 7,1 & 2,3 \\
\hline $\begin{array}{l}\text { Las estrategias de incorporación y adap- } \\
\text { tación de los modelos a la práctica que } \\
\text { en ocasiones se centran en marcos de } \\
\text { valoración que se alejan de los modelos } \\
\text { teóricos }\end{array}$ & 21 & 2 & 10 & 7,1 & 2,6 \\
\hline La falta de apoyo institucional & 21 & 3 & 10 & 7,0 & 1,8 \\
\hline $\begin{array}{l}\text { La divergencia entre el mundo académi- } \\
\text { co y el asistencial }\end{array}$ & 20 & 3 & 10 & 7,0 & 2,1 \\
\hline
\end{tabular}




\begin{tabular}{|l|c|c|c|c|c|}
\hline & $\mathbf{N}$ & Mínimo & Máximo & Media & $\begin{array}{c}\text { Desviación típi- } \\
\text { ca }\end{array}$ \\
\hline $\begin{array}{l}\text { La decisión unilateral de gestores en la } \\
\text { aplicación de modelos sin la implicación } \\
\text { de los propios profesionales }\end{array}$ & 20 & 2 & 10 & 7,0 & 2,5 \\
\hline $\begin{array}{l}\text { La estructura organizacional de las pro- } \\
\text { pias instituciones }\end{array}$ & 21 & 1 & 10 & 6,8 & 2,4 \\
\hline $\begin{array}{l}\text { La falta de autoestima de los propios } \\
\text { profesionales }\end{array}$ & 21 & 3 & 10 & $\mathbf{6 , 7}$ & 2,1 \\
\hline $\begin{array}{l}\text { Las propias características de los mode- } \\
\text { los que en ocasiones no permiten la } \\
\text { adaptación adecuada a la realidad del } \\
\text { centro en el que se aplica }\end{array}$ & 21 & 2 & 10 & $\mathbf{6 , 7}$ & 2,3 \\
\hline $\begin{array}{l}\text { La falta de recursos humanos para el } \\
\text { desarrollo del trabajo enfermero, pre- } \\
\text { sión asistencial }\end{array}$ & 21 & 2 & 10 & 6,7 & 2,5 \\
\hline $\begin{array}{l}\text { El propio lenguaje, la complejidad de los } \\
\text { modelos y su ambigüedad }\end{array}$ & 21 & 3 & 10 & $\mathbf{6 , 7}$ & 1,9 \\
\hline $\begin{array}{l}\text { La operativización que comporta su im- } \\
\text { plementación para poder llevar los } \\
\text { modelos a la práctica (documentación, } \\
\text { informes...) }\end{array}$ & 21 & 2 & 10 & $\mathbf{6 , 4}$ & 2,4 \\
\hline $\begin{array}{l}\text { La falta de efectividad explícita demos- } \\
\text { trada de los modelos en la práctica } \\
\text { clínica }\end{array}$ & 20 & 2 & 10 & $\mathbf{6 , 4}$ & 2,2 \\
\hline La variabilidad de modelos teóricos & 21 & 3 & 10 & $\mathbf{6 , 1}$ & 1,9 \\
\hline $\begin{array}{l}\text { La barrera idiomática que impide cono- } \\
\text { cer de forma profunda los textos } \\
\text { originales de las teoristas }\end{array}$ & 21 & 2 & 9 & $\mathbf{6 , 0}$ & 2,0 \\
\hline $\begin{array}{l}\text { La ausencia de legislación que obligue a } \\
\text { trabajar con metodología enfermera en } \\
\text { las instituciones sanitarias }\end{array}$ & 21 & 1 & 10 & $\mathbf{6 , 0}$ & 2,9 \\
\hline El poder de la clase médica & 21 & 1 & 10 & $\mathbf{4 , 8}$ & 2,9 \\
\hline $\begin{array}{l}\text { Las actuales líneas de pensamiento vin- } \\
\text { culadas a práctica basada en la evidencia }\end{array}$ & 21 & 1 & 10 & 2,5 \\
\hline
\end{tabular}

Además fueron recogidos nuevos comentarios en el espacio destinado a ello, a destacar la relevancia de la formación universitaria en el tema y su papel en la diferenciación que debe de remarcar entre teoría y metodología enfermera. También argumentan el gran papel que ha hecho la informatización de los planes de cuidados, y el éxito de planes de cuidados estandarizados frente a los individuales. 


\subsubsection{Resultados tercera ronda del Delphi}

En esta tercera ronda respondieron al formulario enviado un total de 23 sujetos. En las tablas 44 y 45 se recogen la cantidad de sujetos que priorizaron cada uno de los facilitadores y impedidores de aplicación de modelos en la práctica (debían priorizar 20 de los 25 ofertados en los facilitadores y 20 de los 36 ofertados en los limitadores), además de la puntuación máxima y mínima, la media de la puntuación de priorización y la desviación de cada uno de los ítems. A menor puntuación mayor relevancia del factor sobre la aplicación de modelos teóricos en la práctica (a nivel favorecedor o impedidor).

Los factores facilitadores que fueron priorizados fueron "el liderazgo entre las enfermeras" y "la sensibilidad y necesidad de las Direcciones de Enfermería de aplicar modelos teóricos en los pacientes" (ambos priorizados por 23 de los sujetos). En el caso de los elementos barrera o limitantes fueron priorizados factores ligados a la propia reflexión como profesional enfermero: "el pragmatismo y la falta de reflexión personal de no tener la necesidad de basar la práctica en conocimiento propio" y "la falta de reconocimiento del uso de modelos en el desarrollo como disciplina (sólo se entiende el desarrollo profesional en la organización con el objetivo de la mejora laboral)" priorizados por 21 de los sujetos. Por detrás de estos factores se encuentran "el desinterés profesional por los modelos" y "la falta de condicionamiento de las direcciones enfermeras en el modelo de atención, formación continuada, carrera profesional,... pese a identificarse con un modelo teórico" priorizados por 20 de los sujetos encuestados.

En el espacio destinado a comentarios, se recogieron todavía nuevas aportaciones al tema, aunque en relación a temas ya redundantes en anteriores rondas del Delphi.

Para poder valorar con claridad a los participantes en cada ronda y los elementos finalmente que obtuvieron mayor puntuación, se ha elaborado la figura 20 que resume los hallazgos del estudio Delphi en cuanto a los elementos influenciadores de aplicación de modelos teóricos en la práctica priorizados por los expertos encuestados. 
Tabla 44: Prioridad obtenidas sobre los factores que facilitan la aplicación de modelos en la práctica en la tercera ronda del Delphi Prioridad

en segunda

ronda

FACTORES A PRIORIZAR

Sujetos que lo

priorizaron entre Prioridad Prioridad los 20 primeros

máxima

Media de Desv. prioridad típ.

\begin{tabular}{|c|c|c|c|c|c|c|}
\hline & & & & & & \\
\hline 3 & El liderazgo clínico entre las enfermeras/os & 23 & 1 & 20 & 5,22 & 5,18 \\
\hline 1 & $\begin{array}{l}\text { La sensibilidad y necesidad de las Direcciones de Enfermería de aplicar modelos teóricos en } \\
\text { los pacientes }\end{array}$ & 23 & 1 & 20 & 5,39 & 5,87 \\
\hline 5 & $\begin{array}{l}\text { La creencia y necesidad personal de los profesionales en la aplicación de un modelo de cuida- } \\
\text { dos }\end{array}$ & 22 & 1 & 16 & 5,68 & 4,45 \\
\hline 2 & El uso de estructuras teóricas para la valoración enfermera & 22 & 2 & 19 & 8,45 & 5,22 \\
\hline 4 & El desarrollo del pensamiento crítico en la profesión ya que los modelos facilitan la reflexión & 22 & 1 & 20 & 8,55 & 6,56 \\
\hline 6 & El compromiso de desarrollo como disciplina de docentes asistenciales & 22 & 1 & 19 & 9,05 & 5,30 \\
\hline 17 & El uso de lenguajes comunes, estandarizados & 22 & 5 & 20 & 11,50 & 4,42 \\
\hline 8 & La informatización de la documentación clínica y el plan de cuidados & 21 & 2 & 20 & 10,33 & 5,46 \\
\hline 14 & $\begin{array}{l}\text { La incorporación de los modelos teóricos en la formación universitaria y los nuevos planes de } \\
\text { estudio }\end{array}$ & 21 & 1 & 20 & 12,52 & 4,61 \\
\hline 13 & El cambio del modelo asistencial orientado a paciente y familia & 21 & 5 & 18 & 11,43 & 4,12 \\
\hline 12 & La identificación en relación a un modelo de los centros sanitarios & 21 & 3 & 20 & 12,57 & 4,73 \\
\hline 11 & La investigación y difusión en congresos de trabajos con base teórica y metodológica & 21 & 4 & 18 & 13,00 & 3,91 \\
\hline 7 & $\begin{array}{l}\text { La estrategia de poder para clarificar la aportación personal y diferenciarla de otros profesio- } \\
\text { nales de salud }\end{array}$ & 20 & 3 & 20 & 9,65 & 5,41 \\
\hline 9 & El desarrollo de planes de cuidados en la práctica & 20 & 3 & 20 & 9,95 & 4,94 \\
\hline 20 & La incorporación de NANDA, NIC y NOC en los planes académicos & 20 & 1 & 20 & 13,85 & 5,33 \\
\hline 10 & El interés profesional por definir el producto enfermero & 19 & 2 & 19 & 8,58 & 5,06 \\
\hline 16 & La aspiración de mejorar la práctica enfermera mediante innovación propia & 19 & 4 & 20 & 11,32 & 4,20 \\
\hline 15 & La existencia de literatura científica sobre el tema & 19 & 10 & 18 & 14,26 & 2,81 \\
\hline 19 & El desarrollo de titulaciones de postgrado & 15 & 3 & 20 & 13,20 & 5,65 \\
\hline 21 & La relación entre el coste y la efectividad de los cuidados & 14 & 5 & 20 & 12,50 & 4,78 \\
\hline 22 & El informe de enfermería al alta para la continuidad del cuidado & 13 & 2 & 20 & 12,23 & 6,58 \\
\hline 25 & $\begin{array}{l}\text { La divulgación por los profesores de universidad que los conocen en profundidad y facilitan la } \\
\text { comprensión de los alumnos }\end{array}$ & 11 & 1 & 20 & 12,73 & 6,94 \\
\hline 18 & El papel de las asociaciones científicas & 11 & 2 & 20 & 14,36 & 5,84 \\
\hline 23 & El ser el nexo entre asistencia, gestión y docencia & 10 & 1 & 20 & 13,70 & 6,91 \\
\hline 24 & El trabajo desarrollado por las enfermeras de Atención Primaria & 7 & 2 & 20 & 13,00 & 8,00 \\
\hline
\end{tabular}


Tabla 45: Prioridad obtenidas sobre los factores que impiden la aplicación de modelos en la práctica en la tercera ronda del Delphi

\section{Prioridad}

en segunda ronda

9

8

2

7

1

10

3

\begin{tabular}{|l|}
\hline 5 \\
\hline 6
\end{tabular}

\begin{tabular}{|c|}
\hline 13 \\
\hline 4 \\
\hline
\end{tabular}

\begin{tabular}{|c|}
\hline 4 \\
\hline 11 \\
\hline 12 \\
\hline 20 \\
\hline 16 \\
\hline 15 \\
\hline
\end{tabular}

14

17
FACTORES A PRIORIZAR

El pragmatismo y la falta de reflexión personal de no tener la necesidad de basar la práctica en conocimiento propio

La falta de reconocimiento del uso de modelos en el desarrollo como disciplina (sólo se entiende el desarrollo profesional en la organización con el objetivo de la mejora laboral) El desinterés profesional por los modelos

La falta de condicionamiento de las direcciones enfermeras en el modelo de atención, formación continuada, carrera profesional,...pese a identificarse con un modelo teórico

La falta de investigación en marcos de nuestra propia disciplina

El hecho de que las teorías se utilizaran para ubicar la enfermería como profesión sólo dentro del mundo académico

La organización de las instituciones basadas en el modelo médico (en la enfermedad), que no exige ni potencia el uso de los modelos

La no visibilización de los modelos estudiados una vez la enfermera/o llega a la práctica

La falta de continuidad de los propios modelo durante la formación universitaria, son vistos en unas pocas asignaturas durante la carrera

La falta de formación de los profesionales en modelos teóricos

La ausencia de liderazgo clínico e institucional enfermero

La confusión entre la herramienta y el modelo, los formularios utilizados no sustituyen el pensamiento crítico profesional

El poco interés en reflejar el producto enfermero

El propio dogmatismo profesional por un único modelo teórico

La falta de apoyo por parte de las direcciones enfermeras

El que las enfermeras que se incorporan a la asistencia no integran su aportación en las actuaciones que realizan

La informatización no adecuada (en ocasiones prima el registro de la actividad sobre la misma actividad)

La confusión entre el objeto de la disciplina enfermera y la finalidad de la práctica
Sujetos que lo

priorizaron entre

los 20 primeros

Prioridad $\operatorname{Pr}$

máxima mínima

Media de Desv. prioridad típ.

\begin{tabular}{|c|c|c|c|c|}
\hline 21 & 1 & 15 & 6,9 & 4,4 \\
\hline 21 & 1 & 18 & 8,2 & 4,5 \\
\hline 20 & 1 & 19 & 6,6 & 6,2 \\
\hline 20 & 1 & 20 & 7,4 & 4,6 \\
\hline 19 & 1 & 19 & 8,5 & 7,0 \\
\hline 19 & 3 & 19 & 11,2 & 5,1 \\
\hline 18 & 1 & 20 & 5,6 & 6,1 \\
\hline 18 & 2 & 16 & 7,3 & 4,6 \\
\hline 18 & 1 & 18 & 9,1 & 6,2 \\
\hline 18 & 1 & 20 & 9,8 & 4,9 \\
\hline 17 & 1 & 17 & 4,8 & 4,4 \\
\hline 17 & 2 & 20 & 8,0 & 5,4 \\
\hline 16 & 6 & 17 & 10,5 & 3,2 \\
\hline 16 & 6 & 20 & 13,3 & 4,0 \\
\hline 15 & 2 & 20 & 11,5 & 5,6 \\
\hline 15 & 4 & 20 & 11,7 & 5,2 \\
\hline 14 & 3 & 20 & 11,0 & 4,9 \\
\hline 14 & 5 & 20 & 12,1 & 4,4 \\
\hline
\end{tabular}




\begin{tabular}{|c|c|c|c|c|c|c|}
\hline $\begin{array}{c}\text { Prioridad } \\
\text { en segunda } \\
\text { ronda }\end{array}$ & FACTORES A PRIORIZAR & $\begin{array}{l}\text { Sujetos que lo } \\
\text { priorizaron entre } \\
\text { los } 20 \text { primeros }\end{array}$ & $\begin{array}{l}\text { Prioridad } \\
\text { máxima }\end{array}$ & $\begin{array}{l}\text { Prioridad } \\
\text { mínima }\end{array}$ & $\begin{array}{l}\text { Media de } \\
\text { prioridad }\end{array}$ & $\begin{array}{l}\text { Desv. } \\
\text { típ. }\end{array}$ \\
\hline 21 & $\begin{array}{l}\text { Las estrategias de incorporación y adaptación de los modelos a la práctica que en ocasiones se } \\
\text { centran en marcos de valoración que se alejan de los modelos teóricos }\end{array}$ & 14 & 7 & 20 & 12,9 & 4,2 \\
\hline 18 & La falta de modelos contextualizados en nuestro país (propios) & 14 & 5 & 19 & 13,8 & 4,9 \\
\hline 19 & La falta de utilidad percibida por los profesionales que han trabajado con metodología & 13 & 6 & 20 & 12,3 & 5,4 \\
\hline 23 & La divergencia entre el mundo académico y el asistencial & 11 & 2 & 19 & 12,0 & 6,4 \\
\hline 31 & La falta de efectividad explícita demostrada de los modelos en la práctica clínica & 9 & 8 & 18 & 13,9 & 3,6 \\
\hline 24 & $\begin{array}{l}\text { La decisión unilateral de gestores en la aplicación de modelos sin la implicación de los propios } \\
\text { profesionales }\end{array}$ & 9 & 9 & 20 & 14,3 & 3,0 \\
\hline 25 & La estructura organizacional de las propias instituciones & 9 & 8 & 20 & 15,8 & 4,0 \\
\hline 29 & El propio lenguaje, la complejidad de los modelos y su ambigüedad & 8 & 4 & 18 & 13,0 & 5,0 \\
\hline 32 & La variabilidad de modelos teóricos & 8 & 1 & 20 & 14,3 & 6,3 \\
\hline 22 & La falta de apoyo institucional & 8 & 8 & 19 & 15,1 & 4,0 \\
\hline 28 & La falta de recursos humanos para el desarrollo del trabajo enfermero, presión asistencial & 7 & 3 & 16 & 11,3 & 4,6 \\
\hline 34 & $\begin{array}{l}\text { La ausencia de legislación que obligue a trabajar con metodología enfermera en las instituciones } \\
\text { sanitarias }\end{array}$ & 7 & 14 & 20 & 17,9 & 2,1 \\
\hline 26 & La falta de autoestima de los propios profesionales & 6 & 4 & 20 & 10,8 & 6,2 \\
\hline 35 & El poder de la clase médica & 6 & 17 & 20 & 18,8 & 1,2 \\
\hline 27 & $\begin{array}{l}\text { Las propias características de los modelos que en ocasiones no permiten la adaptación adecuada } \\
\text { a la realidad del centro en el que se aplica }\end{array}$ & 5 & 9 & 18 & 12,8 & 3,6 \\
\hline 30 & $\begin{array}{l}\text { La operativización que comporta su implementación para poder llevar los modelos a la práctica } \\
\text { (documentación, informes...) }\end{array}$ & 5 & 8 & 16 & 13,4 & 3,3 \\
\hline 33 & La barrera idiomática que impide conocer de forma profunda los textos originales de las teoristas & 3 & 17 & 19 & 17,7 & 1,2 \\
\hline 36 & Las actuales líneas de pensamiento vinculadas a práctica basada en la evidencia & 2 & 20 & 20 & 20,0 & 0,0 \\
\hline
\end{tabular}




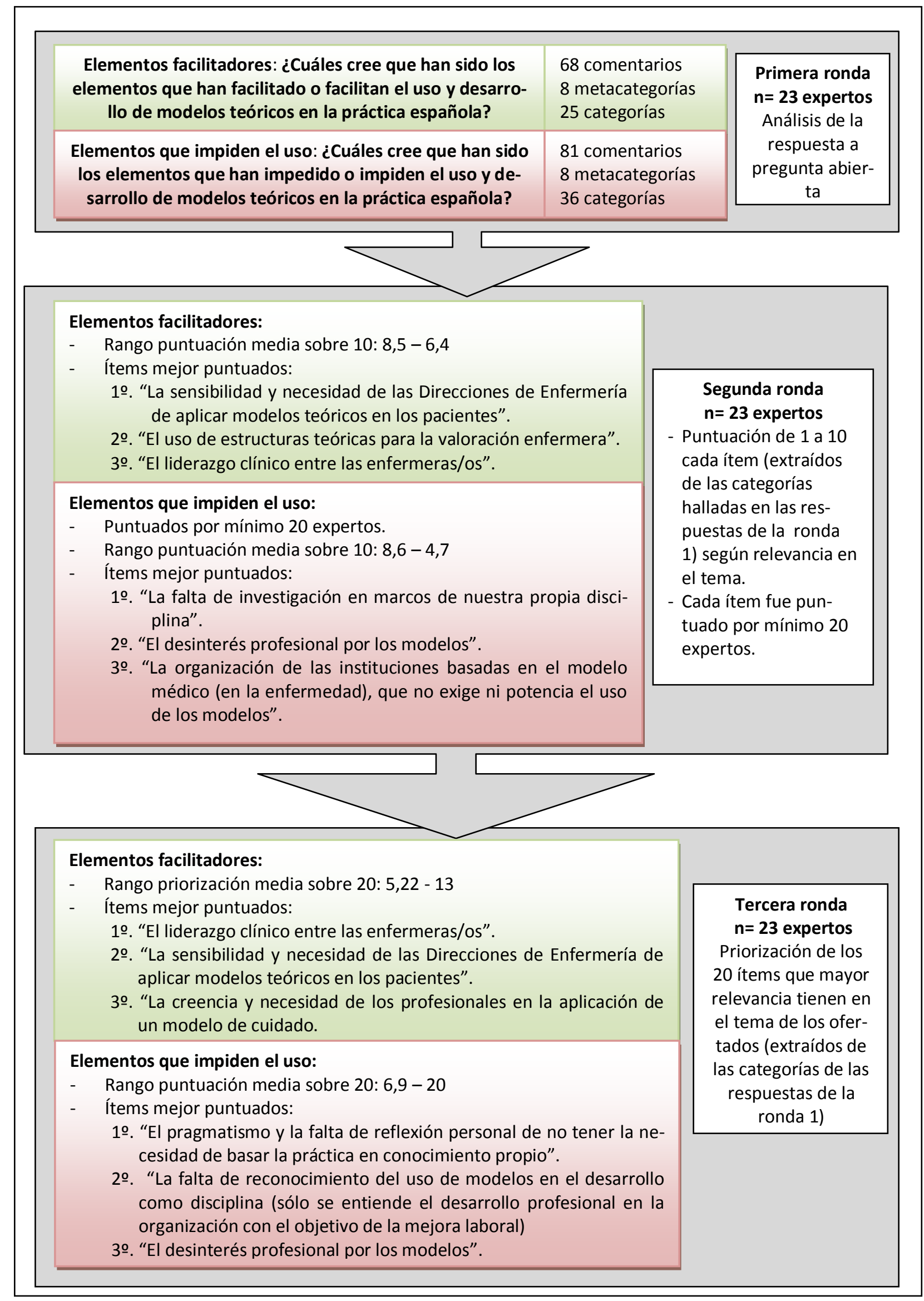

Figura 20: Resumen de los hallazgos del estudio Delphi en cuanto a los elementos influenciadores de aplicación de modelos teóricos en la práctica 


\subsection{Resultados en relación al sexto objetivo: Describir el nivel}

\section{de implantación de modelos enfermeros en la práctica actual a nivel internacional.}

Inicialmente los hallazgos encontrados en la búsqueda de la base de datos de Medline mediante el sistema de Pubmed, se explotaron abruptamente por los términos generales Mesh relacionados con el tema de estudio, con el objetivo de tener una idea global del número de artículos que podrían ser diana para la búsqueda planteada. Los resultados fueron los expuestos en la tabla 46. Este análisis se realizó marcando como fechas de publicación entre el 15 enero de 2008 y el 15 de enero de 2013.

Tabla 46: Publicaciones halladas en Pubmed al utilizar los principales términos Mesh junto a operadores booleanos que describen los artículos indexados en los mismos mediante la teoría enfermera en la base de datos y los artículos indexados en investigación enfermera.

\begin{tabular}{|l|l|l|}
\hline Términos mesh usados & Límites & $\begin{array}{l}\text { Artículos } \\
\text { indexados }\end{array}$ \\
\hline Nursing Research[Mesh] & $\begin{array}{l}\text { Abstract available; Publica- } \\
\text { tion last 5 years }\end{array}$ & 8357 \\
\hline $\begin{array}{l}\text { Models, Nursing[Mesh] OR Philosophy, Nursing[Mesh] OR } \\
\text { Nursing Research[Mesh] }\end{array}$ & $\begin{array}{l}\text { Abstract available; Publica- } \\
\text { tion last 5 years }\end{array}$ & 9918 \\
\hline $\begin{array}{l}\text { Models, Nursing[Mesh] OR Philosophy, Nursing[Mesh] } \\
\text { AND Nursing Research[Mesh] }\end{array}$ & $\begin{array}{l}\text { Abstract available; Publica- } \\
\text { tion last 5 years }\end{array}$ & 1130 \\
\hline Models, Nursing[Mesh] OR Philosophy, Nursing[Mesh] & $\begin{array}{l}\text { Abstract available; Publica- } \\
\text { tion last 5 years }\end{array}$ & 2691 \\
\hline $\begin{array}{l}\text { Models, Nursing[Mesh] OR Nursing Process[Mesh] OR } \\
\text { Nursing Research[Mesh]OR Nursing Evaluation Re- } \\
\text { search[Mesh] OR Clinical Nursing Research[Mesh] OR } \\
\text { Nursing Methodology Research[Mesh] OR Philosophy, } \\
\text { Nursing[Mesh] OR Nursing Diagnosis[Mesh] }\end{array}$ & $\begin{array}{l}\text { Abstract available; Publica- } \\
\text { tion last 5 years }\end{array}$ & 12152 \\
\hline
\end{tabular}

La búsqueda localizó 16.922 artículos potencialmente relevantes en el tema. Tras la valoración de estos estudios, se decidió incluir finalmente un total de 276 artículos que nombraran a alguna teorista concreta de las propuestas (en 80 revistas). El proceso de inclusión y exclusión se resume en la figura 21. La totalidad de los artículos hallados, tipo y resumen de los mismos se halla en el anexo IV, contenido en el Compact Disc (CD) adjunto. Los resultados por autoras y años de publicación se resumen en la tabla 47. 


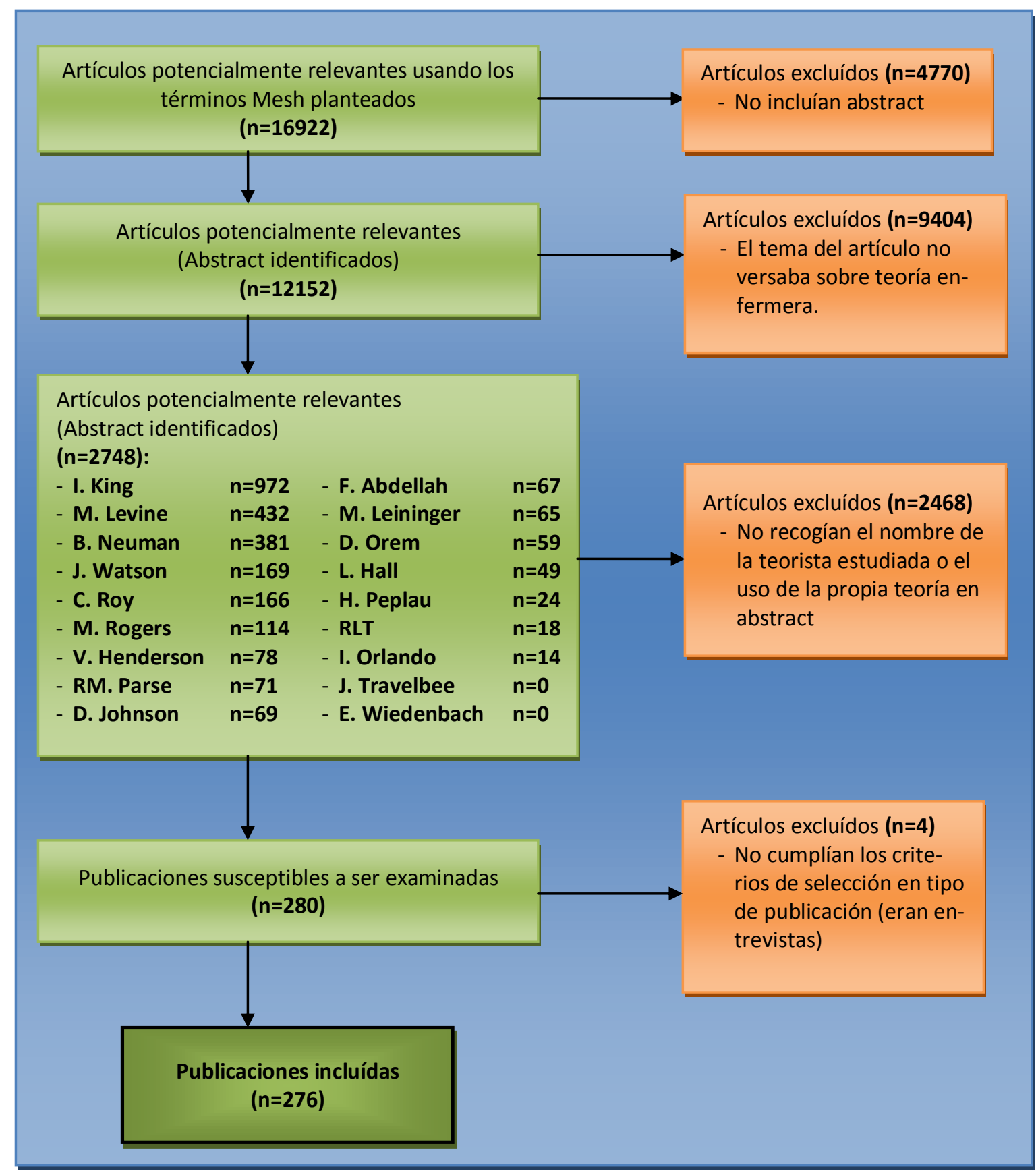

Figura 21: Identificación y selección de los artículos relevantes

La mayoría de los artículos hallados se referían a los modelos de R. Parse (21\%), C. Roy $(15,6 \%)$, D. Orem (13\%) y J. Watson $(11,6 \%)$. El resto de teoristas fueron usadas por menos del $10 \%$ de las publicaciones.

En cuanto a los años en los que fueron publicados, se puede apreciar un número constante anual de publicaciones en relación a modelos teóricos, entre 49 y 55 publicaciones al año, siendo la media de 54,8 publicaciones anuales (ver tabla 46 ). 
Tabla 47: Publicaciones halladas en Pubmed según teorista y años de publicación

\begin{tabular}{|c|c|c|c|c|c|c|c|c|}
\hline & Año $c$ & publi & ación & & & & & \\
\hline & 2008 & 2009 & 2010 & 2011 & 2012 & 2013 & cia total & $\begin{array}{l}\text { publica- } \\
\text { ciones }\end{array}$ \\
\hline Rosemarie Rizzo Parse & 11 & 13 & 12 & 6 & 14 & 2 & 58 & $21 \%$ \\
\hline Sor Callista Roy & 8 & 10 & 6 & 12 & 6 & 1 & 43 & $15,6 \%$ \\
\hline Dorothea E. Orem & 8 & 9 & 6 & 8 & 4 & 1 & 36 & $13 \%$ \\
\hline Jean Watson & 7 & 8 & 9 & 4 & 4 & 0 & 32 & $11,6 \%$ \\
\hline Madeleine M. Leininger & 6 & 7 & 7 & 2 & 5 & 0 & 27 & $9,8 \%$ \\
\hline Betty Neuman & 2 & 2 & 3 & 1 & 10 & 0 & 18 & $6,5 \%$ \\
\hline Martha E. Rogers & 4 & 1 & 5 & 1 & 2 & 0 & 13 & $4,7 \%$ \\
\hline Hildegard E. Peplau & 4 & 0 & 1 & 2 & 4 & 2 & 13 & $4,7 \%$ \\
\hline Virginia Henderson & 2 & 3 & 4 & 1 & 3 & 0 & 13 & $4,7 \%$ \\
\hline Imogene M. King & 3 & 3 & 2 & 2 & 2 & 0 & 12 & $4,3 \%$ \\
\hline Ida Jean Orlando Pelletier & 1 & 0 & 2 & 1 & 0 & 0 & 4 & $1,4 \%$ \\
\hline $\begin{array}{l}\text { Nancy Roper, Winifred Lo- } \\
\text { gan y Alison Tierney }\end{array}$ & 0 & 0 & 1 & 3 & 0 & 0 & 4 & $1,4 \%$ \\
\hline Dorothy Johnson & 0 & 0 & 1 & 0 & 0 & 0 & 1 & $0,4 \%$ \\
\hline Lydia Hall & 0 & 0 & 0 & 0 & 1 & 0 & 1 & $0,4 \%$ \\
\hline Myra Estrin Levine & 0 & 0 & 0 & 1 & 0 & 0 & 1 & $0,4 \%$ \\
\hline Total & 56 & 57 & 59 & 45 & 57 & 6 & 276 & $100 \%$ \\
\hline
\end{tabular}

Para poder establecer una analogía entre los hallazgos de las publicaciones entre las diferentes revistas, se elaboró un indicador fundado en la estimación del número de referencias de autores que habría en 100 artículos (en adelante, artículos estimados), y que estandarizaba la comparación entre las publicaciones. Para su cálculo se multiplicó el número de referencias por cien, y se dividió por el total de artículos publicados en las fechas de la revisión. La revista Nursing Science Quarterly es la que mayor número de artículos recoge tanto a nivel total $(37,7 \%$ de los artículos) como por artículos estimados $(28,1)$. En el resto el porcentaje era inferior al 5\%. Destacar entre los hallazgos, que si realizamos el análisis por el tipo de publicación, hallamos que la mayoría de las publicaciones que usan modelos teóricos de las teoristas buscadas son estudios empíricos (47,1\%). Estos representan 129 del total de 8.357 artículos indexados en investigación enfermera, es decir, un 1,5\% de los mismos. De los 1.130 artículos indexados como artículos de investigación enfermera en base teórica, supondrían realmente el $11,4 \%$. Sin embargo, cuando profundizamos en la metodología de estudio, se objetiva que en la mayoría de los casos el modelo o teoría es usado como marco conceptual explicativo, pero no como uso de la teoría de forma directa en el cuidado de los pacientes. Esto si ocurre de forma explícita en los estudios de casos, pero de 276 publicaciones, sólo 26 (9\%) intentan explicar la efectividad y eficacia del modelo teórico en la aplicación directa (ver tabla 48). 
Tabla 48: Publicaciones según la revista y tipo de de publicación

\begin{tabular}{|c|c|c|c|c|c|c|c|c|c|}
\hline $\begin{array}{l}\text { Título revista abre- } \\
\text { viado }\end{array}$ & $\begin{array}{l}\text { Art. en } \\
\text { los } 5 \\
\text { años }\end{array}$ & $\begin{array}{l}\text { Revi- } \\
\text { sión }\end{array}$ & $\begin{array}{c}\text { Meto- } \\
\text { dológico }\end{array}$ & $\begin{array}{l}\text { Teóri- } \\
\text { co }\end{array}$ & $\begin{array}{l}\text { Estudio } \\
\text { de caso }\end{array}$ & $\begin{array}{l}\text { Empí- } \\
\text { rico }\end{array}$ & $\begin{array}{l}\text { Total } \\
2008- \\
2013\end{array}$ & $\begin{array}{l}\% \text { del } \\
\text { total }\end{array}$ & $\begin{array}{c}\text { Artículos } \\
\text { estimados }\end{array}$ \\
\hline AAOHN J & 306 & 0 & 0 & 0 & 1 & 1 & 2 & 0,7 & 0,7 \\
\hline Adv Skin Wound Care & 436 & 0 & 0 & 0 & 0 & 1 & 1 & 0,4 & 0,2 \\
\hline ANS Adv Nurs Sci & 221 & 0 & 0 & 0 & 0 & 2 & 2 & 0,7 & 0,9 \\
\hline Br J Nurs & 1776 & 0 & 0 & 1 & 1 & 0 & 2 & 0,7 & 0,1 \\
\hline Can Oncol Nurs J & 110 & 0 & 0 & 0 & 0 & 1 & 1 & 0,4 & 0,9 \\
\hline Cancer Nurs & 444 & 0 & 0 & 0 & 0 & 1 & 1 & 0,4 & 0,2 \\
\hline CANNT J & 116 & 0 & 0 & 1 & 0 & 2 & 3 & 1,1 & 2,6 \\
\hline Clin J Oncol Nurs & 614 & 0 & 0 & 1 & 0 & 0 & 1 & 0,4 & 0,2 \\
\hline Clin Nurse Spec & 309 & 0 & 1 & 0 & 0 & 2 & 3 & 1,1 & 1,0 \\
\hline Contemp nurse & 476 & 0 & 0 & 2 & 1 & 2 & 5 & 1,8 & 1,1 \\
\hline Creat nurs & 193 & 0 & 0 & 1 & 0 & 0 & 1 & 0,4 & 0,5 \\
\hline Crit Care Nurs Q & 219 & 0 & 0 & 0 & 1 & 0 & 1 & 0,4 & 0,5 \\
\hline Curationis & 105 & 0 & 0 & 0 & 0 & 1 & 1 & 0,4 & 1,0 \\
\hline Dimens Crit Care Nurs & 265 & 0 & 1 & 0 & 0 & 0 & 1 & 0,4 & 0,4 \\
\hline Enferm Clin & 369 & 0 & 0 & 0 & 4 & 2 & 6 & 2,2 & 1,6 \\
\hline Enferm Intensiva & 111 & 0 & 0 & 0 & 0 & 1 & 1 & 0,4 & 0,9 \\
\hline Gastroenterol Nurs & 277 & 1 & 0 & 0 & 0 & 0 & 1 & 0,4 & 0,4 \\
\hline $\begin{array}{l}\text { Health Care Manag } \\
\text { (Frederick) }\end{array}$ & 219 & 0 & 1 & 0 & 0 & 0 & 1 & 0,4 & 0,5 \\
\hline Holist Nurs Pract & 248 & 1 & 1 & 0 & 1 & 3 & 6 & 2,2 & 2,4 \\
\hline Home Healthc Nurse & 446 & 0 & 0 & 1 & 1 & 0 & 2 & 0,7 & 0,4 \\
\hline Hu Li Za Zhi & 475 & 0 & 0 & 4 & 6 & 0 & 10 & 3,6 & 2,1 \\
\hline Int Emerg Nurs & 217 & 0 & 0 & 0 & 0 & 1 & 1 & 0,4 & 0,5 \\
\hline $\begin{array}{l}\text { Iran J Nurs Midwifery } \\
\text { Res }\end{array}$ & 218 & 0 & 0 & 0 & 0 & 1 & 1 & 0,4 & 0,5 \\
\hline $\begin{array}{l}\text { Issues Ment Health } \\
\text { Nurs }\end{array}$ & 605 & 2 & 0 & 3 & 0 & 0 & 5 & 1,8 & 0,8 \\
\hline J Adv Nurs & 1523 & 4 & 1 & 0 & 0 & 9 & 14 & 5,1 & 0,9 \\
\hline $\begin{array}{l}\text { J Am Psychiatr Nurses } \\
\text { Assoc }\end{array}$ & 216 & 0 & 0 & 0 & 0 & 1 & 1 & 0,4 & 0,5 \\
\hline J Burn Care Res & 808 & 1 & 0 & 0 & 0 & 0 & 1 & 0,4 & 0,1 \\
\hline J Christ Nurs & 302 & 0 & 0 & 0 & 1 & 0 & 1 & 0,4 & 0,3 \\
\hline J Clin Nurs & 2273 & 0 & 0 & 0 & 0 & 1 & 1 & 0,4 & 0,0 \\
\hline J Contin Educ Nurs & 545 & 0 & 1 & 0 & 0 & 0 & 1 & 0,4 & 0,2 \\
\hline J Cult Divers & 119 & 0 & 0 & 0 & 0 & 1 & 1 & 0,4 & 0,8 \\
\hline J Gerontol Nurs & 451 & 0 & 0 & 0 & 0 & 1 & 1 & 0,4 & 0,2 \\
\hline $\begin{array}{l}\text { J Health Hum Serv } \\
\text { Adm }\end{array}$ & 106 & 0 & 0 & 1 & 0 & 0 & 1 & 0,4 & 0,9 \\
\hline J Korean Acad Nurs & 407 & 0 & 0 & 0 & 0 & 3 & 3 & 1,1 & 0,7 \\
\hline $\begin{array}{l}\text { J Natl Black Nurses } \\
\text { Assoc }\end{array}$ & 86 & 0 & 0 & 0 & 0 & 1 & 1 & 0,4 & 1,2 \\
\hline J Neurosci Nurs & 255 & 0 & 0 & 0 & 0 & 2 & 2 & 0,7 & 0,8 \\
\hline J Nurs Educ & 670 & 0 & 0 & 0 & 0 & 1 & 1 & 0,4 & 0,1 \\
\hline J Nurs Manag & 668 & 0 & 0 & 0 & 0 & 2 & 2 & 0,7 & 0,3 \\
\hline J Nurs Res & 161 & 0 & 0 & 0 & 0 & 1 & 1 & 0,4 & 0,6 \\
\hline $\begin{array}{l}\text { J Obstet Gynecol Ne- } \\
\text { onatal Nurs }\end{array}$ & 471 & 0 & 0 & 0 & 0 & 1 & 1 & 0,4 & 0,2 \\
\hline J Pediatr Nurs & 487 & 0 & 1 & 0 & 0 & 1 & 2 & 0,7 & 0,4 \\
\hline J Prof Nurs & 297 & 1 & 0 & 0 & 0 & 1 & 2 & 0,7 & 0,7 \\
\hline
\end{tabular}




\begin{tabular}{|c|c|c|c|c|c|c|c|c|c|}
\hline $\begin{array}{l}\text { Título revista abre- } \\
\text { viado }\end{array}$ & $\begin{array}{c}\text { Art. en } \\
\text { los } 5 \\
\text { años }\end{array}$ & $\begin{array}{l}\text { Revi- } \\
\text { sión }\end{array}$ & $\begin{array}{c}\text { Meto- } \\
\text { dológico }\end{array}$ & $\begin{array}{l}\text { Teóri- } \\
\text { co }\end{array}$ & $\begin{array}{l}\text { Estudio } \\
\text { de caso }\end{array}$ & $\begin{array}{l}\text { Empí- } \\
\text { rico }\end{array}$ & $\begin{array}{l}\text { Total } \\
2008- \\
2013\end{array}$ & $\begin{array}{l}\% \text { del } \\
\text { total }\end{array}$ & $\begin{array}{l}\text { Artículos } \\
\text { estimados }\end{array}$ \\
\hline $\begin{array}{l}\text { J Psychiatr Ment } \\
\text { Health Nurs }\end{array}$ & 668 & 0 & 0 & 2 & 0 & 1 & 3 & 0,7 & 0,4 \\
\hline J Sch Nurs & 293 & 0 & 0 & 0 & 0 & 2 & 2 & 0,7 & 0,7 \\
\hline J Transcult Nurs & 225 & 0 & 0 & 0 & 1 & 4 & 5 & 1,8 & 2,2 \\
\hline $\begin{array}{l}\text { MCN Am J Matern } \\
\text { Child Nurs }\end{array}$ & 381 & 0 & 0 & 0 & 0 & 2 & 2 & 0,7 & 0,5 \\
\hline Nephrol Nurs J & 323 & 1 & 0 & 0 & 0 & 0 & 1 & 0,4 & 0,3 \\
\hline Nurs Adm Q & 281 & 0 & 1 & 1 & 0 & 2 & 4 & 1,4 & 1,4 \\
\hline Nurs Forum & 164 & 1 & 0 & 0 & 0 & 0 & 1 & 0,4 & 0,6 \\
\hline Nurs Health Sci & 378 & 0 & 0 & 0 & 0 & 1 & 1 & 0,4 & 0,3 \\
\hline Nurs Outlook & 351 & 0 & 0 & 1 & 0 & 1 & 2 & 0,7 & 0,6 \\
\hline Nurs Philos & 156 & 0 & 0 & 1 & 0 & 0 & 1 & 0,4 & 0,6 \\
\hline Nurs Res & 309 & 0 & 0 & 0 & 0 & 1 & 1 & 0,4 & 0,3 \\
\hline Nurs Sci Q & 370 & 7 & 13 & 43 & 4 & 37 & 104 & 37,7 & 28,1 \\
\hline Nurse Educ Pract & 397 & 0 & 0 & 0 & 0 & 1 & 1 & 0,4 & 0,3 \\
\hline Nurse Educ Today & 993 & 0 & 0 & 0 & 0 & 1 & 1 & 0,4 & 0,1 \\
\hline Oncol Nurs Forum & 552 & 0 & 0 & 0 & 0 & 2 & 2 & 0,7 & 0,4 \\
\hline Online J Issues Nurs & 69 & 0 & 0 & 0 & 1 & 0 & 1 & 0,4 & 1,4 \\
\hline ORL Head Neck Nurs & 57 & 0 & 0 & 0 & 0 & 1 & 1 & 0,4 & 1,8 \\
\hline $\begin{array}{l}\text { Ostomy Wound Ma- } \\
\text { nag }\end{array}$ & 346 & 0 & 0 & 0 & 1 & 0 & 1 & 0,4 & 0,3 \\
\hline Pain Manage Nurs & 172 & 0 & 0 & 0 & 0 & 1 & 1 & 0,4 & 0,6 \\
\hline Pediatr Nurs & 273 & 0 & 0 & 0 & 0 & 3 & 3 & 1,1 & 1,1 \\
\hline Pflege & 191 & 1 & 0 & 0 & 0 & 0 & 1 & 0,4 & 0,5 \\
\hline Prof Inferm & 136 & 0 & 0 & 0 & 0 & 1 & 1 & 0,4 & 0,7 \\
\hline Prog Transplant & 275 & 0 & 0 & 1 & 0 & 0 & 1 & 0,4 & 0,4 \\
\hline Rech Soins Infirm & 244 & 0 & 0 & 2 & 0 & 2 & 4 & 1,4 & 1,6 \\
\hline Res Gerontol Nurs & 170 & 0 & 0 & 0 & 0 & 1 & 1 & 0,4 & 0,6 \\
\hline Res Theory Nurs Pract & 121 & 0 & 1 & 0 & 0 & 1 & 2 & 0,7 & 1,7 \\
\hline Rev Bras Enferm & 701 & 1 & 2 & 2 & 0 & 4 & 9 & 3,3 & 1,3 \\
\hline Rev Enferm & 504 & 1 & 1 & 1 & 1 & 0 & 4 & 1,4 & 0,8 \\
\hline Rev Esc Enferm USP & 803 & 0 & 0 & 1 & 1 & 1 & 3 & 1,1 & 0,4 \\
\hline Rev Gaucha Enferm & 490 & 0 & 0 & 1 & 0 & 4 & 5 & 1,8 & 1,0 \\
\hline $\begin{array}{l}\text { Rev Lat Am Enferma- } \\
\text { gem }\end{array}$ & 786 & 0 & 0 & 0 & 0 & 2 & 2 & 0,7 & 0,3 \\
\hline Scand J Caring Sci & 600 & 1 & 0 & 0 & 0 & 3 & 4 & 1,4 & 0,7 \\
\hline $\begin{array}{l}\text { Self Care Depend Care } \\
\text { Nurs }^{\mathrm{a}}\end{array}$ & 25 & 0 & 0 & 0 & 0 & 1 & 1 & 0,4 & 4,0 \\
\hline Soins & 1025 & 0 & 0 & 1 & 0 & 0 & 1 & 0,4 & 0,1 \\
\hline Transplant Proc & 4830 & 0 & 0 & 0 & 0 & 1 & 1 & 0,4 & 0,0 \\
\hline $\begin{array}{l}\text { Worldviews Evid Ba- } \\
\text { sed Nurs }\end{array}$ & 126 & 0 & 0 & 0 & 0 & 1 & 1 & 0,4 & 0,8 \\
\hline Totales & 37075 & $\begin{array}{c}24 \\
(9 \%)\end{array}$ & $\begin{array}{c}25 \\
(9 \%)\end{array}$ & $\begin{array}{c}72 \\
(26 \%)\end{array}$ & $\begin{array}{c}26 \\
(9 \%)\end{array}$ & $\begin{array}{c}129 \\
(47 \%)\end{array}$ & $\begin{array}{c}276 \\
(100 \%)\end{array}$ & $100 \%$ & \\
\hline
\end{tabular}

*Art. : Artículos

${ }^{a}$ En Pubmed sólo hay indexado 1 artículo. Los datos hallados de 25 artículos han sido substraidos directamente del contaje manual de los sumarios de la revista de http://www.oremsociety.com/index.php/publications/ios-journal 
Cuando se analiza el país de publicación y de origen del autor, se obtiene que los trabajos son publicados en 18 países, de ellos, la mayoría de los trabajos se publican en EE.UU. (el $68,1 \%)$, seguido muy por detrás por Reino Unido (7,6\%), Brasil $(6,9 \%)$ y España (4\%). Los autores son de una mayor diversidad de procedencia (33 nacionalidades) siendo la mayor parte de EE.UU. (60,9\%), Canadá (7,6\%), Brasil (5,8\%) y España (5,1\%). Vease tabla 49. De los artículos publicados por españoles, sólo 3 fueron publicados en revistas que usaban el inglés como lengua vehicular

Tabla 49: Nacionalidad del autor y lugar de publicación de los artículos hallados.

\begin{tabular}{|l|c|c|}
\hline \multicolumn{1}{|c|}{ País } & $\begin{array}{c}\text { Frecuencia del país del autor de la publi- } \\
\text { cación (Nacionalidad) }\end{array}$ & $\begin{array}{c}\text { Frecuencia país de publi- } \\
\text { cación de la revista }\end{array}$ \\
\hline Alemania & $1(0,4 \%)$ & --- \\
\hline Arabia Saudí & $1(0,4 \%)$ & --- \\
\hline Australia & $2(0,7 \%)$ & $5(1,8 \%)$ \\
\hline Brasil & $16(5,8 \%)$ & $19(6,9 \%)$ \\
\hline Canadá & $21(7,6 \%)$ & $4(1,4 \%)$ \\
\hline Chile & $1(0,4 \%)$ & --- \\
\hline China & $7(2,5 \%)$ & $6(2,2 \%)$ \\
\hline Colombia & $1(0,4 \%)$ & --- \\
\hline Corea & $3(1,1 \%)$ & $2(0,7 \%)$ \\
\hline Corea & $1(0,4 \%)$ & $1(0,4 \%)$ \\
\hline EE.UU. & $168(60,9 \%)$ & $188(68,1 \%)$ \\
\hline Egipto & $1(0,4 \%)$ & --- \\
\hline Escocia & --- & $1(0,4 \%)$ \\
\hline España & $14(5,1 \%)$ & $11(4 \%)$ \\
\hline Etiopía & $1(0,4 \%)$ & --- \\
\hline Finlandia & $1(0,4 \%)$ & $5(1,8 \%)$ \\
\hline Francia & $1(0,4 \%)$ & $1(0,4 \%)$ \\
\hline India & --- & --- \\
\hline Irán & $2(0,7 \%)$ & --- \\
\hline Irlanda del Norte & $2(0,7 \%)$ & $1(0,4 \%)$ \\
\hline Italia & $1(0,4 \%)$ & --- \\
\hline Japón & $1(0,4 \%)$ & $1(0,4 \%)$ \\
\hline Jordania & $1(0,4 \%)$ & --- \\
\hline Kenia & $1(0,4 \%)$ & $21(7,6 \%)$ \\
\hline Polonia & $1(0,4 \%)$ & $1(0,4 \%)$ \\
\hline Reino Unido & $2(0,7 \%)$ & $3(1,1 \%)$ \\
\hline Sudáfrica & $1(0,4 \%)$ & --- \\
\hline Suecia & $3(1,1 \%)$ & $5(1,8 \%)$ \\
\hline Suecia y Noruega & $1(0,4 \%)$ & --- \\
\hline Suiza & $4(1,4 \%)$ & $276(100 \%)$ \\
\hline Taiwán & $9(3,3 \%)$ & \\
\hline Tanzania & $1(0,4 \%)$ & 6 \\
\hline Turquía & $6(2,2 \%)$ & $276)$ \\
\hline Total & $2(100 \%)$ & \\
\hline & & - \\
\hline
\end{tabular}


La distribución de las publicaciones por continentes se puede ver en la figura 22, siendo el mayor porcentaje en América del Norte.

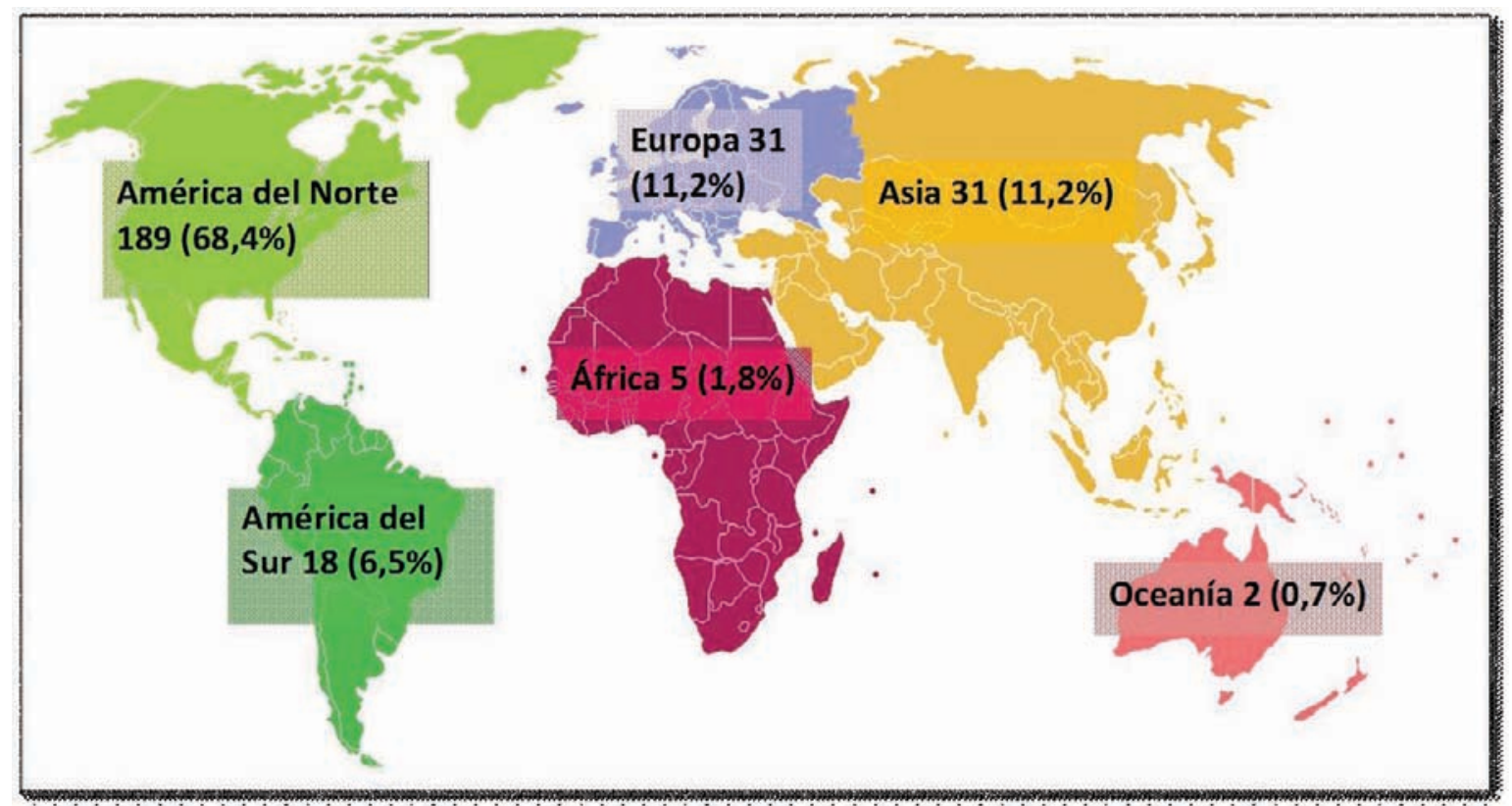

Figura 22: Distribución de los artículos de modelos según continente de publicación

La mayoría de trabajos van firmados por autores que trabajan en el ámbito universitario (al menos adscriben su centro laboral como éste) que son el $82,2 \%$ del total (227 artículos). El resto se dedican a la atención directa en hospitales $u$ otros centros de salud incluyendo centros comunitarios, estatales, preventivos e incluso aparece algún artículo publicado por profesionales militares enfermeros. Ver figura 23.

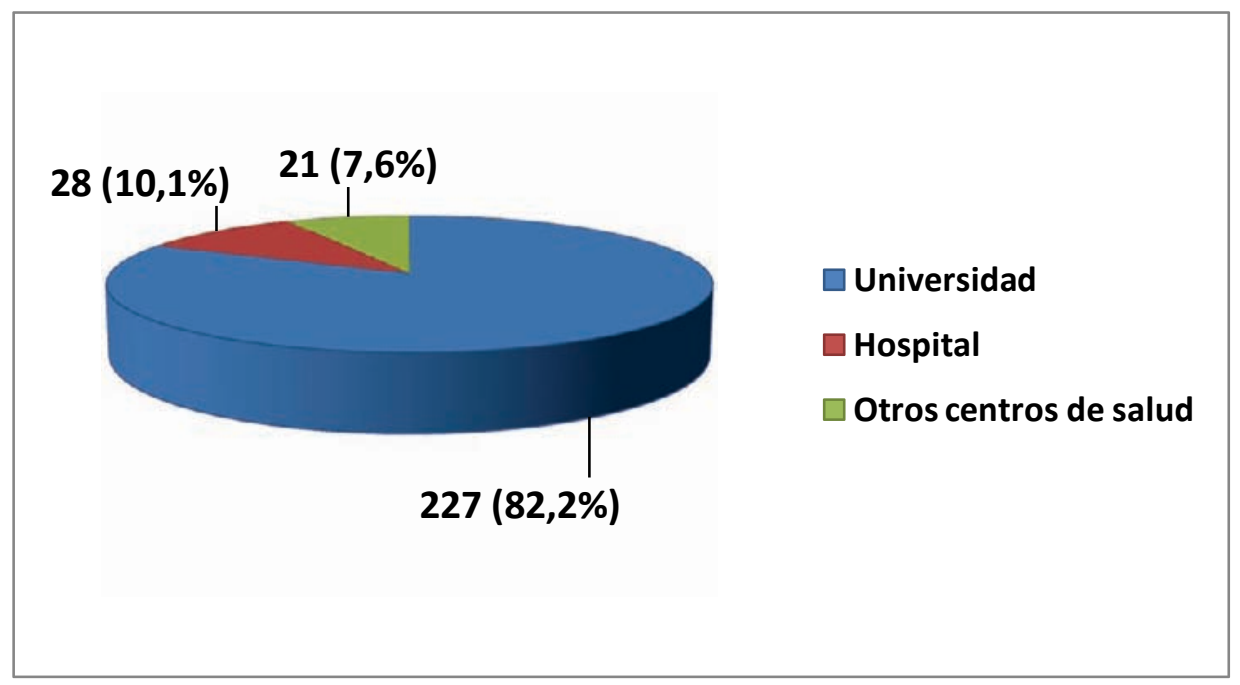

Figura 23: Publicaciones según el lugar de filiación laboral de los autores de los artículos 


\section{Los resultados obtenidos se muestran a continuación, realizando un análisis porme-}

norizado para cada una de las teoristas planteadas:

\subsubsection{Publicaciones elaboradas usando la teoría de Rosemarie Rizzo Parse}

De un total de 71 referencias halladas, 58 se relacionaban directamente con la teoría. De estos artículos aproximadamente la mitad (46,5\%), fueron publicados como artículos empíricos y un $36,2 \%$ se publicó como artículo teórico. La mayoría de los artículos $(86,2 \%)$ están publicados en la Nursing Science Quarterly (EE.UU.). Siendo la mayoría de autores $(65,5 \%)$ de esa misma nacionalidad, seguidos por canadienses (17,24\%). Estos, desempeñaban su labor en la Universidad mayoritariamente (96,5\%). Ver tabla 16.

En cuanto a un análisis cualitativo del contenido de los artículos, en concreto de los empíricos, destacar que varios de ellos fueron estudios que mediante diseños cualitativos estudiaban la comprensión de diferentes experiencias vitales y sentimientos de las personas. Se analizó la experiencia de sentirse fuerte, seguro, la espera, el tener un embarazo de riesgo, el respeto, el diagnóstico de enfermedad mental, la adaptación, la decepción, la experiencia del cuidado, la espiritualidad, el ser madre primípara, la superación de la lesión medular, la experiencia de estudiantes en su práctica y en su tutorización, la de privación de libertad, la fe, el hacer lo correcto, la inseguridad, la confianza, el aburrimiento, la tristeza, la incomprensión, el miedo, el sufrimiento, y la soledad. Incluso también fue utilizado para explicar situaciones catastróficas como la del huracán Katrina o el genocidio en Ruanda. En sujetos ancianos (6 artículos), niños (1 artículo), y adultos (20). En cuanto a patologías, la mayoría de los estudios se hicieron en pacientes sanos, excepto 1 estudio sobre pacientes en espera de trasplante hepático, 1 en pacientes con enfermedad arterial coronaria y 1 en lesionados medulares. Además se hallaron 2 publicaciones que estudiaron a embarazadas, 1 en enfermeras, 2 en estudiantes de enfermería y 1 en cuidadores de pacientes con tumor cerebral.

Otro de los usos del modelo ha sido la argumentación de economizar en salud situando el modelo como eje central del cuidado, en política sanitaria o en teorías de liderazgo. Resúmenes más detallados en tabla 50.

Tabla 50: Publicaciones halladas para el modelo de R. Parse

\begin{tabular}{|l|l|c|c|}
\hline & & Frecuencia & Porcentaje \\
\hline \multirow{4}{*}{$\begin{array}{l}\text { Tipo de publica- } \\
\text { ción }\end{array}$} & Estudio empírico & 27 & 46 \\
\cline { 2 - 4 } & Artículo teórico & 21 & 36,2 \\
\cline { 2 - 4 } & Artículo metodológico & 5 & 8,6 \\
\cline { 2 - 4 } & Artículo de revisión & 2 & 3,4 \\
\cline { 2 - 4 } & Estudio de caso & 3 & 5,2 \\
\hline
\end{tabular}




\begin{tabular}{|c|c|c|c|}
\hline & & Frecuencia & Porcentaje \\
\hline \multirow{8}{*}{$\begin{array}{l}\text { Revista publica- } \\
\text { ción }\end{array}$} & Nursing Science Quarterly & 50 & 86,2 \\
\hline & Journal of Advanced Nursing & 2 & 3,4 \\
\hline & CANNT journal & 1 & 1,7 \\
\hline & Journal Of Continuing Education In Nursing & 1 & 1,7 \\
\hline & Journal of psychiatric and mental health nursing & 1 & 1,7 \\
\hline & Oncology Nursing Forum & 1 & 1,7 \\
\hline & Recherche en soins infirmiers & 1 & 1,7 \\
\hline & Scandinavian journal of caring sciences. & 1 & 1,7 \\
\hline \multirow{5}{*}{$\begin{array}{l}\text { País de publica- } \\
\text { ción }\end{array}$} & EE.UU. & 52 & 89,6 \\
\hline & Reino Unido & 3 & 5,2 \\
\hline & Canadá & 1 & 1,7 \\
\hline & Francia & 1 & 1,7 \\
\hline & Suecia & 1 & 1,7 \\
\hline \multirow{9}{*}{ País del autor } & EE.UU. & 38 & 65,5 \\
\hline & Canadá & 10 & 17,24 \\
\hline & Suiza & 3 & 5,2 \\
\hline & Taiwán & 2 & 3,4 \\
\hline & Australia & 1 & 1,7 \\
\hline & Egipto & 1 & 1,7 \\
\hline & Japón & 1 & 1,7 \\
\hline & Jordania & 1 & 1,7 \\
\hline & Reino Unido & 1 & 1,7 \\
\hline \multirow{3}{*}{$\begin{array}{l}\text { Lugar de filiación } \\
\text { laboral del autor }\end{array}$} & Universidad & 56 & 96,5 \\
\hline & Hospital & 1 & 1,7 \\
\hline & Otros & 1 & 1,7 \\
\hline
\end{tabular}

\subsubsection{Publicaciones elaboradas usando el modelo de Sor Callista Roy}

Se hallaron un total de 166 de referencias y de ellas se seleccionaron sólo 43 artículos que tenían relación con el modelo. Casi la mitad, 21, fueron estudios empíricos (48,8\%). Una tercera parte de los mismos (34,9\%) fue publicada en el Nursing Science Quarterly, EE.UU. y el $62,8 \%$ de los autores eran estadounidenses, seguidos muy por detrás por turcos $(11,6 \%)$ y brasileños (9,3\%). El 81,4\% desempeñaban su labor en centros universitarios. (Ver tabla 51).

Cualitativamente podemos concretar que en los estudios empíricos, se ha usado el mayormente sobre pacientes adultos, excepto un estudio sobre familias, 2 sobre ancianos y uno sobre niños. Ha sido sobre todo usado para evaluar la adaptación de las madres tras dar a luz (tras cesárea o en periodo de lactancia). 
Asimismo se empleó para el estudio de diferentes elementos psicosociales de la persona; por un lado, a nivel personal en el estudio del autoconcepto y por otro, a nivel sociofamiliar con el estudio de la interdependencia y el desempeño del rol. Se estudió el autoconcepto en niños de orfanato, la adaptación psicosocial a la enfermedad y en pacientes con úlcera venosa, VIH, en experiencias traumáticas, lesionados medulares y enfermos colostomizados. También el desempeño del rol en pacientes sometidos a radioterapia, en pacientes tras una lesión medular y sobre los efectos de la diálisis y la colostomía sobre la sexualidad. El modelo además sirvió para evaluar la eficacia de programas de rehabilitación en enfermos con infarto cardíaco y enfermedad pulmonar obstructiva crónica, así como en pacientes etiquetados de sedentarismo.

Otras de las aplicaciones del modelo han sido en programas de prevención y promoción de la salud en educación prenatal, en el control del estrés (mediante meditación, masaje terapéutico y respiración diafragmática) o para el estudio sobre el conocimiento de la hipertensión y en el control del dolor. Además se ha empleado en estudios de casos sobre violencia sexual y propuestas de trabajo para el uso del modelo en enfermos con bulimia.

Tabla 51: Publicaciones halladas para el modelo de Sor Callista Roy

\begin{tabular}{|c|c|c|c|}
\hline & & Frecuencia & Porcentaje \\
\hline \multirow[t]{5}{*}{ Tipo de publicación } & Estudio empírico & 21 & 48,8 \\
\hline & Artículo teórico & 8 & 18,6 \\
\hline & Estudio de caso & 5 & 11,6 \\
\hline & Artículo de revisión & 5 & 11,6 \\
\hline & Artículo metodológico & 4 & 9,3 \\
\hline \multirow{19}{*}{$\begin{array}{l}\text { Revista de publicación (Título abre- } \\
\text { viado) }\end{array}$} & Nurs Sci Q & 15 & 34,9 \\
\hline & J Adv Nurs & 5 & 11,6 \\
\hline & Rev Gaucha Enferm & 3 & 7,0 \\
\hline & Hu Li Za Zhi & 2 & 4,7 \\
\hline & J Korean Acad Nurs & 2 & 4,7 \\
\hline & Pediatric nursing & 2 & 4,7 \\
\hline & AAOHN J & 1 & 2,3 \\
\hline & Creat nurs & 1 & 2,3 \\
\hline & Crit Care Nurs Q & 1 & 2,3 \\
\hline & Issues Ment Health Nurs & 1 & 2,3 \\
\hline & J Clin Nurs & 1 & 2,3 \\
\hline & J Natl Black Nurses Assoc & 1 & 2,3 \\
\hline & Nurs Health Sci & 1 & 2,3 \\
\hline & Nurs Adm Q & 1 & 2,3 \\
\hline & Nurs Res & 1 & 2,3 \\
\hline & Oncol Nurs Forum & 1 & 2,3 \\
\hline & Ostomy Wound Manage & 1 & 2,3 \\
\hline & Res Gerontol Nurs & 1 & 2,3 \\
\hline & Rev Esc Enferm USP & 1 & 2,3 \\
\hline
\end{tabular}




\begin{tabular}{|c|c|c|c|}
\hline & & Frecuencia & Porcentaje \\
\hline $\begin{array}{l}\text { Revista de publicación (Título abre- } \\
\text { viado) }\end{array}$ & Transplant Proc & 1 & 2,3 \\
\hline \multirow[t]{7}{*}{ País de publicación } & EE.UU. & 31 & 72,1 \\
\hline & Brasil & 4 & 9,3 \\
\hline & Reino Unido & 3 & 7,0 \\
\hline & China & 2 & 4,7 \\
\hline & Australia & 1 & 2,3 \\
\hline & Corea & 1 & 2,3 \\
\hline & Corea & 1 & 2,3 \\
\hline \multirow[t]{8}{*}{ País del autor } & EE.UU. & 27 & 62,8 \\
\hline & Turquía & 5 & 11,6 \\
\hline & Brasil & 4 & 9,3 \\
\hline & Corea & 2 & 4,7 \\
\hline & Taiwán & 2 & 4,7 \\
\hline & Colombia & 1 & 2,3 \\
\hline & China & 1 & 2,3 \\
\hline & Corea & 1 & 2,3 \\
\hline \multirow[t]{3}{*}{ Lugar de filiación laboral del autor } & Universidad & 35 & 81,4 \\
\hline & Hospital & 4 & 9,3 \\
\hline & Otros & 4 & 9,3 \\
\hline
\end{tabular}

\subsubsection{Publicaciones elaboradas usando el modelo de Dorothea E. Orem}

Se hallaron 36 referencias de un total de 59 referencias localizadas usando las palabras de búsqueda. De ellas, 18 (50\%) eran estudios empíricos. Una tercera parte se publicaron en la revista Nursing Science Quarterly (33,3\%), seguida de la Revista Brasileira de Enfermagem (11,1\%). Los países de publicación fueron mayoritariamente EE.UU. $(63,9 \%)$ y Brasil $(19,4 \%)$. Siendo el 55,6\% de autoría estadounidense y el 16,7\% brasileña. Existe un artículo de autoría española publicado en la revista Rol de enfermería. La mayoría de los autores desempeñaban su trabajo en la universidad (77,8\%). El resto de los resultados se puede ver en tabla 52.

El modelo ha sido usado para el desarrollo de protocolos en pacientes sometidos a cirugía bariátrica, para desarrollar herramientas de evaluación del autocuidado (en diálisis 4 artículos y 1 en niños con cardiopatía) y en la planificación directa en el cuidado de pacientes quemados, diabéticos, con úlceras en extremidades inferiores, con artrosis, embarazadas e hipertensos. Además, se ha combinado el uso del modelo con el uso de diagnósticos enfermeros siguiendo nomenclatura de taxonomía NANDA.

Igualmente algunos de los artículos inciden en la potenciación de la agencia de autocuidado de las personas, como en mujeres mastectomizadas, en pacientes en radioterapia, en cuidadores de pacientes con AVC y en la alimentación de los niños. 
Se propone su uso en pacientes con trastornos mentales, niños con fibrosis quística así como en la capacitación de las enfermeras de cuidados paliativos o para el estudio del autocuidado de la población general. También se usó para abordar la autogestión de la medicación en pacientes ancianos.

Tabla 52: Publicaciones halladas para el modelo de Dorothea E. Orem

\begin{tabular}{|c|c|c|c|}
\hline & & Frecuencia & Porcentaje \\
\hline \multirow{5}{*}{ Tipos de estudio } & Estudio empírico & 18 & 50,0 \\
\hline & Artículo de revisión & 7 & 19,4 \\
\hline & Artículo teórico & 5 & 13,9 \\
\hline & Artículo metodológico & 4 & 11,1 \\
\hline & Estudio de caso & 2 & 5,6 \\
\hline \multirow{19}{*}{$\begin{array}{l}\text { Revista de publicación } \\
\text { (Título abreviado) }\end{array}$} & Nurs Sci Q & 12 & 33,3 \\
\hline & Rev Bras Enferm & 4 & 11,1 \\
\hline & CANNT J & 2 & 5,6 \\
\hline & J Neurosci Nurs & 2 & 5,6 \\
\hline & J Pediatr Nurs & 2 & 5,6 \\
\hline & Adv Skin Wound Care & 1 & 2,8 \\
\hline & Clin Nurse Spec & 1 & 2,8 \\
\hline & Issues Ment Health Nurs & 1 & 2,8 \\
\hline & J Adv Nurs & 1 & 2,8 \\
\hline & J Burn Care Res & 1 & 2,8 \\
\hline & J Cult Divers & 1 & 2,8 \\
\hline & Nephrol Nurs J & 1 & 2,8 \\
\hline & Pflege & 1 & 2,8 \\
\hline & Rev Esc Enferm USP & 1 & 2,8 \\
\hline & Rev Gaucha Enferm & 1 & 2,8 \\
\hline & Rev Lat Am Enfermagem & 1 & 2,8 \\
\hline & Rev Enferm & 1 & 2,8 \\
\hline & Self Care Depend Care Nurs & 1 & 2,8 \\
\hline & J Sch Nurs & 1 & 2,8 \\
\hline \multirow{6}{*}{ País de publicación } & EE.UU. & 23 & 63,9 \\
\hline & Brasil & 7 & 19,4 \\
\hline & Canadá & 2 & 5,6 \\
\hline & Reino Unido & 2 & 5,6 \\
\hline & España & 1 & 2,8 \\
\hline & Suiza & 1 & 2,8 \\
\hline \multirow{7}{*}{ País del autor } & EE.UU. & 20 & 55,6 \\
\hline & Brasil & 6 & 16,7 \\
\hline & Canadá & 4 & 11,1 \\
\hline & Alemania & 1 & 2,8 \\
\hline & Chile & 1 & 2,8 \\
\hline & China & 1 & 2,8 \\
\hline & España & 1 & 2,8 \\
\hline
\end{tabular}




\begin{tabular}{|l|l|c|c|}
\hline & & Frecuencia & Porcentaje \\
\hline \multirow{2}{*}{ País del autor } & Polonia & 1 & 2,8 \\
\cline { 2 - 4 } & Suiza & 1 & 2,8 \\
\hline \multirow{2}{*}{$\begin{array}{l}\text { Lugar de filiación laboral } \\
\text { del autor }\end{array}$} & Universidad & 28 & 77,8 \\
\cline { 2 - 4 } & Hospital & 4 & 11,1 \\
\cline { 2 - 4 } & Otros centros & 4 & 11,1 \\
\hline
\end{tabular}

4.6.4

Publicaciones elaboradas usando a la teoría de Jean Watson

Se hallaron un total de 169 de referencias en la búsqueda realizada en relación a Watson y de ellas se seleccionaron sólo 32 artículos que tenían relación con el modelo. El 43,7\% eran estudios empíricos. Las revistas en las que fueron publicadas fueron diversas, siendo la $\mathrm{Hu}$ Li Za Zhi (China) la más usada (15,6\%). No obstante, el país en el que se publicaron más artículos fue EE.UU. y por autores estadounidenses (ambos porcentajes fueron del 59,4\%). La mayoría de los autores trabajaban en centros universitarios $(59,4 \%)$ y hospital $(31.3 \%)$. Ver tabla 53.

Se aplicó el modelo sobre pacientes adultos, niños, enfermeras, estudiantes, familia y cuidadores. En cuanto al contenido de los artículos, se ha usado la teoría en estudios empíricos para evaluar el cuidado en urgencias de pediatría y en una unidad de cuidados críticos, igualmente para la mejora de los servicios mediante la reestructuración en base al modelo de una unidad de cuidados paliativos. Fue usado para demostrar asimismo la efectividad de un programa en ancianos sobre la calidad de vida de los mismos. También se ha aplicado para el estudio de la percepción de cuidados culturalmente solidarios por los pacientes, y diferenciar percepciones entre pacientes oncológicos y sus cuidadoras en como afecta la propia compasión en el cuidado. Además, fue la base para el estudio de la mejora de la salud de las enfermeras mediante el uso de prácticas de terapia complementaria como el Reiki y en describir los factores que afectan en el cuidado, como la experiencia de "estar con" el paciente. Del mismo modo, fue empleado en estudios sobre el significado del aprendizaje en los alumnos.

En estudio de caso se ha abordado el cuidado de pacientes paliativos bajo el modelo. Como en el caso de una mujer con cáncer de mama sin recursos, o un paciente con carcinoma nasofaríngeo terminal. Así como ha sido aplicado en el estudio de relaciones como en el abordaje de los propios sentimientos como enfermera, para evaluar la práctica enfermera y en un niño y su madre en la unidad de quemados. 
Metodológicamente se ha argumentado su uso en informatización para el cambio de turno en una unidad hospitalaria, para diseñar una unidad de cuidados críticos, fomentar el liderazgo y hasta hay una experiencia de planificación del cuidado en un hospital magnético.

Tabla 53: Publicaciones halladas para la teoría de Jean Watson

\begin{tabular}{|c|c|c|c|}
\hline & & Frecuencia & Porcentaje \\
\hline \multirow{5}{*}{ Tipo de publicación } & Estudio empírico & 14 & 43,7 \\
\hline & Artículo teórico & 6 & 18,7 \\
\hline & Artículo metodológico & 5 & 15,6 \\
\hline & Estudio de caso & 5 & 15,6 \\
\hline & Artículo de revisión & 2 & 6,25 \\
\hline \multirow{20}{*}{$\begin{array}{l}\text { Revista de publicación (Título } \\
\text { abreviado) }\end{array}$} & Hu Li Za Zhi & 5 & 15,6 \\
\hline & Holist Nurs Pract & 3 & 9,4 \\
\hline & Rech Soins Infirm & 3 & 9,4 \\
\hline & Holist Nurs Pract & 2 & 6,3 \\
\hline & Nurs Adm Q & 2 & 6,3 \\
\hline & Nurs Sci Q & 2 & 6,3 \\
\hline & Res Theory Nurs Pract & 2 & 6,3 \\
\hline & AAOHN J & 1 & 3,1 \\
\hline & Can Oncol Nurs J & 1 & 3,1 \\
\hline & Clin Nurse Spec & 1 & 3,1 \\
\hline & Dimens Crit Care Nurs & 1 & 3,1 \\
\hline & Enferm Intensiva & 1 & 3,1 \\
\hline & J Gerontol Nurs & 1 & 3,1 \\
\hline & J Health Hum Serv Adm & 1 & 3,1 \\
\hline & J Nurs Educ & 1 & 3,1 \\
\hline & Nurse Educ Pract & 1 & 3,1 \\
\hline & Nurs Forum & 1 & 3,1 \\
\hline & Online J Issues Nurs & 1 & 3,1 \\
\hline & Scand J Caring Sci & 1 & 3,1 \\
\hline & J Nurs Res & 1 & 3,1 \\
\hline \multirow{8}{*}{ País publicación } & EE.UU. & 19 & 59,4 \\
\hline & Taiwán & 5 & 15,6 \\
\hline & Francia & 3 & 9,4 \\
\hline & Canadá & 1 & 3,1 \\
\hline & China & 1 & 3,1 \\
\hline & España & 1 & 3,1 \\
\hline & Reino Unido & 1 & 3,1 \\
\hline & Suecia & 1 & 3,1 \\
\hline \multirow{7}{*}{ País del autor } & EE.UU. & 19 & 59,4 \\
\hline & Taiwán & 5 & 15,6 \\
\hline & Canadá & 4 & 12,5 \\
\hline & Arabia Saudí & 1 & 3,1 \\
\hline & España & 1 & 3,1 \\
\hline & Suecia & 2 & 3,1 \\
\hline & Noruega & 1 & 3,1 \\
\hline
\end{tabular}




\begin{tabular}{|l|l|c|c|}
\hline & & Frecuencia & Porcentaje \\
\hline \multirow{4}{*}{$\begin{array}{l}\text { Lugar de filiación laboral del } \\
\text { autor }\end{array}$} & Universidad & 19 & 59,4 \\
\cline { 2 - 4 } & Hospital & 10 & 31,3 \\
\cline { 2 - 4 } & Otros centros & 3 & 9,3 \\
\hline
\end{tabular}

\subsubsection{Publicaciones elaboradas usando el modelo de Madeleine M. Leininger:}

En la exploración de Medline se hallaron un total de 65 artículos de los que se seleccionaron sólo los que estaban relacionados con el modelo de Leininger, un total de 27. De éstos, 14 fueron estudios empíricos (51,8\% de estudios etnográficos). Fueron diversas las revistas de publicación, siendo mayoritarias las estadounidenses $(66,6 \%)$, al igual que el país de origen de los autores (63\% EE.UU.). La mayoría fueron elaborados por profesionales que desarrollaron su labor en la universidad (23 artículos, 85,2\%). Ver tabla 54.

El modelo ha sido usado en población inmigrante de forma mayoritaria sobre diferentes situaciones o patologías, además de ser usado en diversas reflexiones, en la formación y la llamada etnoenfermería para la comprensión cualitativa de diferentes situaciones. Usado para el análisis del homicidio en Tanzania, la indigencia, el cuidado de niños con madres drogodependientes, la adolescencia, la lactancia, y sobre la percepción de cuidadores no profesionales y enfermeras (oncología y cuidados intensivos).

Tabla 54: Publicaciones halladas para el modelo de Madeleine M. Leininger

\begin{tabular}{|l|l|c|c|}
\hline & & Frecuencia & Porcentaje \\
\hline \multirow{4}{*}{$\begin{array}{l}\text { Tipo de pu- } \\
\text { blicación }\end{array}$} & Estudio empírico & 14 & 51,8 \\
\cline { 2 - 4 } & Artículo teórico & 8 & 29,6 \\
\cline { 2 - 4 } & Artículo metodológico & 2 & 7,4 \\
\cline { 2 - 4 } & Estudio de caso & 2 & 7,4 \\
\cline { 2 - 4 } & Artículo de revisión & 1 & 3,7 \\
\hline \multirow{5}{*}{$\begin{array}{l}\text { Revista pu- } \\
\text { blicación }\end{array}$} & J Transcult Nurs & 5 & 18,5 \\
\cline { 2 - 4 } (Título abre- & Contemp nurse & 4 & 14,8 \\
\cline { 2 - 4 } viado) & ANS Adv Nurs Sci & 2 & 7,4 \\
\cline { 2 - 4 } & Home Healthc Nurse & 2 & 7,4 \\
\cline { 2 - 4 } & Rev Bras Enferm & 2 & 7,4 \\
\cline { 2 - 4 } & Cancer Nurs & 2 & 7,4 \\
\cline { 2 - 4 } & Clin J Oncol Nurs & 1 & 3,7 \\
\cline { 2 - 4 } & J Obstet Gynecol Neonatal Nurs & 1 & 3,7 \\
\cline { 2 - 4 } & J Pediatr Nurs & 1 & 3,7 \\
\cline { 2 - 4 } & J Prof Nurs & 1 & 3,7 \\
\cline { 2 - 4 } & Nurs Outlook & 1 & 3,7 \\
\cline { 2 - 4 } & Prof Inferm & & 3,7 \\
\hline
\end{tabular}




\begin{tabular}{|c|c|c|c|}
\hline & & Frecuencia & Porcentaje \\
\hline \multirow{3}{*}{$\begin{array}{l}\text { Revista pu- } \\
\text { blicación } \\
\text { (Título abre- } \\
\text { viado) }\end{array}$} & Rev Enferm & 1 & 3,7 \\
\hline & Scand J Caring Sci & 1 & 3,7 \\
\hline & Soins & 1 & 3,7 \\
\hline \multirow{7}{*}{$\begin{array}{l}\text { País de pu- } \\
\text { blicación }\end{array}$} & EE.UU. & 18 & 66,6 \\
\hline & Australia & 3 & 11,1 \\
\hline & Brasil & 2 & 7,4 \\
\hline & España & 1 & 3,7 \\
\hline & Francia & 1 & 3,7 \\
\hline & Italia & 1 & 3,7 \\
\hline & Suecia & 1 & 3,7 \\
\hline \multirow{9}{*}{$\begin{array}{l}\text { Nacionalidad } \\
\text { del autor }\end{array}$} & EE.UU. & 17 & 63 \\
\hline & Brasil & 2 & 7,4 \\
\hline & Canadá & 2 & 7,4 \\
\hline & España & 1 & 3,7 \\
\hline & Etiopía & 1 & 3,7 \\
\hline & Finlandia & 1 & 3,7 \\
\hline & Francia & 1 & 3,7 \\
\hline & Italia & 1 & 3,7 \\
\hline & Tanzania & 1 & 3,7 \\
\hline \multirow{3}{*}{$\begin{array}{l}\text { Lugar de } \\
\text { filiación la- } \\
\text { boral del } \\
\text { autor }\end{array}$} & Universidad & 23 & 85,2 \\
\hline & Hospital & 3 & 11,1 \\
\hline & Otros centros & 1 & 3,7 \\
\hline
\end{tabular}

\subsubsection{Publicaciones elaboradas usando el modelo de Betty Neuman}

Fueron halladas 381 referencias para los términos de búsqueda en relación al modelo de Neuman. De éstas, 18 fueron artículos relacionados con el modelo. La mayoría se editaron en el Nursing Science Quarterly. Los autores pertenecían ampliamente al ámbito universitario $(77,8 \%)$ y fueron creados y publicados en EE.UU. (77,4\%). Ocho de ellos fueron artículos de investigación, aunque el modelo sólo fue utilizado como marco teórico. Ver tabla 55.

Los artículos explicaron la aplicación del modelo en la formación de estudiantes y en la investigación. Se usó también en el cuidado de pacientes y cuidadores, en paciente con trastorno mental, con fascitis necrotizante y cistitis. De la misma forma fue usado para la explicación de la espiritualidad en ancianos y pacientes con VIH y para el desarrollo de estrategias de control del estrés en estudiantes, adolescentes y enfermeras. 
Tabla 55: Publicaciones halladas para el modelo de Betty Neuman

\begin{tabular}{|c|c|c|c|}
\hline & & Frecuencia & Porcentaje \\
\hline \multirow{5}{*}{ Tipos de publicación } & Estudio empírico & 8 & 44,4 \\
\hline & Artículo teórico & 3 & 16,7 \\
\hline & Artículo metodológico & 3 & 16,7 \\
\hline & Estudio de caso & 3 & 16,7 \\
\hline & Artículo de revisión & 1 & 5,6 \\
\hline \multirow{9}{*}{$\begin{array}{l}\text { Revista de publicación (Título } \\
\text { abreviado) }\end{array}$} & Nurs Sci Q & 8 & 44,4 \\
\hline & J Adv Nurs & 2 & 11,1 \\
\hline & MCN Am J Matern Child Nurs & 2 & 11,1 \\
\hline & Curationis & 1 & 5,6 \\
\hline & Holist Nurs Pract & 1 & 5,6 \\
\hline & Hu Li Za Zhi & 1 & 5,6 \\
\hline & J Christ Nurs & 1 & 5,6 \\
\hline & J Nurs Educ & 1 & 5,6 \\
\hline & J Sch Nurs & 1 & 5,6 \\
\hline \multirow{4}{*}{ País de publicación } & EE.UU. & 14 & 77,8 \\
\hline & Reino Unido & 2 & 11,1 \\
\hline & China & 1 & 5,6 \\
\hline & Sudáfrica & 1 & 5,6 \\
\hline \multirow{5}{*}{ Nacionalidad del autor } & EE.UU. & 14 & 77,8 \\
\hline & China & 1 & 5,6 \\
\hline & Irlanda del & 1 & 5,6 \\
\hline & Sudáfrica & 1 & 5,6 \\
\hline & Turquía & 1 & 5,6 \\
\hline \multirow{2}{*}{ Lugar de filiación laboral del autor } & Universidad & 14 & 77,8 \\
\hline & Otros centros & 4 & 22,2 \\
\hline
\end{tabular}

\subsubsection{Publicaciones elaboradas usando el modelo de Martha E. Rogers}

Se hallaron un total de 114 de referencias y de ellas se seleccionaron sólo 13 artículos que tenían relación con el modelo. En este caso, más de la mitad de los artículos eran artículos teóricos (8), y fueron publicados el 76,9\% en el Nursing Science Quarterly. La mayoría fueron publicados en EE.UU. (92,3\%) y por autores estadounidenses. Todos desarrollaban su trabajo en la universidad. Un artículo fue publicado por un autor español.

El modelo fue empleado en el estudio de la musicoterapia como tratamiento del dolor de pacientes con fibromialgia, en el abordaje de la calidad de vida y otros factores en supervivientes a un cáncer de mama, centrándose en la descripción que la teorista hace de la energía. La mayoría de los artículos simplemente fueron disertaciones teóricas sobre el modelo. Ver tabla 56. 
Tabla 56: Publicaciones halladas para el modelo de Martha E. Rogers

\begin{tabular}{|l|l|c|c|}
\hline \multirow{4}{*}{ Tipo de estudio } & & Frecuencia & Porcentaje \\
\hline \multirow{5}{*}{ Revista de publicación (Título abreviado) } & Artículo teórico & 8 & 61,5 \\
\cline { 2 - 4 } & Estudio empírico & 4 & 30,8 \\
\cline { 2 - 4 } & Artículo de revisión & 1 & 7,7 \\
\cline { 2 - 4 } & Nurs Sci Q & 10 & 76,9 \\
\cline { 2 - 4 } & Hu Li Za Zhi & 1 & 7,7 \\
\cline { 2 - 4 } & J Prof Nurs & 1 & 7,7 \\
\cline { 2 - 4 } & Pain Manage Nurs & 1 & 7,7 \\
\hline \multirow{3}{*}{ País de publicación } & EE.UU. & 12 & 92,3 \\
\cline { 2 - 4 } & China & 11 & 7,7 \\
\hline \multirow{3}{*}{ País del autor } & EE.UU. & 1 & 84,6 \\
\cline { 2 - 4 } & China & 1 & 7,7 \\
\cline { 2 - 4 } & España & 13 & 100 \\
\hline \multirow{2}{*}{ Lugar de filiación laboral del autor } & Universidad & & 7,7 \\
\hline
\end{tabular}

\subsubsection{Publicaciones elaboradas usando la teoría de Hildegard E. Peplau}

Se hallaron un total de 24 referencias de las cuales sólo 13 estaban relacionadas con la teoría. Ocho de ellas fueron estudios empíricos. Hubo mucha diversidad en cuanto a las revistas en las que fueron publicadas. La mitad se publicaron en EE.UU. (46,2\%), seguido por Reino Unido (30,8\%). El país del autor fue EE.UU. en el 61,5\% de los casos. Un 76,9\% trabajaban en la universidad. Ver el resto de los resultados en la tabla 57.

Cualitativamente se puede objetivar que ha sido usada la implementación de la teoría en la atención en emergencia extrahospitalaria, en el estudio de la violencia entre adolescentes, en pacientes con trastorno mental, en los que han sufrido violencia sexual y en intervenciones psicoeducativas en pacientes diabéticas, incidiendo sobre todo en la relación de comunicación que se da entre el paciente y la enfermera.

Tabla 57: Publicaciones halladas para la teoría de Peplau

\begin{tabular}{|l|l|c|c|}
\hline & & Frecuencia & Porcentaje \\
\hline \multirow{4}{*}{ Tipos de publicación } & Estudio empírico & 8 & 61,5 \\
\cline { 2 - 4 } & Artículo teórico & 4 & 30,8 \\
\cline { 2 - 4 } & Estudio de caso & 1 & 7,7 \\
\hline \multirow{4}{*}{$\begin{array}{l}\text { Revista de publicación } \\
\text { (Título abreviado) }\end{array}$} & Issues Ment Health Nurs & 2 & 15,4 \\
\cline { 2 - 4 } & Nurs Sci Q & 2 & 15,4 \\
\cline { 2 - 4 } & J Am Psychiatr Nurses Assoc & 1 & 7,7 \\
\cline { 2 - 4 } & Clin Nurse Spec & 1 & 7,7 \\
\cline { 2 - 4 } & Contemp nurse & 1 & 7,7 \\
\cline { 2 - 4 } & Int Emerg Nurs & 1 & 7,7 \\
\hline
\end{tabular}




\begin{tabular}{|c|c|c|c|}
\hline & & Frecuencia & Porcentaje \\
\hline \multirow{5}{*}{$\begin{array}{l}\text { Revista de publicación } \\
\text { (Título abreviado) }\end{array}$} & J Psychiatr Ment Health Nurs & 1 & 7,7 \\
\hline & J Am Psychiatr Nurses Assoc & 1 & 7,7 \\
\hline & Issues Ment Health Nurs & 1 & 7,7 \\
\hline & Nurse Educ Today & 1 & 7,7 \\
\hline & Rev Bras Enferm & 1 & 7,7 \\
\hline \multirow{5}{*}{ País de publicación } & EE.UU. & 6 & 46,2 \\
\hline & Reino Unido & 4 & 30,8 \\
\hline & Australia & 1 & 7,7 \\
\hline & Brasil & 1 & 7,7 \\
\hline & Escocia & 1 & 7,7 \\
\hline \multirow{6}{*}{ País del autor } & EE.UU. & 8 & 61,5 \\
\hline & Australia & 1 & 7,7 \\
\hline & Brasil & 1 & 7,7 \\
\hline & Irán & 1 & 7,7 \\
\hline & Kenia & 1 & 7,7 \\
\hline & Suecia & 1 & 7,7 \\
\hline \multirow{3}{*}{$\begin{array}{l}\text { Lugar de filiación laboral } \\
\text { del autor }\end{array}$} & Universidad & 10 & 76,9 \\
\hline & Otros & 2 & 15,4 \\
\hline & Hospital & 1 & 7,7 \\
\hline
\end{tabular}

\subsubsection{Publicaciones elaboradas con la filosofía de Virginia Henderson}

Se hallaron 13 publicaciones que nombraron el modelo teórico (de 78 referencias). En 4 ocasiones la filosofía fue usada para guiar investigaciones y fue aplicada en estudio de caso en 4 de los artículos (pacientes en edad infantil y postquirúrgico con un aneurisma de aorta). Se publicaron mayormente en España (61,5\%). Gran parte de ellos fueron publicados por autores españoles $(76,9 \%)$, y por autores que desarrollaban su trabajo en la asistencia $(61,5 \%)$. En algunos de los casos la filosofía fue usada unida a metodología de diagnósticos enfermeros NANDA, la Nursing Intervention Classification y la Nursing Outcomes Classification (Abreviado con NNN). Ver tabla 58.

Se usó para evaluar el perfil tipo de pacientes quirúrgicos, pacientes domiciliarios tras estancia hospitalaria (nivel de dependencia), mujeres inmigrantes marroquís, y para el desarrollo de planes de cuidados estándar para niños con discapacidad mental y pacientes neurológicos. Del mismo modo fue usado para la planificación del cuidado en neonatos, en un niño con problemas de celos y en un paciente con aneurisma de aorta. 
Tabla 58: Publicaciones halladas para el modelo de Henderson

\begin{tabular}{|c|c|c|c|}
\hline & & Frecuencia & Porcentaje \\
\hline \multirow{5}{*}{ Tipo de estudio } & Estudio empírico & 4 & 30,8 \\
\hline & Estudio de caso & 4 & 30,8 \\
\hline & Artículo teórico & 3 & 23,1 \\
\hline & Artículo de revisión & 1 & 7,7 \\
\hline & Artículo metodológico & 1 & 7,7 \\
\hline \multirow{7}{*}{$\begin{array}{l}\text { Revista publicación (Título } \\
\text { abreviado) }\end{array}$} & Enferm Clin & 6 & 46,1 \\
\hline & Rev Enferm & 2 & 15,4 \\
\hline & Hu Li Za Zhi & 1 & 7,7 \\
\hline & Nurs Outlook & 1 & 7,7 \\
\hline & Prog Transplant & 1 & 7,7 \\
\hline & Rev Esc Enferm USP & 1 & 7,7 \\
\hline & Rev Lat Am Enfermagem & 1 & 7,7 \\
\hline \multirow{4}{*}{ País de publicación } & España & 8 & 61,5 \\
\hline & Brasil & 2 & 15,4 \\
\hline & EE.UU. & 2 & 15,4 \\
\hline & China & 1 & 7,7 \\
\hline \multirow{3}{*}{ Nacionalidad del autor } & España & 10 & 76,9 \\
\hline & EE.UU. & 2 & 15,4 \\
\hline & China & 1 & 7,7 \\
\hline \multirow{3}{*}{ Filiación laboral del autor } & Universidad & 5 & 38,5 \\
\hline & Otros centros & 5 & 38,5 \\
\hline & Hospital & 3 & 23 \\
\hline
\end{tabular}

\subsubsection{Publicaciones elaboradas usando el modelo de Imogene M. King:}

Se inicio la búsqueda obteniéndose inicialmente un total de 972 referencias, la mayor parte de ellas no estaban relacionadas con el modelo teórico. De ellas finalmente sólo 12 usaron el modelo enfermero de King. Cinco estudios son empíricos, 3 de revisión y 4 teóricos. La mayoría han sido elaborados por profesores universitarios (75\%). Existe gran diversidad de revistas en las que fueron publicados. Siendo EE.UU. el país con más publicaciones (66,6\%). Ver tabla 59.

Si revisamos el aspecto cualitativo del contenido de los artículos, podemos ver que el modelo se usó para el estudio de las percepciones de hipertensos y de pacientes que han padecido una desfiguración facial. Se hizo una propuesta para usar el modelo en los cuidados paliativos y sirvió para evaluar un programa realizado sobre madres en el cuidado de sus hijos y sobre cómo afecta la relación interdisciplinaria a los efectos adversos. 
Tabla 59: Publicaciones halladas para el modelo de Imogene King

\begin{tabular}{|c|c|c|c|}
\hline & & Frecuencia & Porcentaje \\
\hline \multirow{3}{*}{ Tipo de artículo } & Estudio empírico & 5 & 41,6 \\
\hline & Artículo teórico & 4 & 33,3 \\
\hline & Artículo de revisión & 3 & 15 \\
\hline \multirow{10}{*}{ Revista publicación (Título abreviado) } & Nurs Sci Q & 3 & 25 \\
\hline & Gastroenterol Nurs & 1 & 8,3 \\
\hline & J Adv Nurs & 1 & 8,3 \\
\hline & J Korean Acad Nurs & 1 & 8,3 \\
\hline & J Nurs Manag & 1 & 8,3 \\
\hline & Nurs Adm Q & 1 & 8,3 \\
\hline & Nurs Philos & 1 & 8,3 \\
\hline & ORL Head Neck Nurs & 1 & 8,3 \\
\hline & Rev Gaucha Enferm & 1 & 8,3 \\
\hline & Scand J Caring Sci & 1 & 8,3 \\
\hline \multirow{5}{*}{ País de publicación } & EE.UU. & 8 & 66,6 \\
\hline & Brasil & 1 & 8,3 \\
\hline & Corea & 1 & 8,3 \\
\hline & Jordania & 1 & 8,3 \\
\hline & Reino Unido & 1 & 8,3 \\
\hline \multirow{5}{*}{ Nacionalidad del autor } & EE.UU. & 8 & 66,6 \\
\hline & Brasil & 1 & 8,3 \\
\hline & Canadá & 1 & 8,3 \\
\hline & Corea & 1 & 8,3 \\
\hline & Suecia & 1 & 8,3 \\
\hline \multirow{3}{*}{ Filiación laboral del autor } & Universidad & 9 & 75 \\
\hline & Hospital & 2 & 16,6 \\
\hline & Otros & 1 & 8,3 \\
\hline
\end{tabular}

\subsubsection{Publicaciones elaboradas usando la teoría de Ida Jean Orlando Pelletier}

Se hallaron un total de 14 referencias de las cuáles sólo 4 eran en relación a la aplicación o el uso de la teoría de Orlando. Tres eran estudios empíricos y la mayoría estaban publicados en EE.UU. por profesionales universitarios. Ver tabla 60. En cuanto a los temas tratados en los artículos, se propone su uso en la prevención de caídas en pacientes hospitalizados y aspectos más teóricos sobre su uso en la formación o en el proceso enfermero.

Tabla 60: publicaciones halladas para la teoría de Orlando

\begin{tabular}{|l|l|c|c|}
\hline & & Frecuencia & Porcentaje \\
\hline \multirow{2}{*}{ Tipos de estudio } & Estudio empírico & 3 & 75 \\
\cline { 2 - 4 } & Artículo metodológico & 1 & 25 \\
\hline \multirow{3}{*}{$\begin{array}{l}\text { Revista de publicación (Título abrevia- } \\
\text { do) }\end{array}$} & Iran J Nurs Midwifery Res & 1 & 25 \\
\cline { 2 - 4 } & J Adv Nurs & 1 & 25 \\
\cline { 2 - 4 } & Health Care Manag & 1 & 25 \\
\cline { 2 - 4 } & Worldviews Evid Based Nurs & 1 & 25 \\
\hline \multirow{2}{*}{ País de publicación } & EE.UU. & 3 & 75 \\
\cline { 2 - 4 } & India & 1 & 25 \\
\hline \multirow{2}{*}{ País del autor } & EE.UU. & 1 & 25 \\
\cline { 2 - 4 } & Irán & 4 & 100 \\
\hline Filiación laboral del autor & Universidad & & \\
\hline
\end{tabular}




\subsubsection{Publicaciones elaboradas con el modelo de Nancy Roper, Winifred Logan y}

Alison Tierney (RLT)

Se hallaron un total de 4 artículos relacionados con la base teórica propuesta (de 18 referencias mostradas). Éstos fueron publicados en Brasil y Reino Unido. El modelo de RLT fue aplicado en diferentes tipos de pacientes, dos usaron el modelo como marco teórico para una investigación cualitativa sobre pacientes (prostitutas y pacientes con lepra), en un artículo se usó el modelo para el estudio de caso y el último era una reflexión teórica que argumentaba el uso del modelo sobre el seguimiento de una persona en la etapa infantil. Los autores de los artículos desarrollaban su actividad en el ámbito universitario (ver tabla 61).

Tabla 61: Publicaciones halladas para el modelo RLT

\begin{tabular}{|l|l|c|c|}
\hline \multirow{4}{*}{ Tipo de artículo } & & Frecuencia & Porcentaje \\
\hline \multirow{3}{*}{ Revista publicación } & Estudio empírico & 2 & 50 \\
\cline { 2 - 4 } & Artículo teórico & 1 & 25 \\
\cline { 2 - 4 } & Estudio de caso & 1 & 25 \\
\hline \multirow{3}{*}{ País de publicación } & Rev Bras Enferm & 2 & 50 \\
\cline { 2 - 4 } & Br J Nurs & 2 & 50 \\
\hline \multirow{3}{*}{ País de origen del autor } & Brasil & 2 & 50 \\
\cline { 2 - 4 } & Reino Unido & 2 & 50 \\
\hline Filiación laboral del autor & Brasil & 1 & 25 \\
\cline { 2 - 4 } & Irlanda del Norte & 1 & 25 \\
\cline { 2 - 4 } & Reino Unido & 4 & 100 \\
\hline
\end{tabular}

\subsubsection{Publicaciones elaboradas usando la filosofía de Dorothy Johnson:}

Se localizaron 69 referencias, pero sólo una de ellas estaba relacionada con la base conceptual enfermera. Se traba de una revisión de la literatura realizada por profesores universitarios en China sobre los hábitos de eliminación urinaria en mujeres (publicado por autores universitarios en el Journal of Advanced Nursing en Reino Unido). Usan el modelo como marco conceptual.

\subsubsection{Publicaciones elaboradas usando la filosofía de Lydia Hall:}

Tras la indagación se obtuvieron 49 referencias, de las cuáles sólo dos trataban sobre base conceptual enfermera, pero sólo uno sobre la filosofía de Hall. Se trataba de un ensayo clínico sobre el uso de musicoterapia en mujeres mastectomizadas realizado en China y publicado en el Journal of Advanced Nursing (Reino Unido) por autores universitarios. 


\subsubsection{Publicaciones elaboradas usando el modelo de Myra Estrin Levine:}

Se obtuvieron un total de 432 referencias posibles para las palabras de búsqueda, sin embargo, sólo una de las referencias era un artículo de investigación en el que usaban el modelo teórico como marco conceptual en el estudio de la intensidad de cuidados en unidad neonatal. El estudio fue publicado en el Journal of Nursing Management (Reino Unido) por autores estadounidenses, profesores de universidad.

\subsubsection{Publicaciones elaboradas usando la filosofía de Faye Glen Abdellah:}

Se hallaron un total de 67 referencias para la búsqueda mediante los términos expuestos anteriormente. No hallándose ningún artículo en el que se nombre o aplique la filosofía.

Pese al uso de diversas palabras clave y descriptores en Mesh, no se obtuvieron resultados en relación a ninguno de los dos modelos.

\subsubsection{Resumen de los hallazgos en cuanto a las publicaciones más relevantes:}

La mayoría de las publicaciones se realizan basándose en los modelos de R. Parse, C. Roy y D. Orem, siendo mayormente publicados en la revista Nursing Science Quarterly $(28,1 \%$ artículos estimados). El número de publicaciones se mantiene en los años estudiados. La mayoría de las publicaciones halladas son estudios empíricos (47\%) seguidas por estudios teóricos (26\%). La mayoría de los artículos están escritos por autores estadounidenses $(60,9 \%)$ y publicados en el mismo país $(68,1 \%)$, seguidos por autores canadienses en un porcentaje bastante inferior $(7,6 \%)$ y por Reino Unido como país de publicación (7,6\%). La mayoría de los autores desempeñan su labor en la universidad. Si concretamos entre la relación de la teorista con el país del autor, vemos que todas las teoristas son utilizadas mayormente por autores estadounidenses, excepto en el caso de las publicaciones de V. Henderson que es usada en su mayoría por autores españoles (76,9\%). R. Parse es usada mayormente por estadounidenses $(65,5 \%)$ y canadienses $(17,24 \%)$. C. Roy se usa en publicaciones estadounidenses $(62,8 \%)$ y turcas $(11,6 \%)$. Por otro lado, D. Orem es aplicada por autores de EE.UU (55,6\%) y Brasil $(16,7 \%)$. Y 
en el caso de J. Watson es utilizada en publicaciones de estadounidenses $(59,4 \%)$ y taiwanesas (15,6\%). M. Leininger mayormente es empleada en los estudios por autores de EE.UU (63\%). Finalmente las publicaciones de B. Neuman son de autores estadounidenses $(77,8 \%)$ y británi$\cos (11,1 \%)$.

En cuanto al tipo de artículo y teorista, las teoristas R. Parse, V. Henderson e I. King son usadas casi igualmente para estudios empíricos y teóricos. Sin embargo, C. Roy, D. Orem, J. Watson, M. Leininger, B. Neuman, M. Rogers y H. Peplau son usadas en mayor frecuencia en estudios empíricos, habitualmente como marcos conceptuales de la investigación. 
5. Discusión 
El escaso impacto de los modelos teóricos en la práctica enfermera es un tema que ya ha sido discutido académicamente en el entorno internacional desde hace años (Simpson \& Taylor, 2002; Tierney, 1998). Sin embargo, esta discusión era escasa en estudios realizados en el contexto español, donde el modelo de Henderson de los años 50 , se ha tomado como el eje central de la aplicación teórica en el cuidado. Ha existido asimismo insuficiente crítica tanto sobre el modelo de V. Henderson como sobre el resto de teorías existentes en la literatura en cuanto a si podían dar respuesta real a las necesidades contemporáneas de pacientes y familias. Los artículos hallados relatan solamente resultados sobre el éxito de la aplicación de un modelo teórico en casos o situaciones concretas, pero escasean investigaciones que pongan de manifiesto las limitaciones de los mismos. Con todo, si la utilidad del modelo estuviera tan demostrada y contrastada, todos los centros sanitarios aplicarían un modelo teórico como marco conceptual en el cuidado. Aunque escasea la información objetiva en el tema, hay una clara respuesta real de la falta de aplicación de estos modelos en los cuidados enfermeros actuales.

El presente estudio fue diseñado con el fin de objetivar que factores podrían repercutir en la aplicación de modelos enfermeros nacionalmente en el ámbito asistencial. Para ello se planteó analizar diferentes perspectivas sobre el tema partiendo de aquellos protagonistas y factores relacionados que recoge la literatura. Era cuestión de analizar si los elementos tradicionalmente relacionados con el tema a nivel internacional, eran los recogidos en la práctica española, ya que había pocos estudios sobre la temática en nuestro país. Para ello se concretó en la plasmación de diferentes perspectivas, tanto de estudiantes como de profesionales de diversos ámbitos (hospitales, centros de atención primaria, residencias...), focalizando además el tema entre gestores y profesores universitarios que quizás podrían ser los profesionales expertos que, por su posición, mayor información podrían tener sobre el tema. Cerrando el estudio del fenómeno en toda su complejidad se contrastaron los hallazgos con los del panorama internacional (a través de la búsqueda de publicaciones respecto a experiencias en el tema). Una vez analizados los resultados para cada uno de los objetivos planteados, se llegó a la discusión que aquí se presenta para esclarecer y determinar cuáles han sido los factores asociados a la aplicación de modelos teóricos en la práctica de la enfermería en España. Al igual que para el resto de la tesis, la discusión se llevó a cabo concretándola en cada uno de los objetivos que condujeron al planteamiento de las conclusiones finales y sus implicaciones prácticas. 


\subsection{Discusión objetivo 1: Describir el estado formativo de pregrado que ha podido influir en la implantación de modelos teóricos en la práctica de enfermería.}

Para poder dar respuesta al objetivo, durante 6 meses se analizaron las páginas web de las universidades españolas en las que se cursaba en ese momento la titulación que daba competencias para ser enfermera/o, aunque se hallaron pocas escuelas que hicieron explícito en sus páginas web el modelo enfermero que guiaba su formación. Esto debía de ser un hecho importante, si los modelos teóricos tuvieran mayor relevancia en los planes docentes, ya que los datos en Internet son una herramienta de captación fácilmente accesible para futuros alumnos que podría inclinar la matriculación hacia uno u otro centro. Para conocer la orientación conceptual de las universidades fue necesario profundizar en los contenidos de los planes docentes de las asignaturas relacionadas con Fundamentos de Enfermería.

Pese al gran abanico de posibilidades teóricas, se decantaron mayormente por el modelo de Virginia Henderson, teórica también más referenciada tradicionalmente en las publicaciones españolas relacionadas con planes de cuidados (Escuredo, 2003). Por lo que se podría llegar a la conclusión de que existe escasez de diversidad teórica sobre Modelos y Teorías de Enfermería (fueron pocos los modelos nombrados en los contenidos de la asignatura de la gran pluralidad internacional de modelos existentes en la literatura). En cuanto a poder realizar una comparativa del tema, sólo se ha hallado un estudio similar en Brasil (De Matos, Geisa, Janaína, de Barros \& Pelloso, 2011), aunque en su caso, se medió la consulta a través de entrevista directa a los formadores de la titulación universitaria. De Matos et al. (2011) hallaron que el modelo más frecuentemente usado en la formación fue el de Wanda Horta (teorista brasileña que en 1979 elaboró la teoría de las necesidades humanas basada en Maslow, modelo formativo en el $60 \%$ de las instituciones), seguido de Orem $(17,1 \%)$, Leininger $(11,4 \%)$, y con menor frecuencia otras teoristas como Rogers, Watson, King, Peplau, Orlando, Henderson y Roy. Destacar que tanto el modelo de Horta como el de Henderson están basados en las necesidades de Maslow. Ambos modelos, desarrollados en los años 50' (Henderson, 1958) y 70' (Horta, 1979), son simples en cuanto a su vocabulario y por ello puede ser este el motivo de su elección en la formación de grado de estudiantes con poca capacidad reflexiva por su incipiente introducción en filosofía enfermera. 
Respecto a asignaturas relacionadas propiamente con la base teórica enfermera, se evidenció falta de unanimidad para la denominación de la asignatura del mismo contenido y se hallaron desigualdades en cuanto a créditos posibles relacionados con la base científica enfermera: la media de créditos obligatorios de asignaturas que incluían modelos y teorías fueron de $15 \pm 3,6$ siendo incluídos mayoritariamente en la asignatura de Fundamentos de Enfermería. Además se podía optar a 15,87 $\pm 3,95$ créditos más en los centros en los que se ofertaban asignaturas optativas en relación a los contenidos estudiados.

Destacar como limitación, que sólo se tuvo acceso en web al contenido de las asignaturas en la mitad de los centros universitarios (56\%), por lo que quedaron por analizar casi la mitad de planes docentes. En los planes docentes analizados, se objetivaron elevadas discrepancias entre contenidos teóricos y prácticos incluidos en la asignatura relacionada con modelos teóricos. Pese a que la asignación de créditos teóricos y prácticos en la materia se reparte equitativamente entre ambos, en la mayoría de los centros el contenido práctico es parcialmente "enseñanza clínica". No obstante en otros centros, las únicas prácticas son en laboratorios de simulación por lo que, se manifiestan nuevamente divergencias en cuanto a los contenidos. Se entiende por "enseñanza teórica" el aspecto mediante el cual los estudiantes adquieren conocimientos, la comprensión, las aptitudes y las actitudes profesionales necesarias para planificar, prestar y evaluar los cuidados globales de salud. La "enseñanza clínica” es el aspecto de la formación de los cuidados de enfermería mediante el cual el estudiante aprende, dentro de un equipo y en contacto directo con el individuo sano o enfermo y/o colectividad, a planificar, prestar y evaluar los cuidados de enfermería globales requeridos a partir de los conocimientos y aptitudes adquiridos (Bernués et al, 2004). Además, los planes docentes no nos indican el peso específico que tiene la materia sobre modelos y teorías en tiempo docente respecto a otros contenidos como los históricos, No obstante, a parte de su distribución, se objetiva que son dotaciones de créditos docentes dedicados a la base conceptual enfermera que están muy por debajo por ejemplo a los dedicados en Brasil que dedican entre 36 y 72 créditos a la materia en la titulación de 4 años (De Matos et al.,2011).

Quizás la mayor carencia hallada fue la falta de volver a retomar el contenido teórico en otros cursos diferentes a primero de Enfermería en el que seguramente los estudiantes están faltos de espíritu crítico ante los mismos, por lo que podría impedir la madurez necesaria a nivel formativo que facilitara la integración de la base enfermera. De Mato et al. (2011) destacaron que al igual que pasa en la educación española, en la formación brasileña la mayoría 
del contenido se ofertaba en primer curso (72\%), concretando que este hecho podía dar lugar a dificultades en asociar los contenidos teóricos con la práctica, lo que interfería con la comprensión de lo que representa una teoría enfermera. Como resultado, podría conducir a una falta de intentos de aplicar las teorías en la atención sanitaria para los clientes en la carrera profesional (De Mato et al., 2011). En este punto otra cuestión importante sería revisar si los enfermeros ya integrados en el mundo laboral comprenden la utilidad de los modelos teóricos en su práctica. Hay estudios que evidencian que los modelos teóricos se creen abstractos y poco útiles (M. López et al., 2006). Aunque otros evidencian datos contradictorios, donde son evaluados por los enfermeros de sala como aspectos positivos que mejoran la calidad asistencial (McKenna, 1990; Mckenna, Parahoo, \& Boore, 1995), hallazgos también mostrados por M.E. Moreno (2005) que veririficó la importancia de aplicar un modelo conceptual en la práctica (facilitaba visualizar la contribución de enfermería en los equipos interdisciplinarios y expandir el rol de los profesionales).

Habitualmente se comenta que los contenidos sobre filososfía enfermera forman parte transversalmente de otras asignaturas, no obstante se deberían de profundizar en otras asignaturas con entidad propia ya que, se traduciría en una mayor formación al respecto de los estudiantes y serían tomados como eje vertebrador de la formación enfermera. Además, existiría una mayor adecuación entre el modelo estudiado y las características propias de salud de la persona atendida.

Cualquier modelo teórico puede no ser útil ante la respuesta humana a la situación de salud (Zabalegui, 2000), por lo que seguramente esa mayor visión profesional podría redundar en una mayor adecuación de los planes de cuidados y por lo tanto aumentar la calidad de vida de las personas a las que prestamos atención. De hecho es necesaria la evolución del tema hacia el desarrollo de investigaciones basadas en nuevas teorías de rango medio próximas a la práctica que solucionaran el dia a dia del cuidado (Peterson \& Bredow, 2009).

No obstante, cabe resaltar que este estudio cuenta con la limitación de mostrar únicamente lo que cada universidad oferta en su web, por lo que quizás discrepa con la formación recibida por el estudiante en el aula. Seguramente el nuevo plan de estudios de Grado proporcionará novedades al respecto, por lo que sería interesante el poder repetir el análisis una vez estén consolidados los contenidos de los cuatro años de la titulación. 


\subsection{Discusión objetivo 2: Conocer qué modelo enfermero se}

\section{aplica de forma implícita (sin ser regularizado institucionalmente) en la práctica profesional y su relación}

con la formación recibida.

El estudio sobre profesionales y estudiantes, nos llevó a conocer de forma precisa las percepciones y preferencias teóricas de ambos grupos y sus factores condicionantes. Algunos estudios sobre el tema, han llamado a esta forma de aplicación implícita del modelo la adherencia al modelo, que ha sido medida en forma de comportamiento y conducta (Reyes, Jara \& Merino, 2007). Nosotros podríamos decir que en nuestro estudio se midió la adherencia sobre la actitud. En primer lugar comentar algunas de las limitaciones que pudieron haber influenciado los resultados en el caso de los profesionales. La CSPT en el momento de la recogida de datos carecía de un recuento preciso del total de profesionales de enfermería en activo, ya que estaban incluidos en el departamento de personal como grupo 2 (junto a otros profesionales). El recuento de profesionales es difícil en los hospitales, ya que, las plantillas varían continuamente debido a cambios en dotación de personal en función de la necesidad de los servicios; esto hizo que no se pudiera proceder a la aleatorización de la muestra. Esta circunstancia se intentó paliar, con la entrega en mano del cuestionario a todos los profesionales que se hallaban en su lugar de trabajo en diferentes momentos temporales ( 545 profesionales), incluyendo fines de semana y turno de noche, con la intención de llegar al mayor número de población. Pese a ello, hubo un bajo índice de respuesta, inferior al necesario para ser representativo (eran necesarios 385 profesionales según cálculo de tamaño de la muestra para proporciones en población infinita con un error de estimación del 5\%, y una prevalencia máxima esperada del parámetro a evaluar del 50\%, con la intención de maximizar el tamaño). Asociado a este problema, existía el de la dispersión geográfica entre los diferentes edificios del centro que dificultó el acceso en algún momento a los profesionales. Otros de los factores a tener en cuenta, es que en la entrega de cuestionarios se detectó que muchos profesionales no habían sido informados por sus gestores tal como había sido previsto en la metodología de trabajo, ni habían visto las notas informativas disponibles en las noticias de la Intranet del centro. La comunicación interna entre los diferentes servicios hospitalarios de determinado tamaño es un problema conocido y ya relatado en diferentes trabajos (March, Prieto, Danet, Pérez \& Martínez, 2009). 
Con todo, el índice de respuesta fue diferente en ambos grupos estudiados, se ha de reconocer que la metodología empleada fue diferente. A los alumnos se les convocaba en una sesión de tutoría durante el período de prácticas clínicas en las que se entregaban y recogían los cuestionarios (los rellenaban en aquel momento). Además, los estudiantes están familiarizados con responder a cuestionarios de diversos temas en sus universidades, por lo que acrecentó su índice de colaboración. En cambio, en los enfermeros hubo dificultades para acceder a todo el personal como la eventualidad en la contratación, horarios rotatorios, dispersión geográfica entre ámbitos, etc. Durante las entregas fueron muchos los profesionales que verbalizaron al equipo que percibían elevada presión asistencial que suponía una escasez de tiempo. Esta verbalización de profesionales relacionada con plantillas y adecuación de recursos ya ha sido valorada en algunos estudios como poco favorecedores en el desempeño de las funciones enfermeras (Kutney-Lee et al., 2009). Esto unido a la extensión del cuestionario que requería de 20 minutos de elaboración pudo dificultar su correcta implementación. Estos comentarios reflejan dos hechos hallados en el estudio: una baja tasa respuesta debida por un lado a la elevada carga de trabajo en las unidades y quizás por otro, una falta de interés sobre el tema. Sin embargo, destacar que se objetivó un mayor índice de respuesta en ámbitos de pertenencia de los autores debido a mayor accesibilidad personal y muy probablemente al compañerismo.

El estudió se llevó a cabo sobre población relativamente joven, esto reforzó la conexión con la teoría ya que, su formación era cercana al momento actual. Además aseguró que la mayoría habían recibido formación en planes docentes similares sobre base conceptual enfermera. Un 64,5\% de los profesionales era menor de 40 años, con una media de edad de 38 años, datos similares a otros estudios sobre enfermeros españoles (Aiken, Sloane, Bruyneel, Van den Heede \& Sermeus, 2013). Así como, los años de expertez clínica también se asemejan a los hallados por Aiken et al. (2013). Por lo que de entrada podríamos asumir que su distribución cumpliría criterios de normalidad. Los profesionales del estudio en su mayoría no habían ejercido en otros centros sanitarios (los años de experiencia profesional son similares a los años trabajados en la CSPT). Este hecho favorecía el objetivo de estudio, ya que probablemente su visión no estaría condicionada por posibles variables confusoras. Los estudiantes en una elevada proporción compaginaban su actividad académica con la laboral, este tema en la actualidad se está viendo muy dificultado por las nuevas exigencias de presencialidad y trabajo grupal requeridas por el Espacio Europeo de Educación Superior para la formación de Grado, en ese momento los estudiantes se estaban formando bajo los estudios de Diplomatura. Entre los profesionales hubo hetereogenecidad con respecto a las universidades formadoras, Cata- 
luña cuenta con 17 escuelas diferentes de enfermería, de las cuáles 10 estaban próximas geográficamente al centro de estudio.

El porcentaje de varones fue superior en los estudiantes (16\% frente a un $9 \%$ de los profesionales). El porcentaje de estudiantes fue similar a otros centros universitarios españoles que rondan el 17\% (López-Medina \& Sánchez-Criado, 2005). Sin embargo en el caso de los profesionales es inferior tanto respecto al porcentaje de hombres en la zona de estudio que rondaba el $12,5 \%{ }^{10}$ o a otros estudios en España respecto al mismo tema (19\% hallado por Francisco en 2008). Posiblemente los hombres desarrollan su carrera profesional en ámbitos diferentes al hospitalario o bien, entre los profesionales respondieron en menor proporción. Algún estudio sobre el tema indica que la proporción de varones en relación a las mujeres en puesto base se incrementa al analizarla en puestos de responsabilidad debido a segregación vertical (Blázquez-Rodríguez, 2005). De todas formas, en los últimos años, parece haber un incremento en la matriculación masculina desde que Enfermería empezó a tener salida en el mercado laboral.

Son pocos los profesionales que han recibido formación continuada relacionada con modelos, puede ser debido al elevado coste económico y dedicación personal, la falta de interés (pueden parecer poco motivadores) o la poca implementación de modelos en nuestro sistema sanitario, que provoca que no sean imprescindibles para la entrada al mundo laboral. Muchas de las enfermeras asistenciales se forman en ámbitos relacionados directamente con la clínica y aspectos técnicos (J. López, 2000) y la mayoría de los programas de postgrado y Máster tienen un carácter profesionalizador abordando principalmente especialidades médicas. Si bien con frecuencia estas formaciones incluyen módulos que tienen que ver con modelos y teorías, estos son impartidos o tomados por los profesionales habitualmente como conocimientos secundarios. Excepto en el Máster de Ciencias de la Enfermería (Zabalegui \& Maciá, 2010) que introducen una asignatura sobre Modelos y Teorías de Enfermería de 10 ECTS. Cabe destacar, no obstante, que la formación no siempre garantiza el éxito. Resultados como los de Reyes et al. visibilizan su relevancia (2007). Estos autores en un estudio cuasiexperimental encontraron diferencias significativas en el cambio de actitud hacia la relación de la valoración de enfermería teniendo presente un modelo teórico, la elaboración del plan de cuidados y en sus conocimientos con la capacitación y formación de las enfermeras en el tema. Sin embargo esta capacitación no mejoró la adherencia de las enfermeras a la conducta de

\footnotetext{
${ }^{10}$ En la memoria del Colegio de Enfermeria de Barcelona, habían colegiados un 12,5\% de hombres. Fuente: Infome anual, 2005. COIB, de: http://www.coib.cat/UploadsBO/Generica/Documents/MEMORIA_2005_CAP_2_3.pdf
} 
aplicación del modelo (medida mediante el estudio de los registros). Los autores concluyeron que fueron condicionantes la participación voluntaria activa y dinámica que tuvieron los profesionales de enfermería, tanto en la elaboración del instrumento, como en la capacitación que se efectuó con el grupo de estudio donde se reforzaron tópicos relacionados con la teoría, en concreto la de V. Henderson.

En cuanto a los modelos usados en la formación, existe una mayor diversidad formativa respecto al modelo a seguir entre los datos recogidos en los estudiantes, no obstante en ambos grupos estudiados (estudiantes y profesionales enferneros) el modelo predominante fue el de V. Henderson. Datos hallados también por Francisco (2008) y congruentes con la revisión realizada de la literatura en cuanto a autorías españolas de artículos en relación a modelos presentada en nuestro estudio. No obstante, remarcar que el $11,8 \%$ de los profesionales refirió no haber recibido ninguna formación al respecto y se entre lee una importante confusión de conceptos al observar respuestas como: PAE, patrones funcionales... tanto entre estudiantes como entre profesionales. Así pues, se muestra una necesidad de afianzar la formación en todos los sentidos pre y postgrado y trabajar el tema tomando en consideración las necesidades de los profesionales para su práctica asistencial. En España, no existía la posibilidad formativa sobre Filosofía de la Enfermería, que sí existe desde hace años en América del Norte (Potter \& Perry, 2002), tan sólo recientemente a través del Máster en Ciencias de la Enfermería. Todo este déficit formativo podría argumentar el bajo índice de seguimiento de un modelo en la práctica diaria, la mayoría de los profesionales indican que no lo utilizan. Esta situación concreta se ve agravada por el hecho de que, la institución objeto de estudio, no tiene en la actualidad definido un modelo de enfermería para su práctica diaria. Asimismo, se advirtió pluralidad de respuestas sobre si atienden al paciente con el modelo con el que se identifican, esto refleja una actitud dubitativa, acaso por una falta de reflexión sobre el tema, o una falta de análisis sobre el qué y el cómo del cuidado. En el caso de los estudiantes no son expertos en el tema, quizás es una cuestión compleja para ser analizada durante la etapa formativa.

En los centros donde tenían un modelo definido (UIC y EUICR), los estudiantes afirmaron en mayor proporción que seguían un modelo en su práctica diaria, pero que conciben los estudiantes como modelo: ¿qué impregna su práctica?, ¿su forma de hacer?, o ¿qué se plasma en los registros? Tal y como se formularon las preguntas en el cuestionario, pudieron dar lugar a interpretación por parte del alumno en función de cómo se había trabajado el tema en la formación, si se fundamentaron o no de una filosofía cuidadora. Actualmente en la práctica existe una forma de cuidar más humanista que el propio modelo biomédico previo. Para resolver esta duda podría haber sido interesante formar grupos focales con estudiantes para poder 
indagar sobre su comprensión del término "modelo". No obstante, destacar que en su formación los estudiantes creyeron importante la aplicación de modelos, ya que opinaron que les serán útiles en su práctica.

Asombra que un $16,7 \%$ del personal indique que no ejecutaría su labor bajo ningún modelo enfermero, esto refleja la idea de que con frecuencia, los modelos y teorías de enfermería se relegan de la práctica enfermera porque son complejos y no se conocen en profundidad (Hernández, Moral \& Esteban, 1999). A nivel general hay una falta de credibilidad de las enfermeras en el desarrollo teórico enfermero, y muchas relacionan la aplicación de modelos con la elaboración de planes de cuidado que demandan gran cantidad de tiempo y, en la práctica, son imposibles de aplicar por el elevado volumen de pacientes que tienen a cargo (Lucero \& Guerrero, 2006). Datos publicados recientemente en estudios multicéntricos en Europa revelan que el $42 \%$ de las enfermeras manifiestan que una de las tareas que dejan sin realizar es justamente el desarrollo de planes de cuidados (Ausserhoffer et al., 2014). Por otro lado el porcentaje hallado de incredulidad respecto al tema de los modelos es inferior a investigaciones previas que refieren que un $23 \%$ de las enfermeras en el ámbito de psiquiatría manifiestaban negatividad en relación al tema (McKenna, 1990). En cambio, como aspecto positivo, cabe destacar la voluntad de los profesionales del centro para el desarrollo de un modelo en la práctica (más de la mitad de los entrevistados), la actitud es claramente definitoria de una perseverancia hacia la unificación de criterios entre los profesionales de Enfermería. El uso de un modelo debe ir en beneficio de mostrar indicadores de calidad del cuidado y consecuentemente a ello, del crecimiento de la profesión, relegando lo que en ocasiones se registra como el modelo de estructura - proceso- resultado más relacionado con la visión tradicional biomédica y el procedimiento industrial (Gunther \& Alligod, 2002).

Por los hallazgos podemos ultimar que parece que las enfermeras hallan aplicabilidad a los modelos teóricos enfermeros, si bien un $25 \%$ considera que el modelo que usaba como estudiante no le es ventajoso en su práctica profesional, corroborando la bibliografía (Medina, 2005; Zaragoza, 1999). Los resultados del estudio RN4CAST en España, revelan que las enfermeras están de acuerdo en que en sus lugares de trabajo los cuidados enfermeros están basados en un modelo de enfermería (en lugar del modelo médico) y que existe una filosofía clara de Enfermería que domina el entorno del cuidado del paciente (Instituto de Salud Carlos III, 2011). Estas manifestaciones corroboran la importancia que tiene el tema para los profesionales al igual que en nuestros resultados, sin embargo desconocemos el modelo aplicado por los mismos, o que entienden por filosofía o modelo enfermero de cuidado. Los estudiantes también mostraron una actitud receptiva hacia los modelos teóricos, no hallada en otros estu- 
dios anteriores sobre el tema (J. López, 2000), relacionada posiblemente con su actual formación donde se les expone, argumenta y se critica la necesidad de los mismos para su labor profesional desde el pensamiento reflexivo en los mismos, quizás es por ello que mostraron una actitud menos dubitativa cuando se les preguntó por el modelo que seguirían en la práctica. Además, los estudiantes consideraron más útiles los modelos, tal vez porque les facilita la realización de sus planes de cuidados que son elementos determinantes para el logro de competencias exigidas en los trabajos de su periodo práctico.

Globalmente tres causas motivarían la elección de un modelo teórico por estudiantes y profesionales: la formación (conocimiento del modelo), el dominio (facilidad de aplicación) y la adecuación (características del propio modelo o metodología). Aunque la mayoría de los profesionales han sido formados como Diplomados y bajo la Filosofía de Henderson, sólo el 39,7\% se define por una autora en concreto al cuestionarles directamente por su preferencia a nivel laboral, que mayoritariamente coincide con la que utilizó en su formación pregrado; quizás por el desconocimiento de otras teorías, aunque parece no quedar claro para los profesionales si la elección de un marco teórico debería estar condicionado por las características del paciente a cuidar. Esta ausencia de decantación profesional por un modelo concreto, tal vez denotaría desconocimiento o falta de interés por el tema.

En el caso de los estudiantes, pese a que se nombraron varias teóricas, fue V. Henderson la escogida por más de la mitad de los estudiantes, aunque en dos de las facultades no es la teórica de referencia. Seguramente esta decisión estaba condicionada por los medios científicos de comunicación, en los que predomina el modelo de esta autora en las publicaciones relacionadas con planes de cuidados, sobre todo asociada a taxonomía NANDA, NIC y NOC (Alconero-Camarero et al., 2008; Román et al., 2005), taxonomía que es incluida en la formación de los estudiantes en los tres centros. En cuanto a las diferencias halladas entre las instituciones universitarias, destacar que en EUIG trabajan con el método de Patrones Funcionales de M. Gordon, quizás por ello sus estudiantes optaron mayoritariamente por otros modelos, existiendo mayor variabilidad en la respuesta. En el caso de los estudiantes de la UIC tienen a C. Roy como referente aunque, durante su formación se les instruye en el manejo del programa GACELA que es un aplicativo para el uso del modelo de V. Henderson, por lo que su elección puede estar condicionada. La elección de los los estudiantes de EUICR si que se vio mediada por su educación ya que se decantaron mayoritariamente por su modelo formativo, el de V. Henderson. Vistos los resultados hallados, podríamos afirmar entonces que uno de los pilares fundamentales que condicionan la elección de un modelo es la directriz implementada en la formación universitaria que suele ser limitada, sobre todo en la formación pregrado. Esta 
incluye el dominio por parte del profesional. La visión restringida de la base conceptual, considerada tanto a nivel objetivo en la revisión de los planes docentes, como a nivel subjetivo en la percepción de las enfermeras/os condiciona en gran medida la limitación de desarrollo de marcos teóricos diversos. No obstante aún habiendo un modelo hegemónico, un gran porcentaje de profesionales que dejaron la pregunta en blanco. Existen estudios donde han escogido un modelo de trabajo en los que reconocen que no sólo la formación condiciona en la elección, sino también su pragmatismo, sencillez, apertura y lenguaje comprensible (Atienza, Delgado \& Rubio, 2003), hallazgos similares a los manifestados en la elección de un modelo para el cuidado entre profesionales y estudiantes.

Sin embargo, cuando revisamos el análisis más cualitativo de nuestros resultados, podemos observar una comprensión deficiente de la filosofía del modelo y un conocimiento parcial de éste. Esta información se extrae de textos como "es el que más he usado", "conozco" y "14 necesidades", ya que los encuestados comentan someramente aspectos propios de las peculiaridades de los modelos y no ilustran el papel que desempeña la enfermera en el mismo. En este caso podrían haber argumentado, por ejemplo, la elección de V. Henderson en base a cómo la enfermera realiza las acciones que el paciente no puede efectuar en un determinado momento de su ciclo de vital, fomentando en mayor o menor grado la independencia de la persona, la satisfacción de las necesidades o el rol enfermero de suplencia, apoyo o rol educativo (Marriner \& Raile, 2003). Las argumentaciones en base al modelo se relacionan con un uso del mismo demasiado lineal y organizado (registros soméricos sin reflexión conceptual), sin embargo este es un argumento contradictorio con la realidad del conocimiento, la epistemología enfermera y la forma en que ocurren los fenómenos de salud-enfermedad. Se evidencia falta de crítica sobre los fundamentos y la orientación del modelo, aunque posiblemente se debe a que en su formación profundizan en un modelo concreto, que ven como el ideal y quizás esta visión no permite tener el espíritu crítico que da conocer varias opciones de cuidado.

En las respuestas de los profesionales predominan adjetivos positivos frente a negativos en cuanto a los modelos, es cierto sin embargo, que éste análisis corresponde a los profesionales que voluntariamente quisieron responder, por lo que seguramente ya tenían una propensión manifiestamente acorde con el tema. Aún así también se acopiaron opiniones negativas minoritarias expresadas francamente y de forma refrendada (tanto en los cuestionarios como en las observaciones de campo). Las posturas de total aprobación o rechazo de un modelo problematizan el análisis y la reflexión en el mismo (Benavent, Francisco \& Ferrer, 2001). Parece existir, no obstante, una demanda implícita de los profesionales, de asignaturas 
sobre modelos y teorías de enfermería por el desconocimiento del tema que los propios estudiantes y profesionales manifiestan (no los conocen en profundidad). Se deberían añadir asignaturas sobre el tema al plan de estudios en cursos finales de la formación de Grado, cuando el estudiante tiene mayor poder crítico ante posibles aplicaciones. Quizás se podría plantear el tema de las teóricas enfermeras de forma transversal, integrado en otras materias, además de propiamente en enfermería fundamental, adecuando el modelo teórico al paciente que se describe para que realmente tuviera fundamento (p. ej., se podría usar el modelo de Peplau para el abordaje de la persona en la asignatura relacionada con salud mental). En la mayoría de las escuelas españolas se usa el modelo de V. Henderson (como se vió en la revisión de los planes docentes elaborada en este estudio) y se explican superficialmente el resto de modelos en la asignatura de "Fundamentos de Enfermería" (en el primer curso académico), por lo que falta como ya se ha comentado, una diversificación de teorías.

Por otra parte, posiblemente debemos empezar por valorar la tipología de persona que frecuenta los centros hospitalarios (u otros ámbitos en los que se presta el cuidado enfermero), los recursos disponibles, su demanda (qué espera de Enfermería) y qué objetivo final o resultado se pretende. Debido a este desconocimiento es lógico que el futuro enfermero elija el modelo usado en su formación, pero quizás no sea el más adecuado a las características propias de la sociedad a la que prestamos cuidado. Sociedad con mayor esperanza de vida, en la que aumentará la discapacidad severa y la inversión de recursos para cuidados a largo plazo (Harwood, Sayer \& Hirschfeld, 2004). Resulta anecdótico que, dentro de los comentarios de los estudiantes, no se manifiesten quejas ya características en los profesionales, como son la falta de utilidad de los modelos enfermeros y la carga de trabajo, quizás porque todavía no están inmersos en la dinámica laboral habitual que modifica perspectivas previas formativas del estudiante (Maben et al., 2006). Sus argumentaciones son positivas hacia el uso de teoría enfermera en la práctica, ya que están en una situación inmediata a su formación (Maben et al., 2006). Los hallazgos encontrados son similares a la primera fase del estudio de Wimpenny (2002), quien entrevistó a profesionales recién titulados sobre su experiencia en modelos enfermeros. El autor concluyó que los profesionales recién titulados hablaban de la operatividad del modelo como algo que debía ser impuesto en el área clínica y que debían estar unidos al plan de cuidados y a los registros. Aunque los profesionales (ya inmersos en el área clínica) manifestaron incertidumbre en la adaptación del modelo a la asistencia, opinión parcialmente reflejada en los comentarios obtenidos de los profesionales.

Las suposiciones halladas al respecto son que, el modelo elegido mayoritariamente es el de V. Henderson, que es el que rigió la formación universitaria y resulta de fácil aplicación. 
Es un modelo que está guiando la práctica enfermera española, según se puede evidenciar por las publicaciones realizadas, la formación de las enfermeras y el uso en muchos centros hospitalarios como marco conceptual, sin embargo es una filosofía quizás poco adecuada, con más de 50 años de historia (Marriner \& Raile, 2003), que puede no adecuarse a las necesidades de los pacientes atendidos en los centros hospitalarios en los que apremia las estancias cortas que impiden el desarrollo de éstos (Martinez, 2009). Destacar que la literatura sobre el tema indica que los modelos enfermeros no son usados en la práctica por diferentes variables (Goulet et al., 2003; Maben et al., 2006; Teixidor, 2002a) que confluyen en la CSPT en el momento de la recogida de datos: trabajo diario bajo la hegemonía del modelo biomédico (tareas delegadas derivadas de tratamiento médico), la estructura organizacional de las instituciones (no hay planes de cuidados enfermeros de forma explícita, ni definido un modelo teórico enfermero) y la elevada carga asistencial en las unidades de trabajo (dotación enfermera por debajo de las recomendadas, según perspectiva de los profesionales) y hallados objetivamente en el estudio de la OECD (2013).

Destacar que un 9\% de profesionales se declinaron por una metodología enfermera en vez de un modelo teórico. La causa de tal decisión se desconoce, la incógnita es si es que la prefieren para trabajar o es que confunden metodología y filosofía enfermera. En algunos de los comentarios trasluce la falta de tiempo para su práctica habitual y la escasez de personal que impide, según dicen, el trabajar bajo un modelo enfermero elemento igualmente recogido en otros estudios relacionados con esta temática (Lucero \& Guerrero, 2006; McKenna, 1990; Simpson \& Taylor, 2002). El hecho de que algunos profesionales utilizaran el cuestionario para expresar sus opiniones sobre circunstancias de otra índole, nos hace especular sobre la posible falta de comunicación entre asistenciales y gestores, para poder afrontar temas como el que se plantea, previamente es necesario remediar temas laborales prioritarios para los profesionales, cosa que también podría explicar 300 cuestionarios sin respuesta. Estudios de tópicos similares indican la alta relevancia para los profesionales del soporte y el compromiso de la empresa para poder implementar sistemas de cuidados basados en marcos conceptuales enfermeros (Simpson \& Taylor, 2002), hallazgos también obtenidos en el objetivo estudiado en esta tesis mediante técnica Delphi. 


\subsection{Discusión objetivo 3: Conocer las ventajas y}

\section{desventajas percibidas por los profesionales enfermeros sobre el uso del modelo teórico enfermero para el cuidado.}

Mediante el estudio de los trabajos de los alumnos de Máster de Ciencias de la Enfermería, se pudo evaluar el uso de un modelo teórico para el cuidado tras una reflexión profunda del mismo y partiendo de las propias experiencias en el cuidado de los profesionales en formación de Máster con una asignatura específica sobre este tema (Modelos y Teorias de Enfermería de 10 ECTS). Las teoristas utilizadas en los trabajos fueron elegidas libremente, este hecho pudo provocar que se asociara una mayor elección a aquellas teoristas que fueron más conocidas por los estudiantes. Por este hecho y los resultados obtenidos, podríamos generalizar que es el modelo de V. Henderson el más conocido entre los profesionales, ya que fue el que se eligió en mayor proporción. La causa sería la familiaridad con el mismo, ya que, es el modelo más usado en la mayoría de planes docentes de formación básica enfermera y en centros sanitarios que aplican teoría enfermera en su práctica a nivel nacional (Escuredo, 2003), tal y como ya se ha podido comprobar en objetivos previos de este estudio. Muy de cerca podríamos rebatir que además del modelo de V. Henderson, son las teorizadoras D. Orem, C. Roy y H. Peplau las más populares entre los estudiantes. Si estos resultados los comparamos con los hallados en la web también son los más nombrados en los planes de estudio y los más nombrados en su formación por los profesionales de la CSPT.

Los marcos teóricos usados en los trabajos, coinciden con los hallados en la revisión bibliográfica, exceptuando a Parse, que es un modelo utilizado como base empírica para el estudio de vivencias, pero no diseñado para una aplicación práctica en el Proceso de Atención de Enfermería, tal y como es analizado por Marriner y Raile (2003). Destacar que aparecen porcentajes elevados de elección de modelos que aparecieron en la revisión bibliográfica en los estudio de caso, como son los modelos de V. Henderson, C. Roy y J. Watson, modelos que tienen probada efectividad para ser aplicados en el contexto real del cuidado.

De 373 procesos enfermeros fueron excluidos un total de 124, la mayoría por falta de argumentación sobre la aplicación del modelo. Este hecho revela que la aplicación y reflexión sobre el marco de la profesión es un tema complejo, que ni tan siquiera es dominado por los profesionales que llevan tiempo en la práctica y que de entrada deberían ser competentes en, como mínimo, desarrollo de pensamiento reflexivo. Los conocimientos en filosofía son en muchas ocasiones conceptualizaciones abstractas en una profesión que tradicionalmente ha sido 
considerada una profesión técnica, sobre todo en nuestro entorno inmediato. Los modelos teóricos entraron en la formación universitaria en 1977, sin embargo no parecen haberse consolidado entre los profesionales en España por los resultados hallados en nuestro estudio.

Pese a que los estudiantes sugirieron numerosos lugares de aplicación de los modelos teóricos, la mayoría de recomendaciones carecían de reflexión, esto podría ser debido a una falta de comprensión real y profunda del modelo utilizado. Con todo, cabe subrayar que en la mayoría de lugares en los que no los advirtieron indicados, si que manifestaron los motivos por los que no se ajustaban a los mismos. Por lo que nuevamente podemos objetivar que existen mayores argumentaciones entorno a la poca aplicabilidad de un modelo teórico.

Las propiedades que más valoraron los profesionales como positivas en el uso de los modelos teóricos estuvieron asociadas a la claridad en el lenguaje, el bajo tiempo de implementación, la facilidad para realizar una completa valoración de la persona, familia o entorno, que fuesen generalizables, que describieran claramente la función de equilibrio entre la enfermera y el sujeto de cuidado, que fuesen aplicables en nuestro contexto o situación clínica abordada y que se adaptaran al proceso enfermero. Menos comentarios aparecieron sobre costo-efectividad, sobre la adecuación de su definición de salud, o su uso conjunto con la taxonomía NANDA. Estos aspectos deberían de ser evaluados en los lugares en los que se aplican modelos teóricos tanto en grandes poblaciones como en estudio de casos, tal y como impugna Griffith (1998) la credibilidad de un modelo conceptual se argumenta evaluando la utilidad, congruencia y significado social del mismo. Sin embargo no sucede así, ya que se constata un gran vacío de evaluación de la efectividad de los modelos en términos tangibles (en la revisión llevada a cabo en el último objetivo, ya se evidenció que sólo el 9\% de las publicaciones en relación al tema intentaban explicar la efectividad del modelo).

Si concretamos el análisis por teoristas, podemos apreciar que los modelos de V. Henderson y D. Orem recibieron críticas similares. Seguramente porque ambas comparten muchas similitudes conceptuales ya que, pertenecen a la escuela de las necesidades en la que principalmente la enfermera reemplaza a la persona un tiempo en diferentes actividades para recuperar su salud (Kérouac et al., 1996). Una orientación bastante similar al cuidado que da la enfermera actualmente en los hospitales. No obstante, en ambos casos predominó la crítica favorable. Aunque parece ser que, se centran más en el papel de la enfermera que en el del propio paciente.

El modelo de V. Henderson, modelo impulsado por el Consejo General de Enfermería Española, se aplicó mayormente en adultos, reconociendo su utilidad en ancianos. Fue consi- 
derado un modelo generalista, ya que lo creyeron adecuado para los casos planteados en muchos de los planes y en diversidad de situaciones de cuidado tanto agudas como crónicas. Aunque algunos estudiantes tildan de reduccionista su visión sobre la salud como sinónimo de independencia, advirtiendo una falta de espacio para el abordaje justamente del paciente crónico. Argumentaron la mayoría no ser un modelo adecuado para ser aplicado en unidades de salud mental debido a su orientación basada fundamentalmente en necesidades fisiológicas. Tampoco se recomendó en el cuidado del paciente crítico, ya que, requiere largo tiempo de implementación, tiempo del que se carece en las unidades en las que las decisiones se han de tomar en un tiempo finito, aunque algunos autores crean lo contrario (Avilés \& Soto, 2014). Hallazgos similares en cuanto a prolongados tiempos de implementación del modelo fueron hallados por Martínez, Cañadas, Rodríguez, \& García (2003), sobre todo en la valoración enfermera. Los estudiantes discuten una escasez en la valoración del entorno de la persona, siendo este aspecto imprescindible en la planificación del cuidado, de hecho es uno de los elementos principales del metaparadigma enfermero (Kérouac et al., 1996). Sin embargo no hacen alusión a tener dificultad para valorar la necesidad de creencias y valores, la necesidad de ocuparse y la necesidad de evitar peligros halladas en otros estudios (Martínez et al., 2003), quizás el mayor conocimiento del modelo ha facilitado este aspecto. En algún caso se argumentó su uso en pediatría, sin embargo no se recogió ningún trabajo que aplicara el modelo en ese ámbito. Discutieron que era un marco simple, que tiene en cuenta a la persona y a la familia en el cuidado, aunque le falta definir más claramente cómo proceder en el abordaje de la familia. Es un modelo que, según los estudiantes, fomenta la relación entre el equipo multidisciplinar, hecho importante para ser usado en el ámbito del cuidado donde diferentes disciplinas comparten objetivo común. Además ven de forma muy clara la aplicabilidad de la valoración tal y como la organiza la teorista, y que esta se adecúa de forma muy correcta para ser aplicado en el plan de cuidados de enfermería unido a taxonomía NANDA, tal y como ya hallaron otros autores (Roecklein, 2012; Silva, Alves, Macedo, Bezerra, Almeida, \& Chaves, 2013; Thoroddsen \& Thorsteinsson, 2002). No obstante, critican la poca apreciación que realiza el modelo a aspectos de perfil más psicológico. El modelo de V. Henderson es un modelo asociado a la curación de la enfermedad, un entorno relacionado con la visión biologista de la persona. De hecho, el momento en el que surge el modelo son los años 50-60' en los que imperaba esta visión de la salud - enfermedad (Marriner \& Raile, 2003). Esto puede haber sido el motivo de la controversia generada entre los estudiantes en relación al papel del paciente, algunos argumentaron un papel pasivo de la persona a la que se presta el cuidado, los que difirieron de esta visión seguramente están influenciados ya no por el propio modelo, sino por otros factores presentes en la actualidad del cuidado de la salud como es el empoderamiento 
del paciente hacia su propia autogestión, aunque no todas las enfermeras estén dispuestas a ceder parte del poder de decisión en el cuidado (Henderson, 2003). Otro dato importante a tener en cuenta es que hallan como factor determinante la facilidad de localizar documentación que clarifica el uso del modelo. Esto es así en bibliografía en castellano, ya que si lo comparamos con los artículos publicados en años recientes, es un modelo que aparece en muy pocas ocasiones en las bases internacionales. Autoras españolas como Luis et al. (2007) han realizado manuales actualizados en castellano para facilitar su uso. El conocimiento de las enfermeras en relación al inglés es limitado, y la mayoría de documentos científicos reconocidos se hallan en este idioma. La supremacía del inglés como lengua vehicular del conocimiento científico en ciencias de la salud, y más concretamente en enfermería ha suscitado más de un debate sobre el tema (S. R. López, Martínez \& Quesada, 2008), sin embargo se ha de reconocer su gran influencia al limitar muchos de los temas en los que las enfermeras de habla anglosajona lideran, como es el caso de la aplicación de los modelos teóricos que son en su mayoría productos estadounidenses.

El modelo de D. Orem fue elegido en planes de cuidados con pacientes más jóvenes y fue el segundo modelo más utilizado. La bibliografía hallada encuadra su uso en diferentes etapas etarias como ya se puede apreciar en los resultados del último objetivo. Realmente es un modelo que aparece también como redundante en la literatura de habla castellana al igual que ocurre con V. Henderson, existen algunos manuales de la autora traducidos al castellano, aunque quizás no están contextualizados ni actualizados a la práctica española (Campos, 1991; Orem, 1993) y por eso no sea un modelo tan aceptado. Las teorías de Orem fueron recomendadas en situaciones de cuidado agudas y crónicas, remarcando su utilidad sobre pacientes crónicos, tanto en atención comunitaria como en centros de larga estancia. La aplicabilidad del modelo en comunitaria ya ha sido probada en diversas ocasiones (Arlandis et al., 2008; Navarro \& Castro, 2010). Pese a que autoras como Pereda (2011) argumentan su utilidad en educación y promoción de la salud, los resultados hallados no apoyan tal beneficio, existe controversia en cuanto a su aplicabilidad sobre todo en cuanto a la promoción. Los estudiantes de Máster vieron además restringido el uso en pediatría por la falta de capacidad del niño para realizar el autocuidado, aunque uno de los casos planteados lo halló útil en el cuidado de un niño de dos años con fractura de fémur. No obstante, publicaciones recientes apoyan el uso del modelo en la etapa infantil, como el estudio de caso de Rodríguez-Sandoval, SolorzanoGarcía y Hernández-Cantoral (2013). Al igual que en el modelo de V. Henderson, los estudiantes desaconsejaron su uso en unidades de cuidado crítico y en salud mental por iguales motivos que argumentaron desaconsejar el modelo de Henderson (aunque hubo alguna ex- 
cepción en el tratamiento del paciente psicótico y en la atención al parto en urgencias). La mayoría de estudiantes asumen que la valoración se centra demasiado en la parte fisiológica, teniendo problemas para encasillar aspectos como la autoestima. No obstante, también hallaron inconvenientes para valorar aspectos físicos como el dolor o la higiene. En cuanto a la claridad ven al modelo como reiterativo, sobre todo en relación a sus conceptos. Incidieron en que permitía la colaboración del paciente en su cuidado, aunque justamente era una de las mayores críticas, ya que presuponen una falta de colaboración por aspectos de pasividad en la colaboración en el cuidado del paciente en nuestro entorno inmediato, los profesionales creen que el paciente está tradicionalmente poco acostumbrado a ser sujeto activo en el entorno hospitalario, visión contradictoria con las nuevas tendencias que impugnan el papel activo de los pacientes en su cuidado (González, Fabrellas, Agramunt, Rodríguez \& Grifell, 2008). Argumentan además, dificultad a ser aplicado en un paciente que no precise el sistema completamente o parcialmente compensatorio. Este fue el principal problema hallado al ser usado junto a los diagnósticos enfermeros de la NANDA, por su dificultad a aplicar los diagnósticos recogidos en la taxonomía asociados al déficit de autocuidado, aunque de forma general aceptaron que podría ser útil en el uso de taxonomía, hecho ya referenciado por otros autores (Becker, Teixeira \& Zanetti, 2008; Olivellas, Bastidas \& Castiblanco, 2010). Fue un modelo tildado de generalista, simple y adecuado a muchas de las situaciones presentadas. Ya existen evidencias de su uso en algunos hospitales españoles como el Hospital Universitario de Alicante $^{11}$ o el Hospital Ramón y Cajal de Madrid ${ }^{12}$, justamente este último centro argumenta haberlo elegido como modelo referente (junto al de V. Henderson) por ser el más conocido por los profesionales que en él trabajan y pensar que se adecua al contexto profesional. Otras referencias de su uso son en la elaboración de guías en atención primaria y hospitalaria (Ferrer, 2008; Simmons, 2009; Wilson \& Gramling, 2009). A nivel formativo se evidencia su uso también en diferentes publicaciones (Berbiglia, 2011; Fuentes et al., 2005). Aunque la mayoría de estudios argumentan sólo las bondades del modelo, existen algunos autores que argumentan que es un modelo efectivo, pero que no siempre cubre todas las necesidades de los pacientes cuidados y podría complementarse con la teoría de C. Roy (Wilson \& Gramling, 2009). Destacar que existen estudios desde hace años que ponen en evidencia que las enfermeras no recogen en sus registros temas psicosociales que se comentan durante el cambio de turno de enfer-

\footnotetext{
${ }^{11}$ Fuente: Guía validación de los planes de cuidados estandarizados proceso de validación teórica y clínica. Recuperado el 25 de julio, de: http://cuidados20.san.gva.es/documents/16605/18136/guiaPAE_enero2011.pdf

${ }^{12}$ Fuente: Web hospital Ramón y Cajal: http://www.madrid.org/cs/Satellite?cid=1142436194166\&language=es\&pagename=HospitalRamonCa jal\%2FPage\%2FHRYC_contenidoFinal
} 
mería, por decisión propia y no por carencia de valoración del modelo (en el estudio citado, concretamente en la aplicación del modelo de RLT y el de D. Orem), es decir, identifican problemas verbalmente que no quedan registrados (Griffith, 1998).

El modelo de C. Roy, es un modelo del que se ha trabajado profundamente en la literatura por autores colombianos, en cuyo país parece estar en boga (Gutiérrez, 2007), otros países como Brasil, Chile, Perú y México parecen seguir líneas teóricas similares (MorenoFergusson \& Alvarado-García, 2009). Quizás por este fácil acceso a literatura en castellano, fue otro de los modelos más usados en los trabajos, tanto en situaciones agudas (hospital) como crónicas (mayormente en enfermería comunitaria). No obstante, en el análisis de los planes de cuidados, se evidenciaron más comentarios desfavorables que positivos, hecho contradictorio cuando se revisa el uso el modelo a nivel internacional que aparece a la inversa (tal y como se evidenció en el último objetivo de nuestro estudio). Los estudiantes hicieron inciso en que debía ser aplicado sobre todo en aquellas situaciones que requerían una adaptación de la persona a una nueva situación de salud. Fue uno de los modelos más aconsejados para ser usados en maternidad justamente por el proceso de adaptación que requiere el núcleo familiar ante la llegada de un nuevo miembro. También se recomendó su uso en el abordaje de los cuidadores, experiencias previas en este uso se hallan en Latinoamérica que ya habían sido anteriormente documentadas tal y como señala la revisión de Moreno-Fergusson y Alvarado-García (2009). Al igual que en los modelos anteriormente examinados, objetan inadecuación de su uso en el abordaje de pacientes en situación crítica. El modelo fue calificado de claro, simple y general. Elogiaron por encima de todo el papel que la teorista da al entorno y en la mayoría de los casos, el papel protagonista de la persona en el cuidado, así como la facilidad de elaborar diagnósticos enfermeros tras la valoración de estímulos propuesta por la teorista. Entre los aspectos negativos del modelo, lo vieron reiterativo, con subjetividad en la valoración excesivamente larga y compleja, sobre todo en el momento de identificar y catalogar los estímulos, por lo que el pragmatismo de las enfermeras hizo que lo viesen como poco ventajoso y demasiado teórico. Sin embargo, se han hallado bondades sobre el modelo en la literatura como es el caso del estudio de Villagomez y Jiménez (2011) que pusieron de manifiesto que la implementación del registro clínico de enfermería basado en el Modelo de Adaptación de Roy representó un aumento en el nivel de satisfacción del paciente hospitalizado. Los estudiantes, criticaron del modelo que tenía una visión biomédica que simplificaba la salud a una conducta, siendo muy difícil de aplicar en situaciones en las que el paciente presenta problemas de comunicación. Al igual que en el caso de los anteriores se hallan documentos que argumentan que el modelo es útil para ser usado con la clasificación de diagnósticos NANDA, (Riffo \& Sala- 
zar, 2008), aunque algún estudiante indicó lo contrario en su reflexión, diciendo que el lenguaje usado en el modelo impedía el uso de diagnósticos.

Por otro lado, las indicaciones de uso del modelo de $\mathrm{H}$. Peplau fueron poco argumentadas. Fue recomendado en situaciones agudas y crónicas, aconsejado sobre todo en procesos de salud mental, tal y como ya se argumenta en diferentes publicaciones (Merritt \& Procter, 2010). También se recomienda su uso en unidades de larga estancia como residencias, aunque vieron limitado su uso en situaciones en las existe poca colaboración del paciente o deterioro de la comunicación. Todo ello por la gran importancia que da el modelo a las relaciones interpersonales y al papel activo del paciente (Marriner \& Raile, 2003). Justamente lo hallaron adecuado a los casos planteados, en los que la relación interpersonal era el eje de la atención, ya que eran pacientes con enfermedades que sobrellevaban elevada carga emocional, bien por riesgo vital, como por acompañamiento a familiares, como por duelos, o por pérdidas de miembros corporales. Curiosamente tampoco vieron indicado su uso en situaciones de urgencia, cuando en esas situaciones el componente de ansiedad ante la situación crítica se halla incrementado tanto en el propio paciente como en la familia. Tal vez podría ser de utilidad si se maneja unido a algún otro modelo de orden más biologista como argumentó alguno de los profesionales, ya que, una de las principales desventajas que evidencian del modelo es la escasa evaluación biológica (no tiene guía de valoración explícita); por lo que alguno de los estudiantes lo vio poco resolutivo en procesos terminales o en pacientes que requerían de cuidados físicos además del cuidado psicológico. En línea a la argumentación de los estudiantes, en la literatura consultada se hallaron estudios que evidenciaron el éxito del uso del modelo para la elaboración de guías de acogida en situaciones críticas como en cuidados intensivos (Torrents, Oliva, Saucedo, Surroca \& Jover, 2003) y la indagación emocional en la atención urgente extrahospitalaria como indica Berntsson \& Hildingh (2012); situaciones en las que es importante la relación de ayuda. En cuanto a aspectos negativos destacaron los estudiantes de Máster que requiere de grandes habilidades interpersonales en la enfermera comprendiendo una sobrecarga emocional del profesional. Este hecho queda poco argumentado por el uso del modelo, la sobrecarga emocional de la enfermera va más en consonancia con otros factores de orden tanto interno como externo a los profesionales (Oh \& Gastmans, 2013).

El modelo de B. Neuman se recomendó en hospitalización, atención comunitaria (ámbito muy argumentado por la utilidad del modelo en la prevención) y centros de larga estancia. Así como para el abordaje de cuidadores no profesionales y procesos de duelo. Lo vieron generalizable y lo hallaron útil en los casos planteados. Destacaron el abordaje que 
hacia el modelo del paciente como eje central, la familia y los aspectos preventivos abordados. Respecto a la claridad, destacar que lo señalan de complejo en su lenguaje, con dificultad para la valoración física por el formato de valoración que usa el modelo. Dato que podría reflejar poco conocimiento del mismo, ya que existe una amplia experiencia en elaboración de guías de uso y herramientas prácticas de valoración basadas en el modelo (Fawcett \& DesantoMadeya, 2005), pero no se han hallado estudios que las hayan traducido al castellano. Al igual que otros modelos, se vieron problemas para ser implementado en personas con deterioro de la comunicación y los estudiantes argumentaron que su uso incrementaría el tiempo del cuidado y acomplejaría los registros actuales.

En cuanto a la teoría de I. King, se hicieron pocas recomendaciones de uso. Seguramente por el desconocimiento del modelo. Pese a que plantearon sus trabajos bajo el modelo, esta primera aproximación quizás fue insuficiente e incompleta para la comprensión profunda del mismo. Creyeron que era un modelo claro y sencillo, que evidencia de forma clara el rol de la enfermera. Concluyeron que era adecuado a los casos planteados y por lo tanto general. Destacan el papel que da al individuo como un igual, su valoración psicosocial y la amplia valoración del entorno. Como el resto de modelos, se halla complejidad si el paciente a cuidar padece algún trastorno de comunicación. Estos datos ya fueron hallados por Moreira y Araújo (2002), que además de exaltar el gran rango de amplitud de aplicación, sobre todo en pacientes con patología crónica; criticaron hasta qué punto podrían ser responsables de las propias decisiones sobre tratamiento, siendo justamente este poder de decisión uno de los beneficios mejor valorados de la teoría. Sin embargo estos autores no hicieron alusión a la apreciación recogida de los estudiantes de Máster sobre la percepción de carencia de valoración física y largo tiempo de implementación.

El modelo de M. Leininger, fue recomendado en atención primaria, salud mental y en el abordaje de personas de diferentes culturas a las mayoritarias en una región. Como aspectos positivos argumentan claridad, sencillez y simplicidad, aunque algunos estudiantes encontraron una falta de concreción para ser aplicado. Comentaron que clarificaba el rol enfermero y destacaron la importancia que da el modelo para entender el cuidado desde la perspectiva propia del paciente, adjudicándole al mismo un papel relevante. Aun así remarcar que no siempre fue resolutivo en los casos planteados. Los propios estudiantes hicieron hincapié que aunque por las situaciones planteadas a priori el modelo debía ser de utilidad por el reconocimiento cultural, justamente fue una barrera para la valoración de aspectos más básicos de la persona en relación a valoración de aspectos de orden biofísico. También lo tildaron de larga cumplimentación y no lo vieron muy adecuado para ser usado con el PAE. Comenta- 
ron que lo creían más útil para el estudio de grupos culturales, más que para el estudio de un caso concreto. De hecho esto es muy coherente con las publicaciones halladas que usan el modelo justamente para el estudio de grupos culturales específicos (Wagner, 2009; Woerner et al.,2009).

Los hallazgos encontrados para dar respuesta al objetivo sobre ventajas y desventajas percibidas por los profesionales enfermeros sobre el uso del modelo teórico enfermero para el cuidado, nos llevan a concluir que en una práctica donde la patología o especialidad médica ha sido mayormente la forma de agrupar las formas de cuidado de las personas en los centros sanitarios el modelo no puede ser generalizable a todo tipo de pacientes. Ni tan sólo a pacientes que padecen la misma patología, ya que la forma de vivir la enfermedad es única y propia de cada persona y esto dificulta la aplicación del mismo modelo de forma sistemática y por ello es uno de los factores principales que ha impedido el desarrollo de los mismos en la práctica. Esto podría ser parcialmente tratado (como ya se comentó anteriormente) con el desarrollo de teorías de rango intermedio aclimatadas a nuestro porpio contexto sanitario, porque se enfocan en una dimensión específica de la realidad, tienen un número restringido de conceptos, y son de gran utilidad para comprender y estudiar los fenómenos derivados de la práctica (Moreno-Ferguson, 2012).

\subsection{Discusión objetivo 4: Identificar los elementos que han influenciado el uso teórico y desarrollo profesional de la enfermería en España desde la perspectiva de las enfermeras} en periodo de formación de Máster

Las perspectiva de las enfermeras que cursaban el Máster en Ciencias de la Enfermería en relación al uso y desarrollo teórico y profesional fueron diversas. Sin embargo, se recogen elementos que ya redundan en la literatura como influyentes en los avances profesionales y muy ligados a la aplicación de modelos teóricos, ya que, justamente la aplicación de marcos conceptuales propios es lo que propició el desarrollo de la disciplina como profesión; entendiendo el término profesión como una "ocupación que monopoliza una serie de actividades sobre la base de un conocimiento" (J. Fernández, 2001).

La mayoría de los textos analizados, respondieron a las preguntas realizadas. Curiosamente al analizar barreras y facilitadores, hubo factores que funcionaron en ambos sentidos. 
Pese a que se formularon ambas preguntas a los estudiantes, se recogieron un número superior de trabajos sobre barreras que sobre elementos facilitadores. Esto ya sucede en otros trabajos que estudian temas similares sobre la influencia de factores en el trabajo enfermero (Sangster-Gormley, Martin-Misener, Downe-Wamboldt \& DiCenso, 2011). Podría existir un posible fundamento en este decante numérico por las barreras, las enfermeras ven todavía muchos obstáculos a su trabajo diario, y pese a estar la profesión consolidada entre el colectivo enfermero, ven otros factores en su entorno que no dejan desarrollar la disciplina en toda su potencialidad. Sin embargo, la profesión debería transformarse en una fuerza cada vez más potente y relevante en los resultados en la salud de las personas y siguiendo las recomendaciones de Comités internacionales practicar la totalidad de su enseñanza y formación; es decir, utilizar todas las competencias enfermeras actuales (Institut of Medicine, 2011).

Las enfermeras en nuestro estudio siguen argumentando que los centros sanitarios no facilitan el desarrollo profesional, resultados hallados por otros autores nacionales que muestran que sólo el $31,6 \%$ de las enfermeras se muestran satisfechas con las oportunidades de desarrollo profesional en sus centros (Instituto de Salud Carlos III, 2011). Aspectos como la falta de proyectos propios, poco apoyo al colectivo, la estructura de las instituciones en relación al abordaje de la patología y la rigidez de funcionamiento basada en el trabajo tradicional no lo posibilitan. Además de la desaprobación sobre escasez de recursos, evidenciado también por la Organisation for Economic Cooperation and Development (OECD) que comparando diferentes indicadores de salud entre 34 países, hallaron que aunque en España la ratio enfermera paciente ha aumentado (5,5 por cada 1000 habitantes), aún está por debajo de la media de 8,8 por 1000 habitantes (OECD, 2013). Quizás, como indica Durán (2007), porque Enfermería ha estado demasiado preocupada siempre de llenar el régimen de prescripción médica y esto ha hecho que tanto la modalidad curricular como los contenidos los de los programas docentes de las asignaturas, se basen en áreas de especialización médica. Factores condicionantes similares a los nuestros hallaron en su estudio canadiense los autores Oelke et al., (2008), que revelaron diversos elementos a trabajar para la optimización del rol enfermero, como elevada carga de trabajo, alta gravedad del paciente, falta de tiempo, falta de comunicación e ineficaz trabajo en equipo. Facilitadores identificados por los autores fueron el trabajo en equipo, la gestión y el liderazgo, el soporte y apoyo a la formación continua. Estos elementos han sido similares a nuestros hallazgos y son relevantes si pensamos que las enfermeras son el colectivo de mayor porcentaje en los centros sanitarios y deberían ser el eje vertebrador de las instituciones. Pese a que en España no ha sucedido que un centro sanitario demuestre mejoras en resultados en salud relacionados con el rol del enfermero en la calidad del cuidado del pacien- 
te, liderazgo, toma de decisiones, reclutamiento del mismo... si ha sido demostrado en los hospitales magnéticos sitiados mayormente en EE.UU (Lake, Shang, Klaus \& Dunton, 2010). Aunque algunos estudios como el de Goode, Blegen, Park, Vaughn y Spetz (2011) no hallaron estas mejoras, las políticas sanitarias deberían dirigirse en ese sentido para visibilizar y prestigiar el trabajo enfermero. Cuando la dotación de personal de Enfermería aumenta, el riesgo de complicaciones intrahospitalarias del paciente y la duración de la estancia hospitalaria disminuyen, lo que da como resultado el ahorro de costos médicos, la mejora de la productividad nacional y un aumento de la seguridad en los pacientes (Dall, ChenSeifert, Maddox \& Hogan, 2009). Así como, disminuye la probabilidad de muerte de los pacientes sometidos a cirugía (Aiken et al., 2014). Datos importantes a trabajar cuando la situacion nacional de crisis precisa de enfoques creativos para mantener los costos de atención eficaz al paciente (Zabalegui \& Cabrera, 2010).

Otro de los hechos negativos identificados por los encuestados para el desarrollo es la propia formación profesional. La hegemonía de la medicina sobre la formación enfermera de hace unos años y la falta de homogeneización de los títulos para ejercer la profesión afectaron el avance. Destacar que actualmente se había mejorado este hecho, sin embargo, la entrada al Espacio Europeo de Educación Superior y la Ley de Ordenación Universitaria está provocando dos hechos relevantes contradictorios. Por un lado mejora la formación como profesión permitiendo el desarrollo de la carrera profesional hasta el mayor grado académico. Pero por otro, se solicita que los profesores universitarios sean doctores en un plazo temporal limitado, esto provoca que nuevamente sean profesionales de otras disciplinas los que opten de forma aventajada a los puestos en la formación; debido a que la consecución del doctorado en las enfermeras es posterior al de otras profesiones en las que el doctorado formaba parte de la carrera profesional desde hace años (Doltra, 2012). Resultados similares respecto al tema se han hallado en el estudio RN4Cast que revela que sólo el 46,2\% de las enfermeras están satisfechas con las oportunidades de formación y el $46,6 \%$ con los permisos por estudios en sus centros; es decir menos de la mitad de los profesionales (Instituto de Salud Carlos III, 2011). Todo ello cuando existen estudios que revelan que una mayor formación del personal incrementan los resultados positivos en el paciente (Aiken et al., 2011; Aiken et al., 2014; Kane, Shamliyan, Mueller, Duval \& Wilt, 2007).

Elementos también a trabajar actualmente según las enfermeras, son la concepción de la enfermera a nivel social. El hecho de ser una profesión femenina (aunque en proceso de cambio ya que los estudiantes masculinos actualmente alcanzan el $20 \%$ ), la imagen histórico social subordinada al poder médico o la imagen sexual que aportan series televisivas o promo- 
ciones publicitarias; no favorecen ese reconocimiento como profesión (Heierle, 2009). Aunque ya hay muchos profesionales de los encuestados que creen que se está emprendiendo un cambio en esta concepción de los pacientes sobre el trabajo enfermero. Quizás los profesionales que mantienen esta posición, pertenezcan a campos laborales en los que las enfermeras desempeñan un mayor rol autónomo debido a nuevas necesidades poblacionales, como es el caso de consultas de atención comunitaria, la educación para la salud, etc. Apoyado por políticas de carácter más universal por entidades como la Organización Mundial de la Salud. Cierto es, que las enfermeras, tal y como se recoge en los textos, no siempre han desarrollado actitudes que facilitaran el desarrollo.

Los estudiantes de Máster en Ciencias de la Enfermería, basados en sus propias experiencias, constatan falta de unión y apoyo entre los profesionales, conformidad, baja motivación, poco compromiso, falta de liderazgo... entre otros aspectos como elementos impedidores, elementos estudiados por algunas investigaciones como factores influyentes en el clima laboral (L. Pérez, Soler \& Díaz, 2009). Posiblemente, como ya se recoge en alguno de los trabajos, desde la formación universitaria serán elementos a trabajar profundamente para hacer que estos aspectos se vayan diluyendo en el tiempo y sean sustituidos por valores más acordes a la capacidad profesional. Los estudiantes de este Máster argumentaron capacidades profesionales que facilitan el desarrollo como son empatía, asertividad, capacidad de observación y reflexión, además de la motivación entre otras; por lo que estos son los elementos a consolidar. No obstante resaltar que curiosamente aparece como elemento facilitador todavía la vocación. Son todavía muchos los profesionales los que ven enfermería como una vocación (Santos et al., 2008b), seguramente como bien indica White (2002), Enfermería era una vocación precisamente porque el carácter de la enfermera que se identificó como femenino y maternal. Sin embargo, el modelo profesional de Enfermería puede actualmente separarse conceptualmente de su identificación con estos ideales. Siendo el trabajo de la disciplina conseguir la identificación con el sentido moral y social que le dan su condición científico profesional.

Justamente dentro del rol profesional los estudiantes hacen alusión directa a la importancia de aplicar marcos conceptuales propios unidos a la investigación para visibilizar y demostrar nuestra aportación a la salud profesional, por lo tanto queda argumentada también en los estudiantes la relación simbiótica entre ambos términos planteada al inicio del estudio, un desarrollo profesional no se entiende sin el desarrollo de un cuerpo disciplinar propio; los elementos que afectan a un término, afectarán de forma directa o indirecta al otro. 


\subsection{Discusión objetivo 5: Determinar los elementos que han facilitado y los que han impedido el uso y desarrollo de modelos teóricos en la práctica española desde la perspectiva de enfermeras gestoras y docentes.}

Un vez analizados los elementos facilitadores y barrera en los estudiantes, se indagó sobre la relevancia que tenían estos elementos en los profesionales quizás más influyentes en el desarrollo del marco teórico, concretando solamente en este hecho. De entrada no se predeterminaron para los profesionales las categorías halladas entre los estudiantes para conocer si los expertos coincidirían en los elementos hallados inicialmente por los estudiantes. El porcentaje de respuesta hallado fue bueno una vez los expertos aceptaron formar parte del estudio. De entrada podríamos decir que eran personas sensibles al tema. La mayoría poseían un título universitario superior al Diplomado de Enfermería, esto podría garantizar gran capacidad de reflexión y crítica otorgada por la consecución de una formación más avanzada. Además fueron representativos de la práctica enfermera española ya que provenían de diferentes comunidades autónomas.

Al igual que ocurrió con los estudiantes de Máster, los profesionales enviaron un mayor número de comentarios relacionados con elementos barrera que en relación a elementos facilitadores, similar a los hallazgos de Sangster-Gormley et al. (2011).

En relación a factores que facilitan el uso y desarrollo de modelos teóricos en la práctica española, aparecen reiteradamente en el estudio Delphi, elementos ya identificados por los estudiantes de Máster: la necesidad de gestión enfermera de los centros laborales, la motivación de los profesionales, la autonomía profesional, el pensamiento crítico o reflexivo de los profesionales, la gestión de los centros sanitarios y el uso de metodología enfermera. Factores ampliamente relacionados en la literatura con el aumento de satisfacción laboral (Aiken et al., 2013; Instituto de Salud Carlos III, 2011). La investigación es otro de los elementos relevantes, tema de gran interés para los enfermeros en el que desean participar activamente (Edward \& Mills, 2013). Se objetivan otros factores relevantes como el carácter profesional en cuanto a la creencia de la necesidad de la aplicación de modelos teóricos para diferenciar nuestro trabajo del de otros profesionales de la salud, el compromiso como disciplina, el liderazgo y la infor- 
matización de los planes de cuidados. El liderazgo y el apoyo a las enfermeras por parte de las direcciones de enfermería entre otros, son elementos relacionados con mejores resultados en los hospitales magnéticos (Salmond, Begley, Brennan\& Saimbert, 2009). Sin embargo no aparecen términos como vocación, género, reconocimiento social o políticas estatales, quizás porque son elementos sociales influyentes más en la historia de la disciplina profesional, que en el propio desarrollo teórico. Aunque Meleis (2011) indica que son herencias que han influido también en el progreso del pensamiento enfermero, ya que fueron valores inculcados en la educación enfermera.

La aplicación de metodología, según los profesionales, fue un impulso para el uso de los modelos teóricos, aunque como se objetivaron en los resultados del objetivo relacionado con los trabajos de Máster, algunos modelos tenían problemas para ser utilizados junto a los diagnósticos de taxonomía NANDA, por lo que es de suponer y viendo la bibliografía sobre el tema, los profesionales hablarán de aplicación de modelos centrándose únicamente en los de uso común y conocido en España como son V. Henderson, D. Orem y C. Roy que parece ser que si se adecuan a ser usados unidos a metodología enfermera. Sobre todo el modelo de V. Henderson del que ya se ha comentado durante la discusión ha sido usado de forma continuada junto a lenguaje NANDA, NIC y NOC (Luis et al., 2007). Estos lenguajes podrían encorsetar una práctica centrada en las necesidades individuales de los pacientes, tal y como indica Francisco (2008) en muchas ocasiones la persona es considera una entidad patológica provocando su pérdida de singularidad. Por otro lado, estos elementos metodológicos fueron impulsados por el Consejo General de Enfermería de España (Rivero et al., 2002) y por las escuelas universitarias de Enfermería españolas e industria tecnológica que crea y fomenta el programa informático GACELA. La cuestión principal sería conocer si se hizo un análisis internacional de necesidades o bien se partió desde el punto de vista de las necesidades del paciente en nuestro contexto y realidad actual. La respuesta nos podría orientar en el conocimiento de adecuación de su uso, no obstante no se ha hallado en la literatura la respuesta ante tal pregunta.

Otros de los factores también redundantes han sido los relacionados con la formación, como la incorporación de los modelos teóricos en la formación universitaria y el desarrollo de titulaciones de postgrado; factores a tener en cuenta si se desea aumentar el beneficio en los resultados del paciente (Aiken et al., 2011). La cimientación del cuidado en Fundamentos de Enfermería es un factor reconocido como precursor de la calidad en los cuidados (Salmond et al., 2009). Las titulaciones de postgrado, los nuevos planes de estudio y la divulgación en la formación de los modelos son favorecedores de su uso. Esto va muy en línea a la hegemonía 
del modelo de V. Henderson, que es el más usado en las universidades (tal y como se aprecia en los planes de estudio), centros sanitarios y publicaciones nacionales. Así como, es el modelo mayormente elegido tanto para elaborar los trabajos de Máster como vimos, como para ser usado en la práctica implícitamente como se observó en la elección de profesionales y estudiantes en el segundo objetivo sobre el uso de modelos no institucionalizados. Por ello podemos afirmar que aplicar modelos teóricos que no hayan sido desarrollados durante la formación no es tarea fácil. Quizás las enfermeras tienen poco interés en la Filosofía, ya que de entrada es una profesión bastante práctica y técnica. A esto se le une, según los encuestados, la falta de dominio de otros idiomas, que limita el uso de los modelos a sólo aquellos que han sido traducidos ampliamente al castellano. Provocando el dogmatismo profesional por un único modelo teórico, anulando el potencial de otros modelos que podrían ser más resolutivos en determinadas ocasiones, e incluso abortando posibles modelos elaborados ad hoc para los centros asistenciales, que sólo pueden ser desarrollados por personas con un conocimiento profundo del funcionamiento de la estructura filosófica de conocimiento enfermero. Por ello, se produce una dicotomía significativa, por un lado, los profesionales que desarrollan la teoría enfermera son del mundo académico y por otro, las personas que los han de usar en su día a día desconocen en profundidad el funcionamiento filosófico. Esto debería traducirse en la alianza de ambos esfuerzos con la meta de debatir y elaborar una forma de trabajo que dé respuesta a la necesidad de los sujetos cuidados con el beneplácito de las personas que prestan el cuidado y sustentado en base científica.

El argumento del uso de modelos también se basa en la necesidad de visibilizar el producto enfermero según los profesionales, que no queda definido únicamente por la patología médica (López et al, 2006). Actualmente el modelo de cuidado, tal y como ya se ha comentado en diversas ocasiones, está centrado fundamentalmente en la enfermedad, y deja poco lugar para dimensiones sociales, psicológicas, culturales y espirituales de la salud (Zabalegui, 2003). Sin embargo, los ratios enfermeros en las unidades de trabajo siguen regidos por la asignación de número de camas por enfermera pese a existir herramientas que miden la actividad enfermera (Subirana \& Solà, 2006); no teniéndose en cuenta en la mayoría de las veces, la complejidad de cada una de las respuestas de los pacientes a su situación de salud, es decir, a la necesidad de cuidados individual. Quizás la aplicación de métodos individuales de gestión del cuidado como los modelos teóricos podría dar solución a este tema. No obstante, las enfermeras los ven poco prácticos (M.E. Moreno, 2005), sobre todo en entornos en los que los días de estancia son breves y no permiten desarrollar la filosofía teórica en todo su conjunto (Juan et al., 2010). 
La posición de docentes y gestores en el tema parece algo más bucólica que la propia de los profesionales asistenciales, quizás porque los asistenciales son más pragmáticos, realmente son los que ejercen el cuidado directo y son capaces de objetivar de forma adecuada los problemas que conlleva la aplicación de modelos. Justamente es esta la crítica que realizan sobre los enfermeros en general, los expertos encuestados creen que elementos como el pragmatismo, falta de reflexión, falta de utilidad y formación de los enfermeros asistenciales han impedido el desarrollo teórico en la práctica, unido a que las enfermeras recién tituladas no integran en la asistencia las aportaciones formativas recientes. Esto va muy ligado a lo que los propios encuestados creen en relación a la brecha teórico - práctica, que ven a la élite académica lejos del mundo profesional. No obstante, bien es cierto que el dominio de los modelos teóricos también es dispar en el mundo académico; no todos los profesores los dominan en la misma intensidad, por este tema, son relegados a unas asignaturas más filosóficas en el primer curso de la formación y no se retoman en años posteriores de la formación pregrado, haciendo que los propios estudiantes no exalten la filosofía como parte de su identidad disciplinar.

Otros de los elementos redundantes son el apoyo directivo enfermero al desarrollo de teoría, el auge de la investigación enfermera (mayor difusión de prácticas de diferentes centros) y la informatización que obliga a contextualizar la práctica enfermera. Aunque esta misma informatización es vista como una barrera cuando prima el registro de la actividad sobre la realización de la misma, la amplia documentación empleada para el desarrollo implica un elevado gasto de tiempo, limitado en las unidades de trabajo. Las enfermeras cada día y con mayor frecuencia desarrollan actividades de tipo administrativo, que llenan la mayor parte de su tiempo de trabajo para garantizar el cumplimiento de los procesos de normalización y estandarización (Ausserhofer et al., 2014). Esto ha provocado que en muchas instituciones se haya delegado en el personal auxiliar muchos de los cuidados directos. Tal y como argumenta M. E. Moreno (2005) la falta de oportunidades para el cuidado empobrece el desarrollo disciplinar. Los modelos no se interiorizan, sino se sirven de su lenguaje para formular registros que serán implementados sin que los propios profesionales tengan integrada la filosofía del modelo.

Entre los factores importantes hallados, es el hacer partícipe a los profesionales de la elección de un modelo, por lo que reaparecen como impedimentos la falta de liderazgo como colectivo, la falta de autoestima profesional y el poder de la clase médica sobre la enfermera. Aun así creen que los modelos teóricos son difíciles de usar per se, ya que, su lenguaje en ocasiones es complejo, poco comprensible y limitado al uso de la disciplina enfermera, hallazgos 
ya evidenciado por otros autores como Meleis (2011) que incluso tacha el lenguaje de algunos modelos como esotérico y que encorsetan la práctica por su rigidez en muchas ocasiones. Esto se suma a la falta de modelos creados por y para nuestro contexto inmediato. Comentan que los modelos deberían ser usados en función de las necesidades del paciente, no obstante existe tal número, que impide el conocimiento profundo de todos ellos por las enfermeras. Además, los profesionales critican la falta de estudios que evidencien efectividad explicita de los modelos en la práctica clínica.

Meleis (2011) reconoce en su obra cinco factores que son determinantes de la aplicación de teoría: las barreras humanas (las enfermeras por ser enfermeras y mujeres y los valores tradicionalmente asociados a este estereotipo), las propias teoristas en un nivel de abstracción diferente a la práctica, el conocimiento de otras disciplinas como mejor valorado, bloqueos conceptuales de las enfermeras y la investigación empresarial; elementos que también han sido hallados en nuestra investigación. Meleis (2011) ya indicó que para el desarrollo de teoría se requiere pensamiento, reflexión, cuestionamiento y sobre todo la percepción de la propia persona como ser un profesional capaz de desarrollar conocimiento, o lo que es lo mismo, la propia creencia profesional. Del mismo modo factores en relación a los propios enfermeros vistos como barrera, van en relación al pragmatismo y falta de utilidad por parte de los profesionales, el reconocimiento de la utilidad de los mismos y el propio desinterés profesional. Curiosamente elementos que tradicionalmente están en el discurso de las enfermeras como el poder de la clase médica, la estructura de las organizaciones o la falta de recursos humanos (M. López et al., 2006; Maben et al., 2006) aunque considerados, fueron factores poco puntuados en su influencia. Por lo que podríamos aseverar que según los gestores y profesores universitarios, los factores evaluados como más influyentes en la aplicación de modelos teóricos en la práctica española se relacionan sobre todo con aspectos relacionados con el propio perfil como colectivo.

La mayor parte de los elementos facilitadores identificados de la práctica enfermera basada en modelos teóricos y el desarrollo profesional a los que hicieron referencia tanto profesionales asistenciales (en el cuarto objetivo) como gestoras y docentes (en el quinto), coinciden con las 14 fuerzas del magnetismo que ejercen los hospitales imán que crean entornos de trabajo más óptimos, obteniendo un mayor compromiso profesional (Salmond et al., 2009). Estos factores quedan recogidos por la American Nurses Credentialing Center (ANCC) ${ }^{13}$. Entre los elementos hallados en nuestro estudio y las fuerzas descritas coinciden, la formación

${ }^{13}$ Extraído de: http://www.nursecredentialing.org/Magnet.aspx 
de las enfermeras para el fomento del desarrollo profesional, el liderazgo de calidad en enfermería como soporte al personal, así como elementos la rigidez de la estructura organizacional de los centros, la importancia del apoyo directivo enfermero y reconocimiento del valor enfermero en las unidades y centros de trabajo (salario, beneficios, oportunidades de crecimiento personal, etc.).

Igualmente identifican como positivos los modelos profesionales de atención que ceden autonomía a las enfermeras, las relaciones interdisciplinares y la imagen de la enfermera como profesional esencial. Por este motivo, el compromiso por parte de instituciones y direcciones enfermeras de impulsar estos elementos reconocidos como garantes de aplicación de modelos enfermeros en la práctica no sólo redundaría en este tema, sino que podría garantizar unos mejores resultados en el paciente, tal y como se reconoce en diversos estudios que analizan el efecto de estos elementos sobre los beneficios sobre pacientes y enfermeras (Salmond et al., 2009).

\subsection{Discusión objetivo 6: Describir el nivel de implantación}

\section{de modelos enfermeros en la práctica actual a nivel}

\section{internacional}

A nivel internacional, se recogieron diferentes experiencias en cuanto al uso de los modelos, con el fin de determinar que ocurría con la aplicación de teoría enfermera a nivel internacional, se consultó la bibliografía en búsqueda de estas experiencias particulares. Fueron pocos los estudios hallados que se preocuparan por recoger de forma agrupada tal temática, no sólo a nivel internacional, sino también a nivel nacional (Bond et al., 2011; Richart et al., 1999). De hecho en algunas ocasiones los análisis realizados sobre la literatura científica, no se realizan de forma general en todas las revistas enfermeras, sino se limitan al estudio de un pequeño número de publicaciones como es el caso del estudio de Bond et al. (2011). No obstante, cuando concretamos por teoristas, se hallan estudios sobre revisión de la aplicación concreta de un modelo, como por ejemplo del modelo de C. Roy (Dobratz, 2008), de M. Rogers (Tae Sook, 2008) o D. Orem (Raimondo, Fegadoli, Méier, Wall, Labronici, \& Raimondo-Ferraz, 2012). Incluso se ha podido objetivar que se revisan las aplicaciones de los mismos en situaciones concretas de salud, como es el caso del modelo de C. Roy en la aplicación universitaria (M. 
E. Moreno, Durán \& Hernández, 2009) o el de D. Orem en los pacientes en tratamiento de hemodiálisis o en terapia de quemados (Simons, 2009; Wilson \& Gramling, 2009).

Es obvio, que no siempre es fácil ubicar el problema que se indaga dentro de un marco teórico enfermero, no obstante este proceso resulta propicio para el avance de la ciencia enfermera. Este hecho parecería reafirmado al haber hallado un total de 280 artículos que nombran algún modelo teórico (de los más conocidos internacionalmente) en las publicaciones de estos últimos 5 años en Pubmed en la revisión realizada por nuestro estudio. No obstante, cuando se investiga de forma profunda el tema podemos ver que, pese a que son nombrados en casi la mitad de los trabajos empíricos (en el 46,2\%), sólo son utilizados sucintamente un pequeño número en la aplicación y evaluación directa de los mismos (sólo en el 9,3\% de los casos evalúan su aplicación y eficacia). Si presumimos que, el aumento de la adopción teórica en la investigación es un indicador de que los profesionales enfermeros están construyendo conocimiento científico de disciplina enfermera para mejorar la práctica de enfermería (Bond et al., 2011); según los resultados obtenidos, nos hallamos en un panorama de aplicación directa de modelos limitado. Quizás el uso de los modelos en la aplicación directa está siendo limitado por la crisis económica actual (Dávila \& González, 2009), ya que no parecen haber demostrado su eficacia a nivel de costos. Pero no solamente en cuanto al uso directo en el cuidado, sino también en la aplicación de los mismos en las investigaciones enfermeras. Tal vez los profesionales no los encuentran útiles para enmarcar sus investigaciones (sólo se hallaron los modelos teóricos estudiados en un 1,4\% de artículos indexados como de investigación enfermera). Aunque existen recomendaciones sólidas derivadas de investigaciones como las de A. L. López y Guerrero (2006), que aseveran que la teoría enfermera es útil tanto para la investigación como para la práctica.

La revista Nursing Science Quarterly (NSQ) es la que aglutina el mayor porcentaje de artículos sobre la temática (38,6\% de los hallados). Esta revista es de las pocas revistas dedicadas exclusivamente a la mejora del conocimiento conceptual de enfermería. Publica manuscritos originales centrados en el desarrollo y la práctica basada en la Teoría de Enfermería y la investigación cuantitativa y cualitativa, en relación con los marcos de Enfermería existentes aportados por los principales teóricos, investigadores y directores de enfermería. Los modelos usados en sus publicaciones, en general son los tradicionalmente usados en las investigaciones. Sin embargo, se hallan (aunque en poca proporción), modelos como el de H. Peplau, V. Henderson, I. Orlando, RLT, D. Johnson y L. Hall que no son reconocidos cotidianamente como orientadores de los estudios (Polit \& Beck, 2004); si bien cualquier modelo es susceptible de orientarlas (Marriner \& Raile, 2003). El modelo más referenciado de los estudiados en los 
artículos de los últimos 5 años en la base Medline y en representación creciente, fue el de R. Parse en el $20,7 \%$ de las publicaciones analizadas. Aunque estudios anteriores colocaban el modelo de D. Orem como el líder internacional (Lucero \& Guerrero, 2006), en nuestros hallazgos aparece como el tercer modelo en el ranking precedido por el de C. Roy. Esto podría estar asentado en una doble casuística. La primera es que el uso de un único indicador bibliométrico en la búsqueda pudo limitar los resultados. Por otro lado, el hallazgo pudo tener una elevada relación con que sea la revista NSQ la que reúne el mayor número de artículos sobre el modelo de Parse (un total de 50 artículos en la revista), ya que es ella misma la enfermera fundadora y editora actual de la revista. Este hecho pudo mediar la aceptación de artículos por parte del equipo editorial. Dentro de este equipo editorial destacan otros autores que también son referentes teóricos como I. King con 3 artículos de los 12 hallados y C. Roy con 16 artículos publicados de los 44 hallados en base a esta autora. Sin embargo la revista también tiene un destacado número de publicaciones sustentadas en el modelo de D. Orem que no es miembro de su equipo editorial.

La segunda revista que agrupó un mayor número de artículos fue Journal Advanced of Nursing, pero ya con un porcentaje muy inferior a la primera (sólo un 5\%). Porcentajes menores se dieron en el resto de un total de 80 revistas. No obstante, si hablamos de modelo aplicado en la práctica (y no sólo de teorizaciones), el liderazgo sería de C. Roy y D. Orem, ya que se recogieron muchos trabajos que lo usaron para desarrollar la práctica. Para evaluar la posible repercusión de estos artículos, se puede analizar el índice de impacto de las revistas en las que estaban publicados. El factor de impacto de las revistas es una medida de la frecuencia de la citación y se publica anualmente en el "Journal Citation Reports (JCR)". Aunque su empleo está lleno de controversia debido a los usos que se han hecho del mismo en ámbitos académicos, ofrece un medio sistemático y objetivo para evaluar críticamente las principales revistas del mundo, al menos de forma cuantitativa (Polit \& Northam, 2011). De las 80 revistas que recogieron publicaciones respecto al tema, tenían factor de impacto 38 (47,5\%) según el JCR 2012 Science Edition. La revista Nursing Science Quarterly que inicialmente recogía un mayor número de publicaciones sobre el tema, era una de las revistas con mayor impacto hasta el año 2008, no estando actualmente presente en las listas del JCR. De todas las revistas en las que se hallaron publicaciones, sólo $23(28,7 \%)$ se hallaban en el listado del JCR de los años pertenecientes a la revisión (enero 2008 - enero 2013). Si hacemos este examen por artículos publicados en años en los que las revistas tenían índice de impacto, podemos concluir que el número de artículos en revistas de impacto en los 5 años de revisión fue de 104 (37,4\% del total), de los que sólo 6 artículos tienen un índice de más de 2 puntos (remarcar que son muy 
pocas las revistas enfermeras que sobrepasan este límite). Por lo que se puede especular sobre la baja relevancia del tema en el desarrollo de la profesión enfermera. Algunos de los resultados pueden compararse con los hallazgos de Bond et al (2011). Destacar que a diferencia de este estudio, no se han hallado artículos sobre modelos en las revistas American Journal Critical Care, Journal of Nursing Scholarship, Journal of Nursing Research y en Research and Nursing and Health. Si en Journal of Clinical Nursing (aunque los autores hallaron 112 artículos frente al único hallado en la presente investigación) y en Journal of Advanced Nursing (encontrados 14 frente a los 174 del estudio de Bond et al., 2011). Esto podría ser debido a que los autores integraron cualquier artículo que incluyera teoría enfermera sin ampararse en la singularidad de concreción de una única teorista. Sin embargo, en nuestro estudio se hallaron un número mayor de artículos publicados en Nursing Science Quarterly (108 frente a 39 por Bond et al.), aunque de ellos, sólo 37 eran estudios empíricos por lo que, teniendo en cuenta esta apreciación, los resultados en la revista podrían ser semejantes a los detallados por los autores.

Estudios sobre el tema existen a nivel nacional pero metodológicamente diferentes al presente, lo que obstaculiza el cotejo de resultados. Richart et al. (1999) buscaron contabilizar y comparar el número de referencias de autores de modelos y teorías de enfermería en artículos de investigación e identificar a los autores de modelos más referenciados en investigaciones españolas de las revistas de mayor impacto a nivel nacional (Enfermería Clínica, Revista Rol y Enfermería Científica). Ellos sólo computaron el uso de la referencia del modelo en dos grandes bloques, uno como en el uso empírico y el resto fue catalogado como uso teórico, durante 5 años de publicación. Richart et al. (1999) analizaron referencias y no la presencia del modelo en la publicación (aunque si aparecía en la referencia, debía tener su espacio en el artículo, pero los autores no cuantificaron de forma pormenorizada los artículos, sino las referencias). En aquel momento de las revistas consideradas, Enfermería Clínica era la que acopiaba un mayor número de registros sobre el tema y el modelo que más se registró en las referencias fue el de V. Henderson, coincidiendo con hallazgos de nuestro estudio.

Si hacemos el análisis cronológico de las publicaciones, podemos objetivar que el número de publicaciones anual permanece constante con alguna inflexión mínima, resultados no hallados en otros estudios que indicaban un incremento anual del número de publicaciones sobre el tema, primordialmente en referencias de artículos empíricos (Richart et al., 1999). Esto lleva a pensar que, pese a que había existido una fuerte proyección teórica en años anteriores y el papel de los modelos tuvo un especial auge a nivel internacional. En España ese desarrollo se dio a finales de los 90’ y principios del 2000, ya que por un lado se inició la informatización en muchos sectores (A. M. Rodríguez \& Ferrer, 2002), y por otro, se emprendió el 
desarrollo de formación avanzada en enfermería primero como título propio, y después como Máster en Ciencias de la Enfermería (Zabalegui \& Macià, 2010). Estas premisas facilitaron la entrada de los modelos en los sistemas de cuidados. Sin embargo, actualmente el tema no está incluido en las líneas prioritarias en Enfermería (Comet et al, 2010).

La mayoría de los artículos hallados en nuestro estudio, son estudios empíricos y más de la mitad de los autores son estadounidenses, seguidos por autores de Reino Unido. Destacar que ambos países son de habla inglesa y es la lengua vehicular de la mayoría de las revistas que están indexadas en Pubmed. España es el cuarto país en número de publicaciones indizadas en Medline con artículos que incluyen teoristas (aunque muy por detrás de EEUU). La relación directa puede estar ocasionada como ya hemos comentado, por los problemas de lenguaje, son sólo 3 revistas enfermeras españolas indexadas en la base de datos, y existe poca tradición de publicación de enfermeras españolas en revistas extranjeras (Orts, Richarts \& Cabrero, 2002); aunque este déficit debería ser paliado en los próximos años por el auge científico provocado por los nuevos títulos universitarios. Quizás si la búsqueda se hubiera llevado a cabo en revistas españolas, indexadas o no, estos datos serían mayores. Por otro lado, podemos ver que los modelos son usados a nivel internacional, ya que, los autores son de 32 nacionalidades diferentes y de los 5 continentes. La mayoría de las autorías de los artículos recae sobre profesionales que trabajan en el ámbito universitario, esto circunscribe el ámbito de la aplicación de los modelos teóricos a lugares poco cercanos a la práctica. Pese a que los artículos describen en muchas ocasiones situaciones particulares, son los profesores universitarios los que acaban de pilotar los modelos en diferentes ámbitos. McKenna, Parahoo y Boore (1995), hallaron relación directa entre el uso de un modelo y la mejora de la calidad del plan de cuidados en una unidad psiquiátrica de larga estancia, sin embargo, autores más contemporáneos como M. López et al. (2006) o Medina (2005) cuestionan su utilidad argumentando que los modelos acaban relegándose prioritariamente al ámbito académico como guía para la formación básica y avanzada de Enfermería. Estos hallazgos pueden ser comparados con los hallados en nuestro estudio, al igual que descubrieron Moreno-Fergusson y Alvarado-García (2009) en la revisión de artículos basados en el modelo de C. Roy. La mayoría de los autores de los artículos citados fueron estudiantes de postgrado y docentes quizás, porque como bien argumentaron Simpson y Taylor (2002) estudiando un gran número de hospitales, los sistemas tradicionales de cuidado acaban siendo consistentes y aclaradores para proveer de forma exitosa el cuidado sea o no bajo modelos enfermeros. Este hecho, ha llevado a que la teoría enfermera haya desaparecido del discurso de la enfermería, entre otros factores por no haber satisfecho la doctrina de la práctica basada en la evidencia; pese a que inicialmente la causa de 
su uso fue la propia definición como disciplina (McCrae, 2011). Quizás el futuro del tema pasará por aplicar marcos conceptuales autoelaborados ad hoc para los centros sanitarios a modo de marca de excelencia profesional, como queda patente en la aplicación de los mismos en los llamados hospitales magnéticos que ya se cuestionaron deshechar teorías concretas en la práctica por su reducido margen de aplicación (Menski, Scott, Martin \& Horton, 2011).

Cuando particularizamos este análisis por teoristas podemos objetivar que no todos los modelos han sido aplicados en igual intensidad a situaciones de cuidado concreto.

La teoría de Parse ha sido usada en su mayoría por autores estadounidenses y canadienses según la revisión realizada. En los estudios hallados, la teoría se usó en estudios empíricos sobre todo para explicar sentimientos, emociones o vivencias en situaciones límite como catástrofes, tanto en personas sanas como enfermas. Estos abordajes se realizaron en personas de diferentes edades incluyendo a personas adultas, ancianas y cuidadores no profesionales. Incluso para describir la experiencia formativa de estudiantes de enfermería en diferentes contextos. Estas publicaciones son acordes a la filosofía de la teoría que destaca la calidad de vida subjetiva para la propia persona, su propia visión del mundo y la función de la enfermera como descubridora del sentido de las experiencias vividas para cada familia o persona (Marriner \& Raile, 2003; Parse, 2012). Uno de los elementos importantes de la teoría es lo que Parse llama el poder, relacionado con el tercer principio de la teoría, la cotrascendencia. El poder es un concepto que transmite significado sobre la lucha y la vida y continuar a pesar de la dureza y la amenaza, son significados muy relacionados con la calidad de vida (AcebedoUrdiales et al., 2007). Este hecho seguramente condicionó el uso del modelo en el análisis de situaciones límite como la vivencia del duelo, la muerte, pacientes con lesiones medulares, etc. Sólo se halló un estudio sobre niños determinado probablemente porque la corta edad puede limitar experiencias y el modelo podría ser poco resolutivo. También el modelo fue usado en artículos sobre políticas economicistas sanitarias, destacando el papel de liderazgo de las enfermeras. La autora no hace alusión directa al término liderazgo en su teoría, sin embargo si aboga por el cuerpo de conocimientos propio de la disciplina, diferenciándose de la práctica médica. Quizás este hecho ha provocado que la propia teoría sea utilizada para fomentar el liderazgo de las enfermeras en políticas de salud (Marriner \& Raile, 2003). Sin embargo, no se recogen artículos que prueben su aplicación práctica, quizás siguiendo recomendaciones de Parse que orienta a que las investigaciones han de ser guiadas para potenciar los fundamentos teóricos de su propuesta, pero no para comprobar la teoría (Marriner \& Raile, 2003). A nivel nacional, existen estudios cualitativos que también han usado el modelo como marco conceptual en investigaciones dirigidas a la comprensión de la vivencia de enfermedades crónicas, 
terminales y su relación con la calidad de vida (Lorenzo, 2008; Rodero-Sánchez, AcebedoUrdiales, Vives-Relats \& Pérez-Gurrea, 2006).

En cuanto a C. Roy podemos decir que es uno de los modelos más extendidos en Asia según nuestros resultados. Según se ha visto, parece ser un modelo muy adecuado para ser aplicado en diferentes situaciones de salud, abarcando la planificación del cuidado en la agudización, la evaluación de la rehabilitación y la aplicación de programas de salud. Sobre todo, el modelo proporcionó una base sólida para realizar la valoración completa de la persona y de los estímulos condicionantes para dirigir la actuación enfermera focalizándola en la modificación de comportamientos ineficaces. También fue útil para ser usado en prevención y promoción de la salud, hecho ya reconocido por la teorista. Uno de los supuestos de Roy indica que "el sistema de las relaciones incluye la aceptación, protección y el fomento de la interdependencia", esto incluye tanto el cuidado, como la prevención y la rehabilitación e incluye su interpretación de la salud como un continuum en el que la salud y la enfermedad pueden coexistir (Marriner \& Raile, 2003), por ello se vio empleado en múltiples ámbitos y en usuarios de diferente edad. Según la teorista, Enfermería se centra en los procesos vitales (Marriner \& Raile, 2003) y lógicamente estos se dan en cualquier franja etaria. Los artículos fueron firmados principalmente por autores estadounidenses y brasileños, justamente es en Brasil donde existe un grupo potente de la universidad de la Sabana que adoptaron el modelo como referente a nivel teórico en la formación y a nivel práctico en diferentes centros de salud, por lo que su fomento queda asegurado (M. E. Moreno, 2005). Algunos autores han evidenciado un incremento en las publicaciones relacionadas con el estudio y la aplicación del Modelo de Adaptación de Roy, especialmente en Brasil, México y Colombia, cuyos autores en la mayoría de los casos son alumnos de estudios de post grado y docentes (Moreno-Fergusson \& AlvaradoGarcía, 2009). Cierto es, que se usó de forma amplia en aspectos de valoración psicosocial y vivencias, en la valoración del estado emocional mediante la evaluación del autoconcepto, la interdependencia y el desempeño del rol, tanto de la propia persona como de la familia. También sirvió para evaluar el dolor y la sexualidad. Sin embargo hallazgos contradictorios revelaron otros autores para ubicar ambos términos en la valoración de la persona según el modelo (Cunill \& Santos-Ruíz, 2012). El modelo fue útil para ser implementado junto a taxonomía de diagnósticos NANDA, hallazgos similares a lo encontrado por Moreno-Fergusson y Alvarado-García (2009), que encontraron estudios que analizaron la utilidad de la taxonomía de diagnósticos de enfermería de la NANDA y su relación con los modos adaptativos.

Acerca del modelo de autocuidado de D. Orem fue hallado, en alguna de sus 3 teorías, en artículos publicados mayoritariamente por estadounidenses y fue usado mayormente en 
estudios empíricos y para la planificación directa del cuidado en diversa tipología de pacientes (incidiendo sobre todo en la teoría del déficit de autocuidado). Brasil aportó un número considerado de publicaciones, pero no fue la que más publicó a diferencia de lo que descubrió en su estudio Pereda (2011), que aunque no concreta la metodología utilizada, concluyó que Brasil era el país en el que mayor número de publicaciones se realizaban. Destacar que las bases de datos consultadas por Pereda, discrepan de las del presente estudio, ya que aparte de Medline, la autora consultó repositorios sudamericanos como LILACS, SCIELO o Medagraphic, donde se publican gran número de artículos sudamericanos. No obstante, podemos ver que se trata de un modelo ampliamente aceptado y utilizado a nivel internacional (los autores son de todos los continentes excepto de África y Oceanía). Hallazgos similares sobre la perspectiva internacional de la teoría hallaron A. L. López y Guerrero (2006) en publicaciones durante los años 1992-2001. Sus resultados mostraron también que el modelo había sido usado de mayor a menor representatividad en América, Europa, Asia y Oceanía, siendo los autores de Estados Unidos los que recopilaban un mayor número de artículos. Los hallazgos en cuanto a aplicación directa en el cuidado de A. L. López y Guerrero (2006) y Pereda (2011) y fueron también extensos al igual que en nuestro estudio. Aplicados en múltiples situaciones de cuidado tanto en situaciones agudas como crónicas: quemados, nefrópatas, enfermo mental... tanto en adultos, como ancianos y niños. Tanto en el hospital como en la comunidad. No fue así en los estudios de Raimondo et al. (2012), en los que pese a ser la teoría usada en múltiples situaciones, todas ellas fueron sobre adultos. La teoría también fue empleada durante el tratamiento y en periodos de rehabilitación dirigiendo el cuidado enfermero hacia el empoderamiento de los pacientes generando su propia agencia de autocuidado, por ello, de las tres teorías que definió D. Orem, la teoría del autocuidado y la del déficit de autocuidado son las que se usan en la mayoría de publicaciones (hallazgos ya encontrados por Lucero y Guerrero en 2006). Tal y como ellos ya argumentaron, se evidencia un énfasis en relacionar la agencia de autocuidado con los factores condicionantes básicos y el agente de cuidado al dependiente, con la intención de remarcar el interés de las enfermeras por comprender y potenciar las capacidades de los individuos de diferentes grupos de edad de acuerdo a la visión metaparadigmática de persona formulada por Orem. Por esta reflexión, se podría concluir que la teoría está vigente en nuestros días y tiene una aplicabilidad real. Sin embargo, se cuestiona si analizamos los resultados anualmente, ya que se aprecia un descenso en las publicaciones (al menos en las indexadas en Medline) al contrario que en otros estudios sobre el uso del modelo en los que el número iba en aumento de forma periódica (A. L. López \& Guerrero, 2006). Según la literatura, su uso podría extenderse, ya que es uno de los pocos modelos que se usa exitosamente combinado con la taxonomía NANDA de diagnósticos enfermeros para la elaboración del proceso enfer- 
mero. Este hecho, junto a la gran generalidad en la aplicación de la teoría podría ser la justificación de su uso ya que esta taxonomía es usada actualmente en algunos países como el nuestro para estandarizar la práctica enfermera. Aunque existe controversia a favor de su uso (Cachón, Álvarez-López \& Palacios-Ceña, 2012; Escalada, Muñoz \& Marro, 2013), sin embargo, diferentes autores creen que la taxonomía es ampliamente aceptable en diversas culturas y situaciones a nivel internacional (Almeida \& Chaves, 2013; Roecklein, 2012; Silva, Alves, Macedo, Bezerra; Thoroddsen \& Thorsteinsson, 2002).

Analizando las publicaciones que usaron la teoría de J. Watson vemos que la mayoría de los artículos hallados han sido de origen asiático además de alguno estadounidense. El gran uso de la teoría por enfermeras orientales podría justificarse por la base de la teoría en rasgos espirituales, concretamente en siete supuestos y diez factores de cuidados o factores caritativos de cuidados coherentes con sus valores tradicionales (M. Urra, Jana y García, 2011). De hecho, fue una revista china la que mayor número de publicaciones recopiló de todos los artículos revisados. Por su generalidad, las publicaciones halladas evidencian que el modelo fue usado para planificar el cuidado en diversidad de pacientes, en pediatría, oncología, unidades de cuidados intensivos... pero en su mayoría para el estudio de percepciones y sentimientos relacionados en muchas ocasiones con la compasión y el entorno; tanto sobre pacientes o cuidadores no profesionales, como en enfermeras. También existe alguna aplicación práctica mediante el desarrollo de intervenciones fundamentadas en su teoría del cuidado. De hecho el modelo de J. Watson se centra en el cuidado humano, la atención integral y la relación auténtica entre cuidadores y pacientes (Lukose, 2012). El modelo se aplicó en unidades en las que los procedimientos y la tecnología tienen una gran presencia como urgencias o cuidados intensivos; posiblemente porque una de las mayores virtudes del modelo haya sido la de ser usado en muchas ocasiones para la humanización del cuidado (M. Urra et al., 2011). El objetivo del modelo es retomar el cuidado del paciente hacia relaciones de ayuda y confianza en el centro del cuidado transpersonal, promoviendo el crecimiento de las personas, teniendo en cuenta que, según la teorista, un entorno adecuado de cuidado ofrece el desarrollo del potencial a la vez que permite elegir a la persona la mejor acción en un momento determinado (Marriner \& Raile, 2003). Por lo tanto muestra su utilidad previniendo la deshumanización en unidades con un papel técnico dominante (Arredondo-Gonzalez y Siles-Gonzalez, 2009).

En relación al uso del modelo de M. Leininger, es conocido a nivel internacional, ya que las publicaciones halladas en base al modelo se extienden por varios continentes. Se ha usado principalmente en estudios cualitativos, orientados mayormente en base antropológico - cultural. De hecho, la propia autora confirma como uno de sus principales conceptos el de la 
enfermería transcultural. Leininger argumenta que los cuidados son el eje central de la disciplina, pero siempre entendidos desde el cuidado cultural. Por ello, las investigaciones halladas son principalmente estudios que han usado el abordaje que el propio modelo a través de la aplicación de la etnoenfermería, que es una metodología que se aplica para abordar el contexto cultural y de la atención en salud de una cultura específica para recoger datos cualitativos (Marriner \& Raile, 2003). Pese a que la teoría inicialmente da lugar a reflexionar sobre la congruencia con la situación actual de muchos países por la inmigración, su teoría parece quedarse más en una filosofía hacia el "cómo cuidar" que en un acercamiento concreto a guiar la práctica. La competencia cultural se representa como un conjunto cuantificable de actitudes individuales, comunicación y habilidades prácticas que permiten a la enfermera trabajar con eficacia dentro del contexto cultural de los individuos y las familias de diversa índole (Gustafson, 2005). De la revisión realizada, sólo existe un artículo (Woerner, Espinosa, Bourne, O'Toole \& Ingersoll, 2009) que argumenta el uso de un programa específico de cuidado basado en el modelo de Leininger que demostró que un enfoque culturalmente congruente reduce la hospitalización aguda y visitas a urgencias, así como mejora la gestión de medicamentos, la satisfacción del cliente y de Enfermería. No obstante, algunos autores critican el uso del modelo en los centros de salud, ya que serían difíciles de aceptar prácticas no estandarizadas en los centros sanitarios (como terapias complementarias por ejemplo) o modificar aquellas que creamos que son perjudiciales para los individuos que cuidamos, bien por etnocentrismo o porque realmente sean dañinas para las personas (Gustafson, 2005).

Los documentos hallados que usan el modelo de B. Neuman, prácticamente se centran en EE.UU. Pese a que el modelo está bastante explicitado como para ser usado en la práctica, en la revisión realizada sólo se hallaron 8 estudios empíricos, pero ninguno de ellos probó el modelo, sino que lo utilizó como marco teórico en su diseño.

A partir de aquí, fueron ya pocos los artículos hallados para el resto de teoristas en la revisión, por ello la discusión de los artículos que incluían el resto de modelos parece menos relevante. De hecho, artículos de revisiones extensas de bibliografía sobre teoristas sólo se hallan para los modelos de C. Roy y D. Orem. Esto nos indica que aunque el número de artículos para otras teoristas sea elevado, son las que mayor preocupan a nivel internacional a enfermería y por lo tanto podemos concluir que son las teóricas consideradas más relevantes.

M. Rogers proporciona un marco teórico para que los investigadores prueben su teoría, desarrollen herramientas de medición y generen modelos de práctica (Kim, 2008). Sin embargo, en la revisión realizada en Medline, se evidenció una falta de estudios empíricos del 
modelo, ya que más de la mitad de artículos fueron artículos sobre abordaje teórico. Pese a que la literatura recoge algunas aplicaciones prácticas de la teoría (Madrid, 1996), no se hallaron artículos metodológicos de aplicación clínica, ni tan sólo mediante el estudio de caso. Quizás su lenguaje algo complejo dificulta que las enfermeras vean aplicables sus conceptos en la práctica directa. En la revisión hecha por Kim (2008) sobre el uso del modelo de Rogers entre los años 2004-2007 (previos a los de este estudio), se hallaron un número superior de artículos a los hallados en nuestro estudio. Cabe remarcar que su búsqueda también fue más amplia en cuanto a bases de datos consultadas. Halló un total de 24 artículos empíricos, sobre sujetos de diferentes edades, incluidos niños. Tanto sanos como enfermos (procesos de histerectomía, fibromialgia, enfermedad crónica y dolor). Uno de los artículos hallados en nuestra revisión coincidió en la temática del abordaje del dolor y la fibromialgia mediante musicoterapia, como instrumento que podría modificar la resonancia del individuo a través del entorno del paciente (Onieva-Zafra, Castro-Sánchez, Matarán-Peñarrocha \& Moreno-Lorenzo, 2010). También fue usado en profesionales y estudiantes, hallazgos no contrastados en nuestra revisión.

Estos hallazgos fueron muy diferentes al revisar los documentos basados en $\mathrm{H}$. Peplau. En este caso, más de la mitad de los artículos fueron estudios empíricos. Muchas de las publicaciones se realizaron en revistas cuya temática fue la salud mental, campo en el que se originó el pensamiento filosófico de Peplau, su uso se concretó en situaciones con amplia problemática psicológica en las que la relación comunicativa fuese esencial. La práctica enfermera basada en el modelo exige el desarrollo de competencias en relaciones interpersonales y resolución de problemas (Kérouac et al., 1996; Marriner \& Raile, 2003). La teoría de las relaciones interpersonales, es una terminología clara y que puede ser ampliamente aceptada, quizás por ello, en este caso, la revisión mostró un amplio número de publicaciones en Reino Unido, descentralizando el monopolio estadounidense del resto de las publicaciones de las teoristas.

V. Henderson fue una de las teorías más aplicadas en el estudio de caso. Pese a ser una teorista estadounidense, fueron autores españoles los que publicaron sobre el modelo. La mayoría de los firmantes trabajaban directamente en la asistencia, por lo que podemos discurrir que parece ser el modelo que más se usa en nuestro contexto inmediato sanitario (también es verdad que es el modelo hegemónico en la formación de las enfermeras, como se vio al revisar los planes docentes de las páginas web). Pero es necesario preguntarse si esta elección fue basada en un análisis comparativo con otros modelos o fue una elección sin oponente. Porque este modelo solo se usa mayoritariamente en España frente a otros países europeos, asiáticos o americanos. Realmente en la literatura no se ha hallado este tipo de análisis crítico. Fue 
además una teorista que se usó para trabajar el plan de cuidados asociado a taxonomía diagnóstica NANDA, aspecto relevante en la organización y estandarización del cuidado en España tal y como se argumentó anteriormente. Por ello fue extenso su uso en la estandarización del cuidado (Chirveches-Pérez et al., 2009; Jurado-Campos et al., 2008). Elemento también característico de España a diferencia de la visión internacional que utiliza mínimamente esta terminología en la práctica asistencial. Aunque este no fue el único modelo en el que autores españoles profundizaron. Se halla también algún artículo español basado en otros modelos como D. Orem, J. Watson, M. Leininger o M. Rogers. La teoría de los sistemas de I. King fue aplicada sobre pacientes hipertensos o en unidades de cuidados paliativos, en los que la prioridad es la confortabilidad del paciente y el cuidado de las familias (Gómez et al., 2010), elemento integrado en los sistemas sociales del modelo (King, 1981). Quizás la capacidad de pacto de objetivos con el paciente del modelo hizo adecuada su aplicación en pacientes de atención primaria.

Mínimos estudios fueron hallados de las teoristas D. Johnson, I. Orlando, L. Hall, M. Levine, o del modelo RLT. Justamente si se hallan estudios de RLT en años anteriores ubicados sobre todo en Reino Unido e Irlanda (Griffith, 1998; Murphy et al., 2000), quizás es que actualmente son poco usados en la práctica inglesa.

No fueron halladas publicaciones que utilizaran la filosofía de F. Abdellah, J. Travelbee o E. Wiedenbach. Quizás porque son menos conocidas y difundidas que las anteriores, además son teoristas que hicieron sus últimas publicaciones indexadas en Medline en años previos a la revisión realizada (los últimos artículos hallados indexados de estas autoras son los de: Wiedenbach, 1970; Travelbee, 1964; y la más reciente Abdellah, 2005). 
6. Conclusiones 
Los resultados obtenidos de esta investigación basados en los objetivos establecidos permiten concluir lo siguiente:

1. En cuanto al estado formativo de los estudiantes en España pocas escuelas hicieron explícito el modelo enfermero que guiaba su formación en sus páginas web. Evidenciándose escasez de explicación teórica sobre Modelos y Teorías de Enfermería. Además existió falta unanimidad para la denominación de la asignatura del mismo contenido.

2. Según los datos en web, se mostraron desigualdades en cuanto a créditos posibles relacionados con la base conceptual enfermera en la titulación de Diplomado de Enfermería. Asi como, elevadas discrepancias entre los contenidos incluidos en las asignaturas y falta de inclusión de estos contenidos esenciales enfermeros en cursos avanzados de la Diplomatura de Enfermería en los que los estudiantes tienen un pensamiento crítico y reflexivo más desarrollado.

3. El modelo mayoritariamente identificado por los estudiantes y los profesionales como guía de su formación y para la práctica diaria es el de V. Henderson, con independencia de la escuela donde adquieren su formación. Otros modelos identificados fueron mayormente el de D. Orem, C. Roy y H. Peplau.

4. Se observó que los estudiantes no integran un modelo concreto de forma global, sino que se basan en concepciones tomadas de diversos paradigmas, siendo común el uso de términos vertebradores como holismo, disciplina y humanista.

5. Tanto estudiantes como profesionales indicaron como positivo aplicar un modelo teórico en sus lugares de trabajo, ocasionalmente diferente en función de la persona cuidada. Aunque los estudiantes manifestaron en mayor proporción seguir un modelo teórico en su práctica. Los que así lo hacían indicaron que les era útil y se identificaban con el mismo en su práctica (adherencia teórica).

6. Los factores evaluados para elegir un modelo teórico para la práctica fueron en los profesionales: las características del propio modelo, la identificación con su filosofía, ser la guía en su formación y ser el más usado nacionalmente. Los estudiantes indicaron: uso en la formación, facilidad de aplicación y características del paciente. 
7. Los factores evaluados para no elegir un modelo teórico para la práctica entre los profesionales fueron: la falta de conocimiento, la dificultad de aplicación, la falta de recursos en las unidades, la no adecuación al entorno asistencial o paciente, la percepción de falta de utilidad y la preferencia por otros instrumentos de orden metodológico pero no teórico. Ningún estudiante se planteó no seguir un modelo teórico enfermero en su práctica.

8. Se manifiesta tanto en estudiantes como profesionales, confusión entre metodología y modelo enfermero, por lo que sería necesario una unificación de criterios, conceptos y lenguaje que agilizara la práctica asistencial.

9. La elección de un modelo teórico concreto por los estudiantes para el trabajo de Máster en Ciencias de la Enfermería respondió a factores subjetivos y objetivos. Entre los criterios objetivos se hallaron como factores favorables: la adecuación de la teoría al caso, la claridad del lenguaje, la forma de valoración de la persona, su generalidad, la claridad en la que desarrolla la función enfermera, bajo tiempo de implementación y posibilidad de registro (aunque todos los modelos fueron acusados de largo tiempo de aplicación), la adecuación al proceso enfermero y la adecuación al contexto en el que se va aplicar. Entre los conceptos subjetivos se encontraron la identificación con la teoría, la formación recibida anteriormente y el conocimiento del inglés. Siendo los modelo más elegidos por este orden los de V. Henderson, D. Orem, C. Roy, H. Peplau, B. Neuman, I. King y M. Leininger.

10. Según los resultados obtenidos en los trabajos de Máster en Ciencias de la Enfermería, se evidenció bajo conocimiento de inglés entre las enfermeras españolas, que limita el uso y conocimiento de modelos internacionales distintos a los que se publican en lengua castellana.

11. Según los trabajos de Máster en Ciencias de la Enfermería, no se justificó ningún modelo como adecuado a las situaciones de gravedad como unidades de urgencias o enfermos críticos.

12. En los trabajos de Máster en Ciencias de la Enfermería, el modelo de V. Henderson recibió soporte mayoritariamente. Fue considerado un modelo generalista y simple para adultos y ancianos sobre todo. Fomenta la interdisciplinariedad, indicado en casi todas las situaciones del cuidado de la salud a nivel hospitalario, excepto en cuidados en salud mental, en situaciones críticas y en pacientes crónicos. Es escaso en 
valoración del entorno, en aspectos psicosociales, en relevancia del papel de la persona en su cuidado y en explicación del abordaje de la familia. Es útil para ser usado en el plan de cuidados junto a taxonomía NANDA.

13. En los trabajos de Máster en Ciencias de la Enfermería, el modelo de D. Orem fue valorado principalmente de forma positiva. Fue usado en pacientes de edades jóvenes, tanto en situaciones agudas como en crónicas. Lo ven generalista, aunque contemplan su restricción de uso en el ámbito de la pediatría, unidades de cuidado crítico y salud mental. Es un modelo reiterativo en conceptos, aunque lo ven carente en la valoración psicológica de la persona, valoración del dolor o de la capacidad de higiene. Lo valoraron mayoritariamente como útil para ser usado en el plan de cuidados junto a taxonomía NANDA.

14. En los trabajos de Máster en Ciencias de la Enfermería, el modelo de C. Roy fue evaluado con más críticas negativas que positivas. Fue recomendado en situaciones agudas y crónicas, sobre todo en la maternidad y para el abordaje de cuidadores informales. Fue considerado claro y general, aunque no lo recomendaron en unidades de críticos. Como aspectos negativos lo definieron como reiterativo, subjetivo y demasiado extenso en la valoración. También argumentaron adecuación para ser usado en el plan de cuidados junto a taxonomía NANDA.

15. En los trabajos de Máster en Ciencias de la Enfermería, el modelo de H. Peplau fue aconsejado sobre todo para el abordaje de procesos de salud mental y unidades de larga estancia o en enfermos con elevada carga emocional (como pérdidas vitales o cambios físicos). Vieron limitado su uso en pacientes con deterioro comunicativo.

16. En cuanto a las barreras y los facilitadores hallados para el desarrollo profesional y teórico de le enfermería en España por los estudiantes de Máster en Ciencias de la Enfermería, destacar que se recogen un mayor número de barreras que de facilitadores. Como aspectos barrera o limitantes a destacar los relacionados con los centros (la falta de recursos, falta de proyectos propios, poco apoyo y rigidez institucional de funcionamiento), la propia formación, la infravaloración social de la profesión, el carácter del colectivo enfermero (conformidad, compromiso, motivación, etc.) y la falta de desarrollo del rol propio profesional. Como elementos facilitadores se encuentran la nueva formación avanzada de las enfermeras, el carácter emprendedor de los profesionales (autonomía, empatía,....), los cambios 
sociales, la mejora en gestión de los centros sanitarios y el desarrollo del conocimiento propio de la disciplina (incluyendo la investigación).

17. En cuanto a la perspectiva de gestores y docentes en relación a barreras y facilitadores del uso y desarrollo de modelos teóricos en la práctica española, como elementos barrera o limitantes fueron priorizados el pragmatismo y la falta de reflexión personal de no tener la necesidad de basar la práctica en conocimiento propio, la falta de reconocimiento del uso de modelos en el desarrollo como disciplina, el desinterés profesional y la falta de condicionamiento de las direcciones enfermeras en el modelo de atención, formación continuada, carrera profesional... pese a identificarse con un modelo teórico. Se priorizaron como elementos facilitadores o favorecedores el liderazgo clínico de las enfermeras, la sensibilidad y necesidad de las direcciones de Enfermería en aplicar modelos teóricos en los pacientes y la creencia y necesidad personal de los profesionales en la aplicación de un modelo teórico de cuidados, el uso de estructuras teóricas para la valoración enfermera y el desarrollo de pensamiento crítico en la profesión.

18. Los modelos teóricos, según la revisión de la literatura, son pobremente implementados en la práctica y usados en bajo porcentaje en los artículos de investigación enfermera, sobre todo si concretamos las investigaciones publicadas en revistas de elevado factor de impacto. Sus autores pertenecen sobre todo al ámbito académico, apareciendo porcentajes muy inferiores en ámbitos que tienen relación directa con el cuidado asistencial.

19. El país que principalmente publicó en los últimos 5 años sobre teoría enfermera es Estados Unidos, aunque hay representación de publicaciones sobre el tema a nivel internacional en los cinco continentes. La tendencia mundial en cuanto interés al tema, se mantiene estable.

20. Los modelos más referenciados en los artículos indexados en Medline en los últimos años fueron el modelo de R. Parse, usado como base empírica para el estudio de vivencias y los modelos de C. Roy y D. Orem en cuanto a la aplicación en la práctica. El modelo más referenciado por los autores españoles fue el de V. Henderson.

21. Pese a que a nivel general los modelos teóricos tienen múltiples detractores en la literatura, no ocurre lo mismo cuando se analizan trabajos de aplicación concreta del 
modelo. En ese caso sólo se recogen mayormente las bondades del modelo no evidenciando dificultades en su uso.

\section{Implicaciones para la práctica:}

El establecimiento de un marco conceptual y la definición de modelos son de gran importancia para la profesión, porque definen el papel específico que tiene la Enfermería dentro del equipo de salud. Sin embargo, a causa de que la Enfermería española está desarrollándose y tiene una corta historia como disciplina, los modelos no están debidamente consolidados en la práctica diaria. Por ello, se evidencia la necesidad de aumentar el número de publicaciones que hagan transparente las dificultades de los modelos teóricos, ya que tal y como se ha podido comprobar en los trabajos de Máster en Ciencias de la Enfermería su aplicación es compleja en las unidades de trabajo y es preciso que las escuelas universitarias dediquen un mayor esfuerzo a clarificar conceptos entre metodología y modelo enfermero. Existe la necesidad de mayor formación en el tema, pese a existir una actitud positiva hacia los modelos y teorías enfermeras, se demuestra una actitud indecisa ante un posicionamiento teórico para la práctica, tal y como se ha podido demostrar es poca la carga conceptual que se realiza en los planes de estudio para la comprensión profunda de la base conceptual enfermera. Estas circunstancias generan la necesidad de retomar el tema en el currículo de Grado de Enfermería en años diferentes del primer curso académico o al menos impregnar otras asignaturas con este contenido teórico para facilitar la mejor comprensión de los fenómenos del cuidado.

En nuestro país, parece que el modelo de V. Henderson, es el mejor aceptado porque simula estar adaptado a nuestra cultura y contexto social, siendo aplicable en la mayoría de los ámbitos: asistencial, docente e investigador. Aunque cabe cuestionarse si un modelo creado en los años 50' puede dar respuesta a las necesidades de los pacientes actuales. Cabe destacar que nacionalmente, existe gran controversia en el tema tanto a nivel asistencial como académico y escasez de investigación. Opiniones contrarias, entre quién cree que la teoría permite el crecimiento, orden y aplicación de la metodología enfermera, como aquellos que piensan que los modelos encorsetan la práctica y su única utilidad es la académica, no siendo apropiados porque derivan de contextos completamente disímiles a los nuestros. No obstante, lo deseable será siempre la posibilidad de aplicación de diferentes modelos y la pluralidad ante dar respuesta a los complejos fenómenos que aborda la disciplina enfermera. Se requieren de mayores estudios en nuestro contexto inmediato que pongan en evidencia si realmente la 
aplicación de marcos teóricos propios pueden dar respuesta a las diferentes respuestas de los individuos a sus situaciones de salud y enfermedad, que valoren la efectividad de los mismos.

Es necesario resaltar la importancia de activar el desarrollo sobre todo de la investigación clínica, principalmente en relación a los estudios de caso que permitan validar la teoría o modelo mediante:

- Identificación de variables o elementos clave de modelos enfermeros que visualicen el valor del cuidado enfermero.

- La medición de la congruencia contextual entre modelos y entornos sanitarios en los que se aplican.

- La perspectiva de los pacientes, familias o comunidades sobre el modelo a seguir.

- La determinación del nivel de adaptación de las personas o grupos a los sistemas basados en modelos teóricos.

- La medición del coste y evaluación de la eficiencia del modelo.

- $\quad$ Las necesidades sociales que genere el modelo.

- La interdisciplinariedad entre los diferentes miembros que forman parte del cuidado del paciente.

- La medición de las bondades, pero también de las limitaciones teóricas de las propuestas.

- La evaluación de la mejora en los sujetos en términos tangibles y medibles, como efecto de las intervenciones de enfermería a través del uso del modelo (indicadores de calidad, mejora en la seguridad en el paciente, etc.).

Gracias a los hallazgos de nuestro estudio, podemos tener una idea clara sobre qué factores deberemos sopesar antes de iniciar nuevos proyectos sobre el tema, incluso para la generación de nuevas teorías de rango intermedio que den respuesta a las necesidades reales contextualizadas a los escasos tiempos de contacto con los usuarios en los servicios de salud de nuestro entorno. Destacar que cualquiera que sea el tipo de teoría desarrollada, debe ser como indica Durán (2007) significativa, relevante y sobre todo comprensible. El uso de teoría enfermera unida a la investigación en el campo, pueden ser los agentes de trasnformación que permitan tanto sustentar la práctica como proponer cambios para revaluar los modelos de prestación de cuidados ajustados a las características de los usuarios. 
7. Referencias 
Abdellah, F. G., Eugene, L., Barbara, S., Kelley, P. W. \& Virginia, S. (2005). Military nursing research by students at the graduate school of Nursing Uniformed Services University of the Health Sciences. Military medicine, 170(3), 188-192.

Acebedo-Urdiales, S., Rodero-Sánchez, V., Vives-Relats, C. \& Aguarón-García, M. J. (2007). La mirada de Watson, Parse y Benner para el análisis complejo y la buena práctica. Índex de enfermería, 16(56), 40-44.

Adams, E. (1991). Être infiermière. Un modèle conceptual, $3^{\mathrm{e}}$ éd., Montreal: Études Vivantes.

Aggleton, P. \& Chalmers, H. (1987). Models of Nursing, nursing practice and Nursing education. Journal of advanced nursing, 12(5), 573-581.

Aggleton, P. \& Chalmers, H. (2000). Nursing Models and Nursing Practice (2ª. Ed.). Basingstoke: McMillan Press.

Aiken, L. H., Cimiotti, J., Sloane, D. M., Smith, H.L., Flinn, L. and Neff, D. (2011). The effects of nurse staffing and nurse education on patients deaths in hospitals with different nurse work environments. Medical Care, 49 (12), 1047-1053. doi: 10.1097/MLR.0b013e3182330b6e

Aiken, L. H., Sloane, D. M., Bruyneel, L., Van den Heede, K., Griffiths, P., Busse, R., Diomidous, M., Kinnunen, J., Kózka, M., Lesaffre, E., McHugh, M. D., Moreno-Casbas, M. T.,Rafferty, A. M. , Schwendimann, R., Scott, P.A., Tishelman, C., van Achterberg, T. \& Sermeus, W. (2014). Nurse staffing and education and hospital mortality in nine European countries: a retrospective observational study. The Lancet, 25. doi:10.1016/S0140-6736(13)62631-8

Aiken, L. H., Sloane, D. M., Bruyneel, L., Van den Heede, K. \& Sermeus, W. Nurses' reports of working conditions and hospital quality of care in 12 countries in Europe. (2013). International Journal of Nursing Studies, 50, 143-153. doi: 10.1016/j.ijnursttu.2012.11.009

Alberdi, R., Artigas, B., Cuxart, N. \& Aguera, A. (2003). Guías para implantar la metodología enfermera. Revista ROL de enfermería, 26 (9), 73-74.

Alconero-Camarero, A. R., Cobo-Sánchez, J. L., Casaus-Pérez, M., García-Campo, M. E., GarcíaZarrabeitia, M. J., Calvo-Diez, M. \& Mirones-Valdeolivas, L. E. (2008). Paciente intervenido de aneurisma de aorta abdominal por técnica quirúrgica endovascular. Caso clínico. Enfermería Clínica, 18(2), 96-103. 
Alligood, M. R., Marriner-Tomey, A., \& Monforte, M. R. (2011). Modelos y teorías en enfermería. Amsterdam: Elsevier.

Almansa, P. (2005). La formación enfermera desde la sección femenina. Enfermería Global, 7. Recuperado de: http://www.um.es/ojs/index.php/eglobal/article/viewFile/484/468

Amezcua, C. \& Jimenez, A. (1996). Evaluación de programas sociales. Madrid: Ed Díaz de Santos.

American Psychological Association. (2010). Manual de la publicaciones de la American Psychological Association. Mexico: Manual Moderno.

Antón, P. \& Busquets, M. (1997). Legislación y ética profesional. Barcelona: Universidad de Barcelona.

Arias, J., Aller, M. A., Ignacio, J. \& Lorente, L. (2001). Generalidades Médico - quirúrgicas. Albacete: Tebar.

Arlandis, M., Sellán, M. C., Cuevas, C. Ajejas, J., Gimena, M., Díaz a, Olea, J., Castro M. V. \& Ferrer, C. (2008). Aplicabilidad del modelo de autocuidado de D. Orem: elaboración de un registro de valoración inicial integrado para atención primaria y atención especializada. Nursing, 26(2), 54-61.

Arredondo-González C. P. \& Siles-González, J. (2009). Tecnología y Humanización de los Cuidados: Una mirada desde la Teoría de las Relaciones Interpersonales. Índex Enfermería, 18(1): 32-36. doi: 10.4321/S1132-12962009000100007

Arriaga, M., Baca, J., Cataño, C. \& Montoya M. (2006). Desde Andalucía: mujeres del Mediterraneo. Almería: Arcibel.

Atienza, A., Delgado, M. T. \& Rubio, M. C. (2003). Aplicación práctica del modelo Roper-LoganTierney en la asistencia. Enfermería Clínica, 13(5), 295-302.

Ayuso, D. \& Grande, R. F. (Ed.). (2006). La gestión de enfermería y los servicios generales en las organizaciones sanitarias. España: Díaz de Santos.

Ausserhofer, D., Zander, B., Busse, R., Schubert, M., De Geest, S., Rafferty, A. M., Ball, J., Scott, A., Kinnuen, J., Heinen, M., Strømseng, I., Moreno-Casbas, T., Kózka, M., Lindqvist, R., Diomidous, M., Bruyneel, L., Sermeus, W., Aiken, L. \& Schwendimann, R. (2014). Preva- 
lence, patterns and predictors of nursing care left undone in European hospitals: results from the multicountry cross-sectional RN4CAST study. British Medical Journal quality \& safety, 23(2), 126-135. doi:10.1136/bmjqs-2013-002318

Avilés, L. A., \& Soto, C. (2014). Modelos de Enfermería en Unidades de Paciente Crítico: un paso hacia el cuidado avanzado. Enfermería Global, 13(2), 323-329.

Becker, T. A., Teixeira, C. R. \& Zanetti, M. L. (2008). Diagnósticos de enfermagem em pacientes diabéticos em uso de insulina. Revista Brasileira de Enfermagem, 61(6), 847-52. doi: $10.1590 /$ S0034-71672008000600009

Bello, N. L., León, C., Valdés, C., Fernández, M., Pérez, A., Rivero, O. et al. (2006). Fundamentos de enfermería. Parte I. La Habana: Editorial Ciencias Médicas.

Benavent, M. A., Francisco, C. \& Ferrer, E. (2001). Los modelos de cuidados. En Mompart, M. P., director. Fundamentos de Enfermería. Colección Enfermería Siglo 21. Valencia: Editorial DAE.

Bernués, L. \& Peya, M. (Coordinadores). (2004). Libro Blanco Título de grado de Enfermería. Madrid: Agencia Nacional de Evaluación de la calidad y acreditación.

Berbiglia, V. A. (2011). The Self-Care Deficit Nursing Theory as a curriculum conceptual framework in baccalaureate education. Nursing Science Quarterly, 24(2),137-45. doi: $10.1177 / 0894318411399452$

Berntsson, T. \& Hildingh, C. (2012). The nurse-patient relationship in pre-hospital emergency care: form the perspective of Swedish specialist ambulance nursing students.. International emergency nursing, 13. doi: 10.1016/j.ienj.2012.10.003

Besora, I. (1994). Implantación de una guía de valoración de enfermería en Atención Primaria. Enfermería Clínica, 4(3), 128-136.

Biley, F. (1992). Nursing Models redundant in practice? British Journal of Nursing, 1, 219.

Blázquez-Rodríguez, M. I. (2005). Los componentes de género y su relación con la enfermería. Índex Enfermería,14(51),50-4. doi: 10.4321/S1132-12962005000300010

Bond, A. E., Eshah, N. F., Bani-Khaled, M., Hamad, A. O., Habashneh, S., Kataua, H., al-Jarrah, I., Abu Kamal, A., Hamdan, F. R. \& Maabreh, R. (2011). Who uses nursing theory? A 
univariate descriptive analysis of five years' research articles. Scandinavian Journal Caring Science, 25(2),404-9. doi: 10.1111/j.1471-6712.2010.00835.x

Brazier, H. \& Begley, C. M. (1996). Selecting a database for literature searches in nursing: MEDLINE or CINAHL?. Journal of Advanced Nursing, 24(4), 868-875. doi: 10.1046/j.13652648.1996.26426.x

Brito, P. R. (2007). El camino hacia la identidad enfermera. Metas de enfermería, 10 (2), 51-54.

Buergo, O. (2013). Análisis de la implantación de Planes de Cuidados, a través de GACELA, en las unidades médicas del Hospital Santa Bárbara de Soria. NURE Investigación, 66. Recuperado de:

http://www.nureinvestigacion.es/FICHEROS ADMINISTRADOR/ORIGINAL/NURE66 origin al gacela.pdf

Burney, M. A. (1992). King and Neuman: in search of the nursing paradigm. Journal of Advanced Nursing, 17, 601-603.

Burns, N. \& Grove, S. (2004). Investigación en Enfermería (3ạ Edición). Madrid: Elsevier.

Butler, M., Collins, R., Drennan, J., Halligan, P., O'Mathúna, D., Schultz, T., Sheridan, A. \& Vilis, E. (2011). Hospital nurse staffing models and patient and staff-related outcomes (Review). Cochrane Database of Systematic Reviews, 7. doi: 10.1002/14651858.CD007019

Cachón, J.M., Alvarez-López, C. \& Palacios-Ceña, D. (2012). El significado del lenguaje estandarizado NANDA-NIC-NOC en las enfermeras de cuidados intensivos madrileñas, abordaje fenomenológico. Enfermería Intensiva, 23(2), 68-76. doi: 10.1016/j.enfi.2011.12.001

Campo, M.A., Oriach, M.R., Viladot, A., Espinalt, A. \& Fernández, C. (1999). Servicio de cuidados enfermeros según modelo conceptual de Virginia Henderson. Implantación, resultados y costes. Metas Enfermería, 2(13), 8-14.

Campos, M. C. (1991). La teoría de autocuidado de Dorotea Orem. Chile: Universidad Pontificia Católica de Chile.

Cash, K. (1990). Nursing Models and the idea of Nursing. International Journal of Nursing Studies, 27, 249-256. 
Chirveches-Pérez, E., Roca-Closa, J., Sánchez-Pérez, I., Fernández-Burgos, P., Bisquert-Illa, C., Plana-Capdevila, C., Quer-Vall, X., Oriol-Ruscalleda, M. \& Pinyana-Garriga, A. (2009). The concept of "patient type": utility for the care of surgical patients. Enfermería Clinica. 19(4), 175-83.

Chinn, P. \& Kramer, M. (1998). Theory and nursing: A systematic approach ( $5^{\text {th }}$ ed.). St Louis. Missouri.

Cohen, J. (1991). Two portraits of caring: a comparison of the artist, Leininger and Watson. Journal of Advanced Nursing, 16, 899-909.

Coll, M., Besora, I., Icart, T., Ferré, M.A., Manito, I., Ondiviela, A. \& Pulpón, A.M. (2007). Cuidados enfermeros según Virginia Henderson. Ámbito de la atención domiciliaria. Revista Rol de Enfermería, 30(3), 213-216.

Comet-Cortes, P., Escobar-Aguilar, G., González-Gil, T., De Ormijana-Sáenz, A., Rich-Ruiz, M., Vidal-Thomas, C., Córcoles-Jiménez, P., Izquierdo-Mora, D. \& Silvestre-Busto, C. (2010). Establecimiento de prioridades de investigación en enfermería en España: estudio Delphi. Enfermería Clínica, 20 (2), 88-96. doi: 10.1016/j.enfcli.2009.10.003

Consejo General de Enfermería. (2003). Proyecto NIPE. Diseño metodológico. Recuperado de: http://www.nipe.enfermundi.com/servlet/Satellite?cid=1076600384972\&pagename=NIP E\%2FPage\%2Fplantilla generica

Creswell, J. W., \& Clark, V. L. P. (2007). Designing and conducting mixed methods research. Thousand Oaks, CA: Sage publications.

Cunill, L. \& Santos-Ruiz, S. (2012). Uso de las TIC en la filosofía enfermera: propuesta de mapa mental para la planificación de los cuidados en fibromialgia bajo el Modelo de Callista Roy. Ágora de Enfermería, 16(4), 168-75.

Dall, T. M., Chen, Y. J., Seifert, R. F., Maddox, P. J., \& Hogan, P. F. (2009). The economic value of professional nursing. Medical care, 47(1), 97-104. doi: 10.1097/MLR.0b013e3181844da8.

Dávila, C. D. \& González, B. (2009). Crisis económica y salud. Gaceta Sanitaria, 23(4), 261-265. doi: $10.1590 / S 0213-91112009000400001$ 
De Matos, J., Geisa, L., Janaína, M., de Barros, M. D. \& Pelloso, S. M. (2011). Teaching nursing theories in nursing schools within Paraná State - Brazil. Acta Paulista de Enfermagem, 24(1), 23-28. doi: 10.1590/S0103-21002011000100003

Dobratz, M. C. (2008). Moving nursing science forward within the framework of the Roy adaptation model. Nursing Science Quaterly, 21(3):255-9. doi: 10.1177/0894318408319289

Doltra, J. (2012). Las dificultades actuales en la Carrera Académica. Ágora de enfermería, 16(4), 154-155.

Durán, M. M. (2007). Nursing Theory: A Bridle Path? Aquichán, 7(2), 161-173.

Conferencia de Ministros Europeos responsables de la Educación Superior. (1999). Declaración de Bolonya 19 de junio, 1999. Recuperado de: http://www.ees.es/pdf/Bolonia ES.pdf

Edward, K. L., \& Mills, C. (2013). A Hospital Nursing Research Enhancement Model. Journal of continuing education in nursing, 44(10), 447-454. doi: 10.3928/00220124-20130801-45

Escalada, P., Muñoz, P. \& Marro, I. (2013). Atención de enfermería a pacientes psiquiátricos. NANDA-NIC-NOC: una revisión de la literatura. Revista Rol de Enfermería, 36(3): 166-177.

Escuredo, B. (2003). Humanismo y tecnología en los cuidados de enfermería desde la perspectiva docente. Enfermería Clínica, 13(3), 164-170.

Fawcett, J. (1984) The metaparadigm of nursing: present status and future refinements. Image, 16(3), 84-87.

Fawcett, J. (2005). Contemporary Nursing Knowledge: Analysis and Evaluation of Nursing Models and Theories. (2o ed.). Boston: University of Massachusetts.

Fawcett, J. \& Desanto-Madeya, S. (2005). Contemporary nursing knowledge: Analysis and evaluation of nursing models and theories. Philadelphia: FA Davis Company.

Fernández, J. (2001). Elementos que consolidan el concepto profesión: Notas para su reflexión. REDIE: Revista Electrónica de Investigación Educativa, 3(2), 2.

Fernández, M. C. (1998). Modelo de Hildegard Peplau y relación de ayuda. Enfermería Clínica, $8(1), 24-28$. 
Fernández, R., Johnson, M., Tran, D. T. \& Miranda, C. (2012). Models of care in nursing: a systematic review. International Journal Evidence Based Healthcare,10(4),324-37. doi: 10.1111/j.1744-1609.2012.00287.x.

Fornés, J. (2005). Enfermería de salud mental y psiquiátrica: planes de cuidados. Madrid: Panamericana.

Fornons, D. (2010). Madeleine Leininger: claroscuro trascultural. Index de Enfermería, 19(2-3), 172-176. doi: 10.4321/S1132-12962010000200022

Francisco del Rey, C. (2008). De la práctica de la enfermería a la teoría enfermera. Concepciones presentes en el ejercicio profesional. (Tesis doctoral Universidad de Alcalá. Alcalá de Henares, España). Recuperado de:

http://dspace.uah.es/dspace/bitstream/handle/10017/2700/Tesis De\%20la\%20pr\%C3\%A 1ctica\%20a\%20la\%20teor\%C3\%ADa.pdf?sequence=1

Fuentelsaz, C. (2004). Cálculo del tamaño de la muestra. Matronas profesión, 5(18), 5-13.

Fuentes, P., Gasco, P., Gata, V., Marco, R., Martín, E., Morán, T., Piqueras, P. \& Sobrino, J. A. (2005). Guía de recomendaciones de autocuidado al alta del paciente geriátrico intervenido quirúrgicamente de fractura de cadera. NURE Investigación, 19. Recuperado de: http://www.nureinvestigacion.es/FICHEROS ADMINISTRADOR/PROTOCOLO/protocolo\%2 0193112005111342.pdf

García, C. \& Martínez, M.L. (2007). Historia de la enfermería. Madrid: Elsevier.

Gerrish, K. \& Lacey, A. (2006). Investigación en enfermería. Madrid: McGraw-Hill.

Gobierno de España. Ministerio de Educación. Oferta de titulaciones. Diplomado de Enfermería. Recuperado de: https://www.educacion.es/notasdecorte/jsp/compBdDo.do

Gobierno de España. Ministerio de la presidencia. Real Decreto 1393/2007, de 29 de octubre. Boletín Oficial del Estado. Recuperado de: http://www.scele.enfe.ua.es/web scele/archivos/boe rd 1393 07.pdf

Gobierno de España. Ministerio de la presidencia. Real Decreto 1125/2003, de 5 de septiembre. Boletín Oficial del Estado. Recuperado de: http://www.boe.es/aeboe/consultas/bases datos/doc.php?id=BOE-A-2003-17643 
Gobierno de España. Ministerio de la presidencia. Real Decreto 12388/2008, de 3 de julio. Boletin Oficial del Estado. Recuperado de: http://www.boe.es/boe/dias/2008/07/19/pdfs/A31680-31683.pdf

Gobierno de España. Ministerio de la presidencia. Boletín Oficial del Estado: lunes 22 de octubre de 1984, Núm. 253. RESOLUCION de 19 de septiembre de 1984, de la Secretaría de Estado de universidades e Investigación por la que se acepta lo propuesta de la Comisión de las Pruebas de Idoneidad para el acceso al Cuerpo de Profesores Titulares de Escuelas Universitarias en el área de Enfermería. Recuperado de: http://www.boe.es/boe/dias/1984/10/22/pdfs/A30591-30592.pdf

Gobierno de España. LEY 44/2003, de 21 de noviembre, de ordenación de las profesiones sanitarias. Recuperado de: http://www.boe.es/boe/dias/2003/11/22/pdfs/A41442-41458.pdf

Gómez, M., Altisent, R., Cantera, J., Ciprés, L., Corral, P., González, J. L., Herranz, J. A., Rocafort, J. \& Rodríguez, J. J. Grupo de trabajo Atención médica al final de la vida (2010). Consideraciones de la Organización Médica Colegial para el desarrollo de los cuidados paliativos en España. Revista de la Sociedad Española del dolor, 17(4), 213-5.

González, A., Fabrellas, N., Agramunt, M., Rodríguez, E. \& Grifell, E. (2008). De paciente pasivo a paciente activo. Programa Paciente Experto del Institut Català de la Salut. Revista de Innovación Sanitaria y Atención Integrada, 1(1), 3.

Goode, C. J., Blegen, M. A., Park, S. H., Vaughn, T. \& Spetz, J. (2011). Comparison of patient outcomes in Magnet ${ }^{\circledR}$ and non-Magnet hospitals. Journal of nurse administration,41(12), 517-23. doi: 10.1097/NNA.0b013e3182378b7c

Goulet, C., Lauzon, S. \& Ricard, N. (2003). Enfermería de práctica avanzada: un tesoro oculto. Enfermería Clínica, 13(1), 48-52.

Granollers, R., Montanuy, T., Estany, P., Roca, B. \& Ortega, B. (2006). ¿Utilizan las enfermeras el método científico?. Revista Rol Enfermería, 29(7-8), 509-512.

Griffith, P. (1998). An investigation into the description of patients' problems by nurses using two different needs-based nursing models. Journal of Advanced Nursing, 28, 969-977. 
Gunther, M., \& Alligood, M. R. (2002). A discipline-specific determination of high quality nursing care. Journal of Advanced Nursing, 38(4), 353-359. doi: 10.1046/j.13652648.2002.02201.x

Gustafson, D. L. (2005). Transcultural Nursing Theory from a Critical Cultural Perspective. Advances in Nursing Science, 28(1),2-16.

Gutiérrez, M. C. (2007). Adaptación y cuidado en el ser humano una visión de enfermería. Bogotá: Universidad de la Sabana Colombia.

Harmer, B \& Henderson, V (1955). Textbook of the principles and practice of nursing).New York: McMillan.

Harwood, R. H., Sayer, A. A., \& Hirschfeld, M. (2004). Current and future worldwide prevalence of dependency, its relationship to total population, and dependency ratios. Bulletin of the World Health Organization, 82(4), 251-258. doi: 10.1590/S0042-96862004000400006.

Heierle, C. (2009). La imagen de la enfermera a través de los medios de comunicación de masas: La prensa escrita. Índex de Enfermería, 18(2), 95-98.

Henderson, S. (2003). Power imbalance between nurses and patients: a potential inhibitor of partnership in care. Journal of clinical nursing, 12(4), 501-508. doi: 10.1046/j.13652702.2003.00757.x

Henderson, V. (1958). The basic principles of nursing care. Nursing Mirrow, 107.

Henderson, V. (1966). The nature of nursing: a definition and its applications for practice, research and education. New York: McMillan.

Henderson, V. (1964). The nature of nursing. American Journal of Nursing, 64, 62-68.

Henderson, V \& Nite, G.A. (1978). The principles and practice of nursing. New York: McMillan.

Hernández, F. (1996). Historia de la enfermería en España. Madrid: Síntesis.

Hernández, J. M., Moral, P. \& Esteban, M. (1999). Fundamentos de Enfermería. Teoría y método. Madrid: Mc GrawHill - Interamericana.

Hilton, P. A. (2004). Fundamental Nursing Skills. Philladelphia: Whurr Publishers Ltd. 
Horta, W.A.(1979). Processo de enfermagem. São Paulo: EPU.

Icart , M. T., Fuentelsalz, C. \& Pulpón, A. M.(2001). Elaboración y presentación de un proyecto de investigación y una tesina. Barcelona: EUB, Edicions Universitat de Barcelona.

Institute of Medicine. (2011). The future of nursing: Leading change, advancing health. Washington, DC: National Academies Press.

Instituto de Salud Carlos III (2011). RN4cast. Nurse forecasting in Europe. Informe global hospitales españoles. ISCIII. Recuperado de: http://www.isciii.es/ISCIII/es/contenidos/fd-elinstituto/fd-organizacion/fd-estructura-directiva/fd-subdireccion-general-redes-centrosinvestigacion2/fd-centros-unidades2/fd-investen-isciii-2/docus/Informe global Spain.pdf

International Council of Nursing. (s.f.). La Definición de Enfermería. Recuperado el 1 de julio de 2013, de: http://www.icn.ch/es/about-icn/icn-definition-of-nursing/

ISI Web of knowledge. (s.f.) Journal Citacion Reports. Recuperado el 1 de julio de 2013, de: http://sauwok5.fecyt.es/admin-apps/JCR/JCR?RQ=LIST MARKED

Irigibel-Uriz, X. (2007). Revisión crítica de una interpretación del pensamiento de Virginia Henderson: Acercamiento epistemológico al libro de Luis, Fernández y Navarro. Índex de Enfermería, 16(57), 55-59.

Johns, C. (Eds.). (1994). The Burford NDU Model: Caring in Practice. Oxford: Blackwell Science.

Johnson, D. E. (1987). Evaluating conceptual models for use critical care nursing practice. Dimension Critical Care Nursing, 6(4), 195-197.

Juan, A., Enjamio, E., Moya, C., García, C., Castellanos, J., Pérez Mas et al. (2010). Impacto de implementación de medidas de gestión hospitalaria para aumentar la eficiencia en la gestión de camas y disminuir la saturación del servicio de urgencias. Emergencias: Revista de la Sociedad Española de Medicina de Urgencias y Emergencias, 22(4), 249-253.

Jurado-Campos, J., Anglada-Dilme, M.T., Canet-Ponsa, M., Privat-Marcè, M.L., Fàbrega-Pairó, T. \& Juvinyà-Canal, D. (2008). Implementación de un modelo integrado de enfermería de enlace: un estudio descriptivo. Enfermería Clínica, 18(5), 253-61. doi: 10.1016/S1130$8621(08) 72384-2$ 
Kalideen, D. (1993). Is there a place for nursing models in theatre nursing? British Journal of Theatre Nursing, 3(5), 4-6.

Kane, R. L., Shamliyan, T., Mueller, C., Duval, S., \& Wilt, T. J. (2007). Nurse staffing and quality of patient care. Evidence report technology assessment, 151, 1-115.

Keeney, S., Hasson, E \& McKenna, H. (2001). A critical review of the Delphi technique as a research methodology for nursing. International Journal of Nursing Studies, 38,195-200. doi: 10.1016/S0020-7489(00)00044-4

Kennedy, H. (2004). Enhancing Delphi research: methods and results. Journal of Advanced Nursing 45, 504-511. doi: 10.1046/j.1365-2648.2003.02933.x

Kérouac, S., Pepin, J., Ducharme, F., Duquette, A. \& Major, F. (1996). El pensamiento enfermero. Barcelona: Masson.

Kim, T. S. (2008). Science of Unitary Human Beings : An Update on Research. Nursing Science Quarterly, 21(4): 294-99. doi: 10.1177/0894318408324333

King , I. (1981). A theory for Nursing. New York: Editorial Whiley \& Sons.

Knobel, M. \& Lankshear, C. (2001). Maneras de ver: el análisis de datos en investigación cualitativa. México: Editorial Morelia.

Kramer, M. \& Hafner, L. P. (1989). Shared values: impact on staff nurse job satisfaction and perceived productivity.Nursing Research, 38(3), 172-177.

Kuhn, T. S. (1975). La estructura de las revoluciones científicas. México: Fondo de Cultura Económica.

Kutney-Lee, A., McHugh, M. D., Sloane, D. M., Cimiotti, J. P., Flynn, L., Neff, D. F., \& Aiken, L. H. (2009). Nursing: a key to patient satisfaction. Health Affairs, 28(4), 669-677.

Leininger, M. M. (1995). Transcultural nursing: Concepts, theories, research and practices. New York: McGraw-Hill.

López, A. L. \& Guerrero, S. (2006). Perspectiva internacional del uso de la teoría general de Orem. Investigación y educación en enfermería 24(2), 90-100.

López, C., Riu, M. \& Forner, M. (2005). Cuidados enfermeros. Barcelona: Masson. 
López, F. (2002). El análisis de contenido como método de investigación. Revista de Educación, 4, 167-179.

López, J. (2000). Propuestas para el desarrollo profesional (y II). Enfermería Clínica, 10(4), 157 -62 .

López, M., Santos, S., Varez, S., Abril, D., Rocabert, M., Ruiz, M. \& Mañe, N. (2006). Reflexiones acerca del uso y utilidad de los modelos y teorías de enfermería en la práctica asistencial. Enfermería Clínica, 16(4),218-21.

López, M., Santos, S., Sánchez, G., Bardallo, D., Fernández, L., Zabalegui, A., Abril, D., Varez, S. \& Tomás-Sábado, J. (2009a). Modelos y metodología enfermera: una mirada desde diferentes propuestas formativas. Ágora de Enfermería, 13(4), 138-47.

López, M., Santos, S., Sánchez, G., Bardallo, D., Fernández, L., Zabalegui, A., Abril, D., Varez, S. \& Tomás-Sábado, J. (2009b). Los modelos en la práctica asistencial: visión de los profesionales y estudiantes de Enfermería. Metas de Enfermería, 12(4), 16-26.

López, M., Santos, S., Varez, S. \& Abril, D. (2009). Elemento salud del metaparadigma enfermero ¿Cuál es la visión de los enfermeros asistenciales? Temperamentvm, 9. Recuperado de: http://www.index-f.com/temperamentum/tn9/t1308.php

López, S. R., Martínez A. A. \& Quesada, C. (2008). Investigar en cuidados con o sin barreras. Revista de Administración Sanitaria, 6(4), 673-80.

López, J. (2000). Propuestas para el desarrollo profesional (I). Enfermería Clínica, 10(3), 114118.

López-Medina, I. M. \& Sánchez-Criado, V. (2005). Percepción del estrés en estudiantes de enfermería en las prácticas clínicas. Enfermería Clínica, 15(6), 307-313. doi: 10.1016/S11308621(05)71136-0

Lorenzo, N. (2008). Dar sentido desde la enfermedad terminal. Estudio cualitativo influenciado por la teoría de R. R. Parse. Medicina paliativa, 15(4), 210-219.

Luis, M. T., Fernandez, C. \& Navarro, M. V. (2007). De la teoría a la práctica. El pensamiento de Virginia Henderson en el siglo XXI. 3a ed. Barcelona: Masson. 
Lukose, A. (2011). Developing a Practice Model for Watson's Theory of Caring. Nursing Science Quarterly, 27(1), 27-30. doi: 10.1177/0894318410389073

Maben, J., Alter, S. \& McLeod, J. (2006). The theory-practice gap: impact professionalbureaucratic work conflict on newly-qualified nurses. Journal of Advanced Nursing, 55(4), 465-477. doi: 10.1111/j.1365-2648.2006.03939.x

Madrid, M. (1996). Hospital nursing conducted according to Rogers' theory. The participating process of human field patterning in a clinical environment. Pflege ,9(4), 246-54;

March, J. C., Prieto, M. A., Danet, A., Pérez, O. \& Martínez, F. (2009) Los directivos hospitalarios y la comunicación interna: una asignatura pendiente. Revista de Administración sanitaria XXI. 7(1), 165-82.

Marriner, A. \& Raile, M. (2003). Modelos y teorías en enfermería. (5a ed.). Madrid: Mosby.

Marriner, A. \& Raile, M. (2011). Modelos y teorías en enfermería. (7a ed.). Barcelona: Elsevier Mosby .

Martínez, C. (2009). Nuevos retos del Sistema Sanitario. REDUCA (Recursos Educativos). Serie Medicina, 1(1),19-39.

Martín-Crespo, C. \& Salamanca, A. B. (2007, Febrero). El muestreo en la investigación cualitativa. NURE Investigación, 27(7). Recuperado de: http://www.fuden.es/ficheros administrador/f metodologica/FMetodologica 27.pdf

Martínez, C., Cañadas, A., Rodríguez, E. \& García, S. (2003). Dificultades en la valoración enfermera. Enfermería Clínica, 13(4), 195-201.

McCrae, N. (2011): Whither nursing models? The value of nursing theory in the context of evidence-based practice and multidisciplinary health care. Journal of Advanced Nursing, 68(1): 222-229. doi: 10.1111/j.1365-2648.2011.05821.x

McCutcheon, T. (2004). Statement on Nursing: A personal perspective. Gastroenterology Nursing, 27(5), 226-229.

Mckenna, H. (1990). The perception of psychiatric-hospital ward sisters/charge nurses towards nursing models. Journal of Advanced Nursing, 15, 1319-1325. 
Mckenna, H., Parahoo, K. \& Boore, J. (1995). The evaluation of a nursing model for long-stay psychiatric patient care. Part 2-Presentation an discusion of findings. International Journal of Nursing Studies, 32(1), 95-113.

McKenna, H (1989). The selection by wards managers of an appropriate nursing model for long-stay psychiatric. Journal of Advanced Nursing, 14, 762-775.

Medina, J.L. (2005). ¿Teoría? ¿Práctica? El difícil equilibrio académico y profesional en la España "pre-europea" (II). Revista Rol Enfermería, 28(4), 246-248.

Meleis, A. I. (1992). Directions for nursing theory development in the 21st century. Nursing Science Quaterly, 5(3), 110-117.

Meleis, A. I. (2011). Theoretical nursing: development and progress. $5^{\text {th }}$ Ed, Philadelphia: Lippincott Williams \& Wilkins.

Merino, J. R., López, M., Marinas, M. J., Merino, A., Sánchez, E. \& Vaca, R. (2008). Plan de cuidados estandarizados para pacientes con cirugía percutánea (nefrolitotomía). Aplicación en el programa informático Gacela. ENFURO: Asociación Española de Enfermería en Urología, 105, 6-10.

Merritt, M. K. \& Procter, N. (2010). Conceptualising the functional role of mental health consultation-liaison nurse in multi-morbidity, using Peplau's nursing theory. Contemporary Nurse, 34(2), 158-166. doi: 10.5172/conu.2010.34.2.158

Miles, M. B. \& Huberman, A. M. (1994). Qualitative data analysis: An expanded sourcebook, 2nd Ed. Thousand Oaks, CA: Sage.

Miller, B.A. (1985). The relation between nursing theory and nursing practice. Journal of Advanced Nursing, 10, 417-424.

Mingote, J.C. \& Pérez, S. (2003). Estrés en la enfermería. El cuidado del cuidador. Madrid: Díaz de Santos.

Ministerio de Sanidad y Consumo. Sistema Nacional de Salud. Recuperado el 1 de julio de 2013, de: http://www.msssi.gob.es/estadEstudios/estadisticas/docs/LIBRO-BAJA.PDF

Ministerio de Sanidad, Política Social e Igualdad. Catálogo Nacional de Hospitales 2011. Recuperado el 1 de julio de 2013, de: 
http://www.msc.es/ciudadanos/prestaciones/centrosServiciosSNS/hospitales/docs/CNH2 011.pdf

Morales, J.M. (2004). Investigación de resultados en enfermería el camino hacia la efectividad de los cuidados. Índex Enfermería, 13(44-45), 37-41. doi: 10.4321/S113212962004000100008

Moreira, T. M. M. \& Araújo, T. L. D. (2002). O modelo conceitual de sistemas abertos interatuantes ea teoria de alcance de metas de Imogene King. Revista Latino-Americana de Enfermagem, 10(1), doi: 97-107. 10.1590/\$0104-11692002000100015

Moreno, M. E. (2005). Importancia de los modelos conceptuales y teorías de enfermería: experiencia de la Facultad de Enfermería de la Universidad de La Sabana. Aquichán, 5(1), 4455.

Moreno-Fergusson, M. E. (2012). Metodologías para la aplicación del conocimiento teórico de enfermería. Aquichan, 12(2).

Moreno-Fergusson, M. E. \& Alvarado-García, A. M. (2009). Aplicación del Modelo de Adaptación de Callista Roy en Latinoamérica: revisión de la literatura. Aquichan, 9(1), 62-72.

Moreno, M. E., Durán, M. M. \& Hernández, A. (2009). Nursing care for adaptation. Nursing Science Quaterly, 22 (1),67-73. doi: 10.1177/0894318408327296

Murphy, K., Cooney, A., Casey, D., Connor, M., O'Connor, J. \& Dineen, B. (2000). The Roper, Logan and Tierney (1996) Model: perceptions and operationalization of the model in psychiatric nursing within a Health Board in Ireland. Journal of advanced nursing, 31(6), 13331341. doi: 10.1046/j.1365-2648.2000.01427.x

Navarro, Y. \& Castro, M. (2010). Modelo de Dorothea Orem aplicado a un grupo comunitario a través del proceso de enfermería. Enfermería global, 19. Recuperado de: http://revistas.um.es/eglobal/article/view/106821

Newman, M. A., Sime, A. M. \& Corcoran-Perry, S. A. (1991). The focus of the discipline of Nursing. Advances in Nursing Science, 14 (1), 1-6.

Newman, M. A. (1992). Prevailing Paradigms in Nursing. Nursing Outlook, 40 (1), 10-13. 
Oh, Y. \& Gastmans, C. (2013). Moral distress experienced by nurses: A quantitative literature review. Nursing ethics, 3. doi: 10.1177/0969733013502803

Okoli, C. \& Pawlowski, S. (2004). The Delphi method as a research tool: an example, design considerations and applications. Information \& Management, 42,15-29. doi: 10.1016/j.im.2003.11.002.

OECD (2013). Health at a Glance 2013: OECD Indicators, OECD Publishing. doi: 10.1787/health_glance-2013-en.

Oelke, N. D., White, D., Besner, J., Doran, D., Hall, L. M. \& Giovannetti, P. (2008). Nursing workforce utilization: An examination of facilitators and barriers on scope of practice. Nursing Leadership, 21(1), 58. doi: 10.1111/j.1466-7657.2008.00705.

Olivellas, M. C., Bastidas, C. V., \& Castiblanco, M. A. (2010). Propuesta de una ruta metodológica para implementación del Modelo de Orem en la práctica de enfermería. Salud Uninorte, 26(2), 339-348.

Onieva-Zafra, M.D., Castro-Sánchez, A.M., Matarán-Peñarrocha, G.A. \& Moreno-Lorenzo, C. (2010). Effect of music as nursing intervention for people diagnosed with fibromyalgia. Pain Management Nursing, 25. doi: 10.1016/j.pmn.2010.09.004

Orem, D. E. (1993). Modelo de Orem: Conceptos de enfermería en la práctica. Barcelona: Masson-Salvat.

Organización colegial de Enfermería (2011). Ficha técnica de propuesta de título universitario de Grado según RD 55/2005, de 21 de enero. Recuperado de: http://www.cge.enfermundi.com/servlet/Satellite?blobcol=urldata\&blobheader=applicati on\%2Fpdf\&blobkey=id\&blobtable=MungoBlobs\&blobwhere=1144068552848\&cachecont rol=immediate\&csblobid=KoUdCivJvHNRS1s9czB1rZ1lyp3eMYKhscSN9eKFoBnoNtTBtmLL $\% 211872681766 \% 211244140701942 \&$ ssbinary=true

Organización Panamericana de la Salud (1961). CIE. Principios básicos de los cuidados de enfermería. Washington: Organización Mundial de la Salud.

Orts, M.I., Richart, M. \& Cabrero J. (2002). Factor de impacto en las revistas de enfermería. Enfermería Clínica, 12(6),266-72.

Oteo, L. A. (2006). Manuales de dirección médica y gestión clínica. Madrid: Ed Díaz de Santos. 
Parse, R. R. (2012). New humanbecoming conceptualizations and the humanbecoming community model: expansions with sciencing and living the art. Nursing Science Quarterly, 25(1).44-52. doi: 10.1177/0894318411429068

Pearson, A. (1992). Nursing at Burford: a story of change. Harrow: Scutari Press.

Pearson, A., Vaughan, B., \& FitzGerald, M. (2005). Nursing models for practice. China: Elsevier Health Sciences.

Pereda, M. (2011). Explorando la teoría general de enfermería de Orem. Enfermería Neurológica (Mex), 10( 3), 163-167.

Pérez, C. (2000). ¿¿Deben estar las técnicas de consenso incluidas entre las técnicas de investigación cualitativa? Revista Española de Salud Pública,74, 4, 319-321.

Pérez, L., Soler, S. F. \& Díaz, L. (2009). Ambiente Laboral en los policlínicos universitarios. Educación Médica Superior, 23(2), 0-0.

Peterson, S. J., \& Bredow, T. S. (Eds.). (2009). Middle range theories: application to nursing research. Philadelphia: Lippincott Williams \& Wilkins.

Pina, F., Fernandez, M. P. \& Crespo, C. (1990). Plan de cuidados al niño prematuro. Enfermería Científica, 105, 9-11.

Polit, D. F. \& Beck, C. T. (2004). Nursing Research. Principles and Methods. Seventh edition. Philadelphia: Lippincott Williams \& Wilkins.

Polit, D. F. \& Northam, S. (2011). Impact factors in nursing journals. Nursing Outlook, 59(1), 18-28. doi: 10.1016/j.outlook.2010.11.001.

Potter, P.A. \& Perry, A. G. (2002). Fundamentos de enfermería. Fundamentos teóricos de la práctica enfermera. (Vol. I.). Madrid: Hartcourt - Mosby.

Price, B. (2005). Delphi survey research and older people. Nursing Older People, 17 (3), 25-31. doi: 10.7748/nop2005.05.17.3.25.c2373

Quintairos, S. (2008). Del practicante a la enfermera. 150 años de desarrollo profesional: El papel los colegios profesionales (Tesis doctoral Universidade da Coruña. Coruña, España). Recuperado de: http://ruc.udc.es/dspace/handle/2183/5666 
Raimondo, M. L., Fegadolil, D., Méier, M. J. , Wall, M. L., Labronici L. M, \& Raimondo-Ferraz M. I. (2012). Produção científica brasileira fundamentada na Teoria de Enfermagem de Orem: revisão integrativa. Revista Brasileira de Enfermagem, 65(3), 529-34. doi: 10.1590/S003471672012000300020

Real Academia Española. (2001). Diccionario de la Lengua Española. (22a Ed). Madrid: Real Academia Española.

Reilly, D. E. (1975). Why a conceptual framework? Nursing Outlook, 23 (9), 566-569.

Reyes, J., Jara, P. \& Merino, J. M. (2007). Adherencia De Las Enfermeras/os a utilizar un modelo teórico como base de la valoración de enfermería. Ciencia y Enfermería. 13(1), 45-57. doi: $10.4067 /$ S0717-95532007000100006

Richards, A. \& Edwards, S. (2010). Guía de supervivencia para enfermería hospitalaria. Barcelona: Elsevier.

Richart, M., Cabrero, J. \& Flores, M. (1999). El uso de los modelos de enfermería en la investigación enfermera española: 1992-1996. Cultura de los cuidados, 5, 75-82.

Rivero, A., Pajares, C., Pacheco, E., Rodríguez, J. A. \& Cozar, R. (2002). Proyecto NIPE: Normalización de las Intervenciones para la Práctica de la Enfermería. Madrid, Consejo General de Enfermería, Ministerio de Sanidad.

Rodero-Sánchez, V., Acebedo-Urdiales, S., Vives-Relats, C. \& Pérez-Gurrea, C. (2006). Análisis de los posibles desde la teoría de Parse en una persona con Alzheimer. Índex de Enfermería, 15(54), 44-47. doi: 10.4321/S1132-12962006000200009

Rodríguez , A. M. \& Ferrer, M. A. (2002). Prevalencia de diagnósticos enfermeros de la NANDA y necesidades alteradas de Henderson en una unidad de lactantes. Enfermería Clínica, 12(6), 255-261. doi:10.1016/S1130-8621(02)73762-5

Rodríguez, J.A. \& Bosch, J. LL. (2004). Enfermeras hoy: Cómo somos y cómo nos gustaría ser. Conclusiones del estudio sociológico. Barcelona: Universitat de Barcelona.

Roecklein, N. (2012). Using standardized nursing languages in end-of-life care plans. International Journal of nursing knowledge, 23(3):183-5. doi: 10.1111/j.2047-3095.2012.01211.x. 
Román, M., Campos, A., Viñas, C., Palop, R., Zamudio, A., Domingo, R., López, M. C., de la Torre, I., Díaz, M. A. \& Mansilla, J. J. (2005). Las taxonomías enfermeras NANDA, NOC y NIC en la práctica asistencial hospitalaria. Enfermería Clínica,15 (3),163-166. doi: $10.1016 / \mathrm{S} 1130-8621(05) 71103-7$

Sacristán, J. G., \& Gómez, A. P. (Eds.). (2008). La enseñanza: su teoría y su práctica. Madrid: Ediciones AKAL.

Salmond, S. W., Begley, R., Brennan, J., \& Saimbert, M. K. (2009). A comprehensive systematic review of evidence on determining the impact of Magnet designation on nursing and patient outcomes: is the investment worth it?. The JBI Database of Systematic Reviews and Implementation Reports, 7(26), 1119-1178.

Salsberry, P.J. (1994). A philosophy of nursing: What is it? What is it not? En Kikuchi, J. F. \& Simmons, H. (Eds.). Developing a philosophy of nursing. Thousand Oaks: Sage Publications.

Sánchez, S. \& Salamanca, A. B. (2013). Lectura crítica de estudios cualitativos (I): valoración del rigor. NURE Investigacion, 65. Recuperado de: http://www.nureinvestigacion.es/FICHEROS ADMINISTRADOR/F METODOLOGICA/NURE $\underline{65 \text { formet.pdf }}$

Sangster-Gormley, E., Martin-Misener, R., Downe-Wamboldt, B. \& DiCenso, A. (2011). Factors affecting nurse practitioner role implementation in Canadian practice settings: an integrative review. Journal of advanced nursing, 67(6), 1178-1190. doi: 10.1111/j.13652648.2010.05571.x.

Santos, S., López, M., Varez, S. \& Abril, D. (2008a). Aplicabilidad de modelos y teorías de Enfermería en la realidad asistencial: perspectiva profesional. Resultados primera fase. Metas de Enfermería. 11(6): 50-57.

Santos, S., López, M., Varez, S. \& Abril, D. (2008b). Concepto de Enfermería, mirada profesional del metaparadigma. Temperamentvm 2008, 7. Recuperado de: http://www.indexf.com/temperamentum/tn7/t6682.php

Santos, S., López, M., Varez, S. \& Abril, D. (2008c). Perspectiva de la Enfermería de un centro sociosanitario sobre la aplicabilidad y utilidad de los modelos enfermeros en la práctica. Gerokomos, 19(4): 184-190. 
Santos, S., López, M., Varez, S. \& Abril, D. (2009) ¿El ámbito profesional modifica la conceptualización enfermera? Estudio comparativo entre enfermeras del ámbito médico y quirúrgico. Enfermería global , 17. Recuperado de: http://revistas.um.es/eglobal/article/view/75211/72521

Santos, S., López, M., Varez, S. \& Abril, D. (2010a). Factores que determinan la perspectiva profesional del concepto de persona. Agora de Enfermería, 14(2): 76-82.

Santos, S., López, M., Varez, S. \& Abril, D. (2010b). Visión del profesional de enfermería sobre el entorno como parte integrante del metaparadigma. Enfermería global, 18. Recuperado de: http://revistas.um.es/eglobal/article/viewFile/93711/90901

Santos, S., López, M., Varez, S. \& Abril, D. (2010c). Propuesta de un modelo teórico para la práctica enfermera. NURE Investigación, 7 (44). Recuperado de: http://www.fuden.es/FICHEROS ADMINISTRADOR/ORIGINAL/promodenf.pdf

Silva, E. P., Alves, A. R., Macedo, A. R., Bezerra, R. M., Almeida, P. C. \& Chaves, E. M.(2013). Nursing diagnoses related to breastfeeding in a rooming-in unit. Revista Brasileira de Enfermagem, 66(2), 190-5. doi: 10.1590/S0034-71672013000200006

Simmons, L. (2009). Dorothea Orem's self care theory as related to nursing practice in hemodialysis. Nephrology Nursing Journal, 36(4), 419-21.

Simpson, J. (1998). The perplexities of Conceptual Frameworks. Canadian Nurse, 94(10), 51.

Simpson, J. \& Taylor, D. (2002). Reality check. Do conceptual Models of Nursing Work Today? Canadian Nurse, 98 (2), 24-26.

Subirana, M., \& Solá, I. (2006). Revisión sistemática de los instrumentos que miden la actividad de enfermería y su repercusión sobre los resultados en salud. Metas de Enfermería, 9(6), 22-27.

Subirana, M., Solá, I., Garcia, J. M., Gich, I. \& Urrútia, G. (2005). A nursing qualitative systematic review required MEDLINE and CINAHL for study identification. Journal of clinical epidemiology, 58(1), 20-25. doi: 10.1016/j.jclinepi.2004.06.001.

Teffeteller, S. L. \& Kish, T. M. (2012). Mining internal data to reduce clinical costs. Healthcare Financial Management. ,66(12):80-5. 
Teixidor, M. (2002a). El producto enfermero y la reforma de los procesos asistenciales (I). Revista Rol Enfermería, 25 (4), 252-256.

Teixidor, M. (2002b). El producto enfermero y la reforma de los procesos asistenciales (II). Revista Rol Enfermería, 25 (5), 328-330.

Thorne, S., Canam, C., Dahinten, S., Hall, W., Henderson, A. \& Reimer, S. (1998). Nursing's metaparadigm concepts: disimpacting the debates. Journal of Advanced Nursing, 27, 12561268.

Thoroddsen, A. \& Thorsteinsson, H. S. (2002). Nursing diagnosis taxonomy across the Atlantic Ocean: congruence between nurses' charting and the NANDA taxonomy. Journal of Advanced Nursing, 37(4),372-81. doi: 10.1046/j.1365-2648.2002.02101.x

Tierney, A. J. (1998). Nursing models: extant or extinct?. Journal of Advanced Nursing, 28(1), 77-85.

Torrents, R., Oliva, E., Saucedo, M. J., Surroca, L. \& Jover, C. (2003). Impacto de los familiares del paciente crítico ante una acogida protocolizada. Enfermería intensiva, 14(2), 49-61.

Travelbee, J. (1964). What's Wrong with Sympathy?. The American journal of nursing, 64, 68.

Ullin, P. R., Robinson, E. T. \& Tolley, E. E. (2006). Investigación aplicada en salud pública. Métodos cualitativos. Washington: Organización Panamericana de la Salud.

Universitat de Lleida. Plan de estudios del Máster Universitario en Ciencias de la Enfermería. Facultad de Medicina y Ciencias de la Salud. Recuperado el 25 de febrero de 2011, de: http://www.masterinfermeria.udl.cat/export/sites/Infermeria/Pla dxestudis MASTER.pd $\underline{f}$

Universitat Internacional de Catalunya. Plan de estudios del Máster Universitario en Ciencias de la Enfermería. Facultad de Medicina y Ciencias de la Salud. Recuperado el 25 de febrero de 2011, de: http://www.uic.es/ca/ciencies-infermeria?fitxa basica=5\&item=15

Universitat Rovira i Virgili. Guía docente del Máster en Ciencias de la Enfermería 2010-2011. Escola Universitaria d'Infermeria. Recuperado el 25 de febrero de 2011, de: http://moodle.urv.net/docnet/guia docent/index.php?centre=18\&ensenvament=1860\&a ssignatura $=18605111 \&$ any academic $=201011$ 
Urra, M. E. (2009). Avances de la ciencia de enfermería y su relación con la disciplina. Ciencia y enfermería, 15 (2), 9-18. doi: 10.4067/\$0717-95532009000200002

Urra, M., Jana, A. \& García, V. (2011). Algunos aspectos esenciales del pensamiento de Jean Watson y su teoría de cuidados transpersonales. Ciencia y enfermería, 17(3), 11-22. doi: http://dx.doi.org/10.4067/\$0717-95532011000300002

Varez, S., López, M., Santos, S. \& Abril, D. (2008). Perspectiva sobre modelos y teorías de enfermería en el ámbito de Nefrología. Revista de la Sociedad Española de Enfermería Nefrológica, 11(3):178-183.

Vera, A. (2005). Dialogo entre lo cuantitativo y lo cualitativo en la Investigación científica. El desafío de la triangulación. Ciencia y Trabajo, 7 (15), 38-40.

Vera, A. \& Villalón, M. (2005). La Triangulación entre Métodos Cuantitativos y Cualitativos en el Proceso de Investigación. Ciencia y trabajo, 16, 85-7.

Vernet, F. (2007). Conceptos básicos de enfermería en la atención gerontológica según el modelo de V. Henderson. Gerokomos,18(2),77-83. 10.4321/S1134-928X2007000200004

Wagner, J. (2009). Barriers for Hispanic women in receiving the human papillomavirus vaccine: a nursing challenge. Clinical Journal of Oncology Nursing, 13(6), 671-5. doi: 10.1188/09.CJON.671-675

White, K. (2002). Nursing as vocation. Nursing Ethics, 9(3), 279-290. doi: 10.1191/0969733002ne510oa

Whittemore, R. \& Knafl, K. (2005). The integrative review: updated methodology. Journal of Advanced Nursing, 52(5), 546-553. doi: 10.1111/j.1365-2648.2005.03621.x

Wiedenbach, E. (1970). Comment on" Beliefs and Values: Bases for Curriculum Design". Nursing Research, 19(5), 427.

Wilson, J. \& Gramling, L. (2009). The application of Orem's Self-Care Model to burn care. Journal of Burn Care Research, 30(5), 852-8. doi: 10.1097/BCR.0b013e3181b48a2d.

Villagomez, A. \& Jiménez, M. J. (2011). Implementación del Registro Clínico de Enfermería Basado en el Modelo de Adaptación de Callista Roy. Desarrollo Científico Enfermero, 
19(5). Recuperado el 4 de octubre de 2013 de: http://www.index-f.com/dce/19/19183.php

Wimpenny, P. (2002). The meaning of models of nursing to practicing nurses. Journal of Advanced Nursing, 40 (3), 346-54.

Woerner, L., Espinosa, J., Bourne, S., O'Toole, M. \& Ingersoll, G. L. (2009). Project (inverted exclamation mark) EXITO!: success through diversity and universality for outcomes improvement among Hispanic home care patients. Nursing Outlook, 57(5):266-73. doi: 10.1016/j.outlook.2009.02.001

Yañez, R. \& Cuadras, R. (2008). La técnica Delphi y la investigación en los servicios de salud. Ciencia y Enfermería,14 (1), 9-15. doi: 10.4067/S0717-95532008000100002

Yura, H. \& Torres, G. (1975). Today's conceptual frameworks within baccalaureate nursing programs. NLN Publications ,15-1558,17-25.

Zabalegui, A. (2000). Teoría y progreso de la ciencia de enfermería. Enfermería Clínica. 10 (6), 263-266.

Zabalegui, A. (2003). El rol del profesional en enfermería. Aquichan, 3(1), 16-20.

Zabalegui, A., \& Cabrera, E. (2009). New nursing education structure in Spain. Nurse education today, 29(5), 500-504.

Zabalegui, A., \& Cabrera, E. (2010). Economic crisis and nursing in Spain. Journal of nursing management, 18(5), 505-508.

Zabalegui, A. \& Macià, L. eds. (2010). Desarrollo del Máster y doctorado oficial de enfermería en España. Castelló de la Plana: Publicacions de la Universitat Jaume I.

Zabalegui, A., Macia, L., Márquez, J., Ricomá, R., Nuin, C., Mariscal, I., Pedraz, A., Germán, C. \& Moncho, J. (2006). Changes in nursing education in the European Union. Journal of Nursing Scholarship, 38(2), 114-118.

Zaragoza, A. (1999). El proceso de atención de enfermería. Perspectiva de profesores y estudiantes. Revista Rol Enfermería, 22 (9), 583-590. 
8. Anexos 
Anexo I

Certificados CEIC de Corporació Parc Taulí y Comité de Investigación de Fundació Tecnocampus 


\section{Informe del CEIC de finalització de l'estudi}

Doña COLOMA MORENO QUIROGA, Secretaria del Comité Ético de Investigación Clínica de la CORPORACIÓ SANITȦRIA PARC TAULI DE SABADELL (Barcelona)

Faig constar

Que d'acord amb els antecedents documentals que existeixen en els arxius del CEIC,

SANTOS RUIZ SUSANA

consta en qualitat d'investigador/a principal del projecte:

Aplicabilidad de modelos y teorias de Enfermeria en la realidad asistencial. Primera fase

Codi CEIC 2006508

Va ser aprovat per aquest CEIC el 24/02/2006.

Després de rebre I' informe final del mateix.

Promotor PROPI

Codi Promotor

Col·laboradors de l'estudi:

LÓPEZ PARRA,MARIA

ROCABERT LUQUE,MARIA

VÁREZ PELAEZ,SUSANA

ABRIL SABATER,DOLORS

Dra. Coloma Moreno Quiroga

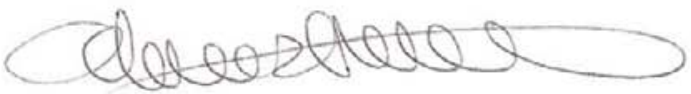

SABADELL a lunes, 10 de marzo de 2008 


\section{Informe del CEIC de finalització de l'estudi}

Doña COLOMA MORENO QUIROGA, Secretaria del Comité Ético de Investigación Clínica de la CORPORACIÓ SANITÀRIA PARC TAULÍ DE SABADELL (Barcelona)

Faig constar

Que d'acord amb els antecedents documentals que existeixen en els arxius del CEIC,

\section{LÓPEZ PARRA MARIA}

consta en qualitat d'investigador/a principal del projecte:

Filosofia del cuidar: perspectiva de los estudiantes de Enfermería versus perspectiva de los profesionales asistenciales

Codi CEIC 2006548

Va ser aprovat per aquest CEIC el 14/11/2006.

Després de rebre l' informe final del mateix.

Promotor PROPI

Codi Promotor

Colllaboradors de l'estudi:

SANTOS RUIZ,SUSANA

VÁREZ PELAEZ,SUSANA

ABRIL SABATER,DOLORS

Dra. Coloma Moreno Quiroga

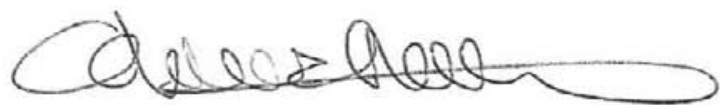

SABADELL a miércoles, 15 de octubre de 2008 


\section{[2. Tesno Campus

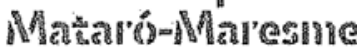

\section{INFORME DE VALORACIÓ DEL COMITÉ DE INVESTIGACIÓN}

El Dr. Marcos Faúndez Zanuy, presidente del comité de investigación de la Fundación Tecnocampus Mataró Maresme,

\section{CERTIFICA:}

Que el comité de investigación de la Fundación Tecnocampus Mataró-Maresme ha realizado la evaluación del proyecto titulado:

"Factores determinantes de aplicación de modelos en la práctica enfermera"

Dirigido por la investigadora principal Susana Santos Ruiz

De acuerdo con los criterios del comité de investigación y las líneas de investigación definidas en el programa estratégico de investigación 2011-2014, cumple con los requisitos metodológicos necesarios y es viable en todos sus términos, por lo que ha considerado adecuada dicha propuesta y ha decidido su APROBACIÓN.

En Mataró, a 18 de Julio del 2012.

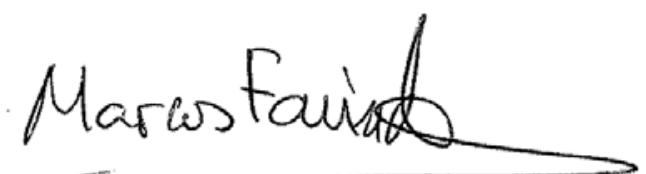

Dr. Marcos Faúndez Zanuy

Presidente del Comité de Investigación Tecnocampus 


\section{Anexo II}

Carta de presentación y cuestionarios usados en relación al segundo objetivo 


\section{A: Profesionales de Enfermería}

Con la presente carta deseamos pediros vuestra colaboración en el estudio "Aplicabilidad de modelos y teorías en la realidad asistencial" con el objetivo de conocer la filosofía del cuidado de los profesionales de enfermería en nuestro centro asistencial.

El uso de un modelo Conceptual de Enfermería en la atención garantiza que todas las enfermeras compartan igual concepción de los conceptos de persona, salud, entorno y rol profesional e igual lenguaje en la orientación de los cuidados. Por lo tanto el enfoque teórico es una herramienta útil para aplicar las prácticas enfermeras de forma ordenada.

El cuestionario posee una serie de preguntas de respuestas únicas (marque con una " $x$ ") y otras de respuestas múltiple que deberá de priorizar $(1,2,3 \ldots)$.

El cuestionario puede ocuparos veinte minutos, rogamos tenerlo cumplimentado en el plazo de una semana, hallareis una urna ubicada en el despacho del /la gestor/a destinada a su recogida.

Os recordamos que la participación es voluntaria y se mantendrá la confidencialidad de los datos.

Con el presente cuestionario os adjuntamos un glosario de términos que puede ser de ayuda para entender alguna de las preguntas expuestas dado que la terminología usada no es siempre la más adecuada y con el fin de que las respuestas sean lo más homogéneas posibles.

Agradecemos de antemano vuestra colaboración, estamos a vuestra disposición para cualquier duda en las extensiones:

- 25011 / 25041 Maria López (mañana), Maria Rocabert (Tarde)

- 21300 Susana Varez (noche)

- 21900 Susana Santos (noche)

- 21271 Dolors Abril (tarde).

Los resultados obtenidos se harán públicos al finalizar la investigación.

Equipo investigador 
TRAYECTORIAS CLINICAS: Son una guía práctica desarrollada por un grupo interdisciplinar que provee secuencia y duración de las intervenciones y resultados esperados de los pacientes para grupos específicos según diagnóstico ${ }^{1}$. Es resultado del consenso entre el personal médico, de enfermería y gerencial $^{2}$.

PROTOCOLO: Programa en el que se especifican por escrito los procedimientos que deben seguirse en el examen de un paciente, en una investigación o en la atención de una enfermedad determinada ${ }^{5}$.

PROCEDIMIENTOS: Método o modo de ejecutar una acción concreta ${ }^{6}$. Serie de pasos por los cuales se logra una resultado deseado ${ }^{7}$.

TAXONOMIA DE NANDA: Codificación de todos los diagnósticos enfermeros para una Clasificación Internacional de la Práctica enfermera ${ }^{4}$.

METAPARADIGMAS: Son el nivel de conocimientos más abstracto de todos. Describen los principales conceptos que hacen referencia al tema principal, así como a la finalidad de una disciplina. Los principales conceptos son el de persona, entorno, salud y enfermería ${ }^{3}$.

FILOSOFÍA DE ENFERMERÍA: Es el segundo nivel de conocimientos, especifica las definiciones de los conceptos en todos los modelos conceptuales de enfermería ${ }^{3}$.

MODELOS CONCEPTUALES: se definen como marcos o paradigmas que suministran un marco amplio de referencia para los enfoques sistemáticos de los fenómenos de los que se encarga la discipli$\mathrm{na}^{3}$.

TEORÍA DE ENFERMERÍA: grupo de conceptos relacionados que se derivan de los modelos de enfermería y se dividen según su nivel de abstracción y contenido en grandes teorías, teorías y teorías de nivel medio ${ }^{3}$.

1. Anders, Robert. Development of a Scientifically Valid Coordinated Care Path. Journal of Nursing Administration.1997; 5: 4552.

2. Gonzalez T. Las trayectorias clínicas permiten agilizar procesos y reducir costes. Diario Médico. 19 de Febrero del 2001. Hallado en internet: http://www.diariomedico.com/gestion/ges190201com.html

3. Marriner A, Raile M. Modelos y teorías en enfermería. 5a Ed. Madrid: Mosby; 2003.

4. Lluis MT. Diagnósticos enfermeros. 3a Ed. Madrid; Harcourt Brace. 1999.

5. Gispert C. Enciclopedia de Medicina y Enfermería MOSBY. Tomo 3. Océano 1992.

6. www.diccionarios.com

7. Dornald. Diccionario Médico de bolsillo. 24 Ed. Madrid: Interamericana-McGraw-Hill. 1993. 
1. Edad

2. Sexo $\mathrm{H} \square \mathrm{M}$

3. Escuela Universitaria donde cursó enfermería

4. Año de finalización

5. Ud es: D.U.E $\square \quad$ A.T.S $\square$

6. Ámbito o unidad dónde trabaja y edificio

7. Turno

8. Años de experiencia laboral

9. Años trabajados en este centro

10. ¿Ha realizado algún máster/ postgrado y/o algún curso relacionado con los modelos de enfermería? Si $\square \quad$ No $\square$

11. En su escuela universitaria, ¿cuál o cuáles modelos utilizaba?
$\square$ V. Henderson
C. Roy
$\square$ Peplau
D. Orem
F. Nightingale
Ninguno

12. En la actividad diaria, ¿sigue algún/os modelo/s de enfermería en concreto?

$\square$ Sí, ¿Cuáles?

13. El modelo de enfermería que utilizaba como estudiante en las prácticas, ¿̇le ha sido útil o facilitado su trabajo día a día?
$\square$ Sí, siempre
A veces

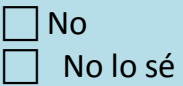

14. Dado que en la CSPT no existe ningún modelo institucionalizado ¿piensa que sería positivo implantar un modelo y trabajar todos con el mismo?
$\square$ Sí
$\square$ No
A veces

15. ¿Cree que es necesario implantar diferentes modelos según las características del paciente?

$\begin{array}{ll}\square & \text { No } \\ \square \quad \text { veces } & \square \text { Sí, ¿̇cuál? }\end{array}$

16. ¿Cuál de las siguientes definiciones crees que se aproxima a tu concepto de enfermería? Si estás de acuerdo con varias márcalas y priorízalas (hasta un máximo de 3):

La que colabora y facilita el proporcionar los componentes principales para la salud.

Ayuda principal al individuo enfermo. Miembro de un equipo. Actúa al margen del médico, pero le apoya.

Proceso importante, terapéutico, interpersonal.

Es un proceso de acción, reacción, interacción y transacción interpersonal.

Es una profesión que requiere aprendizaje y que se puede interpretar como una ciencia y como un arte.

Facilita la adaptación valorando el comportamiento en la adaptación e interviniendo alterando los estímulos que le afectan.

Como la averiguación y la satisfacción de la necesidad de ayuda inmediata del paciente.

Profesión y disciplina humanista y científica que se centra en los cuidados para ayudar, apoyar, facilitar, o capacitar a las personas.

Es una facilitadora. Es la ayuda holística a las personas en las actividades de autocuidado en su relación con su salud.

Ninguna

17. ¿Crees que enfermería principalmente es?

$\square$ Un trabajo
$\square$ Una profesión
$\square$ Ninguno

$\square$ El arte de cuidar
$\square$ Una labor vocacional
$\square$ Otros 
18. ¿Cuál de las siguientes definiciones cree que se aproxima a su concepto de saludenfermedad? Si está de acuerdo con varias márquelas y priorícelas (hasta un máximo de 3):

Condiciones y fuerzas externas que afectan la vida.

Capacidad del individuo para funcionar con independencia. Calidad de vida.

Ha de ser integral. Formas de estar en el mundo.

Déficit de autocuidado, desviación de la salud.

Símbolo de una palabra que implica movimiento de la personalidad y otros procesos humanos.

Estado dinámico dentro el ciclo de la vida, la enfermedad es una interferencia.

Salud es un valor definido por la cultura o el individuo.

Salud: estado y proceso de ser y volverse una persona totalmente integrada. Enfermedad: falla la integración.

Capacidad de actuar de un modo razonable normal.

Estado de bienestar. Capacidad de las personas para realizar sus actividades diarias bajo un modo de vida culturalmente específico, beneficioso y estructurado.

Subjetiva sensación de bienestar respecto propio estado físico-emocional-espiritual.

Es un estado de bienestar físico, social y mental, y no únicamente la ausencia de enfermedad.

Ninguna

19. ¿Cuál de las siguientes definiciones cree que se aproxima a su concepto de entorno? Si está de acuerdo con varias márquelas y priorícelas (hasta un máximo de 3):

Ambiente saludable: luz, agua, aire, alimentación, calor, ventilación, ruido, eliminación.

Compuesto por 14 necesidades: físicas, seguridad, afecto y autorrealización.

Factores condicionantes, requisitos de autocuidado y desarrollo.

Fuerzas existentes fuera del organismo y en el contexto de la cultura.

Entorno es un campo de energía irreductible y pandimensional.

Todas la condiciones y circunstancias que rodean y afectan el desarrollo y comportamiento de la persona.

Es el contexto en el que vivimos, donde participamos activamente.

Conjunto de hechos, situaciones y experiencias en escenarios físicos, ecológicos, sociopolíticos o culturales.

Cualquier aspecto del paciente, la familia o las instituciones que la enfermera o los familiares puedan manipular para que el paciente se sienta más cómodo.

Ninguna

20. En los registros de enfermería utiliza el término (Marque 1 sola opción):

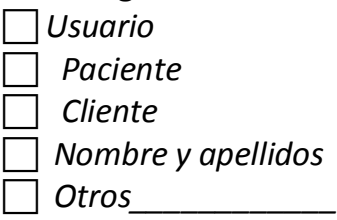

21. Su concepción del individuo es (Marque 1 sola opción):

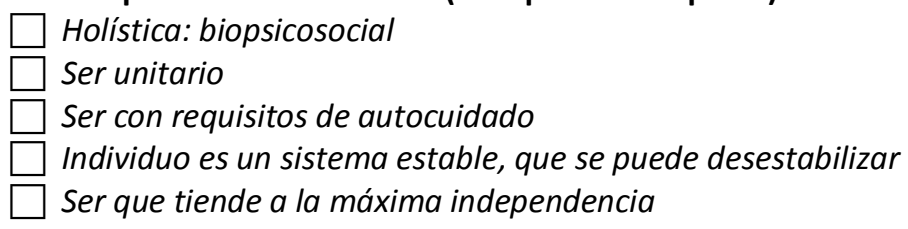


22. ¿Cuál de las siguientes definiciones cree que se aproxima a su concepto de persona? Si estás de acuerdo con varias márquelas y priorícelas (hasta un máximo de 3)

Persona en proceso de reparación.

Paciente/individuo que necesita: voluntad, fuerza, conocimiento.

Agente: persona que se compromete a realizar un curso de acción o que tiene el poder de comprometerse en un curso de acción.

Organismo que vive en equilibrio inestable.

Son sistemas abiertos en transacción con el entorno. Son únicos y holísticos).

Es un sistema abierto en procesos continuo con su entorno.

Es un ser biopsicosocial en constante interacción con el medio ambiente cambiante

Ser capaz de satisfacerse su propia necesidad de ayuda, pero sufre cuando se siente incapaz de ello.

Toda persona que recibe ayuda (atención, enseñanza o consejo).

Un sistema conductual con formas de comportamiento marcadas por un modelo, que vinculan con el entorno.

Seres humanos que necesitan atención, servicios y asistencia.

Ninguna

23. ¿Conoce la taxonomía de la NANDA?

Si

24. ¿Utiliza los diagnósticos de la NANDA?
Sí
No
$A$ veces

25. ¿Conoce las trayectorias Clínicas?
$\square$ Sí
No

26. ¿Conoce los planes de cuidados estandarizados? $\square$ No

27. ¿Cuál cree que es la metodología de trabajo más adecuada?

$\square \quad$ Trayectorias
$\square \quad \begin{aligned} & \text { El modelo biomédico } \\ & \square \quad \text { Proceso de Atención de Enfermería (PAE) } \\ & \square \quad \text { Otros, ¿Cuál? }\end{aligned}$
$\square \quad$

28. En el servicio que trabaja, ¿utiliza protocolos y procedimientos?

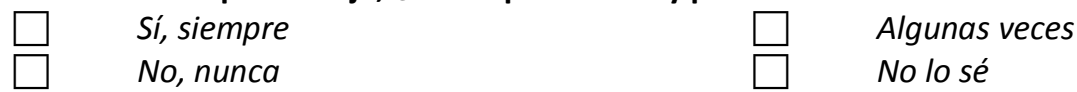

29. ¿Cree que éstos son útiles y facilitan su trabajo?

$\square \quad$ Si
$\square \quad$ No
$\square \quad$ A veces

30. Cuándo quiere ampliar sus conocimientos busca información en (Puede marcar más de 1 opción):

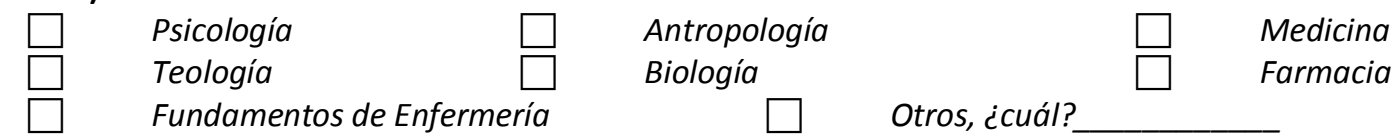

31. ¿Siente que atiende al paciente según el modelo conceptual con el que se identifica? Nunca Casi nunca

$A$ veces Casi siempre

Siempre 
32. ¿Cree que las actuales hojas de registros de su unidad favorecen el poder trabajar bajo un modelo de enfermería?

Sí

No

$A$ veces

33. ¿Utiliza la hoja de valoración de enfermería al ingreso?
$\square$ Sí
No
$A$ veces

34. ¿Le facilita el trabajo la hoja de valoración de enfermería al ingreso?
$\square \quad$ Si
Sí
No
$A$ veces

35. ¿Elabora los registros de enfermería por problemas o diagnósticos de enfermería?
$\square$ Si
Sí
No
$A$ veces

36. Marque en la siguiente relación cuáles son las observaciones que hace y registra de forma habitual (Puede marcar más de una opción):

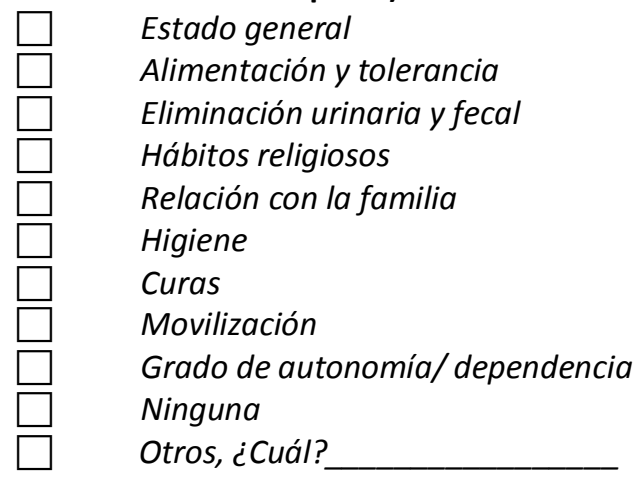

37. Si tuviese que trabajar bajo la directriz de algún modelo de enfermería en concreto ¿Por cuál se posicionarías? ¿Por qué?: 


\section{A: Estudiantes de Enfermería}

Con la presente carta deseamos pediros vuestra colaboración en el estudio: "Filosofía del cuidar: perspectiva de los estudiantes de Enfermería versus perspectiva de los profesionales asistenciales" con el objetivo de conocer la similitud/diferencias en la filosofía del cuidado entre los profesionales de enfermería de nuestro centro asistencial y los estudiantes de enfermería.

El uso de un modelo Conceptual de Enfermería en la atención garantiza que todas las enfermeras compartan igual concepción de los conceptos de persona, salud, entorno y rol profesional e igual lenguaje en la orientación de los cuidados. Por lo tanto el enfoque teórico es una herramienta útil para aplicar las prácticas enfermeras de forma ordenada.

El cuestionario posee una serie de preguntas de respuesta única (marque con una " $x$ ") y otras de respuesta múltiple que deberá de priorizar $(1,2,3 \ldots)$.

El cuestionario puede ocuparos veinte minutos.

Con el presente cuestionario os adjuntamos un glosario de términos que puede ser de ayuda para entender alguna de las preguntas expuestas dado que la terminología usada no es siempre la más adecuada y con el fin de que las respuestas sean lo más homogéneas posibles unificar conceptos.

Agradecemos de antemano vuestra colaboración, estamos a vuestra disposición para cualquier duda en las extensiones del Parc Taulí (93 723 10 10)

25011 / 25041 Maria López (mañana), Maria Rocabert (Tarde), Susana Varez (tarde)

21900 Susana Santos (noche)

21271 Dolors Abril (tarde).

Los resultados obtenidos se harán públicos al finalizar la investigación.

Equipo investigador 


\section{GLOSARIO DE TÉRMINOS:}

TRAYECTORIAS CLINICAS: Son una guía práctica desarrollada por un grupo interdisciplinar que provee secuencia y duración de las intervenciones y resultados esperados de los pacientes para grupos específicos según diagnóstico ${ }^{1}$. Es resultado del consenso entre el personal médico, de enfermería y gerencial $^{2}$.

PROTOCOLO: Programa en el que se especifican por escrito los procedimientos que deben seguirse en el examen de un paciente, en una investigación o en la atención de una enfermedad determinada ${ }^{5}$.

PROCEDIMIENTOS: Método o modo de ejecutar una acción concreta ${ }^{6}$. Serie de pasos por los cuales se logra una resultado deseado ${ }^{7}$.

TAXONOMIA DE NANDA: Codificación de todos los diagnósticos enfermeros para una Clasificación Internacional de la Práctica enfermera ${ }^{4}$.

METAPARADIGMAS: Son el nivel de conocimientos más abstracto de todos. Describen los principales conceptos que hacen referencia al tema principal, así como a la finalidad de una disciplina. Los principales conceptos son el de persona, entorno, salud y enfermería ${ }^{3}$.

FILOSOFÍA DE ENFERMERÍA: Es el segundo nivel de conocimientos, especifica las definiciones de los conceptos en todos los modelos conceptuales de enfermería ${ }^{3}$.

MODELOS CONCEPTUALES: Se definen como marcos o paradigmas que suministran un marco amplio de referencia para los enfoques sistemáticos de los fenómenos de los que se encarga la discipli$\mathrm{na}^{3}$.

TEORÍA DE ENFERMERÍA: Grupo de conceptos relacionados que se derivan de los modelos de enfermería y se dividen según su nivel de abstracción y contenido en grandes teorías, teorías y teorías de nivel medio ${ }^{3}$.

1. Anders, Robert. Development of a Scientifically Valid Coordinated Care Path. Journal of Nursing Administration.1997; 5: 4552.

2. Gonzalez T. Las trayectorias clínicas permiten agilizar procesos y reducir costes. Diario Médico. 19 de Febrero del 2001. Hallado en internet: http://www.diariomedico.com/gestion/ges190201com.html

3. Marriner A, Raile M. Modelos y teorías en enfermería. 5a Ed. Madrid: Mosby; 2003.

4. Lluis MT. Diagnósticos enfermeros. 3a Ed. Madrid; Harcourt Brace. 1999.

5. Gispert C. Enciclopedia de Medicina y Enfermería MOSBY. Tomo 3. Océano 1992.

6. WwW.diccionarios.com

7. Dornald. Diccionario Médico de bolsillo. 24 Ed. Madrid: Interamericana-McGraw-Hill. 1993. 
1. Edad

2. Sexo Hombre $\square$ Mujer $\square$

3. Escuela Universitaria donde cursa enfermería

4. Año de inicio

6. Ámbito 0 unidad dónde realiza 0 ha realizado las prácticas en la CSPT

7. Turno

8. Semanas de prácticas realizadas

9. Ha trabajado en algún centro sanitario previamente (como auxiliar de enfermería, geriatría,...)

¿Cuánto tiempo?

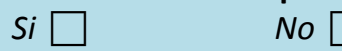

10. ¿Ha realizado alguna asignatura optativa relacionada con modelos de enfermería?

Si $\square \quad$ No $\square$

11. En su escuela universitaria, ¿Qué modelo/s utiliza?

$\begin{array}{lll}\square \text { V. Henderson } & \square \text { C. Roy } & \square \text { F. Nightingale } \\ \square \text { Peplau } & \square \text { D. Orem } & \square \text { Ninguno } \\ \square \text { Otros,cंCuál? } & \end{array}$

12. En sus prácticas, ¿sigue algún/os modelo/s de enfermería en concreto?

$\square$ Sí, ¿Cuáles?_ $\square$ No $\quad \square$ No lo sé.

13. El modelo de enfermería que utiliza como estudiante en las prácticas, ¿cree que le será útil o facilitará su trabajo diario cuando ejerza como profesional de enfermería?
$\square$ Sí, siempre
A veces
$\square$ No

14. Dado que en la CSPT no existe ningún modelo institucionalizado ¿piensa que sería positivo implantar un modelo y trabajar todos con el mismo?
Sí
No
A veces

15. ¿Cree que es necesario implantar diferentes modelos según las características y la patología de la persona?
$\square \quad$ No
$A$ veces
Sí, ¿cuál?
No lo sé

16. ¿Cuál de las siguientes definiciones cree que se aproxima a tu concepto de enfermería? Si estás de acuerdo con varias márquelas y priorícelas (hasta un máximo de 3):

La que colabora y facilita el proporcionar los componentes principales para la salud.

Ayudar al individuo sano o enfermo en la realización de aquellas actividades que contribuyan a su salud o recuperación o a una muerte tranquila.

Campo de conocimiento y servicio humano que tiende a cubrir las limitaciones de la persona relacionadas con la salud.

Proceso terapéutico, interpersonal. La enfermera es suministradora de recursos, educadora, líder, sustituta y consejera.

Es un proceso de acción, reacción, interacción y transacción interpersonal.

Es una profesión que requiere aprendizaje y que se puede interpretar como una ciencia y como un arte.

Ciencia y práctica que amplia la capacidad de adaptación y mejora la transformación el entorno.

Como la averiguación y la satisfacción de la necesidad de ayuda inmediata del paciente.

Profesión y disciplina humanista y científica que se centra en los cuidados para ayudar, apoyar, facilitar, o capacitar a las personas.

Es una facilitadora. Es la ayuda holística a las personas en las actividades de autocuidado en su relación con su salud.

Ninguna 
17. ¿Cree que enfermería principalmente es? (Marque 1 sola opción):

$\square$ Un trabajo

$\square$ Una profesión

Ninguno $\square$ El arte de cuidar

$\square$ Una labor vocacional

Otros

18. ¿Cuál de las siguientes definiciones cree que se aproxima a su concepto de salud? Si está de acuerdo con varias márquelas y priorícelas (hasta un máximo de 3):

Ausencia de enfermedad, sensación de sentirse bien y la capacidad de usar al máximo todas las facultades de la persona.

Capacidad de actuar de forma independiente en relación con las 14 necesidades fundamentales. Estar sano y enfermo se consideran como modos de encontrarse en el mundo.

Estado de ser completo e integrado a sus diferentes componentes y modos de funcionamiento.

Símbolo de una palabra que implica movimiento de la personalidad y otros procesos humanos.

Estado dinámico dentro el ciclo de la vida. Máximo rendimiento para la vida diaria.

Es un valor definido por la cultura o el individuo.

Estado y proceso de ser y convertirse en un ser integrado y completo.

Capacidad de actuar de un modo razonable, normal.

Estado de bienestar. Capacidad de las personas para realizar sus actividades diarias bajo un modo de vida culturalmente específico, beneficioso y estructurado.

Subjetiva sensación de bienestar respecto al propio estado físico-emocional-espiritual.

Es un estado de bienestar físico, social y mental, y no únicamente la ausencia de enfermedad.

Ninguna

19. ¿Cuál de las siguientes definiciones cree que se aproxima a su concepto de entorno? Si está de acuerdo con varias márquelas y priorícelas (hasta un máximo de 3):

Aquellos elementos externos que afectan a la salud de las personas sanas y enfermas: luz, agua, aire, alimentación, calor, ventilación, ruido, eliminación.

Conjunto de todas las condiciones e influencias externas que afectan a la vida y al desarrollo de un organismo.

Factores externos que afectan los autocuidados.

Fuerzas existentes fuera del organismo y en el contexto de la cultura.

Campo de energía irreductible y pandimensional.

Todas la condiciones y circunstancias que rodean y afectan el desarrollo y comportamiento de la persona.

Es el contexto en el que vivimos, donde participamos activamente.

Conjunto de hechos, situaciones y experiencias en escenarios físicos, ecológicos, sociopolíticos o culturales.

Cualquier aspecto del paciente, la familia o las instituciones que la enfermera o los familiares puedan manipular para que el paciente se sienta más cómodo.

Ninguna

20. En los registros de enfermería prefiere el término (Marque 1 sola opción):

$\square$ Usuario
$\square$ Paciente
$\square$ Cliente
$\square$ Nombre y apellidos
$\square$ Otros

21. Su concepción del individuo es (Marca 1 sola opción):

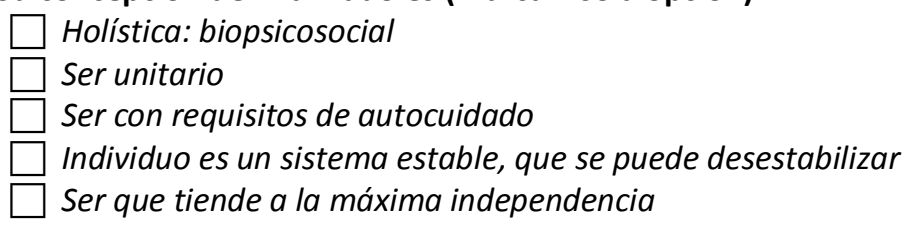


22. ¿Cuál de las siguientes definiciones cree que se aproxima a su concepto de persona? Si está de acuerdo con varias márquelas y priorícelas (hasta un máximo de 3)

Persona enferma o sana compuesta por aspectos físicos, intelectuales, sociales, emocionales y espirituales.

Ser bio-psico-social que necesita ayuda para recuperar su salud y su independencia o para tener una muerte tranquila.

Ser que presenta exigencias de autocuidados universales de desarrollo y ligados a desviaciones de la salud.

Organismo que vive en equilibrio inestable.

Son sistemas abiertos en transacción con el entorno. Son únicos y holísticos.

Es un sistema abierto en proceso continuo con su entorno.

Es un ser biopsicosocial en constante interacción con el medio ambiente cambiante.

Ser capaz de satisfacerse su propia necesidad de ayuda, pero sufre cuando se siente incapaz de ello.

Toda persona que recibe ayuda (atención, enseñanza o consejo).

Un sistema conductual con formas de comportamiento marcadas por un modelo, que la vinculan con el entorno.

Ser humano que se encuentra en un proceso continuo de progreso, evolución y cambio.

Ninguna

23. ¿Conoce la taxonomía de la NANDA?

Si

No

24. ¿Utiliza los diagnósticos de la NANDA?
Sí
No
$A$ veces

25. ¿Conoce las trayectorias Clínicas?

$\square$ Sí $\square$ No

26. ¿Conoce los planes de cuidados estandarizados?

$\square$ Sí $\square$ No

27. ¿Cuál cree que es la metodología de trabajo más adecuada?

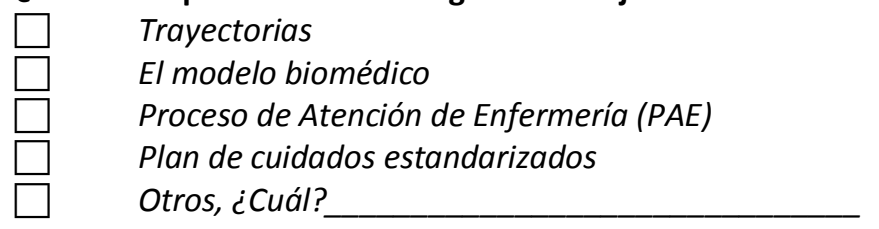

28. En los servicios donde ha realizado las prácticas, ¿utilizaba protocolos y procedimientos?

$\begin{array}{ll}\square \quad \text { Sí, siempre } & \square \quad \text { Algunas veces } \\ \square \quad \text { No, nunca } & \square \quad \text { No lo sé } \\ \square \quad \text { No he realizado prácticas } & \end{array}$

29. ¿Cree que éstos son útiles y facilitan su trabajo?

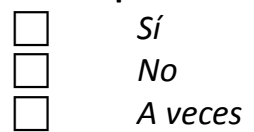

30. Cuándo quiere ampliar sus conocimientos buscas información en (Puede marcar más de 1 opción):

Antropología Biología
Medicina

Farmacia

Otros, ¿cuál? 
31. ¿Siente que atiende al paciente según el modelo conceptual con el que se identifica?

$\begin{array}{lll}\text { Nunca } & \square & \text { Casi nunca } \\ \square & \begin{array}{l}\text { A veces } \\ \text { Siempre }\end{array} & \text { Casi siempre }\end{array}$

32. ¿Cree que las actuales hojas de registros de su unidad favorecen el poder trabajar bajo un modelo de enfermería?
$\square$ Sí
$\square \quad$ No
$A$ veces

33. ¿Utiliza la hoja de valoración de enfermería al ingreso?
Sí
No
A veces

34. ¿Le facilita el trabajo la hoja de valoración de enfermería al ingreso?
$\square \quad$ Si
No
$A$ veces

35. ¿Elabora los registros de enfermería por problemas o diagnósticos de enfermería?

$$
\text { Sí }
$$

No

$A$ veces

36. Marque en la siguiente relación cuáles son las observaciones que hace y que registra de forma habitual (Puede marcar más de una opción):

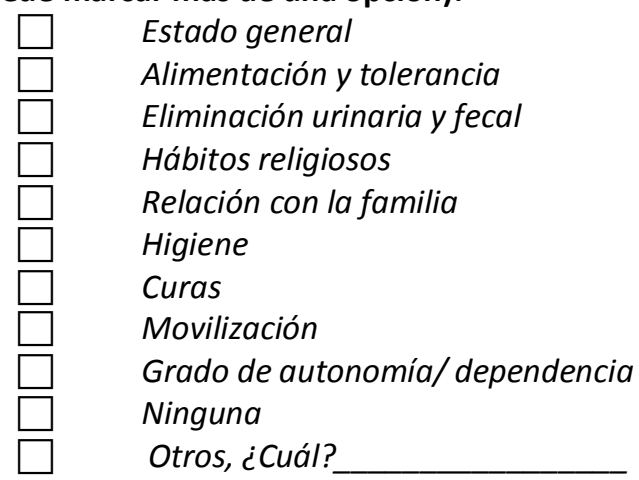

37. Si tuviese que trabajar bajo la directriz de algún modelo de enfermería en concreto ¿Por cuál se posicionarías? ¿Por qué?:

38. En los PAE que realiza en sus prácticas cuál/les de las etapas realiza de forma fiel a la realidad (puede marcar más de una opción):

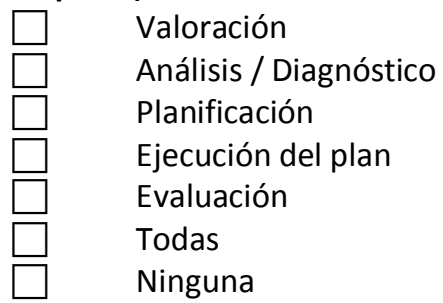


39.¿Y cuál/cuáles son la/s etapa/s en las que tiene mayor problema para poder llevarla/s a cabo normalmente durante sus prácticas? (puede marcar más de una opción):

$\begin{array}{ll}\square \quad & \text { Valoración } \\ \square \quad & \text { Planificación } \\ \square \quad & \text { Diagnóstico } \\ \square \quad & \text { Evaluación } \\ \square \quad & \text { Todas } \\ \square \quad & \text { Ninguna }\end{array}$


Anexo III

Cartas de presentación, mails y cuestionarios enviados a los participantes en la técnica Delphi para dar respuesta al quinto objetivo 
Estimado/a

Mi nombre es Susana Santos y actualmente soy profesora adjunta de la Escuela Superior de Ciencias de la Enfermería del Tecnocampus Mataró, adscrita a la Universidad Pompeu Fabra de Barcelona.

Me hallo en periodo de desarrollo de mi tesis doctoral, que lleva por título: Factores determinantes del uso de modelos teóricos en la práctica enfermera.

Es una tesis que conjuga diferentes metodologías en la recogida de datos, entre ellas se usa la Técnica de Delphi, en el que es necesario contar con un grupo de profesionales que hayan desarrollado algún modelo teórico o teoría en su lugar de trabajo.

Preciso de la búsqueda de expertos sobre la aplicación de modelos teóricos en sus centros de trabajo, en concreto, uno de los perfiles de participante es el de ser gestor de unidades en las que se apliquen modelos teóricos.

Mediante la búsqueda en web, he hallado que en su hospital se desarrolla el trabajo enfermero mediante la aplicación de un modelo teórico.

Es por ello que, me pongo en contacto con usted para proponerle la participación en un Delphi de expertos sobre la aplicación de modelos teóricos.

Necesitaría (si aceptan la invitación) el mail de gestores de su centro que pudieran estar interesados en participar.

La participación no requiere de mucho tiempo, se reciben en total 3 envíos vía mail a los que deberán contestar para el correcto funcionamiento siguiendo la metodología indicada.

El tipo de muestreo utilizado es el de cadena o bola de nieve, por lo que, si además, conociese a alguien que pudiese estar interesado en participar en el estudio (gestor de área clínica donde se apliquen modelos enfermeros o docente de la asignatura de Fundamentos de Enfermería o Modelos y Teorías de Enfermería) ruego me haga llegar el mail para poder invitarlo a la investigación.

Por supuesto los datos recogidos se mantendrán en total confidencialidad y serán informados de los resultados una vez analizadas las respuestas entregadas.

Agradezco de antemano su colaboración y estoy a su disposición por si surgiese cualquier duda en el mail sobre la tesis o cualquier otro tema.

Saludos,

Susana Santos Ruiz

MsU Profesora Adjunta ESCS

ssantos@tecnocampus.cat 
Estimada/o

Mi nombre es Susana Santos y actualmente soy profesora adjunta de la Escuela Superior de Ciencias de la Enfermería del Tecnocampus Mataró, adscrita a la Universidad Pompeu Fabra de Barcelona.

Me hallo en periodo de desarrollo de mi tesis doctoral, que lleva por título: Factores determinantes del uso de modelos teóricos en la práctica enfermera.

Es una tesis que conjuga diferentes metodologías en la recogida de datos, entre ellas se usa la Técnica de Delphi, en el que es necesario contar con un grupo de profesionales expertos en Modelos y Teorías enfermeras.

Mediante la búsqueda en web, he hallado su mail en el programa que usted imparte en la asignatura del Grado de Enfermería relacionada con Fundamentos de Enfermería.

Es por ello que, me pongo en contacto con usted para proponerle la participación en un Delphi de expertos sobre la aplicación de modelos teóricos.

La participación no requiere de mucho tiempo, se reciben en total 3 envíos vía mail a los que deberán contestar para el correcto funcionamiento siguiendo la metodología indicada.

El tipo de muestreo utilizado es el de cadena o bola de nieve, se estudian dos perfiles diferentes: el de gestor de área clínica (hospital) donde se apliquen modelos enfermeros y el de docente de la asignatura de Fundamentos de Enfermería o Modelos y Teorías de Enfermería. Por ello, si además, conociese a alguien que pudiese estar interesado en participar en el estudio, ruego me haga llegar el mail para poder invitarlo a la investigación.

Por supuesto los datos recogidos se mantendrán en total confidencialidad y serán informados de los resultados una vez analizadas las respuestas entregadas.

Agradezco de antemano su colaboración y estoy a su disposición por si surgiese cualquier duda en el mail sobre la tesis o cualquier otro tema.

Reciba un cordial saludo.

Susana Santos Ruiz

MsU Professora Adjunta ESCS

ssantos@tecnocampus.cat 


\section{MAIL}

Apreciado/a compañero/a,

Mi nombre es Susana Santos y soy profesora de la Escuela Superior de Ciencias de la Enfermería Tecnocampus Mataró - Maresme.

Tal y como le informé hace unos días, actualmente me hallo en periodo de desarrollo de mi tesis doctoral, que lleva por título: Factores determinantes del uso de modelos teóricos en la práctica enfermera inscrita en la Universitat Jaume I de Castellón.

Es una tesis que conjuga diferentes metodologías en la recogida de datos, entre ellas se usa la Técnica de Delphi, en el que es necesario contar con un grupo de profesionales que hayan desarrollado algún modelo teórico o teoría en su lugar de trabajo.

El objetivo de estudio concreto al que dará respuesta los resultados del Delphi es: determinar cuál es la perspectiva subjetiva de las enfermeras gestoras y docentes sobre los elementos que han facilitado y los que han impedido el uso y desarrollo de modelos teóricos en la práctica española.

Para ello, recibirá 3 envíos vía mail (este es el primero) a los que deberá contestar para el correcto funcionamiento siguiendo la metodología indicada.

Por supuesto los datos recogidos se mantendrán en total confidencialidad y serán informados de los resultados una vez analizadas las respuestas entregadas.

Las respuestas al primer envío del estudio Delphi, se deben contestar mediante el siguiente enlace http://www.surveymonkey.com/s/X9JNJQH (formulario en surveymonkey).

Una vez haya dado respuesta al formulario que contiene unos mínimos datos demográficos para la descripción de la muestra y 2 preguntas que acompañan al Delphi deberá clicar sobre el botón listo y se habrá enviado su respuesta de forma correcta.

La fecha límite para el envío de este primer formulario es el 5 de noviembre.

Muchas gracias por su colaboración,

Reciba un cordial saludo,

Susana Santos Ruiz

MsU Profesora Adjunta ESCS

ssantos@tcmm.cat

Tecnocampus Mataró-Maresme (Edifici Universitari) |Avinguda Ernest Lluch, 32 (Porta Laietana) 


\section{CUESTIONARIO ADJUNTO A PRIMER MAIL LINKEADO EN SURVEYMONKEY (tal y como era visto por los participantes)}

\section{ESTUDIO DELPHI SOBRE APLICACIÓN DE MODELOS}

1. ESTUDIO DELPHI: FACTORES QUE DETERMINAN LA APLICACIÓN D MODELOS EN LA PRÁCTICA ENFERMERA

Los datos aqui recogidos serán mantenidos en el anonimato.

Recuerde que el plazo máximo de envio es el 5 de noviembre de 2012

*1. Su categoria profesional es...

Profesor universitario de Filosofía/ Fundamentos enfermeros

Gestor de área clínica

Ambos

*2. ¿Cuál es su titulación académica? (Puede marcar más de una opción)

Diplomado en Enfermería

T Máster Oficial

Doctor /a

T Licenciado /a

*3. Ámbito laboral

Hospital

Universidad

Ambos

Otro (especifique)

*4. Provincia en la que desarrolla su trabajo

* 5. ¿Cuántos años lleva ejerciendo su actividad actual como docente universitario o gestor de área clínica?

Menos de 5 años

Entre 5 y 10 años

Más de 10 años

Otro (especifique)

*6. ¿Cuáles cree que han sido los elementos que han facilitado o facilitan el uso y desarrollo de modelos teóricos en la práctica española?

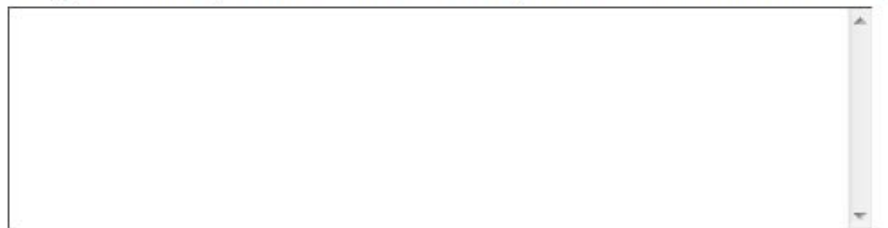

*7. ¿Cuáles cree que han sido los elementos que han impedido o impiden el uso y desarrollo de modelos teóricos en la práctica española?

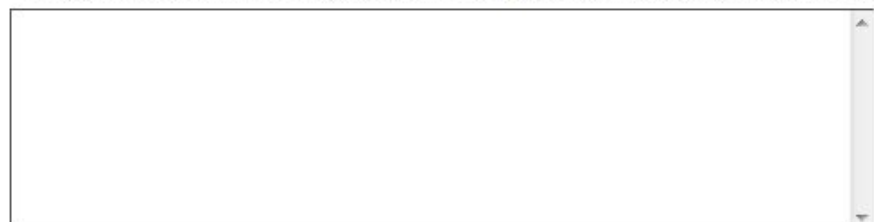

8. Este espacio es por si quiere sugerir o comentar algo sobre el tema de la aplicación de modelos teóricos en la práctica (experiencias, sugerencias, opiniones,...) 


\section{MAIL}

Apreciado/a compañero/a,

Actualmente está en desarrollo la segunda fase del Delphi (del que usted forma parte como experto), de la tesis que lleva por título: Factores determinantes del uso de modelos teóricos en la práctica enfermera, inscrita en la Universitat Jaume I de Castellón. Su objetivo concreto de estudio de la técnica es Determinar cuál es la perspectiva subjetiva de las enfermeras gestoras y docentes sobre los elementos que han facilitado y los que han impedido el uso y desarrollo de modelos teóricos en la práctica española.

Para ello, tal y como le comenté recibirá 3 envíos vía mail (este es el segundo) a los que deberá contestar para el correcto funcionamiento siguiendo la metodología indicada.

Por supuesto los datos recogidos se mantendrán en total confidencialidad y será informado de los resultados una vez analizadas las respuestas entregadas.

Las respuestas al segundo envío del estudio Delphi, se deben contestar mediante el siguiente enlace http://www.surveymonkey.com/s/D7V8RXP (formulario en surveymonkey).

Este cuestionario consta de 2 páginas, una en la que se deben puntuar los elementos facilitadores de modelos en la práctica y otra en la que se deben puntuar los elementos que han impedido la aplicación de modelos teóricos. Además se incluye un espacio abierto para sugerencisa, comentarios, etc. que desee realizar.

Una vez haya dado respuesta al formulario deberá clicar sobre el botón "listo, cliqué aquí y se enviará su respuesta" y se habrá enviado su respuesta de forma correcta.

La fecha límite para el envío de este segundo formulario es el 24 de noviembre

Nuevamente darle las gracias por su colaboración,

Reciba un cordial saludo,

Susana Santos Ruiz

MsU Profesora Adjunta ESCS

ssantos@tcmm.cat

Tecnocampus Mataró-Maresme (Edifici Universitari) |Avinguda Ernest Lluch, 32 (Porta Laietana)

08302 Mataró (Barcelona) | Tel. 931696501 | Fax. 931696505 | http://escs.tecnocampus.cat 


\section{CUESTIONARIO ADJUNTO AL SEGUNDO MAIL LINKEADO EN SURVEYMONKEY (tal y como era visto por los participantes)}

Segundo cuestionario Delphi. Aplicación de modelos teóricos.

ELEMENTOS QUE HAN FAVORECIDO LA APLICACIÓN DE MODELOS EN LA PRÁCTICA

Se halla en la segunda parte del Delphi, en estos momentos se le solicita priorizar los ítems extraídos de las aportaciones de cada experto.

Los datos aquí recogidos serán mantenidos en el anonimato.

Recuerde que el plazo máximo de envío es el 24 de noviembre de 2012.

1. Puntúe de 1 a 10 cada uno de los elementos siguientes, en función de la consideración que tienen cada uno de ellos en FAVORECER la aplicación de los modelos teóricos en la práctica. Siendo 1 la menor influencia y 10 la mayor influencia.

\begin{tabular}{|c|c|c|c|c|c|c|c|c|c|c|}
\hline & 1 & 2 & 3 & 4 & 5 & 6 & 7 & 8 & 9 & 10 \\
\hline $\begin{array}{l}\text { 1. El cambio del modelo asistencial } \\
\text { orientado a paciente y familia }\end{array}$ & 0 & 0 & 0 & 0 & 0 & 0 & 0 & 0 & 0 & 0 \\
\hline $\begin{array}{l}\text { 2. La identificación en relación a un } \\
\text { modelo de los centros sanitarios }\end{array}$ & 0 & 0 & 0 & 0 & 0 & 0 & 0 & 0 & 0 & 0 \\
\hline $\begin{array}{l}\text { 3. La creencia y necesidad personal de } \\
\text { los profesionales en la aplicación de un } \\
\text { modelo de cuidados }\end{array}$ & 0 & 0 & 0 & 0 & 0 & 0 & 0 & 0 & 0 & 0 \\
\hline $\begin{array}{l}\text { 4. La estrategia de poder para clarificar } \\
\text { la aportación personal y diferenciarla } \\
\text { de otros profesionales de salud }\end{array}$ & 0 & 0 & 0 & 0 & 0 & 0 & 0 & 0 & 0 & 0 \\
\hline $\begin{array}{l}\text { 5. La aspiración de mejorar la práctica } \\
\text { enfermera mediante innovación propia }\end{array}$ & 0 & 0 & 0 & 0 & 0 & 0 & 0 & C & 0 & 0 \\
\hline $\begin{array}{l}\text { 6. El compromiso de desarrollo como } \\
\text { disciplina de docentes y asistenciales }\end{array}$ & 0 & 0 & 0 & 0 & 0 & 0 & 0 & 0 & 0 & 0 \\
\hline $\begin{array}{l}\text { 7. El trabajo desarrollado por las } \\
\text { enfermeras de Atención Primaria }\end{array}$ & 0 & 0 & 0 & 0 & 0 & 0 & 0 & 0 & 0 & 0 \\
\hline $\begin{array}{l}\text { 8. El desarrollo del pensamiento crítico } \\
\text { en la profesión ya que los modelos } \\
\text { facilitan la reflexión }\end{array}$ & 0 & 0 & 0 & 0 & 0 & 0 & 0 & 0 & 0 & 0 \\
\hline
\end{tabular}


9. El desarrollo de planes de cuidados en la práctica

10. La incorporación de NANDA, NIC y

NOC en los planes académicos

11. El uso de lenguajes comunes,

estandarizados

12. El uso de estructuras teóricas para

la valoración enfermera

13. El informe de enfermeria al alta

para la continuidad del cuidado

14. El desarrollo de titulaciones de

postgrado

15. El ser el nexo entre asistencia,

gestión y docencia

16. La incorporación de los modelos

teóricos en la formación universitaria y

los nuevos planes de estudio

17. La divulgación por los profesores

de universidad que los conocen en

profundidad y facilitan la comprensión

de los alumnos

18. El interés profesional por definir el

producto enfermero

19. La relación entre el coste y la

efectividad de los cuidados

20. El liderazgo clínico entre las

enfermeras/os

21. La sensibilidad y necesidad de las

Direcciones de Enfermería de aplicar

modelos teóricos en los pacientes

22. El papel de las asociaciones

científicas

O

C

O 0

o

0

O

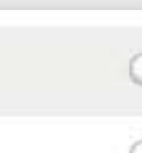

O 0

0

O

O 0

O 0

O 0

O 0

0

000

O

(

O

0

O

O 0

4

O 0

0

O 0

C




23. La existencia de literatura cientifica
sobre el temá
24. La investigación y difusión en
congresos de trabajos con base térica
y metodológica
25. La informatización de la
documentación clínica y el plan de
cuidados




\section{Segundo cuestionario Delphi. Aplicación de modelos teóricos.}

\section{ELEMENTOS QUE HAN IMPEDIDO LA APLICACIÓN DE MODELOS TÉORICOS EN LA PRÁCTICA}

2. Puntúe de 1 a 10 cada uno de los elementos mostrados a continuación, en función de la consideración que tienen cada uno de ellos en IMPEDIR la aplicación de los modelos teóricos en la práctica. Siendo 1 la menor influencia y 10 la mayor influencia.
aplicación de los modelos teóricos en

12

3

4

5

6

1. La ausencia de legislación que

obligue a trabajar con metodología

enfermera en las instituciones

sanitarias

2. El poco interés en reflejar el

producto enfermero

3. La confusión entre el objeto de la

disciplina enfermera y la finalidad de la

práctica

4. El pragmatismo y la falta de

reflexión personal de no tener la

necesidad de basar la práctica en

conocimiento propio

5. La falta de utilidad percibida por los

profesionales que han trabajado con

metodología

6. El que las enfermeras que se

incorporan a la asistencia no integran

su aportación en las actuaciones que

realizan

7. La falta de formación de los

profesionales en modelos teóricos

8. El propio dogmatismo profesional

por un único modelo teórico

9. La barrera idiomática que impide

conocer de forma profunda los textos

originales de las teoristas

O

(2) $-2=$

( )

$\begin{array}{lllll}0 & 0 & 0 & 0\end{array}$

la

O

$\mathrm{O}$

O -9

C

D

$\begin{array}{ll}7 & 8\end{array}$

9

10

0 


\begin{tabular}{|c|c|c|c|c|c|c|c|c|c|c|}
\hline $\begin{array}{l}\text { 10. Las actuales líneas de } \\
\text { pensamiento vinculadas a práctica } \\
\text { basada en la evidencia }\end{array}$ & 0 & 0 & 0 & 0 & 0 & 0 & 0 & O & 0 & O \\
\hline $\begin{array}{l}\text { 11. El desinterés profesional por los } \\
\text { modelos }\end{array}$ & 0 & 0 & 0 & 0 & 0 & 0 & 0 & $\mathrm{O}$ & 0 & O \\
\hline $\begin{array}{l}\text { 12. La falta de reconocimiento del uso } \\
\text { de modelos en el desarrollo como } \\
\text { disciplina (sólo se entiende el } \\
\text { desarrollo profesional en la } \\
\text { organización con el objetivo de la } \\
\text { mejora laboral) }\end{array}$ & 0 & 0 & 0 & 0 & 0 & 0 & 0 & & & \\
\hline $\begin{array}{l}\text { 13. La falta de condicionamiento de las } \\
\text { direcciones enfermeras en el modelo } \\
\text { de atención, formación continuada, } \\
\text { carrera profesional,...pese a } \\
\text { identificarse con un modelo teórico }\end{array}$ & O & 0 & 0 & 0 & 0 & O & C & O & & O \\
\hline $\begin{array}{l}\text { 14. La informatización no adecuada } \\
\text { (en ocasiones prima el registro de la } \\
\text { actividad sobre la misma actividad) }\end{array}$ & O & 0 & 0 & 0 & 0 & 0 & 0 & O & 0 & O \\
\hline $\begin{array}{l}\text { 15. La decisión unilateral de gestores } \\
\text { en la aplicación de modelos sin la } \\
\text { implicación de los propios } \\
\text { profesionales }\end{array}$ & 0 & 0 & 0 & 0 & 0 & 0 & 0 & 0 & 0 & O \\
\hline $\begin{array}{l}\text { 16. La operativización que comporta su } \\
\text { implementación para poder llevar los } \\
\text { modelos a la práctica (documentación, } \\
\text { informes...) }\end{array}$ & 0 & 0 & 0 & 0 & 0 & 0 & 0 & 0 & $\bigcirc$ & 0 \\
\hline $\begin{array}{l}\text { 17. Las estrategias de incorporación y } \\
\text { adaptación de los modelos a la } \\
\text { práctica que en ocasiones se centran } \\
\text { en marcos de valoración que se alejan } \\
\text { de los modelos teóricos }\end{array}$ & 0 & 0 & 0 & O & 0 & $\mathrm{O}$ & 0 & 0 & 0 & $\mathrm{O}$ \\
\hline 18. El poder de la clase médica & 0 & 0 & 0 & 0 & 0 & 0 & 0 & 0 & 0 & 0 \\
\hline
\end{tabular}




\begin{tabular}{|c|c|c|c|c|c|c|c|c|c|c|}
\hline $\begin{array}{l}\text { 19. La falta de autoestima de los } \\
\text { propios profesionales }\end{array}$ & 0 & O & 0 & 0 & 0 & 0 & 0 & 0 & O & 0 \\
\hline $\begin{array}{l}\text { 20. La falta de apoyo por parte de las } \\
\text { direcciones enfermeras }\end{array}$ & 0 & 0 & O & 0 & O & O & O & 0 & O & O \\
\hline $\begin{array}{l}\text { 21. La ausencia de liderazgo clínico e } \\
\text { institucional enfermero }\end{array}$ & 0 & 0 & 0 & 0 & 0 & 0 & 0 & 0 & 0 & 0 \\
\hline $\begin{array}{l}\text { 22. El propio lenguaje, la complejidad } \\
\text { de los modelos y su ambigüedad }\end{array}$ & 0 & 0 & 0 & 0 & 0 & 0 & 0 & 0 & 0 & O \\
\hline $\begin{array}{l}\text { 23. La falta de modelos } \\
\text { contextualizados en nuestro pais } \\
\text { (propios) }\end{array}$ & 0 & 0 & O & O & O & O & O & O & O & O \\
\hline 24. La variabilidad de modelos teóricos & 0 & 0 & 0 & O & O & 0 & 0 & 0 & O & 0 \\
\hline $\begin{array}{l}\text { 25. Las propias caracteristicas de los } \\
\text { modelos que en ocasiones no permiten } \\
\text { la adaptación adecuada a la realidad } \\
\text { del centro en el que se aplica }\end{array}$ & 0 & 0 & $\mathrm{O}$ & 0 & O & C & & 0 & & O \\
\hline $\begin{array}{l}\text { 26. La confusión entre la herramienta y } \\
\text { el modelo, los formularios utilizados no } \\
\text { sustituyen el pensamiento crítico } \\
\text { profesional }\end{array}$ & 0 & 0 & O & 0 & O & 0 & O & 0 & 0 & O \\
\hline $\begin{array}{l}\text { 27. La organización de las instituciones } \\
\text { basadas en el modelo médico (en la } \\
\text { enfermedad), que no exige ni potencia } \\
\text { el uso de los modelos }\end{array}$ & 0 & 0 & O & O & O & 0 & O & 0 & 0 & 0 \\
\hline $\begin{array}{l}\text { 28. La falta de recursos humanos para } \\
\text { el desarrollo del trabajo enfermero, } \\
\text { presión asistencial }\end{array}$ & O & O & O & 0 & O & 0 & O & 0 & 0 & 0 \\
\hline $\begin{array}{l}\text { 29. La falta de efectividad explícita } \\
\text { demostrada de los modelos en la } \\
\text { práctica clínica }\end{array}$ & 0 & 0 & 0 & 0 & 0 & 0 & 0 & 0 & 0 & 0 \\
\hline $\begin{array}{l}\text { 30. La estructura organizacional de las } \\
\text { propias instituciones }\end{array}$ & 0 & 0 & 0 & 0 & 0 & 0 & 0 & 0 & 0 & 0 \\
\hline
\end{tabular}




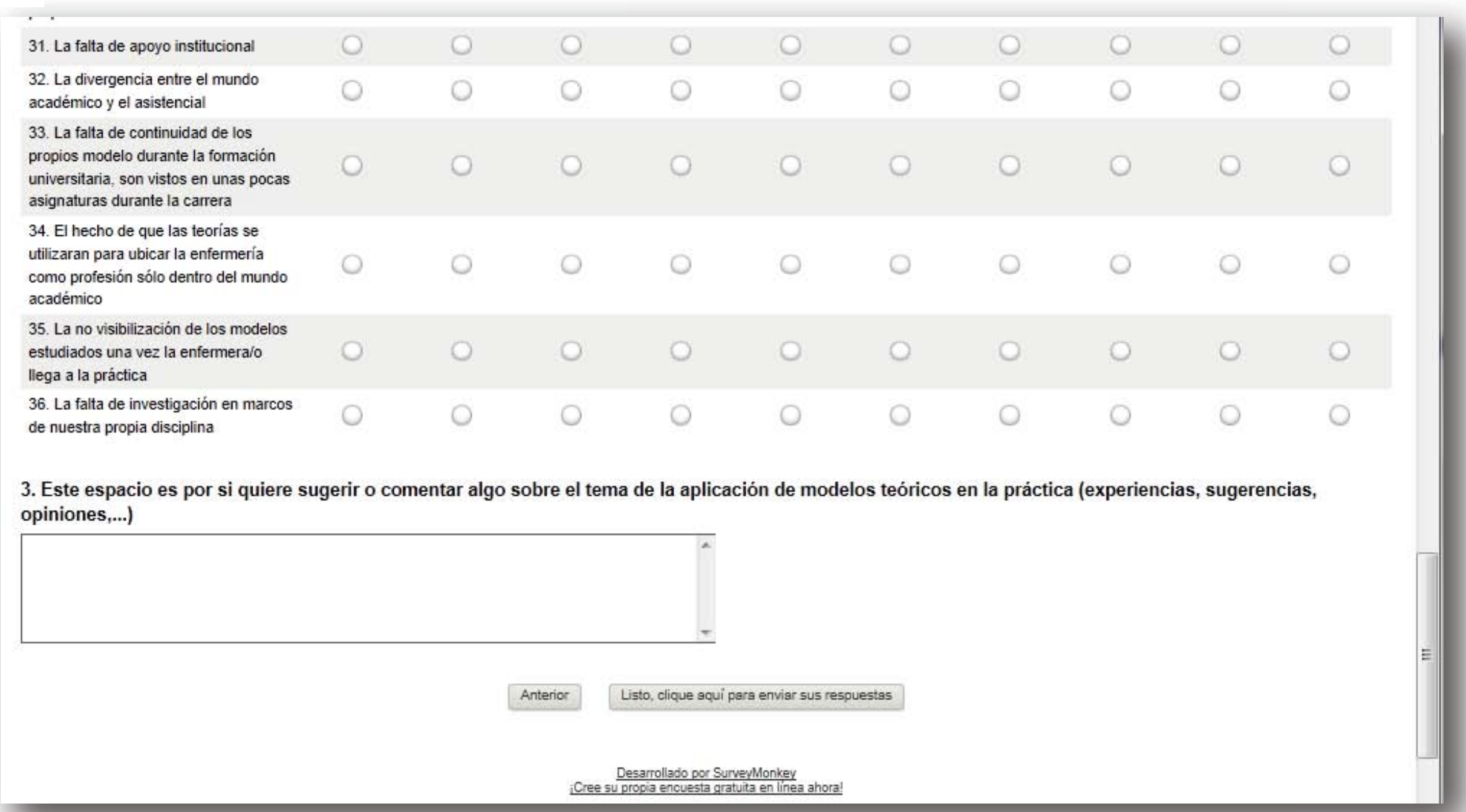




\section{MAIL}

Apreciado/a compañero/a,

Actualmente está en desarrollo la tercera fase del Delphi (del que usted forma parte como experto), de la tesis que lleva por título: Factores determinantes del uso de modelos teóricos en la práctica enfermera, inscrita en la Universitat Jaume I de Castellón. Su objetivo concreto de estudio de la técnica es Determinar cuál es la perspectiva subjetiva de las enfermeras gestoras y docentes sobre los elementos que han facilitado y los que han impedido el uso y desarrollo de modelos teóricos en la práctica española.

Para ello, tal y como le comenté recibiría 3 envíos vía mail (este es el tercero y último) debe contestar siguiendo la metodología indicada.

Por supuesto los datos recogidos se mantendrán en total confidencialidad y será informado de los resultados una vez analizadas las respuestas entregadas.

Las respuestas al tercer envío del estudio Delphi, se deben contestar mediante el siguiente enlace http://www.surveymonkey.com/s/63LDFKF (formulario en surveymonkey).

Este cuestionario consta de 3 páginas y se deben puntuar los elementos facilitadores y desfavorables para la aplicación de modelos en la práctica Además, como en los anteriores, se incluye un espacio abierto para sugerencias, comentarios, etc. que desee realizar.

Una vez haya dado respuesta al formulario deberá clicar sobre el botón final y se habrá enviado su respuesta de forma correcta.

La fecha límite para el envío de este segundo formulario es el 14 de diciembre Nuevamente darle las gracias por su colaboración,

Reciba un cordial saludo,

Susana Santos Ruiz

MsU Profesora Adjunta ESCS

ssantos@tcmm.cat

Tecnocampus Mataró-Maresme (Edifici Universitari) |Avinguda Ernest Lluch, 32 (Porta Laietana) 


\section{CUESTIONARIO ADJUNTO A PRIMER MAIL LINKEADO EN SURVEYMONKEY}

(Tal y como era visto por los participantes)

Tercer cuestionario Delphi. Aplicación de modelos teóricos.

\section{ÚLTIMA FASE DEL ESTUDIO}

Se halla en la tercera y última parte del Delphi, en estos momentos se le solicita volver a priorizar 20 del total de los factores extraídos de las aportaciones de cada experto obtenidas en la primera y segunda ronda.

En las siguientes páginas hallará un listado de factores ordenados por la puntuacion media de cada factor dada por los expertos. Luego se le pedirá que ordene los 20 ítems que crea usted que son los más influyentes de 1 a 20 , siendo 1 el de mayor importancia.

Se requiere de su máxima concentración, y seguro que le costará su tiempo, sin embargo, le recuerdo que con la implemetación de este formulario finalizará su participación en el estudio.

Recordarle como siempre, que los datos aquí recogidos serán mantenidos en el anonimato.

Recuerde que el plazo máximo de envío es el 14 de diciembre de 2012.

Una vez se analice esta última ronda será informado personalmente de los resultados.

Nuevamente agradecerle profundamente su participación en el estudio.

Cordialmente: Susana Santos

Pasar a siguiente página 
Tercer cuestionario Delphi. Aplicación de modelos teóricos.

ELEMENTOS QUE HAN FAVORECIDO LA APLICACIÓN DE MODELOS EN LA PRÁCTICA

Puntuaciones obtenidas en segunda ronda del Delphi de ELEMENTOS FAVORECEDORES (El rango de puntuación se hallaba entre 1 y 10 , siendo 10 la mayor importancia) ELEMENTOS FAVORECEDORES DE APLICACIÓN DE MODELOS

TEÓRICOS EN LA PRÁCTICA. PUNTUACIÓN OBTENIDA EN SEGUNDARONDA DELPH

La sensibilidad y necesidad de las Direcciones de Enfermeria de aplicar modelos

teóricos en los pacientes

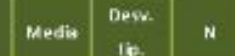

El uso de estructuras teóricas para la valoración enfermera

El liderazgo clínico entre las enfermeras/os

El desarrollo del pensamiento crítico en la profesión ya que los modelos facilitan la

reflexionn

La creencia y necesidad personal de los profesionales en la aplicación de un modelo de

cuidados

El compromiso de desarrollo como disciplina de docentes y asistenciales

Media the n

La estrategia de poder para clarificar la aportación personal y diferenciarla de otros

profesionales de salud

La informatización de la documentación clínicay el plan de cuidados

El desarrollo de planes de cuidados en la práctica

El interés profesional por definir el producto enfermero

La investigación y difusión en congresos de trabajos con base teórica y metodológica

La identificación en relación a un modelo de los centros sanitarios

El cambio del modelo asistencial orientado a paciente $y$ familia

La incorporación de los modelos teóricos en la formación universitaria y los nuevos

planes de estudia

La existencia de literatura cientifica sobre el tema

\begin{tabular}{ll|l}
8,5 & 1,6 & 23
\end{tabular}

La aspiración de mejorar la practica enfermera mediante innovación propia

El uso de lenguajes comunes, estandarizados

El papel de las asociaciones cientificas

El desarrollo de titulaciones de postgrado

La incorporación de NANDA, NIC y NOC en los planes académicos

ta relación entre el coste $y$ la efectividad de los cuidados

\begin{tabular}{|l|l|l|}
8,2 & 1,8 & 23 \\
\hline 8,1 & 2,1 & 23 \\
\hline
\end{tabular}

\begin{tabular}{l|l|l|}
8,1 & 2,1 & 23 \\
\hline
\end{tabular}

\begin{tabular}{l|l|l|}
8,1 & 2,0 & 23
\end{tabular}

\begin{tabular}{l|l|l}
8,0 & 2,6 & 23
\end{tabular}

\begin{tabular}{|l|l|l|}
\hline 7,9 & 1,7 & 23 \\
\hline
\end{tabular}

\begin{tabular}{|l|l|l|}
\hline 7,6 & 2,4 & 21 \\
\hline
\end{tabular}

\begin{tabular}{|l|l|l|}
\hline 7,6 & 1,6 & 23 \\
\hline
\end{tabular}

\begin{tabular}{|l|l|l|}
\hline 7,5 & 2,3 & 23 \\
\hline
\end{tabular}

\begin{tabular}{|l|l|l|}
\hline 7,5 & 2,3 & 23 \\
\hline 7,5 & 2,4 & 23 \\
\hline
\end{tabular}

\begin{tabular}{|l|l|l|}
\hline 7,5 & 2,4 & 23 \\
\hline
\end{tabular}

El informe de enfermeria al alta para la continuidad del cuidado

El ser el nexo entre asistencia, gestión y docencia

El trabajo desarrollado por las enfermeras de Atención Primaria

La divulgación por los profesores de universidad que los conocen en profundidad

facilitan la comprensión de los alumnos 
1. A continuación una vez leídas las puntuaciones dadas por los expertos en segunda ronda, debe ordenar 20 de los siguientes factores FAVORECEDORES para la aplicación de modelos teóricos en la práctica.

- Siendo el primero (marcar 1 en listado de opciones) el de mayor relevancia y el veinteavo el de menor importancia (marcar 20 en listado de opciones).

- Cada factor estará ordenado de forma jerárquica, de forma que ninguno de ellos podrán estar dentro del mismo rango.

EL SISTEMA NO LE DEJARÁ PASAR A LA SIGUIENTE PÁGINA SI NO PRIORIZA 20 DE LOS ÍTEMS

1. La sensibilidad y necesidad de las Direcciones de

Enfermeria de aplicar

modelos teóricos en los pacientes

2. El uso de estructuras teóricas para la valoración enfermera

3. El liderazgo clínico entre las enfermeras/os

\section{El desarrollo del} pensamiento crítico en la profesión ya que los modelos facilitan la reflexión

5. La creencia y necesidad personal de los profesionales

en la aplicación de un modelo de cuidados

1

2

(1)

4

6

7

.

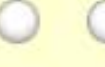

o

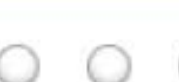

\section{$(1)$}
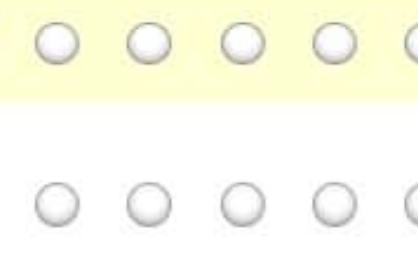
cos chos 


\section{El compromiso de desarrollo como disciplina de docentes y}

asistenciales

7. La estrategia de poder para clarificar la aportación personal y diferenciarla de otros profesionales de salud

8. La informatización de la documentación clínica y el plan de cuidados

\section{El desarrollo de planes de} cuidados en la práctica

10. El interés profesional por definir el producto enfermero

11. La investigación y difusión en congresos de trabajos con base teórica y metodológica

12. La identificación en relación a un modelo de los centros sanitarios

13. El cambio del modelo asistencial orientado a paciente y familia

14. La incorporación de los modelos teóricos en la

formación universitaria y los

nuevos planes de estudio 


\begin{tabular}{|c|c|c|c|c|c|c|c|c|c|c|c|c|c|c|c|c|c|c|c|c|}
\hline $\begin{array}{l}\text { 15. La existencia de literatura } \\
\text { científica sobre el tema }\end{array}$ & 0 & 0 & 0 & 0 & 0 & 0 & 0 & 0 & 0 & 0 & 0 & 0 & 0 & 0 & C & $D$ & 0 & 0 & 0 & 0 \\
\hline $\begin{array}{l}\text { 16. La aspiración de mejorar la } \\
\text { práctica enfermera mediante } \\
\text { innovación propia }\end{array}$ & 0 & 0 & 0 & 0 & 0 & 0 & 0 & 0 & 0 & 0 & 0 & 0 & 0 & 0 & C & D & 0 & 0 & 0 & 0 \\
\hline $\begin{array}{l}\text { 17. El uso de lenguajes comunes, } \\
\text { estandarizados }\end{array}$ & 0 & 0 & 0 & 0 & 0 & 0 & 0 & 0 & 0 & 0 & 0 & 0 & 0 & 0 & C & D & 0 & 0 & 0 & 0 \\
\hline $\begin{array}{l}\text { 18. El papel de las asociaciones } \\
\text { cientificas }\end{array}$ & 0 & 0 & 0 & 0 & 0 & 0 & 0 & 0 & 0 & 0 & 0 & 0 & 0 & 0 & C & D & 0 & 0 & 0 & 0 \\
\hline $\begin{array}{l}\text { 19. El desarrollo de titulaciones de } \\
\text { postgrado }\end{array}$ & 0 & 0 & 0 & 0 & 0 & 0 & 0 & 0 & 0 & 0 & 0 & 0 & 0 & 0 & C & D & 0 & 0 & 0 & 0 \\
\hline $\begin{array}{l}\text { 20. La incorporación de NANDA, } \\
\text { NIC y NOC en los planes } \\
\text { académicos }\end{array}$ & 0 & 0 & 0 & 0 & 0 & 0 & 0 & 0 & 0 & 0 & 0 & 0 & 0 & 0 & C & D & 0 & 0 & 0 & 0 \\
\hline $\begin{array}{l}\text { 21. La relación entre el coste y la } \\
\text { efectividad de los cuidados }\end{array}$ & 0 & 0 & 0 & 0 & 0 & 0 & 0 & 0 & 0 & 0 & 0 & 0 & 0 & 0 & C & D & 0 & 0 & 0 & 0 \\
\hline $\begin{array}{l}\text { 22. El informe de enfermería al alta } \\
\text { para la continuidad del cuidado }\end{array}$ & 0 & 0 & 0 & 0 & 0 & 0 & 0 & 0 & 0 & 0 & 0 & 0 & 0 & 0 & C & $D$ & 0 & 0 & 0 & 0 \\
\hline $\begin{array}{l}\text { 23. El ser el nexo entre asistencia, } \\
\text { gestión y docencia }\end{array}$ & 0 & 0 & 0 & 0 & 0 & 0 & 0 & 0 & 0 & 0 & 0 & 0 & 0 & 0 & C & D & 0 & 0 & 0 & 0 \\
\hline $\begin{array}{l}\text { 24. El trabajo desarrollado por las } \\
\text { enfermeras de Atención Primaria }\end{array}$ & 0 & 0 & 0 & 0 & 0 & 0 & 0 & 0 & 0 & 0 & 0 & 0 & 0 & 0 & C & $D$ & 0 & 0 & 0 & 0 \\
\hline $\begin{array}{l}\text { 25. La divulgación por los } \\
\text { profesores de universidad que los } \\
\text { conocen en profundidad y facilitan } \\
\text { la comprensión de los alumnos }\end{array}$ & 0 & 0 & 0 & 0 & 0 & 0 & 0 & 0 & 0 & 0 & 0 & 0 & 0 & 0 & $\mathrm{C}$ & D & 0 & 0 & 0 & 0 \\
\hline & & & & & Volver : & 7 & erior & & & & le página & & & & & & & & & \\
\hline
\end{tabular}


Tercer cuestionario Delphi. Aplicación de modelos teóricos.

ELEMENTOS QUE HAN IMPEDIDO LA APLICACIÓN DE MODELOS EN LA PRACTICA

Puntuaclones obtenidas en aegunda ronda del Delphl de ELEMENTOS QUE HAN IMPEDIDO Ia apilcacion de modelos en la practica (El rango de puntuacion se hallaba entre 1 y 10 , alendo 10 la mayor Importancla) ELEMENTOS DESFAVORABLES DE APLCACIÓN DE MODELOS

IEÓRICOS EN LA PRÁCTICA. PUNTUACIÓN OBTENIOA EN SEGUNDA RONDA DEPH

La falta de investización en marcos de muestra propia disciplin

La organizacion de las instituciones basadas en el modelo médico fen la enfermedadl. que no exige ni potencia el uso de los modelos

La ausencia de Ederazzo clinico e institucional enfermero

La no vishilizacón de los modelos estudiados unavez la enfermera/o llega a la práctica

La falta de contimuidad de los propios modelo durante la formaciónunizerśtaria, son vistas en unas pocas asienaturas durante la carrera

La falta de condicionamiento de las direcciones enfermeras en el madelo de atención. formadion continuada, carreraprofesional pese a

identificarse con un modelo teórice

La falta de reconocimiento del uso de modelos en el desarrollo como dissiplina lsilo se entiende el desarrollo profegional en la organización con el objetivo de la mejora laberal?

El pragmatismo y la falta de reflexión personal de no tener la necesdad de basar la práctica en conocimiento propio

El hecho de que las teorias se utilizaran para ubicar la enfermeria como profesión sỏlo dentro del mundo acadèmico

La confusión entre la herramienta y el modelo, los formularios ut tilizados no sustituven el pensaniento critico profesional

El poco interés en reflejar el producto enfermero

(a) ocasiones prima el registro de la actividad sobre la misma actividad

El que las enfermeras que se incorporan a la asistenda ne integran su aportadón en las actuaciones que realizan

La falta de apoyo por parte de las direcciones enfermeras

la confusión entre el opjoto de de la disciplina enfermeray la finalidad de la práctica

La falta de modelos contextualizados en nuestro pais tpropios:

La falta de utididad percisida por los profesionales que han trabajado con metodologia

El propio dogmatismo profesional por ununico modelo teoric

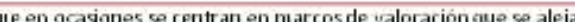

falta de apoye institucional

a divergencia entre el mundo académico yel asistencial

La decisión unilateral de gestores en la apticadón de modelos sin la implicadón de las propios profesionales

Laestructura organizacional de las propias instituciones

Iafalta de autoestima de los movios

Laspropias caracteristicas de los modelos que en ocasiones no permiten la adaptadón adecuada a la realidad del centro en el que se aplica

La falta de recursos humanos para el desarrollo del trabajo enfermero, presón asistencial

El propio lenguaje, la complejidad de los modelosy sil ambiguedad

La operativizadion que comporta su implementación para poder llezar los modelos a la practica (documentadón, informes...)

La falta de efectividad explicita demostrada de los modelos en la práctica dinica

Lavariabilidad de modelos teónicos

La barrera idiomática que impide conocer de ferma profundalos textos originales de las teoristas

La ausencia de legislación que obligue a trabajar con metodologia enfermera en las instituciones sanitarias

Elpoder de la dase médica

Las actuales lineas de pensamiento vinculadas a practica basada en la evidencia

\begin{tabular}{|c|c|c|}
\hline Media & Desv.tip. & N \\
\hline 8,6 & 1,9 & 21 \\
\hline 8,6 & 1,9 & 21 \\
\hline 8,4 & 1,7 & 21 \\
\hline 8,3 & 1,6 & 21 \\
\hline 8,1 & 1,8 & 21 \\
\hline 8,1 & 1,7 & 21 \\
\hline 8,1 & 2,1 & 21 \\
\hline 8,1 & 1,9 & 21 \\
\hline 8,0 & 1,8 & 21 \\
\hline 7,8 & 1,9 & 21 \\
\hline 7,8 & 2,1 & 21 \\
\hline 7,7 & 1,9 & 20 \\
\hline 7,6 & 2,1 & 21 \\
\hline 7,6 & 2,1 & 21 \\
\hline 7,5 & 2,0 & 21 \\
\hline 7,4 & 2,2 & 21 \\
\hline 7,2 & 1,8 & 21 \\
\hline 7,2 & 2,2 & 21 \\
\hline 7,2 & 2,2 & 20 \\
\hline 7,1 & 2,3 & 21 \\
\hline 7,1 & 2,6 & 21 \\
\hline 7,0 & 1,8 & 21 \\
\hline 7,0 & 2,1 & 20 \\
\hline 7,0 & 2,5 & 20 \\
\hline 6,8 & 2,4 & 21 \\
\hline 6,7 & 2,1 & 21 \\
\hline 6,7 & 2,3 & 21 \\
\hline 6,7 & 2,5 & 21 \\
\hline 6,7 & 1,9 & 21 \\
\hline 6,4 & 2,4 & 21 \\
\hline 6,4 & 2,2 & 20 \\
\hline 6,1 & 1,9 & 21 \\
\hline 6,0 & 2,0 & 21 \\
\hline 6,0 & 2,9 & 21 \\
\hline 4,8 & 2,9 & 21 \\
\hline 4,7 & 2,5 & 21 \\
\hline & & \\
\hline
\end{tabular}


2. A continuación una vez leidas las puntuaciones dadas por los expertos en segunda ronda, debe ordenar los siguientes factores QUE HAN IMPEDIDO la aplicación de modelos teóricos en la práctica.

- Deberá puntuar 20 factores, siendo el primero (marcar 1 en listado de opciones) el de mayor relevancia y el veinteavo el de menor importancia (marcar 20 en listado de opciones).

-Cada factor estará ordenado de forma jerárquica, de forma que ninguno de ellos podrán estar dentro del mismo rango.

\section{EL SISTEMA NO LE DEJARÁ PASAR DE PÁGINA SI NO PRIORIZA 20 DE LOS ITEMS}

La falta de investigación en marcos de nuestra propia disciplina

El desinterés profesional por los modelos

La organización de las instituciones basadas en el modelo médico (en la enfermedad), que no exige ni

potencia el uso de los modelos

La ausencia de liderazgo clínico e institucional enfermero

La no visibilización de los modelos estudiados una vez la enfermera/o llega a la práctica

La falta de continuidad de los propios modelo durante la formación universitaria, son vistos en unas pocas asignaturas durante la carrera

La falta de condicionamiento de las direcciones enfermeras en el modelo de atención, formación continuada, carrera profesional, pese a identificarse con un modelo teórico 
La falta de reconocimiento del uso de

modelos en el desarrollo como

disciplina (sólo se entiende el

desarrollo profesional en la

organización con el objetivo de la

mejora laboral)

El pragmatismo y la falta de reflexión

personal de no tener la necesidad de

basar la práctica en conocimiento

propio

El hecho de que las teorias se

utilizaran para ubicar la enfermería

como profesión sólo dentro del mundo

académico

La confusión entre la herramienta y el

modelo, los formularios utilizados no

sustituyen el pensamiento critico

profesional

El poco interés en reflejar el producto enfermero

La falta de formación de los

profesionales en modelos teóricos

La informatización no adecuada (en

ocasiones prima el registro de la

actividad sobre la misma actividad)

El que las enfermeras que se

incorporan a la asistencia no integran

su aportación en las actuaciones que

realizan

La falta de apoyo por parte de las

direcciones enfermeras

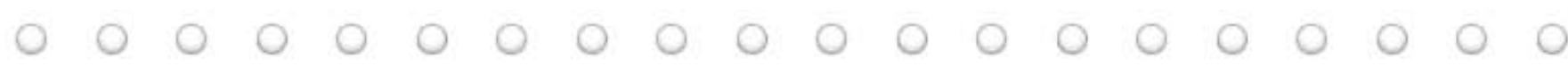


La confusión entre el objeto de la

disciplina enfermera y la finalidad de

la práctica

La falta de modelos contextualizados en nuestro país (propios)

La falta de utilidad percibida por los profesionales que han trabajado con metodología

El propio dogmatismo profesional por un único modelo teórico

Las estrategias de incorporación y adaptación de los modelos a la práctica que en ocasiones se centran en marcos de valoración que se alejan de los modelos teóricos

\section{La falta de apoyo institucional}

La divergencia entre el mundo académico y el asistencial

La decisión unilateral de gestores en la aplicación de modelos sin la implicación de los propios

profesionales

La estructura organizacional de las propias instituciones

La falta de autoestima de los propios profesionales

Las propias características de los modelos que en ocasiones no

permiten la adaptación adecuada a la realidad del centro en el que se aplica

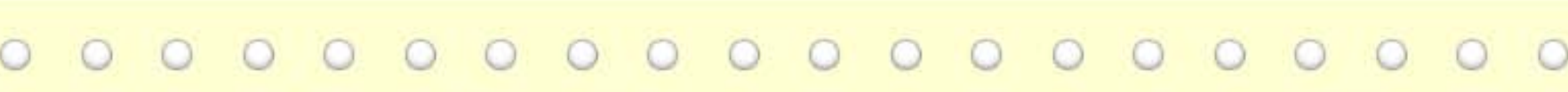

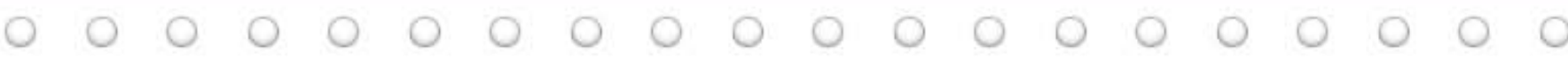

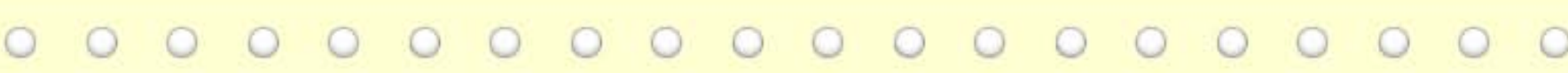

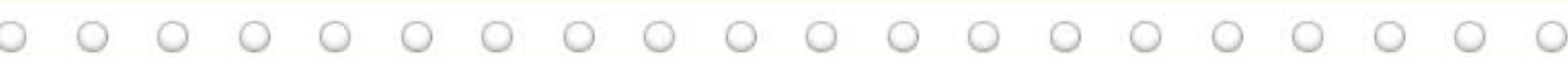

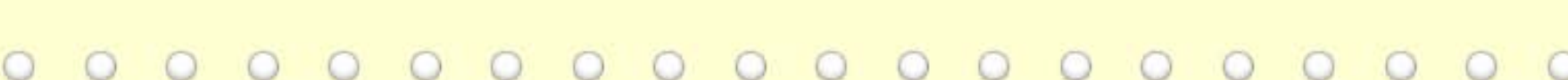

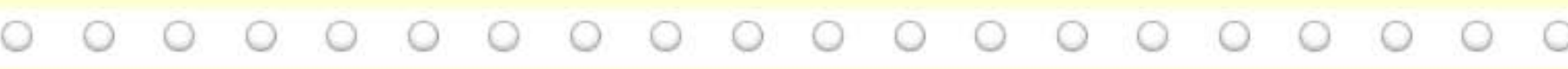

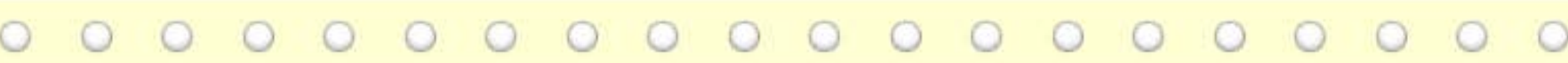

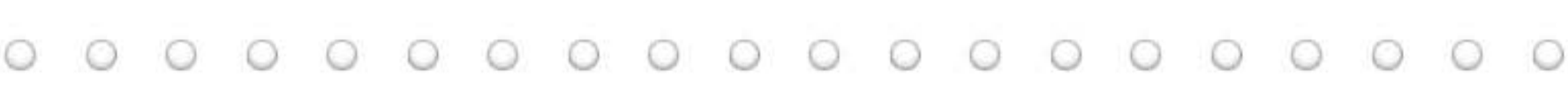

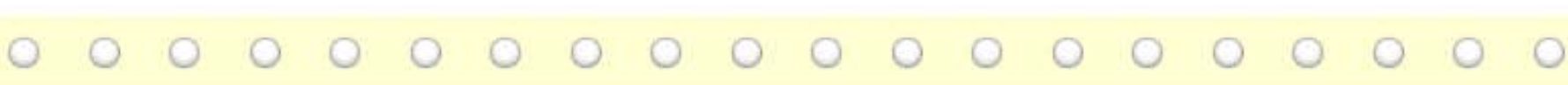

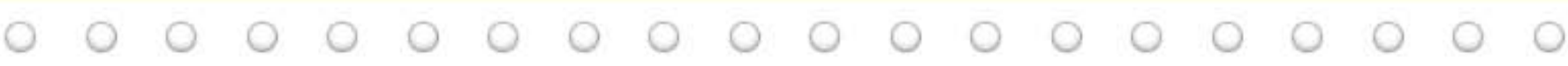

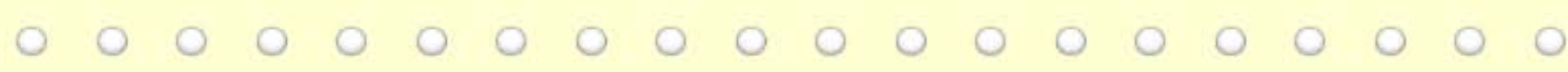


La falta de recursos humanos para el

desarrollo del trabajo enfermero,

presión asistencial

El propio lenguaje, la complejidad de

los modelos y su ambigüedad

La operativización que comporta su

implementación para poder llevar los

modelos a la práctica

(documentación, informes...)

La falta de efectividad explícita

demostrada de los modelos en la

práctica clínica

La variabilidad de modelos teóricos

La barrera idiomática que impide

conocer de forma profunda los textos

originales de las teoristas

La ausencia de legislación que

obligue a trabajar con metodología

enfermera en las instituciones

sanitarias

El poder de la clase médica

Las actuales líneas de pensamiento

vinculadas a práctica basada en la

evidencia 



